\title{
Stepping stone cities? : exploring urban greening and gardening as a viable contribution to global biodiversity conservation
}

Citation for published version (APA):

Beumer, C. (2014). Stepping stone cities? : exploring urban greening and gardening as a viable contribution to global biodiversity conservation. [Doctoral Thesis, Maastricht University]. Universitaire Pers Maastricht. https://doi.org/10.26481/dis.20141204cb

Document status and date:

Published: 01/01/2014

DOI:

10.26481/dis.20141204cb

Document Version:

Publisher's PDF, also known as Version of record

Please check the document version of this publication:

- A submitted manuscript is the version of the article upon submission and before peer-review. There can be important differences between the submitted version and the official published version of record.

People interested in the research are advised to contact the author for the final version of the publication, or visit the DOI to the publisher's website.

- The final author version and the galley proof are versions of the publication after peer review.

- The final published version features the final layout of the paper including the volume, issue and page numbers.

Link to publication

\footnotetext{
General rights rights.

- You may freely distribute the URL identifying the publication in the public portal. please follow below link for the End User Agreement:

www.umlib.nl/taverne-license

Take down policy

If you believe that this document breaches copyright please contact us at:

repository@maastrichtuniversity.nl

providing details and we will investigate your claim.
}

Copyright and moral rights for the publications made accessible in the public portal are retained by the authors and/or other copyright owners and it is a condition of accessing publications that users recognise and abide by the legal requirements associated with these

- Users may download and print one copy of any publication from the public portal for the purpose of private study or research.

- You may not further distribute the material or use it for any profit-making activity or commercial gain

If the publication is distributed under the terms of Article $25 \mathrm{fa}$ of the Dutch Copyright Act, indicated by the "Taverne" license above, 

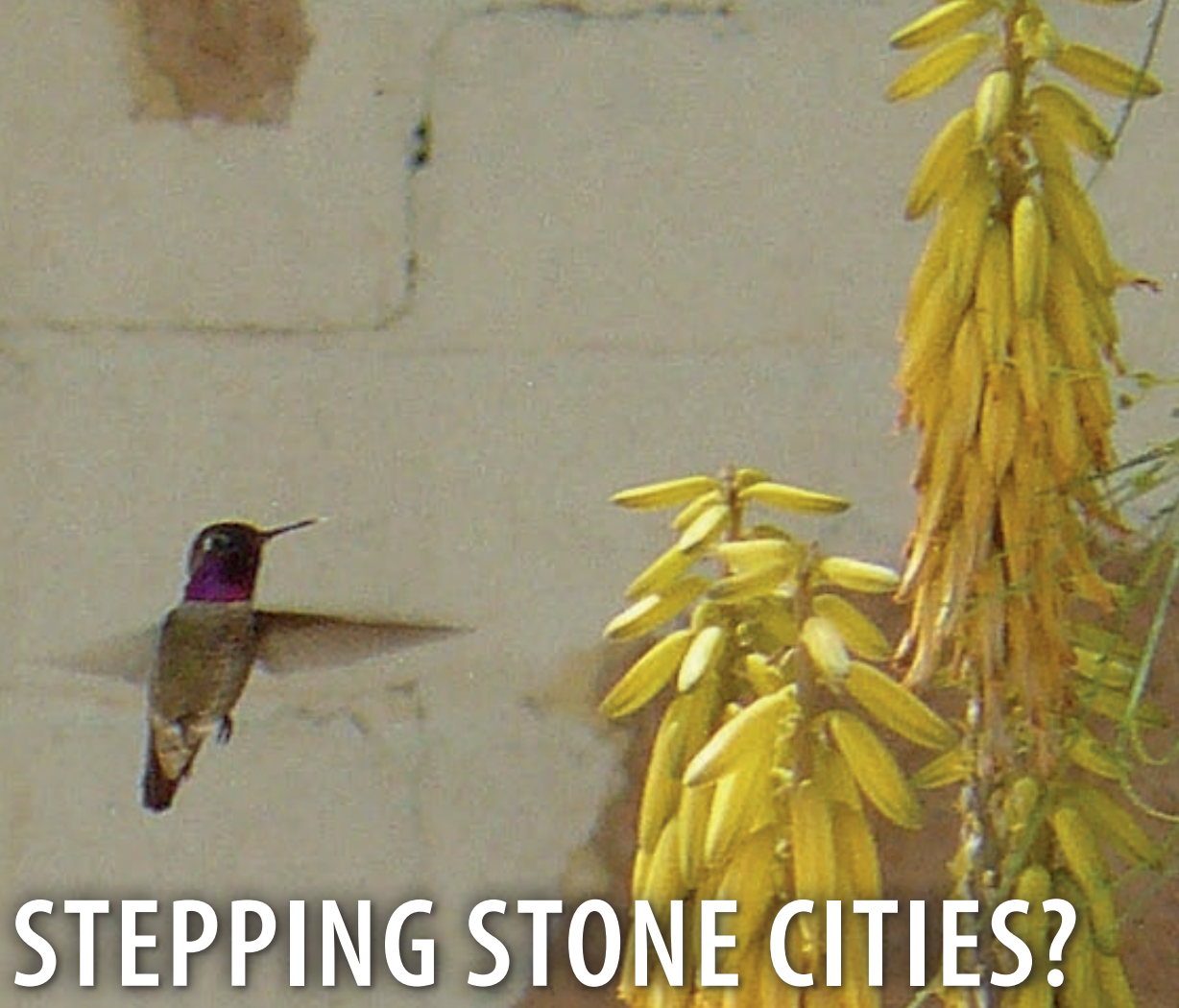

Exploring Urban Greening and Gardening as a Viable Contribution to Global Biodiversity Conservation

\section{Carijn Beumer}
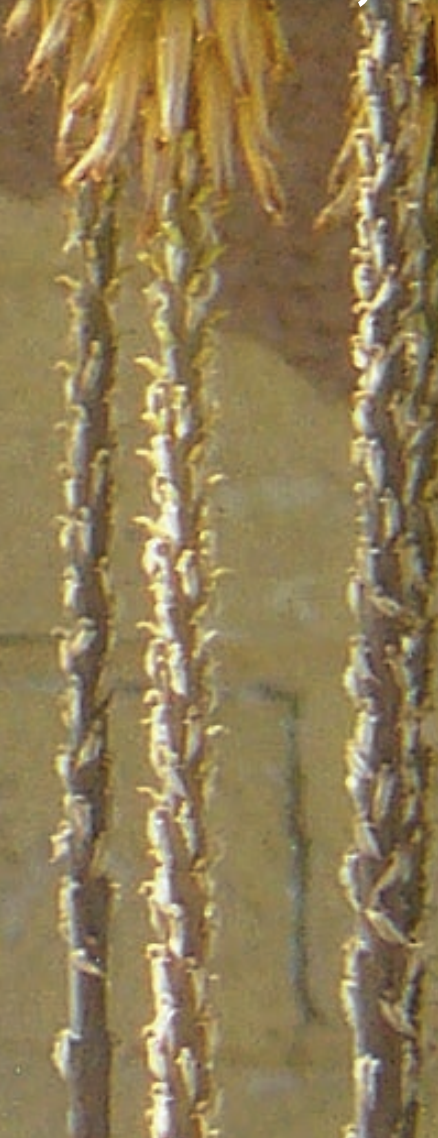
Universitaire Pers Maastricht

ISBN 9789461593849

(C) copyright Carijn Beumer, Maastricht 2014

Printing: Datawyse / Universitaire Pers Maastricht 


\title{
Stepping Stone Cities?
}

\section{Exploring Urban Greening and Gardening as a Viable Contribution to Global Biodiversity Conservation}

\author{
DISSERTATION \\ to obtain the degree of Doctor at Maastricht University, \\ on the authority of the Rector Magnificus Prof. dr. L.L.G. Soete, \\ in accordance with the decision of the Board of Deans, \\ to be defended in public on Thursday 4 December 2014 at 10:00 hours \\ by
}

Carijn Beumer

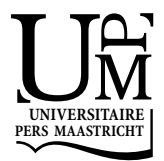




\section{Supervisors}

Prof. dr. Pim Martens

Prof. dr. ir. Harro van Lente

\section{Assessment Committee}

Prof. dr. Jan Stel (chairman)

Dr. Raf de Bont

Prof. dr. Nancy Grimm (Arizona State University)

Dr. Dolf de Groot (Wageningen UR) 


\section{Contents}

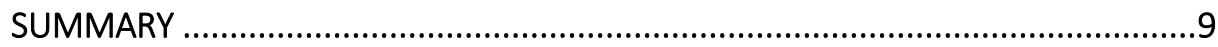

PART I

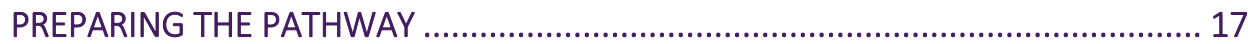

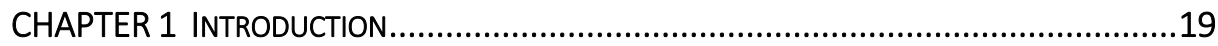

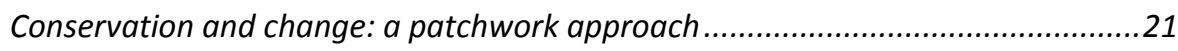

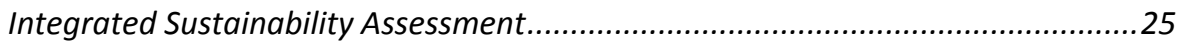

Dissertation structure: stepping stones and jumping patches ..............................27

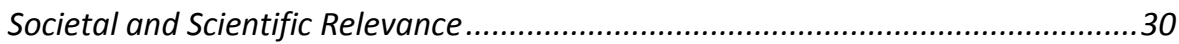

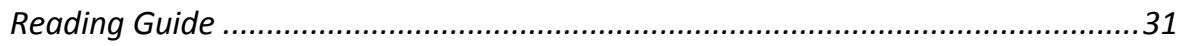

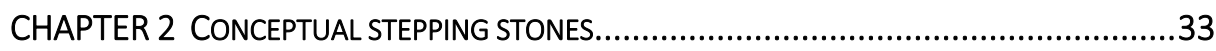

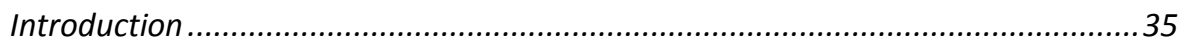

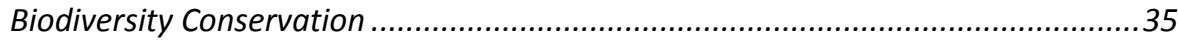

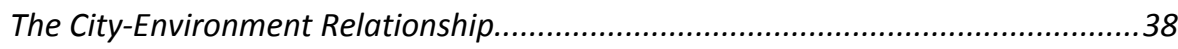

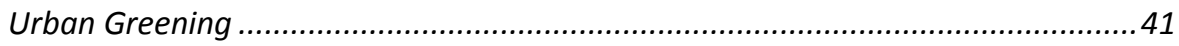

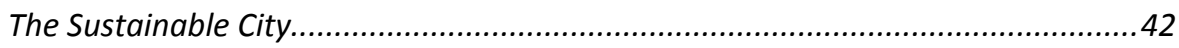

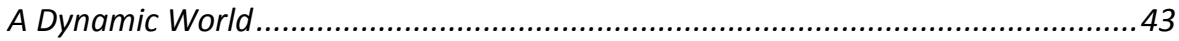

Sustainable Development ........................................................................

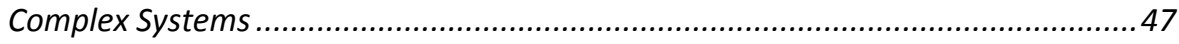

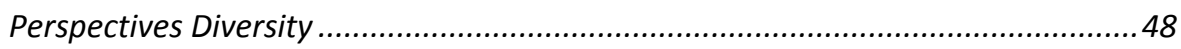

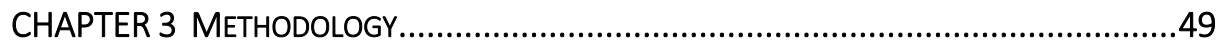

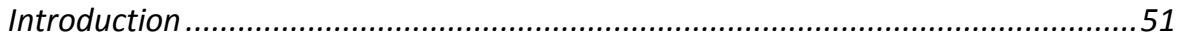

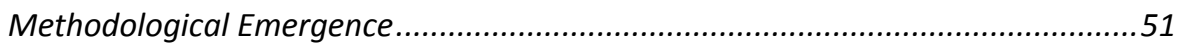

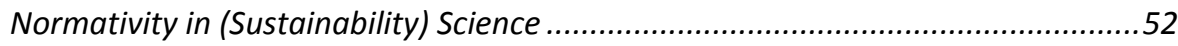

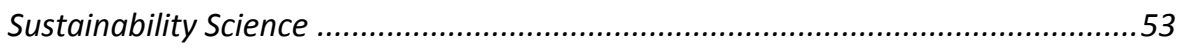

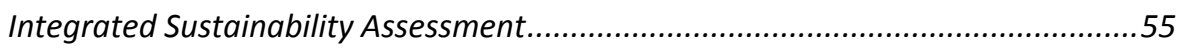

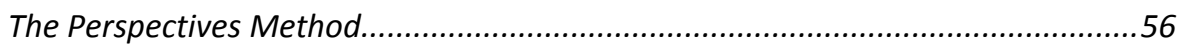

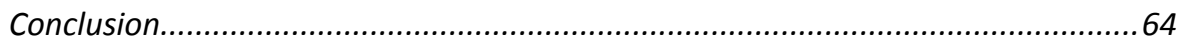




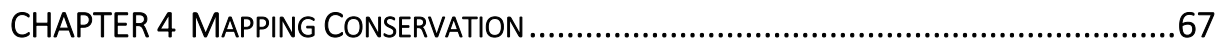

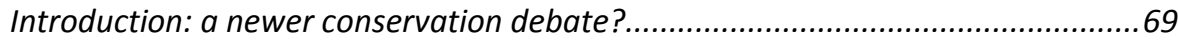

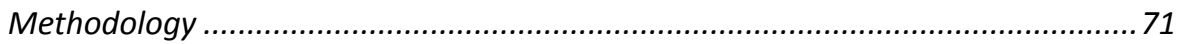

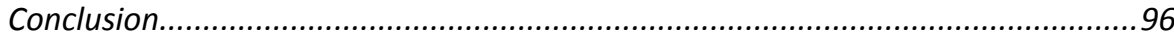

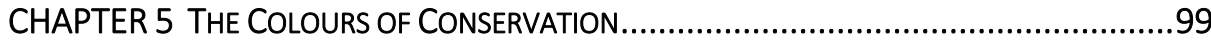

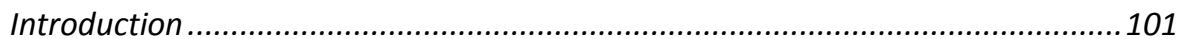

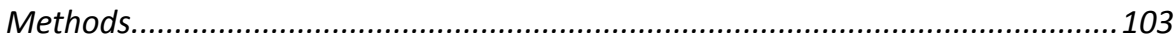

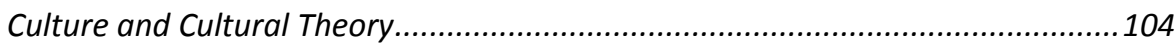

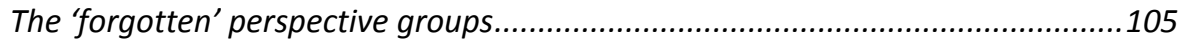

Cultural perspectives in models of global change dynamics?..............................113

The role of the cultural perspectives on the transition levels of $T T$.......................116

The routes of the perspectives on the Transition and Panarchy models ...............119

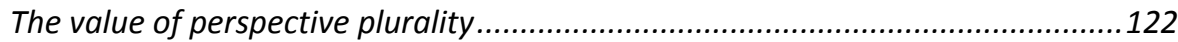

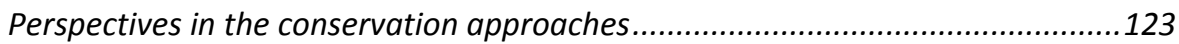

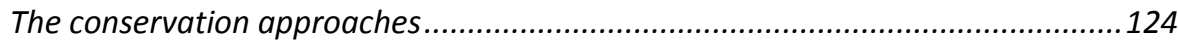

Mapping the perspectives ...............................................................................131

Discussion: the uses of perspective diversity in societal change dynamics.............134

Conclusions: Conservation Dynamics................................................................137

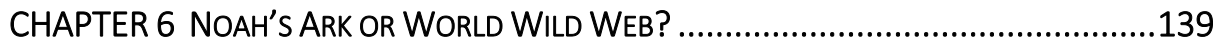

Conservation in a Changing World: Uncertainties and Assumptions ....................141

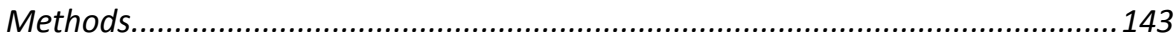

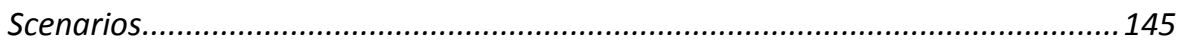

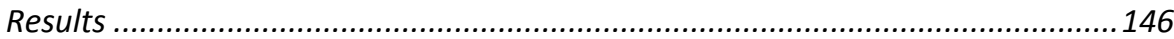

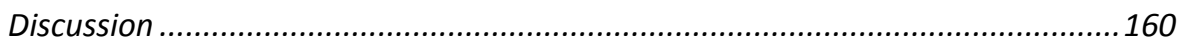

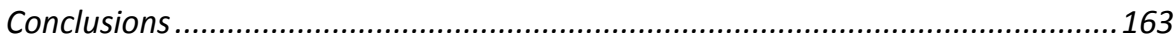

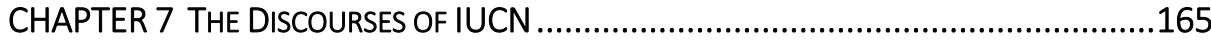

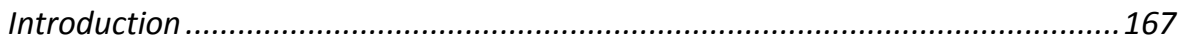

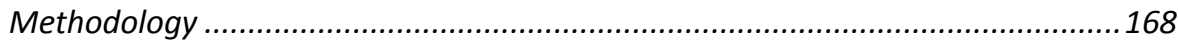

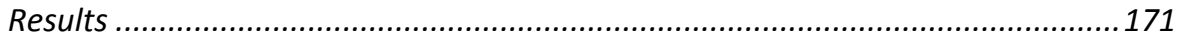

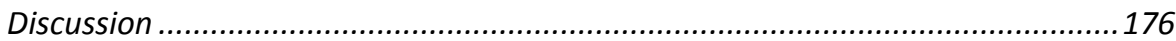

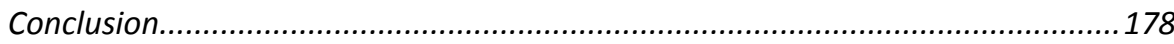




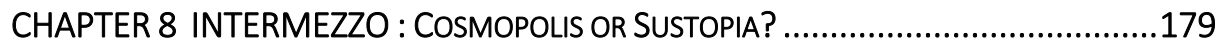

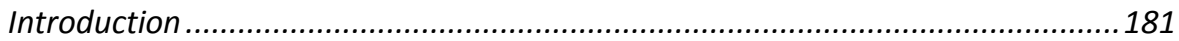

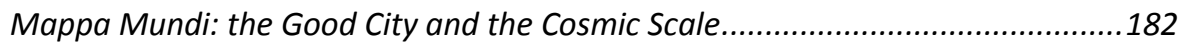

Allowing nature into cities: creating a new order ..............................................184

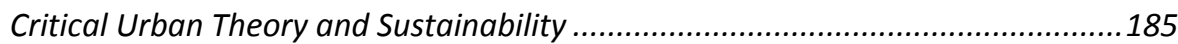

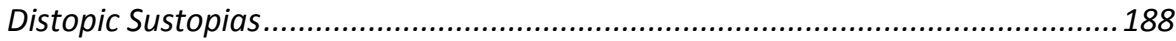

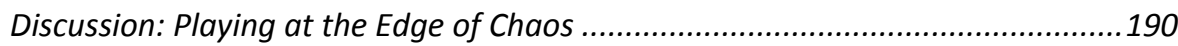

Conclusions: Re-embracing Cosmopolis............................................................191

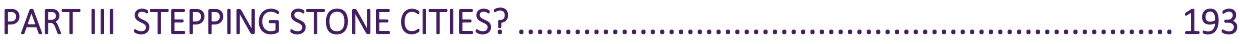

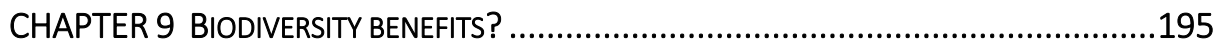

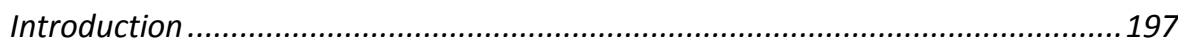

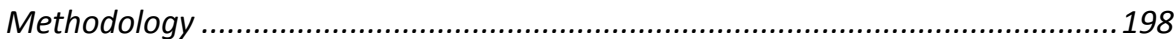

Exploring the Literature on Urban Ecology and Urban Biodiversity ......................202

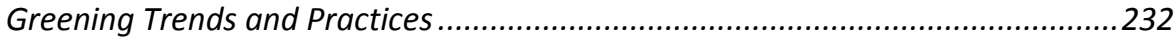

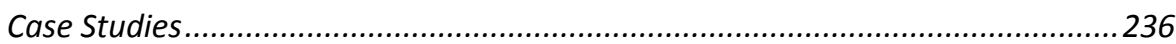

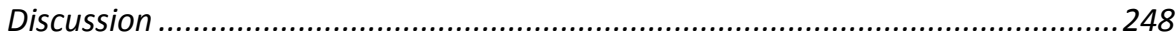

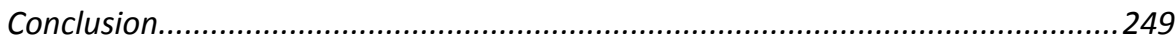

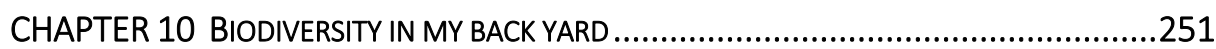

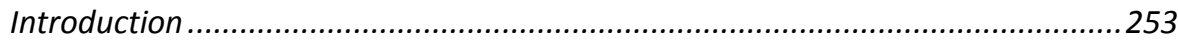

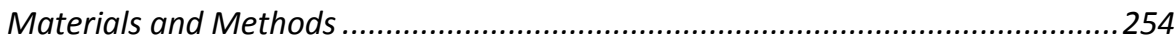

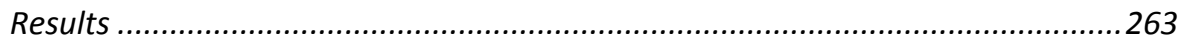

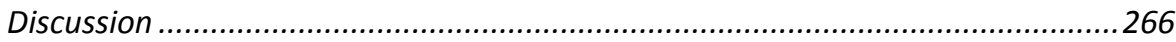

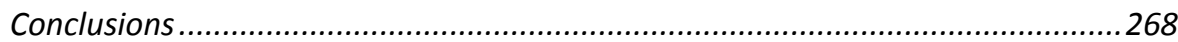

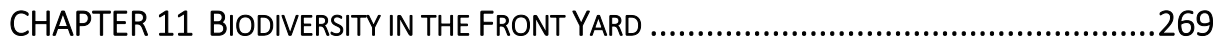

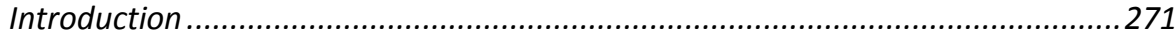

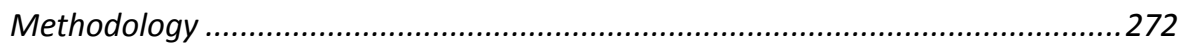

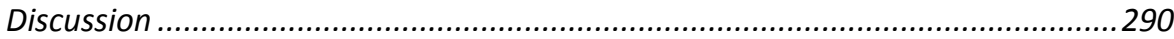

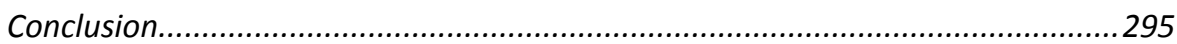

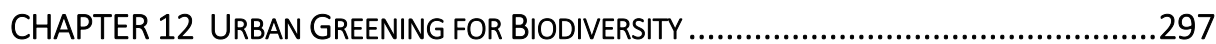

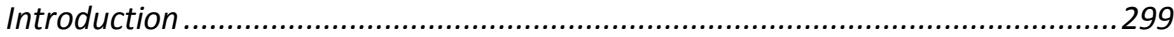

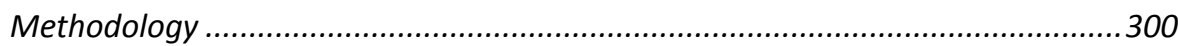

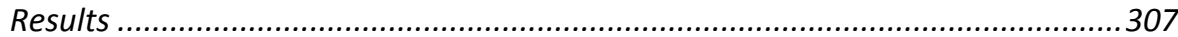




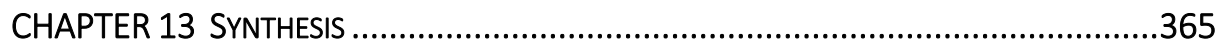

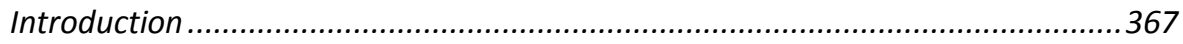

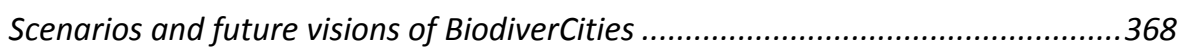

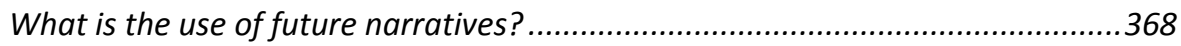

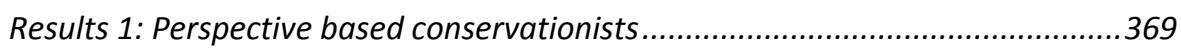

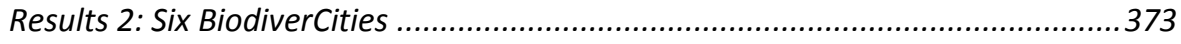

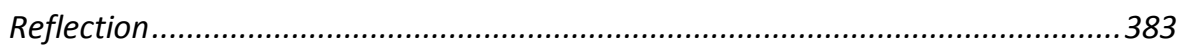

CHAPTER 14 CONCLUSIONS, DISCUSSION AND FUTURE RESEARCH QUESTIONS ..............385

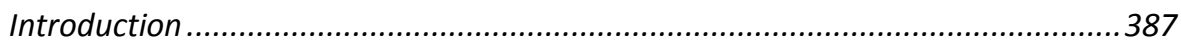

Part I. Reflection on used methods and approaches ..........................................389

Part II. The Status of the Current Conservation Regime .......................................392

Intermezzo: Critical reflection on 'The Sustainable City'.......................................399

Part III. The potential role of urban greening and gardening for biodiversity

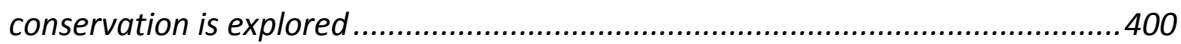

Part IV. Urban based conservation in six BiodiverCities .....................................408

Can urban greening and gardening be a viable approach for addressing global

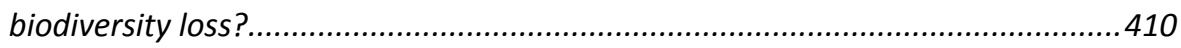

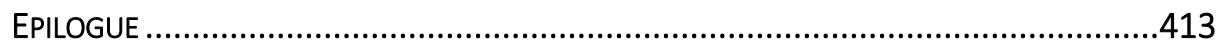

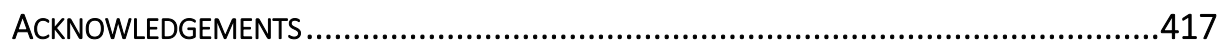

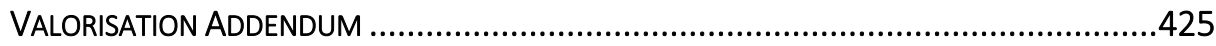

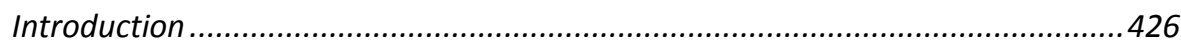

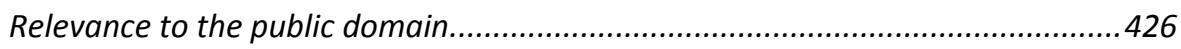

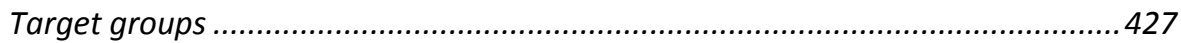

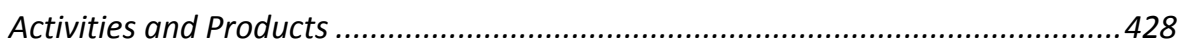

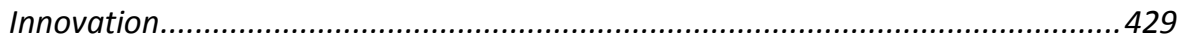

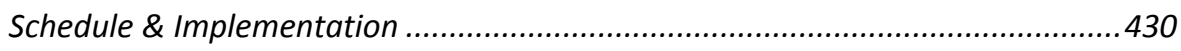

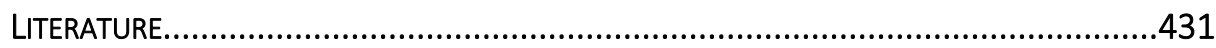

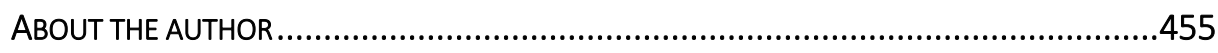


SUMMARY 
"Order is what exists before you start arranging things."

Marty Rubin 
Are urban greening and gardening viable approaches to help addressing global biodiversity loss? In this dissertation I explore biodiversity conservation as a practice with many faces, zooming in from a global conservation perspective to one particular strategy: urban greening and gardening and its potential role for conservation in a rapidly changing world. Not so much an ecological exploration of this question is provided, but one that is mainly based on the cultural perspectives that constitute conservation paradigms on the one side, and human practices and discourses in the field of urban greening and gardening (for conservation) at the other side.

Change is a fundamental characteristic of the global ecosystem and contemporary human practices have accelerated global change in ways that fundamentally transform the global landscape. Crutzen and Stoermer, for example, call the new geological era that emerges from recent and contemporary human impact on the planet the 'Anthropocene' (Crutzen \& Stoermer, 2000). The Anthropocene is a geological era that is characterised by human domination on the planet and it will be described (by potential future generations) for its long lasting remains: e.g. terrestrial- and oceanic pollution, an altered global climate, changed and fragmented ecosystems. Currently, the global ecosystem is strongly impacted by processes of large scale and vast urbanisation: the growing global human population is increasingly seeking life and a living in cities and smaller cities have been turning into megalopolises fast during the last decades. Urban lifestyles, imports and exports of services, resources and wastes are increasingly putting more pressure on the already weakened global ecosystems and on biodiversity (Grimm, N. et al., 2008).

One of the main challenges in the Anthropocene era is to maintain a viable biosphere that is grounded in biological diversity: the variety of living entities on the planet and their complex web of functional relations. Stated by earth system scientists, the urgency of taking action to protect biodiversity from a runaway decline is high (MEA, 2005; Steffen et al., 2005; CBD, 2011; Rolston, 2012; Pimm et al., 2014). However, due to the complexity of the problem it is difficult to set clear priorities and to define undebated pathways (Miller et al., 2011; Minteer \& Miller, 2011; Robinson, 2011). The early conservation movement mainly aimed to protect species and ecosystems. The contemporary conservation movement has broadened its scope and includes the diversity of life, of ecosystems (Takacs, 1996) and of ecosystem services (Costanza, 1997; TEEB, 2009, 2011; Costanza et al., 2014). In this dissertation the field of biodiversity conservation is approached as a patchwork of distinctive yet partly overlapping practices and discourses with many ambiguities and tensions: between stakes and stakeholders, between scale levels, between conservation approaches and conservation priorities and between their underlying basic assumptions and (shifting) cultural perspectives. In general there are two levels on which biodiversity conservation will be explored in this thesis: Firstly, I will look into conservation perspectives on the global level. Secondly, I will explore how the 
perspectives on the global level link up with ideas and practices that are ongoing on the local citizen level.

The practical and theoretical question for the next decades is: can biodiversity conservation be reconciled with a rapidly changing, urbanising world? Such a research ambition requires a variety of approaches and sites. As said before, biodiversity conservation is a patchwork of various practices, means and ends. More importantly, conservation practices are human practices: practices defined by basic assumptions of people about the world (worldviews) and basic assumptions about the right strategies (management styles) to solve problems that occur in the world. As such I define 'conservation practice' in a cultural context: as a patchwork of practical expression(s) (Latour, 1988, 2005; Robinson, 2011) of a variety of cultural perspectives (Verweij et al., 2006). A shift towards including urban areas in the conservation patchwork implies a societal distribution of conservation practice: where conservation has been basically driven by (funded) research and (political and non-political) governance, in an urban context it may have to become carried by the everyday life actions and daily practices of civil society.as well. Is civil society ready to contribute to conservation in that way? Including urban areas and citizens in the conservation patchwork may contribute to halting global biodiversity loss, but it will most probably also be surrounded by new (socio-cultural) complexities and challenges.

In order to better understand the (socio-cultural) complexities in the conservation field and to explore viable approaches for conserving biodiversity for the future, it is important to gain a better insight into the basic assumptions and worldviews underlying the patchwork of conservation practices. It may help address and understand synergies and tensions between different existing conservation approaches and styles. Such insights may help to understand why global targets for halting the loss of biodiversity haven't been met yet. Also it may help to explore the question whether including urban ecosystems as a site for conservation may be a viable approach and an effective cultural practice for maintaining a thriving biosphere.

The methodological framework of this dissertation in based on Integrated Sustainability Assessment (ISA): fitting the complexity and plural character of the topic a set of qualitative and (semi-)quantitative methods are employed to address the main questions. In order to assess conservation as a patchwork of cultural practices grounded in a patchwork of cultural discourses I chose to use the Perspectives Method (Offermans, 2012) based on Cultural Theory (Thompson et al., 1990; Thompson, 1997; Mamadouh, 1999; Verweij, et al., 2006) as the basis for the key-analytical tool for this dissertation research. The Perspectives Method (Offermans, 2012) has earlier proven to be a useful tool in Integrated Sustainability Assessments (Asselt et al., 1995; Rotmans \& De Vries, 1997; Valkering et al., 2006; Valkering, 2009; Offermans, 2012). It has been applied before to 
analyse discourses in water management (Valkering, 2009; Valkering et al., 2009; Offermans, 2012), climate change governance (Verweij, et al., 2006), and uncertainties concerning health, energy, biochemical cycles, and land- and water use (Rotmans \& De Vries, 1997).

Limitations to Cultural theory have been articulated well by Astrid Offermans (Offermans, 2012). One important limitation that is addressed in this dissertation is the empirical problem of distinguishing people according to theoretical dimensions. It is argued that it is not the grid-group based 'boxes' of the theory that are most interesting to learn from, but the combinations, dynamics and functional relations between the plurality of existing dominant and marginal perspectives: no 'culture' on any scale level functions well without a diverse array of worldviews and management styles to address internal and external problems (Erez \& Gati, 2004). An analogy of the value of cultural diversity can be drawn with ecological diversity: diverse ecosystems are resilient ecosystems (McCann, 2000; Gunderson \& Holling, 2002; Folke et al., 2004; Bottrell, 2009; Rees, 2010; MacDougall et al., 2013). The question about the 'value of cultural diversity' for 'biodiversity' is central in my exploration of the patchwork of conservation practices and underlying discourses.

After delineating background concepts and the methodological framework (Part I), Part II of the dissertation starts with the conceptual mapping of a variety of contemporary conservation approaches and practices (CHAPTER 4). A content analysis of documents presenting the approaches gives insight into the cultural perspectives underlying these conservation practices (CHAPTER 5). CHAPTER 6 presents an analysis of the Cultural Perspectives represented by scenario-storylines of two significant global scenario studies: the IPCC scenarios and the Millennium Ecosystem Assessment scenarios. It is evaluated what these storylines and their underlying assumptions mean for the future of global biodiversity and its conservation. Then, I continue towards exploring the cultural perspectives represented in the oldest and largest conservation organisation IUCN (CHAPTER 7).

In Part III I explore the rather novel approach of urban based conservation. Urban based conservation can be seen as a form of 'reconciliation ecology' (Rosenzweig, 2003; Kellert et al., 2008; Mitchell \& Mueller, 2009; Beatley, 2011; Francis \& Lorimer, 2011; Tidball, 2012). Reconciliation ecology aims to bridge the nature-culture divide in conservation thinking by focusing on the greening of cities for biodiversity and for a sustainably living planet (Beatley, 2011). After a theoretical study of the literature on urban sustainability (CHAPTER 8) and urban greening (CHAPTER 9) I explore the viability of the urban based conservation approach by assessing the outlook of Dutch citizens and of international experts on urban greening, represented by contemporary greening trends and gardening practices and designs. Based on the literature study (CHAPTER 8 and 9), empirical fieldwork in front-yards in Maastricht and Phoenix (Arizona) (CHAPTER 10 and 11) and surveys (CHAPTER 12) two frameworks are proposed: one for conceptually discuss- 
ing benefits for biodiversity in urban greening projects: the Biodiversity Benefits Framework, and one for assessing ecological and cultural contributions to biodiversity delivered in domestic gardens and stimulating a societal dialogue about biodiversity and sustainability in and beyond urban areas: the BIMBY framework. The combined results of the various assessments lead to six qualitative Cultural Perspectives based storylines for future biodiversity conservation in an urbanised world (CHAPTER 13).

In Part IV the main findings of the research are presented and discussed and future research questions are identified.

\section{The main conclusions drawn from the results of this dissertation are:}

Urban based conservation may become a viable approach to address global biodiversity loss in the near future. Yet, it is only a potential and there are some difficulties to address before urban based conservation can become viable for biodiversity:

- Until now, urban based conservation seems to be largely driven by academic and institutional elite forces. It hasn't yet trickled down to the core of the conservation regime and the public.

- Urban based conservation is still a largely unintentional process in society: urban greening and gardening are unguided by critical discussions on what are sustainable and desirable outcomes for biodiversity.

- There is a knowledge gap in civil society when it comes to linking urban greening and gardening practices to biodiversity conservation concerns. This can be attributed to the lack of well-functioning frameworks and markers to discuss urban based conservation and its potential and limits.

To overcome these hurdles, some points of departure can become leading:

- Traditional conservation organisations can start playing an important role with regards to increase awareness about the potential of urban areas for biodiversity, closing the knowledge gap, and increasing eco-literacy in (urban) society.

- There is a diversity of academic and societal motivations for urban greening, there is a great variety of practical options for urban greening and gardening, and these have something in them that may be attractive to all sorts of perspectives.

- The Biodiversity Benefits framework and the BIMBY framework can become tools for increasing and structuring a societal discussion about urban based conservation.

- Marginal perspectives can be emphasised as a potential source of critical reflection on the status quo of society, a source of creative innovation and of novel ideas for urban greening and gardening for biodiversity. 
Concluding, it can be said that cities may become important 'hubs' for local and global biodiversity in an urbanising world. Urban based conservation offers a great potential for increasing the quantity and quality of local and global green infrastructures. Equally important: citizen creativity and engagement offers a wide range of additional strategies, tools and practices to the conservation field: urban greening and gardening practices have many forms and features and are limited only by the limits of the human creative potential.

Some caution should also be considered: urban based conservation can never replace the efforts undertaken to protect the few wild areas still left on the Earth. However, in the end Stepping Stone Cities may become important hubs in a global network of ecocultural creativity that enables a sustainable future for biodiversity and life on earth. 
PART I

Preparing the Pathway 

CHAPTER 1

Introduction 
"Clouds are not spheres, mountains are not cones, coastlines are not circles, and bark is not smooth, nor does lightning travel in a straight line."

Benoît B. Mandelbrot 


\section{Conservation and change: a patchwork approach}

Thinking of biodiversity conservation used to take my mind towards wide African savannahs with their elephants, giraffes and lions, towards the impenetrable mysteries of the Brazilian rainforest or the secret and strange life forms that hide in red sandy deserts or in the coral reefs. I often dreamt of living a 'Jane Goodall life', strolling and roaming through forests and pristine areas, studying interesting species that should be kept safe from greedy human project developers, resource exploiters and poachers. Sometimes I would return to 'civilization' to raise awareness and to teach and plea and lobby for the 'good cause'.

This romantic assumption of what conservation is inspired and motivated me to start my $\mathrm{PhD}$ research about biodiversity conservation. Embedded in an academic institute for Sustainability Science and Integrated Assessment I wanted to assess conservation in a context of global change. Change is a fundamental characteristic of the global ecosystem, but contemporary human practices have accelerated global change in ways that fundamentally transform the global landscape. Crutzen and Stoermer call the new geological era that emerges from recent and contemporary human impact on the planet the 'Anthropocene' (Crutzen \& Stoermer, 2000): a geological era that is characterised by human domination on the planet. It will be described (by potential future generations) for its long lasting remains: e.g. land- and oceanic pollution, a geological layer of noncompostable waste, an altered global climate, changed and fragmented ecosystems. Currently, the global ecosystem is strongly impacted by processes of explosive urbanisation: the growing global human population is increasingly seeking life and a living in cities. Smaller cities have been turning into megalopolises fast during the last decades. Urban lifestyles, imports and exports of services, resources and wastes are increasingly putting more pressure on the already weakened global ecosystems and on biodiversity (Grimm, et al., 2008).

As goes along with most research and learning processes: not only is the world changing, my world has been changing too. My perspectives on what conservation is and could be, has drastically shifted during my years of working on this dissertation. And yes, it has become less romantic, but not less interesting.

First of all it became apparent that conservation is a practice with many faces: more a patchwork of a wide array of practices and approaches. Next to the Jane Goodalls and the Jacques Cousteaus, there are the big organizations such as WWF and IUCN, lobbying with governments and businesses to develop more ecologically sustainable policies. There are seed vaults, storing the genetic material of our diverse agricultural species. There are bioengineers working with genetic material to develop 'new species'. There are zoos giving people real life experiences with all sorts of species from all over the 
world. There are breeding programmes for endangered species and there are armed rangers on the ground, protecting wildlife while risking their own lives in battling poachers. There are hunters who were actually the first people to make a case for conserving wild species to be able to continue the sports on the long term (Larson, 2001), and ecotourists give nations and regions economic incentives to maintain and preserve their natural heritage. And this is by far not the whole spectrum.

Most conservation practices represent biodiversity conservation as something taking place over there, in wild places that are not dominated by human species. But what about the biodiversity close to home? In our direct (urban) living environment; in our houses, our parks, our roadsides, gardens? Working on the Interreg SUN Project (Sustainable Urban Neighbourhoods, 2009-2012)1 opened my eyes for the conservation potential of human dominated ecosystems like cities to enhance a more sustainable world. I wanted to learn more about this potential and about the way citizens deal with the conservation potential of cities in practice.

Cities are becoming the hubs of human activity in the world. They are the centres where all the 'bad' and all the 'good' of human existence are coming together (CBD, 2012). As immense resource absorbing and excreting 'organisms' they are the biggest challenges to our global environmental resilience. And to (bio)diversity. Next to their environmental impacts, globalisation processes lead cities to become increasingly uniform around the world: with similar architecture, similar shops, similar parks, similar gardening trends (Ignatieva, 2010). Paradoxically, cities are also called to provide the greatest chance for changing the world into a better, more sustainable place, because of the incredible creativity and human potential that emerges from urban living (Grimm, et al., 2008; Millard, 2010). In accordance to this assumption the sustainable development and the greening of cities are becoming a key issue for policy and civil action the $21^{\text {st }}$ Century.

Indeed, due to ongoing biodiversity loss in this rapidly changing world and an urgent quest for solutions a process has started to redefine the concept and direction of biodiversity conservation (TEEB, 2009; IUCN, 2011e; UNEP-CBD, 2011). Continuing biodiversity loss demonstrates that the efforts of the traditional conservation regime may not be enough to halt the loss of the diversity of life on Earth in time. Instead of conserving wild nature and species out there, efforts are emerging to start looking for other strategies. Terms like integrated conservation, mainstreaming, and engaging businesses and citizens can be found all over the recent literature and reports on conservation. Researchers in the field of ecology and conservation increasingly start looking very close to our

1 Interreg SUN Project 2009-2012: www.sun-euregio.eu 
own homes for solutions: our urban landscapes and ecosystems (Rosenzweig, 2003; Beatley, 2011; Francis \& Lorimer, 2011).

Based on these trends, there are two general levels on which biodiversity conservation will be explored in this thesis: Firstly, I will look into conservation perspectives on the global level. Secondly, I will explore how the perspectives on the global level link up with ideas and practices that are ongoing on the local citizen level.

Until recently, the greatest focus in urban sustainable development and the development of 'green cities' has been on energy use, energy efficiency and on climate adaptation and mitigation. This energy focus on climate change in cities has left a gap in the area of the other 'green stuff' that plays an important role in (urban) sustainable development: biodiversity, the variety of life on the planet. Recently and globally, many citizens have been taking up their shovels to start gardening: lawns are turned into small urban farms to grow herbs and vegetables; brownfields are turned into colourful meadows; forgotten urban niches and roadsides are decorated with plants and flowers by guerrilla gardeners; insect hotels, green roofs and green walls enjoy popularity in commercial gardening centres, and swopping seeds has become a thriving activity in online and offline social networks. Such urban greening and gardening practices are increasingly studied and supported by ecologists, conservationists and policymakers for their potential role for global biodiversity as well (McKinney, 2002; Mathey \& Rink, 2010; Müller et al., 2010; Certomà, 2011; Francis \& Lorimer, 2011; Kowarik, 2011; Cameron et al., 2012; Barton \& Tan, 2013; Lachmund, 2013). These developments have been guiding to formulate the main question of this dissertation: Is a shift towards including urban areas in conservation a viable approach to help addressing global biodiversity loss?

In this introduction I will delineate the research strategy that such a question entails. My strategy is based on three conditions, which render it mandatory to explore various research sites. First, as said before, the field of biodiversity conservation is not homogenous, but a patchwork of distinctive yet partly overlapping practices and discourses. Second, the scale of the practices and discourses varies enormously: it ranges from global issues and national concerns to local initiatives. Third, all efforts to conserve biodiversity are shot through with many ambiguities and tensions: between stakes and stakeholders, between scale levels, between conservation approaches and styles, between conservation priorities and their underlying basic assumptions and between cultural perspectives.

By starting from the patchwork character of the issue at hand, this study differs from and contributes to the increasing body of literature on the role of urban ecosystems for biodiversity (Zerbe et al., 2003; Sukopp, 2008; Müller, et al., 2010; Lachmund, 2013). .Not so much an ecological exploration of this question is provided, but one that is based 
on the cultural perspectives that constitute conservation paradigms and human practices and discourses in the field of urban greening and gardening. Given the characterization of the biodiversity conservation as a patchwork of practices and discourses at different scales of concern, and ridden with tensions, I will proceed in this thesis on two levels (global and local) and in four parts, answering several sub-questions that will be addressed in the consecutive chapters:

In Part I key concepts and methodological approaches are delineated.

In Part II the status of the current global conservation regime is explored. Sub-questions for this part are:

a. What practices and discourses make up the current conservation regime (CHAPTER 4, 6 and 7)

b. What tensions and synergies can be identified in the current conservation regime (CHAPTER 5, 6 and 7)?

In an INTERMEZZO a critical philosophical reflection is given on the idea of the sustainable city (CHAPTER 8).

In Part III the potential role of local urban greening and gardening for biodiversity conservation is explored.

a. What urban greening and gardening practices and regimes can be identified (CHAPTER 9, 10 and 11)?

b. How ready are citizens to intentionally and practically turn home gardens into nature reserves, verges into green corridors and rooftops into stepping stones for biodiversity (CHAPTER 10, 11 and 12)? In other words: Do the greening and gardening practices and discourses reflect a societal support for urban based biodiversity conservation?

In Part IV a synthesis is made of the aggregated research results and the question has been addressed what, based on these results, future cities would look like when taking sustainability and biodiversity concerns into account. These concerns reflect six different cultural perspectives, leading to six narrative future visions of BiodiverCities (CHAPTER 13). This synthesis is followed by conclusions, discussions and questions for future research (Chapter 14).

An urban based conservation approach may be complementary to the established practices and frames in the global conservation regime. It also makes sense to see it as one cloth in the patchwork of conservation practices. I see it as a typical expression of reconciliation ecology (Rosenzweig, 2003). Reconciliation ecology aims to bridge the natureculture divide in conservation thinking by focusing on the greening of cities for biodiversity and for a sustainably living planet (Beatley, 2011). An urban based approach to conservation may overcome certain boundaries to effective conservation, but it may also 
add new questions and dimensions to the conservation debate(s) (Clemmons \& Buchholz, 1997; Kelly, 1997; Escobar, 1998; Sarkar, 1999; McKinney, 2002; Peterson et al., 2003; Meine et al., 2006; Büscher \& Whande, 2007; Büscher \& Wolmer, 2007; Chan, 2007; McLachlan et al., 2007; Hagerman et al., 2010; IUCN, 2010c; Rands et al., 2010; IUCN, 2011b; Kowarik, 2011; Miller, et al., 2011; Minteer \& Miller, 2011; Robinson, 2011). My aim is to contribute to the conservation debate by providing insights into the plurality of the conservation practice and underlying worldviews and particularly by exploring the socio-cultural carrying capacity for cities that function as stepping stones towards global biodiversity. The notion of 'stepping stones' symbolically and practically refers to two things: firstly, it points towards the creation of green havens and green infrastructures in a landscape that is increasingly 'stonified' by urbanisation processes. Ecologists use the term stepping stones for green patches and spaces that functionally connect natural landscapes and species (Rudd et al., 2002; Baum et al., 2004; Kettunen et al., 2007; SS2N, 2012; Mitchell et al., 2013; Saura et al., 2014). Secondly, the notion of stepping stones suggests that urban based conservation through greening and gardening will very likely not be a paved road that unconditionally leads to success. It will be an uncertain endeavour, full of hurdles and difficulties, yet promising, and inspiring to many.

\section{Integrated Sustainability Assessment}

Approaching biodiversity conservation as a patchwork of practices and the four-partcharacter of this dissertation also requires a methodological approach that accounts for the complexity of the topic. The contextual background of global change and urbanisation, the urgency and 'wickedness' of the problem of biodiversity loss, and the plurality of practices, priorities and worldviews that are employed to tackle the problem create a typical case for Integrated Sustainability Assessment (ISA) (Asselt, et al., 1995; Rotmans, 2006; Valkering, et al., 2006; De Ridder et al., 2007; Lotze-Campen, 2008). Paul Weaver and Jan Rotmans (Weaver \& Rotmans, 2006) describe ISA as:

"strategic, sustainability-oriented, constructive and potentially transformative. Its key role is to explore the opportunity-creation and problem-solving potential of framing contexts other than those in place, such as alternative institutions, technologies, spatial and temporal arrangements, [...] and associated policy regimes (Weaver \& Rotmans, 2006)."

The aim and set-up of this dissertation and reflects this description of ISA: it is strategic by the development of concrete tools and frameworks for understanding and discussing urban based biodiversity conservation; it is sustainability oriented by its aim to explore novel ways to sustain ecosystems, biodiversity and quality of life in a changing, urbanis- 
ing world; it is potentially transformative, as it provides novel tools to engage citizens into participatory transformative projects with the aim to increase eco-literacy in society (the BIMBY framework and the Biodiversity Benefits framework); it reflects opportunitycreation and problem solving potential by exploring and systematically framing a novel approach to biodiversity conservation -- urban based conservation - through urban greening and gardening.

In order to operationalise these aims, various tools, theories, and disciplines have been combined to approach the central questions. The research framework as such also consists of a patchwork of strategies combining conceptual mapping exercises, scenario analysis, surveys, fieldwork, discourse- and content analysis, grounded theory, and critical philosophical reflections. Eventually, the juxtaposition of all the different elements has resulted in a dissertation that aims to contribute to an integrative, interdisciplinary and reflective discussion on biodiversity conservation in a changing, urbanising world.

\section{Cultural Theory and the Perspectives Method}

A central analytical tool applied in this dissertation is based on Cultural Theory (Thompson, et al., 1990; Thompson, 1997; Mamadouh, 1999; Verweij, et al., 2006; Offermans, 2012): the Perspectives Method (Offermans, 2012). In earlier ISAs the Perspectives Method has proven to be a useful tool to identify ongoing discourses in a variety of societal practices from water-management (Valkering, 2009; Offermans, 2012) to climate change governance (Verweij, et al., 2006). In this dissertation and publications based on the dissertation research (Beumer \& Martens, 2010; Beumer \& Martens, 2013), the Perspectives Method has been applied to biodiversity conservation for the first time. Some adaptations have been made to the theory to better suit this complex purpose (see CHAPTER 5). Limitations to Cultural Theory have been articulated well by Astrid Offermans (Offermans, 2012). One important limitation that is addressed in this dissertation is the empirical problem of distinguishing people according to theoretical dimensions. It is argued that it is not the categorisation of people or groups into the gridgroup based 'boxes' of the theory (Asselt, et al., 1995) that matter most, but the combinations, dynamics and functional relations between the plurality of existing dominant and marginal perspectives: no 'culture' on any scale level functions well without a diverse array of worldviews and management styles to address internal and external problems (Erez \& Gati, 2004). An analogy of the value of cultural diversity can be drawn with biological and ecological diversity: diverse ecosystems are resilient ecosystems (McCann, 2000; Gunderson \& Holling, 2002; Folke, et al., 2004; Bottrell, 2009; Rees, 2010; MacDougall, et al., 2013). Cultural differences can be seen as a source of strategic stagnation and action inhibiting conflict. However, the contrary is also possible: cultural diversity -- diversity of perspectives -- can also be considered as fundamental capital for cultural resilience: respecting, sharing, integrating and learning about different styles 
and views allows for constructive dialogue (or constructive conflict) (Cuppen, 2012) and creative solutions in a variety of different contexts and changing situations. It allows for greater socio-ecological adaptivity (Olsson \& Folke, 2007; Bottrell, 2009; Krasny et al., 2010; Rees, 2010; Tidball, 2012; Meijer et al., 2013).

\section{Dissertation Structure: Stepping Stones and Jumping Patches}

I emphasise the patchwork character of this dissertation. However, the patches of the work aren't randomly scattered. Biodiversity conservation is the red thread throughout the dissertation. Each patch of the dissertation is represented by a stepping stone towards the next one (see figure 1.1*). After the theoretical and methodological chapters the research starts with assessing conservation at the global level (the Global Scenario Studies). Then a jump is made towards an organisational level (IUCN). This organisational level is still closely linked to the global level of conservation. It delivers an important context for understanding the potential meaning of urban based conservation and the potential contribution of local level practices such as urban greening and domestic gardening to local, regional and global biodiversity. Finally, a synthesis of the results is provided through envisioning narratives for future BiodiverCities. In the following paragraphs, the dissertation patches are more closely described.

\section{Stepping stone 1: concepts, theory and methods}

In CHAPTER 2 the foundational concepts underlying the topic of this dissertation are independently explained and reflected. Discussed are: biodiversity conservation; the cityenvironment relationship; urban greening; the sustainable city; sustainable development; perspectives; a dynamic world; and complex systems. These conceptual stepping stones so to speak -- are meant to give insight into my own assumptions and interpretations of these complex multi-dimensional concepts. In CHAPTER 3 I delineate the methodological framework and assessment-steps taken in this dissertation work.

\section{Stepping stone 2: the global level and the organizational level}

In CHAPTER 4 and 5 I explore the level of global conservation strategies. A range of contemporary conservation approaches and the connections between them has been mapped. By conducting a content analysis of literature, I explored their underlying assumptions and worldviews. In CHAPTER 6 the discourse of two global scenario studies has been analysed: the Millennium Ecosystem Assessment (MA) Scenarios and the IPCC Scenarios. On this level I analysed worldviews on biodiversity represented in these scenario studies and possible links towards the future of conservation were identified. 
Jumping to one particular patch of the conservation practices patchwork (NGOs) was done by thoroughly analysing the discourse of the oldest and largest global conservation NGO: the International Union for the Conservation of Nature (IUCN) (CHAPTER 7).

\section{Stepping stone 3: the urban level}

After analysing IUCN, I jumped to the urban level. CHAPTER 8 and 9 present literature studies on urban sustainability and biodiversity conservation on the urban scale level. They constitute the theoretical stepping stones towards the last three CHAPTERs. CHAPTER 8 provides an independent philosophical reflection on The Sustainable City, which forms a context for the notion of urban based biodiversity conservation. In CHAPTER 9 a theoretical framework is developed and proposed to discuss the Biodiversity Benefits delivered by urban greening projects and practices.

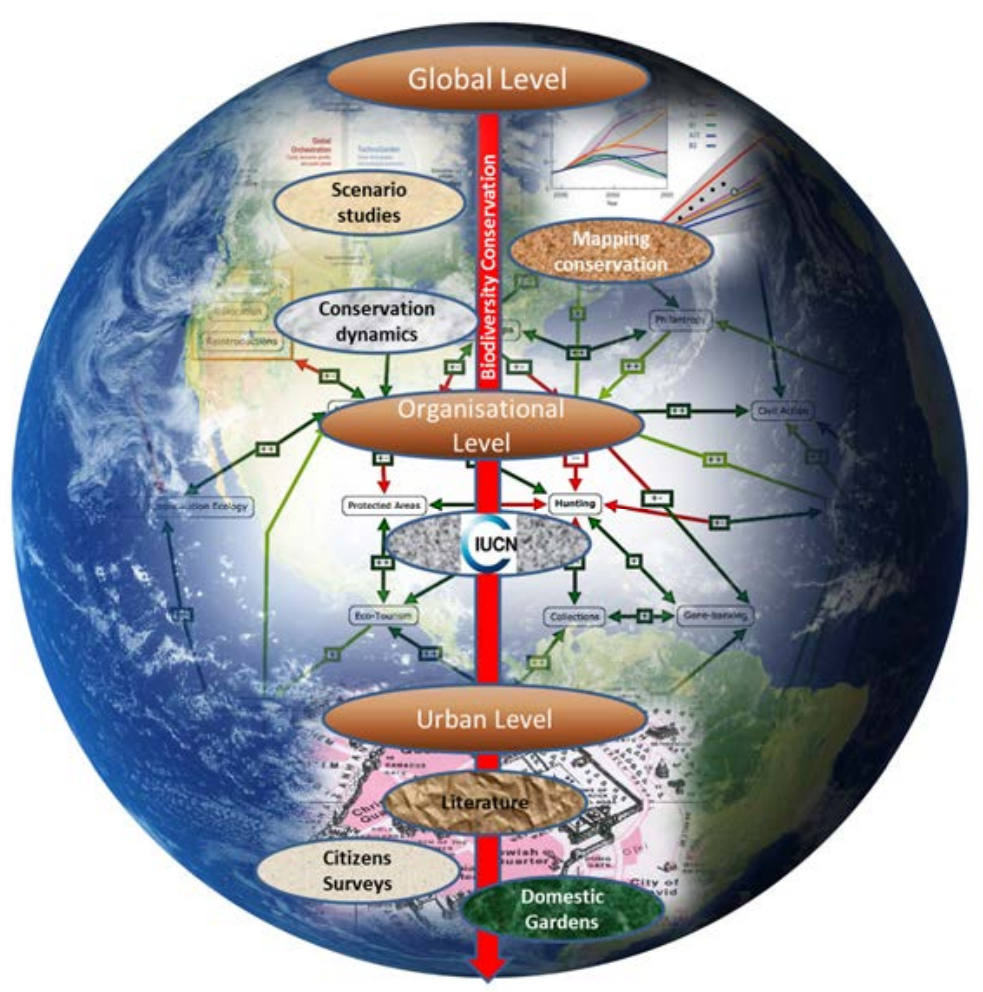

Figure 1.1. Overview Stepping Stones 


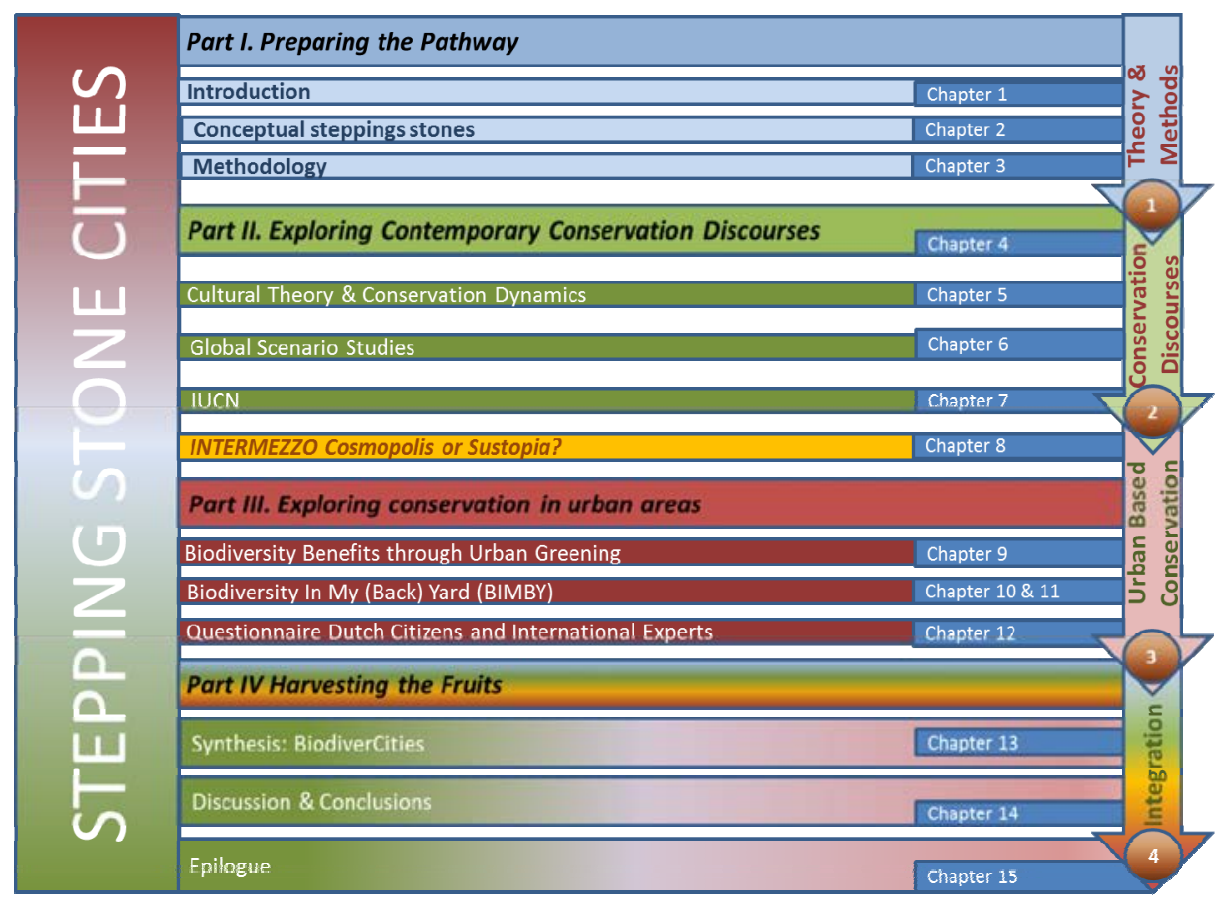

Figure 1.2 Research Steps and Chapters

The following two chapters jump to the level of individual citizens and their proximate living environments. These chapters are based on empirical work. Fieldwork was conducted in front-yards in Phoenix (Arizona) and in Maastricht (The Netherlands) in order to assess the way people design, maintain and use their domestic gardens. The assessment brought forward an indicator framework that can be used to the integrated assessment of ecological and cultural contributions or dis-contributions of domestic gardens to biodiversity and green infrastructures in cities and beyond. This BIMBY framework has the potential to be further developed as a participatory tool for transformative sustainability science (CHAPTER 10 and 11). Through surveys I further explored the perspectives and common gardening activities and preferences of both regular Dutch citizens and international experts in the field of conservation, sustainable development and urban sustainability in order to explore whether and to what extend civil society is aware of the potential of their own private outside spaces for the preservation of living diversity on the earth (CHAPTER 12).

\section{Stepping stone 4: synthesis}

CHAPTER 13 provides a scenario-synthesis where the patchwork of this research's approaches, explorations and conclusions are brought together in a range of Cultural Per- 
spective based narrative future visions for biodiversity in an urbanised world. In figure $1.2 *$ a visual overview is given of the research stepping stones and the connected chapters. In Chapter 14 presents conclusions, reflections and questions for future research.

\section{Societal and Scientific Relevance}

Exploring the literature about urban biodiversity and working together with urban ecologists, planners, landscape architects and practical 'urban greeners' in the SUN project pointed towards the potential role cities can play in conserving local, regional and global biodiversity. Bolund and Hunhammar (1999) point out to studies that show how Italian cities contain almost 50\% of all Italian species and that in Stockholm holds over 1000 different vascular plant species (Hancock, 2010). Many urban areas contain even greater biodiversity than the surrounding agricultural areas (Müller, et al., 2010; Müller \& Kamada, 2011). Gardens, exotic species and the heterogeneous patchwork of habitats account for great diversity of species within cities (Grimm, et al., 2008). The concept of a 'sustainable city' has become a recognized goal in science and policymaking (Newman, 1999; Cranz \& Boland, 2004). Although the focus is often on the climate and energy, the urban sustainability paradigm is increasingly including green infrastructures like parks, roadsides, roofs, wastelands, urban farming and gardening. This inclusion may not only benefit citizens with regards to climate adaptation and mitigation: it may also contribute to biological diversity and larger-scale ecosystemic health (McKinney, 2002; Zerbe, et al., 2003; Tzoulas \& James, 2004; CBD, 2007a; Dearborn \& Kark, 2009; Goddard et al., 2010; Mathey \& Rink, 2010; Müller, et al., 2010; Francis \& Lorimer, 2011; Ignatieva et al., 2011; Kowarik, 2011; CBD, 2012; Lachmund, 2013). Novel insight from urban ecology, coupled with insights from sociology, psychology, and with the arts, architecture, social innovation, participatory policymaking and citizen engagement will play a crucial part in the transition towards sustainable life in and beyond urban areas (Bedsted, 2012; CBD, 2012).

Most of the existing literature about urban biodiversity discusses the impact of local and regional life forms in and around the city, or the impact of cities on local and regional biodiversity (Savard, 2000; Marzluf et al., 2008; Müller, et al., 2010). Literature that reflects research on the role of urban ecology for sustainable development on the global scale level is present as well (Cranz \& Boland, 2004; Grimm, et al., 2008). Urban biodiversity has also already been discussed beyond its relevance for the city level, but these discussions usually reflect the influence of external ecosystems and biodiversity on cities (Hancock, 2010). A dominant paradigm in urban ecology focuses on ecosystem services delivered by urban nature and another dominant one focuses on exchanges of flows of resources and pollution (see CHAPTER 9). Authors on the relation between biodiversity, conservation and culture often pay attention to local rural and indigenous cultures and 
to Traditional Ecological Knowledge (TEK) (Posey, 1999). In 2010 a voluminous edited book was released called Urban Biodiversity and Design (Müller, et al., 2010). This seems to be the first release that also incorporates the human dimension of cities as a real coevolving part in 'the global ecosystem'. It gives a beautiful first insight into the entangled relation between urban culture, citizens, their proximate environment and the potential role of citizens for global biodiversity conservation.

The aim of this dissertation is to contribute to the conservation debate and global biodiversity conservation in a time of rapid urbanisation. Novel in my research approach is the application of the Perspectives Method derived from Cultural Theory on the subject of biodiversity conservation. Broadening the toolbox of Integrated Sustainability Assessment with qualitative methods from the humanities (discourse analysis, content analysis, and critical reflection) is another asset of this dissertation. Also novel is the patchwork of various assessments making it possible to dive into a variety of levels of the topic of biodiversity conservation. With focusing on urban greening and gardening practices as a particular and recently emerging conservation patch that I call urban based conservation, I aim to contribute to exploring the question on how biodiversity conservation and halting global biodiversity loss can be reconciled with a rapidly changing, urbanising world. I synthesise my findings by presenting six narrative scenarios that elaborate six various ways of how cities can become stepping stones for global biodiversity.

\section{Reading Guide}

This dissertation book is inclusive in providing all the relevant research results. However, as some pictures are accompanied by colour legends, the dissertation is also linked to a website* . Pictures accompanied by an asterisk $\left({ }^{*}\right)$ can be accessed on in full-colour on the website. The Appendixes of the dissertation can also be accessed online.

On this website, also a full colour PDF version of the book can be found.

The web-address: www.BIMBY.nl or http://carijnbeumer.wix.com/bimby 



\section{CHAPTER 2}

Conceptual Stepping Stones 
"Life is like an ever-shifting kaleidoscope - a slight change, and all patterns alter."

Sharon Salzberg

"Change is nature, the part that we can influence, and it starts when we decide." Remy in Ratatouille 


\section{Introduction}

In this chapter I provide a conceptual background for this dissertation's topic. This background is approached from various disciplinary perspectives: philosophy, ecology, sociology, urban studies, anthropology, science studies, and sustainability science. Through bringing together these perspectives small semi-independent reflections - 'conceptual stepping stones' -- on key concepts of this dissertation are presented: biodiversity conservation; the city-environment relationship; urban greening; the sustainable city; sustainable development; perspectives; a dynamic world; and complex systems.

As researchers we carry our individual knowledge-legacies, visions, emotions, norms, values, and myths. In brief: our personal perspectives make up substantial part of the choices we make in what we research and how we research it (Latour, 1988). While displaying and describing the variety of key concepts of this dissertation, I also acknowledge that although I try to be integrative, I can impossibly be inclusive of everything. With this chapter, I aim to deliver a theoretical overview on how I, as a researcher with my own (educational) background2 and personal preferences, interpret and use specific key concepts in this dissertation.

\section{Biodiversity Conservation}

The quite recent concept of 'biodiversity' has been coined by Walter Rosen in 1986 (Takacs, 1996). Being shorthand for 'biological diversity' at first, it has become a fashionable term in science that often substitutes the word 'nature' (Takacs, 1996; Sarkar, 1999). 'Nature' on the one hand, is a historically vague term, used and misused in many occasions (Soper, 1995). It often refers to unspoilt and untouched wilderness, but it has many connotations. 'Biodiversity' on the other hand (Sarkar, 1999), may be more specific, more pragmatic and it embraces much more than 'wild nature' at the same time. It refers to "diversity at multiple scales of biological organization (genes, populations, species, and ecosystems) and can be considered at any geographic scale (local, regional, or global) (MEA, 2005, p.2)." The International Union for Nature Conservation (IUCN) defines biodiversity as "the variability among living organisms from all sources including terrestrial, marine and other aquatic ecosystems, and the ecological complexes of which they are part; this includes diversity within species, between species, and of ecosystems (IUCN, 2013a)." It relates to all different 'sub-systems' of ecological organization in the biosphere (MA 2005) including ecosystems where the humans are the dominant species -- like urban areas (Sukopp, 2008). The concept of biodiversity is based in the idea of complex and dynamic ecosystems, including the notion of evolution and natural change

\footnotetext{
2 My academic background is constituted in Culture- and Science Studies
} 
(Takacs, 1996; McCann, 2000; Jagers, 2012): an ever changing dynamic system, sometimes closer to- and sometimes far from equilibrium (Prigogine \& Stengers, 1984; Prigogine, 1996).

Contrary to the dynamic connotations of the concept of biodiversity, 'conservation' literally implies a search for stability and the prevention of change. However, the concept is not always used very literally. In the conservation-preservation debate (Meine, et al., 2006; Miller, et al., 2011; Minteer \& Miller, 2011; Robinson, 2011) conservation does allow for modest human induced change of the environment and it allows the 'wise use' of the Earth's 'resources'(Miller \& Hobbs, 2002; Miller, et al., 2011). Conservation is commonly denoted as a weaker form of caring for the life on earth. Social and economic interests are taken into consideration. Often these stakes collide with the notion of preservation of nature, or wilderness (Sarkar, 1999). Preservationists are usually classified under the label of strong sustainability(Capra, 1996). The preservationists' ethic is eco-centric and he aims to keep and maintain the last untouched wildernesses of the planet (Sarkar, 1999; Giddings, 2002; Robinson, 2004; Williams \& Millington, 2004; DesJardins, 2006). Preservation, in this light seems to be the more static notion of protecting the life of the planet.

In the scientific discourse 'conservation' is used as an umbrella term for every effort -- stronger and weaker, conservationist or preservationist -- to 'save nature and what is left of it'. The meanings and connotations become intermingled again: basically, conservation practice - in practice -- is still rooted in the old Newtonian belief that nature is an inherently stable clockwork that should be kept and maintained as it is (DesJardins, 2006). Seen from this perspective there seems to pop up a paradox: why do we aim to 'conserve' things that are bound to change due to evolutionary and geological processes? I call this the 'biodiversity conservation paradox'.

Although scientific insights have changed rapidly during the last decades and contemporary ecologists are trained with a dynamic systems view, I claim that the present conservation discourse is still basically grounded in the philosophical tradition of seeing the world as a more or less stable place. In this world it is regarded a 'moral good' that things should be kept as they are (DesJardins, 2006). This idea stems from a long philosophical tradition, rooted in Aristotelian teleology. Aristotle argued that all living beings have their own specific potential. Life is the process of these potentials becoming actualized. Teleology is strongly connected to ethics. Aristotle's answer to the idea of what is 'Good' was that all things should be allowed to actualize their potential (Copleston, 1993a; Bechler, 1995; Barnes, 2003; DesJardins, 2006). This idea was further developed by Thomas Aquinas who Christianized much of Aristotelian Philosophy. He interpreted Aristotle's teleology in the way that a divine plan operates in nature, and that as such, the natural order reflects the moral order of the heavens (Copleston, 1993b; DesJardins, 2006). Afflicting change to the natural order seen from this perspec- 
tive is considered ethically wrong. Life should be given the opportunity to fulfil its greatest potential. The best way to treat nature in this mainly bio-centric perspective is to "leave everything in the pristine state, or return it to its pristine state (Rogers et al., 2008, p.23)."

Conservation practice is often divided between the static and dynamic conceptualisations of nature. Contemporary ecological insights are at odds with the static conception of nature. System dynamics, evolutionary processes, energy fluxes and dynamic communities are some concepts which are represented in much of contemporary ecological literature. The discipline has emerged while being closely connected to ideas of complexity and change in the natural world. However, the conservation movement in the field is often based on teleological ethics and individual species survival or animal wellbeing. An example of this can be seen in the public debate going on in the Netherlands about National Park De Oostvaardersplassen: should the animals in the park get additional fodder during wintertime or not; should dead animals be left on the fields or not? Systems-thinking oriented ecologists argue that death is part of the natural cycle of life and the ecosystem. Protective conservationists say we have a moral duty to help decrease the suffering of individual animals (Mennen et al., submitted).

Where the teleological tradition in the conservation discourse focuses on the intrinsic value of life and living individuals on earth, the conservation discourse based on ecological systems-thinking has been profoundly influenced by a more pragmatic and utilitarian philosophy. Utilitarianism is basically founded in hedonism: the idea that human happiness is the highest human good. This idea was propagated by Epicurus and debated by Plato, Aristotle, Augustine and Aquinas (Lowry, 1981). The idea was taken ahead to become political-economic utilitarianism in the $19^{\text {th }}$ century through the writings of Jeremy Bentham and John Stuart Mill (Lowry, 1981; DesJardins, 2006). Utilitarians aim to "produce the greatest good for the greatest number (DesJardins, 2006, p.30)." Environmental utilitarianism can be immediately linked to the 'use values' of nature: things are good when they are good for the greatest number of people. This can be interpreted in a sense that nature is good when it can be turned into a resource that contributes to satisfying (human) needs and happiness. Environmental utilitarianism can also be linked to concepts as functional relations, functional connectivity, food chains and ecosystem goods and services (Costanza, 1997; Groot, 2002). In this thought-tradition nature has instrumental value to the life and well-being of individuals and 'the system' (achieving the greatest good for all). To be able to scientifically grasp what is the 'good' or the 'value' of nature, it has to be quantified (Costanza, 1997; Opschoor, 1998; TEEB, 2009; Aitken, 2012). This quantification of nature makes it easy to subject the value of nature to cost-benefit analyses. The cost-benefit analyses have some fundamental problematic sides: it is for example difficult to include all the values of nature, also the ones that cannot be priced or quantified so easily (DesJardins, 2006). 


\section{Field, regime, approach, practice and discourse}

In this dissertation, conservation is often accompanied by words like 'field', 'regime' 'practice', 'approach' and 'discourse'. With the term conservation field I refer to the whole range of conservation options, actions and approaches that can be found in the world. With the term conservation regime I refer to a specific set of approaches and practices - making up a specific discourse - which is leading in the conservation field. With conservation practice, I refer to conservation actions in a broader sense. With conservation approaches, I refer to specific conservation actions, like protected areas, ecosystem services, or religious approaches. The conservation discourse refers to the language, framing, and the power-implications that are inherent in the level of specific conservation regimes, (sets of) actions or (sets of) approaches.

\section{The City-Environment Relationship}

The growing human population needs more and more space and resources (Meadows et al., 1972) and the benefits and conveniences brought to us by our continuing industrial, technological and economic development make it attractive to increase our ecological footprint (Wackernagel \& Rees, 1996). The ecological footprint of urban areas extends far beyond city boundaries (Grimm, et al., 2008). A study of Folke and colleagues (Folke et al., 1997) estimated that cities claim ecosystem support areas 500 to 1000 times larger than the areas of the cities themselves. Most of this land needed for provisioning and supporting urban living, is gained by converting natural landscape into vast modern agricultural landscapes (MEA, 2005). The land use change through urbanization, agriculture, industry and modern infrastructures causes increasing fragmentation of landscape and habitat (MEA, 2005). In pre-industrial times cities were the 'patches' of human habitat in the wider natural matrix. Nowadays, the picture has inversed: some preserved and fragmented patches of 'wilderness' remain present in the wider matrix of manufactured landscapes (Burtynski, 2006).

Greening cities and making them part of ecological networks and infrastructures (Rudd, et al., 2002; Kettunen, et al., 2007; Mitchell, et al., 2013) seems to be a promising way to tackle the emerging ecological fragmentation. Nevertheless, there are also profound difficulties and tensions in the urban-nature relationship complicating efforts to 'bring nature into the city' that have to be taken into account. Conflicting stakes and perspectives of urban dwellers on green in the city and other socio-cultural, economic and political boundaries need to be addressed in order to co-produce cities that are thriving with life (Lyytimäki et al., 2008).

At the other hand: precisely this diversity of urban dwellers makes cities dynamic centres of creativity and innovation. Recently, in Europe, the US and in other parts of the world as well, many bottom-up initiatives of creatively greening public and private urban 
spaces are emerging. Guerrilla Gardening, Vertical Gardening, Pop Up Parks, Urban Farming, Transition Towns and Permaculture are just a few popular examples of greening 'trends' sprouting in our contemporary cities. Still, the more specific role that cities and urban culture - on the level of citizen lifestyles and practices -- could play for global biodiversity has only very recently become considered in the scientific literature, debates and in policymaking. However, largely ignored still are an integrative methodological assessment of the societal support, the awareness and the cultural perspectives on the potential of advancing cities as green 'stepping stones' for biodiversity.

Talking about biodiversity conservation in a dynamic world is talking about a complex relation between cultural and natural change. Traditionally, in Western philosophy and science, there has been a conceptual dichotomy between the 'two worlds' of nature and culture (Böhme, 1992; Gibbons, W., 1993; Soper, 1995; Takacs, 1996; Snow, 2001 [1959]). There is an extensive body of literature covering the centuries of science and philosophy, witnessing the debate and the history of the boundaries of the two 'domains' (Soper, 1995). Plato's question about the 'true nature' of things and his distinction between the natural world and the world of perfect ideas is often seen as the origin of the nature-culture debate in Western philosophy (Mumford, 1965; Soper, 1995). The question was continued by Aristotle, Aquinas and Augustine. After that Descartes and Rousseau left important imprints on the topic (Nash, 1989; Copleston, 1993a; Bechler, 1995; Takacs, 1996; Keulartz, 1999; Barnes, 2003; DesJardins, 2006). The Romantic and Enlightened philosophers of the $18^{\text {th }}$ century brought the discussion to a new peak (Kluckhohn, 1966; Bortoft, 1996; Capra, 1996; Shapin, 1996; DesJardins, 2006); the Enlightened philosophers objectivising nature which made it possible to employ the idea of the 'laws of physics' for the development of 'enlightened societies' and cultural innovation (Spary, 1999); the Romantics arguing against the rationalisation of nature and stressing the connectedness of human nature to the natural world. Nature wasn't a static object that could be submitted to rational scientific methods. The romantics conceived nature as a dynamic organism in an on-going state of 'becoming'. Not the rational scientific method was the way to understand her, but through connecting with her through arts, literature, poetry and music (Kluckhohn, 1966; Bortoft, 1996). Later (in the late $19^{\text {th }}$ Century) the method of 'Verstehen' or interpretative understanding was introduced in German social sciences, which was also founded in the anti-positivist attitude of the Romantic philosophers (Bortoft, 1996; Elwell, 1996) and carried on by the critical theorists of the earlier 20 ${ }^{\text {th }}$ century (Mumford, 1965; Escobar, 1999; Castro, 2004; Lilley, 2004b; Brenner, 2009; Giddens, 2009; Marcuse, 2010; Redclift \& Woodgate, 2010). This epistemological approach has always remained an apparent 'undercurrent' in the (social) sciences and philosophy, especially in the more eastern parts of Europe.

The current postmodern philosophical movement accentuates the social construction of nature, which is also partly based on this 'Romantic' tradition of understanding the world (Best \& Kellner, 1997). Human beings - also researchers - can never be objec- 
tive observers of nature (Latour, 1988). They will always engage their own norms and values in the decisions they make about methods and tools they use and in the way they interpret processes, theories and contents. Science as such, helps to construct the world around us (Pinch \& Bijker, 1984; Best \& Kellner, 1997) and the distinction between nature and culture in philosophy slowly fades. Due to globalisation processes, influences from other cultures may also help nuance the nature-culture distinction (Nassauer, 1995b; Chesters, 2004; Erez \& Gati, 2004; Nederveen-Pieterse, 2004; Beumer \& Martens, 2010; Jasanoff, 2010). Complexity theory and systems thinking also play their parts in breaking the age old dichotomy (Soper, 1995; Capra, 1996; Takacs, 1996).

Despite these philosophical currents, the nature-culture divide still seems to dominate our daily practices and policymaking. It is reflected in the way we live, build and design our environments and our cities. We still act on the outdated principles of the scientific revolution and Newtonian mechanistic thinking in societal practices, policy and in many scientific and technological disciplines. According to many, this deeply entrenched cultural attitude caused the sustainability problems we are now facing (Capra, 1996).

In this work, I will approach the question of the 'two worlds' from a systems-thinking perspective, regarding the 'two domains' as closely interlinked and intimately coevolving, while at the same time acknowledging that conceptually the separateness of the domains is often practical for clarity reasons. Perhaps the metaphor of a double helix can best envision how I see the relation between the two domains. Erez and Gati (2004) show this entwined and intimate interrelationship in the way they propose to define culture as "what a group learns over a period of time as that group solves its problems of survival in an external environment (Erez \& Gati, 2004)." Steffen and his colleagues show how cultural practices leave earth changing imprints on the planet and as such coproduce our physical environment (Steffen, et al., 2005) resulting in a new geological era coined the Anthropocene by Paul Crutzen (Crutzen \& Stoermer, 2000). Gunderson and Holling (2002) went some steps further and, inspired by the Greek god Pan they drew a conceptual model of unpredictable change in socio-environmental systems and included a notion of hierarchies across scales to represent processes of adaptive co-evolution. They called it the Panarchy model. The model has space for multiple "myths of nature" (i.e. nature is flat, nature is balanced, nature is anarchic, nature is resilient, nature is evolving) and as such it implicitly integrates different subjective views or cultural paradigms on what nature is, how its processes function and what kind of policies could lead to what kind of consequences (Gunderson \& Holling, 2002, p. 12). Throughout this dissertation, I emphasise the plurality of perspectives in how people see the world and in how people cope with the problems we are facing. 


\section{Urban Greening}

Cities are not just a structured pile of bricks with roads in between. Cities are the ultimate 'expressions' of culture and cultural diversity. Humans have built cities to help us cope with the hazards of nature, to survive in collective and organised ways and to become more comfortable (Morris, 1969). But how comfortable and healthy are our current cities really? Do they still help us to survive? And how cooperative are our individualistic ways of modern living really? According to Desmond Morris contemporary city life makes many people sick, lonely or even aggressive (Morris, 1969). Cities seem to be "dynamic machines or [...] voracious monsters (Gandy, 2004, p.364)" where numb minds do their daily numb-making tricks and where people are no more than the economic system's cogwheels. Some people are able to cope and adapt to these environments, others are not (Krupat, 1998) and adaptation also often has its costs (Nasar, 2011). Have contemporary cities exceeded the goal of their initial existence (Gehl, 2010) of protecting people from the hazards of the 'outside world'?

Social and environmental psychologists and health researchers describe numerous negative effects of urban areas on the well-being people, from bad air quality and noise to social pressures, crime and the deprivation of beauty and green (Morris, 1969; Krupat, 1998; Stansfeld et al., 2000; Banerjee, 2003; Wills-Herrera et al., 2009; Grahn \& Stigsdottir, 2010; Nasar, 2011). This is a rather negative view of what the city does to humans. Solutions are found in either moving to the countryside or by bringing green into the urban environments in the form of parks, gardens, green roofs or lawns (Cranz \& Boland, 2004). Traditionally, most of the urban environmental improvement happened as a response to social problems (Cranz \& Boland, 2004; Szilagy, 2011; Hofmann et al., 2012). Green spaces were often implemented and designed as 'pleasure grounds', recreational facilities (with play equipment for children) or open spaces. Green space has been seen as space where people can meet, breathe some fresh air, exercise and have some social control. Aesthetic approaches - based on the idea of mental appreciation -prevailed ecological approaches in the green space design (Cranz \& Boland, 2004). Galen Cranz and Michael Boland (2004) describe a novel emerging model for urban parks that is based on a new set of pressing 'social difficulties:' environmental problems. The new emerging urban parks inherently recognize the conflation of social and ecological problems and are built around the ideas of sustainability and ecological design (Cranz \& Boland, 2004; Cilliers, 2010; Millard, 2010).

However, staying put in creating parks to tackle complex and intertwined issues may be just another 'micromanagement' approach to creating a healthier environment. In my view greening cities may need to go far beyond constructing urban parks and green spaces designed on ecological principles. The focus may be already slowly shifting towards more holistic solutions to improving the quality of life in cities for humans and non-human beings. This is what is made possible by seeing cities as living organisms, vibrant and buzzing with a dynamic metabolism (Newman, 1999; Beumer et al., 2010). A 
holistic view on creating green infrastructures on all scale levels, from large landscape levels to neighbourhood levels through greening domestic gardens fits the dynamic metabolism concept probably best. However, that is my personal normative view on what urban greening 'should' become and it forms the starting point of this dissertation. I don't only focus on urban greening for the well-being of human urban residents, but also as a potential way to enhance the conservation of non-human species diversity on a changing, urbanising planet: in and beyond urban areas. Urban greening, in that sense also may encompass more than creating green spaces, lawns and parks. It may require specific ways and patterns of greening practices: ways that are sensitive to local and regional species and sustainability conditions.

\section{The Sustainable City}

During the past centuries cities have evolved from geographically relatively small, limited and regionally independent focal points of human activity to large, vastly networked urban areas: megapolitan regions with connections all over the world (Grimm, et al., 2008; Bruijn et al., 2009). The majority of the human population now concentrates in cities and urban areas (Grimm, et al., 2008). Worldwide, the population of urban residents increases every year (Savard, 2000; Hancock, 2010). By 2050, two third of the world population is expected to have taken residence in cities (CBD, 2012).

A city takes in required resources and materials and releases products such as wastes and goods to the environment. It needs a variety of types of agents (people, machines, etc.) and infrastructures to organize the flow of stocks -- products, services and wastes -within the city. These city processes reach far beyond the city boundaries. Air, water, and travelling people are the main carriers of such urban processes and products (whether they be beneficial or harmful) into more distant places (Grimm, et al., 2008). Seeing the city as a living organism makes it easier to grasp the complexity of the city system and its relation to its environment and its inhabitants.

There are many levels and scales of stocks and flows (Rotmans, Jan et al., 2000) in a city and they are all interconnected. On a static physical level there are buildings, infrastructure, artworks and green spaces. On a more dynamic physical level there are people, cars, animals, water and goods and on a level of abstract flows there are services, money, skills, ideas and time. These stocks and flows spill over to its broader environment: rural areas, natural areas, villages, other cities and even into other places of the world (Wackernagel \& Rees, 1996; Rees \& Wackernagel, 2008). Simultaneously, outside activities have impact on the functioning of the city and its life quality. It requires a lot of energy to keep the processes of a city intact. A city is a complex and dynamic landscape where human and ecosystem services meet in order to keep the city and its inhabitants alive (Niemala, 1999; Grimm, et al., 2008). The complex processes between cities and 
their environment show the entangled intimacy of their relationship (as earlier imagined with the metaphor of a double helix) and the boundaries of these domains are rather fuzzy.

The urban metabolism concept is not new in urban planning and science. It was coined by Wolman in 1965 in an article in the Scientific American where he "quantified the flows of energy and materials into and out of a hypothetical American city (Niza et al., 2009, p.388)." The metabolism concept is based on the idea that the Earth itself is a living organism. Former NASA scientist James Lovelock formulated the idea as the Gaia hypothesis (Lovelock, 2000). This idea of a living Planet-system could be easily transposed to smaller ecosystems and urban areas, which are also ecosystems with their own dynamics and interactions. During the 1960s researchers mainly focused on the dynamics of the physical infrastructure of the urban ecosystems (Rotmans, Jan, et al., 2000). Afterwards, the urban metabolism concept was further developed through the process of "exploring the interactions among resource flows, urban transformation processes, waste streams and quality of life (Rotmans, Jan, et al., 2000)". It also developed into a useful societal metaphor (Gandy, 2004) in order to explore possibilities and chances for sustainable urban development (Newman, 1999). In the words of Rees and Wackernagel: "as the nodes of energy and material consumption, cities are causally linked to accelerating global ecological decline and are not by themselves sustainable. At the same time, cities and their inhabitants can play a major role in helping to achieve global sustainability (Rees \& Wackernagel, 2008, p.537)."

\section{A Dynamic World}

An ecosystemic way of seeing the world, allows seeing stability and change in the worldsystem at the same time. If we compare the world today to the world of 2500 years ago, the world is very different and very similar at the same time. A Greek philosopher living 300 B.C., visiting our age through a time machine, might regard our place as quite peculiar, but most probably he would not be entirely lost. Our language is different, but he might find people in Europe who still understand his tongue. The physical features of 'Culture' in the 21st Century changed dramatically throughout the centuries, but modern infrastructure and architecture are largely based on formalistic elements and principles of the classical era. Now, there are less 'wild' spaces, and they are more fragmented throughout the industrialized and urbanizing landscape, but a philosopher can still take a walk along the beach or a forest, spot deer and birds, rest against a tree in a field or climb a mountain. He will also find that in Europe we still categorize things according to the logic of Aristotelian thinking and we still use dichotomies based upon even more archaic ideas about good and evil. Although different answers are given to most of the 
same questions the philosopher had asked during his time, nowadays we still try to give meaning to an immensely complex universe.

Questions about the nature of change have always somehow been at the centre of our philosophical and scientific journey towards understanding. Heraclitus, Aristotle, the Stoics, Augustine, William of Auvergne, Aquinas, Newton, Einstein, Spinoza, Nietzsche, Bergson, Foucault, Castells, Prigogine, Giddens and many others have dealt with the question of change, time and eternity. The notions of being and becoming have a central position in most philosophies of change. The scale-level of these concepts differs from the particular or atomic levels through the personal level (growth and individual development) to the universal level (creation and evolution).

Nowadays much effort goes into understanding and influencing evolution, environmental- and social change. The 'growth of knowledge' and the global networks that have evolved in order to gain more knowledge, have not made understanding our world easier (Latour, 1988; Hassan \& Jones, 2003). During the course of time we have developed new mythologies to grasp global complexities (Latour, 1988; Mikulecky, 2007). Instead of gods, holy places, elemental creatures, miracles, powerful monsters and heroes who fight them, we have machines, industries, microbes, gravity, DNA structures, quantum theory, GMOs and scientists who grow human ears upon mice. These new mythologies however, seem not to be the Alpha and Omega to slay the 'monsters' of the contemporary world. On the contrary, they seem to be part of new puzzles, quests and challenges.

Often change is being represented as a crisis. Many authors state that the world is in the state of a global systemic crisis (Capra, 1996; Gallopin et al., 1997; Crutzen \& Stoermer, 2000; Diamond, 2005; Steffen, et al., 2005; Laszlo, 2006): the problems that we are facing (2010) - climate changes, seemingly cascading economic regressions, biodiversity loss, the global food crisis -- are all interrelated crises (Steffen, et al., 2005). And regardless of the question whether the current changes are human induced or not, we created a global context (culturally, socially, economically and environmentally) that makes adaptation to (environmental) changes harder than ever before. When we suffer from climate change it is because of the friction between changing climatic circumstances (which have always taken place in the long course of geological history and thus are nothing new to the history of our planet) and our socio-environmental system which can be described by the historically recent process of exponential population growth, urbanization and fragmentation of landscapes and ecosystems.

Our global biological diversity is threatened by human activity and fragmentation of landscape: extinctions are exceeding the magnitude of past extinction waves (Martens et al., 2003; Carpenter et al., 2005; MEA, 2005). Some researchers claim that the extinction rate of the current sixth great extinction wave is comparable with the extinction wave in the time of the Jurassic species (Steffen, et al., 2005; Mendenhall et al., 2012). This time the extinction is not caused by any 'natural' disaster, but by one dominant species: Ho- 
mo sapiens (IPCC, 2013). Precious known and unknown ecosystems are lost in an accelerating speed. Although the world set a target for 2010 to stop the loss of biodiversity the loss of biodiversity and ecosystems wasn't slowing down and new targets had to be formulated. In October 2012 the Aichi Targets were developed in Nagoya, Japan (UNEPCBD, 2011). They aim for a complete halt in 2050 and set more modest interim targets for 2020 (Nordling, 2009). But what tells us that this time the targets will be met? And how will they be met? These questions are urgent: the stakes are high and time is running out and as such, the 'wicked problem' (Funtowicz et al., 1998) of biodiversity loss has not been solved at this point in time. Innovative approaches seem necessary: a BAU (business as usual) pathway will most probably lead to 'disaster' (UNEP, 2002 ; MEA, 2005; IPCC, 2007).

Meeting environmental protection targets seems more complicated than ever before. Solving problems related to environmental change can no longer solely be a matter of NGOs and volunteers on location. Environmental problems have become complex, intertwined and globalized (Chesters, 2004; Steffen, et al., 2005; Urry, 2005b; Young et al., 2006). Measures cannot be taken only on local and regional scale levels anymore, because they might prove ineffective if they are not taken at the same time in other areas. Besides this spatial interconnectedness environmental problems cannot be seen in isolation from other domains as well. Environmental problems are largely socio-cultural problems, produced by the ideas, technologies and practices of a now globally connected human population (Erez \& Gati, 2004; Diamond, 2005). Due to the processes of urbanization, industrialization, extensive agricultural technologies and human population growth, the quality of human and natural life suffers increasingly.

According to the Nature Conservancy's lead scientist Sanjayan, doom-and-gloom thinking has never brought anything worthwhile (Fothergill, 2006). In China, the word 'crisis' originally refers to opportunity and in ancient Greek it refers to making decisions3. Semanticizing crisis as a 'turning point' may be more constructive than emphasising the increasing entropy and chaos without looking for opportunities ahead. According to Ervin Laszlo, we are now in a typical 'decision window' (Laszlo, 2006) where we still have some options to choose for more sustainable pathways (Loorbach, 2002). Scholars and other people in the sustainability discourse start to discover the need for positive imaging of the present and the future (Wiek \& Iwaniec, 2013). UNEP, for example, presented a report about the opportunities of a Green Economy (UNEP, 2011b), IUCN recently started a video campaign called: 'How to write a love story' about the initial human love for nature and its beauties (IUCN, 2012a). Filmmakers start to realise that calling for positive change based on positive pictures of the future will inspire people more to

3 Crisis: Greek: 'krinomai' : to separate, to sort out, to decide 
change than upheld fingers and scaremongering. Some examples are the Planet Earth series of the BBC, narrated by David Attenborough, or online available movies such as Crossroads: Labour Pains of a New Worldview (Ohayon, 2013) and the movie Home (Arthus-Bertrand, 2009).

\section{Sustainable Development}

"Sustainability is the ability to create, test, and maintain adaptive capability. Development is the process of creating, testing, and maintaining opportunity. The phrase that combines the two -- sustainable development -- is therefore not an oxymoron but represents a logical partnership (Gunderson \& Holling, 2002, p 76)."

John Robinson makes a much used distinction between weaker and stronger sustainability (Robinson, 2004). Sustainability in his view connotes to the strong interpretation which is basically eco-centric. The weaker version is represented by the combined term sustainable development, which refers to (clean) technological fixes to our problems and the idea that enduring economic development is necessary to overcome our societal problems like pollution and poverty (White, 1967; Robinson, 2004; Williams \& Millington, 2004; Martens, 2006).

Present discourse in the media and the larger institutions often represent this weaker notion of sustainable development. As it becomes clear that a business as usual economic development is not sustainable, new 'sustainable' models of economic development - i.e. green economy (UNEP, 2011b) and blue economy (Pauli, 2010) -- start to capture entrepreneurial hearts and minds. What these new models have in common is the perpetuation of the economic growth paradigm. And as such they may initiate some change in niches, but basically they solidify the status quo and the current 'regimes' in power (Beumer \& Martens, 2013; Martens, 2013).

Development and growth can be interpreted differently: the Millennium Development Goals (MDGs), for example place human development in the centre. Ending poverty is the first of the goals followed by achieving primary education for everyone. The next goals are related to equity issues, health and the quality of life and the environment. Ending poverty may be the first goal, but this isn't necessarily the same as stimulating economic growth. Poverty isn't the deprivation of cars, airplanes, factorychimneys, 20 pairs of shoes, vitamin-pills, facial lifts, fast-food restaurants, supermarkets, or numb-making labour. It is a deprivation of physical and psychological health, water, good food, safety, peace, human rights, education, freedom of hearts and minds and of ecological integrity (Sen, 1999; Maathai, 2004, 2011). Charles Eisenstein proposes another way to interpret growth and development. According to him, ecological growth should be the main incentive of society: people use their talents and skills and cultural traditions to work in the service of the growth and development of nature (Eisenstein, 
2013) of biodiversity, and of healthy ecosystems that deliver healthy foods and lush and beautiful environments to recreate in (Mollison, 1988; Hemenway, 2009)? Would there still be poverty in an ecologically abundant world? I find Eisenstein's idea appealing.

\section{Complex Systems}

The key to bridging the differences of teleological and utilitarian thought traditions who both have valuable ethical standpoints -- may be found in the idea of 'complex systems'. Like a river flows, the world is simultaneously full of change and continuity. In a complex system the interrelatedness of connected or embedded subsystems constitute temporary 'dynamic equilibria' (Capra, 1996) intercepted by stochastic shifts and systemic changes. The key to a dynamic equilibrium is the right balance between diversity (plurality) and connectivity (functional or empathic relationships) (McCann, 2000; Gunderson \& Holling, 2002; Folke, et al., 2004; MacDougall, et al., 2013). An extreme level of diversity represents a chaotic unsettled state where nothing is certain and anything can happen. However, a relatively high level of diversity, paired with a good number of functional relations provide a system - like an ecosystem -- with the ability to cope with disturbances like fires, floods and diseases (Gunderson \& Holling, 2002; Folke, et al., 2004; Rees, 2010). The more the diversity of an ecosystem is reduced, for example in mono-cultural agriculture or through extensive fragmentation, the more vulnerable it will be and the less resilient it will be able to respond to surprises and shocks (Rudd, et al., 2002; Steffen, et al., 2005). The same vulnerability accounts when the level of connectivity becomes too high (for example a conservationists empathic focus on protecting one species may impair the health and integrity of the total ecosystem) (Gunderson \& Holling, 2002; Folke, et al., 2004).

Complexity and systems thinking represent a new context-sensitive paradigm in the sciences involving various spatial and temporal scales (Prigogine, 1980; Prigogine \& Stengers, 1984; Capra, 1996; Prigogine, 1996; Gleick, 1998; Laszlo, 2006; Abrams \& Primack, 2011). Sustainability science is based on this context sensitive 'mode 2 ' type of thinking (Funtowicz \& Ravetz, 1993; Gibbons, 2000; Nowotny et al., 2003). It complements Newtonian reductionist linearity (which can often be very useful) by thinking in complex feedbacks and stochastic events where 'the whole' is always more than the sum of its parts (Capra, 1996; Steffen, et al., 2005). Through the lens of the complexity paradigm the world is a system that can be zoomed in and out on as with a virtual mathematical fractal. Processes and events are not only related in ways that can be represented by arrows, but also are they related through their embeddedness. In this 'fractal universe" "[e]very cell is an entire world within itself (...) [and sizes are] doorways within doorways (Abrams \& Primack, 2011, p.27)." 
In my view, the problems we are encountering on the planet are systemic problems. They need to be addressed in a way that is coherent with this fractal reality: simultaneously at each scale level (local, regional, and global) -- taking into account the dynamic levels of time as well (short-term; mid-term; long-term and change). To get a true sense of the similar occurrence of equilibria, evolution and change in fractal universe, perhaps Aldo Leopold's beautiful concept of 'thinking like a mountain (Leopold, 1966)' can be a useful metaphor.

\section{Perspectives Diversity}

Biodiversity conservation is a normative practice, carried out in the context of a perceived wicked problem (Grosskurth, 2009) (biodiversity loss) in our complex socioenvironmental system. It crosses many systemic levels from genes to ecosystems, from local ecosystems to global ones; it involves many institutions and stakeholders on all scale levels and it includes many 'languages', 'discourses' or 'conservation cultures', just to mention a few. As such, biodiversity conservation can be seen as a typical example of boundary work (Star \& Griesemer, 1989; Hoppe, 2010; Star, 2010; Valkering et al., 2013) expressing many different perspectives, goals and means. Many of the boundaries are sought to be bridged and there seems to be an ongoing quest for a common language, perspective or solution in the conservation field. But is this indeed a way to go? Is it realistic and desirable to aim for commonality in a complex and dynamic world?

In my view - and in line with complex systems thinking -- there may be great practical value in the diversity of levels, perspectives and approaches in relation to conservation. In the context of this assumption I chose a typological framework - the Cultural Theory framework by Thompson and his colleagues (Thompson, et al., 1990; Thompson, 1997; Verweij, et al., 2006; Offermans, 2012) -- to work with as an analytical tool for the assessments made in this dissertation. This framework allows for both illuminating differences in worldviews and management styles and at the same time it allows for seeing how the different perspectives are able to complement each other in specific circumstances and contextual situations (Verweij, et al., 2006; Beumer \& Martens, 2010). 
CHAPTER 3

Methodology 
"One of the most highly developed skills in contemporary Western civilisation is dissection: the splitting up of problems into their smallest possible components. We are good at it. So good, we often forget to put the pieces back together again."

Toffler, in Prigogine and Stengers, 1984 


\section{Introduction}

In this chapter the methodologies and frameworks used in this dissertation are described and placed in a context of Sustainability Science and Integrated Sustainability Assessment. These fields emerged from a paradigm shift in the sciences: from a dominant linear reductionist Newtonian scientific paradigm towards a science based on complex systems thinking.

Although each process of analysis is unique because of its specific context (topic, researcher, questions, sources of information and text), it also has to comply with the scientific rules of reproducibility. As Krippendorf (2003) phrases it: "all [text] analyses share a [certain] procedural logic and need to be justified through the use of socially [and scientifically] acceptable criteria (Krippendorff, 2004, p. xxi)". Explicating what I did and how I came to results and conclusions will help others to replicate results of the assessments presented here as well.

\section{Methodological Emergence}

The idea of methodological emergence refers to the acknowledgement that the assessment carried out for this dissertation was not methodologically fixed at the point of departure: there was a topic - biodiversity conservation in a changing world - that had to be tackled with an integrated sustainability assessment (ISA) approach. Integrated research projects often work just like the socio-environmental system. They are complex and there are many surprises. This especially accounts in situations like this one, where different smaller research projects are combined in order to form one larger patchwork assessment of a topic. New insights or gathered results within one sub-assessment may have unforeseen effects, influencing all the other scale levels of the project. This requires readiness and creativity to adapt formerly planned methods and tools. It also requires openness to see (sub-)results and conclusions from earlier stages of the project in a different light over and over again. The methodological emergence probably doesn't immediately become obvious for the readers of this dissertation. The chapters still seem to follow a logical and coherent course. However, any researcher in the field of sustainability science and integrated assessment will acknowledge the adaptive character of the research process. The linear logic of the dissertation chapters is only the end-result of a much 'messier' process. The result, however, may have gained much in depth and richness because of the emergent process-style. 


\section{Normativity in (Sustainability) Science}

A vital overarching meta-question to decide upon the approaches and methods has been beautifully phrased by Michael Weinstein (2011): "At multiple scales [global to local] and over succeeding generations [scenarios], how can the earth, its ecosystems [biodiversity], and its people [urban areas] interact [cultural perspectives] towards [transitions] the mutual benefit [resilience] and sustenance of all [conservation] (Weinstein, 2010, p.4)?" With this question in mind, I emphasise my awareness of the inherent (perhaps even methodological) normativity within the field of integrated sustainability research. Normativity in science does not mean that the knowledge that is being produced is weaker knowledge than so called 'objective knowledge' would be. It just acknowledges -- in the tradition of postmodern constructivism -- that 'objective knowledge' does not exist in any other way than being an assumption and a social construction that can be employed to make claims of power (Latour, 1988; Foucault, 2002). 'Doing science' is making subjective choices. Each methodological or theoretical choice excludes numerous other methods, approaches and theories. Therefore, scientific practice is inherently normative, regardless of the paradigm from within the practices are carried out. Methodological choices are based on the existent knowledge, assumptions, traditions and even 'routines' of the researcher or group of researchers (Latour, 1988).

In the field of sustainability, the normativity of science becomes even more obvious. 'Sustainability' or 'sustainable development' is inherently purpose bound (a quest for a better, balanced or sustained world) and as such, sustainability itself is a normative concept (Robinson, 2004; Martens, 2006; Spangenberg, 2011). Most conceptualisations of sustainability - both the stronger and the weaker notion of it (Robinson, 2004) -- aim at sustaining the existing balance of the economic-socio-environmental system through meeting "the needs of the present without compromising the ability of future generations to meet their own needs (Brundtland-Commission, 1987)." Some theorists, like Banerjee (2003) and Castro (2004) problematize this conceptualisation of sustainability for reproducing a neo-liberal economic growth paradigm where development and increased well-being are inherently linked to 'having more'. Where 'sustainability' becomes institutionalized in policy, international institutions like the United Nations, the World Bank, in business and also in NGOs and academic thinking, a fundamental question should be asked over and over and over again: what is actually being sustained? Is it the economic growth paradigm; the integrity of nature; natural 'capital', 'assets' or 'resources'; human well-being; or existing power structures (Banerjee, 2003)?

Both weaker and stronger notions of the concept of sustainability and sustainable development are highly political and many well-intentioned academics and policymakers make the mistake of treating the concept uncritically as being 'neutral' or even more positivist: as a 'desirable' way into the future. Awareness and reflection about the impli- 
cations of the use of the concept of sustainability should be inherent in any discussion about it: does it maintain the status quo of existing power relations (i.e. reproducing neo-colonialist notions of developed versus developing countries; stakes of large multinational companies versus stakes of local farmers and indigenous peoples) (Banerjee, 2003; Curtis, 2011) or does it -- interpreted differently and from the stronger sustainability perspective -- refer to subversive societal change and reform of regimes and power structures (Capra, 1996) through improving the 'art of living' (Dohmen, 2005) and movements of 'cultural creativity' (Ray \& Anderson, 2000). Interpreted either way, it is hard to keep up the claim that concepts as sustainability or sustainable development are free of any political bias (Spangenberg, 2011). The same constructivist critique accounts for the terms of 'conservation' and 'biodiversity' (Soper, 1995; Takacs, 1996; Jagers, 2012).

In the words of Joachim Spangenberg (2011): "Today sustainability science is usually understood as research providing the necessary insights to make the normative concept of sustainability operational, and the means to plan and implement adequate steps towards this end (Spangenberg, 2011, p. 276)." For sustainability scientists it is important to be aware of the normativity in our work and to transparently reflect upon our position and perspective in the methods we apply. We need to be rigorously explicit about the choices we make and the assumptions they are based on for three reasons:

1. To legitimise what we do, and to legitimise how we do it;

2. To take away the false idea of objective scientific knowledge;

3. To make insightful why and how non-objective knowledge is still valid and valuable knowledge.

Despite the inherent subjectivity in the (sustainability) sciences it remains indispensable to construct sound and reproducible strategies for assessments in order to contribute to 'sound science' and to gain valid and valuable results. In the following paragraphs, I give an overview of the strategies chosen and the reasons for choosing them. The methodologies are more specifically described in the relevant CHAPTERs.

\section{Sustainability Science}

New scientific insights from both the natural sciences -- chaos theory; string theory; systems thinking; complexity (Prigogine \& Stengers, 1984; Capra, 1996; Gleick, 1998; Gleick, 1999; Steffen, et al., 2005) and the social sciences (postmodernism; social constructivism (Pinch \& Bijker, 1984; Best \& Kellner, 1997) -- are leading the old Newtonian mechanistic and linear thought-paradigm towards a more holistic understanding of the interconnected socio-environmental global system (Capra, 1996). The growing recogni- 
tion of the interconnectedness of the socio-environmental system and complexities of the ever changing world also lead to the recognition that the stratification of scientific disciplines and the separation of the humanities and the natural sciences into 'The Two Cultures' (Snow, 2001 [1959]) do not hold any longer to approach the urgent, unstructured, persistent and wicked problems we are facing (Funtowicz \& Ravetz, 1993; Funtowicz, et al., 1998; Grosskurth, 2009). Also the notion of a plurality of perspectives and thought styles (Pohl et al., 2010; Offermans, 2012) involved in the complex web of global changes is gaining recognition increasingly. Figure $3.1^{*}$ visualises the paradigm shift from the Newtonian paradigm of segregated disciplines and domains (social, environmental and economic) towards systems thinking where various disciplines work together in various constellations (often also involving non-scientific actors) to tackle problems of sustainability in a complex and interrelated world-system.

In the field of sustainability studies and the study of socio-ecological systems these developments have led to a new cluster of approaches. Science for sustainability has developed into the new 'trans-disciplinary discipline' of science of sustainability, or 'Sustainability Science' (SS) (Gupta et al., 2006; Spangenberg, 2011). Very slowly and carefully these changes in the sciences start spilling over into policy and governance fields (i.e. the growing acknowledgement of existent uncertainties and systemic dynamics in the world, the necessity of visionary and long-term thinking and the integration of traditionally separated policy-sector). The result is the emergence of a more reciprocal, dynamic and integrated science-policy-interface (Pohl, et al., 2010; Lang et al., 2012).

Sustainability Science - although itself also highly heterogeneous -- can now be called a discipline on its own (Spangenberg, 2006). Post-Normal Science (PNS) (Funtowicz \& Ravetz, 1993; Funtowicz, et al., 1998; Nowotny, et al., 2003; Healy, 2010; Turnpenny et al., 2011), Mode II (Gibbons, 2000; Nowotny, et al., 2003), Integrated Sustainability Assessment (ISA) (Rotmans, 2006; Valkering, et al., 2006), and Resilience Science (Gunderson \& Holling, 2002; Folke, et al., 2004; Rees, 2010) are all similarly holistic approaches to integrating various 'worlds' of the Snowian 'Two Cultures'. In practice it is hard to make concrete distinctions between the approaches: they all have overlapping characteristics. Not the least because the approaches are rather dynamic and coevolving with the complex context surrounding research topics and decision-making. A common aim is to democratize science and the process of knowledge production in a science policy-interface (or even larger extended peer community) (Funtowicz \& Ravetz, 1993) while acknowledging the complexity of the world-system. 
Figure 3.1. Paradigm Shift from Newtonian to Systems Thinking

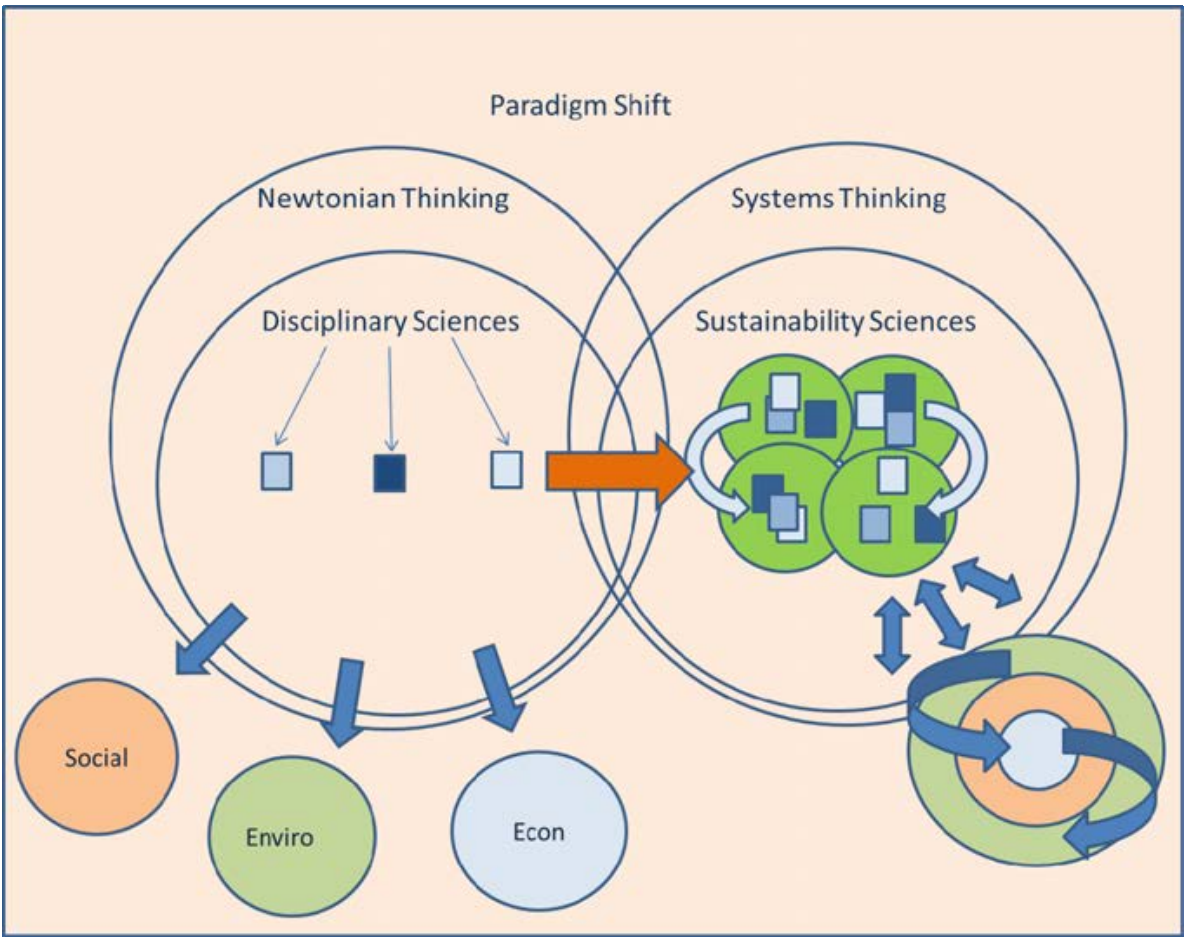

This dissertation research has been developed within the context of this 'new' scientific understanding of a co-evolving dynamic socio-ecological planetary system (Prigogine \& Stengers, 1984; Laszlo, 1996; Gunderson \& Holling, 2002; Steffen, et al., 2005; Boogerd, 2007; Wiek et al., 2012). This systems-thinking lead to specific methodological choices resulting into a patchwork of applied methods.

\section{Integrated Sustainability Assessment}

To gain a better systemic view on contemporary conservation practices and the potential role of urban areas for conservation, in line with the ideas of Integrated Sustainability Assessment (ISA) (Rotmans, 2006; Valkering, et al., 2006; De Ridder, et al., 2007) various tools, theories, scale levels, and insights from various disciplines were combined (see table 3.1). Eventually, the integration of all the elements has resulted in a dissertation that aims to contribute to an integrative, trans-disciplinary and reflective discussion on biodiversity conservation in a changing, urbanising world.

Below, the key methodologies used for this dissertation are described. They make up a set that adds some useful elements from social sciences, humanities and - to a 
lesser extend - ecology to 'traditional' integrated assessment methodologies (Valkering, et al., 2006).

\section{The Perspectives Method}

In 1970, cultural anthropologist Mary Douglas developed a scheme to analyse patterns based on commitment to social units (group) and institutional authority, such as role differentiation, rules and regulations (grid) (Douglas, 1970). This grid-group pattern was further developed as Cultural Theory in order to analyse different perspectives on nature and management styles (worldviews) by Michael Thompson and colleagues (Thompson, et al., 1990). Cultural Theory developed a record of application in a variety of fields -especially in Integrated Assessment and Sustainability Science studies -- ranging amongst others from uncertainty and risk (Asselt, et al., 1995; Rotmans \& De Vries, 1997), climate change (Verweij, et al., 2006) and - as the Perspectives Method (PM) -- water management (Valkering et al., 2008; Offermans et al., 2009; Valkering, 2009; Offermans, 2012).

For the purpose of this dissertation the classical CT framework that is the foundation of the PM has been adapted. The description of the Fatalist perspective has been deepened and the usefulness of the Autonomous perspective in the context of conservation and urban greening has been explored. These two perspectives have been left out in earlier analyses conducted with the traditional CT framework. I explored the hypothesis that both perspectives are relevant in assessment of perspectives on biodiversity and its conservation and play a role in decisions and processes on the policy and conservation level on the ground. I also added a perspective, based on the 'clumsy solutions' concept by Verweij et al. (2006). I call this novel perspective the Dynamic Integrator (see CHAPTER 5).

The Perspectives Method based on Cultural Theory is applied as an analytical framework for the analysis of discourses and content in the Global Scenario studies of the IPCC and the Millennium Ecosystem Assessment (MA) and in the analysis of the IUCN documents (CHAPTERS 6 and 7). Furthermore, the perspectives of CT have been used as structuring principles in the conceptual mapping of conservation practices (CHAPTER 4). It has also been an analytical framework for the analysis of the questionnaire results on urban greening and gardening with Dutch citizens and experts on urban greening and sustainability (CHAPTER 10). With the use of this framework I intended to gain more insight into the way cultural perspectives are represented and distributed in biodiversity conservation discourses and practices. These are finally structured and reflected in scenariovisioning narratives in synthesis CHAPTER 12.

The use of the Perspectives Method is a suitable way to account for the discursive analysis part of this dissertation in three ways: 
1. It enables close reading while taking the context of the analysed text and other related texts into account.

2. It enables the identification of certain power structures and relations between worldviews in the field of analysis.

3. In a later reflective stage of the research, it enables the identification of certain dynamics and possible transitions in these power structures.

As I see biodiversity conservation as a cultural practice, grounded in a plurality of possible discourses, a better insight in the distribution of cultural perspectives - representing worldviews and management styles - is an important asset in the dialogue about practicing biodiversity conservation in a changing, urbanising world.

\section{DISCO Analysis}

A large part of the dissertation assessment involves the analysis of text: policy documents, public journals, scenario reports, and semi-qualitative questionnaire results. These texts functioned as objects in the process of identifying cultural perspectives in the field of (urban based) biodiversity conservation. They deliver an amount of (more or less) unstructured data to work with and in order to make founded inferences about these sources I decided to integrate the traditions of content analysis and discourse analysis.

The methodology to approach the textual sources in this dissertation rests on the combination of content analysis and discourse analysis (DISCO analysis): the combination of a text coding methodology with critical and reflexive reading of the selected sources. This coding-system is based on the Cultural Theory framework (Thompson, et al., 1990; Thompson, 1997; Verweij, et al., 2006; Beumer \& Martens, 2010).

\section{Content analysis}

Content analysis is a set of procedures in order to transform non-structured oral or written information into a format that allows analysis (Hsieh \& Shannon, 2005; Elo \& Kyngas, 2008). Traditional content analysis has been criticised by post-structuralists for focusing on "counting words" (Wilson, 1993, p.1). The method was blamed of squeezing qualitative data into a quantitative jacket and losing the context of what was communicated. Nevertheless, the recent literature on content analysis shows great attention to the contextual meaning of text as well (Wilson, 1993; Holstein \& Gubrium, 2004; Krippendorff, 2004; Hsieh \& Shannon, 2005). It started to "transcend traditional notions of symbols, contents and intents" (Krippendorff, 2004, p. xviii) and began incorporating a more systemic view on text, including interdependencies in communication (networks) and intertextuality (the idea that all texts are linked to other texts in the past and in the present) (Wodak \& Michal, 2008). Qualitative content analysis in brief can be defined as 
a "research method for the subjective interpretation of the content of text data through the systematic classification process of coding and identifying themes or patterns (Hsieh \& Shannon, 2005, pp., p. 1278)." Methods of content analysis facilitate analysts in making structured inferences about the characteristics and meaning of the material (GAO, 1989). Krippendorff (2004) redefines contemporary content analysis as a methodological process that "aligns content - the target of the research - with how contemporary society operates and understands itself through its texts (Krippendorff, 2004, p. xx)." Current software tools for content analysis - such as MAXQDA-have built in features to account for the contextuality of text and communications.

\section{Discourse Analysis}

Discourse analysis stands conceptually and methodologically very close to the contemporary notion of content analysis. Nevertheless, discourse analysis goes a step further. Most importantly, discourse analysis helps gaining insights into how textual information works its way into practices and as such helps shaping the world we live in. It helps understand what certain texts enable or prevent, what is normal and what is abnormal, who becomes included and who is excluded.

"Discourse analysis provides a general framework to problem-oriented social research. It allows the integration of different dimensions of interdisciplinarity and multiple perspectives on the object investigated (Wodak \& Michal, 2008)." It has a track record of use in many disciplines such as anthropology, sociology, philosophy, history, literature studies, science studies, international relations, policy analysis, ethnography and psychology (Bacchi, 2009).

Talking about discourse can be traced back to the ancient Greek philosophers. Plato for example opposed the notion of 'mythos' and 'logos', whereas mythos refers to storytelling (narration) and logos to rational argumentation or philosophy (discourse) (Brisson, 1998). Etymologically the term 'discourse' stems from the Latin word discurrere, which means 'to run back and forth'(Wodak \& Michal, 2008). Discourse analysis as we know it now originates in the philosophical and sociological anti-positivist stream of Critical Theory (kritische Theorie) as advocated by thinkers of the Frankfurter Schule (i.e. Horkheimer, Benjamin, Adorno, Habermas, Marcuse) who in the mid-20 ${ }^{\text {th }}$ Century critically analysed power structures and claims of democracy in western capitalist societies. In the 1960-1970's scholars like Wittgenstein, De Saussure, Derrida and Chomsky enriched the school of Critical Theory with the linguistic deconstruction of narratives, looking for relations, constructions and notions of power through analysing and recognising language as an agent that structures reality (structuralism) (Best \& Kellner, 1997).

The work of the French sociologist-philosopher Michel Foucault is iconic in identifying the way power relations are constructed in (scientific) knowledge systems through claims about what is normal or abnormal (Hall, 2001; Foucault, 2002). He shows how the knowledge in different historical era's is based on sets of basic assumptions that are so 
basic for their times (or knowledge communities) that they are usually not visible to people living and operating in these so called 'epistèmes' or 'discourses'. The way Foucault used the term 'discourse' goes beyond linguistics and vocabulary. He analyses how the use of language in various knowledge paradigms constructs certain structures of power in society. He shows a historical shift in societal power structures from external power (such as kings, emperors and physical punishment, judging on what is good and what is bad) towards more internalised structures of power where individuals internalise knowledge formations as 'the truth' about what is normal and what is abnormal and discipline themselves towards becoming individuals who function and behave according to these societal 'norms'. With his reasoning, Foucault shows how scientific knowledge is far from 'politically neutral', but helps defining norms about what a society should be and how individuals should behave to fit in that picture (Foucault, 2002, 2006, [1977] 1995). Foucault's work has had a large impact on the social sciences and approaches of his constructivistic discourse analysis can be found as a reference framework throughout many works in the fields of the anthropology- or sociology of science (science studies) (Bacchi, 2009). The critical approach hasn't been much applied in the field of Sustainability Science or ISA yet.

Discourse analysis is in the words of Wodak \& Meyer (2009)" not interested in investigating a linguistic unit per se but in studying social phenomena which are necessarily complex and thus require a multi-disciplinary and multi-methodical approach (Wodak \& Meyer, 2009, p.2)." Some characteristic features of discourse analysis are outlined by Wodak and Meyer: there is an interest in 'naturally occurring' language use, a focus on larger textual units than isolated words and sentences, the study of how language use constitutes action and interaction and vice-versa, a focus on "dynamic socio-(cognitive) or interactional moves and strategies (Wodak \& Meyer, 2009, p.2)" and a focus on the social or cultural contexts of language use. Next to that, critical discourse analysis is basically problem oriented and interdisciplinary. Discourse researchers "attempt to make their own positions and interests explicit while retaining their respective scientific methodologies and while remaining self-reflective of their own research process (Wodak \& Michal, 2008; Wodak \& Meyer, 2009, p. 3). All these features of discourse analysis make it a suitable approach to be used within sustainability science assessments. Within this dissertation assessment it helps illuminating the concepts sustainability, biodiversity and conservation as political concepts that guide societies towards internalising new norms and behaviours in their relationships with nature and each other.

\section{Concept Mapping}

Concept mapping is a way to structure and organise unstructured knowledge. Words or fragments of text can be hierarchically ordered and links between concepts can be made visible. Concept mapping is based on learning psychology and has been originally used in education and the intention of concept mapping is to facilitate creative thinking and to 
clarify meanings of specific concepts in their context (Novak \& Cañas, 2007). Concept mapping can be described as a method of discovery. It works as follows: the reader - or researcher - perceives certain key patterns and meanings and maps them in relation to each other. It is very similar to summarizing a text through mind-mapping. It allows the researcher to discover meaningful patterns in texts and between texts (Novak \& Cañas, 2007; Moon et al., 2011). As Joseph Novak - a key scholar of concept mapping says: "[there is a] growing consensus among philosophers and epistemologists that new knowledge creation is a constructive process involving both our knowledge and our emotions or the drive to create new meanings and new ways to represent these meanings (Novak \& Cañas, 2007, p.9)." concept mapping typically departs with a 'focus question', which in this case has been dependent on the specific CHAPTERs and their main question.

In CHAPTER 4 I used concept mapping to assess the various forms of biodiversity conservation and the way they connect to each other. In CHAPTER 9 I used concept mapping to identify key discourses in the variety of urban greening practices which resulted in a framework to discuss urban greening practices and approaches in the context of benefits for biodiversity.

\section{Indicator Framing through Grounded Theory}

Concept mapping is a very suitable tool to use in grounded theory methodologies and framing indicators, especially when literature is used as a source of information and data. Grounded theory methods are qualitative but "systematic inductive guidelines for collecting and analysing data to build middle-range theoretical frameworks that explain the collected data (Charmaz, 2003, p.249-250)." It does not start with a hypothesis but with raw data. These data can be textual sources, empirically gathered data through fieldwork, pictures, artworks or any other systems of unstructured information. The process of framework development through grounded theory is iterative. This means it is based on recurrent evaluations of (new) data and existent frameworks. The process of structuring data - for example through concept mapping -- leads to an initial model or framework. This framework becomes refined when new data are added that are leading to new insights. Several iterative phases lead to a maturing framework that can be further used as a structuring principle or tool for analysis (Charmaz, 2003; Urquhart, 2013). The benefits of grounded theory are the openness to the emergence and inclusion of formerly unexpected insights. The limitations may be in its subjective character. However, when the process of the grounded theory approach is described well it can lead to novel strategies and frameworks that can be valuable to research. In this dissertation grounded theory was applied in CHAPTER 4, CHAPTER 9 and CHAPTER 10. However, I did not apply a pure form of grounded theory. The point of departure was not an entirely blank slate: the concepts of Biodiversity, Sustainability and the Ecosystem Services 
framework have been the initial backbone of the development of novel frameworks through grounded theory.

\section{Fieldwork}

One way to work with grounded theory in this dissertation has been by gathering data through fieldwork. The fieldwork done in the front-yards of Maastricht and Phoenix has been conducted by the method of 'indirect observation'. Observatory methods are often used in anthropology and ethnographic studies (Bernard, 2011). In this fieldwork case I did not apply observation to human behaviour itself, but to the outcomes of the human gardening practices: their gardens. This form of indirectly observing human behaviour is also called the 'archaeology of human behaviour' (Bernard, 2011). Observatory methods take place outside laboratories and leave the studied 'natural' situation intact (Bernard, 2011). I chose to gather information to be found in domestic front-yards to learn more about urban biodiversity and how people may or may not contribute to it. I visited frontyards in Phoenix (Arizona) and in Maastricht and took notes of things attracting my attention. In order to do this, I used all my senses. However, I tried to avoid talking to garden owners, as I wanted to see how much I would be able to learn by only including directly visible information. I also took photos of yards that attracted my attention in both positive and negative ways (with a limitation of subjectivity). The photos made it possible to spend more time thoroughly analysing the visual elements represented in the yards in another place than the fieldwork areas. The gathered information was used to build an eco-cultural indicator framework for assessing biodiversity and ecosystem services delivered by domestic gardens (BIMBY) (CHAPTER 10).

\section{Questionnaires}

Another key part of this dissertation assessment consisted of a survey taken within two groups. The first group has been a representative sample of the Dutch population $(N=517)$. The second group has been a group of international experts $(N=62)$ in the field of sustainability, urban ecology or urban greening. This involved academics as well as practical experts or people from governance.

Next to regular survey questions that allowed for quantitative analysis and a few open questions that allowed for qualitative analysis, a consistent part of the surveys has been based on visual material (pictures). Visual questions have been previously used in various ways, for example through visual preference surveys (Ewing, 2001), Q-Methodology (Cuppen et al., 2010) or Story Card-games (Smith, 2010). Recently, visual preference methodologies have been applied in in the context of urban planning and design (Ewing, 2001; Zheng et al., 2011), perceptions on climate change (O'Neill \& Nicholson-Cole, 2009) and perspectives on water management (Offermans, 2012). Combining textual 
questions and visual questions provides a more inclusive 'measuring' of the worldviews of the respondents: this combination involves emotional parts of the brain: "[v]iewing the symbolic photos [...] serves to stimulate a person's subconscious and past experiences and allows those experiences to emerge as conscious expression (White et al., 2009, p.3)." Visual preferences survey techniques also have the advantage to limit the risk of respondents of giving socially desirable answers (Bernard, 2011) and they are suitable in situations where respondents may lack knowledge of concepts and terminology (Smith, 2010).

For the qualitative part I used the word cloud programme Wordaizer.4 For the quantitative part of the analysis I used IBM SPSS Statistics 20. I chose to use descriptive nonparametric statistics techniques. These are distribution-free methods which are valid under less restrictive assumptions than regular techniques. Nonparametric methods require no strong assumptions about the population distribution. Nevertheless, nonparametric statistics are based on some of the same assumptions as parametric methods: randomness and independence of the samples are still required (Gibbons, W., 1993). Nonparametric methods may have some disadvantages over classical techniques of statistics. They are for example less sensitive to differences between groups. In our case that could have been problematic when statistically comparing the Dutch and the expert sample groups. However, I chose to only compare the descriptive results of both separate samples. In this research case, nonparametric methods have added value over traditional methods, because the data assessed are largely categorical (Pallant, 2005).

The questionnaire design has been based on the Cultural Perspectives typologies framework. I wanted to find out more about the perspectives of Dutch citizens and expert about urban greening and gardening. The questions asked were basically identical for the two groups (some questions were added for the expert group to account for a desert environment). The first part of the survey analysis was to identify the dominant perspectives represented by the respondents. The respondents were grouped according to their dominant perspectives (based on a calculation of the answers they gave to the questions asking about their perspectives). In the second part of the analysis the dominant perspectives were cross-tabulated with the other survey answers. Finally, I qualitatively compared the Dutch citizen results to the results of the experts (CHAPTER 11). The results of the questionnaire were used for sharpening the BIMBY framework of CHAPTER 10. Vice versa, the studies done for the BIMBY framework (literature and fieldwork) helped interpreting some of the survey results. In Table 3.1 below an overview is provided on how the various disciplinary fields, theories and methodologies are applied.

4 For the Wordaizer programme see: www.mosaizer.com/Wordaizer 
Table 3.1. Overview of Integrated Sustainability Assessment

\begin{tabular}{|c|c|c|}
\hline \multicolumn{3}{|c|}{ Integration of Disciplines } \\
\hline Discipline & Applied to & Output \\
\hline Social Sciences & $\begin{array}{l}\text { Scenario Studies IPCC and MA } \\
\text { IUCN documents } \\
\text { Citizen and expert questionnaires } \\
\text { Front-yard design in Maastricht and } \\
\text { Phoenix }\end{array}$ & $\begin{array}{l}\text { Dominant cultural perspectives in } \\
\text { scenario studies } \\
\text { Dominant cultural perspectives in } \\
\text { IUCN } \\
\text { Dominant cultural perspectives on } \\
\text { urban greening and gardening of } \\
\text { Dutch citizens and sustainability } \\
\text { experts } \\
\text { BIMBY indicator framework and pilot } \\
\text { results front-yards Maastricht and } \\
\text { Phoenix }\end{array}$ \\
\hline Humanities & $\begin{array}{l}\text { Dissertation context } \\
\text { Interdisciplinary literature } \\
\text { Research results }\end{array}$ & $\begin{array}{l}\text { Systems thinking } \\
\text { Conceptual maps \& critical essay } \\
\text { Critical reflection on results }\end{array}$ \\
\hline Environmental Sciences & $\begin{array}{l}\text { Front-yard biodiversity in Maastricht } \\
\text { and Phoenix }\end{array}$ & $\begin{array}{l}\text { BIMBY indicator framework and pilot } \\
\text { results front-yards Maastricht and } \\
\text { Phoenix }\end{array}$ \\
\hline \multicolumn{3}{|c|}{$\begin{array}{l}\text { Interdisciplinary Output } \\
\text { A set of complementary research results and insights based on methods from social science, environmental } \\
\text { sciences and humanities. Sensitive towards various scientific approaches, (normative) plurality in society, } \\
\text { complex systems and global dynamics. }\end{array}$} \\
\hline
\end{tabular}

\section{Integration of theories}

\begin{tabular}{|l|l|l|}
\hline Theory & Applied to & Output \\
\hline Complexity \& Systems Theory & Basic paradigm of this dissertation & $\begin{array}{l}\text { Multi-level and multi-perspective } \\
\text { approach }\end{array}$ \\
\hline Cultural Theory & IPCC, MA, IUCN, Questionnaires & $\begin{array}{l}\text { DISCO analysis } \\
\text { Perspectives analysis }\end{array}$ \\
\hline Critical Theory & $\begin{array}{l}\text { Interdisciplinary literature } \\
\text { Research results }\end{array}$ & $\begin{array}{l}\text { Critical evaluation and reflection on } \\
\text { literature and research results }\end{array}$ \\
\hline
\end{tabular}

\section{Systems Thinking Output}

Theoretical research approach that is sensitive towards perspective plurality, different societal and systemic levels, and global dynamics.

\begin{tabular}{|c|c|c|}
\hline \multicolumn{3}{|l|}{ Integration of methods } \\
\hline Tools & Applied to & Output \\
\hline \multirow[t]{2}{*}{$\begin{array}{l}\text { Perspectives Method \& DISCO } \\
\text { analysis }\end{array}$} & Scenario studies IPCC and MA & $\begin{array}{l}\text { Insights into dominant cultural } \\
\text { perspectives on global governance } \\
\text { level }\end{array}$ \\
\hline & IUCN documents & $\begin{array}{l}\text { Insight into dominant cultural } \\
\text { perspectives major global }\end{array}$ \\
\hline
\end{tabular}




\begin{tabular}{|c|c|c|}
\hline \multicolumn{3}{|l|}{ Integration of methods } \\
\hline \multirow[t]{2}{*}{ Tools } & Applied to & Output \\
\hline & & conservation organisation IUCN \\
\hline Conceptual Mapping & Literature on Conservation & $\begin{array}{l}\text { Insights into plurality and systems of } \\
\text { contemporary conservation } \\
\text { practices }\end{array}$ \\
\hline \multirow[t]{2}{*}{ Indicator framing } & Front-yards & \multirow{2}{*}{$\begin{array}{l}\text { BIMBY indicator framework } \\
\text { Insights biodiversity and ecosystem } \\
\text { services in domestic gardens in } \\
\text { Maastricht and Phoenix }\end{array}$} \\
\hline & Literature & \\
\hline \multirow[t]{2}{*}{ Questionnaires } & Dutch Citizens N=517 & $\begin{array}{l}\text { Insights into dominant cultural } \\
\text { perspectives of Dutch citizens on } \\
\text { urban greening and gardening }\end{array}$ \\
\hline & $\begin{array}{l}\text { Experts on (urban) ecology and } \\
\text { sustainability } N=62\end{array}$ & $\begin{array}{l}\text { Insights into dominant cultural } \\
\text { perspectives of (urban) ecology and } \\
\text { sustainability experts on urban } \\
\text { greening and gardening }\end{array}$ \\
\hline Scenario Analysis \& Visioning & Aggregated results & $\begin{array}{l}\text { Six storylines for future biodiversity } \\
\text { in an urbanised world. }\end{array}$ \\
\hline \multicolumn{3}{|c|}{$\begin{array}{l}\text { Integrated Sustainability Assessment Output } \\
\text { Insights into contemporary conservation discourse } \\
\text { Exploration of the potential societal support for urban based conservation } \\
\text { Integrated eco-cultural indicator framework for assessing biodiversity and ecosystem services in and beyond } \\
\text { domestic gardens in trans-disciplinary and transformational way. }\end{array}$} \\
\hline
\end{tabular}

\section{Conclusion}

The strength in the methodological 'patchwork' set chosen for this dissertation assessment can be found in the combination of a variety of methodologies from social sciences, humanities and - to a lesser extent - ecology. The focus of 'traditional Integrated Sustainability Assessment' (ISA) has been on combining modelling methods with scenario studies and/or participatory methods. This dissertation shows that more approaches can be added to the ISA toolbox. Especially methodologies used in the humanities such as discourse analysis (Critical Methods) may add a deeper reflective layer to ISA. Adding principles of grounded theory and concept mapping to the ISA toolset is valuable because it gives space to explore novel constellations of knowledge and insight and even new methodological frameworks, such as the BIMBY framework or the framework for exploring the Biodiversity Benefits of urban greening practices. Both the fieldwork and the literature proved to be valuable sources that can be combined in grounded theory approaches. The surveys conducted have been a valuable contribution to gaining more insight into constellations of dominant societal thought styles with regards to biodiversity, sustainability, urban greening and gardening. 
PART II

The Colours of Conservation

Exploring conservation discourses 

CHAPTER 4

Mapping Conservation 
"We did not inherit the earth from our ancestors; we borrow it from our children."

Chief Seattle 


\section{Introduction: A Newer Conservation Debate?}

Conservation science is a peculiar type of natural science because it has emerged as a response to the crisis of biodiversity loss (Meine, et al., 2006; Redford et al., 2006). As such it is a science with a highly normative mission (Meine, et al., 2006): halting biodiversity loss and safeguarding the integrity of the natural world. This intrinsic ethical commitment seems contradictory to most natural sciences who claim to be 'objective' and 'value free' (Gibbons, W., 1993; Takacs, 1996), a claim - by the way --that social constructivists would reject immediately (Latour, 1988). Differing from most of the natural sciences, conservationists usually acknowledge the mission-drive behind their research (Takacs, 1996). Nevertheless, a lack of clear insight in the spaghetti of values and ideas about the way to approach the mission not conservation led any further (Miller, et al., 2011; Minteer \& Miller, 2011).

Past debates about the protection of nature were highly characterized by the question: 'to conserve or to preserve (Takacs, 1996; Miller, et al., 2011; Robinson, 2011)?' In the conservation-preservation debate stronger versus weaker sustainability values can be identified (Robinson, 2004; Williams \& Millington, 2004), ranging from the stronger eco-centric idea to retreat and tread lightly and save pristine nature or what is left of it by closing it for humans to the more anthropocentric idea of the wise use of nature and its treasures (Sarkar, 1999; Giddings, 2002; Banerjee, 2003; Williams \& Millington, 2004). Alternatives to these two ends of the spectrum were found in Integrated Conservation and Development Projects (ICDPs) where nature became protected through promoting human livelihoods (Miller \& Hobbs, 2002; Minteer \& Miller, 2011). Most often the focus of the ICDPs has been towards the livelihoods of people and communities in developing countries. Regarding the popularity of ICDPs and regarding the contemporary discourse and the wordings used in the literature by ecologist, sustainability scientists, policymakers and the media, 'conservation' nowadays seems to have won over 'preservation'. Although there are some varieties based on the search term combinations used, a general Google Search action for conservation and preservation demonstrates this well: when using various combinations of words with conservation and preservation, 'conservation' shows more hits than the word 'preservation' (see table 4.1). Searching the same word combinations in Google Scholar delivered consistently higher results for conservation hits (see table 4.1). 
Table 4.1. Google search and Google scholar hits for conservation and preservation

Google Search Hits for Conservation and Preservation

\begin{tabular}{lll}
\hline & Preservation Hits & Conservation Hits \\
With “Nature" & 45.700 .000 & 44.800 .000 \\
With "Biodiversity" & 5.790 .000 & 16.900 .000 \\
With "Resource" & 38.800 .000 & 27.400 .000 \\
With “Species" & 27.500 .000 & 85.300 .000 \\
With “Animal” & 23.400 .000 & 80.700 .000 \\
With “Plant" & 31.000 .000 & 28.900 .000 \\
\hline Total & $\mathbf{1 7 2 . 1 9 0 . 0 0 0}$ & $\mathbf{2 8 4 . 0 0 0 . 0 0 0}$
\end{tabular}

Google Scholar Search Hits for Conservation and Preservation

\begin{tabular}{lll}
\hline & Preservation Hits & Conservation Hits \\
With “Nature" & 1.980 .000 & 2.090 .000 \\
With “Biodiversity" & 225.000 & 908.000 \\
With “Resource" & 1.210 .000 & 1.960 .000 \\
With “Species" & 1.930 .000 & 2.200 .000 \\
With “Animal” & 1.810 .000 & 2.160 .000 \\
With “Plant" & 1.630 .000 & 2.130 .000 \\
\hline Total & $\mathbf{8 . 7 8 5 . 0 0 0}$ & $\mathbf{1 1 . 4 4 8 . 0 0 0}$
\end{tabular}

However, according to Miller and his colleagues a new conservation debate has emerged at the end of the $20^{\text {th }}$ century, that is still echoing the classic 'conservationpreservation dichotomy' (Miller, et al., 2011; Minteer \& Miller, 2011). The new discourse is still characterized by the question whether nature (biodiversity and landscapes) or human welfare (poverty alleviation and livelihood improvement) should be prioritized within conservation efforts (Miller, et al., 2011; Minteer \& Miller, 2011). Within this debate Minteer and Miller identify a deeper ethical disagreement "about the proper value and ethical foundations of biological conservation in the age of sustainability (Minteer \& Miller, 2011, p.945)." The dispute is dividing the conservation community "along philosophical, strategic, and disciplinary lines (Miller, et al., 2011, p.948)." In principle the debate seems to have become a debate between stronger and weaker sustainability values (Robinson, 2004; Williams \& Millington, 2004; Adams, 2013).

Although Miller and his colleagues present a number of options for reconciliation of the two broad sides of the debate - the 'nature protectionists' camp that focuses on Protected Areas (PA) versus the sustainable development oriented 'social conservationists' camp that focusses on Integrated Conservation and Development Projects (ICDPs) -- I argue with Robinson (2011) that conservation practice today is much too pluralistic and too complex to be captured in dichotomizing phrases like 'parks versus people' (Minteer 
\& Miller, 2011). I picture conservation practice as a mosaic of different potentially cooperating, often complementary, sometimes contradicting approaches, highly affected by worldviews and dominant discourses.

With Robinson, I suggest to embrace ethical pluralism (Robinson, 2011) within the mosaic of conservation practices, while at the same time emphasizing the need for a 'sustainable conservation practice' that is able to reconcile ecological and human needs (Rosenzweig, 2003) on this one planet (Lemaire, 2006). This means that "in practice, ideology must be replaced by pluralism in the choice of objectives and [conservation] approaches (Robinson, 2011, p.959)." Acknowledging the complexity of the conservation debate and highlighting some important strains of the 'conservation-spaghetti' is crucial in order to become more constructive and effective in targeting global conservation goals. Only then will conservation practice be able to transform from a discipline merely preventing extinction (Redford, et al., 2006) into a cooperative effort to enhance a healthy and thriving planet. In this chapter and in CHAPTER 6 the variety of facets, approaches and views in the conservation arena are systematically explored.

\section{Methodology}

To get a better understanding of the plurality of the conservation practice I dedicate this chapter to the mapping of various contemporary conservation approaches, strategies or styles. A number of important approaches discussed in the literature have been deduced and a matrix of labels is proposed that can be of help by illuminating the character of existing conservation strategies (table 4.2). The labels have been developed based on categories that were deduced from academic literature and popular sources (documentaries, films, popular literature, magazines from NGOs and newspaper articles). The spectrum from weaker to stronger sustainability (Giddings, 2002; Robinson, 2004; Williams \& Millington, 2004) has been a guideline for developing the labels

Sets of labels have been distributed to each identified conservation strategy. An overview table will give more insights into the overlapping or complementing features of each strategy (table 4.3). This is further visualised by a conceptual model where arrows show how the conservation approaches contradict or enforce each other (figure 4.1).

It has to be mentioned that the approaches, strategies or styles discussed in this chapter are not always on the same level. Also the categorisation for the approaches may seem very broad and generalising. In the field, many nuances to the categories I made can be found. However, it has not been the intention of the mapping exercise in this chapter to identify hierarchies and hierarchical links between the conservation approaches, strategies or styles. The aim has been to provide a better insight into the plurality of the conservation field and to identify potential barriers and synergies between the various conservation approaches, strategies or styles. 


\section{Mapping}

The labels help to identify the following characteristics of the most encountered conservation approaches in the literature:

1. Centre: is the approach eco-centric, anthropocentric or holistic?

2. Driver: is the approach driven by ethical values (intrinsic value of biodiversity or the right to live), is it driven by existing policies and regulations, by economic values (ecosystem services, prosperity, profits), or by community values (such as future generations, history, legacy, scientific knowledge or contemporary social values) or by environmental necessity (near extinctions, climate change, disasters)?

3. Focus: is there a focus on species diversity, on individual species, on genetic conservation, on the conservation of landscapes or on the conservation on ecosystems and its functional relations?

\section{Table 4.2. Labels for the Classification of Conservation Approaches}

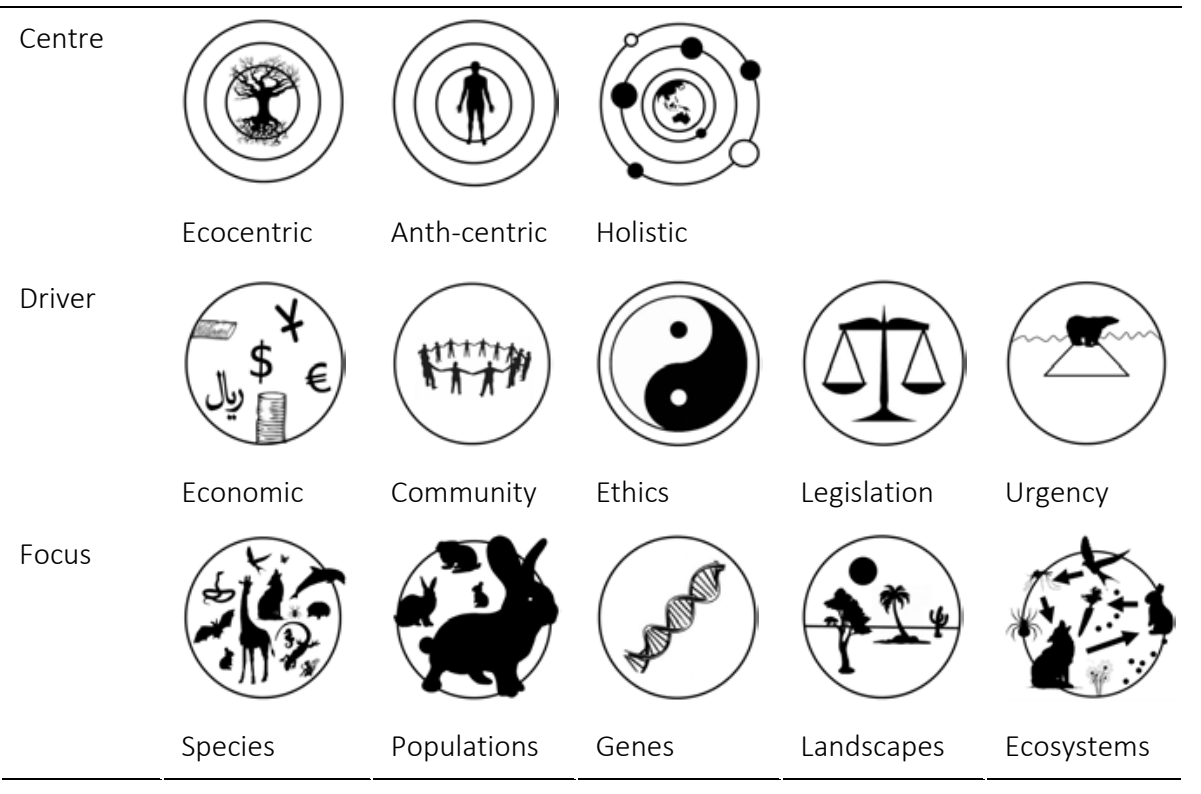

The labels were distributed to the various selected conservation approaches. The list of selected approaches is based on the conservation strategies encountered most in the conservation literature. Included are: legislation and policy (L\&P), religions ( R), collections $(\mathrm{C})$, zoos and botanical gardens $(\mathrm{ZBG})$, hunting $(\mathrm{H})$, gene-banking $(\mathrm{GB})$, protected areas (PA), Non-governmental institutions (NGOs), civil activism (CA), philanthropy (PHI), private-public partnerships (PPP), Ecosystem Services (ES), Ecotourism (ET), Restoration 
(RES), Reintegration (REI), Relocation (REL), Conservation Education (CE), Arts (A) and Reconciliation Ecology (RE) (see table 4.3).

Briefly summarising table 4.3 , it can be seen that all the described conservation approaches are driven by community interests. Most of them have a focus on species. Ecocentric and anthropocentric worldviews are almost equally distributed and only few approaches can be said truly holistic/integrative.

Table 4.3. Overview of labels attached to conservation approaches

\begin{tabular}{|c|c|c|c|c|c|c|c|c|c|c|c|c|c|c|c|c|c|c|c|}
\hline & 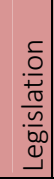 & 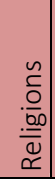 & 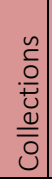 & 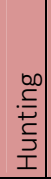 & $\begin{array}{l}\tilde{D} \\
\stackrel{0}{0} \\
\stackrel{0}{n} \\
\tilde{0} \\
\stackrel{0}{N}\end{array}$ & 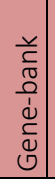 & 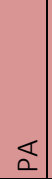 & \begin{tabular}{l}
0 \\
0 \\
\hdashline
\end{tabular} & 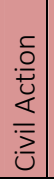 & 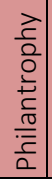 & 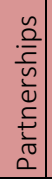 & 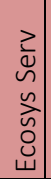 & 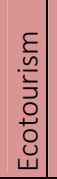 & 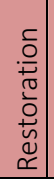 & 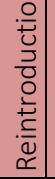 & 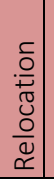 & 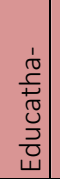 & $\frac{5}{4}$ & 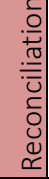 \\
\hline ((6)) & & $X$ & & & $X$ & & $X$ & $X$ & $X$ & $X$ & & & & $X$ & $X$ & $X$ & $x$ & $x$ & $x$ \\
\hline (1) & $X$ & $X$ & $X$ & $X$ & $x$ & $X$ & & & & $X$ & $X$ & $x$ & $X$ & & & & $x$ & $X$ & $x$ \\
\hline (3) & & $X$ & & & & & & & & & & & & & & & $X$ & $x$ & $x$ \\
\hline$(\Delta I \Delta)$ & $X$ & & & & & & $X$ & $X$ & $X$ & & & & & & & & & & \\
\hline 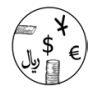 & $X$ & & $X$ & $X$ & $X$ & $X$ & & & & $X$ & $X$ & $X$ & $X$ & & & & & $X$ & \\
\hline (1, & $x$ & $x$ & $X$ & $X$ & $x$ & $x$ & $X$ & $X$ & $X$ & $X$ & $X$ & $x$ & $X$ & $X$ & $x$ & $X$ & $X$ & $X$ & $X$ \\
\hline & $X$ & & & & $X$ & $X$ & $X$ & $X$ & $X$ & $X$ & & $x$ & & & & $x$ & $X$ & & $x$ \\
\hline & $X$ & $X$ & & & & & $X$ & $X$ & $X$ & $X$ & & & & $X$ & $X$ & $x$ & $X$ & $x$ & $x$ \\
\hline 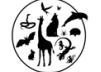 & $X$ & $x$ & $x$ & $X$ & $X$ & $x$ & $x$ & $X$ & $X$ & $X$ & $X$ & & $X$ & & $X$ & $X$ & $x$ & $x$ & $X$ \\
\hline & $X$ & & & $X$ & $x$ & & $X$ & $X$ & $X$ & & & & & & $X$ & $X$ & & & \\
\hline & $X$ & & $X$ & & $X$ & $X$ & & & & & $X$ & & & & $X$ & & & & \\
\hline & $X$ & $X$ & & & $x$ & & $X$ & $X$ & $X$ & $x$ & & & $X$ & $X$ & & & $X$ & $X$ & $X$ \\
\hline & $X$ & & & $X$ & $X$ & & $X$ & $X$ & $X$ & & $X$ & $X$ & & $X$ & & & $X$ & & $X$ \\
\hline
\end{tabular}


Tables like this can be used to look where various approaches can support each other or need to strengthen links, as is shown in the conceptual map (figure $4.1^{*}$ ).

Figure 4.1. Conceptual map of links between conservation approaches

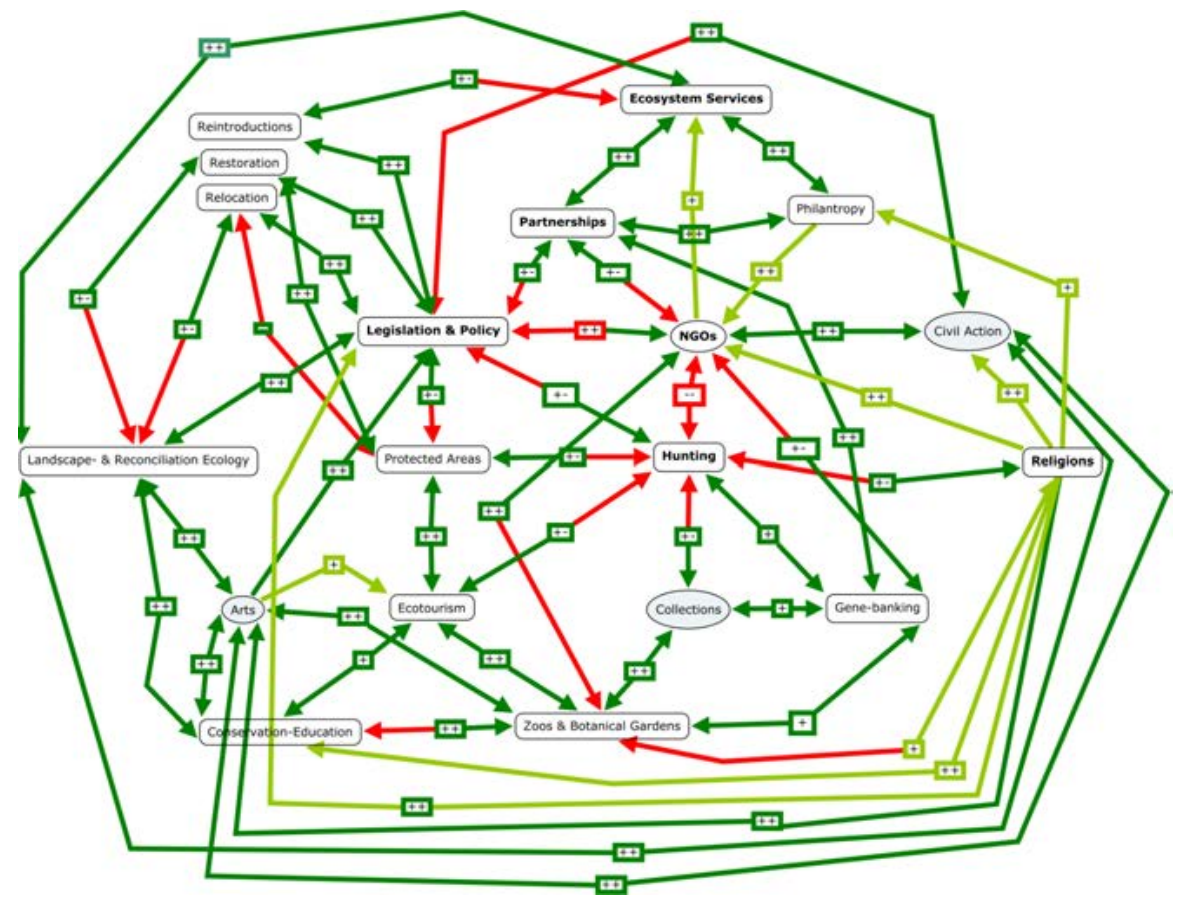

Various types of relationships between the conservation approaches have been identified in the literature and visualised: reciprocal relationships are visualised in dark green. Influencing relationships (one way) are represented in light green. Controversial relationships have one red and one dark green arrow. Negative, hindering relationships are visualised by two red arrows. The strength of the relationships is approached by plus and minus signs: (+ = moderate relationship; ++ = strong relationship; +- = depending on the controversy). If there is no significant relationship, there are no arrows. Three intervention-approaches are clustered together in the orange box. Below, the different conservation approaches and their relationships are discussed in more detail.

Legislation and policies

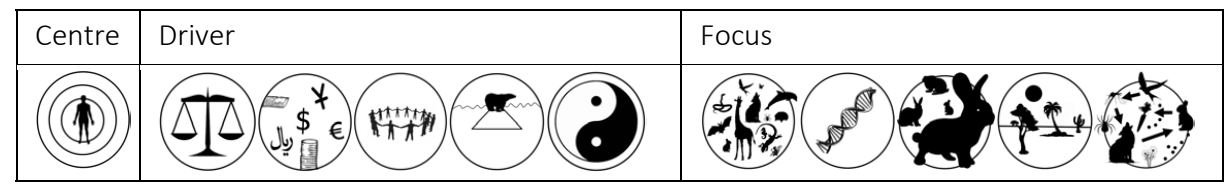


Globally one of the most dominant approaches to conservation is the development and implementation of laws, policies and governing institutions for conservation. Through conservation history, national, regional and global governance systems and institutions became entwined and form a complex interacting policy-network. Some important highlights from various spatial levels - but all with global significance -- are outlined below.

One of the earliest significant conservation accomplishments was the establishment of the Fish and Wildlife Service the U.S. in 1871. In 1966, the U.S. Congress passed the Endangered Species Preservation Act in order to protect 'listed' species and in order to acquire land to preserve habitats for the endangered species. In 1969 the Act also limited import and sale of species in danger of extinction on a global scale (FWS, 2013).

In October 1948 the International Union of Nature Conservation (IUCN) was established in Fontainebleau, France. In 1949 conservation became more strongly institutionalized in global policy agendas through the first United Nations conference on the environment, the Scientific Conference on Conservation and the Utilization of Natural Resources (UNSCCUR, 1948). This conference (indirectly) lead to the establishment of IUCN's sister organization WWF (1961) to help acquire funds for global conservation projects (Christoffersen, 1997; MacDonald, 2003). Both organizations became strong lobbying forces in national and global governance systems. A new milestone for global conservation that evolved during an IUCN conference in Washington D.C. in 1973, where 80 nations signed the Convention on International Trade in Endangered Species of Wild Fauna and Flora (CITES) (CITES, 2013). CITES went into force in 1975.

In Europe, the Natura 2000 is the "centerpiece of EU nature and biodiversity policy (EC, 2013)." Natura 2000 is established under the 1992 Habitats Directive from 1992, which complements the 1979 Birds Directive. Member States under the Habitat Directive can designate Special Areas of Conservation (SACs) and Special Protection Areas (SPAs). In the Natura 2000 Network national governments work together with national and local conservation organizations, farmers and other private or public landowners to establish and advance a network of sustainably managed land (ecologically, economically and socially) where human activity is integrated in the protection of ecologically valuable features, species and landscapes (Evans, 2012). The Natura 2000 Network fulfils a "Community obligation under the UN Convention on Biological Diversity (EC, 2013)."

The contemporary global conservation agenda is set by many engaged and cooperating groups, institutions and organizations. Since the 1990's the notion that conservation amongst other urgent global environmental problems could not be tackled by single states intervention alone, received renewed universal consensus. This resulted in the "search for new institutions, partnerships and governance mechanisms (Lemos \& Agrawal, 2006, p.301)." Visseren-Hamakers, et al. (2012) have coined the term international biodiversity governance system to describe the operating system of all "public, public-private, and private international initiatives working on conservation and sustainable use of biodiversity (Visseren-Hamakers et al., 2012, p.266)." 
Important instruments deployed throughout history within the global biodiversity governance system are UN's global environmental conferences, including the Stockholm Conference on the Human Environment in 1972, the Rio Conference on Environment and Development in 1992, and the Johannesburg World Summit on Sustainable Development in 2002. During the first conference in 1972, the UNEP - the UN Environmental Programme -- was established. The Rio conference in 1992 was arguably the biggest and most successful event in history to advocate in favour for the natural environment. During this conference, most of the world's governments and NGO's participated, resulting in a comprehensive output of binding and non-binding agreements, such as the Rio Declaration on Environment and Development, Agenda 21, the Forest Principles, the Convention on Biological Diversity (CBD) and the Framework Convention on Climate Change (UNFCCC) (Baker, 2006). The World Summit on Sustainability in 2002 encouraged more participation among different stakeholders, including business and NGO's.

The global biodiversity governance regime is still largely governed under the UN organ. However, this doesn't function as a top-down "mono-centric hierarchy (Cole, 2011, p. 405) ," where governing units at the macro-level command and control the lower levels. As proposed by Cole (2011) the global biodiversity governance system is a polycentric governance system. This system is one "in which governmental units both compete and cooperate, interact and learn from one another, and responsibilities at different governmental levels are tailored to match the scale of the public services they provide (Cole, 2011, p.405)."

Recently, IUCN's One Programme Charter (IUCN, 2011e), and the new ecosystem's approach of the Convention on Biodiversity Diversity, including its 2011-2020 Aichi Biodiversity Targets (CBD, 2011; UNCSD, 2012), are prominent examples of cooperative governance policy instruments to enhance global biodiversity. The Aichi Targets fall under the 2011-2020 United Nations Decade for Biodiversity, declared by the UN General Assembly (Rio+ 20) in 2012 (UNCSD, 2012) and are intended to support the development of a Green Economy (Morrow, 2012).

\section{Characterisation and links}

Legislation and policy for biodiversity is mainly anthropocentric in nature. Its drivers can be economic, combine ethical and legal arguments, and aim to benefit communities of people now and in the future. Usually, policy and legislations are reactively driven by environmental pressures as well, such as climate change or the loss of biodiversity. Because of all the levels and scales of legislations and policies, from municipal to global, the conservation focus can include the whole spectrum of approaches from species to ecosystems. In the conceptual map it is visualised that legislation and policy have many links of which most are strong and reinforcing (dark green). The links between some of the other nodes (protected areas, hunting, NGOs) can be called controversial in their reinforcement (red-green arrows). Protected areas, for example, need legislation in order to become established. However, policymakers can also decide for fragile areas to become 
exploited for economic development (e.g. resource extraction or tourism). Hunting can also be enforced or banned by governments. NGOs often put pressure on governments to adjust policymaking for the advantage of the protection of nature. Governments, however, can have other priorities, such as economic development. In the case of partnerships the reinforcements of the links can become weakened (or controversial) when democracy asks for better control or regulation of the partnerships. Relocation, reintroduction and restoration have strong links with policymaking. They are mainly controlled intervention measures decided upon by governance institutions.

\section{Religions}

\begin{tabular}{|l|l|l|}
\hline Centre & Driver & Focus \\
\hline (1) &
\end{tabular}

The best-known conservation story world-wide may be the biblical story of Noah's Ark where two animals of each species were protected of the Great Flood. Although religions are often used as narratives to legitimate human dominion over nature (White, 1967), they usually also emphasize the respect for all life on Earth: religions provide "ethical and social models for living respectfully with nature (Negi, 2005, p.85)." This can be said for the main world religions Christianity, Buddhism, Hinduism and Islam, but also for many small-scale indigenous religions (Gerlitz, 1998). Some authors state that there is a strong and even symbiotic connection between biodiversity and cultural diversity, based on religious traditions and values (Posey, 1999; Negi, 2005). Negi states that "Religious beliefs and rituals [...] are [often] intimately related to [the] management of the ecosystems (Negi, 2005, p.85)." Often religious rituals are accompanied by celebrating specific species and places for their sacred powers and characters (Posey, 1999; DesJardins, 2006; Ura \& Chophel, 2012). Buddhism is the world religion that most explicitly emphasises respect and compassion for all living beings on the planet (Gerlitz, 1998). In many Islamic countries Hima is a central notion in the protection of the earth. Hima means Zones that are designated Hima are prohibited to violate and may not be disturbed in any way through development (Negi, 2005).

Together religious institutions own around $7 \%$ of all land on the planet, and another $8 \%$ of the Earth's surface is connected to sacred links (Bhagwat \& Palmer, 2009). This means that religious institutions can play an important practical role in the protection of nature for future generations as well (Fothergill, 2006). Increasingly, religions are becoming aware of their potential role as emerging powers for the support of conservation, as became also visible in the first speech of the new Pope Francis, where he argued for the protection of nature and the weaker in society (Anonymous, 2013). 


\section{Characterisation and links}

Religions, with regards to conservation, have many influential links (light green). Religion can inspire civil action or philanthropy, or the course of NGOs. Also religious institutions play a strong lobbying role with governments, influencing policy and legislation. With regards to hunting, there can be two ways: religions may glorify the killing of animals, (or put them under other sorts of human domination) or religions can take the stand that all life is sacred and should be protected.

Religions can have an anthropocentric, eco-centric or holistic worldview, depending on the religion and its interpretation. Religious drivers are mostly ethical and community based. Because religions can be directly prescriptive it would make sense to add the label for legislation as well. However, to avoid too much overlap and be as clear as possible, I prefer to use the legislation label for the more profane governance institutions. The conservation focus is most often in sacred landscapes, but also sacred animal species, connected to religious stories are often represented in religions.

\section{Collections}

\begin{tabular}{|l|l|l|}
\hline Centre & Driver & Focus \\
\hline (14) & & \\
\hline
\end{tabular}

Inspired by the dominant idea of 'man' as a 'conqueror' of the planet, one of the oldest approaches for 'conserving' biodiversity also has contributed to a great loss of it at the same time (Larson, 2001). It started in the time of the great exploration-adventures and may have celebrated its most influential peak during the travels of Charles Darwin in the $19^{\text {th }}$ century: it was the collection of species-- the more exotic the better - for the study of biology and evolution. During the collection process and in order to describe them well, many animals and plant species, also very rare ones, where killed for the sake of science and knowledge about the wonders of the natural world. Nowadays, Darwin's collections, and the ones of many of his followers, are stored and exposed in the World's most famous museums of natural history. They still are a source of knowledge to many: scientists as well as museum visitors. Still, new and un-described species are discovered in Darwin's collections in the Museum of Natural History (Larson, 2001).

A common problem to the approach of collection: although they may contain valuable DNA material, the conserved and studied species are dead and outside the context of the original ecosystem. Nevertheless, the collection of species has ignited a new kind of love and interest for nature by a whole new way of seeing nature: through the lens of the theory of evolution. 


\section{Characterisation and links}

Collecting species is a controversial strategy of biodiversity conservation. The approach of collecting species or genes is usually anthropocentric and driven by monetary or community values. The community based value is usually legitimated by gaining new knowledge through research. Collections represent an idea of control over nature and order, and they historically also played a role in authoritative image-building (science and knowledge production). Collections have strong reinforcing links with gene-banks, zoos, museums, and botanical gardens. Basically, nowadays collections are usually kept or presented in such institutions. Hunting is a controversial way to gather collections: it can hamper the ideal to protect living species or individuals. Also, individuals, if kept alive at all, are taken out of their natural habitats. This means that research on collected species can only be done in a more or less artificial, experimental setting. New knowledge on the behaviour of collected species and their ecosystemic relations therefore, will be limited.

\section{Hunting}

\begin{tabular}{|l|l|l|}
\hline Centre & Driver & Focus \\
\hline (10) & & \\
\hline
\end{tabular}

Paradoxically, around the same time as Darwin's voyages took place, hunting started to become the first scene of intentional nature conservation (Larson, 2001). It were hunters who decided to establish rules and regulations around the time and frequency of hunting and they created the first natural reserves, protected areas in Africa and Europe (Mackenzie). The hunters realised that when they would not protect the subjects of their pursue, they would not be able to continue their hobby in a short time (Larson, 2001). Nowadays, hunting often aims to control population sizes and 'balanced' ecosystems. Trophy hunting is also a strategy to finance the conservation of species, especially in African nature parks (Fothergill, 2006)

\section{Characterisation and links}

Hunting is an anthropocentric approach to conservation that can be driven by masculine aspirations, image-building and self-esteem - which can be called community based drivers. Very often big money is involved as a driver as well and this is not only the case with poaching, which is clearly not a conservation strategy and is furthermore excluded from consideration here. Hunting can also be driven by the need to control populations or invasive species (legislation and policy). Hunting has many links to other conservation approaches, of which most are controversial. It has conflicting interests with NGOs that usually aim to protect life. However, often trophy hunting is used to finance the protec- 
tion of a species or their ecosystem. It is also often connected to ecotourism. Also this is a controversial connection, because for most tourists who visit nature parks, hunting is something that contradicts the ethics of conservation (Fothergill, 2006).

Zoos, Aquaria \& Botanical Gardens

\begin{tabular}{|l|l|llll}
\hline Centre & Driver & Focus \\
\hline$(10)$ &
\end{tabular}

Another old and established but evolving form of conservation has emerged from the collection trends of Darwin's time (Baratay \& Hardouin-Fugier, 2002). Zoos, aquaria and botanical gardens have played a large role in the study and appreciation of wildlife (Frost, 2011). They have evolved from displaying 'curiosities' where exotic plants or human and non-human 'savages' were displayed in cages for the engagement of visitors (Rothfels, 2002) into semi-open 'parks' where ecosystems are being reconstructed and 'safaris' can be taken to mimic the experience of visiting 'real' natural parks (Mitman, 1996; Mennen, et al., submitted). Broadening the older rather strict 'species' approach to conservation in zoos, education, creating love and awareness for nature's species is one of the main contemporary ex-situ 'conservation' goals of zoos. This even evolves into a broader strategy of including principles of sustainability into the set ups and visitor-programmes. Also breeding programmes and animal exchanges contribute to the genetic conservation strategies contemporary zoos take. Next to these strategies, an increasing amount of zoos contributes to in-situ study and conservation of species (Mennen, et al., submitted). Botanical gardens also usually aim to conserve species and genes. At the same time, they are often created as scenic landscapes where the ecological values and relations of a region (treasured or endangered) are reflected. Botanical gardens, like the Desert Botanical Garden in Phoenix (DBG, 2013) can become small highly diverse 'ecosystems' themselves, contributing biological diversity to the local and regional ecosystem.

\section{Characterisation and links}

Zoos, aquaria and botanical gardens can differ from an anthropocentric and eco-centric worldview, depending on the broader mission and vision. They have the ability to spillover into the surrounding landscape and into the hearts and minds of their visitors. They can be driven by community values (education, research, saving species for future generations), monetary values and sometimes are directed by environmental urgencies (acute imperilled species or individuals or climate change projections). The focus of their conservation mission can range along the whole spectrum from species to ecosystems. Especially botanical gardens can play a role in conserving landscapes as well (spill-over 
effects). Zoos and botanical gardens represent an idea of control of nature. Zoos and botanical gardens have strong reinforcing links with ecotourism, with collections, with gene-banking and (more controversially) with conservation-education. There exist controversial links as well between zoos and NGOs.

\section{Gene-Banking}

\begin{tabular}{|l|l|l|}
\hline Centre & Driver & Focus \\
\hline (Ni) & \\
\hline
\end{tabular}

Another specific modern version of the collection approach of the $19^{\text {th }}$ century can be found in the ex-situ storage of seeds and genetic material in seed-, or gene-banks (Mills, 2013). In Svalbard, Norway, for example seeds of all our traditional food species are kept safe for an uncertain future (Westengen et al., 2013). In the vault over 500,000 samples of unique crop varieties are stored (Aitken, 2012). These have to guarantee the continuance of breeding old, new and improved varieties in the future, even if global environmental conditions may alter to large extends (Aitken, 2012).

Sperm and gene banks - often financed by large agricultural multinationals -- are being built in various strategic places in the world. Most scientific publications about the conservation of genetic diversity talk about agricultural plant- and domesticated animal species (Blackburn, 2012; Westengen, et al., 2013). But also the ex-situ conservation of wild plant species (Hamilton, 2002) and wild (often endangered) animal species (Witzenberger \& Hochkirch, 2011) is currently part of the on-going global conservation discourse.

\section{Characterisation and links}

Gene-banking is largely driven by anthropocentric worldviews and by monetary or community values (research, preservation of food species for the future). Also urgent environmental problems can drive the depot of genetic material or seeds. The conservation focus is commonly on gene or species. Gene- or seed-banking includes a sense of human control over nature. There are not so many links with other conservation approaches, although they do exist in a reinforcing way with zoos or - more controversially -- with NGOs. Also links with the private sector are strong, for example through the financing by large multinationals. This link with the private sector is represented in the link with partnerships. 


\section{Protected Areas}

\begin{tabular}{|l|l|l|l}
\hline Centre & Driver & Focus \\
\hline & 0 & 0 &
\end{tabular}

In 1872 Yellowstone - the first National Park of the world - was created in Wyoming, U.S. Probably the most well-known form of conservation is the in-situ conservation that takes place within the defined boundaries of national parks, reserves, protected areas, biodiversity hotspots, and sites of world heritage. According to Margules and Pressey (2000) reserves have two main goals: representing samples of biodiversity of each region and separating biodiversity from [anthropogenic] processes that are a threat to its existence (Margules \& Pressey, 2000, p.243). Because of the enclosing character of this type of conservation, some people call it fortress conservation (Fothergill, 2006). Fortress conservation excludes people and their basic activities from protected areas, assuming that people -- especially local inhabitants-and their daily practices are causing damage and destruction to the natural areas (Doolittle, 2007). Usually, only activities like scientific research, (eco)tourism and safari- or trophy hunting are considered as appropriate uses within protected areas (Siurua, 2006; Doolittle, 2007).

In some parts of the world protected areas are surrounded by conflict: rangers need to be heavily armed in order to face poachers or to protect the safety and livelihoods of local communities (Fothergill, 2006); conflicts between indigenous human inhabitants of the protected areas and big predator animals occur frequently (Newmark et al., 1994; Fothergill, 2006) and also sometimes the protected areas are centres of crime and larger conflicts about precious natural resources (e.g. in Congo) (Nelleman, 2010). This type of conservation, fencing off wildlife from everyday human life, is exemplary in demonstrating the human assumption that nature and culture are two separate domains (Soper, 1995; DesJardins, 2006). IUCN categorised protected areas based on the level of protection (categories I-VI) ranging from strictly protected reserves to sustainable use areas (IUCN, 2012d).

Protected areas are increasingly losing their reputation as a panacea for biodiversity conservation and halting its loss (Mora \& Sale, 2011). Changes have been on the way during the last decades, loosening up the ideas of strictly separating natural areas from human areas for their conservation, for example through community based conservation (Miller \& Hobbs, 2002; Büscher \& Whande, 2007; Chan, 2007; Adams, 2013) or the establishment of Peace Parks (Büsscher, 2013). These approaches connect the environment to human co-existence and well-being through efforts of building peaceful communities in cooperation across national borders which nature cannot be boxed in by. Also conservation projects increasingly focus on more integrated sustainable use approaches of landscapes and habitats (IUCN, 2010c, 2011f, 2011e, 2012c). Very often these approaches are serving the idea and the ideal of a 'green economy', which some 
authors identify as 'neoliberal conservation' (Büscher \& Whande, 2007) and critically discuss as distracting the debate from the real drivers of the environmental crisis (Morrow, 2012; Spash, 2012).

\section{Characterisation and links}

Protected areas are based on principles of control, but inspired by an eco-centric worldview, and ethical values. Other drivers for establishing PAs can be acute environmental problems and threats to ecosystems or species within them. Laws can enforce the establishment and protect the areas, often with the help of other legal enforcements, like military surveillance. Also, the areas are often used for scientific research or collecting revenues to maintain the parks through ecotourism. The conservation focus is basically directed towards species and populations. At the same the landscapes that are of crucial importance for these species are conserved, together with the ecosystem services they provide.

The protected areas strategy has strong reinforcing links with ecotourism, controversial links with hunting (trophy hunting or population control). Also the links with legislation and policy can be controversial and counterproductive for conservation: governments can allow certain potentially disturbing activities (culling or logging, or managing the areas based on human aesthetic ideals) or decide that other (developmental) activities are more urgent than establishing new PAs or maintaining existing ones.

\section{Non-Governmental Conservation Institutions (NGOs)}

\begin{tabular}{|l|l|l|l}
\hline Centre & Driver & Focus \\
\hline & & &
\end{tabular}

Internationally, nationally and locally NGOs and conservation institutions play an important role for conservation since the 1940's when the first union for the conservation of nature was established (Christoffersen, 1997; MacDonald, 2003). The red list of threatened species of the IUCN is one important instrument for conservation that is probably most known by the public and policy-institutions (IUCN, 2013e). IUCN is still the largest international conservation organisation, but is publicly lesser known than its offspring WWF. WWF has been established to gather funds for conservation and research on species, habitats and ecosystems (Christoffersen, 1997; MacDonald, 2003). WWF is probably best known for its global awareness raising campaigns. Next to these large global conservation institutions, many small and local institutions contribute their parts to conservation, education, research and awareness-raising. Also the lobbying forces of the non-governmental institutions contribute much to legislation and policy on all scale levels from global to local. 


\section{Characterisation and links}

NGOs are often driven by eco-centric worldviews and strong ethical standpoints on the human-nature relationship. Often they emerge in times of 'need' when these values - or species or environments -- have to be defended against governmental regimes or the private sector. NGOs can be the voice of earlier unheard community members. Often they are driven by the aim to change policies and legislation. The links NGOs have with other conservation strategies are manifold and sometimes conflicting or controversial. The link with policy and legislation is strong, but as NGOs often resist the existing regime, it can be negative as well. Nevertheless, much is accomplished by means of lobbying. Partnerships with the private sector are recently increasing within NGOs but are at the same time highly debated too. A strong reinforcing link exists between civil action and NGOs.

\section{Civil Action}

\begin{tabular}{|c|c|c|}
\hline Centre & Driver & Focus \\
\hline
\end{tabular}

The origin of the big conservation institutions can be found in concerned individuals who were able to gather public momentum to initiate awareness and changes. Still demonstrations and petitions play an important role in influencing policy. Nowadays social media start playing an important part as well. Europe, for example, has recently put a ban on pesticides having deleterious effects on bees and other important pollinators (Carrington, 2013). This decision has come through with a forceful public pressure in the form of an online petition that has been signed by many millions of people from around the world (BBC, 2013). Many small scale civil actions globally result in the preservation of much land.

\section{Characterisation and links}

Civil action for conservation is often based on eco-centric values. It can be driven by ethical concerns, community needs or urgent environmental issues. Also the wish to change policy can be a strong driver for civil action. Civil action often contributes to the protection of landscapes valued by communities (on local scales). The focus can also be towards species, populations or ecosystem services. There are strong reinforcing links with NGOs and strong controversies with existing laws and policies can occur. Civil action is strongly needed in the idea of reconciliation ecology. Arts are often involved as an expression of civil activism. 


\begin{tabular}{|l|l|l|}
\hline Centre & Driver & Focus \\
\hline (1) & \\
\hline
\end{tabular}

There is a form of civil engagement that is nowadays especially suited for the very rich: it's called philanthropy. The term 'philanthropy' originally means love of humanity in Greek. It was coined in the seventeenth century and highly interwoven with the ideas and ideals of the Enlightenment and Christian charity (Holmes, 2012). The concept bloomed in the late nineteenth and early twentieth Century, during the time of Industrial Capitalism. Profits of capitalism should ideally become redirected to societal goals. Many philanthropists choose conservation goals as a way to do good (Holmes, 2012). The Rainforest Trust for example is founded by millionaire Johan Eliash with the aim to save a piece of the amazon forest from logging and creating more sustainable ways to earn money from the forest for local people, like tourism and forest management (Fothergill, 2006). Many forms of philanthropy exist. In conservation practice, most often it involves the buying of land or donating to conservation NGOs, attracted by imperilled flagship species. The well being done also feeds back into the good name of rich individuals or enterprises. In that sense, especially nowadays, philanthropy, corporate social responsibility and partnerships are closely related to each other and to neo-liberal market capitalism (Holmes, 2012). Conservation organisations, NGOs, and also governments are increasingly relying on market mechanisms for conservation (Beumer \& Martens accepted 2013) and one of them is 'selling nature' to the rich in order to save it (Holmes, 2012, p. 188). When governments retreat (due to cuttings for example) and NGOs start lacking financial resources (due to economic crises for example), conservation runs indeed the risk to become dependent on the benevolence and preferences of the wealthy.

\section{Characterisation and links}

Philanthropy can be based on anthropocentric and eco-centric motives. It is often driven by the aim to invest money into something good for the world or society. Sometimes philanthropists are driven by urgent environmental issues. Often they focus on the protection of landscapes or species. Very often natural and human ethical values are considered and combined with monetary values. Philanthropy has strong reinforcing links with the notion of ecosystem services (for example through gaining additional revenues from protecting nature for recreation instead for exploiting it for short-term economic benefits) and with the private sector (partnerships). Also the link to NGOs is influentially strong. 
Partnerships

\begin{tabular}{|l|l|l|}
\hline Centre & Driver & Focus \\
\hline (11) & &
\end{tabular}

In line with mainstreaming biodiversity into other sectors of society (CBD, 2008), new partnerships are emerging, especially between the old established NGOs and the business sector (Christoffersen, 1997; IUCN, 2007a, 2010f). In order to conserve biodiversity, especially large resource extracting and agricultural businesses need to become better engaged to make their practices more sustainable and biodiversity friendly. This engagement can be made practical by forging connections with conservation NGOs. Although the establishment of partnerships may be a necessary step in the development of conservation strategies, there are also some dangers of green-washing. Also some critical questions related to shifting power-relations can be asked: who is cooperating with whom and who has to compromise their 'ideals' and aims in public-private partnerships (MacDonald, 2010)? The analysis of the discourse of IUCN (CHAPTER 7) has demonstrated that the formerly activist - and basically Egalitarian -- language of the protection of nature has changed into Individualist language centred on the idea of stimulating a 'green economy' (Beumer \& Martens, 2013). An assessment of the contributions of private sector partnerships in biodiversity governance demonstrated that the participation of various actors in biodiversity governance hasn't significantly improved (MacDonald, 2003; MacDonald, 2010; Visseren-Hamakers, et al., 2012).

\section{Characterisation and links}

Partnerships are basically anthropocentric: based on economic- and community drivers. Their focus can differ from long term protection of genetic material to landscapes and species. Most importantly is the common ground between NGOs and private partners of conserving ecosystem services for future generations. Partnerships can be called a 'marriage of convenience' between the more activist oriented NGOs and the private sector. The approach is rather controversial for that reason. There are strong supporting links between the private sector-NGO partnerships with philanthropists and with the ecosystem services approach to conservation. 


\section{Ecosystem Services}

\begin{tabular}{|l|l|l|}
\hline Centre & Driver & Focus \\
\hline (1) & & \\
\hline
\end{tabular}

Economically valuating ecosystems for their services is a novel approach for conservation, which started with the famous paper of Costanza and his colleagues (1997) and has become widely integrated in global ecosystem assessments like the Millennium Ecosystem Assessment (MEA, 2005). Looking at nature through the concept of ecosystem services is different from looking at nature and seeing it as a resource per-sé. The ecosystem services approach calculates the long-term value of intact ecosystems and their functions, instead of the short-term revenues of their 'harvest' (TEEB, 2009). Trees for example have a short-term value on the market when they have been logged and can be sold as wood. Trees in woods provide many services, like habitat, shelter, food, shade, water-regulation, air purification, soil formation, jobs for tourist operators etc. (Fothergill, 2006). These services seem invaluable in monetary terms, but they can be calculated by means of calculating the costs of replacing the services provided by the trees by technology, restoration and/or social costs that come with the elimination of these services. Although the approach is appealing to policy and business domains, the ecosystem services approach to conservation is debated (Nunes \& van den Bergh, 2001; Norton \& Noonan, 2007; Redford \& Adams, 2009; Büscher, 2010): it is highly anthropocentric. It keeps intact the old way of thinking in economic terms and the benefits to people. It reduces the values of nature and ecosystems into numbers and calculus. It is ignorant to 'unknown' services and processes going on in nature. Also it is difficult to account for the values that cannot be calculated. It will more easily allow for the loss of services when they can be substituted with technological fixes (Norton \& Noonan, 2007; Redford \& Adams, 2009; Beumer \& Martens, in 2013). Moreover: who decides which ecosystem services are valuable? And who will distribute them? Who pays for them and who gets the revenues (Opschoor, 1998)? According to Redford and Adams (2009) "ecosystem services are not a fractal of nature but represent only part of the full spectrum of biodiversity (Redford \& Adams, 2009, p787)." Also valuation methods can never take the full value of biodiversity into account (Nunes \& van den Bergh, 2001). Therefore, without using the concept with caution and continued debate, it may be applied in short-sighted ways that can be detrimental to nature (Norton \& Noonan, 2007; Redford \& Adams, 2009).

\section{Characterisation and links}

The notion of ecosystem services is based on an anthropocentric worldview. It is driven by at least giving insight into the monetary value of the 'assets' of intact nature. It is also driven by many community values, like future health, well-being and prospective values 
of nature (Nunes \& van den Bergh, 2001). The conservation focus is on the functional relationships in ecosystems. NGOs like IUCN or WWF contribute much to the support of the concept of ecosystem services and there are strong links with philanthropy and private sector partnerships. A controversial relationship exists between the three intervention strategies (restoration, relocation and reintroduction). Although these approaches are sometimes based on the idea to improve ecosystem services, there may be risks and nuisances and disservices involved as well (Lyytimäki, et al., 2008).

\section{Ecotourism}

\begin{tabular}{|l|l|l|}
\hline Centre & Driver & Focus \\
\hline (14) & &
\end{tabular}

When safe enough to visit, protected areas are some of the greatest tourist attractors in the world. Through the revenues of eco-tourism, when fairly managed, local indigenous inhabitants can improve their livelihoods without the need for poaching and with having the incentive to participate in the protection of the natural areas and their species. Revenues of eco-tourism also flow into the research and further protection of species. Although heavily controversial amongst nature lovers, trophy hunting is also an important part of ecotourism, bringing in large amounts of money that can be used for the protection and restoration of nature parks and their species (Fothergill, 2006).

Ecotourism holds promises for the improvement of livelihoods of indigenous communities and is often seen as the ultimate way to integrate biodiversity and human development goals (Fothergill, 2006). The practice is often different, as Coria and Calfucura (2012) argue: "ecotourism has often failed to deliver the expected benefits to indigenous communities due to a combination of factors, including shortages in the endowments of human, financial and social capital within the community, lack of mechanisms for a fair distribution of the economic benefits of ecotourism, and land insecurity (Coria \& Calfucura, 2012, p.47)."

\section{Characterisation and links}

Ecotourism is an anthropocentric approach of biodiversity conservation. Nature can be admired by people, it can be considered a retreat from daily hassle, but it can also involve feelings of adventure and adrenaline. It is largely driven by economic values. Revenues do not necessarily only end up in the pockets of the tourism industry. Often revenues are also used to finance the conservation of specific habitats, landscapes or species. Community values can also play a role. Tourism can be a more sustainable way of supporting the livelihoods of local residents compared to activities such as logging, hunting or mining. Although controversial, strong connections exist between ecotourism and 
trophy hunting. Enforcing strong links exist between ecotourism and protected areas and conservation education. Visiting zoos or botanical gardens can also be considered forms of ecotourism. This basically depends on how the zoos are designed. Some may resemble national parks, mimicking landscapes and animal communities of different places in the world. Others may be hard to link to ecotourism because of their design.

\section{Interventions: Restoration, Reintegration and Relocation}

Global environmental changes - such as Climate Change and Urbanization - pose significant threats to a large number of plant and animal species on the planet. These changes make it necessary to think beyond the preservationist conservation discourse and explore more radical, intervening approaches to conservation. Three significant postpreservationist options are presented in this section and all of them imply a shift away from the idea of preserving wild, pristine nature that is "free from human management nature (Minteer \& Collins, 2012, p.1)." Such approaches raise difficult ethical questions for conservationists. According to Minteer and Collins (2012) species reintroductions, assisted relocation and ecosystem restoration "signal a potential change in conservation philosophy and ethics toward a more pragmatic and manipulative model of humannature relationships (Minteer \& Collins, 2012, p.14)."

\section{Restoration}

\begin{tabular}{|l|l|l|}
\hline Centre & Driver & Focus \\
\hline & &
\end{tabular}

Restoration may seem to be the least radical and least controversial of the spectrum of the 'three Rs' of intervention. Habitats are the centre of the intervention here. Restoration can be defined as broadly defined as the process of rebuilding a former ecosystem and returning it to a healthy state where it is able to sustain itself again. Often restoration implies that the state of the habitat is returned to - at least resembling -- the condition of its former pre-disturbed form. It is often considered a process of 'healing' nature (Keulartz, 2007; Moore \& Moore, 2013). Examples of restoration include restoring tidal flows into restricted wetlands, removing river artificial river banks for natural river flows to return, cleaning polluted habitats, removing invasive species or increasing the structural heterogeneity of ecosystems (Palmer et al., 2010; Andel \& Aronson, 2012). Restoration takes place on small local scales to large international scales where multibillion industries and technological ingenuity are involved (Moore \& Moore, 2013). Nevertheless, many ethical and practical doubts evolve from the restoration approach to conservation. Most importantly, because of the conservation-option of restoration, industries 
are increasingly granted permits to exploit and damage ecosystems, on the proviso they restore them afterwards (Moore \& Moore, 2013). Research has also demonstrated that restored habitats have greater biodiversity than destroyed ones. However, biodiversity in restored ecosystems is only half the quality and amount of undamaged sites (Rey Benayas et al., 2009; Palmer, et al., 2010; Moore \& Moore, 2013).

Also questions are posed with regards to animal welfare within restoration-projects. When species are reintroduced to restored habitats they often have to go through a process of de-domestication (Gamborg et al., 2010). In a major restoration project in De Oostvaardersplassen in the Netherlands the reintroduction of Konik horses and Heck kettle has led to major discussions and public debates: the species should sustain themselves in their new ecosystem, but strong winters and insufficient food have led to high mortality rates. Some people would consider the winter mortality rates 'natural' population dynamics; other people regard it as a cruelty to leave the animals without aid. Keulartz (1999) asked the critical question whether we should sacrifice the health and wellbeing of individual animals in order to restore an ideal of a former pristine ecosystem? Sometimes the land-ethic (Leopold, 1966) seems to directly conflict with the animalethic (Minteer \& Collins, 2012; Harrington et al., 2013).

\section{Characterisation and links}

Restoration usually happens on eco-centric grounds based on historical (community) values (the landscape as it used to be) or on ethical considerations (the landscape as it or ought to be). The focus is mainly on landscapes and functional ecosystems. Quite some links with the three intervention strategies are controversial. The link with protected areas is strong as are the links to conservation policy.

\section{Reintroduction}

\begin{tabular}{|c|c|c|}
\hline Centre & Driver & Focus \\
\hline & & \\
\hline
\end{tabular}

Reintroduction of animal- and plant-species usually take place in restored habitats but it also often occurs in habitats that are not or only partially re-adapted to the species of return (Slats, 2013). In line with the story of De Oostvaardersplassen, some other reintroductions in the Netherlands cause some problems too. The reintroduction of otters that took place in the period between 2002 and 2008 is called successful by Wageningen University (WUR), who led the reintroduction (Kuiters, 2012). Otter populations are increasing in the Netherlands, but at the same time, due to the contemporary tight infrastructural network, many individuals are hit and killed or injured by cars (Kuiters, 2012): the new conditions they were reintroduced to do not match the more undis- 
turbed habitat requirements of these species, leading to the dead and suffering of many individuals (Slats, 2013). Also the reintroduction of beavers in the Netherlands causes some problems. They are doing so well, that they start endangering the Dutch dikes in some places, causing conflicts between human and animal interests (Slats, 2013). Some other problems related to reintroductions, where the land-ethic comes into conflict with the animal-ethic can be found in the control of invasive species, the culling of individuals to manage population size, taking animals captive for breeding and handling them for study purposes or preparing them for the reintroduction (Harrington, et al., 2013). According to Harrington et al, (2013) despite all good intentions, "[a]nimal reintroductions necessitate and provide opportunities for manipulation of conditions that directly affect the health or welfare of individual animals during all stages of the reintroduction process (Harrington, et al., 2013, p.487)."

\section{Characterisation and links}

Reintroductions usually happen on eco-centric grounds based on historical (community) values or ethical considerations. The focus is mainly on species, populations or refreshing gene-pools. Almost all the links with the three intervention strategies are controversial. The one with protected areas is reciprocally strong.

\section{Relocation}

\begin{tabular}{|l|l|l|}
\hline Centre & Driver & Focus \\
\hline & &
\end{tabular}

Relocation - also called translocation or assisted migration -- goes further than reintroducing species to their 'original' habitats. Often the action takes place just before (or near) extinction. Global Climate Change (GCC) is expected to cause many difficulties for species to adapt quickly enough to the rapidly changing circumstances in their original habitats (Minteer \& Collins, 2012; Moritz \& Agudo, 2013; Quintero \& Wiens, 2013). The adaptation-problems can be attributed to the speed and extend of planetary warming combined with fragmented landscapes due to urbanisation, agriculture and other landuse changes (Minteer \& Collins, 2012). Trans-locating species -- where individuals are taken out of their historical habitat to be moved to another place where their chances of survival are estimated to be higher -- could be a pro-active and activist approach to such threats. It invokes images of polar-bears flying through the air in nets and blindfolded giraffes in train-wagons, approaching their new destinations. Obviously, this conservation method is highly controversial. Relocation has also been called 'assisted colonisation.' It reminds of the systemic ecological problems caused by introductions of alien domestic species like rabbits in Australia (Fenner, 2010), pigs in the Galapagos (Larson, 
2001) or Nile perch in Lake Victoria (Sauper, 2004). Legal frameworks for pest-species until now only exist for a subset of species that threaten agriculture (McLachlan, et al., 2007). New international legal frameworks have to be developed with regards to species translocation for conservation purposes. This will not go undebated (McLachlan, et al., 2007; Stone, 2010). Well-intentioned conservation efforts can have far reaching ecological effects. What will the social and environmental risks be in the short and in the long term; how are the risks assessed and addressed; which trade-offs are involved; who will decide what species are moved and where they are moved; how will the ecosystems and species they are moved to be considered and prepared; and who will pay for the costs before, during and after the translocations (McLachlan, et al., 2007; Stone, 2010; Minteer \& Collins, 2012)? These are just a few questions that urgently need to be addressed and that will be extremely difficult to answer: the questions and potential answers are per definition highly normative. While some authors argue that "desperate times need desperate measures (Seddon, 2010; Stone, 2010, p.1592)" some other authors principally call relocation a 'no-go-area (Ricciardi \& Simberloff, 2009).'

\section{Characterisation and links}

Relocation usually happens on eco-centric grounds based on ethical considerations or the urgency to protect highly endangered species from extinction due to changing land uses or land ecosystem conditions. The focus is mainly on species and populations. Control of nature is a basic assumption in this approach. Almost all the links with the three intervention strategies are controversial. The one with protected areas is reciprocally strong.

In all the three intervention-approaches, often holistic systemic reflections and assessments of potential consequences on the long term are lacking.

\section{Conservation-Education}

\begin{tabular}{|l|l|l|}
\hline Centre & Driver & Focus \\
\hline & $(4)$ &
\end{tabular}

Many organisations, larger and smaller are involved in education for conservation. This ranges from global institutions like WWF and IUCN to zoos and many local NGOs. The International Zoo Educators Association (IZEA) defines conservation-education as "the process of influencing people's attitude, emotions, knowledge and behaviours about wild life and wild places (IZEA, 2005)". The IUCN, commission on Education and Communication (CEC) has established specialty groups promoting an increased public awareness (IUCN, 2013c) for endangered species and the urgency of conservation efforts. Under 
the CBD's Aichi target 1 - [b]y 2020, at the latest, people are aware of the values of biodiversity and the steps they can take to conserve and use it sustainably (CBD, 2011) -these specialty groups developed a toolkit for conservation-education institutions worldwide to "motivate and mobilize individual and collective action for conservation and sustainable use of biodiversity [by inspiring messages]" like the 'love, not loss' campaign (IUCN, 2010a).

Educating the public with the aim to increase support for conservation is proposed to increase knowledge about the state of the environment, to increase ecological awareness and promote positive attitudes in favour of the environment (Trewhella et al., 2005). Educational strategies are often rooted in environmental psychology (Kurtz, 2002; Clayton \& Myers, 2010). Ultimately, the goal of conservation-education is an increased environmentally-friendly and sustainable human behaviour (Pearson, et al, 2013).

\section{Characterisation and links}

The centre worldview of conservation education can be eco-centric, anthropocentric or holistic. Its drivers are community based or ethical and sometimes urged by environmental needs. The focus is usually on learning about species, landscapes or ecosystem services and functions. Strong reciprocal relations exist between conservation-education and reconciliation ecology, where civil engagement should be created as much as possible. Strong reinforcing links also exist with ecotourism and with zoos and botanical gardens (Mennen, et al., submitted). It can be influenced by religious considerations or worldviews as well (Gerlitz, 1998; Posey, 1999).

\section{The Creative Arts}

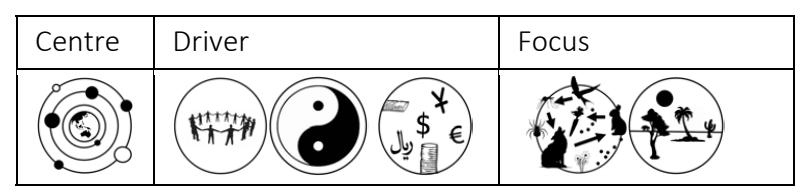

"...[I]f we are going to have a new connection to the environment it will have to happen in individual hearts and souls...the artist can help us fall in love with the earth again (Berensohn in: Jacobson et al., 2002, P.7)." In the 1800's a revolution in the arts took place. Until that time, most paintings and other artworks had been of religious scenes or of human beings and the natural world was often represented as an intimidating 'other' world that had to be conquered. As a reaction to widespread industrialisation, pollution and utilisation in the 1800's, the idea of seeing the beauty and unspoilt pristineness in nature emerged in art and literature (Kluckhohn, 1966). Caspar David Friedrich, John Constable and William Turner first started to paint the splendours of the natural world and philosophers and poets such as Wordsworth in Britain, and Goethe and Novalis in Germany, started to complement Enlightened thinking, which was based on rationalism 
and the utilisation of nature (Hampson, 1968; Spary, 1999). The Romantics aimed to reconnecting human hearts and minds to nature through their arts and through a holistic philosophy of nature that was largely inspired by the ideas of Goethe (Bortoft, 1996). Romantic philosophy and arts are still an important source of inspiration for preservationists and deep ecologists (Capra, 1996).

A century later, in the 1900's, some ground-breaking bestsellers were written in the U.S. John Muir's (1838-1914) many works, books and essays about his adventures in the Sierra Nevada and other natural areas has been largely influential to the beginning of the conservation era in the U.S. Muir's work helped creating the Yosemite national park and the Sequoia National Park and many nature trails are named after him. He also founded the Sierra Club, the most influential conservation organisation of the U.S. (Jones, 1965). A younger time companion of Muir, Aldo Leopold (1887-1948) was highly inspired by Muir's works but had his own important natural considerations to share with the world as well. His most influential book A Sand County Almanac (1966) has been the basis of a new holistic ethics of nature: He described "Conservation is a state of harmony between men and land," and with these "land-ethics" he "enlarge[d] the boundaries of the community to include soils, waters, plants, and animals, or collectively: the land (Leopold, 1966)." Leopold's concept of "Thinking Like a Mountain" inspired many people towards long-term ecological thinking and deep ecology (Naess, 1995; Capra, 1996; Boeckel, 1997). The American marine biologist Rachel Carson (1907-1964) was the next in line to write an important book for the conservation movement: Silent Spring (1962) woke the world for the dangers of the use pesticide like DDT. The aftermath of the book led to a ban on DDT and other pesticides around the world. In the U.S. the book inspired a grassroots environmental movement that led to the creation of the U.S. Environmental Protection Agency (Lewis, 1985).

During the last century many influential documentaries and movies have been made. Jacques-Yves Cousteau (1910-1997) studied ocean life and filmed his work showing many people the underwater world for the first time in their lives (Cousteau \& Dugan, 1956). Cousteau was a pioneer in marine conservation. Extraordinary in touching the hearts and minds of many people around the world is the contemporary BBC documentary series Planet Earth, narrated by David Attenborough (Genton, 2006). Also popular TV channels like Animal Planet, Discovery Channel, and National Geographic reach large audiences with their broadcasts on the beauty of the life on the planet. Films like Home (Arthus-Bertrand, 2009) and Earth (Fothergill et al., 2007), which are freely available on the Internet, contribute to a global general awareness of the perilous state of our planet and all its inhabitants.

Unfortunately, there is not much space here to discuss the vast amount of other influential works of art like the thousands of songs, photography, experimental artworks and even dancers that inspired people towards a more conscious attitude and positive feelings towards the natural environment. Whatever artwork is influential, it usually 
works through evoking emotions and feelings of connectedness, happiness, disgust, sadness, fear or love (Jacobson, et al., 2002). It stirs discussion, debate and interaction among people, sometimes by confusing them, sometimes by inspiring awe and wonder. The danger of many contemporary environmental films is that they are based on images of doom and gloom, arousing anxiety and a feeling of helplessness in people. A challenge for environmental art of the present and the future is to focus on evoking creative inspiration in its audiences or participants. Why not inspiring all people to make their own lives a work of art, positively contributing to a planet that is worthwhile to pass on to next generations (Dohmen, 2005)?

\section{Characterisation and links}

The arts as a tool for conservation can be seen as a holistic strategy, including all aspects of the human being and of nature, crossing nature-culture lines and questioning old dichotomies. Its drivers are often ethical, but also include involving the community to create a better future by participating in art - be it passively or actively. Artists also need money to survive, so often monetary divers exist as well to create. The conservation focus of the arts seems to be interestingly often on landscapes (traditionally). Closely linked to civil action and reconciliation ecology there are many other strong reinforcing or influential links exist between the arts for conservation and other strategies.

\section{Landscape- and Reconciliation Ecology}

\begin{tabular}{|l|l|l|}
\hline Centre & Driver & Focus \\
\hline
\end{tabular}

In his book Filosofie van het Landschap [A philosophy of the landscape](2006), Ton Lemaire defines landscape as the self-representation of culture (Lemaire, 2006, p.72). Nassauer more or less states the same when he writes that "[c]ulture changes landscapes and culture is embodied in landscapes (Nassauer, 1995a, p.229)." Landscape ecology as a discipline has always included the effect of human beings into its research, especially focusing on the effects of policy and popular culture (Nassauer, 1995b). In 2003, Michael Rosenzweig introduced the concept of reconciliation ecology as an approach of conservation that works within the human dominated landscape, instead of fencing off wildlife and landscapes from human use (Rosenzweig, 2003). It is based on an understanding of the so called species-area relationships (SPARs) and patterns (Losos \& Schluter, 2000): large areas are inhabited by more species than small ones (Humboldt, 1807; Rosenzweig, 2003). Rosenzweig reacts to the in his eyes two dominant conservation tactics: reservation ecology (e.g. PAs, nature reserves reserves) and restoration ecology (e.g. restoring habitats, reintroduction of species). These strategies won't cope 
because they will continue seeing habitat becoming more fragmented and species survival chances diminishing, especially under the conditions of Climate Change (Rosenzweig, 2003). Numerous ecological studies researching species distribution and survival within the concept of island biogeography (Whittaker \& Fernandez-Palacios, 2007) (demonstrate that "we cannot preserve the large-scale at the tiny scale (Rosenzweig, p.203)." The strategies of restoration and reservation have to be complemented with reconciliation ecology, a pioneering area in ecology and conservation science and practice. According to Rosenzweig "[r]econciliation ecology discovers how to modify and diversify anthropogenic habitats so that they harbour a wide variety of wild species (p. 201)." It should "grow the earth back (p.201)" and give many species back their habitats and ranges "without taking away ours (p.201)."

My assumptions in this dissertation follow Rosenzweig's theory. Proceeding from the concept of reconciliation ecology I aim to give reconciliation ecology hands and feet by proposing a participatory citizen science framework (BIMBY) (see CHAPTERS 10 and 11) - or as Wiek and his co-autors would call it: a tool for transformative science (Wiek, et al., 2012). BIMBY aims to reconcile people with their environments and contribute to a new emerging paradigm of eco-literacy (Mitchell \& Mueller, 2009) and ecological growth. The idea of reconciliation ecology can be perfectly combined with another concept that emerged lately: that of biophilic cities (Beatly, 2005).

\section{Characterisation and links}

Reconciliation ecology unites anthropocentric and eco-centric values trying to deconstruct the old dichotomy in the human-nature relationship. Therefore, it can be seen as a holistic approach to conservation. Most commonly, community or ethical values drive reconciliation ecology. It is often directed at landscapes (integrating urban and natural landscapes) and enhancing the functional relations within socio-environmental systems to increase well-being for all living entities. Reconciliation ecology has an ideal to create a new socio-environmental paradigm. Especially strong reciprocal links exist with conservation education and the arts. Reconciliation ecology may employ links with the three interventional strategies. However, these links can be called controversial: when building novel ecosystems (Kowarik, 2011) much has also to be learned, discussed and debated. Not every approach may be beneficial for bot people or ecosystems.

\section{Conclusion}

As has demonstrated in this chapter, many different conservation approaches exist and most of them are still entangled in debates about the nature of nature and humannature relationships, attaching to an old philosophical and ethical assumptions and dichotomies. To gain more insight into in the plurality of the various conservation strategies, their worldviews and their relationships, a conceptual mapping exercise was done. 
The results deliver interesting insights that can help structuring the debate on what is the best approach to halt biodiversity loss or contribute to a healthy socioenvironmental system in a changing world. It seems, for example that some currently popular strategies (e.g. governance and NGOs) have a relative significant number of controversial relations and even some negative ones with other approaches; NGOs recent engagement with the private sector for example isn't undebated and research pointed out that is isn't even as effective as it was considered to be (Visseren-Hamakers, et al., 2012). Policy and governance for conservation have a number of significant controversial relationships, which will contribute to slowing highly necessary conservation legislation down. Although also highly controversial, hunting seems to be a spider in the web of conservation, having relatively many connections to other methods. The same accounts for the significance of zoos and botanical gardens: while their existence on itself already may be controversial (Mennen, et al., submitted). Although the relationships between religions and other conservation approaches are basically one-directional, they seem to be of broad influence considering their (inspirational, lobbyist, ethical) links to so many other strategies. The same broad influence accounts for the arts, where most links are even strong and reciprocal.

In this chapter the primary focus has been on direct linkages. It will also be interesting to further asses the indirect connections and more subtle influences between the different conservation strategies. Also conservation impacts (direct and indirect) can be included in such an assessment. In the next chapter I will dive deeper into the characterisation of the different conservation strategies by more systematically analysing their discourses and worldviews. 


\title{
CHAPTER 5
}

\section{The Colours of Conservation}

\author{
Cultural Theory and Conservation \\ Dynamics
}


"The nature of culture is evolution. The practice of culture is adaptation"

(Anonymous)

This chapter is adapted and elaborated from: Carijn Beumer \& Pim Martens (2010). "Noah's Ark or World Wild Web? Cultural Perspectives in Global Scenario Studies and Their Function for Biodiversity Conservation in a Changing World." Sustainability 2, no. 10: 3211-3238. 


\section{Introduction}

In 2010 the Convention for Biological Diversity released the Global Biodiversity Outlook 3 , reflecting on the failed target to reduce global biodiversity loss in 2010 (UNEP, 1992, pp., p.227). In the Outlook it is stated that "urgent action is needed to reduce the direct drivers of biodiversity loss"(CBD, 2010). This conclusion is clear and unanimous. It has led to the establishment of the more programmatic Strategic Plan for Biodiversity 20112020 and the Aichi Biodiversity Targets (CBD, 2011). Still, the specific goals and means to address biodiversity loss are divergent and there seems to be a lack of integrated discussion in the broad conservation arena. What is exactly meant by 'reducing global biodiversity loss' is not (yet) made very operational and remains rather vague and fuzzy. On the level of practical conservation approaches, biodiversity conservation is a pluriform concept.

In order to get more insight into the many facets of conservation some main approaches to conservation have been mapped (see CHAPTER 4 ). As was demonstrated, in practice biodiversity conservation contains many different strategies ranging from park management and ecological network development to the storage of seed material in artificial cryospheres and bio-engineering. The starting point is that I believe there is a lack of integrative discussion between all the various approaches to achieve the goal of reducing global biodiversity loss. A thorough dialogue on the basic assumptions and worldviews underlying these approaches and on how they relate to each other - supporting, complementing or contradicting each other -- is basically missing in the 'conservation arena' and in society in general. The ethical reasons of why we would choose for a post-modern version of Noah's Ark or for a World Wild Web of connected habitat infrastructures instead or the more practical implications of how such diverging strategies could be combined or modelled to develop a robust conservation strategy, remain rarely discussed issues until now.

With this chapter I hope to contribute to a deeper discussion on the aims, means and ethics of biodiversity conservation in a pluralistic and dynamic world. In order to do so, an adaptation of the cultural perspectives framework from Cultural Theory (CT) is proposed (Douglas, 1970; Thompson, et al., 1990; Thompson, 1997; Mamadouh, 1999; Verweij, et al., 2006; Offermans, 2012). This adaptation includes an integration of CT with a theory of change.

CT has been applied as an analytical framework and participatory tool before to a variety of topics. It has initially been developed to analyse and interpret (religious) rituals of communities (Douglas, 1970). Later it has been adopted to analyse different perspectives on nature and resources (Thompson, et al., 1990) and systemic uncertainty (Asselt, et al., 1995). Also it has been applied to the analysis of perspectives on climate change (Verweij, et al., 2006) and most recently on water management (Valkering, et al., 2008; Offermans, et al., 2009; Valkering, 2009; Offermans, 2012). 
In her 2012 dissertation, based on a thorough assessment of a variety of cultural classification systems, Astrid Offermans pointed towards the benefits of using CT as an assessment framework to assess perspectives on complex socio-environmental problems compared to other cultural typology sets such as Motivaction, Spiral Dynamics and Mood Consumption (Offermans, 2012). The main result of Offermans' evaluation of the different typologies is that the CT perspective characterisations are represented in most of the other typologies as well. The perspectives seem recognisable, complete and mutually exclusive compared to the stereotypes in the other typology systems (Offermans, 2012).

Additionally to Astrid Offerman's work, I evaluated the differences between CT and Kluckhohn's and Strodtbeck's model of basic assumptions (Hills, 2002), the value system typology of Geert Hofstede (Hofstede, 1991), Hall and Reed Hall's model of cultural differences (Hall \& Reed Hall, 1990) and Steiner's system of twelve world-outlooks (Steiner, 1914), ranging from materialism to spiritualism. The first three typologies represent a structuralist view to classifications of cultural differences and leave little (theoretical) space for complexity, change and dynamics. Steiner's system includes a dynamic approach towards the perspectives and the history and future of the world. However, this complex system has not been used in scientific assessments before and would need testing that would be worth a dissertation study on its own account (Steiner, 1914).

CT - especially as interpreted by Marco Verweij and his colleagues -- is theoretically also open to ideas of complexity, cultural change and dynamics (Verweij, et al., 2006). This does not only include reactions to surprises (Offermans, 2012); in our view CT has the potential to account for perspective dynamics based on shifting power relations (Castells, 1997; Hall, 2001; Foucault, 2002; Jasanoff, 2004), the formation of coalitions, and contextual learning (Smith \& Mackie, 2000; Erez \& Gati, 2004; Giddens, 2009). However, I assume that these dynamics can only become insightful when more than the three 'traditionally used' perspective groups - the Hierarchist, the Egalitarian and the Individualist - are taken into account in theory and practical analyses.

The Autonomous perspective -- is usually neglected as a valuable perspective in former CT perspective assessments. Additionally, I found that another significant perspective can be relevantly added to the framework: a perspective based on the concept of 'clumsy solutions' by Marco Verweij and his colleagues (Verweij, et al., 2006). This perspective represents the 'systems thinker'.

Below it is explained how I arrived at the adaptations of the CT framework and the inclusion of the additional perspectives. In-depth (re)characterisations of the Fatalist, the Autonomous perspective and the Dynamic Integrator are provided and a novel way of seeing the CT framework is proposed: as a framework that is able to provide insights into the complex dynamics of cultural change. Finally we will return to the conservation strategies that were mapped in CHAPTER 4. They are characterised now according to the CT perspectives. This characterisation exercise aims to shed a light on possible dynamics 
of biodiversity conservation strategies in a changing world. Such outcomes may be useful for scenario work or future visioning exercises (Wiek \& Iwaniec, 2013) (also see CHAPTER 13).

\section{Methods}

Based on qualitative literature assessment (close reading) and the mapping of conservation strategies (CHAPTER 4) the cultural perspectives and discourses on biodiversity and conservation related issues have been explored. The studied literature contained texts ranging from conservation practice, conservation theory, ecological theory, change- and evolution theory, sociology, anthropology, sustainable development and philosophy (e.g.:Odell, 1980; Prigogine, 1980; Noss, 1990; UNEP, 1992; Heywood, 1995; Takacs, 1996; Costanza, 1997; Rotmans \& De Vries, 1997; Gleick, 1999; Posey, 1999; Sarkar, 1999; McCann, 2000; Ray \& Anderson, 2000; Sala et al., 2000; Savard, 2000; Tilman, 2000; Caro \& O'Doherty, 2001; Chapin et al., 2001; Larson, 2001; Nunes \& van den Bergh, 2001; Chivian, 2002; Gitay et al., 2002; Hassan, 2002; Loorbach, 2002; Hassan \& Jones, 2003; Martens, et al., 2003; Rosa, 2003; Folke, et al., 2004; Rodrigues et al., 2004; Swart, 2004; Tzoulas \& James, 2004; McNeely et al., 2005; MEA, 2005; Miller, 2005; Negi, 2005; Steffen, et al., 2005; Notenboom et al., 2006; Spangenberg, 2006; Young, et al., 2006; Bethge, 2007; Büscher \& Whande, 2007; Chan, 2007; Ives \& Carpenter, 2007; Kemp \& Martens, 2007; Loorbach, 2007; Palmquist, 2007; Vaughan, 2007; CBD, 2008; IUCN, 2008g; Mesoudi, 2008; Dearborn \& Kark, 2009; Valkering, 2009; Castells, 2010; CBD, 2010; Hagerman, et al., 2010; Hoppe, 2010; IUCN, 2010c; MacDonald, 2010; Rands, et al., 2010; Rees, 2010; IUCN, 2011d, 2011e; Mora \& Sale, 2011; Reed et al., 2011; WHO, 2011; Aitken, 2012; Bedsted, 2012; Jagers, 2012; Minteer \& Collins, 2012; Wiek, et al., 2012; Adams, 2013; IUCN, 2013a; Moritz \& Agudo, 2013; Skibins et al., 2013). I also included newspaper articles from various (online) Dutch and international newspapers to the literature assessment starting in 2007. The aim of the literature assessment was to compile a general working list of key words and phrases of the CT worldviews in relation to assumptions about biodiversity and conservation strategies more specifically. The basis of this list - containing aspects of worldviews and management styles -- has already been provided by the CT theorists (Thompson, et al., 1990; Asselt, et al., 1995) and by other users of CT (Valkering, et al., 2008; Offermans, et al., 2009; Offermans, 2012). However, the previous lists - or perspective maps (Offermans, 2012) -- have been more or less limited to the Hierarchist, the Egalitarian, the Individualist and to a lesser extent the Fatalist perspectives. Based on the findings in the literature I decided to explore an adaptation of the traditional CT perspective descriptions (Thompson, et al., 1990) and to include one new (the Dynamic Integrator) and more thoroughly integrate two other perspectives (the Fatalist and the Autonomous) that are usually neglected in studies using CT as an assessment framework. 


\section{Culture and Cultural Theory}

In this dissertation a theoretical model of culture as provided by Erez and Gati (2004) is embraced. These authors picture a dynamic and multi-level model of culture where both top-down and bottom-up processes -- from global levels of culture to personal levels of subculture -- affect changes in the other levels of culture. Culture itself is defined in an inclusive sense, involving cultural artefacts and structures, behaviour and practices and on a deeper level -- core values and basic assumptions. Erez and Gati's model of culture reflects a process-based definition of culture by Edgar H. Schein (1990) as: "what a group learns over a period of time as that group solves its problems of survival in an external environment and its problems of internal integration (Schein, 1992)."

CT "puts culture at the centre of the explanation of social life" (Mamadouh, 1999). In CHAPTER 4 biodiversity conservation has been defined as a set of cultural practices. CT is well suited to give more insight into the nature of the diversity of these practices and the assumptions and worldviews behind them. In line with traditional CT, the organization of social relations can be divided into four different basic patterns, namely: (1) Egalitarianism, (2) Hierarchy, (3) Individualism, and (4) Fatalism (Verweij, et al., 2006; Offermans, 2012). These four organizing principles tend to "produce different ways of perceiving (human) nature, and the policy prescriptions [or management styles] that follow from that" (Verweij, et al., 2006, p.819-820). In the Egalitarian perspective, ecosystems are considered to be fragile. In the Hierarchist worldview ecosystems are stable within certain limits. They can be best protected by policies and laws. For the Individualist worldview, ecosystems are either resilient or (in a more rigorous interpretation) irrelevant because their functions can be substituted by technological innovations. The market will guide developments and conservation of nature works best via market-incentives or technological innovation. These three perspectives are well and into depth described in many works preceding ours (Thompson, et al., 1990; Mamadouh, 1999; Verweij, et al., 2006; Offermans, 2012). The fourth, Fatalist, perspective of CT will be discussed in more detail below, together with the Autonomous perspective and the integrative idea of 'clumsy solutions'.

Cultural Theory aims to represent a holistic picture of worldviews, cultural biases and their corresponding management styles by including commitment to social units (group) and institutional authority, such as role differentiation, rules and regulations (grid) (Verweij, et al., 2006; Offermans, 2012). The "level of social stratifications and group solidarity are determining factors of collective thought and behavior" (Verweij, et al., 2006, p. 838). The CT typology integrates both rational choice theory and poststructuralism (Verweij, et al., 2006). Rational choice theorists assume that societies and cultures are fundamentally the same because they consist of human beings who share the same basic needs (Smith \& Mackie, 2000; Kurtz, 2002; Schultz, 2002; Schmuck \& 
Vlek, 2003). Post-structuralists share the view that every person, culture or community is inherently unique (Lyotard, 1979; Funtowicz \& Ravetz, 1993; Best \& Kellner, 1997; Healy, 2010). CT is based on the notion that although cultures do differ, they do not differ endlessly (Verweij, et al., 2006).

Although CT is a valuable tool for analysis of the discourses underlying cultural practices, it is emphasise that I don't propose to use the framework for putting people or practices into narrow boxes. The aim of using $\mathrm{CT}$ is to shed a light on the plurality and interconnectedness of worldviews and practices in relation to biodiversity conservation. Insights based on CT can help explain why global biodiversity conservation targets are so hard to achieve. On the other hand, CT can help to identify constructive links and nodes between the varieties of (sometimes seemingly conflicting) approaches that may now be underexplored and underused for the benefit of achieving conservation targets. Furthermore, I believe that cultural diversity should not be seen as a barrier to solutions of complex problems such as biodiversity loss. Embracing cultural diversity - globally -- is a crucial way to enhance creativity in thinking about- and acting for the future (Bedsted, 2012; Cuppen, 2012; Lang, et al., 2012; Wiek, et al., 2012; Wiek \& Iwaniec, 2013).

\section{The 'forgotten' Perspective Groups}

Analyses applying the CT framework usually limit the range of perspectives employed to the Individualist, Egalitarian and Hierarchist quadrants. However, the grid and group axis (see figure $5.1^{*}$ ) has space for three other perspectives. The first two -- "fatalism" and "autonomy" -- are inherent to classical CT, but are usually neglected in analyses because they do not represent active management styles (Thompson, 1997). I argue that in discussions on biodiversity conservation and sustainability these perspectives do matter, but need to be represented differently. Next to these two perspectives I propose a third additional perspective. It is discussed by Verweij et al. (Verweij, et al., 2006) as a "clumsy solution" because it dynamically and eclectically integrates aspects of all the other perspectives. I propose that the "clumsy perspective" has enough significance and independent features in order to exist as a distinct perspective. I will illustrate that in the context of the rising significance of post-modern - or mode 2 - science (Funtowicz \& Ravetz, 1993; Best \& Kellner, 1997). 


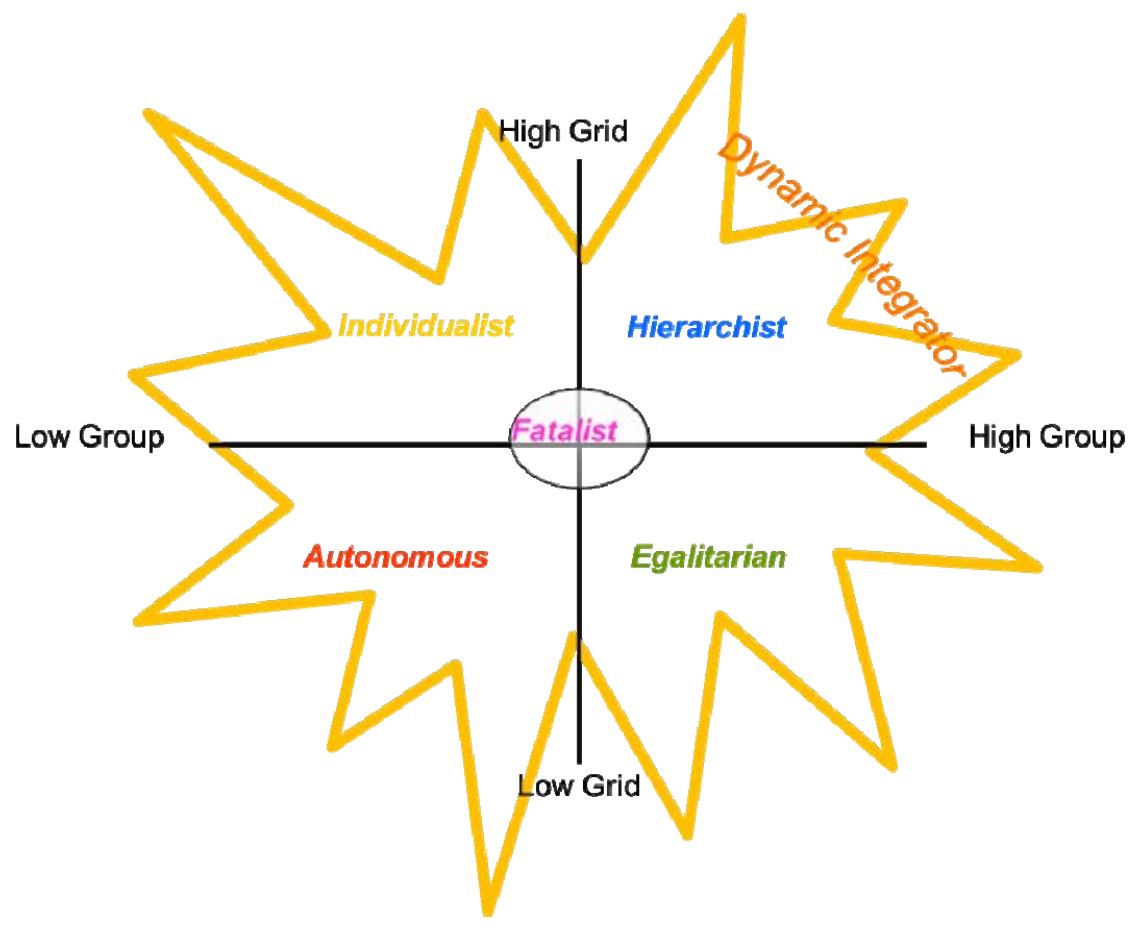

Below follows a (re-) characterisation of the Fatalist, the Autonomous and the 'clumsy' perspectives. This re-characterisation is based on the qualitative literature research that fed into the mapping of relevant key-words related to the 'cultures' of biodiversity conservation (see table $5.1^{*}$ ).

Table 5.1. Refined perspectives map

\begin{tabular}{|c|c|c|c|c|c|c|}
\hline Perspective & Hierarchist & Egalitarian & Individualist & Fatalist & Autonomous & Dyn. Int. \\
\hline \multicolumn{7}{|c|}{ Worldview General } \\
\hline $\begin{array}{l}\text { Basic } \\
\text { Assumption } \\
\text { Nature }\end{array}$ & $\begin{array}{l}\text { Nature is robust } \\
\text { within limits }\end{array}$ & Nature is fragile & $\begin{array}{l}\text { Nature is robust } \\
\text { and resilient }\end{array}$ & $\begin{array}{l}\text { Nature is } \\
\text { capricious }\end{array}$ & Nature is sacred & $\begin{array}{l}\text { Nature is } \\
\text { dynamic \& } \\
\text { complex }\end{array}$ \\
\hline $\begin{array}{l}\text { Basic } \\
\text { Concept } \\
\text { Nature }\end{array}$ & $\begin{array}{l}\text { Nature is } \\
\text { wilderness (to } \\
\text { be tamed) }\end{array}$ & $\begin{array}{l}\text { Nature is Life } \\
\text { and Beauty }\end{array}$ & $\begin{array}{l}\text { Nature is a } \\
\text { resource }\end{array}$ & $\begin{array}{l}\text { Nature is } \\
\text { hazardous and } \\
\text { capricious }\end{array}$ & Nature is giving & $\begin{array}{l}\text { Nature is a } \\
\text { complex } \\
\text { dynamic system }\end{array}$ \\
\hline
\end{tabular}




\begin{tabular}{|c|c|c|c|c|c|c|}
\hline \multicolumn{7}{|c|}{ Worldview General } \\
\hline Nature ideal & $\begin{array}{l}\text { Safe Environ- } \\
\text { ment }\end{array}$ & Wilderness & Treasure & What is Nature? & Paradise & $\begin{array}{l}\text { Healthy } \\
\text { Dynamic } \\
\text { Ecosystem }\end{array}$ \\
\hline $\begin{array}{l}\text { Nature } \\
\text { behaviour }\end{array}$ & $\begin{array}{l}\text { Isomorphic } \\
\text { Nature: } \\
\text { Per- } \\
\text { verse/tolerant }\end{array}$ & $\begin{array}{l}\text { Ephemeral } \\
\text { Na- } \\
\text { ture/vulnerable }\end{array}$ & $\begin{array}{l}\text { Nature Benign } \\
\text { \& Resilient }\end{array}$ & $\begin{array}{l}\text { Nature Capri- } \\
\text { cious }\end{array}$ & Giving Nature & $\begin{array}{l}\text { Nature complex } \\
\text { and dynamic }\end{array}$ \\
\hline $\begin{array}{l}\text { Human } \\
\text { Nature }\end{array}$ & $\begin{array}{l}\text { Human nature } \\
\text { is ignorant and } \\
\text { needs education } \\
\text { and rearing }\end{array}$ & $\begin{array}{l}\text { Human nature } \\
\text { is intrinsically } \\
\text { good, but can } \\
\text { be corrupted }\end{array}$ & $\begin{array}{l}\text { Human nature } \\
\text { is opportunistic }\end{array}$ & $\begin{array}{l}\text { Human nature } \\
\text { is unpredictable, } \\
\text { more hostile } \\
\text { than friendly }\end{array}$ & $\begin{array}{l}\text { Human nature } \\
\text { is spiritual, } \\
\text { essentially good } \\
\text { and devine }\end{array}$ & $\begin{array}{l}\text { Human nature } \\
\text { is complex and } \\
\text { dynamic }\end{array}$ \\
\hline $\begin{array}{l}\text { Human- } \\
\text { Nature } \\
\text { relation }\end{array}$ & $\begin{array}{l}\text { Human } \\
\text { stewardship/ } \\
\text { dominion over } \\
\text { nature }\end{array}$ & $\begin{array}{l}\text { Participation in } \\
\text { nature }\end{array}$ & $\begin{array}{l}\text { Nature is } \\
\text { Resource for } \\
\text { human benefit }\end{array}$ & $\begin{array}{l}\text { Nature reigns } \\
\text { humanity: } \\
\text { human subordi- } \\
\text { nation }\end{array}$ & $\begin{array}{l}\text { Nature mirrors } \\
\text { divinity and } \\
\text { gives life }\end{array}$ & $\begin{array}{l}\text { Dynamic and } \\
\text { reciprocal } \\
\text { functional } \\
\text { relationships }\end{array}$ \\
\hline Lifestyle & $\begin{array}{l}\text { Conserva- } \\
\text { tive/Traditional }\end{array}$ & Alternative & $\begin{array}{l}\text { Progres- } \\
\text { sive/Fashionabl } \\
e\end{array}$ & Depressive & $\begin{array}{l}\text { Sim- } \\
\text { ple/Minimalist }\end{array}$ & Modest \\
\hline Authority & Hierarchy & Equality & $\begin{array}{l}\text { The individ- } \\
\text { ual/Market }\end{array}$ & Destiny & The higher Self & $\begin{array}{l}\text { The } \\
\text { Flow'/Evolution } \\
\text { ary Principle }\end{array}$ \\
\hline $\begin{array}{l}\text { Manageme } \\
\text { nt priority }\end{array}$ & $\begin{array}{l}\text { Political and } \\
\text { social stability }\end{array}$ & $\begin{array}{l}\text { Protection of } \\
\text { the weaker }\end{array}$ & Prosperity & Why bother? & Harmony & $\begin{array}{l}\text { Dynamic } \\
\text { Balance }\end{array}$ \\
\hline $\begin{array}{l}\text { Directing } \\
\text { Principle }\end{array}$ & Law/Legis/ation & Fairness/Justice & $\begin{array}{l}\text { Needs/wants/ } \\
\text { preferences }\end{array}$ & Providence & Love, Dignity & Integrity \\
\hline $\begin{array}{l}\text { Cognitive } \\
\text { Faculty }\end{array}$ & $\begin{array}{l}\text { Rational } \\
\text { thinking }\end{array}$ & $\begin{array}{l}\text { Emotion, } \\
\text { Imagination }\end{array}$ & Instinct & Impulse & $\begin{array}{l}\text { Intuition, } \\
\text { Inspiration }\end{array}$ & Consciousness \\
\hline $\begin{array}{l}\text { Knowledge } \\
\text { Epistemolog } \\
\text { y }\end{array}$ & $\begin{array}{l}\text { Empiricism \& } \\
\text { Expertise }\end{array}$ & $\begin{array}{l}\text { Art \& Poetry \& } \\
\text { Lay/Indigenous } \\
\text { Knowledge \& } \\
\text { Verstehen }\end{array}$ & $\begin{array}{l}\text { Experimentation } \\
\text { \& Exploration \& } \\
\text { Innovation }\end{array}$ & $\begin{array}{l}\text { Agnos- } \\
\text { tic/Opinion }\end{array}$ & $\begin{array}{l}\text { Meditation \& } \\
\text { Prayer \& } \\
\text { Intuition \& } \\
\text { Verstehen }\end{array}$ & $\begin{array}{l}\text { Integrated } \\
\text { Assessment }\end{array}$ \\
\hline $\begin{array}{l}\text { Philosophic } \\
\text { al Tradition }\end{array}$ & Classic & Romanticism & Enlightenment & Fatalism & $\begin{array}{l}\text { Mysti- } \\
\text { cism/Minimalis } \\
m\end{array}$ & Postmodernism \\
\hline Thinker & $\begin{array}{l}\text { Aris- } \\
\text { totle/Aquinas/H } \\
\text { obbes/Newton }\end{array}$ & $\begin{array}{l}\text { Rous- } \\
\text { seau/Marx/Goe } \\
\text { the }\end{array}$ & $\begin{array}{l}\text { Locke/Smith/Mil } \\
\text { I/Nietszche }\end{array}$ & $\begin{array}{l}\text { Sto- } \\
\text { ics/Calvin/Darwi } \\
\text { n/Spinoza/Freud }\end{array}$ & $\begin{array}{l}\text { Bud- } \\
\text { dha/St.Francis/ } \\
\text { Heideg- } \\
\text { ger/Gadammer }\end{array}$ & $\begin{array}{l}\text { Ein- } \\
\text { stein/Gleick/Ca } \\
\text { pra/Prigogine }\end{array}$ \\
\hline $\begin{array}{l}\text { Risk } \\
\text { Approach }\end{array}$ & $\begin{array}{l}\text { Risk Aver- } \\
\text { sion/Controlling }\end{array}$ & Risk Accepting & Risk Seeking & Coping/Luck & Risk avoidance & $\begin{array}{l}\text { Risk anticipat- } \\
\text { ing }\end{array}$ \\
\hline Strenght & Orderliness & $\begin{array}{l}\text { Strong Princi- } \\
\text { ples }\end{array}$ & $\begin{array}{l}\text { Opti- } \\
\text { mism/Opportuni } \\
\text { sm }\end{array}$ & Perserverance & Self Reliance & Openness \\
\hline Pitfall & $\begin{array}{l}\text { Dogma- } \\
\text { tism/Bureaucra } \\
\text { cy }\end{array}$ & $\begin{array}{l}\text { Ideal- } \\
\text { ism/Extremism }\end{array}$ & $\begin{array}{l}\text { Exploita- } \\
\text { tion/Egoism }\end{array}$ & $\begin{array}{l}\text { Nihil- } \\
\text { ism/Pessimism }\end{array}$ & Isolationism & $\begin{array}{l}\text { Vague- } \\
\text { ness/Chaos }\end{array}$ \\
\hline Allergy & $\begin{array}{l}\text { Vague- } \\
\text { ness/Chaos }\end{array}$ & Exploitation & Bureaucracy & Optimism & Nihilism & Dogmatism \\
\hline $\begin{array}{l}\text { Time } \\
\text { manageme } \\
\text { nt }\end{array}$ & $\begin{array}{l}\text { Conserving the } \\
\text { present, } \\
\text { planning for the } \\
\text { future }\end{array}$ & $\begin{array}{l}\text { Idealizing the } \\
\text { Past and Future }\end{array}$ & $\begin{array}{l}\text { Spending time } \\
\text { like money: now } \\
\text { is the mo- } \\
\text { ment/Saving } \\
\text { time, efficiency }\end{array}$ & Fate rules time & $\begin{array}{l}\text { Building good } \\
\text { 'karma', using } \\
\text { time wisely }\end{array}$ & $\begin{array}{l}\text { Times are a- } \\
\text { changing: look } \\
\text { for various long } \\
\text { term develop- } \\
\text { ments/scenario } \\
\text { s(ca. } 50 \text { years) }\end{array}$ \\
\hline $\begin{array}{l}\text { Time } \\
\text { Relation }\end{array}$ & $\begin{array}{l}\text { Future Oriented } \\
\text { (planning } \\
\text { instead of } \\
\text { playing) }\end{array}$ & Past Positive & $\begin{array}{l}\text { Present } \\
\text { Posi- } \\
\text { tive/Hedonistic }\end{array}$ & $\begin{array}{l}\text { Present } \\
\text { Negative (Fated } \\
\text { Life) }\end{array}$ & $\begin{array}{l}\text { Recur- } \\
\text { rence/Reincarna } \\
\text { tion }\end{array}$ & $\begin{array}{l}\text { Change } \\
\text { Oriented Times } \\
\text { are a-changing: } \\
\text { look for various } \\
\text { long term } \\
\text { developments } \\
\text { (ca. } 50 \text { years) }\end{array}$ \\
\hline
\end{tabular}




\begin{tabular}{|c|c|c|c|c|c|c|}
\hline \multicolumn{7}{|c|}{ Ethics \& Values } \\
\hline $\begin{array}{l}\text { Ethical } \\
\text { Philosophy }\end{array}$ & $\begin{array}{l}\text { Natural Or- } \\
\text { der/Virtues }\end{array}$ & $\begin{array}{l}\text { Deontol- } \\
\text { ogy/Social } \\
\text { Justice }\end{array}$ & Utilitarianism & Relativism & Compassion & Pluralism \\
\hline $\begin{array}{l}\text { Ethical } \\
\text { Principle }\end{array}$ & Right is Good & Justice/Fairness & Freedom & Destiny & $\begin{array}{l}\text { Care/Responsibil } \\
\text { ity }\end{array}$ & Flexibility \\
\hline $\begin{array}{l}\text { Moral } \\
\text { standing }\end{array}$ & Anthropocentric & Ecocentric & Anthropocentric & Relativistic & holistic & Inclusive \\
\hline $\begin{array}{l}\text { Moral } \\
\text { incentive }\end{array}$ & $\begin{array}{l}\text { Being a virtuous } \\
\text { person }\end{array}$ & Causing no harm & $\begin{array}{l}\text { The greatest } \\
\text { good for all }\end{array}$ & Destination & $\begin{array}{l}\text { Becoming one } \\
\text { with all }\end{array}$ & Respect for life \\
\hline $\begin{array}{l}\text { Moral } \\
\text { Responsibility }\end{array}$ & Constitution & The Weaker & Welfare & Fate & The higher Self & Future \\
\hline $\begin{array}{l}\text { Moral } \\
\text { question }\end{array}$ & $\begin{array}{l}\text { Are they } \\
\text { normal? }\end{array}$ & Can they suffer? & $\begin{array}{l}\text { Are they } \\
\text { rational? }\end{array}$ & $\begin{array}{l}\text { Are they } \\
\text { different? }\end{array}$ & $\begin{array}{l}\text { Do they have } \\
\text { life? }\end{array}$ & Can they adapt? \\
\hline $\begin{array}{l}\text { General Value } \\
\text { Discourse }\end{array}$ & $\begin{array}{l}\text { Instrumental } \\
\text { value }\end{array}$ & Intrinsic value & $\begin{array}{l}\text { Use/non-use } \\
\text { value }\end{array}$ & Chance & Spiritual value & Plural values \\
\hline Values Nature & Stability & Intrinsic value & $\begin{array}{l}\text { Growth of } \\
\text { Resources }\end{array}$ & $\begin{array}{l}\text { Survival of the } \\
\text { fittest }\end{array}$ & Pristinity & $\begin{array}{l}\text { Evolution \& } \\
\text { Adaptation }\end{array}$ \\
\hline Values Society & $\begin{array}{l}\text { Human well- } \\
\text { being }\end{array}$ & $\begin{array}{l}\text { Social Equity and } \\
\text { Equality }\end{array}$ & $\begin{array}{l}\text { Economic } \\
\text { Development }\end{array}$ & $\begin{array}{l}\text { Access to Basic } \\
\text { Needs \& survival }\end{array}$ & $\begin{array}{l}\text { Spiritual } \\
\text { Growth/ } \\
\text { Personal } \\
\text { Development }\end{array}$ & $\begin{array}{l}\text { Respect \& } \\
\text { Adaptation }\end{array}$ \\
\hline $\begin{array}{l}\text { Value Material } \\
\text { Welfare }\end{array}$ & High & Relatively low & High & High & Low & Relatively low \\
\hline
\end{tabular}

\begin{tabular}{|c|c|c|c|c|c|c|}
\hline \multicolumn{7}{|c|}{ Relationships } \\
\hline Relationships & $\begin{array}{l}\text { Hierar- } \\
\text { chic/Power }\end{array}$ & Dialectic & $\begin{array}{l}\text { Egois- } \\
\text { tic/Competitive }\end{array}$ & Determined & Karma/Love & Pluralistic \\
\hline $\begin{array}{l}\text { Ethical } \\
\text { Attitude }\end{array}$ & $\begin{array}{l}\text { Conquer- } \\
\text { ing/Demarcating }\end{array}$ & $\begin{array}{l}\text { Protect- } \\
\text { ing/Sharing }\end{array}$ & Sustainable Use & Taking & Caring/Giving & Adapting \\
\hline $\begin{array}{l}\text { Human (ideal) } \\
\text { position in } \\
\text { Nature }\end{array}$ & Conquerer & Protector/Equal & Innovator & Playball & Protector/Equal & Partner \\
\hline $\begin{array}{l}\text { Nature- } \\
\text { Culture } \\
\text { Relation }\end{array}$ & $\begin{array}{l}\text { Dichotomy: } \\
\text { Civilize Culture } \\
\text { versus Savage } \\
\text { Nature }\end{array}$ & $\begin{array}{l}\text { Embeddedness: } \\
\text { Culture corrupts } \\
\text { nature }\end{array}$ & $\begin{array}{l}\text { Dichotomy: } \\
\text { Nature serves } \\
\text { culture }\end{array}$ & $\begin{array}{l}\text { Dichotomy: } \\
\text { Nature Reigns } \\
\text { Culture }\end{array}$ & $\begin{array}{l}\text { Dichotomy: } \\
\text { Culture Corrupts } \\
\text { Nature }\end{array}$ & $\begin{array}{l}\text { Holism: Dynami- } \\
\text { cally complex } \\
\text { interconnected } \\
\text { socio- } \\
\text { environmental } \\
\text { system }\end{array}$ \\
\hline $\begin{array}{l}\text { Ideal living } \\
\text { habitat }\end{array}$ & $\begin{array}{l}\text { Family and } \\
\text { community }\end{array}$ & $\begin{array}{l}\text { Rural area and } \\
\text { natural sites }\end{array}$ & Urban area & A safe place & Dwelling & The world \\
\hline Activity & Policy & $\begin{array}{l}\text { Civil Disobedi- } \\
\text { ence }\end{array}$ & $\begin{array}{l}\text { Technological } \\
\text { Innovation }\end{array}$ & Passivity & Self Realization & $\begin{array}{l}\text { Integrated } \\
\text { Assessment }\end{array}$ \\
\hline $\begin{array}{l}\text { Conflict } \\
\text { Resolution }\end{array}$ & $\begin{array}{l}\text { Punish- } \\
\text { ing/Rewarding }\end{array}$ & $\begin{array}{l}\text { Deliberation, } \\
\text { Dialogue \& } \\
\text { Dialectics }\end{array}$ & Trade-offs & Battling & Peacebuilding & Collaboration \\
\hline $\begin{array}{l}\text { Management } \\
\text { attitude }\end{array}$ & $\begin{array}{l}\text { Monitoring \& } \\
\text { controlling, }\end{array}$ & $\begin{array}{l}\text { support \& } \\
\text { guidance }\end{array}$ & $\begin{array}{l}\text { Leadership/ } \\
\text { Innovation }\end{array}$ & Coping & Teaching & $\begin{array}{l}\text { Co-evolution \& } \\
\text { engaging }\end{array}$ \\
\hline
\end{tabular}




\begin{tabular}{|c|c|c|c|c|c|c|}
\hline \multicolumn{7}{|c|}{ Nature Models, Concepts and Attitudes } \\
\hline $\begin{array}{l}\text { Natural } \\
\text { Philosophy }\end{array}$ & Natural Law & Eco-Fenminsim & $\begin{array}{l}\text { Ecosystem } \\
\text { Services }\end{array}$ & Social Darwinism & Deep Ecology & $\begin{array}{l}\text { Environmental } \\
\text { Pragma- } \\
\text { tism/Pluralism }\end{array}$ \\
\hline Outlook & Anthropocentric & Biocentric & Anthropocentric & Misanthropic & Ecocentric & Ecocentric \\
\hline $\begin{array}{l}\text { Wilderness } \\
\text { Model }\end{array}$ & Frontier & $\begin{array}{l}\text { Inno- } \\
\text { cence/Garden }\end{array}$ & $\begin{array}{l}\text { Waste- } \\
\text { land/Commodity }\end{array}$ & Hell/Myth & Paradise & Dynamic System \\
\hline $\begin{array}{l}\text { Wilderness } \\
\text { Attitude }\end{array}$ & $\begin{array}{l}\text { Puritan: } \\
\text { Con- } \\
\text { trol/Tame/Conq } \\
\text { uer/Master with } \\
\text { Reason }\end{array}$ & $\begin{array}{l}\text { Romantic: } \\
\text { Preserve/Restore } \\
\text { with Passion }\end{array}$ & $\begin{array}{l}\text { Lockean: } \\
\text { Con- } \\
\text { serve/Manage/U } \\
\text { se with Reason }\end{array}$ & Fear & $\begin{array}{l}\text { Marvel \& } \\
\text { Wonder, with } \\
\text { Humility }\end{array}$ & $\begin{array}{l}\text { Respect, } \\
\text { Modesty \& } \\
\text { Flexibility }\end{array}$ \\
\hline $\begin{array}{l}\text { Wilderness } \\
\text { Scope }\end{array}$ & $\begin{array}{l}\text { Non-cultivated } \\
\text { land }\end{array}$ & $\begin{array}{l}\text { Land 'untram- } \\
\text { meled' by man }\end{array}$ & $\begin{array}{l}\text { Non-cultivated } \\
\text { land }\end{array}$ & $\begin{array}{l}\text { Outside/the } \\
\text { unknown }\end{array}$ & $\begin{array}{l}\text { Un- } \\
\text { touched/pristine } \\
\text { nature }\end{array}$ & Non-existent \\
\hline $\begin{array}{l}\text { Natural State } \\
\text { of Ecosystem }\end{array}$ & Stability & Equilibrium & Resilience & Entropy & Harmony & $\begin{array}{l}\text { Cha- } \\
\text { os/Flux/Dynamic } \\
\text { Equilibrium }\end{array}$ \\
\hline Evolution & $\begin{array}{l}\text { Control Evolu- } \\
\text { tion }\end{array}$ & Guide Evolution & Make Evolution & $\begin{array}{l}\text { Survival of the } \\
\text { fittest }\end{array}$ & Moral Evolution & Co-Evolution \\
\hline $\begin{array}{l}\text { Favour of } \\
\text { human } \\
\text { interest }\end{array}$ & $\begin{array}{l}\text { high conserva- } \\
\text { tive }\end{array}$ & relatively high & high progressive & $\begin{array}{l}\text { high conserva- } \\
\text { tive }\end{array}$ & principally low & $\begin{array}{l}\text { depending on } \\
\text { situation }\end{array}$ \\
\hline $\begin{array}{l}\text { Favour of } \\
\text { nature } \\
\text { interest }\end{array}$ & relatively low & High & Low & $\ldots$ & principally high & $\begin{array}{l}\text { high with } \\
\text { exceptions }\end{array}$ \\
\hline
\end{tabular}

\begin{tabular}{|c|c|c|c|c|c|c|}
\hline Biodiversity & $\begin{array}{l}\text { Spe- } \\
\text { cies/population }\end{array}$ & $\begin{array}{l}\text { Communi- } \\
\text { ties/Habitats }\end{array}$ & $\begin{array}{l}\text { Genes and } \\
\text { ecosystem } \\
\text { services }\end{array}$ & $\begin{array}{l}\text { Animals and } \\
\text { plants }\end{array}$ & Life on earth & $\begin{array}{l}\text { Planetary life } \\
\text { support system }\end{array}$ \\
\hline $\begin{array}{l}\text { Ecosystem } \\
\text { Model }\end{array}$ & $\begin{array}{l}\text { Static Mechanis- } \\
\text { tic Order }\end{array}$ & $\begin{array}{l}\text { Or- } \\
\text { ganic/Communit } \\
y\end{array}$ & $\begin{array}{l}\text { Dynamic } \\
\text { Mechanistic } \\
\text { Energy }\end{array}$ & $\begin{array}{l}\text { Scientific } \\
\text { construct }\end{array}$ & Holistic & $\begin{array}{l}\text { Dynamically } \\
\text { complex } \\
\text { interconnected } \\
\text { socio- } \\
\text { environmental } \\
\text { system }\end{array}$ \\
\hline $\begin{array}{l}\text { Biodiversity/ } \\
\text { Conservatio } \\
\text { n Focus }\end{array}$ & $\begin{array}{l}\text { Spe- } \\
\text { cies/populations/ } \\
\text { Parks }\end{array}$ & $\begin{array}{l}\text { Communi- } \\
\text { ties/Habitats }\end{array}$ & $\begin{array}{l}\text { Genes/Ecosyste } \\
m \text { Services }\end{array}$ & $\begin{array}{l}\text { Survival of the } \\
\text { fittest }\end{array}$ & $\begin{array}{l}\text { Natural Har- } \\
\text { mony }\end{array}$ & $\begin{array}{l}\text { Earth Sys- } \\
\text { tem/Functional } \\
\text { Relations }\end{array}$ \\
\hline $\begin{array}{l}\text { Conservatio } \\
\text { n Strategy }\end{array}$ & $\begin{array}{l}\text { Fortress } \\
\text { Conserva- } \\
\text { tion/parks }\end{array}$ & $\begin{array}{l}\text { Awareness } \\
\text { Raising/Nature } \\
\text { Restoration/ }\end{array}$ & $\begin{array}{l}\text { Ecosystem } \\
\text { Services/Eco- } \\
\text { tourism }\end{array}$ & $\begin{array}{l}\text { Survival of the } \\
\text { fittest }\end{array}$ & $\begin{array}{l}\text { Consuming } \\
\text { less/lifestyle } \\
\text { changes }\end{array}$ & $\begin{array}{l}\text { Pluralistic } \\
\text { Approach }\end{array}$ \\
\hline $\begin{array}{l}\text { Managemen } \\
\text { t style }\end{array}$ & Control & $\begin{array}{l}\text { Preven- } \\
\text { tion/Precaution }\end{array}$ & $\begin{array}{l}\text { Engage- } \\
\text { ment/Lobbying }\end{array}$ & Coping & Retreat & Adaptation \\
\hline $\begin{array}{l}\text { Sustainabilit } \\
\text { y model }\end{array}$ & $\begin{array}{l}\text { Regulating } \\
\text { people, planet } \\
\text { and profit }\end{array}$ & $\begin{array}{l}\text { Planet \& People } \\
\text { first }\end{array}$ & $\begin{array}{l}\text { Profit is prereq- } \\
\text { uisite for people } \\
\text { and planet }\end{array}$ & $\begin{array}{l}\text { Survival of the } \\
\text { fittest }\end{array}$ & Planet & $\begin{array}{l}\text { Integrating } \\
\text { people, planet } \\
\text { and prosperity }\end{array}$ \\
\hline Agriculture & Traditional Farm & Organic Farm & Bio-Industry & $\begin{array}{l}\text { hunting \& } \\
\text { gathering }\end{array}$ & $\begin{array}{l}\text { Self-sufficient } \\
\text { vegetable } \\
\text { garden }\end{array}$ & Permaculture \\
\hline Urbanization & Regulated & $\begin{array}{l}\text { Community } \\
\text { building }\end{array}$ & Innovation & Urban Sprawl & Retreat to nature & $\begin{array}{l}\text { Urban Ecosystem } \\
\text { Approach }\end{array}$ \\
\hline
\end{tabular}


Biodiversity, landscape, sustainability and conservation

\begin{tabular}{|l|l|l|l|l|l|l|}
\hline $\begin{array}{l}\text { Garden } \\
\text { design }\end{array}$ & $\begin{array}{l}\text { Classical garden } \\
\text { (structured and } \\
\text { tidy) }\end{array}$ & Wild Garden & $\begin{array}{l}\text { Fashionable } \\
\text { Garden }\end{array}$ & $\begin{array}{l}\text { Concrete/Tile } \\
\text { Garden }\end{array}$ & $\begin{array}{l}\text { Eden (nature and } \\
\text { food) }\end{array}$ & Permaculture \\
\hline Garden use & $\begin{array}{l}\text { Keeping the pets } \\
\text { and playground } \\
\text { for the children }\end{array}$ & $\begin{array}{l}\text { Sharing time } \\
\text { with } \\
\text { friends/family }\end{array}$ & $\begin{array}{l}\text { relaxing (sun- } \\
\text { bathing, reading } \\
\text { a book etc) }\end{array}$ & $\begin{array}{l}\text { parking the } \\
\text { car/hanging the } \\
\text { laundry/storing } \\
\text { bikes etc. }\end{array}$ & growing food & $\begin{array}{l}\text { watching things } \\
\text { grow and unfold }\end{array}$ \\
\hline $\begin{array}{l}\text { Gardening } \\
\text { Reason }\end{array}$ & $\begin{array}{l}\text { keeping the } \\
\text { garden tidy }\end{array}$ & $\begin{array}{l}\text { helping local } \\
\text { biodiversity }\end{array}$ & Relaxing & $\begin{array}{l}\text { Low mainte- } \\
\text { nance }\end{array}$ & $\begin{array}{l}\text { Being one with } \\
\text { nature }\end{array}$ & $\begin{array}{l}\text { watching things } \\
\text { grow and unfold }\end{array}$ \\
\hline
\end{tabular}

\section{The Fatalist}

The way Verweij and his colleagues (Verweij, et al., 2006) position the Fatalist perspective on the grid/group axis, in our view is not consistent with the actual Fatalist worldview. Because the Fatalist regards nature and man capricious and untrustworthy, he has gained a place on the "low group" quadrant. This seems plausible. Nevertheless, the Fatalist's management response is: "why bother?" (Verweij, et al., 2006). As such, high stratification (compliance to institutional authority, role differentiation, rules and regulations) does not make ideological sense for the Fatalist at all. Although the Fatalist may surely submit to existing power structures, rules and regulations are rather a waste of money and time instead of effective management approaches. Nevertheless, traditional CT categorizes the Fatalist on the "high grid" quadrant. Because of the ideological indifference and passivity of the Fatalist, I propose to re-position this perspective on the zero-point of the grid/group axis and give him more "voice" in discussions and analyses at the same time. Although he has a non-active character and is pessimistic about any management approach, he does play an important role in the field of conservation and sustainable development: he stimulates other groups and individuals to think about the unpredictable side of nature and about the practical and ethical consequences of inaction. He motivates active attitudes in others by annoying them with his passive antagonist or sometimes 'victimised' style of relating to the things happening around him. The Fatalist sees biodiversity loss as a (natural) and determined process that can't be stopped. Darwinist conceptions of "survival of the fittest" are linked to the notions of chance and coincidence (Vaughan, 2007; Mesoudi, 2008). Trying to minimize changes in biodiversity therefore is regarded as a futile effort. The Fatalist perspective can also be connected to the determinism represented in some religious worldviews where the future is controlled by God's will (DesJardins, 2006).

\section{The Autonomous}

I believe that the Autonomous perspective, which is also called the "hermit" in CT, fits better into the "low group-high grid" quadrant than the Fatalist does. However, when comparing the Autonomous perspective to the Individualist perspective, the Individualist 
- although striving for innovation - tends to do this within the existing power-structures. The Individualist in society nowadays for example reproduces the globally leading neoliberal growth paradigm. The Autonomous perspective seeks to retreat from this 'regime' and seeks for alternatives that are 'off-the-grid'. Therefore, I propose a relocation of the Individualist on the group-grid axis: in the high-grid/low-group quadrant. The Autonomous perspective can be best located in the low-group/low-grid quadrant of the axis.

I prefer to use the term 'Autonomous' instead of 'hermit' for this perspective because autonomy does not include the sometimes negative connotations of peculiar personalities connected to the term 'hermit'. I visualize the Autonomous as someone who tries to stay independent, distances himself from "group-think" and actively avoids sticky social units. His management style is a "sustainable retreat" (Lovelock, 2006). Traditional CT represents the retreat of the Autonomous as passive, and therefore the Autonomous perspective is hardly mentioned in papers discussing policy and management issues. I argue that the act of retreat is active instead of passive. The retreat of the Autonomous originates from his strong ethical imperative: strong norms and values (often, but not necessarily based in holistic spiritual conceptions) about how to live life make him actively withdraw from a society that in his eyes is corrupted by materialism and greed. He can be seen as an activist in the private sphere. He shares much of the values of the Egalitarian, but his management style opposes the Egalitarian action approach based on stimulating social participation and common action grounded in solidarity. Living better by consuming less originates from individual voluntary motivation (Jackson, 2008), regardless of what other people tend to think about it. The Autonomous tries to tread lightly on the ecosystem and minimizes his ecological footprint by consuming less. He finds inspiration in Buddhist and Franciscan oriented philosophies of compassion and simplicity. Examples of the Autonomous in society can be found in the "downshifting" and "voluntary simplicity" movements (Jackson, 2008). Conservation is to consciously leave nature in peace and undisturbed by human interference. Natural integrity is treasured as something sacred.

\section{The Dynamic Integrator}

I regard it valuable to claim a place on the grid/group axis for "clumsiness" as described by Marco Verweij and his colleagues (Verweij, et al., 2006) as a distinct perspective. Verweij describes "clumsy solutions to complex problems" as "those institutional arrangements in which none of the voices [ . . ] is excluded, and in which the contestation is harnessed to constructive, if noisy, argumentation" (Verweij, et al., 2006, pp., p.839). Clumsiness can be seen as the core of how to see CT, because it "is an effort to outline which combinations of interests, norms, perceptions, time horizons, strategies and emotions prevail in which particular social settings" (Verweij, et al., 2006, pp., p.836). It embraces the idea(I) of cultural diversity. Clumsiness bonds to social units when necessary, 
but also listens closely to the Fatalist, it holds the values of the Egalitarian and the Autonomous high and it considers technological solutions for specific problems just as feasible as a retreat in other areas.

This eclectic or holistic approach to problems in our eyes reflects post-modern thinking - which is rather post-structuralist in nature -- and sees a plurality of possible "truths" and solutions to management problems. Society and established policy and (conservation) science regimes are still used to more structuralist modes of management (Loorbach, 2002). It is still largely organised on the principles of stratification and silos. The holistic approach that aims to look beyond the silos is rather "new" in Western science and policy practice, and is still on a transition pathway from being a niche to becoming the new paradigm (Loorbach, 2002; Kemp et al., 2007). As an infant, the agent of the holistic approach sometimes clumsily stumbles while running through all the perspectives and their plurality of management options (Valkering, 2009). In time, the clumsy agent becomes more skilful in his dynamic attitude and the clumsiness fades. Therefore I rather prefer to call him the "Dynamic Integrator". He brings a new dimension of motion and dynamics to the grid and group axis, which can be metaphorised as a "strange attractor", showing emergent patterns of collaboration, alliances and alienation between the other perspectives. Panta Rhei (everything flows) is the Dynamic Integrators device. The Dynamic Integrator holds value to the notion of evolution, but sees it in a different light than the "blind and undirected" (Mesoudi, 2008) way of the Fatalist's conception of evolution. Evolution is "portrayed as a form of discontinuous change characterized by emergent properties that take on an intrinsic quality with respect to the object(s) (...) involved. Causal leaps, not continuous development, characterize (...) evolution" (Palmquist, 2007, pp., p. 9). The more 'unconscious' evolution of the 'bio-sphere' co-evolves hand in hand with intentional and consciously chosen directions of the 'human sphere,' leading to complex feedback loops and unexpected change patterns. The dynamically occurring patterns of perspective-changes and perspective combinations are represented by the orange star-shape in figure 5.1*.

The Dynamic Integrator belongs to the advancing subculture of relatively independent individuals who are called Cultural Creatives (Ray \& Anderson, 2000). Society can be changed - not by retreating from it or by fighting it, but by building new cultures within the existing regime. The Dynamic Integrator is not always understood - sometimes considered vague -- by advocates of the other perspectives, because he does not seem to fit inside any box. He acknowledges the "myth of objectivity in science (Mikulecky, 2007)" and the relativity of knowledge. He recognizes implicit values, norms and subjectivity of human choices in scientific research (Lakoff \& Johnson, 1980; Latour, 1988; Funtowicz \& Ravetz, 1993; Funtowicz, et al., 1998). The integrator is inspired by postmodern science, especially by chaos and complexity theory. He believes the complex web of nature can never be fully understood and grasped (Beumer et al., 2008).

However, the complexity of the issues at stake is no reason either to be passive, relativistic or to behave "unethically". Ethical decisions in his view depend on the contex- 
tual situation. The integrator weighs the circumstances using both conscious cognitive reasoning processes and his moral intuition before taking any ethical approach or action (Steiner, 1964). Because of its habit to base decisions on contextual evaluations, the Dynamic Integrator and his ideas are often considered to be vague and confusing in the eyes of other professionals, disciplinary scientists and the 'lay public'. In his eyes there is a plurality of ethical options: "Although no single approach provides all the right answers, we need them all (DesJardins, 2006, pp., p.265)." In the tradition of the French postmodern philosopher Lyotard, the integrator assumes that constructing fixed new (grand) narratives, or meta-narratives (Lyotard, 1979) is an illusionary pathway. Therefore, any conservation approach should be flexible and adaptive to new insights and emergent situations (Grosskurth, 2009). Considering these approaches, the Dynamic Integrator in action can often be discerned in the field of integrated assessment for sustainable development, mode 2 science, or sustainability science. With respect to biodiversity and ecosystem services, the Dynamic Integrator aims to construct new approaches within and complementary to the existing regime and tries to connect and combine approaches into novel constellations. The basic idea behind the connectivity approach of the Dynamic Integrator is that the whole always is more than the sum of its parts (Capra, 1996). This systems thinking also involves accepting the emergence of unanticipated surprises and risks and readiness to adapt.

\section{Cultural Perspectives in Models of Global Change Dynamics?}

Considering the human side of global systemic change becomes increasingly relevant. The environmental crisis, for example, is often referred to as a cultural crisis (Capra, 1996; Laszlo, 1996; Wackernagel \& Rees, 1996; McNeely, et al., 2005; MEA, 2005; Laszlo, 2006; Rees, 2010; IPCC, 2013). A way of seeing this is that 'global culture' got locked in a materialistic economic growth paradigm (Daly, 1987; Capra, 1996; Pauli, 2010; ETCGroup, 2011; UNEP, 2011b; GesNaT \& BUKO, 2012; Hoedeman, 2012; Kenis \& Lievens, 2012; Spash, 2012; Martens, 2013). All efforts taking place on the regime level to counter our crises have the tendency to reproduce the current regime and to continue with business as usual as soon as possible (Laszlo, 1996, 2006; Rees, 2010; Kenis \& Lievens, 2012). Although many diverse small scale alternative initiatives (Ray \& Anderson, 2000) and even larger demonstrations against political-economic status quo are popping up all over the globe (i.e. the Arab Spring or The Occupy Movement) (Chesters, 2004), culturalpsychological undercurrents and their potential change-forces seem to be largely forgotten when global change dynamics are being discussed (Loorbach \& Lijnis Huffenreuter, 2013). Although several authors recognize this negligence (Chesters, 2004; Offermans, et al., 2009; Offermans, 2012) and stress the importance of including human values and assumptions (Rees, 2010; De Vries, 2013) no real efforts have been initiated to link hu- 
man perspectives to existing theoretical models representing global systemic change dynamics.

\section{Change models}

Change - even from a post-normal science point of view (Funtowicz \& Ravetz, 1993; Healy, 2010; Turnpenny, et al., 2011) -- is not always purely random and unexpected and researchers around the world identified certain patterns and phases that make up complex processes of change (Prigogine, 1980; Prigogine \& Stengers, 1984; Capra, 1996; Prigogine, 1996; Gleick, 1998). In order to theoretically connect CT with models of change dynamics, potential linkages of CT perspectives with existing theories of change have been explored. I looked for models that are grounded in systems and complexity thinking and that are at the same time widely used and recognised in sustainability research and in Integrated Sustainability Assessment projects. Both the Panarchy model of change (Gunderson \& Holling, 2002) and the Transition model (Rotmans, J et al., 2000; Loorbach, 2002; Brugge, 2004; Kemp, et al., 2007) complied to these criteria and both models prove to be suitable to theoretically connect to the CT perspectives.

Integrating human worldviews and basic assumptions in models of societal or socioenvironmental change will enable the emergence of important insights into possible change directions and the potential cultural character of socio-environmental changes (Offermans, 2012). Some change directions may be regarded as surprises when the effect of human perspectives on global change dynamics is not considered. Integrating human perspectives in anticipatory change models and scenarios - not only as narrated outcomes in storylines, but as effective change effectors in society -- is a crucial step to take when constructively thinking about sustainable future pathways. Integrating human agents into assessments of global change dynamics asks for getting a better view on the 'cultural psychology' underlying the human practices and discourses that are constitutive to our societies. The following questions can be raised in this respect: what cultural perspectives dominate the status quo of our time? What worldviews are challenging that cultural status quo (what are the undercurrents (Offermans, 2012))? To what kind of landscape - macro level -- can fundamental changes in the cultural status quo lead (scenario development)? Asking such questions helps to theoretically connect CT to Panarchy Theory and Transition Theory. These theoretical connections are illustrated in the following paragraphs.

\section{Transition Theory}

Transition Theory (TT) describes the dynamics of societal changes, "whereby the structure of society (or a subsystem of society) fundamentally changes (Rotmans, J, et al., 2000). It builds on a multi-phase and multi-scale model of the socio-environmental system, where the landscape (the highest macro scale-level) is co-determined by slow or 
rapid changes enforced or prevented by the regime (meso scale-level) or activated through niche players (micro scale-level) (Kemp, et al., 2007). Transitions unfold when developments on the three scale-levels move into the same direction (Brugge, 2004). Changes in the socio-environmental system take place in four phases: predevelopment, take off, acceleration and stabilization (Brugge, 2004). The transition model has been used (especially in the Netherlands) in a variety of cases; for example in the assessment of changes in water management (Brugge, 2004), energy (Rotmans, J, et al., 2000), waste (Kemp, et al., 2007), mobility (Dijk, 2010) and the economic crisis (Loorbach \& Lijnis Huffenreuter, 2013).

\section{Panarchy Theory}

Panarchy Theory (PT) - also called Resilience Theory -- (Gunderson \& Holling, 2002) describes adaptive cycles of overlapping, hierarchical systems (ecosystems, human systems and combined systems) which evolve through recurring processes where (relatively) resilient structures grow more vulnerable through the loss of diversity and growing dependency. The model is named after the Greek God Pan who represents the unexpected powers of nature and the interrelated cycle of creativity and destruction of nature (Gunderson \& Holling, 2002). PT is built on the concept of resilience which can be defined as "the capacity of a system to absorb disturbance and reorganize while undergoing change so as to retain essentially the same function, structure, identity and feedbacks (Folke, et al., 2004)." Systems are most resilient when there is a low level of connectivity and a high level of diversity (McCann, 2000; Ives \& Carpenter, 2007). In a resilient system, adaptations to changes can be most easily made by shifting alliances, collaborations and combinations of actors in the field. A resilient system resembles a typical heterogeneous open 'network' structure as opposed to a close homogenic 'community' structure (Chesters, 2004). The levels of diversity and connectivity determine the pattern of relations between socio-ecological agents in a system. Resilience of a system, in other words, can be seen as the emergent property of the structure and process of relations in that system. A system comes never alone, but is always nested in other systems, which are nested in other systems etc. Such a cross-scale set of dynamic nested systems is reflected by the concept of 'panarchy' (Folke, et al., 2004). The ability of a system to reorganize after disturbance and change not only depends on internal resilience but also on the influences of scale levels above and below the system that is changing (Folke, et al., 2004).

\section{Connecting Panarchy, Transitions and Cultural Theory}

Both Panarchy Theory (PT) and Transition Theory (TT) do not integrate a more explicit understanding of how the values and worldviews of societal agents play a role in affecting change. PT is oriented towards socio-environmental processes of change and adaptation in complex systems. The level of connectedness of the system's components - or 
agents -- is of crucial importance here (McCann, 2000; Ives \& Carpenter, 2007). However, the change affecting role of the internal value systems of the human agents (the agents' characters or profiles) remain largely undiscussed. Agents of change are represented mainly by external ecosystemic disturbances such as fires, storms, or diseases (Gunderson \& Holling, 2002, p.35) and internal cultural patterns like institutions, political decisions, norms and rules (Gunderson \& Holling, 2002, p.332). Although Gunderson and Holling (2002) describe how people regard processes of socio-environmental change, and how these outlooks are based on their particular 'myths of nature' (which are in the PT case also grounded in the CT typology), they do not explicitly regard these myths as effective change forces working through agents.

TT is oriented towards the various scale levels on and through which systemic change takes place (Loorbach, 2002; Brugge, 2004; Kemp, et al., 2007; Loorbach, 2007). There are dynamic interactions between the scale levels: the regime level (ongoing paradigm, established power structures, cultural assemblages and institutes) basically aims at maintaining the status quo while changes unfold from both of the two other directions: the landscape level (i.e. through natural disasters, biodiversity loss, climate change, economic crises) and the niche level (i.e. through alternative ways of thinking, protests, pioneering activities) (Loorbach, 2002; Kemp, et al., 2007). Human agents in TT are most active on the regime level and the niches level, affecting shorter term changes on these scale levels and longer term changes on the macro level or landscape. However, also in this theory of change, no explicit notion is taken of the role various cultural perspectives themselves play in processes of systemic change.

Is there space in TT and in PT for integrating a cultural outlook of the human agents of change and their intrinsic motivational patterns, management styles and worldviews? Below - in a thought experiment -- a potential way of linking both TT and PT to the perspectives of CT is explored.

\section{The Role of the Cultural Perspectives on the Transition Levels of $\Pi T$}

\section{The landscape level}

The Landscape or macro level can be seen as the world stage where large encompassing processes (social, economic and environmental) take place, like evolution, crises, climate change, biodiversity loss, tectonic plate movements or socio-political revolutions. The landscape level is full of uncertainties, chaotic events, surprises, diversity, and complex dynamic processes. The Dynamic Integrator acknowledges this character of the landscape level. He aims to make processes taking place on this level insightful to players who are more focused on processes on other levels of the transition model (for exam- 
ple: competition on the niches level or the maintenance of the regime). Changes in the landscape are complexly - often slowly -- effected through practices on the regime level (i.e. cultural traditions, uses of technology, (persistent) policies). When not blindfolded by competition, the niche players may recognize certain changes and potential problems being affected on the landscape level (climate change, biodiversity loss, economic crises) and try to attribute them to the existing regime. The niche players come up with solutions and alternative practices that can be considered 'outside the box'. Usually the regime tries to keep control on subversive niche forces (often by implementing new regime reinforcing policies or rules, controlling measures, public disparage, or with Machiavellian divide-and-conquer tactics) for the niche players could potentially cause a shift of power when gaining (too) much critical mass.

\section{The regime level}

The regime level (whatever it looks like) is typically guarded by Hierarchist forces who like to keep control and feel safe in the world as they know it. Changes should only take place incrementally and should be based on the idea of optimizing or stabilising the current situation. Traditions and established norms should be treasured and safeguarded. Revolution and uncertainties should be avoided. Changes at the landscape level and forces from the niche level are both seen as threathening.

\section{The niche level}

Niches are typically taken by a mosaic of Individualists, Egalitarians, Autonomous and Fatalists in different combinations and constellations. Individualist forces try to soften regime-power by opposing governance regulations in general. Especially policies considered hurdles for individual freedoms, the liberal market and free technological innovation are lobbied against. They have a strong allergy against the bureaucracies, norms and principles that inhibit the freedom and speed of transforming new ideas and opportunities into reality.

Egalitarians have another way of challenging the regime. Egalitarian forces tend to gather critical masses for democratically enforcing fast regime shifts. Egalitarians aim to emancipate minorities on the basis of the ideals of equality and solidarity with the weaker. They don't shy away from revolution and rebellion. Raising awareness about problems that are affecting the landscape level is also a typical Egalitarian technique. When enough critical mass is reached, revolutions in the regime may take place and systemic change can happen. The once subversive ideas and ideals then settle and become established in the new regime, often embodied by new laws, rights and regulations. 
Autonomous forces oppose the regime through their retreat from the established society and/or the dominant culture. Retreat in the classical CT is considered passive and therefore not so relevant in the playing field of societal relations and management styles. I consider the retreat of the Autonomous as an active personal choice to benefit the quality of life on the landscape level through sacrificing the comforts that belong to conforming to the dominant regime. The Autonomous can also realize changes in the regime by playing the silent example-figure for other people.

Fatalists are passively accepting the status quo or changes that take place on the landscape or the regime levels. As such they help stabilizing the dominant system, culture or societal model. When a new societal model is emerging, Fatalist forces help stabilizing it through their inactivity to react to it in either a positive or a negative way. If a regime is very stable, (strong connectivity) the Fatalist may be omnipresent in the niches level.

The Dynamic Integrator (Beumer \& Martens, 2010) plays a special role. As already mentioned above, he accepts and acknowledges the dynamic and complex character of the landscape. He plays a role in both the niche and the regime levels, trying to increase communication and understanding between the various players with their different stakes, worldviews and management-styles. He strives to reconcile the best of opposing worldviews for gaining pragmatic results and answers to problems. Each situation is specific and there does not exist one blueprint for an ideal world. The Dynamic Integrator is aware of the ever changing, evolutionary nature of societies and tries to keep up with the changing times to find tailor-cut solutions with something in it for everybody. The Dynamic Integrator can be seen as the glue in a society between the regime and the niche level, and between the competing actors on the niches level. He mediates and assists people to adapt to unavoidable surprises, complex and structural changes taking place on the landscape level (Rees, 2010, p.6). In figure 5.2* the thought experiment of how the cultural perspectives could play a role in the Transition model is visualised. 

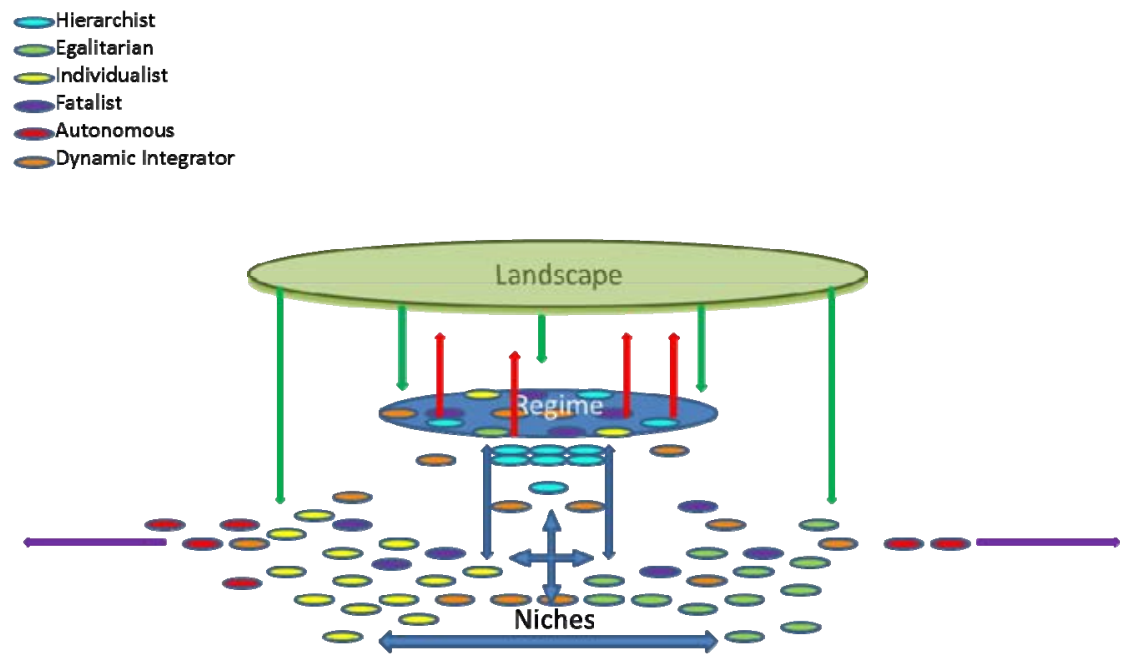

Red arrows: pressure on landscape through established practices

Green arrows: impact of landscape on regime and niches level, raising awareness about necessity of solutions in all the players

Blue arrows: competing Interests between the varlous perspectives and levels

Purple arrows: easing pressures by retreat from the established regime

\section{The Routes of the Perspectives on the Transition and Panarchy Models}

The Panarchy model does not include the more or less 'static' layers of scale levels as represented by the Transition model. The Panarchy model is characterised by its representation of the dynamic adaptive cycle (Gunderson \& Holling, 2002; Folke, et al., 2004). This adaptive cycle has some similarities with the S-curve of TT.

\section{Transition routes}

Transition Theory describes the processes of change in phases taking place. In the Transition model there are four main phases: 1) predevelopment; 2) take off; 3) acceleration; and 4) stabilization, backlash, lock-in or system break down (see figure 5.3*) (Loorbach, 2002; Kemp, et al., 2007; Loorbach, 2007). The direction of the fourth phase depends on the character and outcome of the competition process between the various innovative forces. When enough critical mass is reached for one of the alternative options, it may settle down into a new stabilised regime. However, when competing alternatives remain equal in sizes (i.e. due to a lack of decision making for one of the alternatives), the alternatives remain locked inside their niches as niche players and no real regime shift occurs. Backlash may also occur when perspectives are too scattered to assemble critical power for change. However, when too much energy is put into only one particular solution, 
system breakdown may occur due to lack of resilience that emerges only at a certain level of optional diversity and not too strong connectivity (McCann, 2000; Gunderson \& Holling, 2002; Loorbach, 2002; Ives \& Carpenter, 2007; Loorbach, 2007; Loorbach \& Lijnis Huffenreuter, 2013; MacDougall, et al., 2013).

\section{Figure 5.3. Perspective routes on the Transition model}

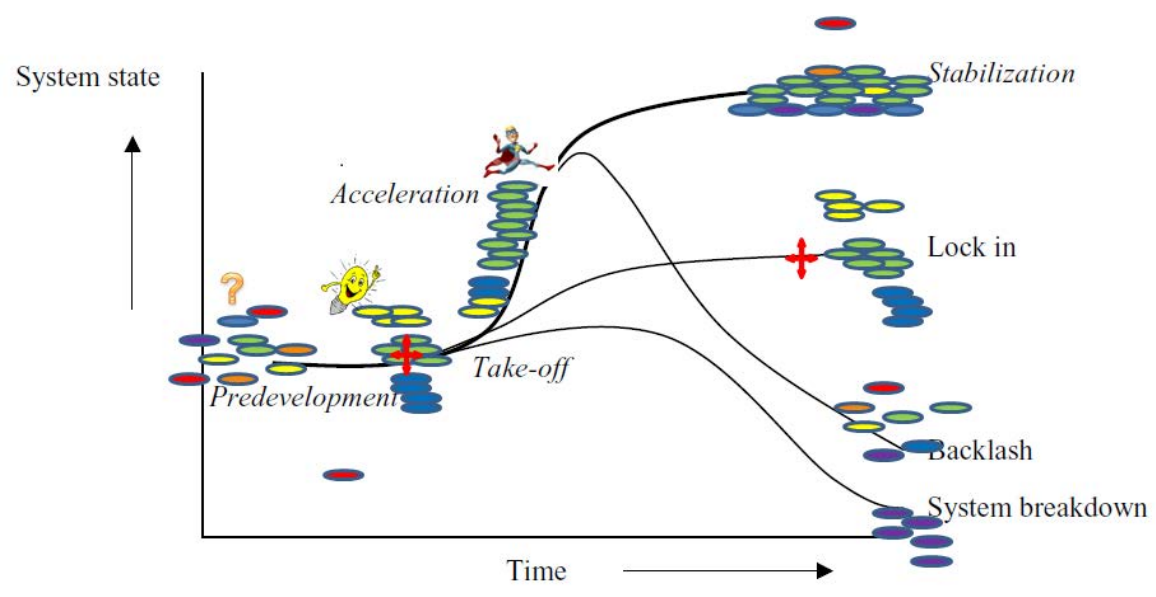

Figure adapted from Kemp, Loorbach and Rotmans, 2007

The perspective groups are playing specific roles in specific phases of the Transition model (see figure $5.3^{*}$ ). In the predevelopment phase players from all perspective groups (represented by the dots in the various colours), but especially the dynamics identify some problems occurring on the landscape level. The Hierarchists, Egalitarians, Individualists and Autonomous start wondering what is happening and start investigating into solutions in their own ways. In the take-off phase the niche-players start competing with the regime and with each other. Hierarchists call for order and stability by changing policies or making new ones. Autonomous forces start retreating from the established society. Individualist forces call for innovation and Egalitarian forces call for democratic change of power or start up a revolution. The run for power between Hierarchists, Individualists and Egalitarians speeds up during the acceleration phase. In the stabilisation phase, the winning perspective becomes supported by Hierarchist forces and by Fatalist forces. Opposition is tolerated to a certain level (to ensure enough diversity for a resilient system) and mediated to the regime stabilisers (Hierarchist forces and Fatalists) by the Dynamic Integrator.

\section{Adaptive pathways: levels of connectivity in the Panarchy model}

Panarchy theory describes the phases of change in a similar way as the Transition model. The first phase of the adaptive cycle of PT consists of rapid growth (of a species or com- 
munity in nature or of an idea or initiative in society). In this phase, pressure on the environment and resources increases. The second phase consists of continuing exploitation because of consolidation and conservation of the exploiting system (Gunderson \& Holling, 2002). This can be compared to the tendency of maintaining the regime or status quo in TT. In the third phase, when connectivity becomes too tight, the pressure on resources becomes too high, or a regime becomes too rigid, a tipping point is reached, leading to systemic collapse or release. The final phase is the initiation of a new adaptive cycle: the reorganisation or reassembling of the released resources. What makes the Panarchy model different from the Transition model is the focus on the level of tightness of relationships existing of levels of diversity and connectivity (McCann, 2000; Gunderson \& Holling, 2002; Folke, et al., 2004; Ives \& Carpenter, 2007).

The perspective groups are playing specific roles in specific phases of the adaptive cycle as well (see figure 5.4*). Phase changes can be related to the levels of connectivity and diversity of both human forces and landscape constellations: in the exploitation phase one of the perspectives gains strength over the others and leaves other players behind as niche players. In the conservation phase the new regime tightens and through Hierarchist forces aims to retain its status quo, supported by Fatalist forces who refrain from being active into any other direction. In the meantime the pressure on the landscape has grown to a maximum and when no diversity or innovation in options or solutions for easing the pressure exists or is allowed in the regime (low resilience), a tipping point will be reached that will lead to collapse of the existing system. The pressure on the landscape will be 'automatically' released in this phase of disorder and fragmented plurality. The disorderly period will be followed by a phase of reorganisation. Perspectives groups will find each other and start forming new alliances and bonds. Finally one of the perspectives gains in popularity and a new exploitation phase will start, leaving other players behind as niche players. Autonomous forces will retreat from the competition at this time too, easing the pressure on the system. The Dynamic Integrator is especially active in the time of release. He is able to relate to chaos in an optimistic way and points towards potential new patterns and alliances.

The basic adaptive cycle as explained here does not provide the whole story of possible adaptive pathways. It only shows what happens when resilience becomes low due to strong connectivity and low diversity, leading to collapse (Gunderson \& Holling, 2002; Ives \& Carpenter, 2007; MacDougall, et al., 2013). Of course, Egalitarian forces, Individualist, and dynamic integrative forces can form strong undercurrents that are able to loosens up the regime and allow for either innovation (Individualist), dynamic alliances (Dynamic Integrator), or revolution (Egalitarian) before the tipping point is reached.

In figure 5.4* the thought experiment on integrating cultural perspectives into the adaptive cycle of PT is visualised. 


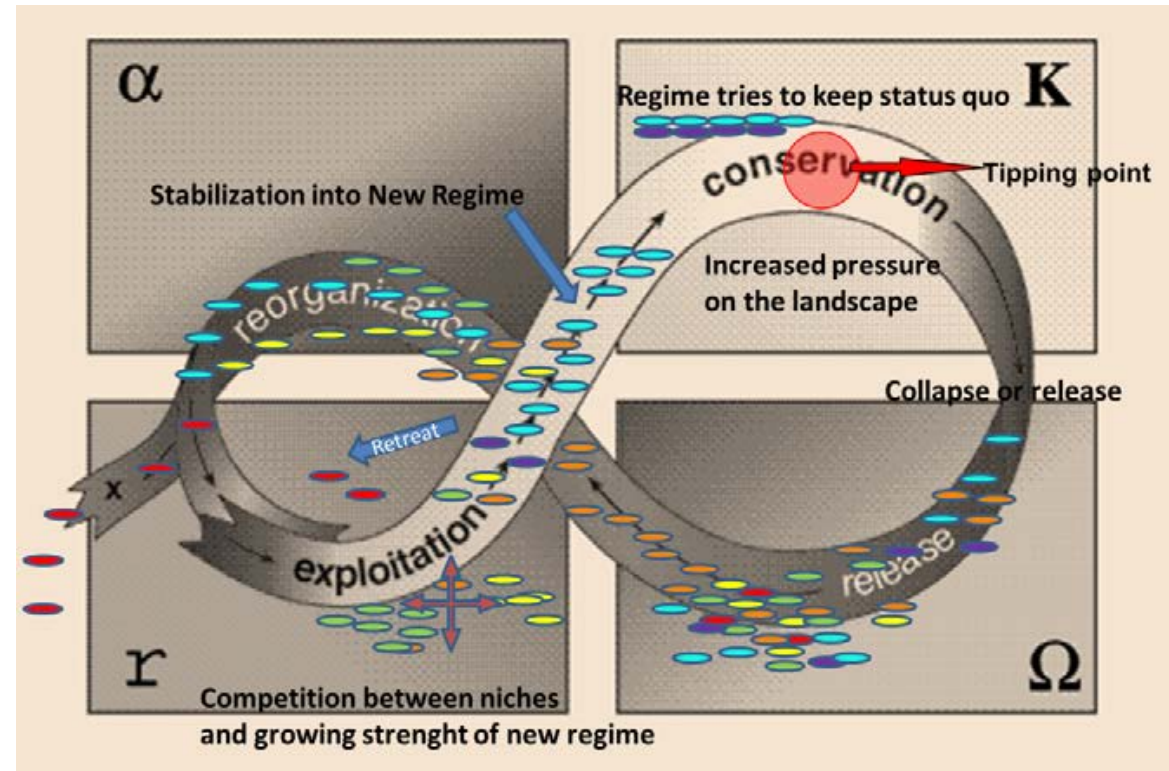

Figure adapted from Gunderson and Holling, 2002

\section{The Value of Perspective Plurality}

In a healthy society - Gunderson and Holling say (2002) -- "each level of society is allowed to operate at its own pace, protected from above by slower, larger levels but invigorated from below by faster, smaller cycles of innovation (Gunderson \& Holling, 2002, p.76)." In our view, all the perspectives - containing conservative and innovative powers, revolutionary or regressive powers and dynamically connecting (or networking) powers - are necessary to keep a healthy, sustainable society going. This is also stated by Marco Verweij when he shows how all the perspectives need each other to keep societies healthy in both flexible and at the same time relatively stable ways (Verweij, et al., 2006). Baldly speaking about the qualities the different perspectives bring along to balance each other: without the Hierarchist there would be no stability in society; without the Egalitarian there would be no democratic activism; without the Individualist free unbounded creative innovation would be difficult; without the Fatalist there would be no critical questions about the use of actions; without the Autonomous modesty and time for deeper reflection would be missing; without the Dynamic Integrator there would be less mediation and networking between opposing stakes and worldviews of the other perspective groups: less cross-fertilisation and unexpected emerging novelty. 
In the following paragraphs the relevance and the role of the CT perspectives in the field of biodiversity conservation through a content analysis of written sources will be explored. What perspectives are dominant in the conservation debate and practice, what are the undercurrents and what kind of cultural (change) patterns can be revealed looking at the perspectives that are ongoing in conservation?

\section{Perspectives in the Conservation Approaches}

Before anything can be said about the question whether biodiversity conservation is going through a transition, the following question needs to be asked: what cultural perspectives can be identified in the various conservation approaches that were mapped in CHAPTER 4? This question was approached by conducting a content analysis of text sources using the content analysis software MAXQDA. The analysis has been based on a lexical search strings related to each individual perspective group (see table 5.2). The terms for the search string have been selected from words that were encountered often in the body of literature that was reviewed for this dissertation.

In order to get a quick insight into the discourses of the different conservation strategies I applied the text analysis on one key academic paper per conservation strategy (to account for the academic representation of the topic) and on one Wikipedia page for each conservation strategy (when available) (to account for the global public representation of the topic).

Table 5.2. Search strings for MAXQDA content analysis

\begin{tabular}{|l|l|l|l|l|l|}
\hline Hierarchist & Egalitarian & Individualist & Fatalist & Autonomous & Dynamic \\
\hline Human & Natur & Resource & Surviv & Retreat & Dynamic \\
People & Equal & Opportunity & Faith & Harmony & Complex \\
Management & Equity & Econom & Coping & Lifestyle & Integrat \\
Law & Participat & Innovat & Cope & Reduc & Ecosystem \\
Legislation & Aware & Goods & Uncertain & Love & System \\
Policies & Precaution & Services & Flexible & Cultur & Scenario \\
Policy & Principle & Resources & Decline & Footprint & Evolution \\
Governance & Vulnerable & Chance & Lack & Whole & Cooperation \\
Risk & Communit & Benefit & Loss & Holistic & Co-creation \\
Control & Local & Price & Little & Consumption & Open \\
Mainstreaming & Sharing & Pricing & Accept & Life & Change \\
Order & Share & Market & Unpredictable & Living & Adapt \\
& \multicolumn{2}{|l}{} & & & \\
\hline
\end{tabular}


Key academic articles were selected by the following criteria:

1. they give a broader insight into the conservation approach through presenting a (literature) review, a general overview of the topic or integrative discussion on the issue;

2. they are referred to more than ten times by other authors. The number of citations has been checked with the citation index of Google Scholar;

3. the selection of research papers was restrained by the ability to transform PDF texts into Rich Text Formats, which is necessary to insert them into the MAXQDA software.

A shortcoming of the type of content analysis presented here is that the textual context of the keywords used for analysis hasn't been taken into account. Analysis based on software alone makes it hard to capture the context of the words searched, the subtleties of the texts and the things said in between lines. The results of the MAXQDA lexical search have been summarised and visualised by making text portraits of each conservation strategy (see figures 5.5* 5.6* and 5.7*).

A further limitation of the content analysis in this chapter is that it is based on a limited amount of resources and on only two categories of producers of text. Websites of zoos, or of companies that offer eco-touristic trips, or of specific protected area sites, for example, have not been visited and included in the analysis. It can be expected though that such different particular institutions or organisations are constructed from very different angles and viewpoints, also depending on when and where they have been set up. Going that deep into analysing all the different individual actors in the field is beyond the scope of this dissertation. However, I made an exception for a number of global conservation NGOs in this respect.

\section{The conservation approaches}

In the analysis of the conservation approaches I had to make some exclusive choices: I excluded the conservation approach of collections, because this historically important conservation strategy has nowadays been taken over by zoos, aquaria and botanical gardens. Civil action for conservation is a topic too heterogeneous for a Wikipedia article. Therefore I couldn't include it here.

Inclusive articles on biodiversity conservation and the creative arts are hard to find, both as scholarly articles as in Wikipedia. This may indicate that although many arts are used to stimulate conservation (e.g. film-making, literature, and music) they aren't commonly seen as a 'form of conservation'. However, I considered this approach too important to exclude it from this study. Therefore, I made a starting point by assessing the perspectives represented in three classic books from conservation literature: Rachel 
Carson's Silent Spring (1962), Henri David Thoreau's Walden, or: Life in the Woods (1854) and three essays from Aldo Leopold's book A Sand County Almanac (1966): The Land Ethic; On a Monument to a Pigeon; and Thinking Like a Mountain (see figure $5.5^{*}$ ). Literature is the easiest art form to convert into analysable text. Besides, these chosen texts have always been a very influential source of inspiration and guidance for most conservationists (practical and academic) in many corners of the world. A limitation of course, of this choice for literature is that all other art forms (like music or films) are excluded and a more complete picture of the perspectives on conservation represented by the arts cannot be delivered here.

\section{Figure $5.5^{*}$. Perspective portraits of classic conservation literature}
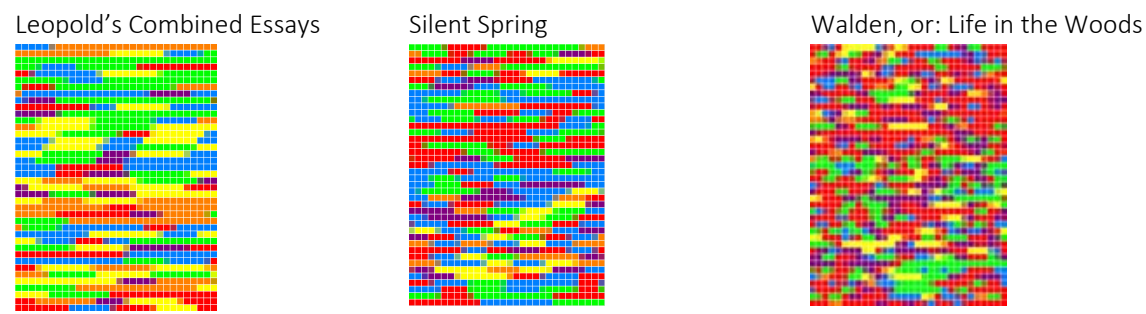

Legend

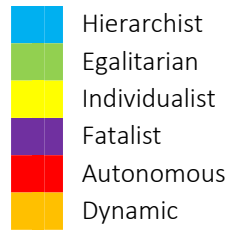

The portrait of Leopold's combined essays represents all the perspective colours in a more or less balanced way. The Egalitarian perspective dominating the upper part of the portrait (The Land Ethic), and the dynamic perspective dominating the middle (On a Monument to a Pigeon) and the lower part (Thinking Like a Mountain). The portrait of Silent Spring shows a dominantly Hierarchist -Autonomous combination, freckled with quite a portion of green Egalitarian colour. Thoreau's Walden has a clearly dominant Autonomous character. Combined, the Autonomous perspective scores highest in the classic texts (37\%). The Dynamic Integrator is least represented (5\%) (see table 5.3).

Table 5.3. Coding results for combined conservation classics

\begin{tabular}{llllllll}
\hline Hierarchist & Egalitarian & Individualist & Fatalist & Autonomous & Dynamic & Total & \\
\hline 216 & 221 & 102 & 172 & 453 & 56 & 1220 & Segments \\
$18 \%$ & $18 \%$ & $8 \%$ & $14 \%$ & $37 \%$ & $5 \%$ & $100 \%$ & Percentage
\end{tabular}




\section{Conservation NGOs}

NGOs also deserve some special attention. It was not really possible to include them in the perspective portrait series of academic articles and Wikipedia pages. The topic is too heterogeneous because of the many older and emerging types of conservation NGOs (Bode et al., 2010) (see figure 5.6*)

\section{Figure 5.6. Portraits of Websites Global Conservation NGOs}

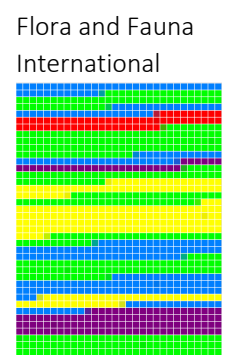

The Nature Conservancy

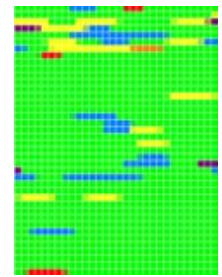

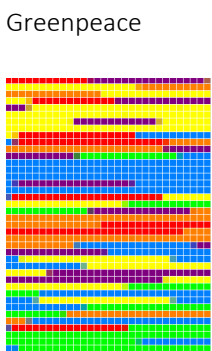

WWF

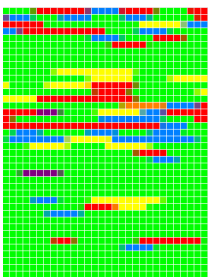

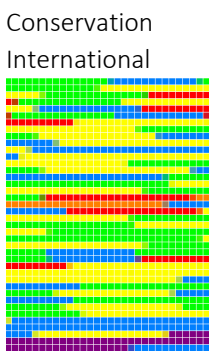

IUCN

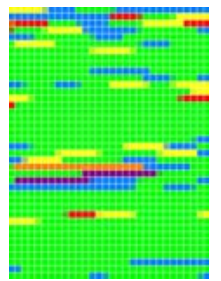

Besides, there is no special summarising Wikipedia page on NGOs for biodiversity conservation. However, I consider it important to shed a special light on 'the NGO perspective' because it conceptually links to so many other conservation approaches (see figure $\left.5.7^{*}\right)$.

NGOs are often providing the financial means for other strategies (through membership fees and fundraising), and they are strong lobbying forces that enable enforcement of policy and practical conservation in the field (Bode, et al., 2010). Therefore, I decided to include an analysis of six conservation NGOs with a global outreach: WWF, Greenpeace, Flora and Fauna International, IUCN, The Nature Conservancy, and Conservation International. I analysed the mission and vision statements of their websites and included the Wikipedia descriptions of the organisations. Per NGO, all the gathered text was pasted in a separate document (see figure $5.6^{*}$ ).

In Flora and Fauna International and Conservation International the portraits balance Egalitarian, Hierarchist, and Individualist perspectives, with a touch of Fatalist and Autonomous perspective in both and only a few text fragments of Dynamic Integrator in Conservation International. Greenpeace seems to be most diversified in its perspective 
portrait whereas WWF, the Nature conservancy and IUCN have a strongly Egalitarian focus. Overall, calculating the text segments of all four NGOs, the Egalitarian perspective comes out strongest (71\% of the text segments), followed by the Hierarchist (12\%), the Individualist (8\%), the Autonomous (5\%), the Fatalist (3\%) and the dynamic (1\%) (see table 5.4).

In CHAPTER 6 the International Union for the Conservation of Nature (IUCN) will be more extensively and into depth studied for its perspectives and discourses. The analysis for the mission and vision statements on the website and the Wikipedia page show a highly Egalitarian image of IUCN (see figure 5.6*). The results of the extensive analysis will show that this public image that is being presented is rather different compared to the results of zooming in to a variety of documents that are more detailed on the values and assumptions represented by the organisation, such as Vision and Mission Documents, Annual Reports, Practice Reports, and the communicative publication series World Conservation Magazine (see CHAPTER 6).

Table 5.4. Coding results for combined NGOs

\begin{tabular}{llllllll}
\hline Hierarchist & Egalitarian & Individualist & Fatalist & Autonomous & Dynamic & Total & \\
\hline 114 & 673 & 79 & 24 & 52 & 12 & 954 & Segments \\
$12 \%$ & $71 \%$ & $8 \%$ & $3 \%$ & $5 \%$ & $1 \%$ & $100 \%$ & Percentage
\end{tabular}

Figure 5.7. Perspective portraits of key academic texts and Wikipedia articles

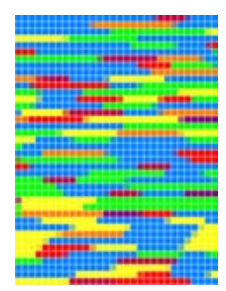

Zoos, Hutchins 2003

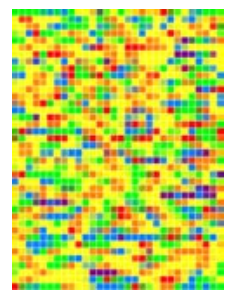

Ecosystem Services, TEEB, 2009

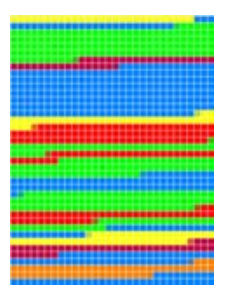

Zoos, Wikipedia 2014

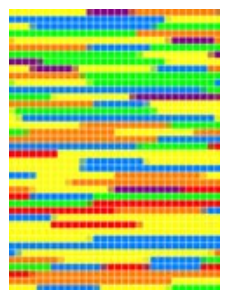

Ecosystem Services, Wikipedia 2014

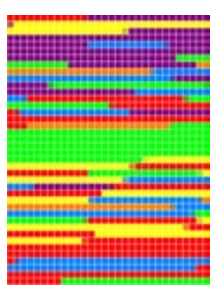

Conservation

Education, Scott et al.

2011

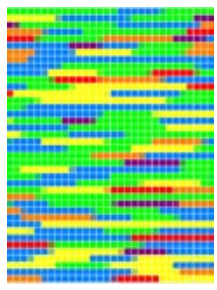

Ecotourism, Catibog-

Sinha, 2008

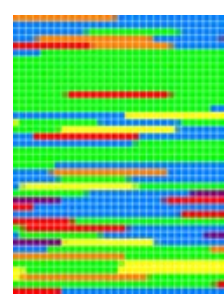

Conservation

Education, Wikipedia

2014

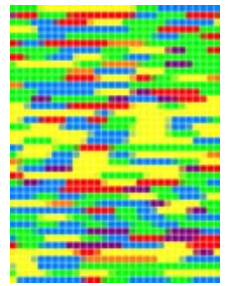

Ecotourism, Wikipedia 2014 
Figure 5.7. Perspective portraits of key academic texts and Wikipedia articles

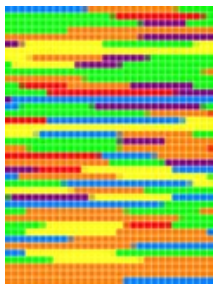

Gene Banking,

Hamilton, 1994

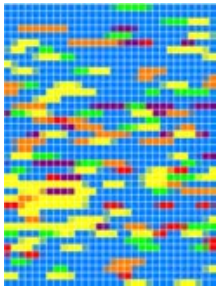

Policy, Sampford, 2002

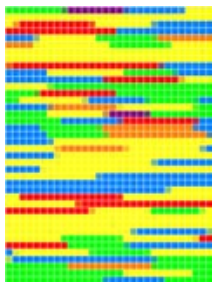

Philantrophy, Holmes, 2012

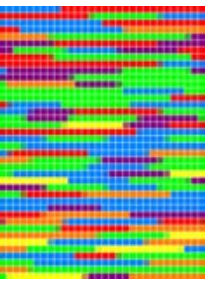

Reconciliation Ecology,

Rosenzweig, 2003

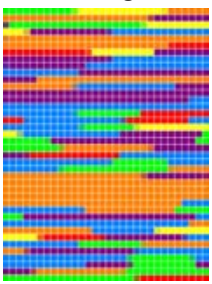

Reintroduction,

Armstrong \& Seddon, 2007

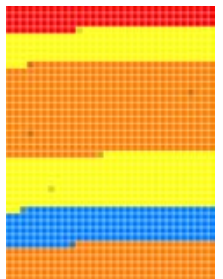

Gene Banking,

Wikipedia 2014

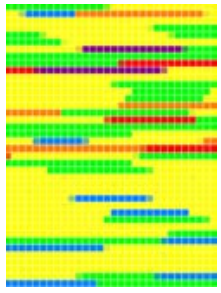

Policy, Wikipedia (CBD)

2014

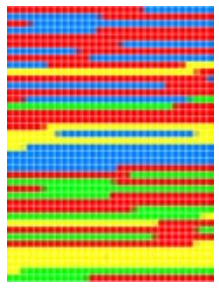

Philantrophy, Wikipedia 2014

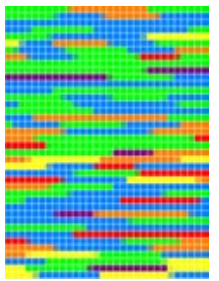

Reconciliation,

Wikipedia 2014

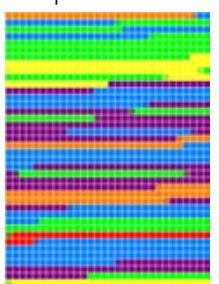

Reintroduction,

Wikipedia 2014

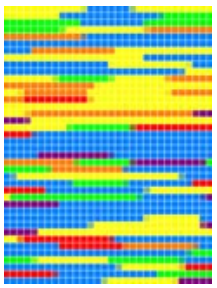

Trophy Hunting, Harris et al. 2013

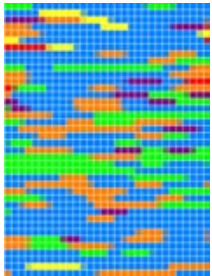

Partnerships, Visseren-

Hamamakers et al.2012

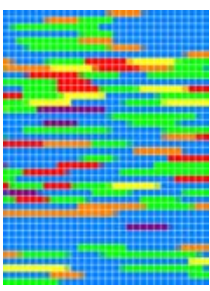

Protected Areas,

Dudley et al. 2010

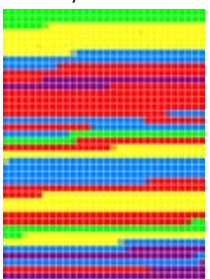

Religions, Boyd, 1984

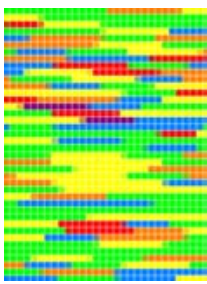

Restoration, Aronson et al. 2006

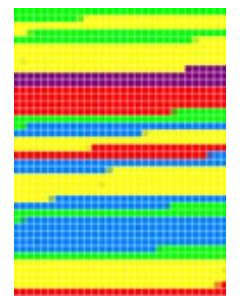

Trophy Hunting,

Wikipedia 2014

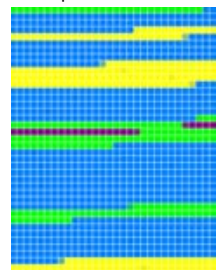

Partnerships, Wikipedia 2014

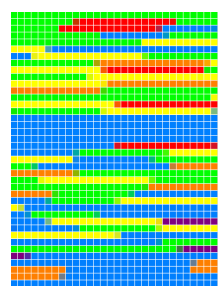

Protected Areas,

Wikipedia 2014

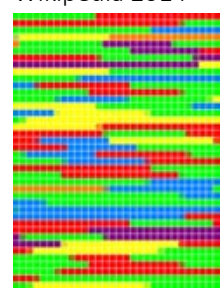

Religions, Wikipedia 2014

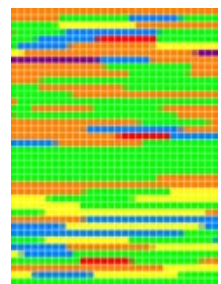

Restoration, Wikipedia 2014 
Figure 5.7. Perspective portraits of key academic texts and Wikipedia articles

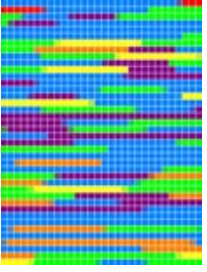

Relocation, McLachlan et al. 2007

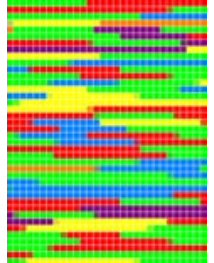

Relocation, Wikipedia 2014

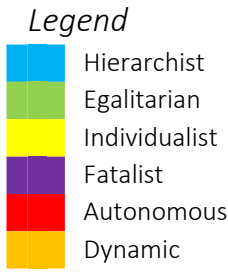

The other approaches

The perspective portraits of the various conservation strategies (figure $5.7^{*}$ ) show some interesting differences and similarities between each other and between the academic papers and the Wikipedia articles. Starting with the zoos, relatively well matching perspective colours between Hutchins paper (2003) (+ 22 citations) and the Wikipedia article were identified. The green and the blue of the Egalitarian and the Hierarchist are the dominating colours. The Wikipedia article seems to have a little more space for the Autonomous perspective.

The portraits for conservation education differ to quite an extent. The scholarly article (Scott et al., 2011) (+10 citations) basically combines fatalism with Egalitarianism and autonomy, whereas the Wikipedia article on conservation education shows a Heirarchist-Egalitarian image.

The approach of Ecosystem Services (ESS) is generally Individualist for both source types. The Dynamic perspective is also frequently represented here. Ecotourism is portrayed more Egalitarian in the academic article (Catibog-Sinha, 2008) (+ 13 citations) compared to the Wikipedia article, which shows a higher Individualist colouring. However, generally the two portraits match each other pretty well. Although the portraits for gene banking look rather different in perspective distribution, the dynamic orange colour makes up a good part of both source types. Nevertheless, the scholarly article (Hamilton, 2002) (+84 citations) includes quite some green whereas the Wikipedia article doesn't include any green.

The scholarly article by Harris et al. (2013) on trophy hunting presents a Heirarchist character with an Individualist edge, whereas in the Wikipedia article trophy hunting is characterised by Individualist words mostly, having a Hierarchist edge. Also remarkable is the thick Autonomous line in the Wikipedia article.

Perhaps most striking are the differences in the portraits on policy for conservation. The scholarly article (Sampford, 2002) (+43 citations) discusses governance for biodiversity in a general sense. The Wikipedia portrait is based on the article for the Convention on Biological Diversity, which represents the general global biodiversity policy frame- 
work. Where the academic article shows a Hierarchist character, the Wikipedia article presents a highly Individualist portrait.

Partnerships for both sources are represented dominantly Hierarchist and philanthropy has a clear individual touch in both sources, but stronger in the scholarly paper (Holmes, 2012) (+10 citations) than represented in Wikipedia. The Wikipedia article on partnerships shows a more dominant Autonomous colour.

Protected areas are dominantly Hierarchist in both sources, having an Egalitarian edge. Reconciliation ecology has a similar pattern in both source types, however, the founder of the theory, Rosenzweig (2003) (+171 citations), includes clearly more Autonomous characteristics than the Wikipedia page.

Religions seem to represent all the perspectives rather evenly, except for the dynamic perspective. This is more or less missing by both the scholarly article (Boyd, 1984) (+12 citations) and the Wikipedia page. The Autonomous perspective is comparably strong in the religions approach to conservation.

The portraits for reintroduction show a dominant combination of Hierarchist and Fatalist. In the scholarly article (Armstrong \& Seddon, 2007) (+309 citations) the Dynamic Integrator is also strongly represented. Restoration shows a dominantly Egalitarian portrait for both source types (Aronson et al., 2006) (+68 citations). The Wikipedia page leaves quite some space for the dynamic perspective too. The scholarly article emphasises an Individualist edge. The scholarly article for relocation - or assisted migration colours Heirarchistically blue with a Fatalist dimension (McLachlan, et al., 2007) (+361 citations), whereas the Wikipedia article seems to portray the strategy as a highly diverse strategy with almost equal space for all the perspective groups. Only the dynamic perspective is represented to a lesser extent.

When calculating the total scores for the coded segments of all the documents together (including the NGO documents and the classic conservation literature) the highest score is reserved for the Egalitarian perspective (28\%), closely followed by the Hierarchist (26\%). The Individualist and the Autonomous score are also close to each other (see table 5.5).

Based on these results it can be concluded that the conservation discourse (or regime) seems to be dominated by Egalitarian-Hierarchist perspective forces with Individualist and Autonomous undercurrents (or niches). The Fatalist and the Dynamic Integrator hardly play a role. For the Fatalist perspective this can be explained through the more activist character of conservationism in general. Conservationists are usually future optimists - believing that conservation efforts will pay off in the end (Takacs, 1996). But why is the dynamic evolutionary view on nature - the foundation of biological and ecological thinking - so weakly represented? 
Table 5.5. Total of perspective codes for all coded documents

\begin{tabular}{llllllll}
\hline Hierarchist & Egalitarian & Individualist & Fatalist & Autonomous & Dynamic & Total & \\
\hline 1712 & 1843 & 1138 & 467 & 986 & 549 & 6695 & Segments \\
$26 \%$ & $28 \%$ & $17 \%$ & $7 \%$ & $15 \%$ & $8 \%$ & $100 \%$ & Percentage
\end{tabular}

\section{Mapping the Perspectives}

For gaining a better insight into the mutual relations between the various conservation strategies, the results of the content analyses above were combined and a dominant perspective or dominant perspective combination (of maximal two perspectives) has been defined for each conservation strategy.

Figure 5.8. Mapping the perspectives of the conservation approaches

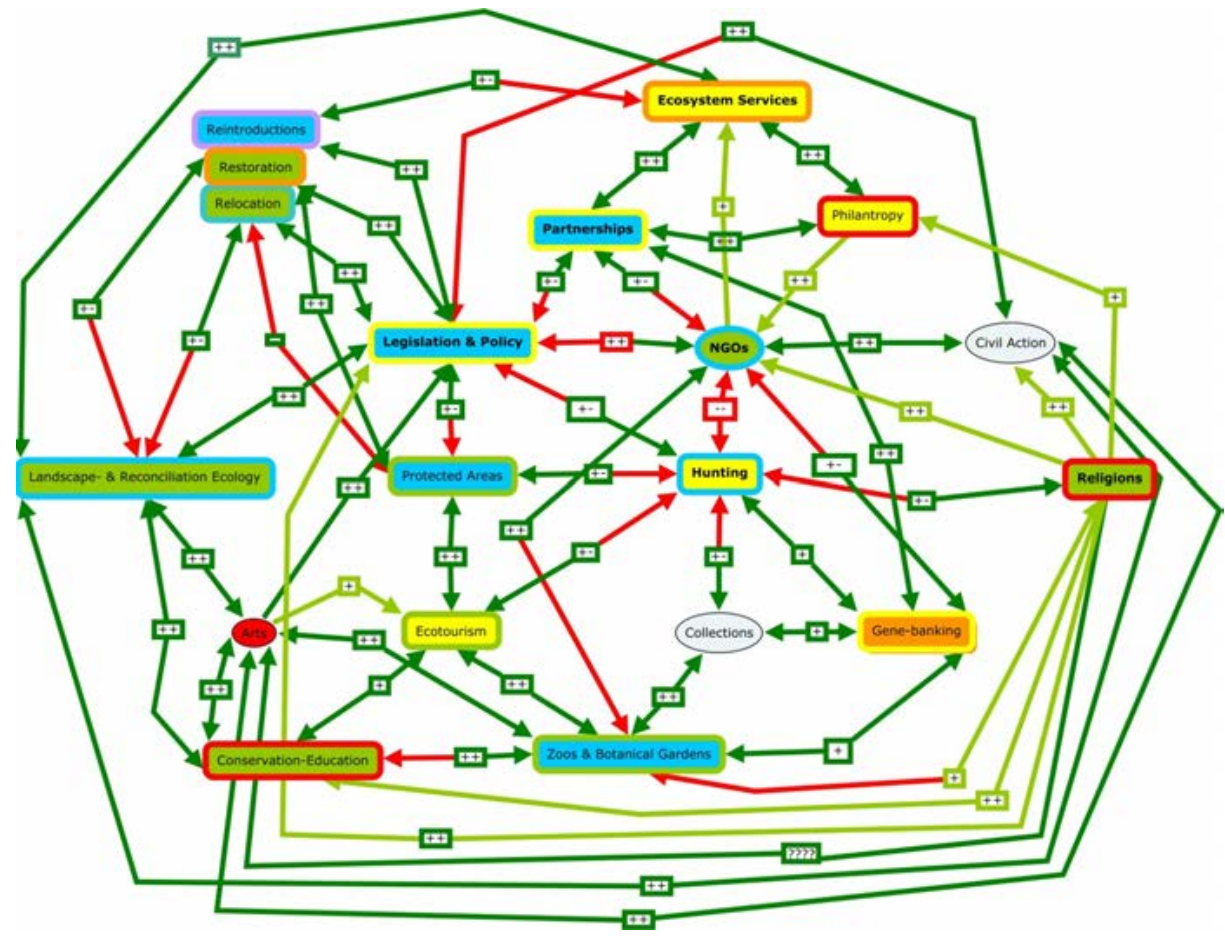

A little more emphasis on the Wikipedia articles has been put in the cases where it was hard to decide on which two perspectives should be allocated to each strategy. The reason for this allocation emphasis is that I expect Wikipedia to represent the general public's view on the topics better than the scholarly articles do, which are - although not always -- often developed in closed academic communities. 
Figure 5.8* shows the resulting map of conceptual relations between conservation approaches of CHAPTER 4, now also including the perspective characterisations that were allocated to each conservation approach. By means of this picture it is possible to identify where conceptually reinforcing strategies (green arrows) are also alike based on their dominant worldviews and are as such easy to link in cooperative projects. Likewise, it is possible to identify conflicting strategies (red arrows) and opportunities to find some common ground based on their worldviews. And of course, fundamental tensions also become apparent. Below some patterns and peculiarities that have become visible are elaborated.

\section{Relational patterns}

Overall, it is possible to state that the perspectives in the conservation field are heterogeneous, but dominantly characterised by the Egalitarian (6 approaches), the Hierarchist (5 approaches) and the Individualist (4 approaches) worldviews. In this picture, the Dynamic Integrator and the Fatalist are not really represented in the conservation area. Curiously, also the Autonomous perspective hardly finds a place. That is interesting when I compare these results to the three classical books from conservation literature which are guiding many conservationists hearts and minds -- where especially Silent Spring and Walden represent strongly an Autonomous perspective (see figure $5.5^{*}$ ). Somehow this perspective, although ideologically important, disappears from the more practical conservation arena. However, it is marginally present in the religions and in conservation education.

Looking into the more specific relationships between the conservation approaches the following patterns have been identified:

Trophy hunting is a conceptually controversial conservation approach in its relation to many other approaches (see CHAPTER 4). Here, its core perspective is identified as Individualist. However, because the current practice of trophy hunting is also including the Hierarchist perspective (trophy hunting is limited to strict rules and regulations for example), it is able to fulfil a complementary place in the protected area arena. Trophy hunting brings in a large of financial resources to protect and maintain protected areas, for example. These ideas may be conflicting with most ethical and/or religious views on nature: respecting all life (Autonomous) and the vulnerability of the defenceless beings (Egalitarian)(DesJardins, 2006; Fothergill, 2006; Genton, 2006).

Strong connections can be found between the approaches of ecosystem services, partnerships, and philanthropy (also see CHAPTER 4). Although there are differences, the binding factor is the Individualist perspective. An interesting field of tension in the rela- 
tionship of this conceptual triangle may be the Autonomous edge of the philanthropic approach.

Reconciliation ecology (Egalitarian-Hierarchist), Relocation and NGOs have more or less identical perspective-characters and they also may go along well with the worldviews of protected areas (Hierarchist-Egalitarian) and zoos and botanical gardens. However, direct conceptual links seem to be still missing from the scene here.

Although reintroductions and relocation are sometimes conceptually tense with other conservation strategies, there may be a cause for strengthening connections with other approaches based on the underlying worldviews that match with many others.

An unexpected result is that legislation and policy for biodiversity - as made explicit on the Wikipedia page for the Convention of Biological Diversity - seems to have a strong Individualist character. Based on the general qualitative literature research and conceptual mapping exercise (CHAPTER 4), I expected this conservation approach to be much more Hierarchist. I cross-checked the unexpected Individualist results for policy by conducting an additional MAXQDA content analysis on the Global Biodiversity Outlook 3 (GBO3) (CBD, 2010), and the Strategic Plan for Biodiversity conservation 2011-2020 and the Aichi Targets (CBD, 2011)(see figure 5.9*).

\section{Figure 5.9. Text portrait of Global Biodiversity Outlook 3}

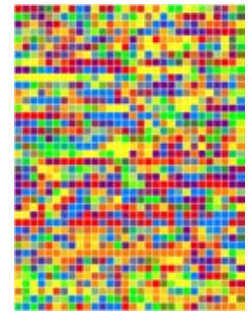

Global Biodiversity Outlook 3, CBD 2010

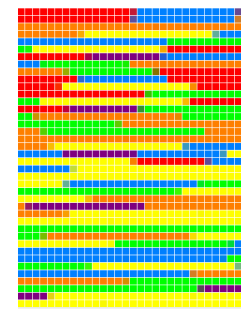

Aichi Targets, CBD 2011

The portrait of the GBO3 (CBD, 2010) is much richer in perspective diversity than the Wikipedia page of the Convention of Biological Diversity would suggest. However, the Hierarchist (324 text segments) and the Individualist perspective (261 text segments) are both represented highly, unexpectedly combined with a slightly higher occurrence of the Fatalist perspective (263 text segments) compared to the Individualist. This high Fatalist occurrence may be attributed to the year of publication (2010, the International Year of Biodiversity Conservation), where biodiversity loss should have been halted, but the target was by far not achieved. The Egalitarian perspective is least represented (159 text 
segments); the dynamic perspective counts 167 segments and the Autonomous perspective does pretty well with 205 segments.

The content analysis of the Aichi Targets (CBD, 2011) shows a dominantly Individualist worldview (18 text segments), combined with an equal amount of Egalitarian and Hierarchist perspective (14 text segments). Based on these results combined with the earlier ones (figure 5.7*) I decided to characterise the current conservation governance approach as basically Individualist (see figure 5.9*). Furthermore, by analysing two additional scholarly articles on biodiversity governance (Smith et al., 2003; KluvánkováOravskál et al., 2009), I found there may be likely a gap in worldviews between academia and policy-practice on this particular conservation strategy (see figure 5.10*).

\section{Figure 5.10. Additional scholarly articles on biodiversity governance}

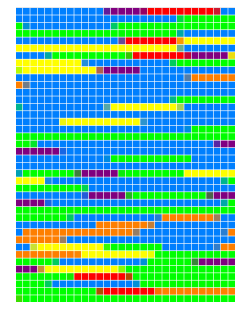

Smith et al, 2003

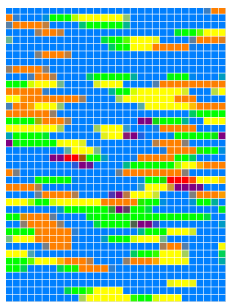

Kluvánková-Oravskál et al., 2009

\footnotetext{
Legend

Hierarchist

Egalitarian

Individualist

Fatalist

Autonomous

Dynamic
}

\section{Discussion: The Uses of Perspective Diversity in Societal Change Dynamics}

In the GBO 3 the CBD states that a "key lesson from the failure to meet the 2010 biodiversity target is that the urgency of a change of direction must be conveyed to decisionmakers beyond the constituency so far involved in the biodiversity convention (CBD, 2010, p.83)." Clifford Geertz says: "scientific concepts change with change in the sorts of concerns to which scientists address themselves (Geertz, 1985, p265)." Is biodiversity conservation also changing with the changing tides? There seems to be a rather large ideological gap between the mid- $20^{\text {th }}$ century conservation inspirations delivered in the Autonomously coloured classical conservation literature on the one hand and the more recent Individualistically coloured approaches based on concepts of economic incentives 
and ecosystem services on the other hand. Has the discourse and practice of conservation been changing during the last decades or has there always been a gap between ideology and practice?

In the inter- and trans-disciplinary studies of 'wicked' socio-environmental problems, the value of diversity of perspectives is generally accepted and considered important. The 'uses of diversity' (Geertz, 1985) for societal change have been studied in literature ranging from social psychology (Smith \& Mackie, 2000; Bandura, 2004) to anthropology and ethnography (Keesing, 1974; Geertz, 1985; Taylor, 1995; Posey, 1999) and taken up by Integrated Assessment (Asselt, et al., 1995) and Sustainability Science (Funtowicz \& Ravetz, 1993; Funtowicz, et al., 1998; Gibbons, 2000; Nowotny, et al., 2003; Verweij, et al., 2006; Cuppen, 2012; Offermans, 2012). However, it hasn't been studied what different roles of the different cultural perspectives from CT (or other typologies) are playing in societal or systemic change dynamics.

There are suitable settings to test the roles of cultural perspectives in societal change dynamics. Using diversity in stakeholder dialogue, for example through facilitating situations of constructive conflict (Cuppen, 2012), has proven beneficial to the enrichment of policy processes with different types of knowledge, values or expertise (Cuppen, et al., 2010; Cuppen, 2012). The benefit of facilitating constructive conflict is that there isn't too early and too easy consensus in a stakeholder dialogue. Rather than resulting in consensus or flattened compromises, a dialogue based on constructive conflict may lead to a synthesis of the broad range of present perspectives, solutions and management styles (Verweij, et al., 2006; Cuppen, 2012; Hegger et al., 2013). Research has pointed out that there is more creativity in groups that criticise and contest each other's ideas compared to groups that do not allow conflict (Nemeth et al., 2004).

From a social psychology/sociological point of view Eefje Cuppen identifies three properties of diversity: variety (referring to the number of categories into which specific elements can be divided); balance (referring to the distribution of the elements among the categories); and disparity (referring to the degree and nature of the differences between the categories themselves) (Cuppen, 2012). Similar descriptions of diversity can be found in ecological studies (McCann, 2000; Gunderson \& Holling, 2002; Folke, et al., 2004) and innovation systems literature (Hekkert et al., 2007; Musiolik et al., 2012). With the right level of connectivity between elements in a system (or, in psychological terms, "optimal cognitive distance"5 (Nooteboom et al., 2007), diversity increases the resilience - or adaptive (learning) capacity -- of socio-ecological systems (Keesing, 1974; Gunderson \&

\footnotetext{
5 Optimal cognitive distance suggests that when information is shared in a group, there is a highest learning capacity in the group when the information that is shared is different from 'mainstream' or familiar information, but not too different for people's ability to relate or connect to it, (see: Nooteboom, 2007, and Cuppen, 2011).
} 
Holling, 2002; Rees, 2010). Diversity in a system increases options to turn to and in this context there is special value in minorities or marginalities (niches). The inclusion of nonmainstream thinkers, minority dissent, small entrepreneurs - or niche players - facilitates attention towards alternative solutions or options ("minority-induced divergent thinking" (Brodbeck et al., 2002)).

According to Roger M. Keesing (1974), if we really want to understand cultural change and diversity, we have to conceptualise culture as "complex cybernetic systems of humans-in-environments (p.91)." This means that ideational models of culture (representing culture as sets of values, symbols, shared meanings etc.) need to be combined with theories of change and adaptation for the following reason: ideational models help correct and enrich overly simplified ecological models of culture (captured in terms of natural selection), whereas the ecological/adaptationist models help to better understand patterns of change in socio-environmental systems (Keesing, 1974). Such a combined model is what has been proposed above with combining Transition Theory and/or Panarchy Theory with Cultural Theory. Focusing on the diversity of perspectives in society can be seen as the key for combining ideational and adaptive theories of culture. It directly relates the interactions between various worldviews and management styles to adaptive cycles of change, or societal transitions, as has been illustrated above.

The key of using diversity in a constructive way is "not that we must love one another or die [...]. It is that we must know one another, and live with that knowledge, or end marooned in a Beckett-world of colliding soliloquy (Geertz, 1985, p.271)." In a complex world where taking action is urgent and stakes are high it may be necessary to go one step beyond Geertz's idea of "living in a collage": it may become important to be ready to transform the pictures of the collage into different constellations of perspective and seeing to what future pathways they point for conservation. What constellations of perspective can be identified in current conservation discourse and practice? What types of power struggle do these constellations reveal? What kind of alternative options - or marginal perspectives in conservation -- can be explored to benefit the future of biodiversity?

From the MAXQDA content analysis it was concluded that the conservation regime seems to be dominated by Egalitarian-Hierarchist perspectives, broadly constituted by NGOs and the global policy-field. The contradictory worldviews of the Individualist and Autonomous forces seem to compete for power in the conservation-undercurrent. When looking at the rising popularity of the approach of ecosystem services in policy and sciences (IUCN, 2008e, 2009e; TEEB, 2009; IUCN, 2010c, 2010b, 2011d, 2011b, 2012b, 2012c; Marton-Lefèvre \& Xinsheng, 2012) and partnerships between publicly funded conservation NGOs and large businesses (Turner, 2010; Visseren-Hamakers, et al., 2012), a shift in the conservation regime may be expected towards stronger alliances 
of the regime with the Individualist perspective (also see CHAPTER 6 and 7). If this is indeed the case, that would suggest an ideological alienation from the more Autonomous-Egalitarian ethics that primarily constituted and guided conservation thinking during the last century.

What role then, does the Dynamic Integrator play and how will this role evolve? Evolutionary- and complexity-thinking doesn't seem to play a significant role in the current conservation discourse. This seems strange, because it underpins the disciplines of biology and ecology that scientifically constitute conservation. Perhaps this minor presence of the Dynamic Integrator can be attributed to a hypothesis that dynamic thinking (systems thinking, complexity thinking, and evolutionary thinking) is still an exclusive way of thinking of an educated 'elite'. (This hypothesis has been confirmed by the surveys in CHAPTER 10.) Perhaps also, the minor presence of the Dynamic Integrator explains the 'conservation-paradox' discussed in CHAPTER 2. For the general public it is (still) hard to conceptually combine conservation and change.

\section{Conclusions: Conservation Dynamics}

The results of the content analyses of texts that describe or discuss the various conservation approaches indicated that the broad field of biodiversity conservation is dominated by the Egalitarian and the Hierarchist perspective. The dynamic and Fatalist perspective are represented least. The Autonomous perspective seems to be a guiding force in classic conservation literature, and as such it has always been an ideological authority. However, recent popular approaches to biodiversity conservation - like the Ecosystem Services approach advocated by the Millennium Ecosystem Assessment and TEEB (2009) - reveal a more Individualist discourse that is ideologically tense with the Autonomous and Egalitarian perspectives. The Fatalist perspective - although present for a little bit in most occasions - may not fit the pro-active conservationist style. Conservationists would not be conservationists if they would not bother about doing things about biodiversity loss (Takacs, 1996). The dynamic perspective that has its fundaments in the ecological discipline and sees the wold as a complex evolutionary system also seems to be underrepresented in the contemporary conservation discourse.

In order to be able to better explore (shifting) power relations between the ongoing perspectives in the 'conservation arena' (discourse and practices), in the following two chapters the dominant and marginal perspectives represented in the conservation field are more deeply explored. First, in CHAPTER 6, an analysis is provided of two important and large scale global scenario studies (the IPCC SRES Scenarios and the Millennium Ecosystem Assessment Scenarios) that have been influential guiding forces in thinking about sustainable development and the future of biodiversity. The cultural perspectives 
they implicitly or explicitly represent are explored. Secondly, in CHAPTER 7 the dominant and marginal perspectives of the oldest and largest global conservation organisation IUCN are assessed while keeping in mind the key question: "does IUCN's conservation strategy fit a rapidly changing world?" 


\section{CHAPTER 6}

Noah's Ark or World Wild Web?

The discourses of two global scenario studies 
"Always in motion is the future"

Master Yoda

This chapter is adapted from and based on: Carijn Beumer \& Pim Martens (2010).

"Noah's Ark or World Wild Web? Cultural Perspectives in Global Scenario Studies and Their Function for Biodiversity Conservation in a Changing World." Sustainability 2, no. 10: 3211-3238. 


\section{Conservation in a Changing World: Uncertainties and Assumptions}

Biodiversity "includes diversity at levels from genetic diversity within species-to-species diversity to landscape diversity" (Chapin, et al., 2001). Two important aspects of biodiversity are its quality and its quantity. The quantity can be expressed in terms of the size of the population, the abundance of different species, as well as the surface area and number of ecosystems in an area (Begon et al., 2006). Quality (or integrity) relates to the genetic diversity and the vitality or resilience of a species, ecosystem or natural area (Folke, et al., 2004). Conservationists and policymakers are facing challenges of an unprecedented magnitude. Biodiversity loss is growing from a local and regional issue into a global concern. Urbanization, intensive agriculture and infrastructure are fragmenting ecosystems and landscapes, threatening the means of existence for many species, populations and genetic diversity. Production and consumption of an expanding global human population are mounting the pressures on natural resources and the biosphere. The main factors impacting biodiversity are related to demographic, cultural and socio-economic developments (UNEP, 1992). The threats differ per region (Chapin, et al., 2001). Climate change is another major factor putting additional pressures on the already "weakened" natural system (Sala, et al., 2000; Gitay, et al., 2002). The question is how resilient our ecosystems are in order to sustainably deal with these combined, largely human induced pressures (Cumming et al., 2005).

The question of resilience has to be seen broader than from a conservation ecology perspective alone (Folke, et al., 2004; Hagerman, et al., 2010). Socio-cultural, ethical and economic factors play an important role in the sustainable conservation of biodiversity and of ecosystem services (TEEB, 2009). Conservation practices aiming to counter environmental degradation often seem to oppose economic development and as such often delicate, difficult and time consuming trade-offs are being made, resulting in slow progress on the urgent issue of halting biodiversity loss (Costanza, 1997). In the previous chapter (CHAPTER 5) the many various approaches to conservation have been mapped and their varying underlying worldviews have been made more explicit. The complex global developments seem to ask for innovative and integrated approaches for conservation in order to stimulate the creation of more sustainable pathways into the uncertain future (Martens, 2003). In order to gain insightful discussions on what such approaches may entail, an increased level of awareness of the worldviews, assumptions and ethical perspectives underlying biodiversity conservation and management strategies is required. 


\section{Uncertainties}

Three important current uncertainties for biodiversity and ecosystems can be identified:

1. How resilient are ecosystems by nature?

2. How resilient are ecosystems under human pressure?

3. Can ecosystem goods and services be substituted by alternatives? (Folke, et al., 2004; Cumming, et al., 2005).

These uncertainties together lead to the following central question: How much (anthropogenic) change can ecosystems cope with before important services are lost (Carpenter, 2002)?

\section{Assumptions}

Perspectives on nature play a crucial role for answering this question. When ecosystems are considered to be vulnerable (the Egalitarian and Autonomous basic assumption about nature), thresholds are easily crossed and the ethical principle of precaution (COMEST, 2005) is often regarded to be the most promising management style. This also accounts for the assumption that ecosystems are complex structures characterized by non-linear dynamics (Folke, et al., 2004). Although trial and error is the only way to learn about what really works, these learning processes better be fast (the Dynamic Integrator basic assumption about nature). When ecosystems are considered to be relatively resilient, it is assumed that human behaviour will have less impact and that many anthropogenic environmental problems will be reversible and manageable. The ethical approach of this view is based on "keeping the natural order by law", but there is more time to learn from mistakes (reflecting the Hierarchist basic assumption about nature). Nature can be regarded as irrelevant under the assumption that the goods and services ecosystems provide can be substituted by technology. According to this view, humans are inventive enough to be able to synthesize or augment the ecosystem services relevant for our survival and well-being (Cumming, et al., 2005; Goklany, 2009). This is a rather utilitarian view, reflecting the Individualist basic assumption about nature.

\section{Aim of this Chapter}

In this chapter an assumed need is reflected upon (Christoffersen, 1997; IUCN, 2004; Spangenberg, 2006; IUCN, 2007a, 2008b, 2008c, 2009e, 2010c; Rands, et al., 2010; IUCN, 2011e, 2011b, 2011d; Mackey \& Liang, 2012): the need for a more integrated discussion on the uncertainties of biodiversity. This reflection is done by analysing the perspectives and discourses apparent in two Global Assessments (GA) of which the scenario studies are the subject for analysis: the Intergovernmental Panel on Climate Change Special Report on Emissions Scenarios (IPCC SRES) (IPCC, 2000) and the Millennium Ecosystem Assessment (MA) (MEA, 2005). The IPCC and the MA scenarios were 
chosen for analysis because: 1 . they display a global socio-environmental context of biodiversity loss; and 2. their analysis accumulates insights for the development of more specific biodiversity scenarios. Global Scenarios for Biodiversity Conservation will play an important role in the Intergovernmental Science Policy Platform on Biodiversity and Ecosystem Services (IPBES) (UNEP, 2010). They are also given an important role in the Global Biodiversity Outlook 4 and in achieving the Aichi Targets of the Convention of Biological Diversity (CBD) (CBD, 2011).

The analyses of the IPCC and the MA scenarios reveal some cultural perspectives apparent in their storylines. The aim of this exercise is to make the worldviews and ethical principles underlying their narratives more explicit in order to stimulate integrated discussions and to ease the task of building bridges between science, policy and society (Valkering, et al., 2008; Offermans, et al., 2009; Valkering, 2009) in order to support biodiversity conservation. The Perspectives Method as proposed in CHAPTER 5 has been used as a framework for analysis. The aim of analysing the two scenario studies is to open a door for discussion on the value of the CT perspectives framework for stimulating an integrated discussion in the field of biodiversity conservation.

\section{Methods}

The IPCC and MA scenarios form two significant assessments which implicitly discuss changes in global biological diversity. We chose to focus on the qualitative, written text of the scenarios for our analysis. For a proper analysis of the IPCC studies we also used information on climate change in the quantitative IPCC scenarios, in order to make up for some lacking information about environmental change in the qualitative IPCC scenario narratives. The chosen scenarios do not explicitly mention biodiversity and ecosystems in a conservation context. However, they do discuss them in the broader context of sustainable development.

The scenarios are built according to variable drivers of change. Significant drivers of environmental change mentioned in various scenario studies are globalization, climate change, human population growth, socio-cultural and political stability, decentralization of authority, economic development, energy use, infrastructure, technological innovation and urbanization. Direct pressures generally mentioned in relation to changes in biodiversity are fragmentation, land use change, resource use and pollution (Heywood, 1995; Sala, et al., 2000; Chapin, et al., 2001; MEA, 2005; Spangenberg, 2006). Nearly all of the drivers and pressures are human induced. The IPCC and the MA scenario studies integrate the social, ecological and economic domains in their storylines. In addition to the scenario narratives, we selected one document (or chapter) from each GA that explicitly discusses biodiversity and ecosystem services. We did this in order to be able to compare the outcome of the scenario narrative perspective(s) with the perspective of the scenario study group. We called this additional GA document the "key source". 
The results of the analysis of this key source are useful because they give an indication of the actual (real) worldview(s) of the sustainability discourse. The key source results were utilized to mirror the results of the scenario analyses. The Cultural Perspectives Axis (CPA) (see figure 5.1* CHAPTER 5) was used as a framework for an in depth deductive qualitative content analysis combined with discourse analysis (DISCO analysis) of both types of narratives (GAO, 1989; Hsieh \& Shannon, 2005; Elo \& Kyngas, 2008) (see box 6.1 and CHAPTER 3).

\section{Box 6.1. The applied DISCO analysis method}

For the DISCO analysis of the GSS the same coloured labels were used for each perspective as in CHAPTER 5: blue was applied to Hierarchist content and discourse; green for the Egalitarian; yellow for the Individualist; purple for the Fatalist, red for the Autonomous; and orange for the Dynamic Integrator. The labels were used to code units of the texts of the scenario narratives and the selected key documents. The paragraphs of the texts were numbered and in a process of close reading words and phrases were coded and assigned weights related to the frequency of their occurrence and to their intensity. The frequency was counted by giving points to the title, the subtitle and to single words. When these elements represented a certain perspective, they were given a weight of 1 point. The occurrence of a few terms together, connecting a line of words representing one of the perspectives, were given 2 points. A full paragraph coloured in a certain perspective was given 5 points. Sometimes words or phrases reflect more perspectives at the same time. In such cases we double or even triple-coded the fragments with the corresponding perspective colours. In such cases an orange line was added in the margin to refer to the Dynamic Integrator (see Box $6.2 *$ ). Weighing the intensity of meaning was also accomplished by coding the text margin with a perspective colour when the intensity occurred to be strong. Intensity coding requires the analyst to recognize more subtle connotations of the text (GAO, 1989; Holstein \& Gubrium, 2004). This process of content analysis remains largely subjective (Holstein \& Gubrium, 2004).

In preparation of the scenario analyses, a literature study has been carried out to explore the cultural perspectives on biodiversity and conservation. The studied literature contained texts ranging from conservation practice, ecological theory, evolution theory, sustainable development and philosophy. Also included have been newspaper starting in 2007. The goal was to compile a general working list of key words and phrases of the CT worldviews in relation to assumptions about biodiversity and conservation strategies (see CHAPTER 5).

The reliability of the assessment was improved by cross checking the results with two research assistants who carried out the same coding process for the same documents. The gained weights were assembled and calculated in a prepared excel sheet and the numerical results were transformed into a graphic table (see tables 6.1-6.4*). This coding process resulted in the visual percentages of perspectives per scenario narrative and of the key documents. 


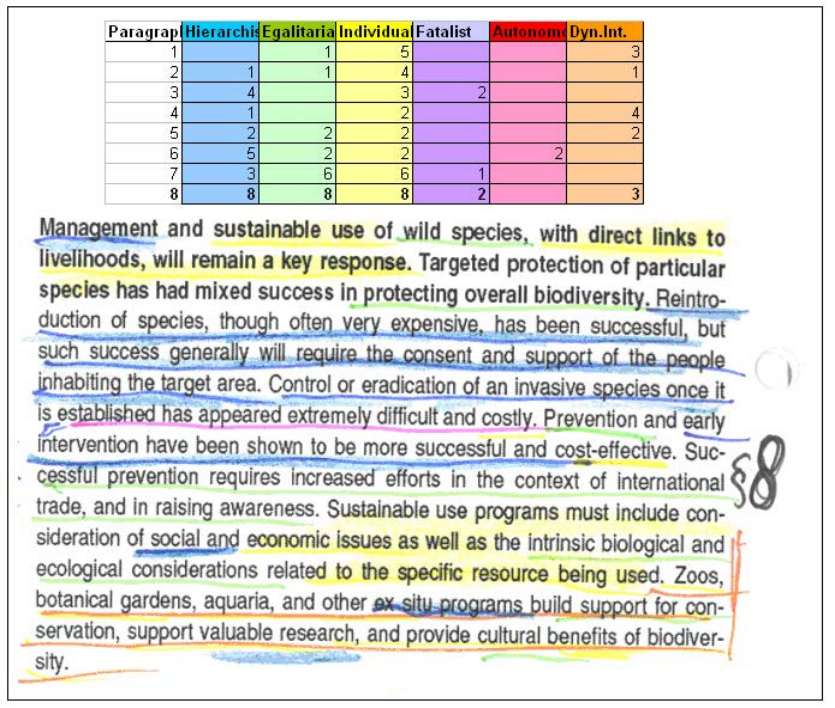

The global scenarios can be seen as a tool for policymakers and conservationists to stimulate discussion on the development of transition pathways to stop biodiversity loss in a changing world. The storylines can "help to think through uncertainties about the future and make decisions that are robust to a variety of possible outcomes" (Cumming, et al., 2005, pp., p.143). Many conservationist and policymaking eyes are turned towards these global scenario studies in order to plan for sustainable development and biodiversity conservation. In the analysed scenario narratives, underlying assumptions and worldviews are rather implicit. This makes it difficult to grasp the social and cultural side of the choices, management styles and policy-practices that may influence our future pathways. This lack of explicitness might also affect the consistency of the scenarios and as such affect the robustness of the practical strategies developed with the scenarios in mind (Van Asselt et al., 2005).

The aim of this qualitative assessment was to reveal the assumptions underlying the scenario studies and the scenario storylines. Making these assumptions more explicit will help policymakers and conservationists to discuss the development of flexible and robust solutions for future biodiversity and ecosystem management, based on the trends and the needs of our complex and changing socio-ecological system.

\section{Scenarios}

"A scenario is a story, told in words and numbers, concerning the manner in which future events could unfold and offering lessons on how to direct the flow of events to- 
wards desirable pathways and away from undesirable ones" (Gallopin, et al., 1997, pp., p.vi). Scenarios are used in the field of conservation and policymaking as a "framework for developing more resilient conservation policies when faced with uncontrollable, irreducible uncertainty" (Peterson, et al., 2003, pp., p.358). The question about which pathways are desirable and which ones are not, are coloured by the cultural perspectives and ethical standpoints we inhabit and the way we are able to bring the variety of perspectives together to workable solutions for our urgent problems.

Instead of predicting the future, scenario studies help to outline the uncertainties of a complex and dynamic world (Gallopin, et al., 1997; Notten, 2005; Van Asselt, et al., 2005). In the last few years a number of other global scenario studies have been carried out in order to scientifically depict the environmental uncertainties of our changing global system. The Global Biodiversity Outlook 3 (CBD, 2010) and The Global Environmental Outlook 3 and 4 (UNEP, 2002 2007) include prospects for future biodiversity-although their scope is usually broader and not specifically targeted on biodiversity. The Global Biodiversity Outlook 4, which will be released in October 2014, will contain scenarios for the future of biodiversity.

The scenarios developed by Sala's group (Sala, et al., 2000) focus on biodiversity merely from an ecological point of view. What the majority of global scenarios have in common is the aim to bridge the gap between scientific knowledge and policymaking. In our post-modern age, scientific knowledge and practice are undergoing a change of character. Instead of telling 'The Truth', scientists increasingly acknowledge their task to show the uncertainties of a dynamic and complex world (Best \& Kellner, 1997) while at the same time recognizing that the stakes are high and the issues they are dealing with are urgent (Funtowicz \& Ravetz, 1993; Funtowicz, et al., 1998). When decisions on such issues have to be made they should be at the same time flexible and robust (Valkering, et al., 2008). They have to take into account a wide range of possibilities (Cumming, et al., 2005) and a long term perspective. Additionally, a strong social basis has to be created carrying the decisions; containing a plurality of stakeholder perspectives on the problem; and possible solutions. This involves complicated ethical discussions as well, about the values of nature (UNEP, 2002 2007); about what choices are to be made; and about what these choices mean in the short and long term.

\section{Results}

\section{The IPCC Key-Document}

The analysis of the IPCC scenario storylines are complemented to the text of the IPCC Technical Paper on Climate Change and Biodiversity (Gitay, et al., 2002) (the keydocument for the IPCC analysis). The analysis of this technical paper discloses a narrative with a generally Hierarchist perspective (43\%, see table $\left.6.1^{*}\right)$. Especially the first part of 
the document, describing the possible changes and the relations between climate and biodiversity, is largely Hierarchist. The underlying assumption is that change is something which has to be controlled. The focus in the document is on expert knowledge, scientific research data and the modelling of data in order to be able to develop policies to mitigate and adapt to the potential impacts of climate change on biodiversity and the impacts of changing biodiversity on the climate system.

\section{Table 6.1. Perspectives in the IPCC Technical \\ Paper on Climate Change and Biodiversity}

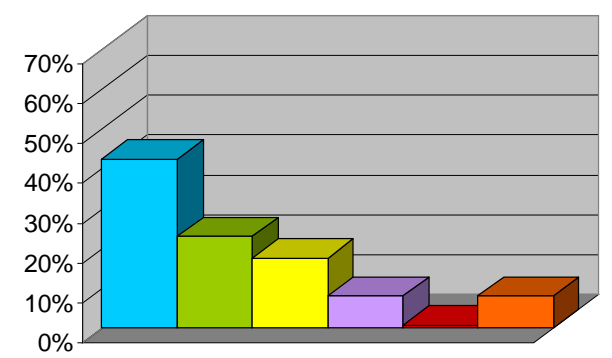

Legend

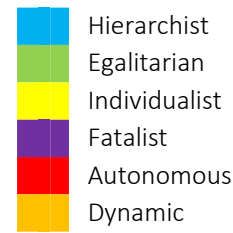

With $23 \%$ of the Egalitarian perspective apparent in the scenario, it can be said that the authors assume the ecosystem to be relatively vulnerable. The "precautionary approach" is regarded as a valuable choice available for the "enhancement and preservation of natural protection" (Gitay, et al., 2002, pp., p.43). When human society is discussed, most attention is paid to participation of local communities in developing countries and to their dependence on wildlife and the ecosystem services biodiversity provides. This feeds to the assumption that management strategies of developing policies and regulations to control changes that may affect human livelihood, are seen as the best "precaution". Nevertheless it is often implicit that many changes cannot be stopped or controlled, which accounts for a reflection of the Fatalist (8\%). Lack of knowledge and data is seen as the main reason for failing environmental protection strategies (Hierarchist). Knowledge is largely lacking due to the complexities of the natural system (Dynamic Integrator: 8\%). Controlling policies go along with opportunities in technological development, especially in alternative energy uses and more efficient agriculture (Individualist: $18 \%$ ).

Biodiversity is mainly regarded valuable with regards to the ecosystem services it provides for human well-being, subsistence and (economic) development (Individualist). 
In some occasions the loss of ecosystem services and biodiversity functions such as pest control can be compensated with other species or with artificial innovations (Individualist), but this is regarded as expensive at the same time and possibly causing new problems such as pollution or new pests; a Fatalist standpoint. The Autonomous perspective, indicating that individuals should retreat from activities that could disturb biodiversity or ecosystem services, is hardly represented in the document (1\%). The Dynamic Integrator, although not very often explicit, has a strong say with relation to conservation: "Conservation of the broadest possible range of ecosystems requires that natural ecosystem dynamics continue" (Gitay, et al., 2002, pp., p.43).

\section{The IPCC Scenario Narratives}

The IPCC scenario narratives all display a strong representation of the Individualist perspective (see table $6.2^{*}$ ). This is interesting especially because the technical paper presents only a modestly Individualist worldview. The Egalitarians score higher there. This seems to imply that the working group foresees a change to a more Individualist world in any of the scenario storylines (IPCC, 2000).

\section{Utility Treasure: the A1 Scenario}

The A1 scenario in our view could be renamed the "Utility Treasure". It projects a change in global temperature between $2.4^{\circ} \mathrm{C}$ and $4{ }^{\circ} \mathrm{C}$ between 2090 and 2099 relative to the period of 1980-1999 and a sea level rise of $0.20 \mathrm{~m}$ to $0.59 \mathrm{~m}$ in the same time periods (IPCC, 2000). The A1 scenario offers an unfavourable perspective for the pressure on biodiversity. When we consider the main driving forces of biodiversity change, we see that the population will rise to more than eight billion people in 2050, after which it slowly declines to seven billion. Economic growth is the strongest of all scenarios, which will lead to a significant increase in the consumption of natural resources and energy. Technological improvements, in combination with the high levels of income, result in a considerable improvement in communication and transportation facilities. These developments will put significant pressure on both the quantity and quality of biodiversity. Although the A1 scenario projects almost no changes in total land use, it is very likely that many pristine natural areas with a large degree of biodiversity will be converted into man-made areas. Probably, new natural areas will be created but these will have significantly less biodiversity, as they require time to restore.

The narrative of A1 is strongly Individualist (67\%). Economic growth is seen as the main driver of development and technological innovation making resources more accessible. Some communities, though, could be excluded and income growth could go hand in hand with an increased pressure on the global commons (Egalitarian, 10\%). The Hierarchist perspective (16\%) in this storyline is represented by the emphasis on a change from "conservation of nature" to "active management of natural and environmental services". 
The focus on ecosystem services shows the potential of natural resources for human and economic development, which is again rather Individualistic. It is believed that ecological resilience can be increased through taking a proactive approach which is made possible through economic growth combined with active management of the global resources. Nature is regarded a "utility treasure" and in such a world conservation strategies are implemented through technological innovation for more efficient, cleaner and sustainable resource use.

In this predominantly Individualistic world another fitting approach to biodiversity conservation would be putting monetary values on ecosystem services (TEEB, 2009; Büscher, 2010). Combining biodiversity conservation with economic benefit by "internalizing the externalities"(TEEB, 2009) would enable an Individualistically minded global culture to preserve, and perhaps even enhance, ecological resilience. A risk of this approach is that the ethical side, the existence values or intrinsic values of wild biodiversity (DesJardins, 2006) and ecosystems are overlooked, which could lead to a simplification of nature and a loss of natural resilience. This risk is also identified in the TechnoGarden scenario of the Millennium Ecosystem Assessment.

\section{Table 6.2. The IPCC SRES scenarios}

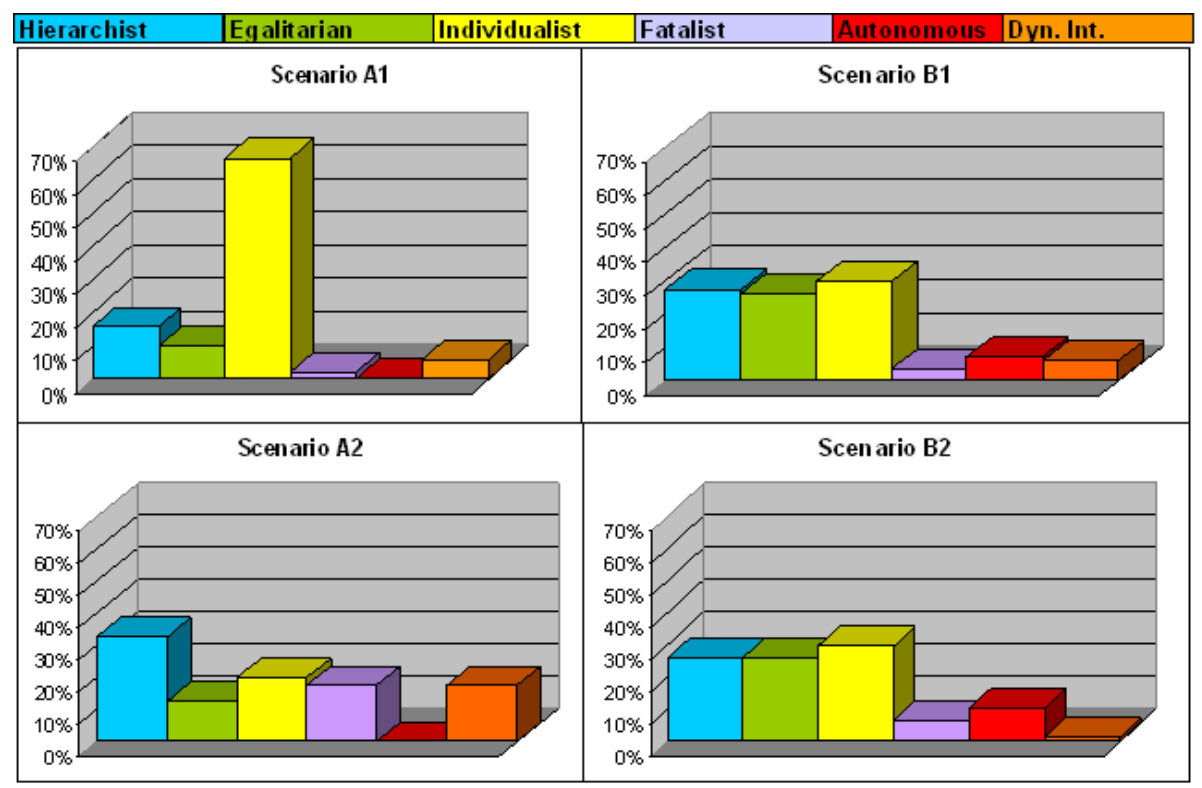

\section{Efficient Combinations: the B1 Scenario}

We would propose to rename B1 "Efficient Combinations". B1 and B2 present rather similar graphics, with strong and almost equal Hierarchist, Egalitarian and Individualist assumptions. With $1.8 \mathrm{C}$ projected temperature-rises and $0.18-0.38 \mathrm{~m}$ sea level rises; 
the B1 scenario narrative shows least changes in climate and sea level. B1 offers a more favourable perspective for biodiversity. A sharp reduction in arable farming and cattle breeding acreage is expected, coupled to a strong increase in productivity. After a slight reduction in tropical rain forests world-wide, there is an increase in the second half of this century. Natural ecosystems are less affected, both in quantity and quality. The estimated temperature increase is not particularly high, resulting in less pressure on biodiversity than in the other scenarios, and the pressure from population growth is considerably lower. Furthermore, a lot is done to improve ecological capital. The speed with which such a transition to a balanced development takes place determines the reduction of threatening factors and prospects for biodiversity.

The Egalitarian perspective (26\%) is found in the high level of environmental and social consciousness of B1. This is brought about by clear evidence and by education of the impacts of natural resource use on the ecosystem and on human life on Earth (Hierarchist: $27 \%$ ). Resource friendly lifestyles, founded on Autonomous and Egalitarian worldviews, are based on clean technologies, accounting for a strong Individualist percentage of $30 \%$. Parallel to that, strengthened institutional cooperation shows a Hierarchist favour for regulation, whereas a reduced level of (meat) consumption and a trend of dematerialization demonstrate the share of the Autonomous perspective (7\%) in the B1 society. Combinations of investments are made to achieve a more sustainable world: improved efficiency of resource use, research and development, incentive systems, increasing equity, developing social institutions and environmental protection measures (Dynamic Integrator: 6\%). B1 combines technical and global organizational change with individual footprint reduction. Conservation efforts are grounded in strategies of lowimpact agriculture-a Hierarchist-Autonomous combination-along with the maintenance of large wilderness areas (Egalitarian-Autonomous) and tightly controlled (sub) urban development (Hierarchist).

Climate change and sea level rise will have the least impact on biodiversity in this scenario. It seems to be a promising scenario for sustainable development; interestingly representing people (Hierarchist), planet (Egalitarian-Autonomous) and profit (Individualist) percentually on an almost equally balanced level. For conservationist this would imply a necessity to work trans-disciplinarily and to increase awareness of the potentials of a pluralistic but integrated global approach to conservation.

\section{Local Techno-management: the B2 Scenario}

B2 could be called "Local Techno-Management". This scenario narrative $\left(2.4{ }^{\circ} \mathrm{C}\right.$ temperature rise and 0.20 to $0.43 \mathrm{~m}$ sea level rise) differs from B1 because of the decline of international institutions and global strategies to address environmental problems. $A$ world unfolds in which the approach to social, economic and ecological problems is primarily a local one. In such a future world, the pressure on natural system is greatly reduced, due to high average educational levels and the high degree of organization 
within communities. As a result, energy and material-efficient techniques can be developed. The regional differences are also very large, so that a global trend in biodiversity is difficult to estimate.

There is a strong focus on "group" via regional, local and community based governance (Egalitarian 26\%) in addition to technical solutions (Individualist 30\%). High educational levels are pursued and regional environmental policy and land use management lead to success in the management of some transboundary environmental problems (Hierarchist 26\%). The scenario narrative shows a rather Individualist discourse when discussing the decline of international cooperation and of uneven investments in technology development for energy, also resulting in some Fatalist discourse (6\%). The Autonomous perspective is, with $10 \%$, the highest in this scenario compared to the other scenarios, pointing to low levels of car dependency, low (meat) consumption, reduced environmental pressures due to a transition away from the use of fossil fuels in a predominantly hydrocarbon based global energy system. The Dynamic Integrator is relatively absent in the B2 narrative. Conservation according to this storyline may work when policies are decentralized and technological innovations on community level join forces with individual responsibility and footprint reduction.

It could be said that through the strong emphasis on local and regional social and technological regulations, protection of nature and the environment receives a high priority. As a result, the availability of natural acreage could increase and the loss of species could be brought to a standstill. Nevertheless, sea level rise and climate change will impact biodiversity more in this scenario. This might indicate that in order to stimulate sustainable development and protection of ecosystems and biodiversity, global institutional approaches and regulations, complementary to local communitarian solutions, may be desirable additions to a B2 world.

\section{Fundamental Differences: the A2 Scenario}

The A2 storyline, which could be renamed "Fundamental Differences", represents a differentiated world. It has the most diversified perspective and has the highest projected rise in temperature $\left(3.4^{\circ} \mathrm{C}\right)$ and the highest sea level rise $(0.23$ to $0.51 \mathrm{~m})$. An important characteristic of the A2 scenario is a continually growing human population that is expected to reach a total of almost 15 billion in 2100. This will significantly increase demand for cultivated land (agricultural and municipal areas) and related transportation infrastructures. Although economic growth is limited, the total consumption of natural resources will be considerable. The main focus will be on regional and local culture in an extremely heterogeneous world. Initiatives to preserve global natural resources are more difficult to implement regionally.

The prospects this scenario presents for biodiversity are not very encouraging: sharply increasing demand for food, water, energy and land will result in a significant loss of natural ecosystems and species. Therefore, the quantity of biodiversity will be 
substantially reduced. The same can be estimated for the resilience of ecosystems. The relatively low level of economic growth may result in slower improvements in production methods and thus greater pressures on the quality of biodiversity (e.g., through pollution and locally high uses of pesticides).

The A2 narrative shows a rather Hierarchist (33\%) controlling society but it is described in a rather Individualist discourse. Economic, social, institutional and technological developments are kept under regional control. Mobility has decreased which also reduces the spread of innovation and ideas. Environmental problems are regionally and locally dealt with (Egalitarian 13\%). The Dynamic Integrator scores highest in this scenario (18\%) compared to the other three. Diversified problem solutions and the increasing acceptance of cultural diversity and fundamental differences between people contribute to this percentage. Nevertheless, this seems contradictory in a world tending to protect local and even national interests, which is better reflected in the Fatalist percentage of $18 \%$. Economic growth is hampered by protectionist trade blocks. Not much is said about environmental values, policies or protection, which accounts for the relatively low Egalitarian and Autonomous percentages. Environmental concerns are related to agriculture and food production on local and regional scales.

Biodiversity will be under pressure in this scenario. The plurality of local approaches with a lack of real (global) integration and coherence and a lack of environmental concern does not seem to lead the world to a path onto sustainable development. This outcome is comparable to the world described in the Order from Strength narrative of the Millennium Assessment.

\section{The Millennium Ecosystem Assessment Key-document}

For the analysis of the Millennium Ecosystem Assessment (MA) storyline perspectives, we used the four scenarios from CHAPTER 8 of Ecosystems and Human Well-being: Scenario: Findings of the Scenarios Working Group (Carpenter, et al., 2005). We selected CHAPTER 5 of the Assessment of Policy Responses (McNeely, et al., 2005) as the key document to identify the overall MA perspectives on biodiversity and conservation. The assessment of policy responses shows a predominantly Hierarchist perspective (34\%) (see table 6.3*). Much emphasis is put on the need of scientific research and the necessity of increased knowledge of complex biodiversity relations in order to design effective policy responses. In this document, the Hierarchist is accompanied by the Individualist (27\%) and by the Egalitarian (23\%). The other three perspectives are relatively unvoiced. Although emphasis is put on combining strategies for sustainable conservation, the Dynamic Integrator scores relatively low because it only becomes explicit in the later pages of the document. 
The basis assumption of McNeely and his colleagues is that protecting vulnerable global biodiversity is essential (Egalitarian). The intrinsic value of biodiversity (Egalitarian) is mentioned ((McNeely, et al., 2005, p.122)), but, foremost, biodiversity is seen as crucial to sustain human well-being and subsistence (Hierarchist). It also provides for a wide range of goods and services for pharmacy and industry (Individualist). In spite of the Egalitarian basic assumption of the authors, their discourse is rather utilitarian. "User needs" and "option values" are mentioned implicitly and explicitly throughout the document. In the view of the authors the major opportunity to effectively protect biodiversity is to move away from protection, based on the assumption that human activities negatively impact biodiversity, species and landscapes. This implies a move away from the strong ethical perspective of the Autonomous. The "negative" supposition that we have to "retreat" from actions that impacts the biosphere, should be redirected towards a "positive" view on the current and future value biodiversity has for human subsistence, well-being, and for continuing economic growth. The "ecosystem services" delivered by species and landscapes to us and our businesses should become the central point of departure for conservation. In this way, the corporate sector will become engaged in conservation, which is seen as a necessary condition for conservation to become successful. At the same time the so called conservation community will "accept that business has a role to play in the debate" (McNeely, et al., 2005, pp., p.147).

Table 6.3. Ecosystems and Human Well-being: Findings of the Scenarios Working Group (McNeely, et al., 2005)

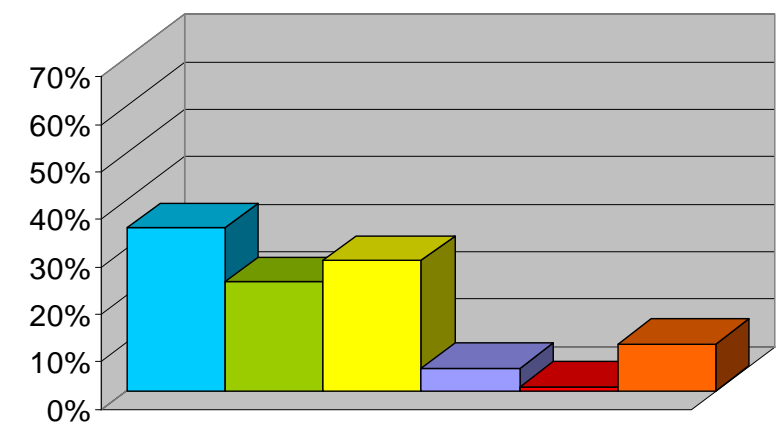

Legend

Hierarchist

Egalitarian

Individualist

Fatalist

Autonomous

Dynamic 
Nature is implicitly seen as a resource. This utilitarian point of view is not debated in the document. It is seen as the key to effective conservation, if combined with the Egalitarian assumption that nature is vulnerable. Starting with Costanza's well-known article in Nature (Costanza, 1997) this approach is increasingly popular in business, for example in the Cradle to Cradle movement (McDonough \& Braungart, 2002) and in academic debates (Nunes \& van den Bergh, 2001; Norton \& Noonan, 2007; TEEB, 2009; Büscher, 2010). Nevertheless, the "technology" side of the Individualist coin is rarely mentioned by the authors. This is in contrast to the scenario storylines; in some of them technological developments are outspokenly present. Because of the vulnerability of nature, the engagement of business in conservation should be backed up, complemented and stimulated through policies concerning biodiversity and ecosystem services on all levels. To help improve and implement such policies research priorities should be directed towards a better quantification of biodiversity values (McNeely, et al., 2005, pp., p.163). This again contributes to the Hierarchist percentage.

Other main conservation responses are discussed in the document as well: much attention is given to protected areas and to "native" species within such areas. This type of widespread in situ conservation regards "nature" as specific wild or semi-wild places where typical endemic, often iconic, species ought to reside. In the context of climate change linking up protected areas in networks (Rodrigues, et al., 2004; Hagerman, et al., 2010). This is becoming a well-established approach for conservation as is shown for example in the expanding Natura 2000 Network of the European Union (Bishop et al., 1995; Jongman, 1995). Nevertheless, such networks are hardly discussed by McNeely and his colleagues. Protected area management of specific habitat sites combines Egalitarian precautionary principles with Hierarchist policy and control strategies. Complementarily to protected areas, the authors discuss the relevance of integrating biodiversity conservation into regional planning and into the agriculture, forestry and fishery sectors. This is called "mainstreaming", which refers to the Hierarchist connotation of the strategy of developing defined "regimes". Mainstreaming is also linked to considerations regarding the empowerment of local communities. These should become better enabled to maintain their basis for subsistence, customs and traditional cultivation techniques. This reflects Egalitarian "group" ethics. Notably, "local communities" often refer to smaller social structures in developing countries and not so much to societies of industrialized nations or regions. Good governance is also mentioned in this context, combining Egalitarian and Hierarchist principles.

Another strategy discussed by the authors is the improvement of international cooperation through multilateral environmental agreements. These strategies need better monitoring and controlling mechanisms in order to enhance compliance, showing the high grid inclinations of the Hierarchist. Education and awareness raising principles are discussed in the context of non-formal (Egalitarian) educational programs provided by "museums, zoos aquaria, botanical gardens, field study centres, protected areas educational and interpretative programs, and ecotourism" (McNeely, et al., 2005, pp., p.160). 
Although "communication, education, and public awareness provide the link from science and ecology to people's social and economic reality" (McNeely, et al., 2005), the Egalitarian minded work of large NGOs such as WWF, IUCN or Greenpeace, or of art and broadcasting is not explicitly mentioned in this context, whereas NGOs find a place in some of the scenario narratives.

\section{The Millennium Ecosystem Assessment Scenarios}

The assumption that we live in a predominantly Individualist world is also reflected in the four MA scenario storylines (see table $6.4^{*}$ ). In all of them the Individualist perspective scores highest, with the exception of the "Adapting Mosaic" scenario. There the Egalitarian and the Individualist score the same (both 28\%). The MA scenario storylines are remarkable for their detail, the plurality of drivers of global change used as variables (important ones are population growth, economic and technological development, habitat change, various ecological uncertainties, the level of global integration and of environmental awareness) and for their evolution through time. Especially the latter feature protects them from pinpointing them down to one-dimensional worldviews, which again, makes the CT framework a useful instrument for analysis, because it allows for flexible perspective combinations.

Table 6.4. The Millennium Ecosystem Assessment scenarios

Hierarchist 1 Egalitarian




\section{Global Orchestration}

Global Orchestration (GO) narrates about a world of 'reactive individualism'. It shows an overall Individualist world (48\%), striving for economic and technological growth. Remarkably, it more or less resembles the A1 scenario of the IPCC. The distribution of perspective percentages and the perspective content are alike in both storylines. The main difference between the two scenarios is that in GO the notion of ecosystem services is not taken up as an approach to ecological dilemmas (Alcamo et al., 2005, pp., p.231).

In GO cultural and economic globalization are increasing and economic growth allows for "smart policies and technological solutions" (Alcamo, et al., 2005, pp., p.231) to fix ecological and socio-cultural problems. An increased awareness of the risks of globalization stimulates the governance systems to become more transparent and participatory, which meets a combination of increased Egalitarian (19\%) and Hierarchist (23\%) sentiments on the functioning of power. The growing global connectedness and the appraisal of cultural variety are also slightly reflected in the Dynamic Integrator (6\%). Nevertheless, the increased transparency and possibility for participation in the democratic system appear to be largely window-dressing. The real power seems to be in the hands of large multinationals. People in the storyline are quite comfortable with that, because they benefit from the prosperity and they hardly see the environmental degradation, because problems are backed up by technological fixes (Individualist).

Nature in this scenario is regarded resilient within limits () but this is mainly related to the fact that people have a strong belief in technology and in economic growth as the answer to all inconvenience (Individualist). Nevertheless, responses in this scenario are rather reactive, directed towards controlling occurring problems. This can be seen as a Hierarchist tendency. Technology may fix, but lessons are learned slowly. Due to the successes of economic growth and technological development environmental issues, such as climate change or biodiversity loss, are "more or less ignored" (Alcamo, et al., 2005, pp., p.234).

Egalitarian or Autonomous assumptions on the intrinsic value of nature and biodiversity are hardly discussed or present in the global orchestration society. The loss of biodiversity becomes apparent in the decreased fertility of highly intensified and industrialized agricultural land, of the decline in food variety and genetic diversity due to the patents claimed by many large multinational companies and of a decline in natural controls on diseases and pests. Chemicals and fertilizers where used in combination with low levels of environmental protection. The environmental pitfalls of the Individualistic world become apparent when the storyline unfolds towards 2050. They are approached with Hierarchist strategies based on controlling the course of events in order to maintain human well-being which would be at stake by that time. In this Individualist world, many ecosystems collapse. Concern about the loss of ecological knowledge () is growing only slowly due to human inventiveness. But the costs of restoring previous ecosystem services and functions have become high. Moderately, human activities become greener, but still, solutions are sought in technology and control. Changing consumption patterns, 
behaviour, or mind (Autonomous values) and Egalitarian counter movements are not much discussed in the storyline.

It becomes more apparent that many cost-effective (pro-active) opportunities for conservation of ecosystems were lost in this Individualist coloured world. Ecosystems, for example, seem to be rather disregarded in the course of time of this storyline. The role of ecosystems dynamics and interdependencies only becomes evident after ecosystems collapsed. Conservation in this scenario focuses on species and genetic diversity. Conservation of this species/genes-related diversity is based on "preserving representative examples in parks and museums" (Alcamo, et al., 2005, pp., p.235). This can be seen as a combination of Hierarchist control with a touch of Individualist optimism about the future, where ecosystems seem to be largely irrelevant. The establishment of genebanks containing wild varieties of crops and seeds shows the predominantly Individualist management style with the aim to control availability of genetic material for the future.

\section{Order from Strength}

Order from Strength (OfS) shows a highly compartmentalized world moving into a downward spiral of increasing fatalism (26\%). The picture of this scenario is quite similar to A2 of the IPCC. The major difference is that in OfS a "clash of civilizations" (Huntington, 1992; Nederveen-Pieterse, 2004) seems to take place, whereas in A2 a respect for different cultures prevails, which accounts for a higher percentage of the Dynamic Integrator, whose perspective is virtually absent in OfS. The OfS storyline is characterized by an inward focus of national states as a response to experienced threats and instabilities caused by globalization processes. The implementation of strong national security policies and the control of state borders become the paradigmatic response to feelings of insecurity and the economic crises occurring everywhere in the world, which shows a Fatalist- Hierarchist spiral: the Fatalist feeling that such problems can't be countered, results in an increased demand of strongly Hierarchist control policies, which again fuels the Fatalist perspective of a world running down and out of control.

The Individualist pillar of this storyline results from the belief in technological fixes, but just as in the GO scenario, approaches to deal with environmental problems are reactive (Hierarchist). Because global environmental problems, such as climate change, air pollution and biodiversity loss are also, often unsuccessfully, dealt with locally, a global decline in ecological quality takes place. The Fatalist feeling that nature is capricious and cannot be controlled or protected seems to be the basic assumption of this narrative. Local environmental policies do exist but are only secondary on the agenda, because of urgent social and economic threats. National security prevails, often at the cost of environmental security. In developing countries agriculture expands vastly. Forest products are increasingly harvested in order to stimulate earnings and to maintain income. These developments result in an increased loss of species and ecosystems are pushed beyond their capacity to produce. The only light point in the downward spiral is 
that climate change is moderate because people all around the world were forced to live simpler lives. People with an Autonomous perspective hardly exist in this Fatalist world, just as there is least space for Egalitarians in this scenario because altruism, solidarity and ethical behavior are seen as inconsistent with the paradigm of individual interests and survival of the fittest.

Conservation approaches are fragmented and directed towards securing natural resources for local peoples. Often conflicts arise over the distribution of the resources. Nature is being valued for its services, but many services can be substituted or repaired by technology (Individualist). Recreational, cultural and existence values of biodiversity are considered a luxury for affluent nations. Some representative samples of ecological systems are maintained for as long as the reservists do not hamper economic development. The discourse of the scenario narrative is clearly pessimistic over the course of events that take place in OfS. For conservationists this unfolding world might be a worst case scenario, because there is hardly any proportional environmental awareness despite the occurring global devastation.

\section{Adapting Mosaic}

Adapting Mosaic shows a world of "Egalitarian opportunists". Comparing Adapting Mosaic (AM) to the IPCC scenarios, conceptually it shares the most with B2. Like B2, AM shows a world where new partnerships are made between civil society, NGOs and business, resulting in relatively high Egalitarian (28\%) and Individualist (28\%) percentages of perspective. There is a strong emphasis on learning about socio-ecological systems through adaptive management, which is based on balancing people, planet and prosperity on local and regional scales, a typical feature of the Dynamic Integrator (11\%), which in this scenario scores highest of the Millennium Assessment scenarios. Pro-active approaches to maintain the balance are encouraged by participatory and adaptive types of governance, which combines an Egalitarian sense of community with Hierarchist management approaches. The fundamental differences between AM and B2 are the percentages of Autonomous perspective (higher in B) and of the Dynamic Integrator (higher in $A M)$.

Nature in Adapting Mosaic is seen as vulnerable (Egalitarian), but there is also humility with regards to the unexpectedness of some of her processes. This does not result into fatalism and fear, but more into integrating the Egalitarian and Autonomous sense of respect. People are aware of the importance of biodiversity and ecosystems for the services and functions they provide for human well-being and economic development (Individualist), but nature is also valued intrinsically (Egalitarian/Autonomous) and as a part of local and cultural identity (Egalitarian). The AM storyline is one of so called "glocalisation" (Alcamo, et al., 2005, pp., p.251), integrating local and cultural values into the progressive dynamics of globalization (Dynamic Integrator). Learning about socioecological relations is facilitated by modern communication technology, which combines 
Egalitarian values with Individualist drive for progress. There are large investments in human capital and knowledge.

Conservation is based on adaptive management on local levels. The adaptive and locally varied approaches to conservation increase much of the resilience of ecosystems. Reformations in agriculture towards a larger share of organic food increase the quality of much of agricultural landscapes. NGOs in AM function as expert lobby groups. Their Egalitarian ideals become institutionalized and professionalized. Nevertheless, local measures of environmental management do not seem to help solving problems with the global commons. Therefore, deterritorialised (Scholte, 2002) expert networks are developed to better manage these commons. For some commons though, like ocean fisheries tragedies that have already occurred due to failed experiments and the learning process only having come too late. This is reflected in the relatively high Fatalist percentage (11\%). The AM world evolves into a mixture of successes and failures in different world regions.

Reflecting on the meta-discourse of the AM narrative, we see a Scenario Working Group which is rather optimistic about the chances for biodiversity and ecosystem services in this scenario, accounting for their high Egalitarian and Individualist perspectives. This is also reflected in the analysis of McNeely et al. (McNeely, et al., 2005). The Hierarchist share of their worldview is reflected in the overall assumption that environmental problems should also be tackled through strong international institutions and cooperation. This discourse is also discernible in the B2 scenario of the IPCC.

\section{TechnoGarden}

TechnoGarden (TG) is a world where a combination of technology and market oriented institutional reform aims to improve the reliability of ecosystem services. The discourse of the scenario is strongly Individualist (40\%), but in a much more pro-active manner than Global Orchestration. In contents TG is similar to the IPCC A1 scenario. The fundamental difference between these two scenarios is the strong emphasis on technocratic regulation and control. The underlying assumption of TG is the belief that the environment is basically vulnerable, but resilient if managed right. "Managing right" in this scenario refers to transforming the market towards a global trend of "natural capitalism" and designing policies to stimulate the agricultural sector to focus on ecosystem services instead of focusing on pure crop production all over the world (Hierarchist -Individualist).

Global economic integration is increasing in TG. Ecosystem services provide many opportunities for designing new property rights and trading systems. This results in the increase of multifunctional landscapes, better regulation of the global commons through treaties and strong international institutions, and economic profit at the same time. TG combines Egalitarian (18\%) ethics of natural protection with the more Individualist notion of the utility opportunities of nature. This results in strong pro-active market based environmental regulation, founded in merging Hierarchist (22\%) and the Individualist 
perspectives. At the same time, business, states and individuals are encouraged to adjust their practices and consumption patterns to lower impact levels (Autonomous, 4\%).

To improve ecosystem services, many investments and activities take place in the field of eco-engineering and biotechnology. Especially in rapidly urbanizing areas, spatial planning is centred on applying innovative eco-technologies and improving ecosystem services in cities in order to counter ecological and health problems in densely populated regions. Because of the sometimes occurring unintended consequences of such technologies, strict testing and regulating programs are implemented, accounting for the strong Hierarchist demand for controlling unexpected events in this storyline. In the field of conservation ecological Egalitarian minded restoration projects, which aim to re-wild landscapes and ecosystems, are competing with designer ecosystems.

Although the discourse of this scenario narrative is rather optimistic about TG, it questions, in an Egalitarian minded way, whether intensive technocratic management of ecosystem services is wise (Alcamo, et al., 2005, pp., p.264). The authors try to rebalance the Individualist optimism with a reminder of the need of Hierarchist regulation which should be aimed at the priority of protecting the natural resilience of the global environment. Because of the market driven emphasis on increasing the provisioning services of ecosystems in this scenario, ecosystems were simplified, biodiversity and wilderness declined. In a world like TG, ecosystems will become less resilient in nature, vulnerable to disruption and management failures, and, most of all, have become dependent on continuous human management. The lesson for conservationists from this technocratic scenario is: had there been more attention to monitoring the technology and its effects on natural ecological balance and feedbacks, much of biological diversity and natural resilience could have been spared. This is a fairly Hierarchist statement.

\section{Discussion}

It can be estimated that the worlds of the B1 scenario (Efficient Combinations), Adapting Mosaic and TechnoGarden, show the most promising prospects for conservation. This is also reflected in the meta-discourse of the narratives (Hyland, 1998; Ifantidou, 2005). As it comes to evaluating the sustainability conception of the two GSS, their discoursesboth in the key documents and in the scenario narratives-reveal a tendency towards weaker sustainability (Robinson, 2004). Although the basic assumptions of the scenario studies seem to be rather Egalitarian, founded on the fragility of natural resilience, they share a preference for a relatively Individualist management style, with a focus on the question of how to implement innovative, often techno-economic strategies through policies and governance. Solutions based on Individualistically tainted economic approaches (ecosystem services) have a high occurrence in the scenario storylines and the key documents of the two GSS. The culturally advancing movement of consumption reduction, creative individuals (Autonomous) was hardly touched upon. Perhaps this is 
related to the fact that this concerns a movement of independent Individualist actors rather than a policy discourse. In our view, this movement should not be neglected in narratives outlining possible future pathways of biodiversity protection. The Autonomous way represents a decrease in the use of natural resources and pressure on biodiversity and ecosystem services in a direct manner. In order to see the value of the Autonomous perspective for biodiversity conservation though, we have to step outside the black-box of conservation ecology (Spangenberg, 2006).

Additionally, we expected to find a higher percentage of the Dynamic Integrator perspective in the narratives we analysed, especially in the key documents which are developed in the trans-disciplinary context of integrated sustainability assessment. The relative low percentage of the Dynamic Integrator can be attributed to the dominating representations of the Individualist and Hierarchist worldviews. This observation, in combination with the other observation that the GSS represent "weaker sustainability", might lead to a discussion on how "sustainable" the GSS are in themselves. It could be questioned whether the scenarios are able to really inspire thinking outside the box or whether they largely compromise the status quo of existing regimes while outlining possible future pathways.

Another question related to the issue of the "sustainability" of the scenarios is whether certain combinations of perspective could exist in real life. Some scenarios seem to be inherently dystopias to each other, such as the Individualist and the Egalitarian perspective. As we found scenarios where both of these perspectives were strongly represented at the same time, it could be questioned whether such scenarios are realistic representations of "dynamic integration" or whether they are actually merely a cognitive dissonance. Inview the perspective combination of the Egalitarian and the Individualist could prove to be a valuable contribution to sustainable development and biodiversity conservation, whilst there is a clear balance between entrepreneurship and ethical consciousness. Therefore, we consider such a perspective combination as potentially sustainable as well. However, there is the risk of becoming blind-focused on the economic benefits of ecosystem services and of insufficiently valuing ecological integrity and the intrinsic and existence values of biodiversity and ecosystems. This might result in the decline of natural resilience and a dependency of ecosystems on human management. More research and discussion on the practical feasibility of combinations of inherently conflicting worldviews would be valuable in our view. The optimism surrounding the three "most sustainable" scenarios lies both in the way the world system unfolds, but also in the pro-activeness of approaches and in a relatively high level of environmental awareness.

If the world unfolds into one of the other less optimistic directions, conservation may become a greater challenge. Awareness raising activities might become priority number one in order to change people's basic assumptions about nature and their relation to it. Without having people, policymakers, businesses, civil society on the side of realizing the importance of global biological diversity, any considerable effort to con- 
serve species, ecosystems or landscapes will be a calling in the desert. Changing peoples' minds and hearts (Corcoran, 2005) takes time if we do not want to impinge on values of freedom of thought and lifestyle (Sen, 1999).

Another observation made in the analysis, is that MA scenarios come closest to showing interlinkages and interdependencies of the various cultural perspectives by describing changes in approaches, strategies and lifestyles due to the course of events in a time frame towards 2050. Nevertheless, the awareness of such interlinkages remains rather implicit in the storylines. This vagueness around the influence of the change of patterns of basic assumptions in combination with the detail of description of events, results in storylines which are unlikely to unfold. The risk of such scenario storylines is that they are considered too complex to be guiding principles. Making the basic assumptions more explicit could counter the impression of vagueness of these narratives.

The IPCC scenarios are much more static and more homogenous than the MA scenarios. This makes them easier to understand on the one hand, but on the other hand they demonstrate less explicit awareness of developments through time, the complexities of socio-environmental dynamics, and their background in the ever shifting various cultural basic assumptions. Especially in the complex, dynamic and heterogeneous field of biodiversity conservation, static narratives could become counterproductive.

If scenario narratives are to function as a tool for policymakers and conservationists to help define and develop sustainable future conservation pathways, discussion needs to be stimulated on the question as to what makes a scenario storyline useful for decision-makers? What is the right balance between static simplicity and dynamic complexity of the storyline? To what level can uncertainties and unforeseen events be pronounced without making the storylines unlikely? What is the right balance of explicitly presenting various basic assumptions, worldviews and ethical perspectives directing the course of events without assuming a completely "makeable" world? In other words: how can scenario-narratives be best designed in order to be effective tools for fruitful discussion in the context of conservation policy and planning? These questions become especially relevant in the process of designing specific global biodiversity scenarios in a pluralistic world.

In a pluralistic and globalizing world, it becomes increasingly important to be aware of the variety of worldviews and management styles that complement and compete with each other to achieve the "good cause". In our view a consistent part of the reason why the 2010 Biodiversity Target of the CBD (UNEP, 1992) has not been reached, is the lack of awareness of the various cultural perspectives among well-intentioned policymakers and conservationists. In principle, an ethical debate seems to be going on, without much explicit awareness of the basis of the ethical claims and arguments that are used by the different stakeholders. Global success for sustaining future biodiversity and ecosystems highly depends on successful communication, trust and understanding of conflicting and converging worldviews (Posey, 1999). Not only between stakeholders with divergent 
stakes and perspectives on various scales, but also between conservationists and policymakers pursuing the same goals, but with different means and intentions. Perceptions, images of the future and cultural repertoires are no molecules in the void. They are generated and reproduced in countless daily interactions and practices of a plurality of actors. In order to map possible transition pathways towards a more sustainable future of planet Earth, an integration of awareness about the basic assumptions that influence scientific, professional, private, and policy practice deems necessary. While taking social, ecological and time uncertainties into account, we need to be very clear on what we want and why we want it. If we aim to envision the future, we also have to become better aware of the various basic assumptions and values that underlie such visions. The Global Scenario studies that have been evaluated here do not explicitly show such a (self-) consciousness. This complicates the challenge to apply the existing scenarios as a fruitful discussion tool for future proof environmental policy and conservation practice.

\section{Conclusions}

In this chapter the Perspectives Method has been used to assess the basic assumptions of nature and management styles in the IPCC and the MA scenario studies. Conservation of global biological diversity in a changing world formed the context of the assessment. We consider the Perspectives Method as a useful tool for assessing the underlying assumptions and dynamics of both textual discourses and (policy) practice. In this regard, we explored the relevance of some CT perspectives (Fatalist, Autonomous and Dynamic Integrator) which are usually neglected in assessments, for the field of biodiversity conservation in a changing world. Whereas these ethically based perspectives are abundant in the studied literature, we found them weakly represented in the GSS. More specifically we expected especially the Dynamic Integrator to be more present in the typical integrated assessment documents of the IPCC and the MA.

Assessing the cultural perspectives of the GSS provides fuel for discussing the design and the appearance of contents of global scenarios, in order to be effective discussion tools in the hands of policymakers and conservationists. We propose that awareness of the socio-cultural assumptions about nature and management styles underlying the scenario narratives should be made more explicit in order to stimulate constructive discussions on how we visualize proceeding towards a more sustainable world full of biological diversity. This is especially relevant when developing specific scenarios for global biodiversity. It can be said that the problem of biodiversity decline is not just an environmental problem; it is largely a socio-economic problem and on a deeper level it can be assigned as an ethical-cultural problem. Perhaps, with biodiversity, this is even more so than with other environmental problems (Posey, 1999; Erez \& Gati, 2004). For conservation this implies that in order to become really effective, the protection of biodiversity needs to get out of the preservation niche (Spangenberg, 2006); conservation 
should be defined more broadly. Therefore, we propose it is necessary to include all the diverse perspectives on biodiversity and conservation into loss-reducing strategies. Awareness of the importance of biodiversity should trickle down into daily consciousness and practice on all levels, from civil society, to education, media, scientists, policymakers, large corporations, NGOs and conservationists. We may need to become more aware of the various underlying basic assumptions about nature, because they define our relation to biodiversity and ecosystems. They determine the practices we undertake in order to both increase human well-being and to conserve the biosphere. If we are more aware of basic assumptions, we will be better able to determine whether we wish to take the pathway of saving species and genes in a postmodern version of Noah's Ark or whether we see more future in a World Wild Web of connected habitat structures. 


\section{CHAPTER 7}

\section{The Discourses of IUCN}


"Alice: How long is forever? White Rabbit: Sometimes, just one second."

Lewis Carroll, Alice in Wonderland

This chapter is based on: Carijn Beumer \& Pim Martens (2010). "Noah's Ark or World Wild Web? Cultural Perspectives in Global Scenario Studies and Their Function for Biodiversity Conservation in a Changing World." Sustainability 2, no. 10: 3211-3238. 


\section{Introduction}

Four years after the globally set 2010 deadline of halting biodiversity loss, the decline of the diversity of life is still a growing global issue. The loss of biological diversity is a typical wicked, persistent and complex problem (Grosskurth, 2009). Its causes are plural and are interrelated with many societal, economic and cultural factors. Main drivers of biodiversity loss are identified as being part of larger global changes such as climate change, invasive species and poaching. Landscape fragmentation caused by urbanization and land use changes for agriculture are recognized as the largest causes for biodiversity loss (MEA, 2005; CBD, 2012). What kind of conservation practice will be able to deal with a changing planet and an uncertain future in the long run?

As we already saw in previous chapters, biodiversity conservation is not a clear-cut practice and there is no blueprint for how to best halt the loss of biological diversity. It involves much more than saving flagstone species (Caro, 2010) in nature reserves and national parks. Various conservation approaches are surrounded by a variety of basic assumptions about the world, nature and the human-nature relationship. These assumptions are more often implicitly hidden in practices and discourse than explicitly accounted for in the conservation discourses. It becomes increasingly important to be aware of the various types of human-nature relationships that exist. These relationships define the way conservation practices are envisioned and produced. They express certain worldviews and management styles within the conservation practices and discourses. Sometimes these practices co-evolve and sometimes they seem to compete with each other to achieve the same good cause.

Traditionally, measures to reverse the trend of biological loss have been largely developed in the context of 'conventional' conservation practices, which were often dichotomizing nature and culture (Soper, 1995). Protected areas and wildlife reserves, national parks, natural heritage sites and species recovery programmes all have in common to save nature, wilderness or wildlife in specific locations outside of humanly cultivated ecosystems.

With the increasing awareness about need to address and understand the interconnected complexities of our time (Crutzen \& Stoermer, 2000; Rees, 2010) and in order to guide transitions towards a sustainable world (Loorbach, 2002; Steffen, et al., 2005; Kemp, et al., 2007; Loorbach, 2007), increasing attention has been given by major conservation organisations like IUCN and WWF to developing so called 'integrated' conservation approaches (Christoffersen, 1997; IUCN, 2012e). Mainly these approaches have been directed at integrating with (official) development assistance (ODA) and engagement in new partnerships, with for example businesses (Adams, 2013). Via the lens of Cultural Theory (Thompson, et al., 1990; Thompson, 1997; Verweij, et al., 2006) we ask: how 'integrative' are these new 'integrated' approaches to conservation really? Are they able to transcend the ancient dichotomy between nature and culture? Do they fit this 
complex and uncertain world? Are they able to contribute to gaining new perspective on how to work towards sustaining healthy global ecosystems? In brief: do they represent the idea that the total can be more than the sum of the parts?

The aim of this chapter is to contribute to the on-going discussion on how to halt the loss of biodiversity in a pluralistic and dynamic global socio-ecological system. We will present an analysis of the worldview(s) and management style(s) of the oldest and largest global conservation organization: the International Union of Nature Conservation (IUCN). The organisation presents a wide variety of conservation approaches and the organization looks far beyond its central role of the conservation of species, populations and genetic diversity: links to climate change, energy, human well-being and the economy are all included (Christoffersen, 1997; IUCN, 2011a). Nevertheless, the discourse analysis demonstrates that although IUCN employs this strongly pluralistic approach to conservation, it is difficult to speak of a truly integrative approach yet.

\section{Methodology}

The IUCN conservation discourse was evaluated in the context of the main drivers of global change: the human species (Wackernagel \& Rees, 1996; Crutzen \& Stoermer, 2000; MEA, 2005; Steffen, et al., 2005) and its cultural basic assumptions (Verweij, et al., 2006; Beumer \& Martens, 2010). In analysing the case study we asked two questions:

Which basic assumptions about nature, the human-nature relationship and which management styles are represented in the IUCN discourse? Do the ideas and basic assumptions of biodiversity conservation within the IUCN match the reality of a complex, dynamic and globalizing world?

For the analysis various IUCN reports were selected that reflect the organisation's vision, mission, communications and practices. The publication timeframe 2007-2013 was used in order to gain insight into contemporary conservation discourses. This timeframe is based on the online availability of resources: qualitative, written and publicly accessible texts. Based on a triangulation of text-types reflecting 'idealistic views', 'practical discourse' and the way IUCN 'communicates' its achievements and practices to the outside world, the documents were categorised into 'Annual Reports (AR)', 'Vision and Mission Reports (VM)', 'Practice Reports (PR)' and 'Communication and Public Awareness (CA)' documents. Accessibility was best for the AR of the 'Business and Biodiversity Programme' (IUCN, 2007a, 2008b, 2009e, 2010d, 2011d). For the years 2010 and 2011 general IUCN annual reports were available online (IUCN, 2011f, 2012e). Two annual reports of the Commission for Education and Communication were also included in the analysis (IUCN, 2011c, 2013c). The CA documents we analysed were issues of the World Conservation Magazine (IUCN, 2008g, 2008d, 2008f, 2009a, 2009b, 2010f, 2011b). The 
PR and the VM documents consist of various other general reports about IUCN activities, vision and mission (IUCN, 2005a; Adams, 2006; IUCN, 2007b, 2008c, 2008e, 2008a, 2009d, 2010e, 2010c, 2012c; Marton-Lefèvre, 2012; Marton-Lefèvre \& Xinsheng, 2012).

Cultural Theory (CT), as applied in Beumer and Martens (2010), was used as an analytical framework for an in depth deductive qualitative DISCO analysis of the narratives of the documents (GAO, 1989; Hsieh \& Shannon, 2005; Elo \& Kyngas, 2008) (also see Box 6.1 CHAPTER 6 and CHAPTER 3) The framework is based on a 'grid' and a 'group' axis, indicating lower or higher autonomy in a social context and lower or higher conformation to societal norms, rules and regulations (Verweij, et al., 2006; Beumer \& Martens, 2010).

In preparation of the narrative analyses, a broad literature study was carried out to explore the various cultural perspectives on biodiversity and conservation existent in the academic literature and in popular scientific books, newspaper and magazine articles. This has been done in order to map the existent perspectives on nature and on-going management approaches in the conservation field (also see CHAPTER 5). The studied literature contained texts ranging from conservation theory and practice (Norton, 1987; Heywood, 1995; Sarkar, 1999; Margules \& Pressey, 2000; Sala, et al., 2000; Caro \& O'Doherty, 2001; Chapin, et al., 2001; Peterson, et al., 2003; Meine, et al., 2006; Redford, et al., 2006; Bethge, 2007; CBD, 2007b; Chan, 2007; Whittaker \& FernandezPalacios, 2007; Caro, 2010; Hagerman, et al., 2010; Rands, et al., 2010; Miller, et al., 2011; Minteer \& Miller, 2011; Robinson, 2011; UNEP-CBD, 2011; Minteer \& Collins, 2012; Adams, 2013), global reports (Gitay, et al., 2002; MEA, 2005; TEEB, 2009; CBD, 2010, 2011; UNEP-CBD, 2011), ecological theory (White, 1967; Hagen, 1992; Opschoor, 1998; McCann, 2000; Tilman, 2000; Groot, 2002; Rosenzweig, 2003; Cumming, et al., 2005; Begon, et al., 2006; Hart, 2007; Ives \& Carpenter, 2007; Norton \& Noonan, 2007; Whittaker \& Fernandez-Palacios, 2007; MacDougall, et al., 2013), biology, evolution theory and complexity (Capra, 1996; Prigogine, 1996; Gleick, 1998; Larson, 2001; Gunderson \& Holling, 2002; Folke, et al., 2004; Steffen, et al., 2005; Young, et al., 2006; Boogerd, 2007; Palmquist, 2007; Whittaker \& Fernandez-Palacios, 2007; Rees, 2010; Jagers, 2012), sustainable development (White, 1967; Hardin, 1968; Harlem, 1987; Wackernagel \& Rees, 1996; Giddings, 2002; Banerjee, 2003; Castro, 2004; Jackson et al., 2004; Robinson, 2004; Williams \& Millington, 2004; Adams, 2006; Martens, 2006; UNCSD, 2012; Martens, 2013) and philosophy (Schulz, 1985; Norton, 1987; Noske, 1988; Böhme, 1992; Naess, 1995; Soper, 1995; Bortoft, 1996; Mitman, 1996; Takacs, 1996; Posey, 1999; Sarkar, 1999; Crutzen \& Stoermer, 2000; Diamond, 2005; Adams, 2006; Abrams \& Primack, 2011; Aitken, 2012). Novels (Carson, 1962; Mowat, 1963; Leopold, 1966), documentaries and movies (Genton, 2006; Fothergill, et al., 2007) were also part of the literature assessment. The goal was to compile a general categorized working list of key words and phrases and position them in the framework of CT worldviews in order 
to extrapolate assumptions about biodiversity and conservation strategies (Beumer \& Martens, 2010).

Similar to the analysis of the Global Scenario Studies in CHAPTER 6, the reliability of the qualitative assessment was improved by cross checking the results by means of a triangulation. First, two research assistants carried out the same coding process for the same documents. The analysed documents were finally coded three times in total. The gained weights were assembled and calculated in a prepared excel sheet and the numerical results were transformed into percentage tables. This coding process resulted in the representation of percentages of perspectives per document category (see table 7.1). We discussed the results in a small focus group in a semi-structured qualitative way to compare the outcomes and their validity. Within the focus group it was decided that based on the shared interpretation of the context the tripled analysis was of significantly overlapping character in order to positively approve the validity of the results once a further sensitivity-analysis would also deliver proximate results.

Table 7.1. Research assistants' results of the qualitative content analysis

\begin{tabular}{lllllll}
\hline Hier & Ega & Ind & Fat & Aut & Dyn & Total \\
\hline 203 & 159 & 237 & 37 & 8 & 153 & \\
$25 \%$ & $20 \%$ & $30 \%$ & $5 \%$ & $1 \%$ & $19 \%$ & $100 \%$
\end{tabular}

Additionally, a sensitivity analysis was done using the text-mining software MAXQDA for a lexical search. Frequencies were counted of 7 key words per perspective (see figure $\left.7.1^{*}\right)$.

Figure 7.1. Keywords per perspective used in the MAXQDA lexical search

\begin{tabular}{|llllll|}
\hline Hierarchist & Egalitarian & Individualist & Fatalist & Autonomous & Dynamic \\
human & nature & resource & uncertainty & wilderness & dynamic \\
management & participation & opportunity & coping & harmony & complex \\
law/legislation & equality/equity & economy & adapting & lifestyle & (eco)system \\
policy & awareness & innovation & decline & love & integration \\
governance & precaution & goods/services & lack/little & culture & scenario \\
risk & community & benefit & loss & reduction & network \\
control & vulnerable & price & acceptance & footprint & evolution \\
\hline
\end{tabular}

Here, the Hierarchist scored highest (33\%). The Egalitarian (24\%) and the Individualist (21\%) scored close to each other. Table 7.2 shows that the Fatalist (6\%) and the Autonomous (6\%) perspectives scored equally low and the Dynamic Integrator (10\%) a little lower than in the manual analyses (see table 2). We found that the differences with the manual analyses can be attributed to the contextual interpretations of the researchers. This - together with the student validation -- allowed us to consider the manual results reliable. 
Table 7.2. Frequencies and perspective percentages of the MAXQDA lexical search

\begin{tabular}{lllllll}
\hline Hier & Ega & Ind & Fat & Aut & Dyn & Total \\
\hline 3935 & 2850 & 2495 & 704 & 758 & 1137 & 11879 \\
$33 \%$ & $24 \%$ & $21 \%$ & $6 \%$ & $6 \%$ & $10 \%$ & $100 \%$
\end{tabular}

The aim of the qualitative review was to reveal the assumptions underlying the narratives of the IUCN documents. Illuminating the discourses used by conservation organisations like IUCN will help policymakers and conservationists to better discuss the development of resilient solutions for future biodiversity and ecosystem protection.

\section{Results}

Generally, all analysed report-categories represent a rather consistent view (see table 3 and table 4). In brief, the Hierarchist, Egalitarian, and Individualist perspectives are best represented in all the documents. The Fatalist and the Autonomous perspective are underrepresented in the IUCN documents. With an appearance of $14.80 \%$ the Dynamic Integrator occurs quite steadily but moderately throughout the documents (see table 7.3).

Table 7.3. Overview perspectives of the IUCN documents ( $N=30$, mean in \%)

\begin{tabular}{llllllll}
\hline Perspective & $\mathrm{N}$ & Range & Minimum & Maximum & Sum & Mean & St.Deviation \\
\hline Hierarchist & 30 & 20 & 15 & 35 & 768 & 25 & 6.106 \\
Egalitarian & 30 & 41 & 17 & 58 & 917 & 30 & 8.274 \\
Individualist & 30 & 36 & 11 & 47 & 704 & 23 & 9.336 \\
Fatalist & 30 & 14 & 0 & 14 & 105 & 3 & 3.026 \\
Autonomous & 30 & 7 & 0 & 7 & 57 & 2 & 1.709 \\
Dynamic & 30 & 24 & 8 & 32 & 444 & 14 & 4.286
\end{tabular}

The Vision and Mission (VM) documents represent the highest Egalitarian score (29\%), immediately followed by the Hierarchist (28\%). The Individualist (20\%) and the Dynamic Integrator (18\%) are close to each other too (see table 7.4 ).

In the category of Annual Reports the Egalitarian perspective scores highest (32\%), which is basically attributed to the high Egalitarian representations in the Reports of the Commission on Education and Communication. The Individualist (25\%) scores highest in the AR of the Business and Biodiversity Programme (BBP).

The IUCN Practice Reports (PR) category score highest on the Hierarchist and Egalitarian perspectives (both 29\%), followed the Individualist (23\%). All PR put effort in promoting and explaining the strategic shift towards engaging with the private sector, linking eco- 
nomic development to biodiversity conservation (IUCN, 2010c). Rather than speaking about adversities, an optimistic language about sensitive issues (such as biodiversity loss, the economic crisis and poverty issues) seen as opportunities to cooperate with the business sector stands out in all the PR documents.

The Communication and Awareness (CA) discourse is based on the World Conservation Magazine of the period 2007-2011. The magazine appeared once or twice per year for more than 50 years. The magazine used to be a platform for debate and for airing the wide variety of views within IUCN. In 2011 the Hierarchist last issue was released (IUCN, $2013 b)$. In the CA category the Egalitarian perspective scores highest (31\%). The Individualist perspective is relatively well represented (24\%) and the Hierarchist (22\%) scores slightly lower than in the other publication types. The other three perspectives score more or less similar compared to the other publication categories: Fatalist 5\%, Autonomous $3 \%$ and the dynamic $14 \%$.

Table 7.4 IUCN perspective percentages per document category

\begin{tabular}{llllllll}
\hline Category & Hier & Ega & Ind & Fat & Aut & Dyn & Total \\
\hline VM & 196 & 201 & 140 & 24 & 8 & 129 & \\
$\%$ & $28 \%$ & $29 \%$ & $20 \%$ & $3 \%$ & $1 \%$ & $18 \%$ & $100 \%$ \\
PR & 117 & 118 & 94 & 13 & 4 & 55 & \\
$\%$ & $29 \%$ & $29 \%$ & $23 \%$ & $3 \%$ & $1 \%$ & $14 \%$ & $100 \%$ \\
AR & 258 & 321 & 247 & 17 & 20 & 135 & $100 \%$ \\
$\%$ & $26 \%$ & $32 \%$ & $25 \%$ & $2 \%$ & $2 \%$ & $14 \%$ & $100 \%$ \\
CA & 156 & 216 & 170 & 38 & 20 & 98 & $14 \%$ \\
\% & $22 \%$ & $31 \%$ & $24 \%$ & $5 \%$ & $3 \%$ & 417 & 2795 \\
Frequency & 727 & 856 & 651 & 92 & 52 & $15 \%$ & $100 \%$ \\
Percentage & $26 \%$ & $31 \%$ & $23 \%$ & $3 \%$ & $2 \%$ &
\end{tabular}

\section{The Hierarchist}

The Hierarchist believes nature is stable within limits. He is risk avoiding, anthropocentric, aiming for a world of justice and organised stability and favouring sound scientific and expert knowledge over other kinds of knowledge (Verweij, et al., 2006; Beumer \& Martens, 2010). The Hierarchist in IUCN is mainly represented by the discussion of the institutional structure of the organization, strengthening the institutional capacity, and its emphasis on the role expert-knowledge to guide and influence policy-making on global, national and local levels. The discourse can be distinguished in phrases like "avoiding catastrophic tipping points", "setting professional standards", "implementing the Convention", "mainstreaming environmental policy", "strengthening legal and administrative instruments", "knowledge management", "developing more effective and strategic interventions", "planning, implementing, monitoring and evaluating the con- 
servation work", "using and developing indicators to measure progress (i.e. the IUCN Red List of Threatened Species)", "providing structures and frameworks", "achieving strategic objectives and scalable targets" and the "reputation [of IUCN] for generating and disseminating sound scientific knowledge"(IUCN, 2010c). The Hierarchist discourse is also represented in the goal of biodiversity conservation to ensure food security, poverty eradication and healthy societies and to avoid dangerous ecological tipping points. The controlist approach of the Hierarchist can be distinguished in the assumption that the loss of biodiversity can be 'halted". As an institute of "expertise" and "credible knowledge on the status of the earth's natural resources" IUCN develops "key indicators" and "standards" such as the IUCN Red List of Threatened Species and the Protected Areas Category System. IUCN also employs its credibility built on its expertise in order to influence and help constitute national, regional and international policies, regulations and governance arrangements, particularly through its Commission on Environmental Law (IUCN, 2008a, p.26) which includes both soft and hard law instruments. A belief in the reversibility of the trends of environmental degradation through strong and knowledge based ecosystem management shows the Hierarchist belief in the controllability of problems and also the idea that nature is tolerant within limits. These limits should be identified and defined by the best available science. The negative impacts of globalisation and market processes (for example invasive alien species, wildlife crimes and resource exploitation) should be kept under control by regulation and concerted regional and international actions.

\section{The Egalitarian}

The Egalitarian believes that awareness should be raised about the fragility of nature. The Egalitarian engages in civil movement, NGOs an participatory approaches to conservation and strives for the empowerment of vulnerable groups. The precautionary principle is guiding in decisive issues. Most IUCN documents score best in the Egalitarian quadrant. The Egalitarian discourse is largely made up by the focus on the idea that business as usual will not achieve the mission of halting biodiversity loss (IUCN 2010, p.4). In Shaping a Sustainable Future (IUCN, 2008e), IUCN recognizes and emphasizes the intrinsic value of nature and focuses on the vulnerability of nature and the importance of enabling natural processes to proceed. Land use change, overuse of natural resources and other human activities and cultural values (undervaluing nature, or seeing it primarily as a resource for production and consumption) are seen as the main pressures on the fragile ecological system and on biodiversity. Other central Egalitarian issues discussed in the document are "democratic and open communication between civil society and governments (IUCN, 2005b, 2008e, 2008a, 2010c)." Most documents consider nature to be "vulnerable", "fragile" or "sensitive". Egalitarian conservation approaches can be found in the discourse on the focusing on stakeholder participation and engagement of community groups, stressing the important role of empowering indige- 
nous peoples, local communities and women, fair and equitable sharing (of benefits derived from natural resources and/or ecosystem services [Individualist]), policy and governance reforms and including traditional ecological knowledge (TEK). Communication and awareness-raising, especially within governance institutions and the private sector, is considered a relevant approach to conservation too. This should be accomplished by setting up "constructive dialogue among sectors (IUCN, 2010c, p.8)".

The discourse of the documents of the Commission on Education and Communication (CEC) (IUCN, 2010a, 2013c) and the video "Love not Loss" (IUCN, 2010a) are aimed to change narratives from 'scaremongering' and making people feel guilty, towards making people act by inspiring and "celebrat[ing] the awe and wonder we all feel for nature (IUCN, 2011c)." The CEC increased its activity in social media channels like Facebook, Twitter and YouTube. Also a new video How to tell a Love Story (IUCN, 2012a) was released in 2012 based on the message of regaining our innate love for nature.

\section{The Individualist}

The Individualist is optimistic about the future. He believes in the resilience of nature and may there be cases of collapse, the human capacity to invent innovative technologies will help to substitute for suffered losses. For many Individualists the guiding principle is the free market. The Individualist sees opportunities instead of problems. In almost all IUCN documents a kind of Individualist optimism is presented about the new opportunities for conservation due to partnerships with private parties. The gravity, urgency and complexity of biodiversity loss are tackled with the feeling that the "challenges are not insurmountable (IUCN, 2008a, p.8)."

Much of the IUCN discourse is oriented on the sustenance of economic growth through saving 'ecosystem goods and services' and emphasising the benefits derived from these goods and services and the conservation of natural 'resources' for human well-being, livelihoods and the economy. Environmental values should be internalized in economy, policy and markets through the use of economic incentives. One of the main 'tools' discussed is the strategy of setting up partnerships with large business corporations, especially the so-called 'large-footprint industries' like Shell, Holcim Group, Total, Rio Tinto, E.ON and the ACCOR Hotels Group. In the Annual Report for 2011 IUCN states that the "growing work with business is a key part of delivering the Union's mission. IUCN is more often optimistic than critically reflective in its narratives about the publicprivate partnerships and about the 'chances' and 'opportunities' these collaborations generate. Biodiversity loss is optimistically referred to as a 'challenge' to be tackled instead of a humanitarian or ecological 'problem' or 'disaster'. Conservation tools that are mentioned are amongst others: 'Markets for Ecosystem Services', 'Market Opportunities for Biodiversity Business', 'Ethical Trade', 'Leaders for Nature', 'Capacity Building for Engagement with the Private Sector' and 'Financial Offset Schemes'. 
In the latest World Conservation issue (IUCN, 2011b) the economic crisis is mentioned as a catalyser for new ideas on economic development and the popularity of the Green Economy idea as "an attractive alternative to a bruised and weakened economic model (IUCN, 2012e, p.8)." Critics of the Green Economy, who see this model as "supporting the capitalist status quo (IUCN, 2011e, p.9)" are told that, "whether they like it or not", a transition towards a Green Economy transition is "bound to happen; if not by design, then by default (IUCN, 2011b, p.9)."

The Fatalist

The Fatalist waits and sees. He does not believe in active and concerted solutions to global problems and believes he has to learn to cope with changes and environmental unpredictability. He has the capability to question the approaches of the other perspectives and may be seen as the critical voice in debates. In the IUCN rhetoric the Fatalist is only mentioned in passages about the continuing decline of biodiversity.

\section{The Autonomous}

The Autonomous perspective regards individual retreat from the established system as a solution towards a more sustainable planet. Footprint reduction, self-sufficiency and downshifting consumption are his strategies. These strategies should be based on a fundamental change of values and they require a strong amount of creativity and outside-the-box thinking. The Autonomous is modest and a minimalist in many ways and he does not try to dictate others to engage in his lifestyle. Nevertheless, he may inspire other people to change values and live off-the-grid as well. The Autonomous perspective resembles the so called Cultural Creatives (Ray \& Anderson, 2000). In the IUCN documents, the Autonomous perspective is represented in a very limited way.

\section{The Dynamic Integrator}

The Dynamic Integrator is a systems thinker. He believes nature is complex and dynamic. Therefore anticipation is the best attitude towards the future. Integrative approaches are needed to maintain the dynamic balance of evolutionary processes. The Dynamic Integrator is represented moderately through words and phrases referring to 'networks' and 'integration', 'integrative approaches', 'linkages' and 'adaptation' to 'constantly changing conditions' and the 'complexity' of the issues at stake. The Dynamic Integrator was also identified in phrases where 'local communities, policymakers and the private sector' where mentioned in one breath and where the 'complex interface between environmental, economic and socio-cultural components' became equally related to sustainable development. The IUCN Programme 2013-2016 (IUCN, 2012c), which discusses the conservation strategies adopted by the IUCN World Conservation Congress in Jeju, September 2012 is a document with a relatively high occurrence of the Dynamic Integrator perspective (23\%). Central to the document is the notion of 'nature-based solutions'. 
This approach emerged as a novel way to contribute to the objectives of the UN Framework Convention on Climate Change (UNFCCC) to find solutions for mitigating and adapting to climate change (IUCN, 2012c). It should also help the conservation community to reach beyond its traditional frames, addressing the complex interconnections of climate, biodiversity and human societies. Through the One Programme Charter (IUCN, 2011e) -- endorsed in May 2011 by the IUCN council -- IUCN seeks to better connect the different parts of the organisation in order to maximize its programme results.

Scientifically, a shift can be identified from a disciplinary research orientation of monitoring species towards more integrated studies on the complexities and the functional relations of socio-environmental systems and the links between species. Fundamental cultural and institutional differences should be overcome and academic traditions should be complemented with traditional ecological knowledge and other knowledge systems (IUCN, 2008b). Diversifying stakeholders and engaging in new partnerships are regarded crucial strategies for successful conservation.

\section{Discussion}

IUCN is more than just a conservation organisation. It is an ideological actor as well. As the world's oldest and largest conservation institution it produces and circulates a "definition of what constitutes conservation (MacDonald, 2003, p.1)." Having illustrated the basic perspectives disseminated by the four categories of IUCN publications, the results of the analysis open up corridors for discussion. Some of these corridors we highlight in the hope that they may contribute to the discussion on the future of biodiversity conservation.

In the early years the Union's strategy was to form opposition against nature-exploiting (governmental) regime players by delivering knowledge based on sound scientific methods (Christoffersen, 1997). IUCN's approach for engaging with the private sector only became more visibly framed in 2004 as the Private Sector Strategy (IUCN, 2009c).6 Within this strategy, IUCN believes that large resource extracting businesses can be helped to change from within through working with them and raising the awareness of the opportunities that ecosystem services and biodiversity provide for their long term existence (TEEB, 2009; IUCN, 2012b). Some of IUCN's "Business and Biodiversity" partnerships are highly controversial, such as the partnership with Royal Dutch Shell, which was signed in 2007. In August 2011 UNEP released a report confirming Shell's role in large scale oil pollution in Ogoniland, Nigeria (UNEP, 2011a). On-going large environmental and social problems in areas where Shell drills and a lack of concrete improvements during the

6 The Private Sector Strategy was endorsed by the IUCN Council in 2004 (Council Decision C/60/58). 
years of partnership could raise the question whether institutions as IUCN can maintain their integrity and can continue pursuing their mission according to their vision if their projects become entangled with the activities of large multinationals (FOEI, 2009; Turner, 2010). Also, IUCN support to investigate the aspirations of Shell to drill for oil in the Artic could negatively impact the image and integrity of IUCN as a nature-protecting organisation (IUCN, 2013d).

Under the umbrella of the shift towards a 'Green Economy', the 'Business and Biodiversity' approach of IUCN seems to be directed at maintaining the economic growth paradigm without questioning it much. There is an inherent Individualistic optimism - or perhaps Egalitarian naivety - revealed by the IUCN discourse about the good intentions of the partnering corporations. It may be worthwhile to remember that, although it may indeed be a very valuable and necessary strategy to build bridges between conservation and business and to create more awareness in businesses about their long-term dependence on ecosystems, ecosystem services and biodiversity, their utmost goal remains to make profit. Personal consumption reduction of affluent citizens, value changes and alternative life styles as represented by the Autonomous perspective are avoided as topics in the analysed documents. Instead, discourse and practices are directed at empowering local communities in developing countries: much effort revolves around helping these already relatively low environmental impact communities to more efficiently and sustainably use the environmental resources surrounding them and to participate as stakeholders in decision-making processes related to the use, access to- and benefit sharing of land and life-forms (IUCN, 2010b).

In February 2011 UNEP released an extensive report on the Green Economy (UNEP, 2011b). The concept was at the heart of the Rio+ 20 Conference, which was held in Rio de Janeiro in June 2012. In many of the analysed documents it becomes clear that IUCN wholeheartedly embraced the green economy. Recently, increasing criticism on the green economy is coming from various corners (Kenis \& Lievens, 2012): being fixated on niche markets and consumer products the green economy is still lacking a systemic view, while maintaining an optimistic faith in enduring economic growth (Pauli, 2010). The green economy is often used to green-wash certain activities and products (Hoedeman, 2012; Plec \& Pettenger, 2012). It is based on the same old thinking and it distracts the debate from the real drivers of the environmental crisis (Spash, 2012). It is a narrow, economy centred re-orientation of the much broader concept of sustainable development (Morrow, 2012). The green economy model is keeping old regimes and powers in their saddles and extending corporate control into natural areas by commodifying nature through the use of price mechanisms designed to protect it (ETC-Group, 2011). The green economy concept is also depoliticising the societal debate about important issues such as the transition towards a more sustainable world (GesNaT \& BUKO, 2012; Patel \& Crook, 2012). For these and other reasons, it is questionable whether a green economy can sustain a growing world population without compromising biodiversity in the long 
run. "A Green Economy will only be able to reposition [the planetary] limits (GesNaT \& BUKO, 2012)." Organisations like IUNC may benefit by opening a more critical discussion on this green economy approach and may also embrace other perspectives, such as the Autonomous as an important contributor to the conservation of biodiversity.

\section{Conclusion}

This chapter will be concluded by answering the questions we started with: firstly, which basic assumptions about nature, the human-nature relationship and which management styles are represented in the IUCN discourse? Analysis of the chosen IUCN documents portrays the Union as a basically Egalitarian-Hierarchist-Individualist organisation. The Dynamic Integrator is steadily present, aiming to connect the three basic perspectives. Sometimes, but not too often, the more fundamental complexity-view of the integrator is operationalized as well. The Fatalist and the Autonomous perspective are hardly represented.

Secondly, do the ideas and basic assumptions of biodiversity conservation within IUCN match the reality of a complex, dynamic and globalizing world? A truly integrative approach to conservation that is also adaptive to changing global circumstances and that is able to gather all the human forces necessary to save biodiversity for the future, may require more than integrating conservation with development assistance, cross-sector policies and engagement of the private sector. The Autonomous perspective -- where individual creativity, downshifting and alternative lifestyles are advocated -- gets ample space in the assessed IUCN texts, even though the perspective is representing a rapidly increasing civil 'movement' of highly engaged individuals in global society (Ray \& Anderson, 2000). Integrative approaches to conservation need better inclusion of fundamental debates on our lifestyles and our consumption patterns and attitudes. Although very open to many perspectives, ideas and strategies for conservation, IUCN now seems to have chosen the pathway of engaging with an Individualist discourse where nature ("wilderness and its constituent elements (MacDonald, 2003, p.7)" is replaced by natural resources ("the environmental basis of building economies (MacDonald, 2003, p.7)." For IUCN to become like a Dynamic Integrator in the conservation field, the Autonomous perspective has to become better recognised and included in the debate and the design of strategies for biodiversity conservation. Until that time is ripe, it may be necessary to put critical Fatalist question-marks by the effectiveness and integrative character of the employed strategies to halt global biodiversity loss. 


\section{CHAPTER 8}

\section{INTERMEZZO \\ Cosmopolis or Sustopia?}

A critical reflection on the sustainable city 
"This city is what it is because our citizens are what they are."

Plato

This Chapter has been submitted as:

Carijn Beumer (submitted). Cosmopolis or Sustopia? A critical reflection on the sustainable city. Cities and the Environment. 11 October 2014. 


\section{Introduction}

This essay is an intermezzo between PART II en PART III of this dissertation. A critical reflection is given on the notion of the sustainable city. Literature from various disciplines, such as philosophy, history, sociology, urban studies, ecology, and sustainability science are employed to answer the central question: how can the idea of a sustainable city be best conceptualised taking into account its inherently dynamic and complex character? It is argued that experimenting with ways of improving the quality of life in urban environments asks for 'unfixed' ways of urban development and letting go of the ideas of structural planning of 'Sustopolis'. Such an approach demands a fundamental shift in how we see the world. Primarily, it involves transcending the ancient nature-city dichotomy. In order to assist such a process, the notion of Cosmopolis is explored and how it can be helpful in developing the human consciousness towards one that is able to embrace multiple spatial and temporal scales. Such a broader view on the planet and how we relate to is necessary to effectively answer urgent sustainability questions that emerge in and beyond cities.

Cities are ambiguous systems: they are seen as 'good, 'bad, 'aesthetic' or 'ugly' places, benefiting the well-being of people, harming the well-being of people and impacting the integrity of natural ecosystems. In this essay I present an image of cities as systems at the edge of chaos (Braun, 2005; Karmanov \& Hamel, 2008). Along this edge, cities are windows of opportunity for bringing about a sustainable planet. As William Rees and Mathis Wackernagel (Rees \& Wackernagel, 2008) say: cities are the planet's hubs of unsustainability while at the same time they are the key to sustainability. This idea is not new: seeing the sustainable city as a solution for many global problems has recently become popular in academia and governance (Grimm et al., 2008; Rees \& Wackernagel, 2008; Weinstein, 2010; Beatley, 2011; ICLEI, 2012; Shmelev, 2012; Dalsgaard, 2013). The image of the sustainable city seems to have become the widely embraced Utopia of the $21^{\text {st }}$ Century. I call the archetypical ideal image of The Sustainable City: Sustopia. Although cities provide much potential for increasing planetary sustainability in many ways, this essay contains a critical reflection on the ideal of Sustopia.

Sustopia, as any Utopia in history has demonstrated, should be handled with caution: 'blueprinting' an ideal form or organisation of a community (be it city, state or governance structure) often results into Dystopia. As Lewis Mumford phrased in 1965: "[c]ompared with even the simplest manifestations of spontaneous life within the teeming environment of nature, every utopia is, almost by definition, a sterile desert, unfit for human occupation (Mumford, 1965, p.278)." Rather than seeking to build Sustopia, which will only lead to "arrested development (Mumford, 1965, 278)" -- or even worse I argue that we may need to experiment with ways of improving the quality of life in urban environments in a fundamentally 'unfixed' way: acknowledging their complex, 
dynamic and even 'wild' character. This means that fundamental shifts in how we see the world may be necessary. Primarily, this involves: transcending - or messing up -- the ancient nature-city dichotomy. Therefore, the central question to this essay is: how can the idea of a sustainable city be best conceptualised taking into account its inherently dynamic and complex character? The argumentation that helps constructing the answer to this question is built on literature from a variety of disciplines, such as philosophy, sociology, history, urban studies and sustainability science.

\section{Mappa Mundi: the Good City and the Cosmic Scale}

As will be demonstrated in this essay, early ways of conceptualising the city are still meaningful when seeking to understand the contemporary world and the role contemporary cities can play for planetary sustainability. Therefore, let's first plunge into an iconic reflection on the morphology of ancient and medieval cities. These cities have been ingrained with archetypical concepts of what the Good City is, or ought to be.

In the time of the flourishing of Egyptian and Mesopotamian culture, but also in the civilisations of the Incas and the Aztecs, and in ancient Asia, the city was something created by a king who acted in the name of (a) god. The first thing the king did during his time of rule was erecting a temple (a pyramid or a ziggurat). This temple was enclosed by walls to protect it from outside forces. At the same time, the walls aimed to concentrate, protect and employ the community living in the proximity of the temple. As such, cities were the outcome of the act of creating a sacred place (Mumford, 1965).

In Ancient Greece, for Plato, the city state (Polis) had a similar role and function. Plato saw the Polis as a place where relationships are fostered between people to help each other to participate in 'the Good' (Pickstock, 2001). Plato drew a comparison between the Polis and the human body where the human limbs and faculties represented the larger scale arrangements and order of the 'cosmic body'. In Platonic and in later medieval times the city was seen as a Cosmopolis: a micro-cosmos that reflected the larger structure and order of the divine macro-cosmos (Lilley, 2004b, 2004a). In Plato's Cosmopolis the centre of the city represented the highest order of the moral hierarchy (high reason, represented by the governing 'head' located in the citadel), whereas towards the fringes and outside of the city, the lower moral 'faculties' (or limbs) were represented, from sentries to farmers and wild, uncivilised nature outside the city walls. Achieving the highest 'Good' -- becoming a Philosopher King, or for Aristotle, realising one's true human potential (Mendieta, 2010) -- was possible only through the symbolic and social geographies embedded in the structural and physical geography of the Polis (Mumford, 1965; Pickstock, 2001; Lilley, 2004b, 2004a; Mendieta, 2010). 
In $12^{\text {th }}$ Century Europe urban life was rapidly expanding. In this time platonic thought was flourishing within Christian thinking and it highly influenced writing, thinking and building the image of the 'Good' city in the shape of cathedral towns (Lilley, 2004b, 2004a). Medieval maps (Mappa Mundi) often show a world that is placed over the body of Christ. The city of Jerusalem - with its circle of walls and gates opening towards the four corners of the wind -- is presented as Christ's navel. As Lilley (2004a) describes in his symbolic deconstruction of the medieval city, the geometry of cities was key to the path to God. Not only the physical urban structure - often a walled circular shape with a church in the centre and main roads connecting the (divine) centre with the (lower) peripheries -- played a symbolic role, but also Christian rituals such as processions from the city-periphery to the centre symbolised the path to God. Churches were usually placed in the centre of the city-cosmos. The medieval city was symbolically constructed to reflect the divine hierarchical order, consistent of microcosms within a macrocosm (Lilley, 2004b, 2004a).

In the Cosmopolis concept (Lilley, 2004a) the city became unified with the 'divine' (Logos or ratio) and the cosmos. Paradoxically, the Cosmopolis concept helped separating the 'higher city' from the 'lower nature' outside the city walls. With the Cosmopolis concept, the world outside the city borders was placed on a lower level in the moral hierarchy. This is also reflected in the words of historian Lewis Mumford (1965): "the very first act of King Utopus, when he invaded the land of Utopia, was to put his soldiers and the conquered inhabitants to work digging a broad canal that turns the territory into an island and cuts it off from the mainland (Mumford, 1965, p.277)." The urban hinterland represented the wild, the untamed and the 'uncivilised'. The city gates or canals protected the urban inhabitants from the savage outside world and invaders of any kind (Braun, 2005).

In his influential book Cosmopolis: the hidden agenda of modernity (1992), Stephen Toulmin describes how the concept of Cosmopolis is still strongly present in Western philosophy and science (Toulmin, 1992). However, the character of the nature-city dichotomy has turned around during the past ages. The city is often seen as 'the Bad' and the 'Ugly': the disrupter of human well-being, non-compliant with respect to evolutionary human nature itself (Morris, 1969; Clement, 2010). Pollution, crowdedness, noise, dangerous traffic, a lack of aesthetics, a lack of green and also 'inhumane' architecture are often blamed on the physical sphere (Gehl, 2010), just like the rush of life, the individualism and superficiality of many social relations that are blamed in the relational sphere (Morris, 1969; Lachmund, 2013). Also the loss of a cosmic scale perspective during the age of materialism may have contributed to the rise of life-unfriendly cities. In most literature discussing the urban-nature relation, urbanization is often depicted as harmful for the environment (Clement, 2010). This is especially articulated in the concept of the 'metabolic rift' first described by Marx who was concerned about the way 
soil fertility and its depletion was related to an urban accumulation of waste (Clement, 2010). Later, the scale-perspective on the effect of cities on the environment became broadened by the concept of the ecological footprint (Wackernagel \& Rees, 1996; York et al., 2003; Rees \& Wackernagel, 2008; Clement, 2010).

\section{Allowing Nature into Cities: Creating a New Order}

During the Industrial Revolution and the rapid expansion of large European cities, the image of the city turned from the place to achieve 'the Good' into a place of moral decline, filth, unhealthiness and ugliness. In this time, nature (and a symbolic or literal return to it) became idealised especially by the Romantic philosophers and artists of Germany and Britain (Kluckhohn, 1966; DesJardins, 2006). Instead of the 'wild untamed and uncivilised beast' nature became characterised as innocent and pure (Soper, 1995). To cure some of the urban illnesses, people went into retreat in the mountains for rehabilitation. And nature was brought into cities. The greening of Paris and the construction of Parks in London for example (Marzluf et al., 2008; Sukopp, 2008) emphasised the regenerative qualities and powers of sunlight and greenery for stressed, ill, or hardworking citizens (Lilley, 2004a; Tzoulas et al., 2007; Lachmund, 2013).

When nature has been allowed into cities, it has usually been in ways that represented an idealisation of the Ancient and Medieval 'universal order': many influential parks and gardens in Western history have been designed based on geometric principles reflecting and symbolising the divine order and celebrating God as an 'architect' of the cosmos (Lilley, 2004a). Great examples are the medieval monastery gardens or the gardens of Versailles in France. Later, as a contrast to the rapid urbanisation of the $19^{\text {th }}$ century, and based on romantic ideas of the goodness of nature, gardens or parks are seemingly allowed to be wilder (Lachmund, 2013). Often their design has been based on principles reflecting an ideal human-nature relationship of harmony and aesthetic beauty (e.g. Victorian gardenesque-, picturesque- or cottage gardens). Also motivations for urban greening based on health and human well-being helped to constitute urban greenspaces, making them suitable for leisure, regeneration and exercise. Therefore, large open spaces were created (Lachmund, 2013).

As Philip Sheldrake says in an article about the relation of the city and the human spirit: "[c]ities have always been powerful symbols of how we understand and construct community (Sheldrake, 2007)." Whether the design or development of a city takes a 'greyer course' or a 'greener course', it can always be linked to a "neverending process[...] of creating order (Lachmund, 2013, p.9)." What values and worldviews are reflected by contemporary cities? Many people would say that in the present day cities the central role of cathedrals has been replaced by central shopping districts, central banks, global 
trade centres and other symbols of money and economic power (Brenner, 2009). When these new 'gods' are threatened or fail to provide human needs, citizens start looking for alternative ways to enhance their quality of life. This has been especially visible in cities struck by economic crises or socio-economic trouble, like Berlin during its slow economic recovery after the World War II (Lachmund, 2013), Manchester during the 1960s (Hospers \& Pen, 2008) or more recently Detroit (McClintock, 2010), cities with shrinking populations (e.g. Heerlen) (LaCroix, 2010) or in cities anticipating effects of climate change (e.g. Rotterdam) (Sheldrake, 2007).

During times of economic crisis, greening cities seem to become a new focus of urban civil activity (Schmelzkopf, 1995). It may sometimes be a kind of "urgent biophilia" induced by necessity and an evolutional tuning for survival, as Keith Tidball suggests in his article about biophilic attraction sprouting up in humans in times of need as a form of disaster resilience (Tidball, 2012). It may be guided by policies anticipating or mitigating climate change (Simonis, 2011). In many cases and in many cities also the optimistic, creative and subversive human spirit can be found behind it, sometimes with the aim to give anthropogenically claimed space back to nature (Rand, 1995; Van der Ree, 2000; Chen \& Wu, 2009; Samiei, 2013; Van Ham, 2013). Also very often motivations can be found in the wish to take back control over (or care of) one's own life, livelihood and subsistence (Certomà, 2011; Barton \& Tan, 2013). Practicing activities such as urban greening and growing food may be the symbols of the desire to scale down production and consumption from a de-humanised corporate (global) scale to the human graspable size (Gehl, 2010; Dalsgaard, 2012).

Urban sociologists Kingsley Davis stated that "the sine qua non of urban existence [is] the concentration in one place of people who do not grow their own food (Davis, 1955, p.430)". Following this statement, it becomes feasible to believe that recent urban developments and the popularity of urban greening and urban farming activities point towards a revolution in what it means to be a citizen. Do the current urban greening trends like permaculture (Mollison, 1988), reconciliation ecology (Rosenzweig, 2003; Francis \& Lorimer, 2011) or other biophilic practices (Beatley, 2011) that emerge all over the world herald a new nature-city relation?

\section{Critical Urban Theory and Sustainability}

In his essay called The Right to the City, sociologist David Harvey (2003) pleas for a "right to remake ourselves by creating a qualitatively different kind of urban sociality (Harvey, 2003, p.939)." In critical urban theory 'the right to the city' is a central notion (Marcuse, 2010). Critical urban theory calls for a reflexive attitude towards urban developments and to evaluate them in the context of existing or developing power-regimes and struc- 
tures (Brenner, 2009; Marcuse, 2010). This sociological movement is founded in the Kritische Theorie of the Frankfurter Schule where influential thinkers like Horkheimer, Adorno, Marcuse and Habermas, amongst others, reflected on how societal trends and institutions were shaped in the context of post-war capitalism (Brenner, 2009; Agger, 2014). The scholars of the Frankfurter Schule aimed to demarcate an alternative sociology, by finding an alternative to bourgeois philosophy on the one hand and technocratic approaches to social science, on the other (Brenner, 2009; Agger, 2014). In their 'critique of the instrumental reason', the critical theorists denounced the positivist idea that science can make "institutional arrangements more effective, to manipulate and dominate the social and physical world (Brenner, 2009, p.202)" and as such acts as a solidifier and legitimator of existing forms of power (Hall, 2001). In this context, they argued for an explicit engagement with normative questions and a conscious attitude of any researcher or 'knower' that (s)he is embedded within exactly that practical social context that (s)he is investigating (Escobar, 1999; Redclift \& Woodgate, 2010).

Urban critical theory explores normative questions of power and knowledge in the context of contemporary urban development in a globalising world (Brenner, 2009). It contrasts the more technocratic approach to urban sociology of the influential Chicago School -- the cradle of urban sociology-- (Lachmund, 2013) and criticises the way science is often employed to legitimize policies that are constituted in the context of a neoliberal global system (Marcuse, 2010). Pointing to new 'slogans' such as the 'global city (Sassen, 1991)', the 'smart city (Caragliu et al., 2011)' the 'world city (Friedman, 1986)', or networked cities (Hall, 2001; Castells, 2010), urban critical theorists unravel the way contemporary information, knowledge and power structures strengthen urban issues. Examples of this unravelling can be seen in the identification of the (ancient) unequal development between city centres and the periphery (Freidberg, 2004), spatial polarisation (Kim, 1999), marginalisation and exclusion (Marcuse, 2010) or access to facilities and resources such as healthy food or green spaces (Lang et al., 2012; Wiek et al., 2012). In the words of Eduardo Mendieta "[a]॥l critical urban theory tears at the Potemkin façades of neoliberal megapolises of affluence and megaurbs of destructive accumulation to unveil the realities of squalor and dispossession (...) so that we may claim our place in the properly human polis (Mendieta, 2010, p.444)." Critical theorists demonstrate that the established 'regime' is fundamentally ignoring deeper questions about the cause of the crisis which is considered to be rather systemic than purely economic (Kim, 1999; Harvey, 2003; Brenner, 2009; Marcuse, 2010; Smith \& Doel, 2010; Martens, 2013). Science is often instrumentally employed to legitimise the power of the regime (Latour, 1988; Hall, 2001; Foucault, 2002).

Next to being reflexive and critical of instrumental science and existent power relations in society, the critical theorists - the 'classical' critical thinkers as well as the recent ones -- emphasise the exploration of democratic and emancipatory alternatives of organising 
social capacities and human-nature relations (Brenner, 2009; Mendieta, 2010). This is where strong links can be found between Critical Theory and Sustainability Science, with its emphasis on participative knowledge production (Funtowicz \& Ravetz, 1993; Funtowicz et al., 1998; Nowotny et al., 2003; Silvertown, 2009), scenario-studies (Swart, 2004; Notten, 2005; Bishop et al., 2007), visioning work (Wiek \& Iwaniec, 2013), actionable knowledge (Lang, et al., 2012; Wiek, et al., 2012), transitions (Asselt et al., 1995; Rotmans et al., 2000; Rotmans, 2003; Brugge, 2004; Kemp et al., 2007; Loorbach, 2007) and perspectives (Beumer \& Martens, 2010; Offermans, 2012; Beumer \& Martens, 2013). The main aim of Sustainability Science, with its many facets and tools, is to explore democratic and participatory ways to foster integrative solutions to acute and anticipated socio-environmental problems. It is a subversive discipline itself, working to 'overthrow' cocooned disciplinary and linear regimes of thinking and taking uncertainty in the world -- rather than striving for certainty -- as a point of departure. As such, Sustainability Science is deeply rooted in Post-Normal Science, or Mode 2 Science (Funtowicz \& Ravetz, 1993; Funtowicz, et al., 1998; Gibbons, 2000; Nowotny, et al., 2003; Martens, 2006).

Yet, sustainability scientists do not often explicitly refer to the intellectual tradition of critical thinking. Nevertheless, interesting lessons can be learned by better studying these critical philosophers and connecting their insights to the context of the contemporary trans-disciplinary struggle for a sustainable world. Especially in the debate between weaker and stronger sustainability (Robinson, 2004), the stronger, eco-centric movement could benefit (both rhetorically and practically) by the systematic intellectual exploration and unravelling of existent 'regimes' based on the methodological examples of Critical Theory.

However, there also lies a danger in Sustainability Science. Due to its highly normative and integrative character, the urgent socio-environmental problems and the high stakes involved, the temptation of uncritically employing this 'trans-discipline' as an applied science and instrumentalising it without any reflection, lurks in every corner. Of course, the main aim and legitimation of Sustainability Science is to find solutions to wicked problems (Funtowicz \& Ravetz, 1993; Funtowicz, et al., 1998; Grosskurth, 2009). Nevertheless, uncritically applying techniques and tools of sustainability science and a lack of reflection on what forces are legitimised and strengthened by adopting the 'sustainability discourse' in trans-disciplinary settings may only lead to a reinforcement of the status quo and business as usual. And this is exactly what I believe sustainability scientists want to avoid. Embracing the tradition of Critical Theory may help prevent unthoughtful instrumental use of the toolkit of sustainability science, or even better: contribute to the development of a more critical and self-reflective sustainability science (Campbell, 1996; Banerjee, 2003; Turnpenny et al., 2011). 
From a strong sustainability perspective, sadly, on the global scale the effect of an instrumental and technocratic employment of the sustainability trans-discipline can already be seen in the 'hijacking' of the concepts of sustainability and sustainable development by companies who use it to greenwash their products, policies and actions only to have higher profits and a better name (Plec \& Pettenger, 2012; Spash, 2012). Perhaps even worse, the global governance discourses on sustainability of the United Nations and of large environmental NGOs such as IUCN, seem to be currently going through a discursive shift, replacing the concept of sustainability with the 'Green Economy' (Beumer \& Martens, 2013). The once rich and subversive concept of sustainability that may have been able to change global structures for the better, is quickly eroding and slipping like sand though the hands of people who handled it in constructive and creative ways. Some authors are even proposing to replace it with other terms, such as resilience (Gunderson \& Holling, 2002; Rees, 2010) or land health (Newton \& Freyfogle, 2005), while others, such as Pim Martens, defend sustainability against all the colours invented to propose a 'new' and 'better' growth-economy: from grey to green to blue (Martens, 2013).

It may be clear that I take a 'strong-sustainability' position in this essay. I argue against the 'commodification' of sustainability as a concept and as a way of life. Hopefully the reader notices that this position isn't unreflected. With taking a perspective-position, I aim for a broader societal discussion on this point and to emphasise the importance of an ongoing critical reflection on the meaning(s) of sustainability and sustainable development for defining, developing and constructing cities and urban life (Campbell, 1996; Banerjee, 2003; Castro, 2004).

\section{Distopic Sustopias}

Perhaps, the systemic crisis on all levels, including (and perhaps especially on) the urban level, is saving sustainability from its own conceptual crisis. The increased civil activity in fostering creative solutions like urban farming, transition towns, permaculture practice, guerrilla gardening, vertical gardening, rooftop farming and earthship-building taking place all over the world, may indeed be called subversive: it represents ways of (re)making cities as "cities for people, not for profit (Kim, 1999, p.371)." These urban greeners - who could be also labelled 'Cultural Creatives' (Ray \& Anderson, 2000) -- take their 'right to the city'. They may be called pioneers of turning critical theory into critical practice (Brenner, 2009). They may be the greatest advocates for sustainability by demonstrating how small and local scale positive action can inspire new positive action and creativity all over the world (Ray \& Anderson, 2000). 
Providing space for bottom-up, democratic and participatory subversivity in cities will be a key in avoiding tragedies of Sustopia becoming Dystopia. Dystopic Sustopias already emerged in some places: Dongtan near Shanghai in China, for example, has been designed and constructed from scratch. Dongtan was supposed to become a model for what it means to build an eco-city. It became a model of how such a city should not be built. The construction started but the completion mainly failed because of corruption and funding issues. Another Dystopic Sustopia, a collaborative project between China and Singapore, is the eco-city Tianjin. The city has been constructed towards a mature phase. However, hardly any people moved in to start living there. Mobility problems, lack of diverse employment opportunities and pollution of the surrounding environments are some of the factors contributing to this well-planned eco-city becoming a ghost-town. Around Chongqing, Shiyan, Yichang, Lanzhou and Yan'an whole mountains are flattened and valleys filled up in order to stimulate "the creation of an environmentally sustainable economy based on energy-saving industries (Ross, 2014)". Environmental catastrophes are only waiting ahead in this mega-experiment of 'moving mountains.' Not even mentioning the irreversible loss of unique landscapes, ecosystems, rock formations, land flora and fauna. The interpretation of the meaning of 'environmental sustainability' can be called questionable. What really makes an eco-city an eco-city?

I believe that rather than looking for blueprints for The Real Eco-City or The Sustainable City, we might start reflecting on what it truly means to be human. Who are we and how do we want to be now and in the future? Sustopia will never exist. Sustainable people and sustainable communities might be able to exist. Plato said: "this city is what it is because our citizens are what they are." A city that will be able to durably function as a 'Good Place', small or great, will be one where its inhabitants are fundamentally ready for personal change and transformation when quality of life is at stake for any of its inhabitants.

When we are indeed zoon politkon, as Aristotle and Plato stated, the human potential will be best actualised in an urban context (Mendieta, 2010) where people grow and change because of each other. However, as Desmond Morris describes in his book The Human Zoo (Morris, 1969), many cities have already grown into places that do not fit 'human nature' anymore. They are not made by its inhabitants anymore, but they turn their citizens into sick, dumb, depressive, and aggressive captive animals (Morris, 1969). In such cases, the other side of the coin of Plato's citation becomes urgent: as Harvey states: citizens should be given "the right to change [their]selves by changing [their] cities (Harvey, 2008 as cited in: Mendieta, 2010, p.445)." 


\section{Discussion: Playing at the Edge of Chaos}

As has been argued above, the 'Good City' - a sustainable city -- is a city made by its inhabitants. It is a city where people are allowed to creatively engage with each other and with their direct environment (Florida, 2002; Hospers \& Pen, 2008). The sustainable city demands more than a top-down design and implementation of sustainability measures, technologies and infrastructures. It demands bottom-up involvement, but also it demands from its inhabitants, politicians and entrepreneurs a certain level of openness to unexpected events (Smith \& Doel, 2010). Living in a sustainable city involves being ready to learn from surprise and being ready to adapt when necessary. As such, a sustainable city is based on principles of resilience rather than stability and structural planning (McCann, 2000; Gunderson \& Holling, 2002; Folke et al., 2004; Olsson \& Folke, 2007; Bottrell, 2009; Rees, 2010; Tidball, 2012; Meijer et al., 2013). Creativity is the fundament of resilience. A creative city, according to Hospers and Pen (2008), is a city that knows to combine a concentration of people that enables a density of interaction, it is a city that knows variation between citizens and structures, it allows a degree of instability (Hospers \& Pen, 2008) and abandons ideas of control and management (Healy, 2010). In other words: a creative city is a city where its inhabitants are allowed to play at an "edge of chaos"(Braun, 2005; Karmanov \& Hamel, 2008).

However, in some conceptualisations of the sustainable city as a creative city lies a risk as well. This becomes clear in the way Hospers and Pen (2008) frame the aim of the creative city: it should help politicians to advance competitiveness on the 'global city market' and stimulate economic growth. This conceptualisation only seems to feed the business as usual paradigm of a world where economic growth is the 'god' to be served. Therefore, any institutionalisation of civil creativity needs to be monitored with critical caution. With mainstreaming initially bottom-up carried initiatives like urban agriculture, urban greening and gardening into local policy, these practices run the risk of becoming incorporated and applied to serve neo-liberalist governance structures and intentions. This will, firstly, lead towards a loss of the original subversive emancipatory intention of such practices: the city will be taken out of the hands of the citizens again. Secondly, potentially emancipatory creative urban greening projects will be employed to maintain and feed the status quo of a market driven society where governments retreat, global corporations rule, protection of the weaker fades, environmental health declines, and where people have to solve their own problems without facilitation delivered by democratically chosen representatives. Therefore, a 'truly sustainable city' is as fragile as life itself and in constant need of critical reflection, creative nurturing and enlightened engagement of citizens with a well-developed consciousness. 


\section{Conclusions: Re-embracing Cosmopolis}

Based on the reflections above I will now formulate an answer to the central question of this essay: how can the idea of a sustainable city be best conceptualised taking into account its inherently dynamic and complex character? Where humans are involved in coproducing nature, nature is involved in co-producing cities (Larson et al., 2010; Chowdhury et al., 2011; Cook et al., 2012; Lachmund, 2013; Mitchell et al., 2013). Thanks to this insight of contemporary (critical and integrative) ecologists, it may be possible to transcendent the ancient nature-city dichotomy in an intellectual, fundamental and practical way. Human nature, the city, and the planet are tightly related. This becomes evident in our times of ecological crises that affect the whole planetary life system. The necessity of these times demands a broadened human consciousness that embraces the full spectrum of spatial scale levels and of temporal scale levels at the same time.

As such, indeed the concept of Cosmopolis may become more relevant than ever before (Toulmin, 1992). However, the ancient Platonic-Aristotelian hierarchical conception of Cosmopolis provides space for a creative God and less for creative humans, who are merely the result or the play-ball of God's creation. In order to realise creative human potential, we need to reconceptualise who we are and the place we have in this world. Seeing ourselves as constituents of dynamic, multi-level networks, instead of cogwheels in the hierarchy of an economically organised order may be helpful here. According to Bruno Latour we are embedded in multi-actor networks of 'associations' (Latour, 2005). This postmodern conception of dynamic trans-social relations that include people, artefacts, technologies and nature are not yet reflected in how sustainable cities are developed and designed. A novel post-hierarchical conceptualisation of the concept of Cosmopolis -- one that is rather based on the idea of networks (Castells, 2010) -- may help in replacing the innate urge to create structural and well-planned order by embracing evolutionary notions of dynamic equilibrium and surprise in a complex universe (Steffen et al., 2005; Karmanov \& Hamel, 2008). It may help develop a human consciousness that is based on the notion of interconnectedness between the individual, the planetary, and the cosmic scale (Capra, 1996). In other words: between the back-yard and the Solar System. 


\section{PART III}

Stepping Stone Cities?

Exploring support for conservation in urban areas 



\section{CHAPTER 9}

\section{Biodiversity benefits?}

Towards a framework for discussing urban greening practices for biodiversity 
If you ever get close to a human,

And human behaviour

Be ready, be ready to get confused

Björk 


\section{Introduction}

Increasing emphasis is paid in conservation-policy and sciences fields on creating ecological networks and enhancing connectivity of green space for biodiversity (Jongman, 1995; Rodrigues, et al., 2004; Haase \& Schetke, 2010; Müller \& Kamada, 2011; Evans, 2012; EC, 2013). Europe wide, for example, the key ecological policy -- Natura 2000 -- is based on the idea of creating ecological networks through increasing structural and functional connectivity in the landscape (Kettunen, et al., 2007; Evans, 2012; EC, 2013). Generally, this policy focuses on 'natural-' and agricultural landscapes. Although increasingly recognised and explored by ecologists, the potential of cities as 'stepping stones' for biodiversity, has hardly been explored as a concrete policy-option. Civil and scientific trends point towards the need for a more systematic exploration of the ideas and practices -- integrating ecological and cultural realms -- constituting the stepping stone potential of urban areas for biodiversity (Cilliers, 2010; Millard, 2010; Chowdhury, et al., 2011; Cook, et al., 2012; Mitchell, et al., 2013). A framework to systematically address and discuss the values of urban greening practices for biodiversity and its conservation on various scale levels is still missing. The aim of this chapter is to construct such a framework building on academic interdisciplinary literature about urban greening and urban ecology.

\section{Biodiversity benefits through urban greening}

In general, urban greening practices have focused on the role of green for socio-culturaland physical and psychological well-being of inhabitants (Lachmund, 2013), for climate change mitigation through for example storm-water mitigation (Smith \& Porter, 2009), reducing the urban heat island effect (Bird \& Pinkava, 2007), noise reduction (Van Renterghem et al., 2013), carbon capturing trees (Oldfield et al., 2013) and food production (Mansfield \& Mendes, 2013): ecosystem services delivered by nature to human beings (Bolund \& Hunhammar, 1999; Beatley, 2011).

The other direction -- people delivering ecosystem services to nature or human activities benefiting biodiversity in urban areas -- is not often considered. A more systematic exploration of this direction is relevant for the discussion of the potential role of urban areas for the conservation of biodiversity in an urbanising world. Some integrative approaches to urban ecology emphasise the interconnectedness and the co-producing qualities of human and non-human nature (Larson, et al., 2010; Chowdhury, et al., 2011; Cook, et al., 2012; Mitchell, et al., 2013). Such approaches may pave the way for a better understanding of ecosystem services (or dis-services) (Lyytimäki, et al., 2008) delivered (aware or unaware) through anthropogenic activities to the ecosystem and to biodiversity. Nevertheless, the potential role of such urban based approaches for conservation hasn't been systematically explored yet. In this chapter I present an exploration of conceptual representations of urban ecosystems in the literature of various disciplines. I 
explore how these representations feed into various motivations for urban biodiversity conservation and urban greening and how through various sets of practices and ideas a variety of urban greening regimes can be identified. The central question addressed in this context is: how can urban greening practices become connected to an understanding of their potential benefit for biodiversity?

The exploration results into a framework that can be used to address both the discursive background of specific urban greening activities and the general benefits delivered to biodiversity. Through conducting three different case studies in the region of South Limburg (the SUN Vegetable Garden, Frontenpark and De Groene Loper) it is demonstrated how the building blocks of the framework can be configured in case specific ways, delivering visual representations of the regimes, motivations and biodiversity benefits underlying the specific projects.

The resulting framework can be used as a tool for discussing the benefits for biodiversity resulting from urban greening practices and for addressing potential synergies and conflicts based on motivational backgrounds, aims and worldviews that are constitutional to the projects. Above all, I believe that providing a framework to more systematically discuss urban based conservation through greening and gardening can be a way forward towards embedding and mainstreaming biodiversity and sustainability concerns in the daily course and practices of urban life.

\section{Methodology}

The methodology used in this chapter is based on grounded theory (Urquhart, 2013). Grounded theory is a method used in social sciences that generally starts with data collection instead of departing from a hypothesis. The aim is to work towards processing new theories or frameworks. A circular process of inductive and deductive analysisprocess is a key to grounded theory. The method of grounded theory gives space to find new categories, models or conceptualisations without strongly preconfigured frameworks or theories, but through the analysis process certain inferences can be made that lead the assessment towards next steps (Urquhart, 2013). Literature from various disciplines like urban ecology, sociology, environmental sociology, philosophy, and conservation studies was used in this exploration: the integral articles and books were approached as qualitative datasets. This literature has been qualitatively (inductively and deductively) studied in order to answer the following questions:

1. What urban ecological factors are considered beneficial to biodiversity?

2. What significant models of integrative urban-nature relationships can be identified?

3. What important motivations for conserving biodiversity in an urban context can be identified? 
4. What major paradigms -- or regimes -- within the field of urban greening can be identified?

I started by clustering the literature and by mapping and describing the answers that I found to these questions. For question 1 , this resulted into the emergence of a shortlist of biodiversity benefits (centre of figure 9.1* and figure 9.2). Answering question 2 resulted into the identification of seven models of the urban ecosystem. Question 3 lead to seven motivational grounds for considering biodiversity in urban contexts. Answering the fourth question resulted in to the identification of seven urban greening regimes. Also a list of popular contemporary urban greening trends and practices has been established (see box 9.1).

Figure 9.1. Urban greening and biodiversity benefits: a framework for discussing discourses and practices

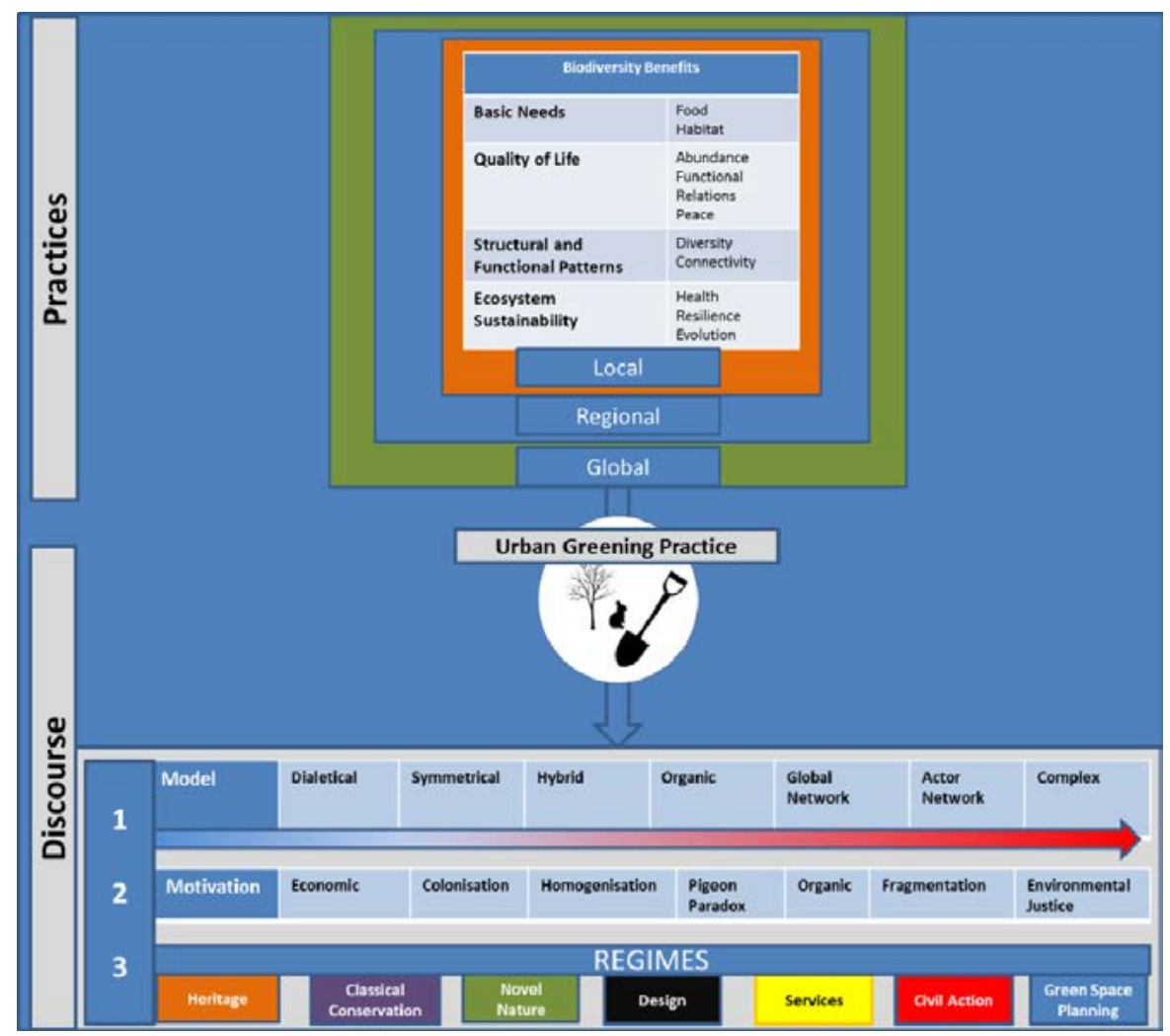

There is no particular vertical order between the horizontal sections or layers. However, the models of the urban ecosystem presented at the top layer can be seen as organised from simple models at the left, where relations between the urban and the natural are conceptualised in a rather dualistic and linear way, towards complex models on the right, where relationships are networked or non-linear. 
Figure 9.1* presents the total framework that emerged from the literature exploration. Central in the framework that emerged are the specific and concrete urban greening practices. These practices can be assessed into two directions: firstly, the discourse of the urban greening practices can be defined by configuring the blocks on the various levels in certain case-specific ways. This can be done intuitively, based on the context and information provided on the specific urban greening projects and the ideas and ideals behind them. Exploring such constellations delivers some interesting insights into heuristic sets that form the basis of specific urban greening practices and projects. I estimated that each specific urban greening practice or project, coming from different sets of motivations and models of the urban ecosystem, can have a different meaning for different people in different sets of circumstances. Drawing the constellations can help understand these differences and the basic assumptions underlying the practices being applied. The second route leads to the assessment of urban greening practices for their benefits to biodiversity. Combined with the underlying sets of assumptions and discourses, valuable new insights about urban greening and its benefits for local, regional and global biodiversity can emerge.

In the sections below, the outcomes of the systematic literature explorations are displayed. I start with a description of the identified biodiversity benefits. Then I continue with conceptual narratives of the urban ecosystem models, the motivations for urban greening and the urban greening regimes. Finally, the emerged framework has been on three urban greening cases: the SUN vegetable garden in Heerlen, Frontenpark in Maastricht and De Groene Loper in Maastricht.

\section{Box 9.1. Overview of urban greening trends and practices}

\begin{tabular}{|c|c|c|}
\hline Generic Trends & Specific Practices & Description \\
\hline \multirow[t]{8}{*}{ Urban farming } & Community farming & $\begin{array}{l}\text { Growing food together with people from a community or } \\
\text { neighbourhood. }\end{array}$ \\
\hline & Rooftop farming & Growing food or keeping bees on rooftops \\
\hline & Guerrilla farming & Growing food in public spaces or ruderal areas \\
\hline & Hydroponics & $\begin{array}{l}\text { A farming method using mineral solutions in water, without } \\
\text { soil (hydroculture) }\end{array}$ \\
\hline & Vertical farms & Growing food on walls or tower-like structures \\
\hline & Allotment gardens & Classical food garden, usually away from home \\
\hline & Permaculture & Ecosystemic food garden or food forest \\
\hline & Window farming & $\begin{array}{l}\text { Small scale food production in windows, often based on } \\
\text { hydroculture }\end{array}$ \\
\hline
\end{tabular}




\section{Box 9.1. Overview of urban greening trends and practices}

\begin{tabular}{|c|c|c|}
\hline Generic Trends & Specific Practices & Description \\
\hline $\begin{array}{l}\text { Green/blue } \\
\text { Infrastructures }\end{array}$ & $\begin{array}{l}\text { Green/Blue belts } \\
\text { Green/Blue ways }\end{array}$ & $\begin{array}{l}\text { Greening to increase structural or functional connectivity of } \\
\text { ecosystems. Stepping stones, corridors etc. }\end{array}$ \\
\hline \multirow[t]{4}{*}{ Vertical gardens } & Green walls & Often artistically planted wall-design \\
\hline & Moss graffiti & Often to convey a message to the public \\
\hline & Food towers & See vertical farms \\
\hline & Flower towers & Flower design on vertical structures \\
\hline \multirow[t]{3}{*}{ Community gardens } & For food & See community farming \\
\hline & For flowers & $\begin{array}{l}\text { Greening the neighbourhood for aesthetic reasons or to attract } \\
\text { beneficial insects or other animals }\end{array}$ \\
\hline & For social cohesion & $\begin{array}{l}\text { Greening the neighbourhood to increase social cohesion, } \\
\text { connections and feelings of safety and well-being }\end{array}$ \\
\hline \multirow[t]{2}{*}{ Civil Action } & Guerrilla Gardening & $\begin{array}{l}\text { Planting food or flowers in public or ruderal spaces } \\
\text { See vertical gardens }\end{array}$ \\
\hline & $\begin{array}{l}\text { (Moss) graffiti \& } \\
\text { Street art }\end{array}$ & $\begin{array}{l}\text { Creating message about the planet or (urban) } \\
\text { ecosystems through art-works or (green) graffiti. }\end{array}$ \\
\hline Wildscapes & $\begin{array}{l}\text { Valuing ruderal } \\
\text { nature }\end{array}$ & $\begin{array}{l}\text { Ruderal nature and old or new ruins or abandoned } \\
\text { buildings/spaces are valued for their potential for novel } \\
\text { biodiversity assemblages and species succession processes. } \\
\text { Often accentuated by artistic expressions. }\end{array}$ \\
\hline \multirow[t]{4}{*}{ Design } & $\begin{array}{l}\text { Underground } \\
\text { homes }\end{array}$ & Building in a way that gives back or sustains space for nature \\
\hline & Green roofs & $\begin{array}{l}\text { Substituting space taken away by the construction of buildings } \\
\text { on rooftops, potentially fulfilling a number of functions, such as } \\
\text { climate regulation, insulation, storm-water sequestration, } \\
\text { aesthetics, food, pollination or biodiversity enhancement } \\
\text { (especially birds and insects). }\end{array}$ \\
\hline & Architecture & $\begin{array}{l}\text { Building design that takes into account living space and habitat } \\
\text { possibilities for wild plant and animal species. }\end{array}$ \\
\hline & Parks & $\begin{array}{l}\text { Currently, many cities are developing new parks, often based } \\
\text { on landscape design. Biodiversity benefits can be central or } \\
\text { secondary. }\end{array}$ \\
\hline
\end{tabular}


Box 9.1. Overview of urban greening trends and practices

\begin{tabular}{|c|c|c|}
\hline Generic Trends & Specific Practices & Description \\
\hline \multirow[t]{5}{*}{ Home-Gardening } & Native gardens & $\begin{array}{l}\text { Planting native species to make garden fit regional biodiversity } \\
\text { and climatic conditions }\end{array}$ \\
\hline & Green gardens & Green garden of any design type \\
\hline & $\begin{array}{l}\text { Artificial animal } \\
\text { shelters/nesting }\end{array}$ & $\begin{array}{l}\text { Installing or building shelters, nesting or fodder places for wild } \\
\text { animals. }\end{array}$ \\
\hline & Insect hotels & $\begin{array}{l}\text { Creating structures that attract and deliver shelter, cocooning } \\
\text { or wintering possibilities for beneficial insects }\end{array}$ \\
\hline & $\begin{array}{l}\text { Porous walls, } \\
\text { hedges }\end{array}$ & $\begin{array}{l}\text { Walls or hedges that are constructed while considering } \\
\text { structural and/or functional, migration potential and nesting } \\
\text { and feeding of wild animal species. }\end{array}$ \\
\hline \multirow[t]{4}{*}{ Parks } & $\begin{array}{l}\text { Temporary } \\
\text { Park/Pop-Up Park }\end{array}$ & $\begin{array}{l}\text { Hundreds of park types exist, but three park-types are typical } \\
\text { in contemporary greening practices. Temporary parks, or pop- } \\
\text { up parks are often created in participation with a community } \\
\text { with the idea to make a space temporarily functional to the } \\
\text { public until final destinations of the space are defined. Often } \\
\text { this type of park appears in areas with shrinking populations or } \\
\text { economies. }\end{array}$ \\
\hline & Pocket Park & $\begin{array}{l}\text { Pocket parks are small parks, often with high design qualities, } \\
\text { that contribute to social and aesthetic needs and often at the } \\
\text { same time contribute to biodiversity (although often } \\
\text { indirectly). }\end{array}$ \\
\hline & Participatory park & $\begin{array}{l}\text { Parks usually used to be part of urban planning by local } \\
\text { governments. Presently, there is a trend of engaging citizens to } \\
\text { participate in designing and defining functional destination of } \\
\text { open spaces. }\end{array}$ \\
\hline & Classical Park & $\begin{array}{l}\text { Involving all styles of classical urban landscaping and park } \\
\text { design }\end{array}$ \\
\hline
\end{tabular}

\section{Exploring the Literature on Urban Ecology and Urban Biodiversity}

In this section the results of the inductive literature research, based on the method of grounded theory are presented. First, the identified biodiversity benefits are described. Next, I continue with discussing the identified conceptual models of urban-ecosystems. This is followed by the various motivations underlying urban greening practices. Finally, the identified urban greening regimes are discussed. 


\section{Biodiversity Benefits}

Important for exploring the potential of urban greening for global biodiversity conservation is identifying the benefits that specific urban greening practices in specific contexts deliver to local, regional and possibly global biodiversity. I call these benefits delivered by human practices to biodiversity: biodiversity benefits. Biodiversity benefits contribute to a well-functioning ecosystem and healthy levels of biodiversity. They can be defined or identified on a local, regional or global level (see figure $9.2 *$ ).

Figure 9.2. Biodiversity Benefits

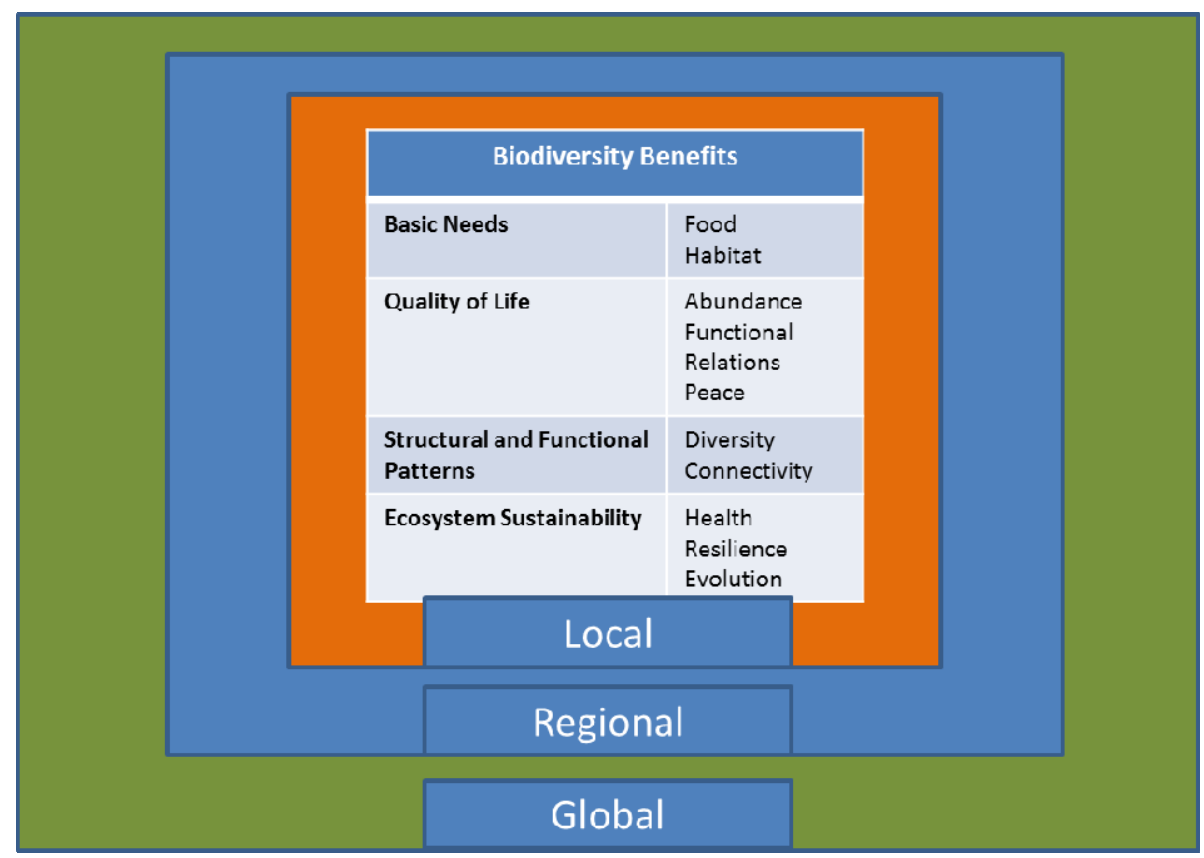

The shortlist of biodiversity benefits has been created through inductive literature assessment. An important input has been the concept of ecosystem services (MEA, 2005; TEEB, 2009, 2011). This has been combined with various definitions of biodiversity and ecosystems (Takacs, 1996; McCann, 2000; MEA, 2005; Begon, et al., 2006; Redford, et al., 2006). The shortlist involves concepts that refer to prerequisites for survival of individuals, communities and species, such as food and habitat; fundamental aspects that point towards quality of life such as a relatively undisturbed peaceful life, abundance of resources and functional relations (Redford, et al., 2006; Kettunen, et al., 2007; Whittaker \& Fernandez-Palacios, 2007; Lyytimäki, et al., 2008); aspects indicating the presence of structural and functional patterns such as diversity and connectivity (McCann, 2000; Whittaker \& Fernandez-Palacios, 2007); and finally system-dynamic aspects that contribute to a dynamic equilibrium of an ecosystem (Capra, 1996) or, in 
other words: to ecosystem sustainability. I define ecosystem sustainability as an interplay of systemic processes contributing to ecosystem health and allowing for both resilience and evolution to occur (Losos \& Schluter, 2000; McCann, 2000; Folke, et al., 2004; Whittaker \& Fernandez-Palacios, 2007). Although the biodiversity benefits are closely connected to the concept of ecosystem services (TEEB, 2009, 2011), they focus more on the services delivered to biodiversity and ecosystems by humans than on services delivered to people by ecosystemic features. By providing such benefits - which can happen intentionally but also unintentionally -- people can directly and indirectly contribute to conservation on various scale levels. Urban based conservation, therefore, is also interesting to consider for its unintended positive effects for biodiversity, which could be called surprise conservation. An example for surprise conservation is illustrated by recently published findings that spiders in urban areas thrive by artificial lighting and hard surfaces (Lowe et al., 2014). Other well-known examples can be found for example in solitary bees nesting in small holes in walls of buildings, or swallows finding a home under broad roof edges.

\section{Urban Ecology}

Ecology (coined in 1866 by Ernst Haeckel) (Takacs, 1996) has never been a scientific discipline in the traditional disciplinary sense (Takacs, 1996; Lachmund, 2013). In the first place ecology was basically used as a label to build bridges between the distinct disciplines of zoology, biology, botany, physiology and geography (Young, 2009; Jax, 2011; Kroll, 2012). Secondly, the study of 'ecology' has always had a highly normative character (Takacs, 1996). Closely tied to semi-academic organisations like natural history societies -- usually befriended with movements and people advocating the protection of nature (especially nowadays with the increase of global environmental problems) ecologists have often connected their research objectives to political agenda's or vice versa: stakeholder groups or policymakers hire ecologists as advisors in matters of landscape planning and development (Lachmund, 2013). Fuelled by the environmental crisis the historical development of ecology as a discipline has been characterised by a development towards explicitly integrating humans and human dominated environments into the network of ecosystems, resulting into the sub-discipline of urban ecology (Young, 2009).

In a (2003) paper, Marcotullio and his colleagues identified three main areas in the study of urban ecosystems: The first study-area is the relation between human health and the environment in the city; the second field of study is on how cities can be defined and regarded as ecosystems themselves and the third study-field concerns cities as modifiers of ecosystems (Marcotullio, et al., 2003). This classification illustrates a classical vision of urban ecologists on the city-nature relationship. In this classical vision, human individuals or communities aren't really regarded as active agents who both physically and cogni- 
tively contribute to the urban landscape through their culture, lifestyles and activities (Lachmund, 2013). People are either regarded as unconscious material forces in the urban metabolic system (Newman, 1999; Gandy, 2004) or as visual consumers of the urban and bio-urban spaces (Lachmund, 2013).

One of the most important turns in urban ecosystem research - a development that is still in process -- is the explicit recognition within ecology that human beings and their intentional and non-intentional cultural practices have to be incorporated into ecological studies (Pickett et al., 1997; Grimm et al., 2000; Felson, A. \& Pickett, S., 2005; Marzluf, et al., 2008; Larson, et al., 2010; Beatley, 2011; Chowdhury, et al., 2011; Cook, et al., 2012; Lachmund, 2013; Mitchell, et al., 2013). People have become key factors affecting and co-producing the landscape and environmental processes that take place (Crutzen \& Stoermer, 2000; Adams, 2013). In the history of sociology a similar process can be defined. For ages, there had existed a paradigm of "human exemption" (Rands, et al., 2010, p.292) in sociology. Since the growing environmental concerns starting to take off in the 1970s sociologists started to embrace the idea that nature and the interactions of people with their environment had to be incorporated in the study of societal systems. This eventually resulted into the sub-discipline of environmental sociology (Rands, et al., 2010). In both 'novel' directions of ecology and sociology the city-system emerged as the core research focus (Marzluf, et al., 2008; Sukopp, 2008).

Ecology and sociology are not the only disciplines concerned with urban ecosystems. There exists a fuzzy world of various sub-disciplines that have concerned themselves with 'the urban'. They are all looking to find ways to (better) conceptually link and integrate the artificially separated social and ecological realms. To mention a few: environmental history, (critical) urban theory, urban sociology, human ecology, urban geography, social geography, anthropology, political ecology, urban planning, and more recently: landscape architecture, architecture, conservation and sustainability science.

Assessing the literature from these various angles reveals that all these disciplines and sub-disciplines have been basically cocooning. If there is something like 'the wheel' in the integration of studying society and nature as a holistic system, scientists in their own disciplinary specialisation have been reinventing it many times (Clement, 2010) and in many ways. In an attempt to find some synergies and differences in the variety of integrated studies of urban ecosystems, I identified seven basic models where both natural scientists and social scientists aimed to transcend the nature-society dichotomy on the stage of the urban landscape. 


\section{Integrated models of urban ecosystems}

In order to identify the integrated models of urban ecosystems, the literature analysis was organised according to some key sub-questions: what is the central conceptual focus presented in the literature (focus); what are the guiding forces that are playing a central role in the urban ecosystem (forces); what relations to conservation are implicitly or explicitly addressed (conservation potential); what scale (local, regional or global) is being addressed? Table 9.1 presents an overview of the identified urban ecosystem models.

Table 9.1. Overview of the urban ecosystem models

\begin{tabular}{|c|c|c|c|c|c|c|c|}
\hline Model & Dialectic & Symmetric & Hybrid & Organic & Global Network & Actor Network & Complex \\
\hline Focus & Inside-Outside & $\begin{array}{l}\text { Structure \& } \\
\text { patterns }\end{array}$ & Novel nature & Metabolism & $\begin{array}{l}\text { Deterritorialisa } \\
\text { tion }\end{array}$ & Assemblages & Integration \\
\hline Force & Dialectic & Evolution & Fusion & $\begin{array}{l}\text { Socio-ecological } \\
\text { dynamics }\end{array}$ & $\begin{array}{l}\text { Time-space } \\
\text { compression }\end{array}$ & Networking & $\begin{array}{l}\text { Complex } \\
\text { dynamics }\end{array}$ \\
\hline $\begin{array}{l}\text { Conservation } \\
\text { Potential }\end{array}$ & Preservation & $\begin{array}{l}\text { Design \& } \\
\text { learning }\end{array}$ & $\begin{array}{l}\text { Creative } \\
\text { diversity }\end{array}$ & $\begin{array}{l}\text { Footprint \& } \\
\text { lifestyle }\end{array}$ & $\begin{array}{l}\text { Dematerialisati } \\
\text { on \& } \\
\text { information } \\
\text { ecology }\end{array}$ & $\begin{array}{l}\text { Education, } \\
\text { awareness, } \\
\text { social justice }\end{array}$ & Co-production \\
\hline Scale Levels & $\begin{array}{l}\text { Local } \\
\text { Regional }\end{array}$ & Local & $\begin{array}{l}\text { Local } \\
\text { Regional } \\
\text { Global }\end{array}$ & $\begin{array}{l}\text { Local } \\
\text { Regional } \\
\text { Global }\end{array}$ & Global & $\begin{array}{l}\text { Local } \\
\text { Regional } \\
\text { Global }\end{array}$ & $\begin{array}{l}\text { Local } \\
\text { Regional } \\
\text { Global }\end{array}$ \\
\hline
\end{tabular}

The dialectical model

The classical dialectical model of the relation between the urban and the natural is still present in thinking about the city-nature relationship; it cannot be neglected it in the framework constructed below. However, I refrain from further discussing this classical dialectical model of the relationship between the natural and the social and from models that describe the interdependency between the two realms: these models have always existed (see the old ideas about Cosmopolis in CHAPTER 8) and, although they aim to bring societal and ecological stages together, they inherently maintain and reinforce the nature-society divide (Clement, 2010). I am particularly interested in models that aim to find novel ways of capturing and describing the two historically separated domains holistically. I believe such integrative models better represent the world as a complex and dynamic place (Gunderson \& Holling, 2002). They also better represent what sustainability scientists are looking for when describing the world (Valkering, et al., 2006; Weinstein, 2010; Spangenberg, 2011; Lang, et al., 2012; Wiek, et al., 2012). 


\section{The symmetrical model}

In the first of the identified integrative models, cities and nature are portrayed as qualitatively indifferent. I call this the symmetrical model. Geographers Hinchcliff and Whatmore (2006) propose convivial symmetry between animals and human citizens as a model for studying the constitution of cities (Hinchcliff \& Whatmore, 2006; Lachmund, 2013). Lewis Mumford called cities a product of the earth (Mumford, 1938, 1961). They are in his view the same thing as a beehive to the bees, an ant-heap to the ants or burrow-systems to rabbits. Alexander Wilson (Wilson, 1992) took the opposite view with the same implication: ant-heaps and burrow-systems are metropolises. They exist and are constructed within global flows of commodities and functionally linked together in tight circuits that Wilson qualifies as just as political, economic and cultural as the processes that take place in human dominated metropolises (Wilson, 1992). Matthew Gandy (2004) places cities in a special category of nature, calling it "metropolitan nature (Gandy, 2004)." He sees the urbanization process as a particular way nature organises itself into an integrated socio-ecological system (Gandy, 2004) .

\section{The hybrid model}

In the next model that was identified -- the hybrid model -- the social and the natural sphere are permeating each other in urban environments. This results into a new kind of nature, that would not exist outside of cities (Kowarik, 2011; Lachmund, 2013). The model clearly reflects the idea of the whole as being something more than the sum of its parts (Capra, 1996). Although with varying emphasis, a number of authors from diverse disciplines - also outside of ecology -- propose ways of seeing the urban-nature relationship in this way. Social philosopher Donna Harraway (1999), for example, links the hybrid city with the notion of Cyborgs - "imploded germinal entities, densely packed condensations of worlds, shocked into being from the force of the implosion of the natural and the artificial, nature and culture, subject and object, machine and organic body, money and lives, narratives and reality... (Harraway, 1999, p.42)"-- connected to each other in the global village of a digitalising universe (Hassan, 2002; Hassan \& Jones, 2003). This represents a more socio-technical way of conceptualising hybridity. There are also more ecologically oriented descriptions of hybrid urban systems. In a colourful bundle of essays, for example, landscape architect Anna Jorgensen and artist Richard Keenan (2012) describe the new type of nature by featuring overgrown derelict marginalised and 'forgotten' spaces in the urban realm, created by the synergies and fusion of human and natural forces (Jorgensen \& Keenan, 2012). In such areas entirely unique ecological and socio-ecological combinations may exist. The risk of these ecologically oriented hybrid models is that they envision cities as self-containing spaces that do not take into account what constituting forces play a role beyond their boundaries and in which way cities themselves are transformative on the regional and global scale levels. This potential shortcoming is anticipated by models that extend hybridity beyond the 'local' urban 
realm such as the organic model and the Actor Network (ANT) model which will be discussed ahead.

\section{The organic model}

The hybrid model and the symmetrical model both directly link to the probably most well-known and debated model of the integrated view on urban ecosystems: the 'organic model' based on the idea of an urban metabolism. The concept of urban metabolism originates in 1965, being coined by Wolman in an article in the Scientific American where he "quantified the flows of energy and materials into and out of a hypothetical American city (Niza, et al., 2009, p.388)." The metabolism concept can be compared well to the ancient Cosmopolis idea (Toulmin, 1992; Tzoulas \& James, 2010) where cities are a 'small scale' sample of the natural order of the larger world and cosmos (Lilley, 2004b). Nancy Grimm and her colleagues (2008) argue that "cities themselves represent microcosms of the kinds of changes that are happening globally, making them informative test cases for understanding socioecological system dynamics and responses to change (Grimm, et al., 2008, p. 756)." Cities assessed as metabolic systems, are analysed for their inflows and outflows of materials and energy. Their metabolic character makes them "hotspots that drive environmental change at multiple scales (Grimm, et al., 2008, p. 756)." In the idea of the urban metabolism, local phenomena become interconnected with global dynamics. In the words of Braun (2005) the metabolic relationship between society and nature shows how "urbanization processes are producing local and global environments in new and consequential ways (Braun, 2005, p.635)."

Environmental historian Matthew Gandy (2004) merges the urban metabolism concept with ideas of hybridity. In his eyes, nature has been urbanised in cities by being assimilated into systems like urban water, highways or parks which all extend the city limits into the wide world (Gandy, 2004; Lachmund, 2013). In the case of water, Gandy describes how water, both as a natural element and a commodity is culturally and integrally linked to the dynamics of capital accumulation (Gandy, 2004). These dynamics cross scales from the local to the global. Erik Swyngedouw (2009) connects to this view by explaining how urban water is culturally transformed ('metabolized') by the processes it goes through (pumping, purification, regulation, canalization, etc.). He explains that if you look at a cup of water you can find the following elements: nature and culture, city and country, local and global (Swyngedouw, 2009). All in one cup. According to authors as Gandy and Ilya Prigogine the same cultural transformations and extensions take place in green urban 'socionature' (Prigogine, 1996; Gandy, 2004). In parks or urban green areas, air, water, animal and plant-species, seeds, vectors, foods grown there, and cultural practices undertaken, are not confined to the park or city limits. They disperse, mould and influence cultural/natural processes elsewhere as well. Like seeds being taken to another city through bird's excrements, or inspiration from a cultural event or park design that spreads to the other side of the globe. 
The metabolic concept is also the basis of the 'ecological footprint' concept: a measure for the human impact on the planet (Wackernagel \& Rees, 1996; York, et al., 2003; Rees \& Wackernagel, 2008) and in the concept of Cradle to Cradle of McDonough and Braungart (2002) where material life cycles and nutrient flows are dissembled into resources that either belong to a technosphere or to a biosphere (McDonough \& Braungart, 2002). Embedded in this dynamic context of flows, urban ecosystems are systems in nonequilibrium states evolving through stochastic processes rather than through slow and deterministic evolution (Prigogine, 1980; Prigogine \& Stengers, 1984; Capra, 1996; Prigogine, 1996). Formerly, the metabolic model was usually applied in a black-box like way: without taking into account (creative or destructive) human cultural forces; only looking technically at the materials that were put into the system and how the resulting processes affected the system (Lachmund, 2013). Now, the concept becomes increasingly entwined with the notion of human beings as active and conscious co-shapers of the socio-ecological system (Pickett, et al., 1997; Grimm, et al., 2000; Felson, A. \& Pickett, S., 2005; Larson, et al., 2010; Chowdhury, et al., 2011; Cook, et al., 2012; Lachmund, 2013; Mitchell, et al., 2013). Peter Newman (1999) explicitly expands the metabolism model towards an inclusion of normative notions of liveability. In this way, he aims to point towards a more integrative conceptualisation and to increasing the practical meaning of the metabolic concept to sustainability (Newman, 1999).

\section{The network model}

The urban metabolism model quite fluently leads to the concept of a 'network' model of urban constituencies. Here, I distinguish between a global network model (Hassan, 2002; Hassan \& Jones, 2003), the actor-network model (ANT) (Latour, 2005).

\section{The global network model}

In the global network model cities are understood as part of global networks of information flows and the notion of bounded space disappears (Scholte, 2002; Urry, 2005b, 2005a). Jan Aart Scholte talks about this global situation as deterritorialised (Scholte, 2002). The discourse handled is one of globalisation, time, speed, non-linearity, complexity, events and novelty (Sassen, 1991; Castells, 1997; Hassan, 2002; Scholte, 2002; Hassan \& Jones, 2003; Chesters, 2004; Steffen, et al., 2005; Urry, 2005b; Young, et al., 2006). The model approximates the idea of the global village but even extends this concept by its networked complexity and emphasis on flows and communications beyond the human and physical scale (Hassan, 2002; Hassan \& Jones, 2003).

Very often life - human and non-human - totally disappear from the stage in this deterritorialised model that tends to focus on abstract material and non-material (virtual) flows, stocks and resources that run to and fro on the spiderweb-lines of a complex globalised world (Urry, 2005b; Castells, 2010). This is the case for example, in a paper by Hospers and Pen (2008) who reduce Richard Florida's notion of creative cities (2002) to 
creativity in the sphere of market-mechanisms, image, competitiveness and space- and time-shrinking technologies. These elements come together in an image of cities as socalled knowledge-economy which should be made attractive to 'investors' and 'tourists' (Hospers \& Pen, 2008). The human-nature dichotomy in this model becomes transcended by excluding both humans and nature from the discourse. Oran Young and his colleagues (2009) also conceptually dehumanise urbanisation processes by suggesting that it is urbanisation itself that is "drastically altering human-environment relations in cultural as well as material terms (Young, et al., 2006, p.307)." Peter Diamandis and Steven Kotler (2012) have the optimistic thought that in a global knowledge society, the ecological footprint imposed on the planet will decrease by an emerging economy based on exponential technological improvements and innovations in energy systems, food (production) systems and health (Diamandis \& Kotler, 2012). This innovation-economy will be characterised by a shift away from a natural resource based market towards a knowledge based market.

John Urry (Urry, 2005b, 2005a) describes a world that is smooth: "de-territorialized and decentred, without a centre of power and with no fixed boundaries or barriers (Urry, 2005a, p.236)." it is a world where "[a]ll is movement (Urry, 2005a, p.236)." The concept of 'empire' is used to suggest the way power has transformed from something persons - like kings, governments or dictators - can be held accountable for, to something that has become intangible and runs through multiple networked institutions, multi-national corporations, and ever shifting assemblages of virtualised flows of money and knowledge. Power becomes democratically ungraspable and demanding accountability and transparency from responsible parties becomes hard to do in a smooth and complex networked world (Urry, 2005b, 2005a).

The ground-breaking book The Chronoscopic Society: Globalization, Time and Knowledge in the Network Economy, Robert Hassan (2003) coins the term 'information ecology'. This 'virtual environment' affects society, culture and individuals in the same way as the natural environment does. The most important 'product' produced in the information ecology is "network time" as the new "real time." It is time compressed by an overload of digital connectivity that 'promises' to save us time, but paradoxically results into a lack of (clock)time to connect to the 'real' world: friends, family and other beings and things we love. Hassan argues that the "technological, the informational and their progeny, the network, become our standard reference points in the information ecology (Hassan \& Jones, 2003, p.134)." The notion of information ecology transcends the nature-city dichotomy by virtually taking people out of the real world: the network is becoming "the global non-space, the vacuum of all vacuums [...] wherein so deeply have we internalized its logic, we do not even know that we are alienated any more (Hassan \& Jones, 2003, p.134)." People or other living beings in the information ecology, have become 'consumers', 'niche markets', 'demographic statistics', 'data-bases', or 'customer profiles' or 'extinction lists' (Hassan \& Jones, 2003, p.137). One of the most important aspects in this global network-discourse is that the talk of concrete 'down to earth' ur- 
ban space and nature is rather quickly abandoned. There is no inside, there is no outside, no social and no natural; only (cyber)space, networks, time, information and events. Scholte might call the discourse of the global network model a deterritorialised narrative (Scholte, 2002). In order to escape this void of real connectivity and lack of groundedness because of -- "the chronoscopic treadmill (Hassan \& Jones, 2003, p.173)" - Hassan, in the tradition of critical theory, proposes not to go back to caves and abandon all the digital and virtual technology and the whole network society, but to embrace ICTs and make them work for us -- societies, communities and individuals, -- instead of letting them control us and enslave us by their pace and rhythm (Hassan \& Jones, 2003). This is where Hassan, in contrast to many other global network thinkers, comes back to planet earth again.

In the global network model people seem to be detached and perhaps even alienated from the flesh and blood world. In the sense of on the ground action for biodiversity and direct benefits it doesn't provide much information, except for the central notion of creativity and the prospect of innovative (technological) solutions. In case of the network society evolving into a (virtual) information economy based on technological innovations, new forms of energy and food production, in theory, pressure could be taken off of many natural resources and elements like food and habitat for all sorts of species. Based on the global network model, people like Diamandis and Kotler (2012), for example, even see a green future full of abundance for all planetary beings emerging from the dematerialisation of the economy (Diamandis \& Kotler, 2012). Nevertheless, this abundance-society is an uncertain future scenario based on unbridled technological optimism (Giddings, 2002; Huesemann, 2003; Robinson, 2004) and the assumption of continued economic growth (Kenis \& Lievens, 2012; Martens, 2013). The dematerialised urban model could also result into negligence of care for the physical world, which could either lead to abundance or to devastation, depending on the choices people make in their lifestyles and cultural habits. The same accounts in relation to technological developments that may either speed up evolutionary patterns by increasing technologically advances species, or hamper natural evolution to occur through decreasing natural diversity. In this sense, this urban ecosystem model is surrounded by great uncertainty.

\section{The Actor Network Model}

The Actor Network model - also called the 'sociology of translation' -- coined by Bruno Latour (2005) integrally abandons concepts as ecology, sociality, flows or spatial scales. These are, according to Latour, nothing more than social constructs or "artificial conundrums (Latour, 2005, p.107)" that do not add any real understanding to the world. In Latours actor-networks action is assembled and the world is composed of associations (Latour, 2005; Smith \& Doel, 2010). In this world of associations everything is flat and sequences cannot be skipped. In this sense, one could say, everything that happens does so in the realm of the constellation of assemblages. Networks, in the eyes of Latour, are 
heterogenous associations or assemblages that function as "transformations [or translations] manifested by the many unexpected events triggered by [...] mediators that follow them along the line (Latour, 2005)." Latour proposes that the connectivity of actors does not exist by any external force or relationality other than through the way they make others do things: "there is no society, no social realm, and no social ties, but there exist translations between mediators that may generate traceable associations (Latour, 2005, p.108)." Actors, or mediators, in this sense, can be anything: bosses, stories, viruses, Charlie Parker, swallow excrements, a cup of tea, Belgian chocolate, whirl-doors, daisies, traffic bumps, scientific articles, plastic bottles, clocks or rabbits. In simple words: all the things that interact -- human or non-human -- can make up an assemblage that could be called a city. The coincidental assemblages of the actors -- who can become 'included in, or excluded from the 'actual' city assemblage -- define how a city develops and how it through its local assemblages -- associates with the rest of the world 'assemblages'. In Latour's world of associated assemblages, the dichotomy between city and nature, or social and ecological disappears by radically denouncing the concepts (Latour, 2005; Smith \& Doel, 2010). The ANT model has close links to critical theory and political ecology, with strong concerns for social justice. It is also intimately linked to the emergence of the concept of co-production (Escobar, 1999; Jasanoff, 2004, 2010; Redclift \& Woodgate, 2010; Lachmund, 2013).

In the ANT model, functional relations between actors of any quality on the range from non-human to human become central notions when talking about the meaning of this model for biodiversity. An assessment of the meaning of specific assemblages for powerstructures (equality, fairness and justice) may lead to better environmental awareness and towards a process of de-marginalising non-human actors/species and/or their habitats. Also the ANT model can fuel a search for novel and effective actor-networks or assemblages to directly or indirectly benefit local and global biodiversity conservation. To gain insight into the evolutionary aspects and dynamics of assemblages and their implications for power-dynamics on any scale level, educated minds are needed. When assemblages between technologies, humans, non-human species and landscapes are unreflected and taken for granted, outcomes could have marginalising or unforeseeable effects due to certain powers taking undemocratic and selfish leads. The ANT model thus, can directly and indirectly contribute to biodiversity and its conservation but a democratic course of the model can only take place when human actors are able to reflect in an enlightened way on (future) implications of specific assemblages.

\section{The complex dynamic model}

Since the end of the 1990s, a rather novel model for studying human-nature relations in the urban realm emerged. This model hasn't yet been extensively reviewed or discussed by urban theorists, critical urban theorists, urban sociologists or environmental sociologists. A growing number of ecologists express the need for integrated concepts for un- 
derstanding the role of humans in ecosystems (Pickett, et al., 1997). In the words of Steward Pickett and his colleagues (1997) there is a gap in the knowledge about urban ecology that "deprives basic ecology of the understanding of a widespread and extreme form of human interventions in the biosphere (Pickett, et al., 1997, p.183)." This knowledge gap limits the possibilities to improve the well-being, health and quality of life of urban residents. Pickett et al. (Pickett, et al., 1997) propose the concrete linkage of social, economic and cultural processes with biophysical processes and at the same time include a time perspective: assessment of changes on the long-term. Including history and future projections into ecological systems research is of crucial importance, because the socio-ecological system constantly changes. In this model the human-nature dichotomy is transcended by seeing humans as functionally connected to other systemic elements. The ecosystem is a dynamic socio-ecological system. The ecologists bridge the gap by focusing on a combination of the classical ecosystem approach, that is concerned with fluxes of matter and energy (also see the urban metabolism concept) and an approach that focuses on patch dynamics, spatial heterogeneity and diversity (Pickett, et al., 1997). By studying these elements, no real distinction has to be made between 'the social' and 'the natural'. The processes follow similar structures and laws of adaptation through panarchic cycles of growth, decline and renewal in search of intersystem resilience and health (Also see Grimm, et al., 2000; Gunderson \& Holling, 2002; Folke, et al., 2004).

Models of this kind are often uncritical, political and instrumental. This is expressed in narratives about how the models can be used and applied in management strategies, urban planning and the improvement of human well-being. This has become especially apparent after 1997, when the socio-ecological system model has embraced the now widely adopted concept of ecosystem services (Costanza, 1997; Groot, 2002). Although quite some critical literature on ecosystem services has emerged, the criticism usually focuses on monetising the 'invaluable': ecosystem services that are hard to express in numbers and calculus. Critical evaluation of the implications of the ecosystem services concept for power-relations and environmental justice -- Who decides on the value of ecosystem services? How are the services distributed? Who defines about access and exclusivity? -- are still scarce. The early complex dynamic system model also neglects to a large extent to include psychological and cultural aspects, such as values, norms, intentions, preferences, ethics, attitudes, lifestyles and motivations: the system is merely regarded from a point of behaviouristic interactivity that is devoid of any deeper psychological or cultural complexity of its actors.

However, a young generation of ecological scholars proposes frameworks that include these deeper human characteristics in identifying them as crucial drivers of how people engage with-, and co-produce their environment. The need for this inclusion is well represented by the way Edgar Schein (1990) proposes to define culture as: "what a group 
learns over a period of time as that group solves its problems of survival in an external environment and its problems of internal integration (Schein, 1990, p.111; Erez \& Gati, 2004)." By proposing integrated, multi-scalar frameworks to approach ecological dynamics in urban landscapes, the new generation of ecologists empirically zoom in to how people relate to their residential areas and landscapes. Authors such as Rinku Chowdhurry (2011), Elizabeth Cook (2012) and Kelli Larson (2010) intriguingly manage to build assessment models that take into account ecological factors such as patch dynamics, spatial differentiation, diversity, scale-dynamics, time and history and at the same time they reach out to psychological and cultural factors playing a role in the co-evolution of urban landscapes. Ecosystem services and disservices play important roles in these frameworks. Here, concepts form the starting point to critically reflect on the political implications of their models and point towards challenges and questions of environmental justice inequality and democracy that should be taken into account.

Herewith, these authors outline possibilities to bridge another gap: the one between theory and practice that has been identified in much work on urban ecosystems (Savard, 2011; Cook, et al., 2012; Wiek, et al., 2012; Mitchell, et al., 2013). The empirical focus on residential areas combined with a critical outlook holds promise for applying integrated assessment models like these on all ecological scales (Larson, et al., 2010; Chowdhury, et al., 2011; Cook, et al., 2012), without losing sight of questions concerning environmental justice and civil democracy. It reflects a good aim for a holistic study of ecology of cities, replacing (or complementing) the former focus on studying ecology in cities (Marzluf, et al., 2008; Sukopp, 2008; Cilliers, 2010). Such an integrative approach has some promising features when it comes to protecting local, regional and global biodiversity - including the diversity inherent to the human species and its cultures -- in a bright and wellreflected sense. Connecting ecological theory with societal practice by focusing on proximate and accessible spaces that have direct connections to citizens' lifestyles may lead to increasing environmental awareness, knowledge and feelings of 'ownership', attitude shifts, changing landscape design patterns and changing consumption and lifestyles patterns. Directly, enhancement of (functional) relations and abundance through connectivity of local-, regional and global biodiversity can impact biodiversity and evolutionary processes positively. A prerequisite for a well-functioning version of this model is a well-educated civil society that is able to reflect on potential implications of their activities from different angles.

\section{Motivations for Biodiversity Conservation in Urban Areas}

Focusing on biodiversity conservation in cities and other areas of human settlement is only a young area in conservation and ecology (Miller \& Hobbs, 2002). Traditionally, the protection of biodiversity and nature has been seen as something taking place in 'the wild', outside of densely populated landscapes (Dearborn \& Kark, 2009; Kurz \& Baudains, 2012; Lachmund, 2013). In this paragraph I categorise some key motivations for shifting 
towards a conservation focus in urban areas that were derived from the inductive qualitative literature assessment.

Many different motivations can be found for including urban areas into conservation. Dearborn and Kark (2009) identified seven motivations for urban biodiversity conservation: "preserving local biodiversity, creating stepping stones to nonurban habitat, understanding and facilitating responses to environmental change, conducting environmental education, providing ecosystem services, fulfilling ethical responsibilities, and improving human well-being (Dearborn \& Kark, 2009)." According to the authors, these different goals need different strategies to achieve them. Prioritising the motivations in one or the other way also reveals the way how biodiversity is viewed and valued (Dearborn \& Kark, 2009). In its still short tradition of studying conservation in or via urban areas, most literature has been focusing on biodiversity in- or proximate to the urban area (Savard, 2000; Cornelis \& Hermy, 2004; Heezik et al., 2012; Kurz \& Baudains, 2012). However, along with the shift towards a holistic dynamic conceptualisation of city systems, an increasing amount of authors are turning to a more global and systemic view for motivating biodiversity conservation in the urban context. Below some of these 'systemic' or 'global' motivations are conceptually explored. I identified motivations that I call: urban colonisation, global urban homogenisation, the pigeon paradox, the organic system, fragmentation and environmental justice (see figure 9.3*). The motivations can be linked to the underlying models of the urban ecosystem. These connections are explained in more detail in the descriptions of the different motivations below.

Figure 9.3. Motivations for Urban Conservation related to Urban Ecosystem Models

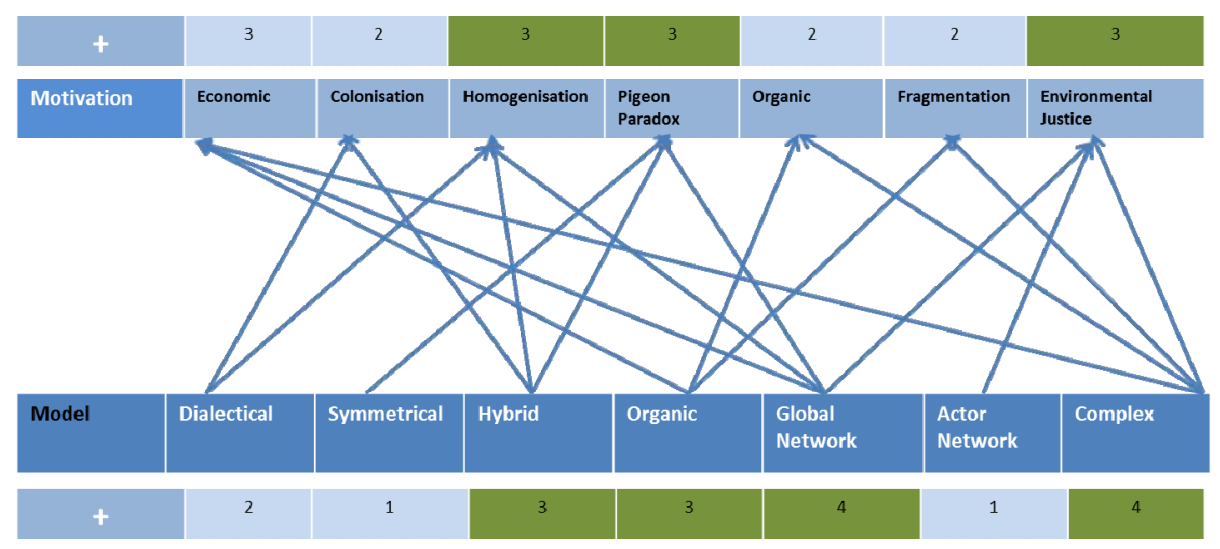

The economic motivation

Especially the literature on ecosystem services demonstrates economic motivations for paying attention to urban biodiversity (Bolund \& Hunhammar, 1999; Appleton, 2002; TEEB, 2011). Often links are made to human quality of life that is grounded in the goods 
and services ecosystems deliver for free. Maintaining or promoting green cities, therefore, will be much cheaper than substituting the free ecosystem services with technological innovations (Goklany, 2009). The economic motivation for ecosystem services can be linked to the complex dynamic model for its inclusiveness regarding the biodiversity benefits that deliver ecosystem services to human beings. The global network model is connected to the economic motivation through the creation of abundance by efficient and effective use of resources. The organic model also constitutes the economic motivation for urban biodiversity conservation through its emphasis on cross scale in- and outflows or resources. Increasing ecological productivity in urban areas, for example, can reduce the need for importing goods and services from other parts of the world.

\section{The colonisation motivation}

An important argument for motivating the study of urban areas for biodiversity conservation is that urban and suburban growth are affecting biodiversity in many places and ways (Miller \& Hobbs, 2002; Mcdonald et al., 2008). Mcdonald and his colleagues (2008) describe the implications of urbanization for global protected areas and biodiversity hotspots from the side of conflict between urbanization and biodiversity conservation (Mcdonald, et al., 2008), suggesting that more urbanization means less wild space and protected areas for biodiversity. This urban colonisation motivation does not really point into a direction of what could be done on the urban level to protect biodiversity. It pictures the urban as 'the bad' and separates it from 'good' nature. In line with this, but more positive is the argument given by Dearborn and Kark (2010) that "[b]ecause urban landscapes are increasingly large, they can be an important component of regional or global biodiversity (Dearborn \& Kark, 2009, p. 433)." Nevertheless, the colonisation motivation is based on a dialectical view on the urban-nature relationship. The colonisation motivation can also be seen as a reaction to 'novel nature' emerging in cities and as such a reaction against the notion that urban ecosystems are hybrid systems.

\section{The global homogenisation motivation}

The same dichotomised view can be traced in the motivation of global homogenisation, pointing out the loss of (bio)diversity due to the globalisation of the urban landscapes. McKinney (2002), for example, argues that cities are great homogenising forces: they look increasingly similar globally with the same shops, same parks and same skyscrapers. This global homogeneity also accounts to the diversity of species in cities: species that adapt to cities easily - such as pigeons, mice and rats -- become common in cities all over the world (McKinney, 2002), often displacing native local species (Millard, 2010). Although increasing global homogeneity (Scholte, 2002) is an interesting motivation for studying urban biodiversity and the globalisation of cities and biodiversity, just as the colonisation motivation, it particularly connects to classical conservation concepts or paradigms of saving pristine nature from 'destructive' urbanisation processes. The global homogeneity motivation can be linked to a negative evaluation of the hybrid model of 
the urban-nature relationship (novel nature) and as a reaction to homogenising forces of globalisation processes visible in the global network model.

\section{The Pigeon Paradox motivation}

More constructive within the urban realm and perhaps exemplary for most literature motivating the need to focus on urban areas for conservation is the 'pigeon paradox', a term coined by Robert Dunn and his colleagues (2006) for the situation that conservation increasingly becomes dependent on "the ability of people in cities to maintain a connection to nature (Dunn, et al., 2006, p.1814)." Dearborn and Kark, for example, argue that fostering personal experiences with proximate nature will determine policy and the fate of biodiversity in the urban "and wilder" areas (Dearborn \& Kark, 2009, p. 435). Also conservation activity in urban areas can motivate people to take part or be "supportive of other efforts at biodiversity conservation (Dearborn \& Kark, 2009, p. 436)." Therefore, conservation in urban areas has great educational, social and cultural value (Miller \& Hobbs, 2002; Cilliers, 2010; Millard, 2010; Beatley, 2011). The pigeon paradox motivation can be linked to the urban-nature relationship models of city=nature - where learning about natural structures, functions and relations for design is fundamental. It also links to the global network model, where proximate nature enforces a continuing loop of nature conservation, learning from proximate green and innovation. Through this loop the ecosystem is (ideally) maintained by dematerialisation of the economy through social and technological innovation. The hybrid model of the urban ecosystem - where novelty is embraced and ideally leads to learning and openness towards other life forms -- is also feeding in to the pigeon paradox.

\section{The metabolic system motivation}

Another motivation - the metabolic system motivation -- is based in the observation of 'indirect' metabolic effects of cities on global biodiversity (McKinney, 2002; Grimm, et al., 2008; Puppin de Oliveira et al., 2011). This motivation can be directly linked to the organic model of the urban-nature relationship explored above. Grimm et al (2008) mention that "because the urban footprint extends far beyond municipal boundaries, urbanization may also reduce native species diversity at regional and global scales (Grimm, et al., 2008, p.759)." Changes in resource use and distribution, increasing efficiency of in- and outflows of energy and material and altering urban productivity and lifestyles can be appointed as strategies for the improvement of global biodiversity. The motivation is also grounded in acknowledging the feedback loops that emerge in the complex dynamic model of the urban ecosystem.

\section{The fragmentation motivation}

Linking to the metabolic system motivation is the argument that the fragmentation of landscapes is a hammer for biodiversity (Miller \& Hobbs, 2002; Rudd, et al., 2002; Müller

\& Kamada, 2011; Mitchell, et al., 2013). Greening the urban environment and 
(re)establishing functional connectivity through stepping stones, corridors, greenbelts etc. can all be employed in the context of the fragmentation motivation. Cornelis and Hermy (2004), for example, focus on urban parks and their role as "stepping stones between isolated (semi-) natural habitats (Cornelis \& Hermy, 2004, p. 399)." The importance of connected networks of smaller and larger green nodes in urban areas is also emphasised by authors referring to island biogeography (Rudd, et al., 2002; Marzluf, et al., 2008; Mitchell, et al., 2013). Goddard et al. (2010) depart from gardens and argue that most literature on the role of urban private gardens for biodiversity conservation overlooks the need to embed urban greening and gardening activities in the surrounding landscape and in larger scales of interconnected networks of green space and habitat patches (Goddard, et al., 2010). Both the organic motivation and the fragmentation motivation aim for integrated views and/or integrated landscape connectivity. They can be linked to the complex dynamic ecosystems model of the urban-nature relationship and to the organic model of the urban ecosystem.

\section{The environmental justice motivation}

Arguments of environmental justice in relation to urban biodiversity conservation are introduced by Will Turner and his colleagues (2004). They compare five metropolitan areas across the globe to assess the global level of displacement of humans from biodiversity (people living in "biological poverty"), which is affecting both human well-being and the appreciation of nature in general (Turner, et al., 2004, p. 588; Cilliers, 2010). In a recent book on the history of the greening of Berlin, Jens Lachmund (2013) makes the reader aware of the co- evolutionary processes that take place between nature, civil activists, ecologists and policymakers. In this context, he describes the inherent normative and political characteristics of greening: it can be seen as an expression of how power-relations are aligned and how they change over time (Lachmund, 2013). Conservation in this context is often employed as a democratic or participative engagement in urban greening activities giving people access to nature and improving a feeling of community, connectedness, social cohesion and overall well-being (Kirmer \& Tischew, 2010). The environmental justice motivation finds connections with the Actor Network model and with the Global Network model - sometimes in negative interpretations of these models. Also the complex dynamic model is a basis for the environmental justice motivation: seeing the urban environment as a complex system brings into question the way the system is organised for the benefit for all and especially for the weaker and the marginalised. In the complex dynamic system the global complexities that the urban system is part of are acknowledged, but lead to the question of how the city can be developed towards the human scale (Gehl, 2010). One very important measure of the human scale as defined by architect and theoretician Jan Gehl are access to green public space (Gehl, 2010). 
As can be seen in figure 9.3*, some urban ecosystem models lead to more types of motivation for urban greening than other models. The complex model and the global network model, for example, both have four motivational connections. The symmetrical model only one. This may indicate that some urban ecosystem models may include a broader palette of arguments for motivating urban biodiversity conservation than others. At the other side, the motivations themselves can also be grounded in more or less urban ecosystem models. The economic motivation, the homogenisation motivation, the pigeon paradox motivation and the environmental justice motivation have more connections to urban ecosystem models than the colonisation motivation, the organic motivation and the fragmentation motivation. This may indicate that the first set of motivations may have more societal support than the latter set.

\section{Urban Greening Regimes}

To what type of urban greening practices and discourses do the motivations and models described and explored above lead? Below, I continue describing the results of the literature analysis by exploring urban greening regimes that I identified in the literature.

In his book Greening Berlin: the Co-Production of Science, Politics, and Urban Nature, (2013) Jens Lachmund -- in the footsteps of Arturo Escobar (Escobar, 1999; Redclift \& Woodgate, 2010) -- uses the concept of nature regimes to indicate specific types of the co-production of nature in science-policy-physical assemblages (Lachmund, 2013). In the specified context of the history of the greening of Berlin, Lachmund identifies five nature regimes: 1) green planning; 2) classical nature conservation; 3) organic urbanism; 4) landscape care; and 5) biotope protection. The explorative journey took me beyond the practical and conceptual borders of a specific city. Therefore, in this paragraph -- partly following Lachmund's categorisation and partly broadening it with insights gained through my own literature review -- I constructed seven significant contemporary paradigms of urban greening. Instead of nature regimes (Lachmund, 2013), I use the word greening regimes. I believe this term better indicates the process-character reflected in the various practices of urban greening and gardening. Besides, it abandons the historically debated concept of 'nature' and its reinforced meaning as an opposition of 'culture' (Soper, 1995).

\section{The green space planning regime}

Green space planning has a long tradition and is mostly traced back to the Industrial Revolution (Millard, 2010; Lachmund, 2013). Andy Millard defines urban green space as "open space that can support vegetation and hence make a significant contribution to urban biodiversity (Millard, 2010, p. 60)." He sees a much longer history of the intentional establishment of urban green space, which has usually been linked to notions of paradise (the old Persian word for paradise etymologically means park) represented by various cultural mythologies (Millard, 2010). We have also seen it in the late Middle Ages 
where the concept of Cosmopolis was realised in the gardens of monasteries and cathedral towns (Tzoulas \& James, 2004, 2010) (also see CHAPTER 8). Other ancient, sometimes even mythic examples comprise the Mesopotamia gardens (i.e. Hanging Gardens of Babylon), The Canyon gardens of the Native American civilizations, the gardens of Herculaneum and Pompeii, the parks of Rome, the Scandinavian green roofs, traditional Japanese gardens and a variety of ancient botanical gardens around the world (Marzano, 2008; Sukopp, 2008; Qviström, 2013).

In many historical periods, the greening of urban spaces and the design and construction of gardens reflected the wealth and well-being of its owners. The English Picturesque landscape style of the late $18^{\text {th }}$ and early $19^{\text {th }}$ century reshaped not only the English landscape, but also the gardens and parks in other European countries and in the British colonies. The Picturesque park is characterised by curved lines, gentle slopes, large lawns, small groups of trees or scattered single trees, scenic views, ponds or small lakes and pavilions or bridges (Ignatieva, 2010). The Picturesque style has become representative for the design of public urban green spaces in many parts of the world (Cranz \& Boland, 2004; Ignatieva, 2010). During the Industrial Revolution the natural-appearing Picturesque style was followed up by the more extravagant looking Gardenesque or Victorian design concept. It embraced exotic plants collected from all over the world and they were displayed in botanic gardens, in colourful flowerbeds in vast green lawns or in greenhouses (Ignatieva, 2010). At the same time planning green space in the form of parks or gardens became an intentional way to battle the stresses of the rapidly growing dangerous, dirty and unhealthy cities of an industrialising Europe (Cranz \& Boland, 2004). The more exclusive gardens and estate parks of the wealthy were designed to represent an image of a 'Lost Eden' (Ignatieva, 2010). The parks planned into the urban space of the working class of the Industrial Revolution had a different character. These so called 'reform parks' did not reflect any exotic, rural or Arcadian ideals of nature (Ignatieva, et al., 2011) but were small, rectilinear and often had a club house or play equipment for children (Cranz \& Boland, 2004). The main aim of these parks in the US was socialisation (of working immigrants) and reducing class conflict (Cranz \& Boland, 2004). In Europe the main focus was on improving the health and sanitation of workingclass citizens by giving them better access to light, fresh air and exercise (Lachmund, 2013). Parks had to function as green "islands in the sea of buildings (Lachmund, 2013, p.20)."

'Healing the urban ills' (Beatley, 2011) was also the cornerstone of the so called Garden Cities development (Hardy, 1991). During the late 1800's and the early 1920's state and city regulation had to combat the social and health excesses of the laissez faire politics of the Industrial growth era. An era of pioneering new town-planning models emerged (Hardy, 1991). The Garden City - with its design emphasis on spacious green within and surrounding the cities as green belts, with self-sustaining communities and proportioned areas of residences, industries and agricultural activity -- was one of such 
models that became very influential for future planning of residence areas in Europe and the rise of suburbs in the US (Ignatieva, et al., 2011; Lachmund, 2013).

Planning parks and urban green spaces has until now remained an antidote for the stresses, social and environmental problems emerging with city life (Beatley, 2011). During the course of history discourse and models have changed from pleasure grounds (e.g. Central Park in New York or Bois de Vincennes in Paris) to reform parks (e.g. Chicago's Pulaski Park, New York's Steward Park and San Francisco's Funston Park) (Cranz \& Boland, 2004), from open space planning and zoning (e.g. Berlin) (Cranz \& Boland, 2004; Lachmund, 2013) to urban national parks (e.g. Tijuca National Park in Rio de Janeiro or Pori National Urban Park in Finland) (Campbell, 1996) and from pocket parks (e.g. in New York, London, Paris and Heerlen) (Beumer \& Valkering, 2012) to the design of ecological networks (e.g. Boston's Metropolitan Park System) (Rudd, et al., 2002; Condon, 2010; Haase \& Schetke, 2010; Mitchell, et al., 2013).

Environmental justice based principles (Campbell, 1996), such as hygiene, health, well-being and access to green, but also (social) order, safety (Lachmund, 2013), and increasing attractivity (Ignatieva, 2010; Beatley, 2011) have been the main motivations being communicated for the legitimation of the planning of green urban spaces. Fragmentation of landscapes is another main motivation for green space planning. The aim then, is mostly to increase structural or functional connectivity of patches and processes. Especially when it concerns processes, the green space planning regime can also be linked to the organic motivation. Economic motivations also lead the green space planning regime: this can be expressed in cultural ecosystem services such as increased property value through aesthetic enhancement, but also in terms of regulating and provisioning services (Bolund \& Hunhammar, 1999). Preserving and enhancing the ecological and social values of ecosystem services is often a key issue for green space planning.

Cranz and Boland (2004) add a recent planning model: the sustainable park, which next to addressing the traditional issues as health, alienation from nature and social well-being integrates old urban infrastructures, waterways, derelict sites, industrial venues and 'new ruins' or Wildscapes (Jorgensen \& Keenan, 2012). The sustainable park includes education on heritage and nature, functions as a vehicle for citizens to discover and explore ecological processes and social interactions. It furthermore plays a role in conservation and addresses climate adaptation and mitigation (Cranz \& Boland, 2004; Simonis, 2011). The sustainable park represents an aesthetic shift from "ordering form" to "ordering processes". There is space for evolution, dynamics and chaotic creativity (Cranz \& Boland, 2004; Jorgensen \& Keenan, 2012). Civil participatory design processes and municipal facilitation instead of implementation represent a 'controlled' retreat of governance and planning (Cranz \& Boland, 2004; Beatley, 2011).

In the nature regime of planning of green spaces, often trade-offs have to be made between recreation and conservation or conservation and development (Böhme, 1992; Kirmer \& Tischew, 2010). Anthropocentric values (well-being, health, aesthetics etc.) are historically clearly prioritised. Although the shift to the sustainable parks paradigm ap- 
pears to loosen up the foremost Hierarchist management style of controlled planning on the drawing-table (Mathey \& Rink, 2010; Kowarik, 2011), the creation of green spaces in urban derelict sites - traditionally called 'wastelands' -- in times of economic decline are often only a temporary social and aesthetic solution awaiting economic better times when investments and project development in the traditional sense can take over again (Beumer \& Valkering, 2012; Jorgensen \& Keenan, 2012). Participation stimulated by governments can be a method of cutting expenses on public services and the common good. Genuine public participation can also lead to social innovations, novel ways of town planning and of infrastructure designs. This can be found in the example of Transition Towns (Hopkins, 2008).

Past and present innovative town planning concepts such as garden cities (Hardy, 1991), the concept of suburbs as suggested by Le Corbusier's 'city of tomorrow', eco-cities like Tianjin and Curitiba or the concept of mile high cities (Denver) or vertical cities (proposed in Dubai) to save terrestrial space are all examples of technological innovative changes in the socio-spatial sphere. Other typical urban greening activities for the green space planning regime are the construction of greenways, parks, pocket parks, corridors and stepping stones. These practices, especially the ones focused on infrastructures, represent a worldview of ecological interconnectedness and interdependency.

\section{The classical conservation regime}

Traditionally, conservationists have battled the trend of urban sprawl and the way cities changed natural lands into human dominated sites. Conservationists valued cities as places with an ecologically poorer quality (Mcdonald, et al., 2008). The focus of the conservationists was often at the fringes of the city, reproducing the ancient dichotomy of an 'inside' and an 'outside' of the city (Lachmund, 2013). Protection values of the old homeland and designating natural monuments, reserves, identity and memories of culture and a greener past have been key in this greening paradigm (Lachmund, 2013). Human interference with the natural landscapes should be limited by norms and rules for keeping the quiet and natural circumstances intact. Sometimes the protection accounts individual species in the urban environment, such as ancient trees or rare species. Often the protection of natural features coincides with the protection of cultural heritages and sites such as castles or ruins (Sukopp, 2008; Millard, 2010; Jorgensen \& Keenan, 2012; Lachmund, 2013). More recently the focus has shifted to the protection of diversity and the ecologically functional relations between species (Rudd, et al., 2002; Zerbe, et al., 2003; Müller, et al., 2010; Müller \& Kamada, 2011; Mitchell, et al., 2013). In the 1970s Herbert Sukopp was pioneering with the mapping of biotopes as a tool for protecting urban biodiversity itself (Sukopp, 2008; Ignatieva, 2010; Lachmund, 2013). He was one of the first to point towards the specific new ecological constellations and ruderal species typical for frequently disturbed urban space (Lachmund, 2013). 
The classical conservation regime can be connected to the motivations of protecting green space and biodiversity from urban colonization or from increasing global homogeneity. In the classical conservation regime of urban greening a shift can be distinguished from a protective view on nature where people should retreat and have to be restricted in their (overall destructive) interactions with nature, towards a view where the diversity of species is being evaluated within the context of a plurality of urban conservation aims and goals. Typical urban greening activities within the classical conservation regime are the constitution of fundraising NGOs, parks -- often protected by fences and regulated by policy. Frequently, education for conservation is linked to landscape protection by providing excursions or information panels. Civil action can also contribute to the protection and availability of patches, corridors or stepping stones of remnant nature. Townand infrastructure planning are also important classical tools for maintaining or enhancing existing green in cities.

\section{The monument and heritage regime}

Closely connected to the classical conservation regime is the tradition of monumental care. I don't directly follow Lachmund's (2013) description of this landscape care regime, because it is strongly focusing on the specific Berlin situation of the 1950s. I broadened the scope by generalization and providing some examples from various places around the world that demonstrate how heritage protection also influences biodiversity.

The regime of conserving monument and landscape heritage becomes particularly popular in times when cities are modernised. When cities are being adapted to new times and circumstances, when urban areas or fringes become destined for project development, this often results in the demolition of old structures, buildings and natural features like old trees, hedges, meadows or integral landscapes. Not only does the physical appearance change drastically, but also the life that developed on and along with the old assemblages of structures and features. A dramatic example may have been the constructions and housing replacements of citizens in Beijing in advance of the Olympic Games in 2008. Many old city-quarters with historically developed ecological and human value were wiped away to build the novel structures for the games. Sometimes the old structures were 'faked over' (Appleton, 2002), as has been the case with Qianmen, a historic marketplace that was demolished to be totally rebuilt. More than a million residents were displaced not being able to afford a life in the new luxury residences and commercial areas (Appleton, 2002). Even more extreme is the example of displacement of cities by the construction of the Three Gorges Dam affecting millions of people, plants and animals (Gellert \& Lynch, 2003). A change of cultural landscape cannot be separated from changes in the total set of systemic assemblages (Posey, 1999; Latour, 2005; Hancock, 2010).

In an older example from the Netherlands, the Association Natuurmonumenten was founded in 1905. Its aim since then has been to protect natural and cultural heritage at the same time by buying sites of considered value from its previous owners or the state. 
Special value emphasis is placed in this regime on the historical values that have evolved over time. Castles, forests, ruins, lakes or traditional agricultural lands are some examples of venues that have been bought by Natuurmonumenten in order to save the sites for modernization or project development (Hancock, 2010).

The regime of monument and landscape heritage is founded in the appreciation of tradition, old things and a certain level of nostalgia. Often the protection of sites is combined with a recreation value and with education about the past (Lachmund, 2013). Motivationally it can be linked to the aim to prevent urban colonisation or homogenisation. Greening trends that can be typically attached to this urban greening regime are the protection of existing green infrastructures and the constitution of parks potentially resulting into corridors and stepping stones for biodiversity (provisioning ecosystem services). Also the concept of Wildscapes can be relevant when it comes to the protection of old and new ruins or historically relevant sites.

\section{The novel nature regime}

Biotope protection described by Jens Lachmund can be identified as the emerging tendency of urban conservation since Sukopp (see above) (Lachmund, 2013). It is characterised by ideas of ecological networks, system dynamics, functional relations, diversity and it embraces the idea of new (hybrid) urban natures (Makhzoumi, 2000; Miller, 2005; Hofmann, et al., 2012; Jorgensen \& Keenan, 2012). The classical conservation regime emphasises the protection of the classical concept of nature and natural remnant vegetation (McKinney, 2002; Miller, 2005). Contrary, in the novel nature regime novel constellations and culturally emerged assemblages of species and functional relations are considered and valued for protection (Kowarik, 2011).

In the novel nature regime, sites that have been traditionally called 'wasteland' are valued for their specific and authentic ecological features and qualities (Jorgensen \& Keenan, 2012). Jorgensen and Keenan renamed such places with a name sounding more positive: Wildscapes (Jorgensen \& Keenan, 2012). The succession dynamics of species in ruderal sites is a process of increasing special interest for ecologists (Makhzoumi, 2000; Sukopp, 2008), as is the inclusion of pioneer species (formerly often negatively called weeds) (Holmgren, 2011). Also exotic and introduced species that can be found in domestic gardens and designed parks are included in the study of novel nature (Mathey \& Rink, 2010). Their functional relations to native plant and animal species (Miller, 2005) are considered windows of opportunity to learn for the context of on-going globalisation, urbanisation and a changing climate that could lead to massive shifts and transformations of species distributions and patterns globally. Urban environments can be testlabs for such potential circumstances (Mathey \& Rink, 2010).

The shift from classical conservation to novel nature represents the shift from looking at the ecology in cities towards the ecology of cities (Marzluf, et al., 2008; Sukopp, 2008; Cilliers, 2010). Also the loosening of formerly strict planning approaches (see above) that emerge in many socially and economically shrinking cities (Miller, 2005; 
Mathey \& Rink, 2010; Kowarik, 2011; Hofmann, et al., 2012) contribute to the novel nature regime. They are the places where the Wildscapes (Jorgensen \& Keenan, 2012) emerge and evolve and where abandoned urban spaces are conceptually and practically revitalised either through their neglect or through the co-production of (novel) assemblages of scientists, policymakers and civilians (Lachmund, 2013).

The novel nature regime is grounded in motivational ideas of environmental justice, the pigeon paradox and the impacts of fragmentation. The focus on networks, evolutionary processes, plurality and inclusion of formerly 'marginalised' spaces characterises this greening paradigm. Typical trends are guerrilla gardening, landscape design, architecture and various forms of urban farming. Also community gardening, home gardening and botanical parks can typically increase novel diversity in the urban landscape. All these trends contribute new biotic and abiotic varieties and functional relations to the urban ecosystem.

\section{The design regime}

The global spread of the Picturesque and Victorian ideals for landscape- and gardening design and the wide spread concept of modern cities, makes a number of authors reflect on the globalisation - seen as global homogenisation -- of urban design (Sassen, 1991; Nederveen-Pieterse, 2004; Nassauer \& Opdam, 2008; Cilliers, 2010; Ignatieva, 2010). The process of the homogenisation of the design of cities around the world shows that cultural change and the transformation of landscapes are intrinsically linked (Nassauer, 1995b; Ignatieva, 2010). In his inaugural speech on the natural connections between garden- and landscape architecture Erik de Jong illustrates the idea of Landscapeenhancement (Landschaftsverschönung) with his interpretation of the central notion of Goethe's book Die Wahlverwandschaften: the attractivity between people and nature leads to a process of mutual transformation: the new original reality of a park (De Jong, 2006; Hong et al., 2007). Close to the planning regime is the greening regime of landscape- and gardening design. It differs from planning in a sense that occasionally it can be more spontaneous, giving space to natural processes or being politically decentralised (Hosking, 2009).

Landscapes and gardens are not of the same category. Gardens are usually smaller 'patches' in the wider landscape. The landscape encompasses greater spatial heterogeneity (Pickett, et al., 1997; Beriatos \& Gospodini, 2004; Mak \& Ng, 2005). Landscapes can consist of e.g. lakes, mountains, urban shopping centres, roads, golf courses and residential areas at the same time. Nevertheless, the cultural practices of landscaping and gardening have much in common. They shift between ecosystemic approaches, based on scientific landscape ecology and aesthetic approaches, based on architectural or other artistic and cultural concepts (De Jong, 2006; Haase \& Schetke, 2010; Ignatieva, 2010). Currently, in the context of finding sustainable landscape solutions, synergies between the two landscaping approaches are being sought (Mak \& Ng, 2005; De Jong, 2006; Hosking, 2009; Termorshuizen \& Opdam, 2009; Holmgren, 2011). Landscape con- 
nectivity (greenbelts, green infrastructure) is a central focus for merging aesthetic and ecological principles (Rudd, et al., 2002; Chen \& Wu, 2009; Goddard, et al., 2010). Also emphasis is placed on the quality of life for humans and the exploration of ways to engage citizens in seeing beauty and relevance in ecologically based design principles (Chen \& Wu, 2009). Interestingly, many landscape architects see the environmental crisis as a design crisis: "a consequence of how things are made, buildings are constructed, and landscapes are used (Mak \& Ng, 2005, p.1016)." Landscape design has to include ecological aspects, human well-being and aesthetics in order to become sustainable and significantly contribute to sustainability (Mollison, 1988; Hemenway, 2009; Hosking, 2009; Ignatieva, 2010).

Enigmatic approaches that holistically integrate human well-being, ecological principles and design can be found all over the world. The ancient Chinese design philosophy of Feng Shui, for example, has traditionally influenced the landscape of many East Asian countries (Hong, et al., 2007). It has also become very popular in Europe and the US (Mak \& Ng, 2005; Hong, et al., 2007) and its inclusive philosophy bears many relations with deep ecological thought, such as Aldo Leopold's land ethic (Leopold, 1966; DesJardins, 2006). A recent example of a project based on Feng Shui principles can be found in the Cheonggyecheon creek that flows from the west to east of Seoul, South Korea. In this project, Qi was restored by eliminating the highway that covered and blocked the river and transforming the riverbed and edges into a public park (Hong, et al., 2007).

Xiangqiao Chen and Jianguo Wu (2009) discuss the relevance of traditional Chinese landscape architecture for sustainability. Feng Shui is not only a design principle. It is a world view and a way of life. It is based on the dualistic principle of Yin-Yang and a deep understanding of the qualities and the the variety of constellations and relationships of the Five Elements (Mak \& Ng, 2005; Hong, et al., 2007; Chen \& Wu, 2009). Aesthetics ideals are based on concepts such as a "peach blossom spring" - a paradisiacal image of a spectacularly scenic and unspoiled world -- and the "world-in-a-pot" - expressing infinite imagination of the wonders of nature and bringing them into a particular, often enclosed space (Chen \& Wu, 2009). But, perhaps most fundamentally is the basic Taoist idea of a 'unity' or 'harmony' between man and nature (Chen \& Wu, 2009). This harmony or unity can be achieved through the creation of patterns and processes that result into a design that dialectically evolves into something that is - like Goethe envisions in his Wahlverwandschaften (De Jong, 2006) -- is 'beyond' nature (Mak \& Ng, 2005). Feng Shui is based on a dynamic worldview (Mak \& Ng, 2005) and its main premise is that the relationship between humans and their environment (the quality of life) can be positively or negatively influenced by the manipulation of the vital force (energy) that drives all change, Qi (Mak \& Ng, 2005; Chen \& Wu, 2009). Ecological conditions can be improved - and so, life energy Qi can be enhanced -- by implementing optimal spatial arrangements and proper balancing of the elements (Hong, et al., 2007). 
In contrast to Western landscapes, often fragmented by permanent buildings that demonstrate an ideal of taming nature (e.g by building dams or dwellings that exclude nature from the interiors, exteriors and materials), East Asian landscapes emphasise the proper flow of Qi and the design of buildings, structures and textures that express respect for the forces of nature and the attitude of working with them instead of against them (for example by using bio-degradable and soil nurturing materials such as bamboo or wood; building on water or building pole-houses; using soft edges or rough textures in the design). Chen and Wu (2009) argue for extending Feng Shui based design principles - that are contemporarily basically confined to buildings, gardens and parks - into the general livelihoods and production activities of people (Chen \& Wu, 2009).

Another recent example of landscape design serving conservation can be found in the idea of Permaculture (Mollison, 1988). Permaculture originates in Australia in the 1970s as a design philosophy aiming for sustainable agriculture, living, land use and conservation. It is inspired by aboriginal agriculture and way of life. Permaculture combines the words 'permanence', 'agriculture' and 'culture'. It is based on the idea that good care for the ecosystem and taking notion of eco-systemic behaviour and functional relations in the design of (agricultural) landscapes, evolves into sustained life and sustained human culture. Agriculture should be transformed into a form of gardening where beneficial eco-systemic processes can be combined with human desires for design aesthetics and food production. Proper observation of the specific local situation and learning by experience are the key. In the ideal of Permaculture, people are not using the land to grow food pur sang, but to socio-ecologically co-produce healthy land and soil with the additional gift of an abundance of a variety of food (Mollison, 1988; Hemenway, 2009).

Permaculture embraces the idea of 'novel nature' (Miller, 2005; Kowarik, 2011; Hofmann, et al., 2012; Van den Berk \& Meyer Swantee, 2012) by looking to establish assemblages of species (both native to a country and naturalized or introduced) that are beneficial to each other and a help to build healthy soils and ecosystems. Healthy land will lead to an abundance of natural surplus. The idea of working with indigenous and non-indigenous species to build ecosystems sometimes conflicts with traditional conservation ideas of protecting natives and exterminating 'invasive alien species' or pests (Van den Berk \& Meyer Swantee, 2012). The founders of the permaculture concept - David Holmgren and Bill Mollison -- argue that in the global situation we have now, it is naïve to think we can eradicate non-native - naturalized - 'weeds.' It will only cost large amounts of money spent on oil-based technologies that furthermore do not benefit ecosystemic relations and the soil health. It will be hard to continue such strategies into the future (Rand, 1995). The founders demonstrate how novel ecosystems, combining native and exotic species, have value for global biodiversity. Especially the 'weedy' species have valuable functions as pioneers, quickly sequestering carbon and fixing nitrogen: they are fast soil builders. They have the ability of quickly building biomass, stabilise soils, build microclimates and function as disease buffers for 'desired' crop species 
(Hemenway, 2009; Van den Berk \& Meyer Swantee, 2012). Some spectacular results have been made in degraded areas in China and Jordan, where desertificated and degraded land was turned into thriving, lush green and diverse vegetated area again where food can be grown to sustain local populations (Van der Ree, 2000). Especially with the forecast of disruptive climate change, novel ecosystems -- especially apparent in urban environments - can function as laboratories where the combination of native and naturalized or exotic species can be studied (Mollison, 1988; Van den Berk \& Meyer Swantee, 2012). Therefore, the permaculturalists argue, it is necessary to let go the traditional worldwide established conservation paradigm of undesirable invasives (Van den Berk \& Meyer Swantee, 2012). Permaculture design principles can be easily linked to the novel nature regime that gives space to non-traditional constellations of species in unexpected areas, landscapes or patches.

Very significant but often overlooked as an opportunity of greening through design is the built environment itself. The idea of green building isn't new. In northern Scandinavia it used to be the traditional architecture to build homes with green roofs for insulation during the cold months. In the other parts of Europe, during the late $19^{\text {th }}$ century and early $20^{\text {th }}$ century organic architecture entered the architectural landscape as a reaction against the Bauhaus and the International Style with its straight lines and focus on pure human functionality. This style and its philosophy resulted into cities that can be described as 'living machines (Gehl, 2010; Dalsgaard, 2013).' Architects like Frank Lloyd Wright sought to build structures that blended into the natural environment they were built, by using natural materials from the spot or close surroundings (references). Henry van de Velde, Gaudí, Rudolf Steiner (references) (Samiei, 2013) and Friedensreich Hundertwasser (Rand, 1995) for example, designed structures that both reflected the organic forms of nature outside and the qualities of the human soul (Rand, 1995). In Steiner's eyes architecture should function as a bridge between the sensual and the spiritual world. For Hundertwasser architecture should be seen as the third skin (following the biological skin and clothes). It should fit the human body and psyche. Hundertwasser was very radical and political in his ideas: he argued for a 'window right' and a 'tree duty': people should claim their right to express their personality on the façade of their homes and everyone should be given the duty to plant trees in, around and on their homes. Everything that can be covered with snow during winter, Hundertwasser argued, should be given back to nature in the form of green(ed) space. Green roofs replacing the occupied earth had a high priority in his design concepts (Rand, 1995).

Since then, organic architecture has never really disappeared from the scene, but has remained an undercurrent in urban planning and design. It has evolved, nevertheless, from architecture that focused on the organic qualities of form and shape towards styles that integrate ecological processes like the use of waste materials (e.g. Earthships) and energy-use by using solar panels, wind turbines, heat pump, water recycling systems and insulation (e.g. the zero-emission buildings of BedZed in Beddington (Chance, 2009) 
or the Autark Passivhaus in Maastricht by architects Van de Hoek, Coenengracht and Kromwijk (Kellert, et al., 2008; AutarkHome, 2013). Nevertheless, despite the rapid increase of attention for sustainable housing, the idea of sustainability in architectural design has gotten stuck more or less on waste recycling and energy saving measures. Explicit biodiversity friendly houses are hard to find in the literature on sustainable architecture and sustainable cities.

In the cities and Biodiversity Outlook of the CBD (CBD, 2012), architects are mentioned as key actors in the debate of greening cities, but the role that architecture could play for biodiversity is not further elaborated. Green roofs are basically the only thing briefly mentioned as a possibility for creating micro-habitats and connectivity for biodiversity. But only after discussing other ecosystem services, such as their insulating functions, reducing urban heat island effects and their potentials for storm-water retention and food production (CBD, 2012). The same accounts for the WWF document Urban Solutions for a Living Planet (WWF, 2012). Green roofs are only mentioned for their capacities of mitigating heat waves. The possibility of including architecture into urban solutions for sustainability hasn't been mentioned once. Housing and construction are only mentioned in their relation to CO2 saving possibilities (WWF, 2012). The report on the Curitiba meeting, where guidelines were developed for the future role of cities for biodiversity also mentions the relevance of green buildings in the context of energy and recycling. Architectural design is discussed once in the context of considering biodiversity (Van Ham, 2013). Also the urban biodiversity literature primarily focuses on green infrastructures, parks, gardens, landscape design and other forms of urban greening, but does not structurally and substantially include the design of residence, public or commercial buildings themselves.

A handful of examples can be found though: IUCN (Baldwin et al., 2011) recently posted a link to a blog by Kaveh Samiei (2013), an Iranian architect and landscape designer. Samiei pleas for better integration of biodiversity considerations and habitat in the design of buildings and he collected some best practices examples in Iran. In his book Biophilic Cities (2011), Timothy Beatley's CHAPTER on biophilic and healthy buildings primarily focuses on "blur[ring] the lines between indoors and outdoors in home design (Beatley, 2011)." Human health and well-being advanced by green features and natural elements are discussed extensively, as in most other articles on biophilic architecture and design (Kuyken, 1989; Joye, 2007; Shin, 2012). A short section elaborates on inviting wildlife to the home, referring to the suggestion of the Australian biologist Nick Mooney to construct a house with a central well with one-way glass windows where the home owners can watch the life of possums (Beatley, 2011, p.118). Also green roofs and vertical walls are mentioned in accordance with their opportunities for biodiversity, reestablishing native populations and providing habitat for threatened species. The main aim of the idea biophilic design principles as formulated by Beatley (2011) and Kellert (Joye, 2007; Kellert, et al., 2008) is bringing people (back) into touch with nature via their 
(urban) living environments, urban tourists trips, enhancing urban qualities of life and reestablishing a balanced human-nature relationship (Kellert, et al., 2008; Beatley, 2011). This has - of course -- important indirect value for the conservation of biodiversity. Nevertheless, designing buildings as habitat for plant and animal species can be said to be under-explored. Samiei (2013) and Beatley (2011) provide the best example to be found on the topic so far. This leads to the conclusion that in the field of design and architecture there is a great opportunity and an interesting niche for the exploration of building and designing for biodiversity.

Motivations for greening in this regime are voiced in terms of increasing connectivity and reducing fragmentation of landscapes and ecosystems. Learning through aesthetic inspiration refers to the motivational basis of the pigeon paradox. Also the impression of homogenisation of urban areas may lead to artistic design approaches to diversify. Nevertheless, creating green urban spaces through design can also lead to more homogenisation of the urban environments, locally, regionally and globally, as can be seen in the historic example of the picturesque and the gardenesque landscape ideals.

Typical greening trends are -- next to the design trends such as vertical gardens, green roofs, Earthships, Cobworks, Permaculture etc. - to be found in larger or smaller green or blue infrastructure projects or urban farming activities such as window farming, hydroponics or vertical farming. However, greening urban space can also mean the creation of large monotonous patches of lawn-parks or lakes or ponds that are treated with copper sulphate (CuSO4). These 'green areas' may be aesthetically nice, but the benefit for biodiversity will be almost insignificant and perhaps even detrimental.

\section{The ecosystem services regime}

Based on global strategies to embed urban areas in conservation planning, the concept of ecosystem services (Costanza, 1997; TEEB, 2009) applied as a conservation tool has taken flight in urban areas as well (Fish \& Wildlife-Service, 1973; Folke, et al., 1997; Pickett, et al., 1997; Bolund \& Hunhammar, 1999; Savard, 2000; Sheldrake, 2007; Lyytimäki, et al., 2008; Cook, et al., 2012; Mitchell, et al., 2013). Instead of asking people for their willingness to pay for certain services provided by the ecosystem (DesJardins, 2006) the long-term value of intact ecosystems and their functions, instead of the shortterm revenues of their 'harvest' are considered (TEEB, 2009) by calculating what the substitution costs of the service would be when they have to be provided by policies or technological measures. In the regime that is proposed here, the concept of ecosystem services is central. It is based on the notion of explicit inclusion of positive and negative economic externalities in business, decision making and land use planning.

Key examples of ecosystem services based greening of urban areas are the Catskill Watershed of New York where the choice was made for ecological restoration of the hinterland as a measure to provide clean drinking water instead of building a water purification factory (TEEB, 2011). This decision saved the city an annual cost of $\$ 300$ and 
additionally $\$ 6$ to 8 billion of construction costs, whereas the restoration of the Catskills ecosystem has been realised for 1 to 1.5 billion US dollar (Bolund \& Hunhammar, 1999; TEEB, 2009). Another example can be found in Durban, South Africa. The city examined the role of open space, and its function for meeting basic needs of the poorer population. This group has worse access to infrastructures and other municipal services. The assessment showed that the city's open space system significantly improved the quality of life of the poorer population. By providing water, firewood and food the open spaces helped meeting their basic needs (TEEB, 2011). A third enigmatic example can be found in Kampala, Uganda: the Nakivubo Swamps at the outskirts provide an important biological waste water filter. An assessment of this regulating service demonstrated that an artificial facility with the same capacity would cost an annual sum of 2 million US\$ (TEEB, 2011).

Urban greening trends affiliated to the services regime are typically design trends (parks, rooftops) infrastructure projects (green or blue belts) or urban farming. Ecosystem services are primarily focused on benefiting people through fostering and enhancing cultural, provisioning and regulating services. An example of the combination of these services through an urban greening project can be found in the Interreg IV SUN project, where a vegetable garden was co-created by the municipal government, artists, inhabitants and scientists in order to stimulate social cohesion, to contribute to cost reduction in food consumption for inhabitants, increase aesthetics and safety in the neighbourhood, educate children about the origins of food and increase physical and psychological health of the inhabitants (Beumer \& Valkering, 2012; Valkering, et al., 2013).

Typical motivations for thinking in terms of the externalities regime can be found in the economic motivation, the pigeon paradox when it concerns learning about ecosystem services; creating access to ecosystem services for public or private reasons (environmental justice motivation); and creating as many as possible beneficial ecosystem processes and functional relations (organic and fragmentation motivation).

\section{The civil action regime}

Environmental activism and civic disobedience for the cause of nature have a long history in conservation, often resulting into more broadly carried environmental movements or becoming institutionalised in NGOs (Certomà, 2011). On the urban scale level Chiara Certomà (2011) describes urban greening as a "form of post-environmentalist political practice (Certomà, 2011, p.977)." In practices like guerrilla gardening -- where people plant seeds or plants in public or private 'grey' or 'brown' spaces -- political statements are made through the use of biological material. Planting and gardening becomes a form of political expression where claims are made about better access to green, a better quality of life and taking better care for the environment. At the same time the societal status quo is challenged through many greening activities (Harvey, 2003; Mendieta, 2010; Meijer, et al., 2013). The unregulated, subversive ways of the guerrilla gardeners are a form of practicing direct democracy by directly demanding civil 
participation in the socio-environmental urban landscape. Often it is a form of protest against economic globalisation and (neo-) liberalisation of markets and basic life sources (Harvey, 2003; Marcuse, 2010). Many forms of artfully greening urban spaces, like moss graffiti, vertical gardens, the creation of community gardens and urban farming practices, often turn public or private spaces into protest sites against industrialised production, consumption and lifestyle regimes, claiming back the right to live healthy, creative, spontaneous, abundant and thriving lives; of making life a work of art itself (Dohmen, 2005; Marcuse, 2010; Mendieta, 2010). Guerrilla gardening can be seen as claiming the 'right to the city' in practice (Harvey, 2003; Barton \& Tan, 2013) or as claiming back the human scale of urban life (Gehl, 2010; Dalsgaard, 2013).

The key motivation of the civil activism regime can be found in aspirations to increase environmental justice. Other motivational grounds can also be identified, such as homogenisation, colonisation and fragmentation motivations. Meijer and his colleagues see a tremendous increase of urban grassroots initiatives over the last ten years (Meijer, et al., 2013). They identify two groups of civil activists: people prompted by immediate cases like disasters or crises and people driven by long term ideals, often resulting into movements like Transition Towns (Hopkins, 2008) or Permaculture (Mollison, 1988; Hemenway, 2009; Holmgren, 2011). Meijer et al. (2013) see urban grassroots initiatives and the enabling improvised and self-organising responses to the urban situation or events that occur as crucial for maintaining social-ecological resilience of cities (Gunderson \& Holling, 2002; Folke, et al., 2004). Often, civil activism (indirectly) results into the establishment of policies, laws or NGOs. Civil engagement can also be reflected by a retreat from consumption society. Often alternative living forms (socially or architecturally) are being sought, based on subsistence and self-sufficiency.

\section{Greening Trends and Practices}

Various contemporary urban greening trends and practices were identified as categorical, based on combining the contents of a number of relevant scientific articles ranging from 1996 to 2013 (Campbell, 1996; Bolund \& Hunhammar, 1999; Makhzoumi, 2000; Savard, 2000; McKinney, 2002; Harvey, 2003; Beriatos \& Gospodini, 2004; Chiesura, 2004; Cranz \& Boland, 2004; Gaston et al., 2005b; Larsen \& Harlan, 2006; CBD, 2007a, 2007b; Hong, et al., 2007; Tzoulas, et al., 2007; Loram et al., 2008; Beumer \& Martens, 2010; Condon, 2010; Ignatieva, 2010; LaCroix, 2010; McClintock, 2010; Müller, et al., 2010; Beatley, 2011; Francis \& Lorimer, 2011; Ignatieva, et al., 2011; Kowarik, 2011; Simonis, 2011; Szilagy, 2011; Zheng, et al., 2011; Cook, et al., 2012; Hofmann, et al., 2012; Jim, 2012; Jorgensen \& Keenan, 2012; Kendal et al., 2012; WWF, 2012; Barton \& Tan, 2013; Lachmund, 2013; Meijer, et al., 2013; Samiei, 2013; Schäffler \& Swilling, 2013; Van Ham, 2013), global governance reports (CBD, 2012; ICLEI, 2012; WWF, 2012), 
popular sources such as books, gardening magazines, annual trend overviews (Jaarboek Tuin 2011 and 2012; Husqvarna Global Garden Report 2010, 2011, 2012), the Dutch commercial television programmes Eigen Huis en Tuin and Rob's Grote Tuinverbouwing and by following a number of Facebook pages and groups concerned with urban greening, gardening and design in a timeframe of three years (2011-2013).7

\section{Figure 9.4 Regimes and Trends}

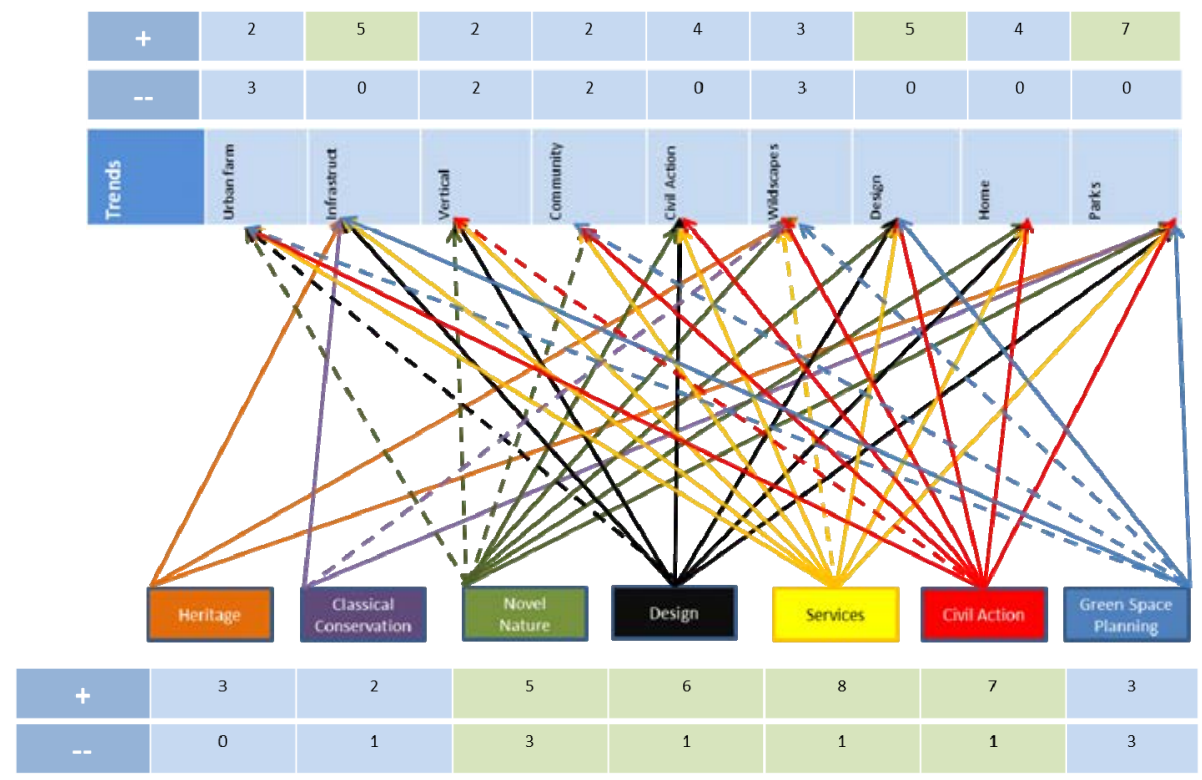

Box 9.1 shows a list of the most important contemporary urban greening trends that were identified in the various sources. In the first column the generic trends are represented. In the second column a list of specific activities is shown that can be found within each generic trend. In the third column a brief description is given of each connected specific practice.

Figure 9.4* presents schematic linkages between the urban greening regimes and the general trends with arrows. The strength between the connections is suggested by the shape of the arrow: an undashed arrow represents a strong connection; a dashed arrow a weaker connection. The arrows are drawn on the basis of the regime descriptions above and the way the literature and other sources representing the regimes referred to specific urban greening trends and practices.

7 Facebookgroups: Urban Gardeners Maastricht; Urban Gardens; Urban Organic Gardener; Urban Farm \& Garden; Mesa Urban Garden; Permaculture; Urban Green Lab; Urban Biodiversity Unit; Urban Ecosystems and Biodiversity; On Guerrilla Gardening. 
The strength of the arrows has been defined on the basis of explicit reference (strong) or implicit reference (weaker) to the practices in the sources representing specific urban greening regimes. Not only written reference was taken into account but also visual reference, for example in pictures that were shared in the Facebook groups.

It has to be taken into account that these links are based on literature and other visual or written sources. The connections are not necessarily translated into success in the 'real world'. However, linking the urban greening regimes to the more specific urban greening trends delivers some interesting insights. The services regime, for example, is represented in the largest number of urban greening trends ( 8 strong connections and 1 weaker), followed by the civil action regime ( 7 strong connections and 1 weaker). The heritage regime and the classical conservation regime both have the least links to popular urban greening trends. Also green space planning has relatively little strong links to urban greening trends. These results may indicate that the more traditional oriented urban greening regimes have less practical windows of opportunity available than the regimes that take a more novel, unexpected or even radical approach, like the novel nature regime, the design regime, the services regime or the civil action regime.

Looking at the picture from the other side reveals that the trends of parks, design and infrastructure are distributed the highest number of arrows. The park-trend is connected to 7 regimes by strong arrows, the design-trend and the trend of creating green infrastructures both to 5 regimes by 5 strong arrows. Also the trend of greening private space (home) and civil action like guerrilla gardening and street art are relatively well connected to a diversity of regimes. This may suggest that these trends have a larger potential to be brought into practice in a global context because of the larger diversity of regimes they can be embedded in. Table 9.2 shows a specification of practices that are connected to the trends. 
Table 9.2. Trends, specified practices and their links to regimes

\begin{tabular}{|c|c|c|c|c|c|c|c|c|c|c|c|c|}
\hline \multirow[t]{2}{*}{ Generic Trends } & \multirow[t]{2}{*}{ Specified Practices } & \multicolumn{11}{|c|}{ Regimes } \\
\hline & & 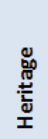 & $\begin{array}{l}\bar{\circlearrowright} \\
\text { पूर } \\
\frac{\pi}{0}\end{array}$ & $\begin{array}{l}\bar{\Xi} \\
\text { ¿o }\end{array}$ & $\frac{\sqrt[]{\mathrm{y}}}{\bar{y}}$ & 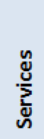 & 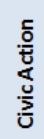 & $\begin{array}{l}\stackrel{\infty}{\frac{0}{5}} \\
\frac{\pi}{a} \\
\frac{\pi}{a}\end{array}$ & 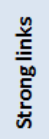 & 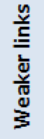 & 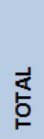 & 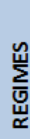 \\
\hline \multirow[t]{8}{*}{ Urban farming } & Community farming & & & $\bar{x}$ & & * & * & & 1 & 2 & 3 & \multirow{8}{*}{5} \\
\hline & Rooftop farming & & & $x$ & & * & * & & 1 & 2 & 3 & \\
\hline & Guerrilla farming & & & $x$ & & * & * & & 1 & 2 & 3 & \\
\hline & Hydroponics & & & & & $\mathrm{x}$ & & & 1 & 0 & 1 & \\
\hline & Vertical farms & & & * & & $x$ & & & 1 & 1 & 2 & \\
\hline & Allotment gardens & & & * & & $x$ & & * & 1 & 2 & 3 & \\
\hline & Permaculture & & & $x$ & $\mathrm{x}$ & $x$ & $x$ & & 4 & 0 & 4 & \\
\hline & Window farming & & & & & $x$ & & & 1 & 0 & 1 & \\
\hline \multirow[t]{2}{*}{ Infrastructure } & Green/Blue belts & $x$ & $x$ & & $x$ & $x$ & & $x$ & 5 & 0 & 5 & \multirow{2}{*}{5} \\
\hline & Green/Blue ways & $x$ & $x$ & & $x$ & $x$ & & $x$ & 5 & 0 & 5 & \\
\hline \multirow[t]{4}{*}{ Vertical gardens } & Green walls & & & * & $x$ & $x$ & $x$ & & 3 & 1 & 4 & \multirow{4}{*}{4} \\
\hline & Moss graffiti & & & * & $x$ & & $\mathrm{x}$ & & 2 & 1 & 3 & \\
\hline & Food towers & & & * & $x$ & $x$ & $x$ & & 3 & 1 & 4 & \\
\hline & Flower towers & & & * & $x$ & $x$ & & & 2 & 1 & 3 & \\
\hline \multirow[t]{3}{*}{ Community gardens } & For food & & & * & * & $x$ & $x$ & & 2 & 2 & 4 & \multirow{3}{*}{5} \\
\hline & For flowers & & & * & * & $x$ & $x$ & & 2 & 2 & 4 & \\
\hline & For social cohesion & & & * & * & $x$ & $x$ & * & 2 & 3 & 5 & \\
\hline \multirow[t]{3}{*}{ Civil Action } & Guerrilla gardening & & & $x$ & $\bar{x}$ & $x$ & $x$ & & 4 & 0 & 4 & \multirow{3}{*}{4} \\
\hline & Moss graffiti & & & $x$ & $x$ & & $x$ & & 3 & 0 & 3 & \\
\hline & Street art & & & $x$ & $x$ & & $x$ & & 3 & 0 & 3 & \\
\hline \multirow[t]{3}{*}{ Wildscapes } & Ruderal nature & & & $\bar{x}$ & & * & $x$ & & 2 & 1 & 3 & \multirow{3}{*}{4} \\
\hline & Old and new ruins & $x$ & & $x$ & & * & $x$ & & 3 & 1 & 4 & \\
\hline & Abandoned spaces & & & $x$ & & * & $x$ & & 2 & 1 & 3 & \\
\hline \multirow[t]{4}{*}{ Design } & Underground homes & & & & $x$ & $x$ & $x$ & $x$ & 4 & 0 & 4 & \multirow{4}{*}{5} \\
\hline & Green roofs & & & $x$ & $x$ & $x$ & $x$ & $x$ & 5 & 0 & 5 & \\
\hline & Architecture & & & $x$ & $x$ & $x$ & $x$ & $x$ & 5 & 0 & 5 & \\
\hline & Parks & & & $x$ & $\mathrm{x}$ & $x$ & $x$ & $\mathrm{x}$ & 5 & 0 & 5 & \\
\hline \multirow[t]{5}{*}{ Home-Gardening } & Native gardens & & & & $\bar{x}$ & $x$ & $x$ & & 3 & 0 & 3 & \multirow{5}{*}{4} \\
\hline & Green gardens & & & $x$ & $x$ & $x$ & $x$ & & 4 & 0 & 4 & \\
\hline & Shelter, nesting, food & & & & $x$ & $x$ & $x$ & & 3 & 0 & 3 & \\
\hline & Insect hotels & & & & $x$ & $x$ & $x$ & & 3 & 0 & 3 & \\
\hline & Porous walls, hedges & & & & $x$ & $x$ & $x$ & & 3 & 0 & 3 & \\
\hline \multirow[t]{4}{*}{ Parks } & Temporary Park & & & $x$ & $x$ & $x$ & $x$ & $\mathrm{x}$ & 5 & 0 & 5 & \multirow{4}{*}{7} \\
\hline & Pocket Park & & & $x$ & $x$ & & & $x$ & 3 & 0 & 3 & \\
\hline & Participatory park & & & $x$ & $x$ & $x$ & $x$ & $x$ & 5 & 0 & 5 & \\
\hline & Classical Park & $x$ & $x$ & * & $x$ & $x$ & & $x$ & 5 & 1 & 6 & \\
\hline \multicolumn{2}{|l|}{ Strong Links } & 4 & 3 & 17 & 24 & 28 & 28 & 10 & & & & \\
\hline Weaker Links & & 0 & 0 & 10 & 3 & 3 & 0 & 2 & & & & \\
\hline TOTAL & & 4 & 3 & 27 & 27 & 31 & 28 & 12 & & & & \\
\hline
\end{tabular}

I indicated the strong potential for practices occurring within a regime with an $\mathrm{X}$ and the ones with less potential with an asterisk (*). The results indicate that within the trend of urban farming Permaculture has connections to the largest diversity of regimes, but does not link to the more traditional regimes of urban greening. Window farming and 
hydroponics, often represented as urban greening practices in literature and on websites, usually only relate to indoor ecosystem services delivered to humans. They are practices not really connected to the outside urban ecosystem.

The trend of creating green infrastructures through green belts or blue belts, green ways or blue ways, or other forms of landscape connectivity, is strongly represented in the classical urban greening regimes of heritage, classical conservation and urban planning. Also creating green infrastructures is an important practice within the design and services regimes.

Within the vertical gardening trend, practices like food towers and green walls find connection with the largest diversity of urban greening regimes. Within the trend of community gardening the type where social cohesion is most important relates to the largest number of regimes. However, these are mainly weaker connections. Within civil action, guerrilla gardening practices are represented within the highest diversity of regimes. However, guerrilla gardening isn't represented in the more classical urban greening regimes. Wildscapes is one of the few trends being represented in the heritage regime, especially when greening is related to old or new ruins.

The trend of designing urban green in the form of landscaping or architecture finds a strong basis in all the urban greening regimes, except for the heritage regime and classical conservation. Related to that, smaller scale urban green design around private homes and gardens is represented within the novel nature regime, the design regime, the services regime and the civil action regime. Often the novel nature that emerges through gardening practices isn't positively valued by representatives of the classical conservation regime.

Parks are most widely represented in the regimes. They are strongly linked to all seven of them. Especially the classical park finds itself back in most of the regimes. Also the creation of temporary parks and participatory parks are practices represented by a large diversity of regimes. These exclude the more traditional ones though.

\section{Case Studies}

Although interesting patterns seem to emerge, the explorations above are still only conceptual and general. Below the theoretical framework is tested on three cases. The casechoice is based on a diversity of character of contemporary projects based in the South of the Province of Limburg. The SUN vegetable garden is a project embedded in the trend of urban farming; De Groene Loper is based on a large infrastructural design project in Maastricht; Frontenpark is a novel participatory public park development approach of the city of Maastricht. 


\section{The SUN Project Vegetable Garden in MSP Heerlen}

The Interreg IVa SUN project (Sustainable Urban Neighbourhoods)8 has been one of the many projects being involved in the refreshment of the clustered neighbourhood Meezenbroek, Schaersbergerveld and Palemig (MSP) in Heerlen, the Netherlands. The objective of the SUN project has been to engage seven urban neighbourhoods of the Meuse-Rhine Euregio into new dynamics for sustainable development through projects based on four themes: greening, energy renovation, social cohesion and economic vitality. The SUN neighbourhoods all have industrial era legacies. The SUN project involved 65,000 residents of the appointed neighbourhoods from the seven cities, five academic partners (ICIS at Maastricht University, LEMA at Université de Liège, Universiteit Hasselt, Fachhochschule Aachen and Volkshochschule Aachen) and many associative and economic players. SUN has been constructed as a cross-disciplinary and multi-level research-action, at the interface of cities, academics, citizens and private society. As one of the academic participants to the SUN project, we have been evolved in monitoring and evaluating the developments initiated by the project in MSP.

Historically, the environment where MSP has been built used to be an agricultural area. Most of the homes in the area were privately owned farms. Between 1920 and 1940, Heerlen became the centre of the coal industry in Limburg. During that time the population started to grow rapidly and in 1950's there had been a lot of construction in the area: the neighbourhoods emerged. Many of the people who lived there worked in the mines. Each family had a small home with a garden that was often used to grow vegetables and herbs. With the economic growth the mines brought, the gardens were increasingly turned into ornamental gardens. After the closure of the mines in 1965, many educated people left the area. The more recently built gallery flats owned by housing companies began to grow into clusters which attended the lower socio-economic residential groups. The social cohesion that was brought into the neighbourhoods through the hard life working in the mines disappeared gradually. The public green spaces of MSP lost its social gathering function and became increasingly unattractive (Beumer \& Valkering, 2012).

Due to the social-economic problems that emerged, MSP has been appointed a Dutch problem neighbourhood (Vogelaarwijk). The physical degradation of the area added to a feeling of unsafety and a reduction of well-being of the neighbourhood inhabitants and visitors. The Vogelaarwijk qualification allowed for many projects to become funded and the restructuring of MSP to take off in 2007. In the restructuring approach, public green space gets much attention with the aim of improving the quality of life and bringing people together again. The green - MSP activities are embedded in the Groenstructuur-

8 For more information on the SUN project see the project website: sun-euregio.eu 
plan Heerlen. The priority of the plan is to develop a green network to encourage naturedevelopment, and to strengthen the potential for inhabitants to be able to experience green in their own living environment through recreation and social activities (Beumer \& Valkering, 2012).

The polycentric structure of Heerlen has led to the emergence of a number of valuable ecological zones in and around the city, where many plant and animal species can be found that would normally not live in a city (badgers, foxes, bats, butterflies, etc.). Green in the city (including the ecological functions) is a theme that is widely supported within the field of urban development of Heerlen. However, the image of Heerlen is far from being green. This can be attributed to the fact that not much greenery is present in the downtown area. Fragmentation of the green areas through increasing urbanization leading to more construction and infrastructure, are putting pressure on a well-functioning ecosystem. The creation of green networks and connections between green spaces through the greening of neighborhoods is seen as a worthy goal that fits within the European Natura 2000 guidelines for conservation and in other national, regional, provincial, and local policy frameworks (Beumer \& Valkering, 2012).

Interviews with municipality officials that were involved in the restructuring of MSP, pointed out that they see nature in the city as having an important educational value. Besides, it promotes wellbeing and socially and environmentally responsible behaviour. Also the contribution of green to economic value of real estate is considered important. Urban green space contributes much to the image, character and popularity of a neighbourhood. However, many of the existing green areas in MSP were neglected and therefore vulnerable to vandalism. Instead of a positive and attractive atmosphere, a growing sense of insecurity had developed. The Green projects currently being installed and carried out have to turn this tide (Beumer \& Valkering, 2012).

The restructuring started with the demolishing of the old gallery flats in 2009. Due to the population decline and economic problems in the area, it was not immediately clear what had to be done with the new fallows. The planning department of Heerlen came up with some ideas that were immediately embraced by the residents. In 2008 the SUN Project facilitated the sowing of sunflower seeds in the fallows by school children, to give the area a more enjoyable atmosphere. In 2009 a group of enthusiast inhabitants started working on an initially temporary vegetable garden on a plot that was intended to become a development site for a shopping mall and health centre. Due to the ongoing economic crisis and the success of the vegetable garden, the city of Heerlen decided that the garden can stay until the inhabitants lose their interest (Beumer \& Valkering, 2012).

People of all kinds of national backgrounds and of all ages tend small plots in the vegetable garden. The garden has space for around forty gardeners and all the plots are occu- 
pied. There are picnic benches and there is a trailer where materials can be stored. The garden has become a place of social encounter, picnics, barbeques, parties, and of exchange of vegetables and seeds. Interviews with the inhabitants working in the garden revealed that the most important motivations for participation in the garden was to show the children how vegetables grow, to save some money while still eating healthy, and to get new social contacts. One of the participants told that he expected the garden to become frequently vandalized by the youth of the neighbourhood, but nothing like that has ever happened yet. People seem to enjoy and respect the place (Beumer \& valkering, 2012).

\section{The discourse of the SUN vegetable garden}

Applying the framework on the SUN vegetable garden project shows that this example urban farming is basically grounded in the services regime. Cultural Ecosystem services that increase the well-being and social safety of the inhabitants, the real estate value in the neighbourhood and aesthetic attractivity played an important role for the municipality to initiate and support the project. Learning to take care for the social and physical environment was also considered an important function of the project. Therefore, the project can be clearly linked to economic motivations, environmental justice and the pigeon paradox. The interview results show that inhabitants and municipal facilitators share the same motivations. However, inhabitants themselves tend to emphasize the economic motivations whereas the project facilitators emphasize social aspects related to environmental justice and the learning effects that can be related to the pigeon paradox.

However, there is a larger policy-context in which the greening activities and projects in Heerlen are embedded. The Groenstructuurplan Heerlen (reference) and the more recent Groenbeleidsplan (reference) reveil the character of this larger context. The municipal focus is on connecting the urban green space with the green space outside the urban areas in order to increase the quality of ecological infrastructures within the context of the Dutch policy-framework Ecologische Hoofdstructuur and the European Natura 2000 Network. It represents the complex model of the urban ecosystem, connecting it structurally and functionally to surrounding environments, involving inhabitants to cocreate new socio-environmental connectivity. This model can be linked to the fragmentation motivation. Figure 9.6* demonstrates how a local action like the SUN vegetable garden (orange colour) is being motivated by the regional consideration of reconnecting fragmented landscapes (blue colour). This motivation embeds the other three motivations relevant to the SUN vegetable garden. The figure also represents the embeddedness of the services regime within the larger green space planning regime.

\section{The Biodiversity Benefits of the SUN vegetable garden}

Considering the biodiversity benefits emerging from the SUN vegetable garden, it can be argued that the garden provides for food for insects, small mammals and birds. The 
habitat benefit can be largely neglected because of the anthropogenic disturbances taking place through the activities and the relative 'neatness' of the garden. Abundance for biodiversity isn't a direct objective represented by the project. This also relates to the relative small size of the garden.

Figure 9.6 SUN Vegetable Garden in Heerlen

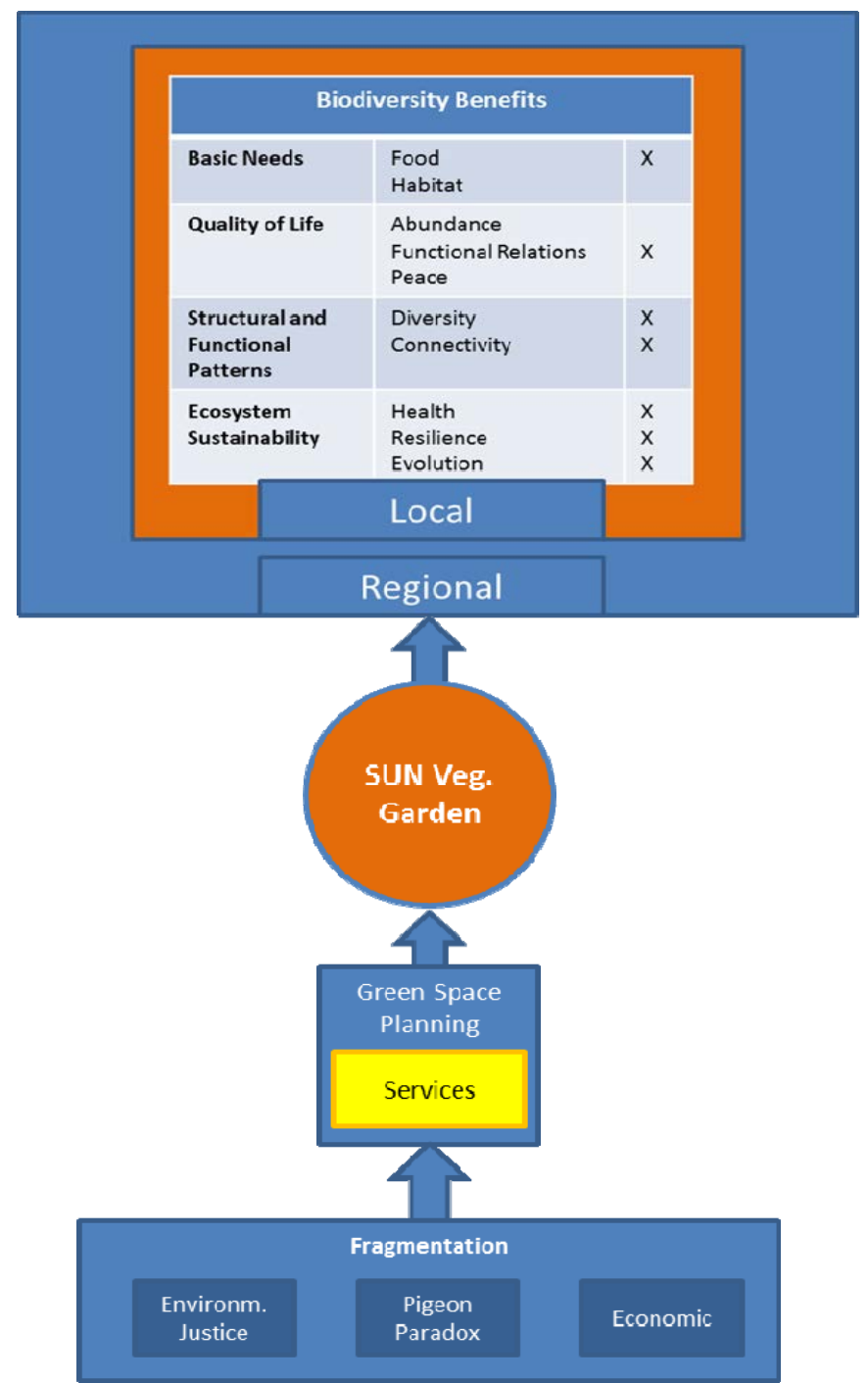

Because of the diversity of people gardening in the plot, a diversity of plant species will most probably emerge due to personal preferences. This potentially attracts a diversity of insects and small soil species. Connectivity is basically functional. The structural connectivity to the wider environment is facilitated by the larger park the garden is situated 
in and the proximity of a number of larger green patches. The garden is maintained without pesticides and herbicides and contributes to the health and resilience of people and non-human species being connected to the garden. Because of the diversity that emerges from the garden and its functional connectedness and structural proximity to larger green patches in the surrounding environment, the garden contributes to ecosystem resilience and maintains the potential of evolution.

\section{The Frontenpark in Maastricht}

Adjacent to the city centre of Maastricht in the Netherlands an area is located that has long been forgotten but has maintained interesting cultural and historical features, such as old fortifications, a railway-track, an old harbour and some old industrial buildings. Ecologically the area has developed into a rough and diverse area, with many differences in heights, water, steep slopes where wall-lizards live (the most nordic population of Europe) and many niches and corners that function as microclimates for a variety of species. The area is enclosed by some busy roads and the river Meuse that has a small finger into the area where beavers leave their traces, right in the middle of the city.

In the spring of 2013, the area has been opened up as a participatory novel urban park, where inhabitants of Maastricht can contribute to ideas and activities to take place in the area. Together with the Centre for Nature Education of Maastricht (CNME) and some other local NGOs the municipality has arranged for a series of participatory sessions where people were invited that have some connection with the area or the creation of urban parks. As a researcher on biodiversity conservation in urban areas, representing Maastricht University in the diverse group, I have also participated in the sessions. The sessions functioned as inspiration for the municipal city planners and landscape architects, who took up to work on the ideas that we shared. The sessions resulted into the idea of the creation of a participatory park that respects the emerged wildness of the area and its historical cultural and ecological assets. The charm of the area is its potential for historically or ecologically explorative and adventurous hikes. Its wildness and decor delivers creative inspiration and calls for artistic expressions based on the integrity of the site.

The west end of the park is in the immediate proximity of De Timmerfabriek, which is an old factory that is currently being transformed into the key cultural centre of Maastricht. The park is also embedded in a more fundamental restructuring programme of the north side of Maastricht. The bridge that now overarches the park area will be transferred to the north. This also changes the route of the busy traffic to Belgium and will leave the Frontenpark area more quiet and pedestrian-friendly. The redevelopment of the Frontenpark is being organised in a way that the municipality provides for the basic 
infrastructure and subsidises some local NGOs (amongst others CNME9 and Stichting Maastricht Vestingstad10) for supervision, maintenance and the organisation of events that invite citizens to co-create the park and its happenings. Yet, it is exciting to see how the park will develop in the short term and how it will adapt to changing times and needs on the longer term.

\section{The discourse of the Frontenpark}

The motivation for the creation of the park is founded the ambition of the city of Maastricht to create a stronger green infrastructure and embed the park into the larger policy framework of the Ecologische Hoofdstructuur, the Dutch policy to contribute to the European Natura 2000 Network. Opening up the new public park also contributes to a better economic connection between the North of Maastricht and the city centre, especially once the new cultural centre in De Timmerfabriek has taken off. The other main motivation is to open up the park is to make the more or less forgotten space that has a lot of interesting values available to the public. Citizens are invited to experience the past, to dream about the future and to make it concrete in activities and co-creationary processes. The motivational building blocks for the Frontenpark therefore can be basically found in the fragmentation motivation, the pigeon paradox and economic motivations. The latter motivation also relates to the participatory approach that has been chosen for the development of the park: due to the economic crisis, there isn't much money to develop the area into other purposes or to design a fancy public park that is fully dependant on municipal financial power.

The regime represented by the Frontenpark is a combination of green space planning (due to the embeddedness in the EHS and the restructuring of the infrastructure of the north area of the city), the heritage regime (the maintenance and conservation of the historical values and the species that found their niches in that area), and civil action. For the latter regime, however, the activities and actions haven't been initiated by the citizens themselves. Citizens have initially been engaged and inspired by the municipality and the NGOs to participate. Nevertheless, on the long run, the idea is that citizens take the lead in creating their own park, being supervised by the local NGOs who are especially concerned about the cultural and ecological heritage of the area. The Frontenpark can be called a representation of the hybrid model of the urban ecosystem due to the high interactivity and processes of co-creation that will take place between the human visitors and the site.

\section{Biodiversity benefits of the Frontenpark}

With regards to the biodiversity benefits the Frontenpark can be embedded into the local, regional and global context see figure $9.7^{*}$. The ecological local focus is on con-

9 http://www.cnme.nl/

10 http://maastrichtvestingstad.nl/en/ 
serving habitat for the species that developed their lives in the specific niches of the area. The regional focus is on increasing structural and functional connectivity and connecting the park into the EHS. Speaking about global biodiversity benefits, the park is intended to attract visitors and tourists, which could lead to the dissemination of the ideas behind the park and to conservation of natural and cultural values elsewhere in the world.

Food and abundance aren't directly addressed by the Frontenpark, however, there is space for the development of the ideas of citizens and through informal meetings and discussions with interested people it will be likely that some area of the park will be turned into urban agriculture. Then, it of course depends on what type of urban agriculture will be practiced if it benefits biodiversity. Diversity will most probably emerge from the park, because it intends to combine so many cultural and ecological functions. The whole structure of the park, with the fortifications and variations in slopes and elevation, already contributes to a large diversity of microclimates that are suitable for different species.

The opening of the site to the public also requires the sanitation of some of the industrial remnants, like the water-body, which has been polluted. Also the restructuring of the infrastructure around the park will contribute to the ecological health (mainly the air quality), resilience and peace (especially a decrease of danger and noise caused by motorised traffic) of the park and the north part of the city centre. However, although some vulnerable ecological parts of the Frontenpark will be protected from human disturbance, the area will be more disturbed by anthropogenic activities than it used to be before its opening to the public. Because of the high intended interaction of the public with the site, the park will be an interesting site to study processes of socio-ecological co-evolution. 
Figure 9.7. Frontenpark Maastricht

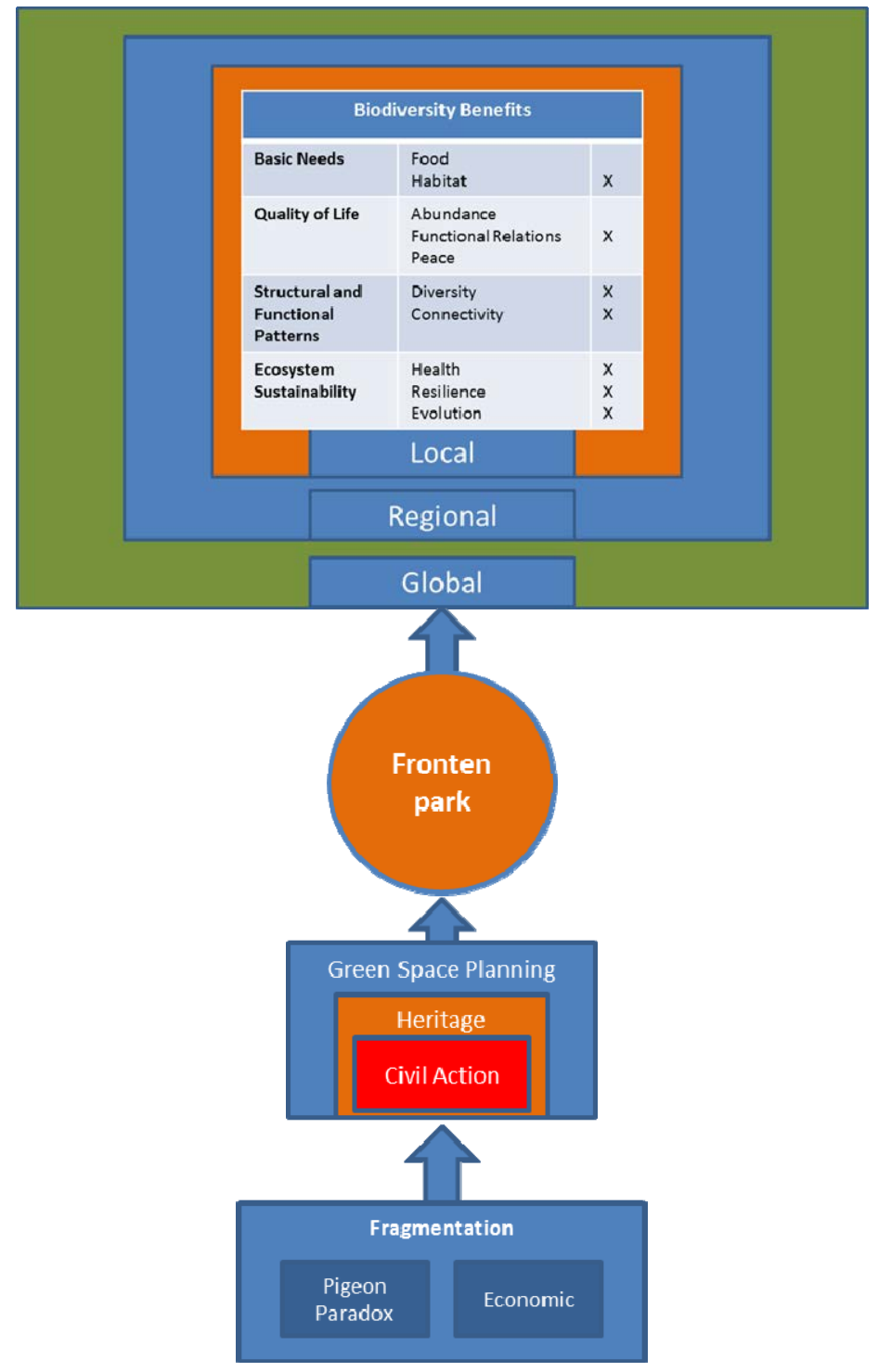

\section{De Groene Loper}

In the large infrastructural redevelopment project Avenue2, Rijkswaterstaat and the city of Maastricht aim to improve grey and green infrastructural connections between the north and the south side and better social and economic connections between the east and the west side of the city. One part of the project concerns the construction of a tunnel for the highway A2 (Avenue2), the other part of the project concerns the creation 
of De Groene Loper, a large green corridor on top of the new tunnel (Projectbureau A2 Maastricht, 2009b, 2009a)11.

Nowadays, the highway A2 is cutting the city into two parts, causing a lot of air and sound pollution for the residents due to frequent large traffic jams right in the middle of the city. The Avenue2 reconstruction will lead the highway through a double-decker tunnel where local traffic and thoroughfare are separated to improve the flow of the traffic. Local quality of life of the inhabitants will be improved thoroughly, especially through the creation of a large green corridor following the highway below from north to south. The corridor - called De Groene Loper -- will consist of a number of 2000 linden trees at the central Parklaan and will meander from south to north where it will reconnect some rural estates with high cultural and ecological value with the city of Maastricht. Key of the defragmentation (ontsnippering) emphasised by the redevelopment project is the structural reconnection of the historic estates (Landgoederen zone) with the city. Through a cycling path embedded in De Groene Loper citizens can easily access the area. Leisure-activities and recreation in De Groene Loper are encouraged within the design that is also based on Cradle2Cradle (C2C) principles (McDonough \& Braungart, 2002; Projectbureau A2 Maastricht, 2009b, 2009a). The central Parklaan will also function as a natural corridor for birds, bats and other small mammals and one of the effects is the enlargement of the living space of the Northern crested newt (Triturus cristatus), a salamander species that lives in water.

The improvement of this large green infrastructure is embedded in the Dutch EHS and in the European Natura 2000 policy frameworks. The Natura 2000 site Geuldal is within the range of influence of the development project. The potential ecological effects of the whole project have been extensively studied and evaluated in an ecological impact assessment (Projectbureau A2 Maastricht, 2009b). Not much harm is expected. However, where necessary, the project foresees in compensation of ecological losses through the creation of new nature (i.e. the Milleniumbos at the Cannerberg) and by the improvement of the ecological quality of existing sites and the water-system, and by the construction of green and blue (water) corridors in the existing area. New habitat for badgers and ponds are created and a stream (De Kanjel) has been relocated and naturalised to increase its functional properties for wildlife. Furthermore the nature on both sides of the A2 highway will become structurally reconnected. The development of wildlife tunnels and fly-over passages now reconnects the forests of Bunde (Bunderbos) and Meerssen (Kalverbos) that had been separated by the highway. The idea behind the nature-development that takes place parallel to the tunnel construction is a better connection of the natural landscape and cultural heritage in the north to the city of Maastricht. The launching of the project took place in 2011. The estimated date for opening

11 See the website A2Maastricht for visualisations and more information about the full development project: http://www.a2maastricht.nl/ 
the tunnel is in 1016. In 2026 the Groene Loper on top of the area will be completed (Projectbureau A2 Maastricht, 2009b, 2009a).

\section{The discourse of De Groene Loper}

For the evaluation of the discourse of De Groene Loper, the focus is placed on the green infrastructure part of the project. The highway itself and the tunnel are not in the scope of our focus. The entire project including the tunnel and the green infrastructure is promoted in terms of reconnection and defragmentation. Clearly, the main motivation for realisation of De Groene Loper can be found in the fragmentation of the landscape through creating green and blue infrastructures parallel to the improvement of the grey infrastructure underneath and in-between. The project is embedded in the green space planning regime: it is a top-down project lead by national, provincial and local governments and embedded within the European policy framework for nature, Natura 2000. Planning, design and implementation are all realised by official and contracted parties. Inhabitants were heard about their preferences when a choice had to be made between three projects. But the project-plans had already been developed by companies running for tender. Also the realisation of the project doesn't involve inhabitants. In practice, they are final users. Design plays a large role in the project, just as the conservation and rehabilitation of the cultural heritage in the Landgoederenzone. Therefore, it can be said that the design regime and the heritage regime play an embedded role within the green space planning regime (see figure $9.8^{*}$ ).

Also classical conservation strategies are employed through the ecological impact assessment that has been carried out before the project was allowed to start and through the European, National and Provincial legal- and policy-frameworks protecting existing ecological values, species and habitat. Where habitat could not be saved, compensation efforts had to be implemented. Finally, the project is also aiming to increase human quality of life through a greener environment and the reduction of air and noise pollution and through the creation of possibilities for recreation and leisure. Connecting the east and the west-side of the city emphasises the improvement of social connectivity and the potential of new economic opportunities. Therefore, also the services regime can be considered a part of the project.

\section{Biodiversity Benefits in De Groene Loper}

De Groene Loper includes local, regional and global biodiversity benefits. The local ones are especially related to food, habitat, structural and functional connectivity, abundance through connectivity and the creation of new green space and the improvement of ecological health through the decrease of air pollution. Local benefits extending to regional benefits are the increase of the ecological resilience and evolutionary potential of the area and the species in the area through the creation of new structural and functional connections. This will also result in larger genetic pools and new genetic exchanges. 
Figure 9.8 De Groene Loper Maastricht

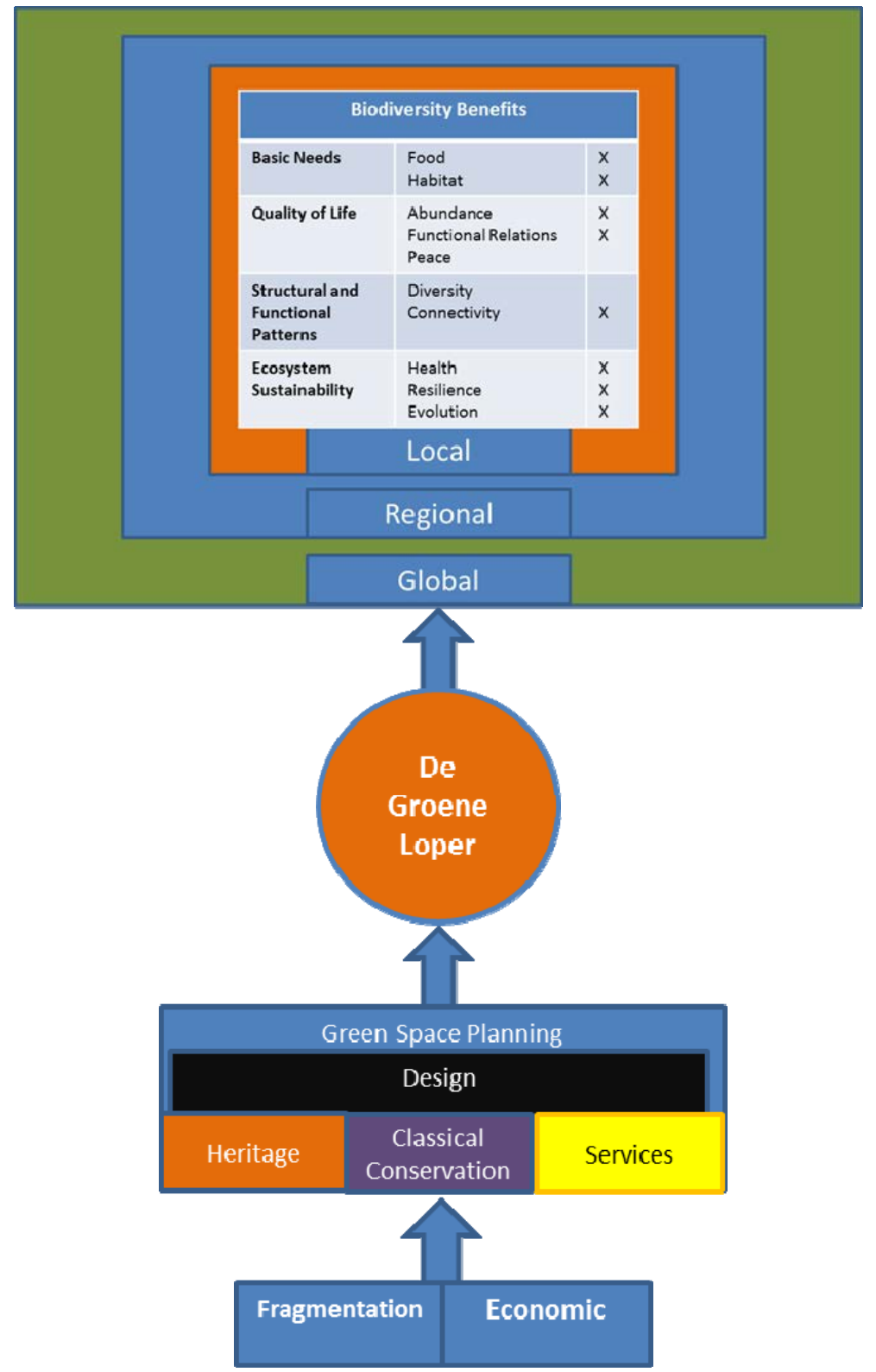

However, in the design of De Groene Loper the aspect of diversity has been largely forgotten. Diversity can be rather considered a side-effect of the new connections than an explicit aim of the project. This is especially emphasizes by the choice for 2000 trees of the same linden species. This choice may hamper the resilience of the whole area and it 
may especially become apparent in the case of the occurrence of a tree disease or pestinvasion. Also the single tree species will not contribute to the local biodiversity in the sense that they only attract specific insects and birds. The trees will most likely also contribute to certain homogeneity of soil composition in the long run.

However, De Groene Loper has an important function in the larger green infrastructure of the Netherlands and the Euregio, because it contributes to the EHS and functionally connects a number of natural sites (Projectbureau A2 Maastricht, 2009b, 2009a). Regionally it increases connectivity, diversity, functional relations, resilience, evolutionary potential and more resources become available for more species (abundance of food and habitat). Through visitors, tourists or dissemination of information about the project over the Internet, De Groene Loper has the potential to inspire projects elsewhere in the world as well.

\section{Discussion}

Why is it relevant to assess the discourses and biodiversity benefits of urban greening projects and initiatives? City ecosystems are and have always been "subject to strong and extremely variable anthropogenic influences (Sukopp, 2008, p. 86)" and to cultural, economic and social trends and developments (Giddens, 2009). It will therefore depend on the creativity of people living in the urban 'nodes' in a globally interconnected socioecological network to bring forth a sustainable planet thriving with life (Beatley, 2011; Mitchell, et al., 2013).

A societal and scientific gap exists in systematically addressing the value and benefits of urban greening practices for biodiversity. In this chapter I presented the quest for a model that can be helpful for assessing and discussing urban greening efforts and their potential benefits to biodiversity. Guided by four questions I assessed interdisciplinary literature and identified seven models of the urban ecosystem, seven motivational reasons for considering biodiversity in urban areas and seven urban greening regimes. These different sets of seven blocks can be configured in different case-specific ways. The connections provide interesting space and direction for discussing societal support for certain urban greening approaches. In order to see how the framework can become useful for specific urban greening projects, three case studies were conducted: the SUN Vegetable Garden, Frontenpark and De Groene Loper. I assessed which of the building blocks best fit to the cases. This resulted into different visual constellations of various motivations and urban greening regimes that are connected to the projects.

What do the results of the case studies suggest and how can these results be useful? The framework that emerged from the inductive literature assessment can be useful as a tool for discussion when decisions have to be taken about specific urban greening prac- 
tices. When applying the building blocks to a case study, they help framing the practice in a way that delivers insights into the context the case represents. They clarify motivational backgrounds, ideas and ideals behind the practices. Through making the ideological backgrounds of practices more explicit, the aims, goals and means can be discussed and shaped in more conscious manners. Through connecting the discursive backgrounds of greening practices and projects to the biodiversity benefits, the value of urban greening practices for biodiversity may be taken more consciously into account and can be more systematically discussed.

The presented Biodiversity Benefits framework is basically intended to initiate debate about the values of urban greening practices for biodiversity conservation, it is not intended and designed to deliver detailed and specialised information about the local ecosystem, its species and patterns. When necessary, ecological impact assessments are in place to deliver such information. Such assessment results are also useful to further feed the discussion on biodiversity benefits and ecosystem services. The aim of the Biodiversity Benefits framework is to attract citizens and stakeholders to think and discuss about greening efforts and practices in the context of biodiversity conservation. The framework is based on building blocks which can be taken apart or assembled in the context of specific urban greening practices. Each specific practice results into a unique visualisation of the motivational context, the underlying greening regime(s) and the connected biodiversity benefits. Such visualisations provide insights into potential synergies and frictions between regimes and motivations within or between the projects or practices. In De Groene Loper, for example, economic motivations and motivations to reduce infrastructural fragmentation seem to go along well. However, within the regimes that were identified for the project, the design regime can collide with the classical conservation regime and the heritage regime. This is especially the case when it concerns trade-offs that have to be made between design for human leisure and convenience at the one hand and the conservation of existing ecological values at the other hand. In this case, the legal and policy-frameworks which constitute the whole project mediate such trade-offs: Dutch and European Laws compensate the natural values that are lost through the large infrastructural design project. Next to providing insights into the discursive background of urban greening projects and practices, applying the framework to specific cases also helps identifying the gaps that can be addressed when considering the benefits for biodiversity of the urban greening practices.

\section{Conclusion}

Although increasingly recognised and explored by ecologists, the potential of cities as 'stepping stones' for biodiversity, has until now hardly been explored as a concrete conservation option. Civil and scientific trends point towards the need for a more systematic 
exploration of the ideas and practices constituting the stepping stone potential of urban areas for biodiversity. The aim of this chapter has been to contribute to an exploration of urban greening practices as a conservation approach that could be a valuable addition to other strategies aimed at halting the global loss of biodiversity. Through an inductive literature assessment the Biodiversity Benefits framework has been developed. I applied the building blocks of the framework to three different case studies in the South of Limburg in the Netherlands. The case studies showed how the building blocks can be configured in case specific ways, delivering unique but still systematic visual representations of the connected regimes, motivations and biodiversity benefits underlying the specific projects. The building blocks can be used for more systematically discussing the benefits for biodiversity resulting from urban greening practices and for addressing potential synergies and conflicts based on motivational and ideological backgrounds leading to different constellations of discourses and practices. With the biodiversity Benefits framework I intend to fill a gap where it concerns reflected and systematic societal discussion of the value of urban greening for local, regional and global biodiversity and its conservation.

In the next chapters the biodiversity benefits will be further explored by focusing on the design and maintenance of domestic yards and how these small urban patches potentially contributes or dis-contributes to biodiversity and ecosystem services. Finally, surveys are used with a representative sample of the Dutch population and with experts on urban greening, sustainability and ecology to explore which cultural perspectives can be attached to specific design styles and urban greening practices. 


\section{CHAPTER 10}

\section{Biodiversity in my back yard}

The Development of a

Socio-Ecological Assessment

Framework for Garden-Biodiversity 
"Weeds are flowers too, once you get to know them."

A. A. Milne

This chapter is based on:

Carijn Beumer \& Pim Martens (2014). Biodiversity in my (back) yard: towards a framework for citizen engagement in exploring biodiversity and ecosystem services in residential gardens. Sustainability Science, No. SUST-D-14-00022R1 


\section{Introduction}

In this paper a framework is proposed for fostering a dialogue about the potential role of domestic gardens for the enhancement of green infrastructure and the conservation of biodiversity and ecosystem services in and beyond urban areas. According to many authors "experiencing urban biodiversity will be the key to halt the loss of global biodiversity, because people are most likely to take action for biodiversity if they have direct contact with nature (Müller, et al., 2010, p.26)." Much space in urban landscapes exists of private or semi-private outdoor spaces such as gardens, patios, courtyards, balconies and roof-terraces. This means that many citizens may have their main experiences with urban biodiversity in their own gardens (Dunn, et al., 2006; Cilliers, 2010; Millard, 2010). It also means there is a great and still largely unexplored potential to increase biodiversity, green infrastructures (Rudd, et al., 2002; Tzoulas, et al., 2007; Cameron, et al., 2012) and related ecosystem services (Costanza, 1997; TEEB, 2009, 2011; Costanza, et al., 2014) in the context of urban sustainable development. Finally, domestic gardens are hidden treasures of information about small scale urban landscape design, urban biodiversity and the relation between citizens and their (direct) living environments (Miller \& Hobbs, 2002; Galluzzi et al., 2010; Goddard, et al., 2010; Cameron, et al., 2012; Heezik, et al., 2012; Kurz \& Baudains, 2012).

Cities and citizens are becoming increasingly recognized as important players for the implementation of international environmental agreements like the Convention on Biological Diversity (CBD) (Müller, et al., 2010; Puppin de Oliveira, et al., 2011). As more than half of the world population lives in cities (Butler \& Spencer, 2010), it will be important to embed conservation efforts in urban environments and human lifestyle-practices (Cilliers, 2010). Citizens can become important agents in creating ecological connectivity within and beyond cities (Rudd, et al., 2002) and by contributing to biodiversity conservation through greening their own yards (Miller \& Hobbs, 2002; Rudd, et al., 2002; Galluzzi, et al., 2010; Goddard, et al., 2010; NWF, 2013). The need for inclusion of cities and citizens in conservation practices is also reflected in strategic goal A of the Aichi Biodiversity Targets: it aims to "[a]ddress the underlying causes of biodiversity loss by mainstreaming biodiversity across government and society (CBD, 2011)."

A still underexplored way of engaging citizens for conservation and sustainability is through involving their domestic outside spaces in the debate. This gap is addressed by proposing a framework that addresses ecological and cultural elements that can be encountered in domestic gardens. Yard-management decisions impact socio-ecological systems in various ways, for example through irrigation patterns, fertilization or the use of pesticides (Larson, et al., 2010), or through the choice for exotic species that may become invasive over time (Kendal, et al., 2012). But yard-management decisions can also positively influence the presence of pollinators, (Gaston et al., 2005a; Smith et al., 2006; Matteson et al., 2008; Goddard, et al., 2010; Samnegård et al., 2011) improve soil quality (Dewaelheyns et al., 2013) or even foster small scale 'Wildlife Habitats' (NWF, 
2013) or 'Garden Reserves' (IVN, 2013) that can function as stepping stones for biodiversity and increase connectivity of the wider environment (Rudd, et al., 2002; Cameron, et al., 2012).

Most research on the household-parcel scale until now has been focusing on either ecological garden-structures and -features (e.g. Cornelis \& Hermy, 2004; Gaston, et al., 2005b; Hope et al., 2006; Baker \& Harris, 2007; Burghardt et al., 2008; Loram, et al., 2008; Martin, 2008; Kendal, et al., 2012), or on factors that influence human choices and preferences for certain types of yards (Nassauer, 1995b; Larsen \& Harlan, 2006; Larsen \& Swanbrow, 2006; Lyytimäki, et al., 2008; Larson et al., 2009; St.Hilaire et al., 2010; Zheng, et al., 2011; Heezik, et al., 2012; Kurz \& Baudains, 2012). Although urban residential landscapes and domestic gardening preferences, values and drivers are increasingly studied in the context of sustainable development and biodiversity conservation (Miller \& Hobbs, 2002; Gaston, et al., 2005b; Larsen \& Harlan, 2006; Mathieu et al., 2007; Loram, et al., 2008; Galluzzi, et al., 2010; Goddard, et al., 2010; Larson, et al., 2010; St.Hilaire, et al., 2010; Chowdhury, et al., 2011; Zheng, et al., 2011; Cook, et al., 2012; Heezik, et al., 2012; Kurz \& Baudains, 2012) there is still much to be learned on how cultural elements and human preferences represented in domestic gardens (e.g. design style, maintenance need, artefacts) influence habitat value, ecosystem services and sustainability in and beyond human settlement areas (Dunn, et al., 2006; Galluzzi, et al., 2010; Larson, et al., 2010; Chowdhury, et al., 2011; Cook, et al., 2012; Heezik, et al., 2012).

Integrative approaches that combine ecological and cultural factors in domestic landscaping practices and design are available but scarce (Larson, et al., 2010; Cook, et al., 2012). In order to facilitate pioneers in this area we developed an instrument to increase awareness and to stimulate dialogue and knowledge co-production on the values, uses, and small-scale biotic and a-biotic structures that enhance or hinder the quality, richness and abundance of biodiversity in and beyond urban areas.

Based on an analysis of pictures taken of front-yards in Maastricht (Netherlands) and in Phoenix (AZ, United States) we developed a framework that can be considered to assess domestic garden biodiversity, ecosystem services (Costanza, 1997; Groot, 2002; Norton \& Noonan, 2007), disservices (Lyytimäki, et al., 2008) and the way gardens are used, maintained and valued by their owners in a trans-disciplinary and participatory way. We call the framework BIMBY, which is an acronym for Biodiversity in My (Back) Yard.

\section{Materials and Methods}

The starting point for developing this framework has been the 'pigeon paradox', the assumption made by Robert Dunn and his colleagues (2006) that global conservation can be advanced when citizens are promoted to have more direct positive experiences with 
urban species (e.g. through feeding pigeons or other birds) (Dunn, et al., 2006). Furthermore, the key concept of ecosystem services (Costanza, 1997; MEA, 2005; TEEB, 2009, 2011; Costanza, et al., 2014) has helped to structure the BIMBY framework and its indicators towards a tool that enables looking beyond biodiversity and towards its meaning in the context of (urban) sustainability. The framework development went through an iterative process: based on recurrent evaluations of literature and empirical data and their role and contribution to the emerging framework. Three main phases resulted into different 'products' that were used to construct the framework (see box 10.1). The final result presented in this paper is the BIMBY framework itself.

\section{Box 10.1. Phases of framework development}

\begin{tabular}{|c|c|}
\hline Phases of framework development & Products \\
\hline $\begin{array}{l}\text { Phase 1: Gathering Information } \\
\text { a. Neighbourhood visits Phoenix and Maastricht } \\
\text { b. Literature Research }\end{array}$ & $\begin{array}{l}\text { Phase } 1 \\
\text { a. Photos and notes } \\
\text { b. Indicator selection }\end{array}$ \\
\hline $\begin{array}{l}\text { Phase 2: building the BIMBY framework } \\
\text { a. Developing preliminary indicator set } \\
\text { b. Pilot analysis of photos }(\mathrm{N}=512) \text { with preliminary indicators } \\
\text { c. Evaluation sessions of methodology and indicators }\end{array}$ & $\begin{array}{l}\text { Phase } 2 \\
\text { a. Indicator set } \\
\text { b. Pilot results } \\
\text { c. Adjustment criteria }\end{array}$ \\
\hline $\begin{array}{l}\text { Phase } 3 \\
\text { Adjusting indicators and framework }\end{array}$ & $\begin{array}{l}\text { Phase } 3 \\
\text { BIMBY framework }\end{array}$ \\
\hline
\end{tabular}

\section{Phase 1. Gathering information}

\section{Neighbourhood visits}

In order to develop a framework that is both robust and at the same time flexible enough to use in various climatological, eco-systemic and cultural settings, two substantively different cities (different size, climate, biophysical conditions, culture, history, demographic structure, urban design) have been chosen as pilot case areas: Maastricht and Phoenix (see box 10.2 for a more detailed description of both cities and their context). We visited easily accessible front-yards in six neighbourhoods in Phoenix and six neighbourhoods in Maastricht. We included centrally located neighbourhoods, peripheral and semi-peripheral suburbs, and neighbourhoods that are part of the larger agglomeration. We also included different neighbourhood ages (built 0-10, 10-30, 40-70 and 80 or more year ago), and different housing prices based on high income, middle income, lower middle income and low income (based on information from real estate websites). However, selection was also based on accessibility and mobility criteria for the field researcher. The neighbourhood visits took one day per neighbourhood in spring and early summer of 2013. During the neighbourhood visits the lead author of this paper 
took photos and field notes of her visual and other sensory observations (for the photos see Appendixes $\left(\right.$ and $D^{*}$ ).

\section{Box 10.2. Case study selection}

In order to develop the BIMBY framework, we carried out two case studies on residential urban green in two totally different climatological zones: the temperate climate of the city of Maastricht in the Netherlands that allows for lush, diverse and green vegetation and the extreme desert climate of Phoenix in Arizona (U.S.) which comes with many challenges in the context of urban greening and gardening (Larsen \& Harlan, 2006;

Martin, 2008; St. Hilaire, et al., 2010).

Maastricht and Phoenix have comparable basically 'western oriented' cultural settings but are worlds apart at the same time. Maastricht is part of a triangle of European countries (Euregio). Phoenix has many immigrants from Latin American countries -especially Mexico -- and a number of Native American reservations in its near proximity. The number of inhabitants in both cities differs greatly as does the space and the composition of the urban environment: Maastricht is a small Provincial capital city with around 121.000 inhabitants (CBS, 2013). It has its roots in Roman and Medieval European history. Maastricht has a relatively high population density which is built around a core historic centre. Phoenix is the metropolitan capital city and largest city of the state or Arizona in the U.S. It is a new world city founded only in 1861, counting almost 1.5 million people in the city itself (USCB, 2013b) and almost 4.5 million inhabitants in the greater metropolitan area (USCB, 2013a). Phoenix has a relatively small high rise built downtown centre, where some commercial activities and the city's governmental activities take place. The Phoenix residential environment is highly dispersed. Most neighbourhoods consist of floor-level bungalows with often a spacious front and back yard.

Outside of the city and agglomeration boundaries, both Phoenix and Maastricht are surrounded by natural and/or semi-natural landscapes that give space to native wildlife and plant species. Both cities also have - relative to the city size-- some spacious nature parks, like South Mountain, Papago Park, the Echo Canyon Trailhead and Piestewa Peak Park in Phoenix; and the Savelsbosch, Pietersberg and Frontenpark in Maastricht. These 'natural areas' provide potential connectivity to the ecosystems and wildlife of the larger regions and they provide access-routes for some species right into the urban areas.

\section{Literature research}

In the literature research phase the visually gathered information was interpreted in the context of existing research on residential yards and human preferences. Also we compared existing indicator sets and methods for assessing (urban) biodiversity (Hermy \& Cornelis, 2000; Nagendra, 2002; Spellerberg \& Ferdor, 2003; Keylock, 2005; Martin, 2008; Tzoulas \& James, 2010; Farinha-Marques et al., 2011). Generally, the existing 
research and indicators did not combine ecological, cultural and preference related factors in a way that can be called scientifically integrative and easily approachable for the general public at the same time. Therefore, the BIMBY framework draws on elements from a variety of articles: the method for a rapid assessment of urban biodiversity from Tzoulas and James (2010); the categorisation of habitat types as used in Martin (Martin, 2008) and Larson et al. (2010); the ecological assumption that structural and compositional patterns in ecosystems can be used as an indicator for the biological diversity (Noss, 1990; Cornelis \& Hermy, 2004; Hart, 2007; Tzoulas \& James, 2010) and other insights from literature on biodiversity indicators (Noss, 1990; Nagendra, 2002; Spellerberg \& Ferdor, 2003; Keylock, 2005; Caro, 2010; Tzoulas \& James, 2010), urbanand garden biodiversity (Bolund \& Hunhammar, 1999; Savard, 2000; McKinney, 2002; Zerbe, et al., 2003; Gaston, et al., 2005b; Baker \& Harris, 2007; CBD, 2007a; Loram, et al., 2008; Sukopp, 2008; Dearborn \& Kark, 2009; Galluzzi, et al., 2010; Müller, et al., 2010; Beatley, 2011; Müller \& Kamada, 2011; Jim, 2012; Jorgensen \& Keenan, 2012; Kendal, et al., 2012); on literature on biodiversity governance at the urban scale (Miller \& Hobbs, 2002; Zerbe, et al., 2003; Goddard, et al., 2010; Francis \& Lorimer, 2011; Müller \& Kamada, 2011; Puppin de Oliveira, et al., 2011) and on literature on gardening styles and preferences (Larsen \& Harlan, 2006; Larson, et al., 2010; St.Hilaire, et al., 2010; Cook, et al., 2012; Kurz \& Baudains, 2012). Finally we searched the literature for valuable information on ecosystem services connected to urban biodiversity and more specifically on ecosystem services that can be found in residential yards (Costanza, 1997; Opschoor, 1998; Nunes \& van den Bergh, 2001; Appleton, 2002; Groot, 2002; McNeely, et al., 2005; MEA, 2005; Norton \& Noonan, 2007; Lyytimäki, et al., 2008; TEEB, 2009; Hancock, 2010; Shin, 2012; Qviström, 2013).

\section{Phase 2. Developing the framework}

\section{Developing preliminary indicators}

In order to equip theframework with accessible and graspable indicators, we mediated between biotic and a-biotic yard-features and the comprehensibility of the framework. Some trade-offs had to be made to keep the model understandable for non-scientists. We decided for example to exclude elements such as species names and chemical soil composition, but focused instead on abundance and variations of plants, included broad animal categories, and asking for soil cover types. Decisions were also taken based on suggestions for further research made in the assessed literature. This process finally resulted in the first indicator set that involves both ecological and cultural factors. The decision process also lead to the exclusion of indicators for ecosystem dynamics and functional relations (see box 10.3) as they were found too difficult to understand by nonecologists. 
In the BIMBY framework, we did not explicitly include dynamic and functional relationships of biodiversity as indicators (Noss, 1990; Grimm et al., 2000). From an ecological point of view that may be a violation, but including such relationships would require more detailed ecological knowledge than most potential participants to the framework possess. It would over-complicate the framework as a suitable and effective object for citizen science. Nonetheless, new insights on ecological relationships may become apparent by patterns that will emerge from a quantity of observations and gathered data. Trained ecologists can use the emerging data to analyse and map such dynamic functional relationships by comparing them to data from other ecological datasets. Connecting the BIMBY data to results of surveys, interviews or socio-economic data can help increase insights in how social factors and ecological factors co-evolve in complex urban ecosystems.

\section{First pilot analysis}

In the first statistical analysis (using IBM SPSS Statistics 19) of the photos ( $N=512 ; N=185$ for Phoenix and $\mathrm{N}=328$ for Maastricht) we tested the new indicator set for the total sample. We rendered a Kolmorov-Smirnov test, made histograms, normal Q-Q plots, detrenched normal Q-Q plots and box-plots for checking on outliers and for testing normality (Beumer \& Martens, in review-a). The results of this first pilot analysis helped to define lower, medium and higher levels of garden-contributions to biodiversity in the samples on a scale from -10 (damage to biodiversity) to 50 (very high contribution to biodiversity) (see table 10.1) (Beumer \& Martens, in review-a). It also helped to further sharpen the indicator framework in reconsidering the inclusion of indicators based on identifying visual elements available in the gardens (e.g. plastic mulch was not encountered in the existing literature, but present in many yards), or values given to elements of the indicator set.

Table 10.1. Descriptive statistics Diversity Contribution on full sample level N=512

\begin{tabular}{|c|c|c|c|}
\hline & & Statistic & St.Error \\
\hline Mean & & 15,5801 & ,39378 \\
\hline \multirow[t]{2}{*}{ 95\% Confidence Interval for Mean } & Lower Bound & 14,8065 & \\
\hline & Upper Bound & 16,3537 & \\
\hline 5\% Trimmed Mean & & 15,6050 & \\
\hline Median & & 15,0000 & \\
\hline Variance & & 79.391 & \\
\hline Std.Deviation & & 8,91015 & \\
\hline Minimum & & $-5,00$ & \\
\hline Maximum & & 47,00 & \\
\hline Range & & 52 & \\
\hline Interquartile Range & & 12,00 & \\
\hline Skewness & & 0,69 & 108 \\
\hline Kurtosis & &,- 150 & ,215 \\
\hline
\end{tabular}




\section{Evaluation sessions}

To further evaluate the indicators that emerged from the first pilot-results, we organised one small group evaluation sessions and one session of individual consultations with stakeholders. We wanted to see whether both ecologists and non-ecologists would easily understand the indicator framework. Also we wanted to see whether the framework would be considered useful by different groups of stakeholders. The group evaluation session involved six colleagues of various disciplinary backgrounds (social science, ecology, economy, innovation management and philosophy). All of them have been as well trained as sustainability scientists. In the group session the inclusive approach combining ecological, cultural and preference factors was valued. However, the main conclusion of the group session was to keep the framework simple in order to become an applicable tool for participatory research.

In the individual consultation session different potential stakeholder groups were represented: (citizens $(n=2)$, governance $(n=3)$, design $(n=2)$ and commerce $(n=1)$. These representatives) individually reflected on the final selection of indicators to make sure they are comprehensible to them. One citizen's feedback was that it was interesting to go into the garden with the framework as it provided a new perspective on what a garden is. However, she also found it a bit difficult to immediately understand the meaning of all the layers of the framework. It required some studying. The governance representatives (spatial planning) were interested in how the tool would be able to link domestic gardens to broader landscapes and green infrastructures beyond cities. Including domestic gardens to the idea of green infrastructure was a novel and promising approach in their view. The two designers (landscape architecture and architecture) immediately asked whether they could collaborate in order to better integrate biodiversity concerns into their concepts.

However, the main feedback given by almost all evaluators was that in order to become an attractive participatory and transformative tool the BIMBY framework needs to be simplified and further developed towards becoming a playful visual game.

\section{Phase 3. Adjusting the indicators and the framework}

In the third phase I adjusted the indicators and the framework based on many suggestions made in the evaluation sessions (see figure $10.1^{*}$ and table $10.2^{*}$ ). The layers of the conceptual framework, for example, were clarified by adding colours for the key sections: green for the ecological factors, red for the cultural factors and blue for the issues that are dependent on human valuation (see figure 1). Also we increased the meaning of the BIMBY framework in a broader landscape setting by including a qualitative indicator that enables describing the context and location of the studied yards. Another example of adjustments based on the evaluations was to reposition maintenance features like pesticides and herbicides into a separate category that was called 'signs of conflict' (see figure 1). Some other signs of conflict were added as well. In a follow up 
project a larger number of non-academic citizens will be asked to take part in the codevelopment of the framework towards an effective tool for transformative transdisciplinary science.

\section{Methodological limitations}

The development of the BIMBY framework has been framed by some practical and temporal limitations: due to the analysis based on photos we were only able to assess directly visible biotic and cultural indicators. Less tangible and dynamic aspects such as animal species, pesticide use, irrigation, disease or subjective impressions can only be meaningfully explored on-site and in consultation with garden owners. Further on-site empirical testing and further evaluating and adapting the tool towards differences in cultural and eco-systemic settings with various stakeholder groups and non-expert citizens will be a crucial task for the next phase of the development of the indicator framework if it has to become a meaningful and inviting tool for transformative knowledge production (Lang, et al., 2012; Wiek, et al., 2012).

\section{Table 10.2 BIMBY indicator set, used indicators CHAPTER 11 shaded in grey}

\begin{tabular}{|c|c|c|c|c|c|}
\hline \multirow[t]{2}{*}{ Spheres } & \multirow[t]{2}{*}{ Variable } & \multirow[t]{2}{*}{ Description } & \multirow[t]{2}{*}{ Value } & \multirow{2}{*}{$\begin{array}{l}\text { Treatment in } \\
\text { Analysis }\end{array}$} & \multirow[t]{2}{*}{ Indicator } \\
\hline & & & & & \\
\hline \multirow[t]{2}{*}{$\begin{array}{l}\text { Objective } \\
\text { Contextuality }\end{array}$} & $\begin{array}{l}\text { City and } \\
\text { Neighbourhood }\end{array}$ & $\begin{array}{l}\text { Context and location } \\
\text { of yard }\end{array}$ & Nominal & $\begin{array}{l}\text { Qualitative } \\
\text { Contextualization with } \\
\text { Virtual Maps like Google } \\
\text { Earth }\end{array}$ & $\begin{array}{l}\text { Context of infrastructure, } \\
\text { surrounding land use, } \\
\text { habitat, fragmentation or } \\
\text { connectivity }\end{array}$ \\
\hline & Yard size & $\begin{array}{l}\text { Size of the Yard or Outside } \\
\text { Space }\end{array}$ & $\begin{array}{l}0=<10 \mathrm{~m} 2 ; 1=10 \mathrm{~m} 2- \\
30 \mathrm{~m} 2 ; 2=30 \mathrm{~m} 2>\end{array}$ & $\begin{array}{l}\text { Dependent on other } \\
\text { variables: points: } 0= \\
\text { discontribution, } 1=\text { small } \\
\text { contribution, } 2= \\
\text { contribution }\end{array}$ & $\begin{array}{l}\text { Potential contribution or } \\
\text { discontribution to local } \\
\text { environment \& } \\
\text { biodiversity related to } \\
\text { yard-size }\end{array}$ \\
\hline \multirow[t]{5}{*}{ Ecological } & Habitat type & Hydric, Mesic, Oasis, Xeric & $0=$ no; $1=$ yes & $\begin{array}{l}\text { Dependent on native } \\
\text { vegetation-climate zone: } 1 \\
\text { point for match } 0 \text { points } \\
\text { for mismatch local } \\
\text { environment }\end{array}$ & $\begin{array}{l}\text { habitat; water need; } \\
\text { design }\end{array}$ \\
\hline & Soil cover & $\begin{array}{l}\text { Water, Aquatic Foliage, } \\
\text { Lawn, Green Cover, Mulch, } \\
\text { Granite, Bare Soil, } \\
\text { Pavement, Rocks }\end{array}$ & $\begin{array}{l}0=\text { no; } 1=<10 \% ; 2=10 \%- \\
50 \% ; 3=50 \%-100 \%\end{array}$ & $\begin{array}{l}\text { Dependent on vegetation- } \\
\text { climate zone, points: } 0=\text { no } \\
\text { diversity } 1=\text { medium } \\
\text { diversity, } 2=\text { high diversity, } \\
3=\text { high diversity \& match } \\
\text { with local environment }\end{array}$ & $\begin{array}{l}\text { Habitat; soil life; water } \\
\text { run-off; abundance }\end{array}$ \\
\hline & $\begin{array}{l}\text { Green Coverage } \\
\text { Abundance }\end{array}$ & $\begin{array}{l}\text { Percentage of plant } \\
\text { species covering yard, } \\
\text { other than ground cover }\end{array}$ & $\begin{array}{l}0=\text { no } 1=<10 \% ; 2=10 \%- \\
50 \% ; 3=50 \%-100 \%\end{array}$ & $\begin{array}{l}\text { Points: } 0=\text { none, } 1= \\
\text { medium, } 2=\text { high }\end{array}$ & $\begin{array}{l}\text { Plant abundance, habitat, } \\
\text { food availability }\end{array}$ \\
\hline & Permeability & $\begin{array}{l}\text { Soft surface, medium } \\
\text { surface, hard surface, } \\
\text { mixed surface }\end{array}$ & $\begin{array}{l}0=\text { hard }=\text { low } ; 1=\text { medium; } \\
2=\text { soft }=\text { high } 3=\text { mixed }\end{array}$ & $\begin{array}{l}\text { Points: } 0=\text { hard }=\text { low; } 1= \\
\text { medium; } 2=\text { soft }=\text { high } 3= \\
\text { mixed }\end{array}$ & Soil Life \\
\hline & Plant Species Abundance & $\begin{array}{l}\text { Occurrence of annual } \\
\text { and/or perennial PLANTS }\end{array}$ & $\begin{array}{l}\text { Estimate number of } \\
\text { annual/perennial PLANTS } \\
0=0 ; 1=1-5 ; 2=5-10 ; 3=10- \\
25 ; 4=25-50 ; 5=50-100 ; \\
6=100>\end{array}$ & $\begin{array}{l}\text { Points: as number in } \\
\text { category and additionally: } \\
0=\text { none; } 1=\text { only annuals; } 2 \\
\text { is only perennials; } 3= \\
\text { annuals and perennials }\end{array}$ & \\
\hline
\end{tabular}




\begin{tabular}{|c|c|c|c|c|c|}
\hline Spheres & Variable & Description & Value & $\begin{array}{l}\text { Treatment in } \\
\text { Analysis }\end{array}$ & Indicator \\
\hline & Plant Species Richness & $\begin{array}{l}\text { Occurrence of Exotic } \\
\text { and/or Native SPECIES }\end{array}$ & $\begin{array}{l}\text { Estimate number of native } \\
\text { and/or exotic SPECIES: } 0= \\
0 ; 1=1-3 ; 2=4-10 ; 3=11-20 \text {; } \\
4=21-30 ; 5=30>\end{array}$ & $\begin{array}{l}\text { Points: as number of } \\
\text { category and additionally: } \\
0=\text { none; } 1=\text { only exotics; } 2 \\
\text { is only natives } 3 \text { = natives } \\
\text { and exotics }\end{array}$ & $\begin{array}{l}\text { Reproduction, Habitat and } \\
\text { food for native wild-life }\end{array}$ \\
\hline & Plant Species Composition & $\begin{array}{l}\text { Occurrence of Trees, } \\
\text { Shrubs, Flowers }\end{array}$ & $0=$ no; $1=$ yes & $\begin{array}{l}\text { Points: } 0=\text { none, } 1=1 \text { of } \\
\text { them, } 2=2 \text { of them, } 3=\text { all } \\
\text { three }\end{array}$ & $\begin{array}{l}\text { Vertical diversity, Habitat, } \\
\text { Food, Shelter }\end{array}$ \\
\hline & Weeds & $\begin{array}{l}\text { Occurrence of non- } \\
\text { desirable plant species }\end{array}$ & $0=$ no $; 1=$ yes & $\begin{array}{l}\text { Points: } 0=\text { no weeds; } 1= \\
\text { weeds }\end{array}$ & Perspective on Wildness \\
\hline & Animal Species Abundance & $\begin{array}{l}\text { Birds, Mammals, Insects, } \\
\text { Arthropods, Molluscs, } \\
\text { Worms, Reptiles, Fish }\end{array}$ & $0=$ no $; 1=1 ; 2=2-5 ; 3=5>$ & $\begin{array}{l}\text { Points: } 0=\text { none; } 1=1 ; 2= \\
2-5 ; 3=5>\text { Additionally } 1 \\
\text { point for each occurring }\end{array}$ & $\begin{array}{l}\text { Species Groups \& } \\
\text { Abundance }\end{array}$ \\
\hline & Animal Species Richness & $\begin{array}{l}\text { Counting number of } \\
\text { animal species }\end{array}$ & $\begin{array}{l}0=\text { no; } 1=1-5 ; 2=5-10 ; \\
3=10>\end{array}$ & $\begin{array}{l}\text { Points: } 0=\text { none; } 1=1-5 \\
2=5-10 ; 3=10>\end{array}$ & Species Richness \\
\hline \multirow[t]{10}{*}{ Cultural } & Infrastructure & $\begin{array}{l}\text { Boulders, Walls, Fences, } \\
\text { Hedges, Water }\end{array}$ & $0=$ no; $1=$ yes & $\begin{array}{l}\text { Evaluate in context: points } \\
1 \text { for }+ \text { contribution, }-1 \text { for } \\
\text { fragmentation }\end{array}$ & $\begin{array}{l}\text { Positive or negative } \\
\text { contribution to habitat and } \\
\text { connectivity }\end{array}$ \\
\hline & Features Contributing & $\begin{array}{l}\text { Containers, Compost, } \\
\text { Organic Matter, Wild } \\
\text { Food, Feeders, Nesting, } \\
\text { Insect hotels, Bathing }\end{array}$ & $0=$ no; $1=$ yes & 1 point for each & $\begin{array}{l}\text { Positive or negative } \\
\text { contribution to habitat, } \\
\text { food, mobility, } \\
\text { connectivity, or } \\
\text { disturbance }\end{array}$ \\
\hline & Features Disturbance & $\begin{array}{l}\text { Furniture, Swimming Pool, } \\
\text { Play Equipment, Vehicles, } \\
\text { Light, Plastic mulch }\end{array}$ & $0=$ no; $1=$ yes & -1 point for each & \\
\hline & Pets & $\begin{array}{l}\text { Dogs, Cats, Rodents, } \\
\text { Domestic Birds }\end{array}$ & $\begin{array}{l}0=\text { none } 1=\text { dogs, } 2=\text { cats, } \\
3=\text { rodents, } 4=\text { birds }\end{array}$ & $\begin{array}{l}-1 \text { for dogs and cats; }+1 \\
\text { for rodents and domestic } \\
\text { birds } \\
\text { Per category }\end{array}$ & $\begin{array}{l}\text { Disturbance or attraction } \\
\text { by presence of domestic } \\
\text { species }\end{array}$ \\
\hline & Irrigation & $\begin{array}{l}\text { Sprinklers, Hoses, } \\
\text { Dripping, Deep Irrigation, } \\
\text { No }\end{array}$ & $0=$ no; $1=$ yes & Points: $0=$ no; $1=$ yes & $\begin{array}{l}\text { Attraction of Animal } \\
\text { Species for water, } \\
\text { coolness, bathing, food } \\
\text { (not related to water use) }\end{array}$ \\
\hline & $\begin{array}{l}\text { Maintenance Need of Yard } \\
\text { Design }\end{array}$ & High; Medium; Low & $\begin{array}{l}0=\mathrm{low} ; 1=\text { medium; } 2= \\
\text { high }\end{array}$ & $\begin{array}{l}\text { Low }=\text { Wild: } 2 \text { pts, High }= \\
\text { controlled: Opts Low }= \\
\text { Paved: } 0 \text { pts, High = Lush: } \\
\text { 2pts }\end{array}$ & $\begin{array}{l}\text { Dependent on level of } \\
\text { 'wildness' or 'barrenness' }\end{array}$ \\
\hline & Maintenance Level & High; Low & $0=$ low $; 1=$ high & $\begin{array}{l}\text { Low }=\text { Wild: } 2 \text { pts, High }= \\
\text { controlled: } 0 \text { pts Low }= \\
\text { Paved: } 0 \text { pts, High = Lush: } \\
\text { 2pts }\end{array}$ & $\begin{array}{l}\text { Dependent on level of } \\
\text { 'wildness' or 'barrenness' }\end{array}$ \\
\hline & Signs of Conflict & $\begin{array}{l}\text { Artificial Fertilizer, } \\
\text { Pesticides, Herbicides, } \\
\text { Damage, Disease }\end{array}$ & $0=$ no; $1=$ yes & -3 points for each & $\begin{array}{l}\text { Sustainability, Habitat, } \\
\text { Hood, Ecosystem Health, } \\
\text { Disturbance }\end{array}$ \\
\hline & Level of Intentional Design & $\begin{array}{l}\text { Signs of intentional human } \\
\text { control, structures and } \\
\text { patterns }\end{array}$ & $\begin{array}{l}0=10 w ; 1=\text { medium } ; 2= \\
\text { high }\end{array}$ & $\begin{array}{l}\text { Points: } 0=\text { low } ; 1= \\
\text { medium } ; 2=\text { high }\end{array}$ & $\begin{array}{l}\text { Relates to: perspective, } \\
\text { lifestyle, time, } \\
\text { preferences, }\end{array}$ \\
\hline & Design Style & $\begin{array}{l}\text { French/Versailles, English, } \\
\text { Japanese, Vegetable } \\
\text { Garden, Modern Garden, } \\
\text { Wild Garden/Flowers, Wild }\end{array}$ & Nominal & Nominal & $\begin{array}{l}\text { Relates to: perspective, } \\
\text { lifestyle, time, } \\
\text { preferences, }\end{array}$ \\
\hline
\end{tabular}




\begin{tabular}{|c|c|c|c|c|c|}
\hline Spheres & Variable & Description & Value & $\begin{array}{l}\text { Treatment in } \\
\text { Analysis }\end{array}$ & Indicator \\
\hline \multirow{4}{*}{$\begin{array}{l}\text { Subjective } \\
\text { Contextuality }\end{array}$} & & $\begin{array}{l}\text { Garden/Forest, Healing } \\
\text { Garden, Desert Garden, } \\
\text { Courtyard, none. }\end{array}$ & & & \\
\hline & Contextual Diversity & $\begin{array}{l}\text { Perception of (Biotic \& } \\
\text { Abiotic) diversity } \\
\text { compared to surrounding } \\
\text { local environmental } \\
\text { context }\end{array}$ & $\begin{array}{l}0=\text { lower } ; 1=\text { average } ; 2= \\
\text { higher }\end{array}$ & $\begin{array}{l}\text { Points: } 0=\text { lower; } 1= \\
\text { average; } 2 \text { = higher }\end{array}$ & $\begin{array}{l}\text { Participants' perception of } \\
\text { contribution to green } \\
\text { space }\end{array}$ \\
\hline & Diversity Within Yard & $\begin{array}{l}\text { High/Medium/Low } \\
\text { combination of: habitat } \\
\text { types, soil coverage types, } \\
\text { permeability levels, native } \\
\text { and exotic species, vertical } \\
\text { diversity, variety of plant } \\
\text { and animal species, } \\
\text { features }\end{array}$ & $\begin{array}{l}0=l o w ; 1=\text { medium } ; 2= \\
\text { high }\end{array}$ & $\begin{array}{l}\text { Points: } 0=\text { low } ; 1= \\
\text { medium } ; 2=\text { high }\end{array}$ & $\begin{array}{l}\text { Biotic and Abiotic diversity } \\
\text { in the yard }\end{array}$ \\
\hline & $\begin{array}{l}\text { Diversity Across } \\
\text { Neighbourhood }\end{array}$ & $\begin{array}{l}\text { High/Medium/Low variety } \\
\text { of Habitat Types, Levels of } \\
\text { Intentional Yard Design } \\
\text { and Design Styles across a } \\
\text { neighbourhood }\end{array}$ & $\begin{array}{l}0=\text { low; } 1=\text { medium; } 2= \\
\text { high }\end{array}$ & $\begin{array}{l}\text { Points: } 0=\text { low; } 1= \\
\text { medium; } 2=\text { high }\end{array}$ & Neighbourhood Diversity \\
\hline \multirow[t]{8}{*}{$\begin{array}{l}\text { Ecosystem } \\
\text { Services \& } \\
\text { Disservices }\end{array}$} & \multirow[t]{2}{*}{ Provisioning } & $\begin{array}{l}\text { Services: e.g. Food, } \\
\text { Medicines } \\
\text { Firewood, Gifts } \\
\text { (i.e.flowers), Seeds }\end{array}$ & $\begin{array}{l}1 \text { point for each service } \\
-1 \text { point for each disservice }\end{array}$ & $\begin{array}{l}1 \text { point for each service } \\
-1 \text { point for each disservice }\end{array}$ & \multirow[t]{2}{*}{$\begin{array}{l}\text { Sustainability, } \\
\text { Values \& Preferences }\end{array}$} \\
\hline & & $\begin{array}{l}\text { Disservices: e.g.Invasive } \\
\text { alien species, nuisances } \\
\text { (e.g. leaves in autumn or } \\
\text { bird excrements) }\end{array}$ & & & \\
\hline & \multirow[t]{2}{*}{ Regulating } & $\begin{array}{l}\text { Services: e.g. Cooling, } \\
\text { shade \& reduced climate } \\
\text { regulation costs, pest } \\
\text { regulation }\end{array}$ & $\begin{array}{l}1 \text { point for each service } \\
-1 \text { point for each disservice }\end{array}$ & $\begin{array}{l}1 \text { point for each service } \\
-1 \text { point for each disservice }\end{array}$ & \multirow[t]{2}{*}{$\begin{array}{l}\text { Sustainability, } \\
\text { Values \& Preferences }\end{array}$} \\
\hline & & $\begin{array}{l}\text { Disservices: e.g. Urban } \\
\text { heat island, water run-off, } \\
\text { poisoning }\end{array}$ & & & \\
\hline & \multirow[t]{2}{*}{ Supporting } & $\begin{array}{l}\text { Services: e.g. Nutrient } \\
\text { availability, soil species, } \\
\text { soil structure }\end{array}$ & $\begin{array}{l}1 \text { point for each service } \\
-1 \text { point for each disservice }\end{array}$ & $\begin{array}{l}1 \text { point for each service } \\
-1 \text { point for each disservice }\end{array}$ & \multirow[t]{2}{*}{$\begin{array}{l}\text { Sustainability, } \\
\text { Values \& Preferences }\end{array}$} \\
\hline & & $\begin{array}{l}\text { Disservices: e.g. } \\
\text { Eutrophication, excess soil } \\
\text { nitrates, (Soil) erosion }\end{array}$ & & & \\
\hline & \multirow[t]{2}{*}{$\begin{array}{l}\text { Cultural: Ecosystem to } \\
\text { Society }\end{array}$} & $\begin{array}{l}\text { Services: e.g. Well-being } \\
\text { health, sense of place, } \\
\text { identity, social } \\
\text { interactions, leisure } \\
\text { property value, cost- } \\
\text { reduction, safety }\end{array}$ & $\begin{array}{l}1 \text { point for each service } \\
-1 \text { point for each disservice }\end{array}$ & $\begin{array}{l}1 \text { point for each service } \\
-1 \text { point for each disservice }\end{array}$ & \multirow[t]{2}{*}{$\begin{array}{l}\text { Sustainability, } \\
\text { Values \& Preferences }\end{array}$} \\
\hline & & $\begin{array}{l}\text { Disservices: e.g. } \\
\text { annoyance, sounds, } \\
\text { smells, fear, time-related } \\
\text { factors, cost-related } \\
\text { factors }\end{array}$ & & & \\
\hline
\end{tabular}


Table 10.2 BIMBY indicator set, used indicators CHAPTER 11 shaded in grey

\begin{tabular}{|c|c|c|c|c|c|}
\hline \multirow[t]{2}{*}{ Spheres } & Variable & Description & Value & $\begin{array}{l}\text { Treatment in } \\
\text { Analysis }\end{array}$ & Indicator \\
\hline & $\begin{array}{l}\text { Cultural: Society to } \\
\text { Ecosystem }\end{array}$ & $\begin{array}{l}\text { Services: e.g. Pollination, } \\
\text { Habitat, Nesting, Soil, } \\
\text { Green infrastructure, } \\
\text { Species migration, edge- } \\
\text { effects, Irrigation } \\
\text { Disservices: e.g. } \\
\text { disturbance, extinction }\end{array}$ & $\begin{array}{l}1 \text { point for each service } \\
-1 \text { point for each disservice }\end{array}$ & $\begin{array}{l}1 \text { point for each service } \\
-1 \text { point for each disservice }\end{array}$ & $\begin{array}{l}\text { Sustainability, } \\
\text { Values \& Preferences }\end{array}$ \\
\hline
\end{tabular}

\section{Results}

The main result of this project is the BIMBY framework itself. This framework consists of two parts: 1. a visual conceptual framework and 2. an indicator set. Below we describe these elements in more detail. The results of the full pilot analysis of eight neighbourhoods in Phoenix and Maastricht are presented in Beumer and Martens (in review-a).

\section{The Structure of the Conceptual BIMBY Framework}

A visual representation of the BIMBY framework is pictured in figure $10.1^{*}$. The framework can be read from the bottom to the top (the reading direction is represented by the thick blue arrow). It is structured around the core components of the ecological factors section and the cultural factors section, with infrastructure as a more fuzzy line in the middle.

The bottom of the framework is defined in terms of ecological indicators representing the amount of potential moisture take-up occurring in a specific habitat: the mesic (high moisture take up), xeric (low moisture take up) and oasis (mixed moisture take up) habitat types (Martin, 2008). For wetter contexts we also added the hydric habitat type (e.g. lakes or wetlands) to the analysis (Davies et al., 2004).

The next bar of the framework describes the type of soil 'coverage' which also relates (see purple arrows) to the level of soil permeability and soil nutrition (Vrščaja et al., 2008; Davis \& Whiting, 2013). We differentiated between four types of easily identifiable soil coverage: water or aquatic foliage, lawn, green low growth foliage, decomposed granite or mulch, bare soil, and pavement. The soil cover types also relate to the level of moisture of the four habitat types, the level of soil permeability and it is an indicator for the level and quality of soil life. 
Figure 10.1. Conceptual BIMBY framework

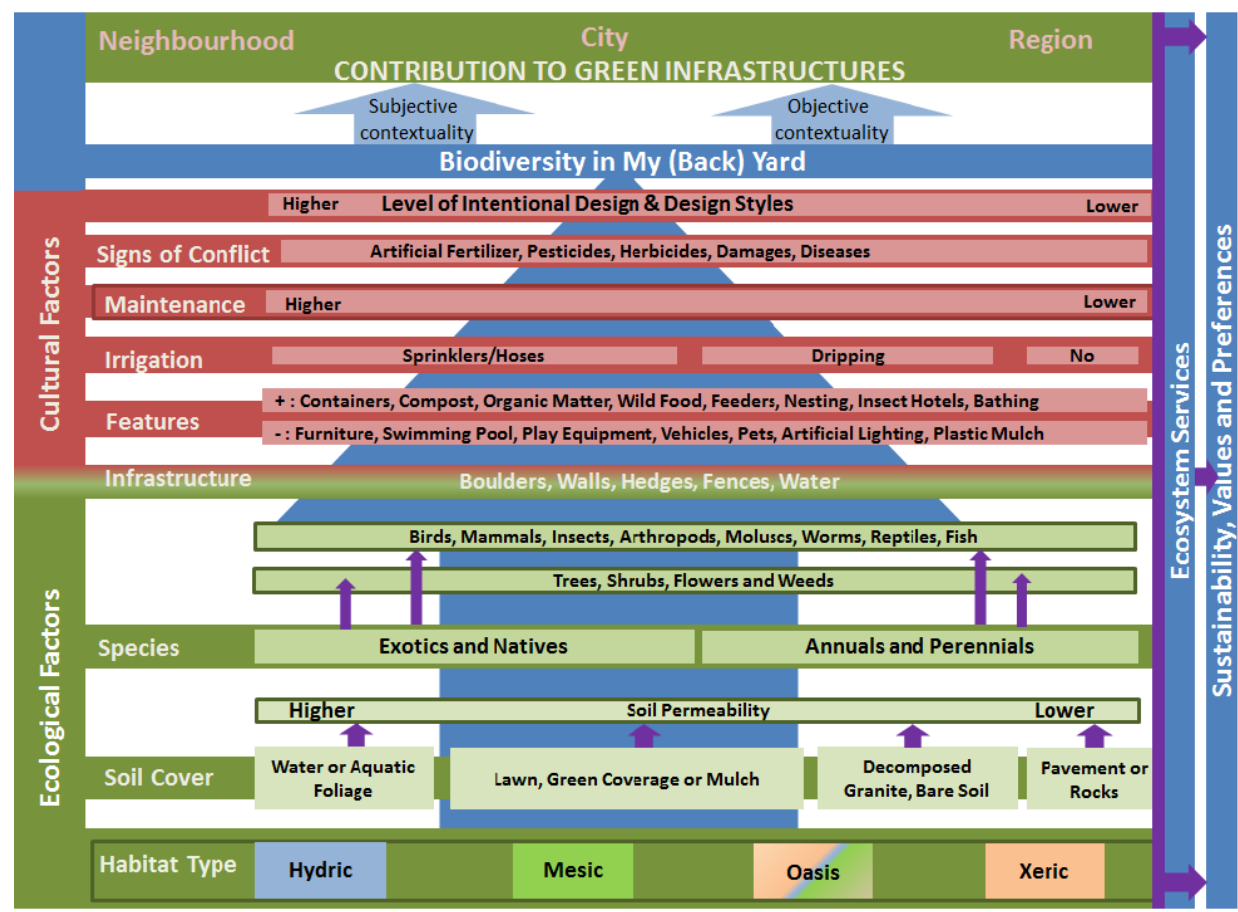

The following bar in the framework is defined to indicate the variety of species. Without assuming that most people can make a basic distinction between native and exotic species, we still included this distinction in the framework. Because this indicator is very complex it should be treated with great caution. It may be better suited to find assumptions on what people believe are native or exotic species, instead of finding results that can be counted as objective facts.

Next, there is space to mention the occurrence and abundance of trees, shrubs, flowers and weeds. This bar aims to indicate the presence of an edge effect in the yards (Casey, 2011). Edges are "the transition areas between adjacent habitats (Hart, 2007, p.103) and are recognized as areas of increased biodiversity (Hart, 2007; Casey, 2011). Nevertheless, edges can also create a loss of biodiversity, especially when they are anthropogenic alterations of (horizontal) landscapes leading to habitat fragmentation. This can lead to species isolation (Hart, 2007) and even extinction (Diamond, 1975; Rudd, et al., 2002).

The vegetation structure and composition and the species richness and abundance are important indicators for the biological diversity of landscape patches (Tzoulas \& James, 2010). In the BIMBY framework it is possible to indicate the presence and abundance of animal categories: birds, insects, mammals, arthropods, molluscs, worms and reptiles. Both the plant and animal species can be more precisely described when par- 
ticipants know their names, but they can also just be categorized into the broader categories by counting the occurrence of individuals from the species-groups. A special section is the intermediate bar between eco-systemic and cultural factors. It is characterised by infrastructural components like hedges, fence, water or walls that either increase or obstruct connectivity.

The third section of the framework consists of cultural factors. We included this section because people are the most important shapers of the urban ecosystem (Grimm, et al., 2000; Müller, et al., 2010). Many objects people use and the design they apply to their yards directly or indirectly provide ecosystem services (Groot, 2002) or disservices (Lyytimäki, et al., 2008) to animals or plant species. At the same time, garden designs and levels of maintenance and care can help providing information about the values, preferences, lifestyles, and the ecological knowledge and awareness of the gardenowners. Firstly, we distinguished factors potentially contributing to biodiversity: plantcontainers, compost, organic materials such as fallen branches, leaves or decomposing wood, wild food sources (i.e. berry carrying shrubs), water-features such as fountains, ponds or bird-baths, animal feeders and nesting facilities such as bird-houses or insecthotels. Secondly, we distinguished potential disturbing features which point towards a level and style of human usage of the yard and could potentially scare away small animals. We included furniture, swimming pools, play equipment, pets, vehicles, plastic mulch and pollution by artificial light (Lyytimäki, et al., 2008).

On the succeeding bar, we look for the visible presence of irrigation systems, such as sprinklers, hoses and dripping systems. We include this as a positive indicator for the attraction of animal species and plant growth (Gandy, 2004; Palmer, et al., 2010; St.Hilaire, et al., 2010; Mee, 2011), but relative to the environment where irrigation systems are used, irrigation can also point towards unsustainable use of water. In the desert biome of Phoenix, for example, this is a pressing issue (Zube et al., 1986; Larsen \& Harlan, 2006; Larsen \& Swanbrow, 2006; Martin, 2008; Larson, et al., 2009; Palmer, et al., 2010; St.Hilaire, et al., 2010; Mee, 2011; DBG, 2013). This means that contextualization of the indicators and the data is always of crucial importance to gain a better understanding of broader sustainability questions related to biodiversity.

Next, the framework intends to indicate the level of yard-maintenance (higher or lower maintenance). We also include the level of intentional design, design style and the need for maintenance of the specific design style as cultural indicators. This indicator may provide more information about the way yard-preferences are connected to lifestyles and the way people perceive and care for the world. Nevertheless, caution must always be in place when interpreting these factors without more qualitative information on (cultural) context and information given by the yard-owners themselves, for example through surveys. Research has also pointed out that in many cases (especially in the U.S.) front-yards represent other factors like inheritance, social- and neighbourhood norms or 
restrictions imposed by home Owner Associations (HOAs) more than individual designpreferences and choices (Chowdhury, et al., 2011; Cook, et al., 2012).

Together, the ecological and cultural factors point towards the experience of ecosystem services and disservices and their relation to values, preferences and sustainability (right side of figure 1). The total picture integrates objective and subjective criteria for assessing garden biodiversity and its relation to green infrastructure on neighbourhood level, city level, and regional level.

\section{The indicator set}

The indicator set (see table $10.2^{*}$ ) is a more technical representation of the conceptual BIMBY framework as presented above. It shows more precisely how the yard features described above can be measured and how they can be treated in an analysis. Simple values have been attributed to the variables. They ask e.g. for approximations of yard size, counting of species, indicating categories of soil cover or the presence of specific cultural factors like irrigation, bird-houses, and design style. The variables can be used in statistical programmes. The results can be discussed in the contextual situation of the urban area and compared to local and regional datasets: What design and maintenance principles are popular and what roles do they play in the urban green infrastructure? Do the yards contribute or dis-contribute to local and regional biodiversity?

The final section on ecosystem services and dis-services has to be further co-developed with stakeholders in the follow up project: the experience of services and disservices is highly dependent on cultural values and preferences of residents (Kumar \& Kumar, 2008).

The visual conceptual framework can provide a basis for developing an understandable tool for citizens to explore their yards, gather data, discuss and compare the outcomes with other participants and become inspired to transform their gardens into biodiversity hotspots. The indicator set is intended for researchers who are able to analyse and evaluate the data in their contexts and potentially link them to other qualitative or qualitative datasets.

\section{Discussion}

The BIMBY framework we presented in this paper differs from other indicators for assessing biodiversity in domestic gardens in the way that it explicitly combines ecological factors, cultural elements and citizen preferences. Much information about ecological and cultural qualities can be derived by researchers on the basis of visual information that yards provide. However, the subjective elements (values, preferences, uses, con- 
flicts, and beliefs about the role domestic gardens can play for the larger green infrastructure and biodiversity conservation) can only be communicated by the garden owners.

The BIMBY framework intends to transcend traditional indicator sets by functioning as an integrative and accessible tool for increasing societal dialogue about biodiversity, ecosystem services and sustainable living environments. Additional steps are to be taken where citizens will be involved as users and co-developers of the framework as an attractive tool (e.g. an interactive app, game or online platform) for exploring and learning about biodiversity, ecosystem services and sustainability in and beyond urban ecosystems. Ideally, the BIMBY tool will be able to fulfil transformative needs in society on multiple levels: 1 ) it transforms citizen science (Silvertown, 2009) into a trans-disciplinary process of the co-production of "actionable knowledge" (Pohl, et al., 2010; Lang, et al., 2012; Wiek, et al., 2012, p.22; Lachmund, 2013); 2) it transforms society towards higher levels of eco-literacy (Mitchell \& Mueller, 2009; Beatley, 2011); 3) it helps transform cultural landscapes into biodiversity hotspots and better connected habitats (Rudd, et al., 2002; Cameron, et al., 2012; Mitchell, et al., 2013). Integration of the data gathered by citizens with other data-sets (e.g. spatial, demographic, climatological, biophysical, cultural, and psychological) can enrich the insights into emerging patterns, functional relationships and complex dynamics in socio-ecological systems.

The presented BIMBY framework is not a fixed framework. It should be open and adaptive to specific environmental and cultural contexts in order to create a meaningful dialogue about biodiversity, sustainability and ecosystem services in society. Green gardens in Phoenix with lawns, colourful annuals and lush trees, for example, may increase the biodiversity of the city and the region and also provide short-term beneficial ecosystem services to residents, like cooling through evaporation and shade. However, such gardens consume more water resources than can be considered sustainable for an arid region. Municipal projects are now starting to promote xeric gardens that better fit the desert environment. For such reasons we consider it important that results that can be gained through the BIMBY indicator framework are always evaluated in the light of the specific socio-environmental context and of larger sustainability questions like: how do we find a healthy and sustainable balance in the way we protect biodiversity and work towards living together with it on our urbanising planet? How can we benefit most the services provided for free by nature and how can we become more serviceable towards non-human life in and beyond urban environments (Costanza, 1997; Lyytimäki, et al., 2008; TEEB, 2009, 2011; Costanza, et al., 2014)? Finally, how can we create new sustainable 'design-paradigms' (Felson, A. \& Pickett, S. T. A., 2005) where aesthetic pleasure and practical functionality of home gardens can become combined with ecological integrity and awareness of ecosystem processes and relations? 


\section{Conclusions}

Can we find a healthy and sustainable balance in the way we protect biodiversity and work towards living together with it (Rosenzweig, 2003) on our urbanising planet? This is a relevant and highly normative question and its discussion in society has to be fuelled by engaging citizens in exploring the biodiversity and ecosystem services in their gardens. By doing so, citizens can help deliver sound data that are sensitive to interpretation in local socio-cultural contexts and to regional climates and ecosystems. Citizens can also start thinking constructively about how they can transform their gardens to functional ecological nodes in the larger green infrastructure. We aim to contribute to this potentially transformative discussion by developing a framework that accounts for both ecological as well as cultural features, and for the more subjective values and life-style preferences represented in domestic gardens. Gardens are small parts of the urban ecosystem that are closest to residents and have a great potential for contributing to larger green infrastructure and (urban) ecosystem services. BIMBY is meant to become a flexible and adaptive tool that intends to contribute to the field of trans-disciplinary and transformative knowledge production (Lang, et al., 2012; Wiek, et al., 2012) in order to advance sustainability in and beyond our direct living environments. 


\section{CHAPTER 11}

\section{Biodiversity in the Front Yard}

Case Studies in Phoenix and

Maastricht 
"They paved paradise to put up a parking lot"

Joni Mitchell

This CHAPTER is based on:

Carijn Beumer \& Pim Martens (in review). "BIMBY's first steps: a pilot case study on biodiversity and ecosystem services in domestic front-yards in Phoenix and Maastricht" is ready for viewing. Urban Ecosystems, submitted on 17 February 2014. 


\section{Introduction}

Large parts of urban space around the world exist of small-scale plots such as patios, courtyards, balconies, roof-terraces and gardens. These small-scale urban spaces carry potential for enhancing sustainability and ecosystem services in and beyond cities. Domestic gardening and residential garden designs are often guided by aesthetics and ease more than by the aim to create habitat and biological diversity. Yard-management decisions impact socio-ecological systems in various ways, for example through irrigation patterns, fertilization or the use of pesticides or through the choice for exotic species that may become invasive over time. However, yard-management decisions can also positively influence the presence of pollinators, improve soil quality or even foster small scale 'Wildlife Habitats' or 'Garden Reserves' that can function as ecological stepping stones to the wider environment. Domestic gardens have a great potential to become part of green infrastructure projects that stretch far beyond the city system. In this paper we present a pilot assessment of the biodiversity and ecosystem services delivered in front-yards in Phoenix (Arizona) and Maastricht (The Netherlands) by applying the BIMBY (Biodiversity in My (Back) Yard) framework. The aim of the framework is to enhance societal dialogue about biodiversity, ecosystem services and sustainability.

As more than half of the world population lives in cities (Butler \& Spencer, 2010) it will be increasingly important to reconcile conservation efforts in urban environments with human lifestyle-practices (Rosenzweig, 2003; Cilliers, 2010). Large parts of urban space exist of gardens, patios, courtyards, balconies and roof-terraces. This means there is a great and still largely unexplored potential to increase ecological connectivity and green infrastructures in the urban context (Beumer \& Martens, 2014). Citizens can become important agents in creating this ecological connectivity within and beyond cities (Rudd, et al., 2002) by greening our own yards. Domestic gardening and residential garden designs are often guided by aesthetics and ease more than by the aim to create habitat and biological diversity (Cranz \& Boland, 2004; Martin, 2008; Ignatieva, 2010). Yardmanagement decisions impact socio-ecological systems in various ways, for example through irrigation patterns, fertilization, species introductions or the use of pesticides (Larson, et al., 2010; Kendal, et al., 2012) or by attracting pollinators, improve soil quality or even foster small scale 'Wildlife Habitats' (NWF, 2013) or 'Garden Reserves' (IVN, 2013) that can function as stepping stones to the wider environment (Rudd, et al., 2002). In this paper we present a pilot assessment of the biodiversity and ecosystem services delivered in front-yards of Phoenix (Arizona, US) and Maastricht (The Netherlands) through applying the BIMBY framework (Beumer \& Martens, submitted). The framework's design includes ecological and anthropogenic indicators and aims to integrate natural and social science-disciplines. On a societal level, the framework aims to foster transformational societal dialogue (Lang, et al., 2012; Wiek, et al., 2012) on the question: how can we reconcile living comfort, aesthetics and ease at the one hand and 
the protection of biodiversity and ecosystem services at the other hand, in the way we design our residential areas (Rosenzweig, 2003)?

\section{Methodology}

The development of the BIMBY framework has been based on the concept of grounded theory (Charmaz, 2003; Urquhart, 2013). The framework has been built on observatory field visits in Phoenix and Maastricht, photos* taken of front-yards during the field visits, and on literature from various disciplines such as ecology, urban ecology, landscape ecology, sustainability science, preference studies and landscape design (Phase 1 and 2). A first pilot analysis and evaluation sessions with sustainability scientists and people representing relevant stakeholder groups led to the adaptation and improvement of the indicators and the framework (Phase 3) (Beumer \& Martens, 2014). In the fourth phase, which is presented in this CHAPTER, a second pilot analysis of the photos ( $N=512)$ taken during the field visits in Phoenix and Maastricht has been done. The analysis is based on the revised BIMBY indicator framework. Phoenix and Maastricht were chosen as case cities because of the large eco-systemic and climatological differences of their locations. A broad comparability of socio-economic status in the neighbourhoods (high, middle, average and low) (see table 11.1) was chosen as a selection criterion for the selection of neighbourhoods (Hope, et al., 2006; Martin, 2008). The information on socio-economic status has been derived from real-estate websites where we compared house prices to the countries modal income. The number of the photographed yards varies per neighbourhood due to neighbourhood size, density of yards and safety of entering the neighbourhood (see table 11.1). This resulted in a comparably low number of photographed yards $(\mathrm{N}=11)$ for Lancaster Manors in Phoenix.

Table 11.1. Selection of neighbourhoods in Maastricht and Phoenix

\begin{tabular}{lllll}
\hline Maastricht & Number of yards & Phoenix & Number of yards & $\begin{array}{l}\text { Socio-economic } \\
\text { Status }\end{array}$ \\
\hline Sint Pieter & $\mathrm{N}=80$ & Palmcroft & $\mathrm{N}=44$ & High \\
Vroendaal & $\mathrm{N}=51$ & Santo Tomas & $\mathrm{N}=56$ & Mid-Range \\
De Heeg & $\mathrm{N}=121$ & Fairview Place & $\mathrm{N}=73$ & Average \\
Blauwdorp & $\mathrm{N}=76$ & Lancaster Manors & $\mathrm{N}=11$ & Low \\
Total & $\mathrm{N}=328$ & Total & $\mathrm{N}=184$ & \\
\hline
\end{tabular}

We used variables from the indictor set for the analysis that could be derived by solely looking at the photos. The employed indicators are shaded in grey (see table 10.2 CHAPTER 10*). The photo-data are suitable to do assessments on various levels: 
For the total of the sample $(\mathrm{N}=512)$

On the city levels of Maastricht ( $N=328)$ and Phoenix ( $N=184)$

On the level of the individual neighbourhoods $(\mathrm{N}=8)$

On the individual yard level $(\mathrm{N}=512)$

In the analysis we primarily focused on the city level and on the neighbourhood level. In order to prepare the analysis on these levels, we assessed the goodness of fit of a normal model to the data for the first three levels (total sample, city levels, neighbourhood levels). We used descriptive statistics in SPSS 19 to do this. The resulting values of the calculations for each level have been called Total Diversity (TD). We rendered a Kolmorov-Smirnov test, we made histograms, normal Q-Q plots, detrenched normal Q-Q plots and box-plots. Not all the tests showed normal distribution, which can be explained by looking at the box-plot of for normality for TD on the neighbourhood levels (figure 11.1).

Figure 11.1. Boxplot normality for TD for each neighbourhood

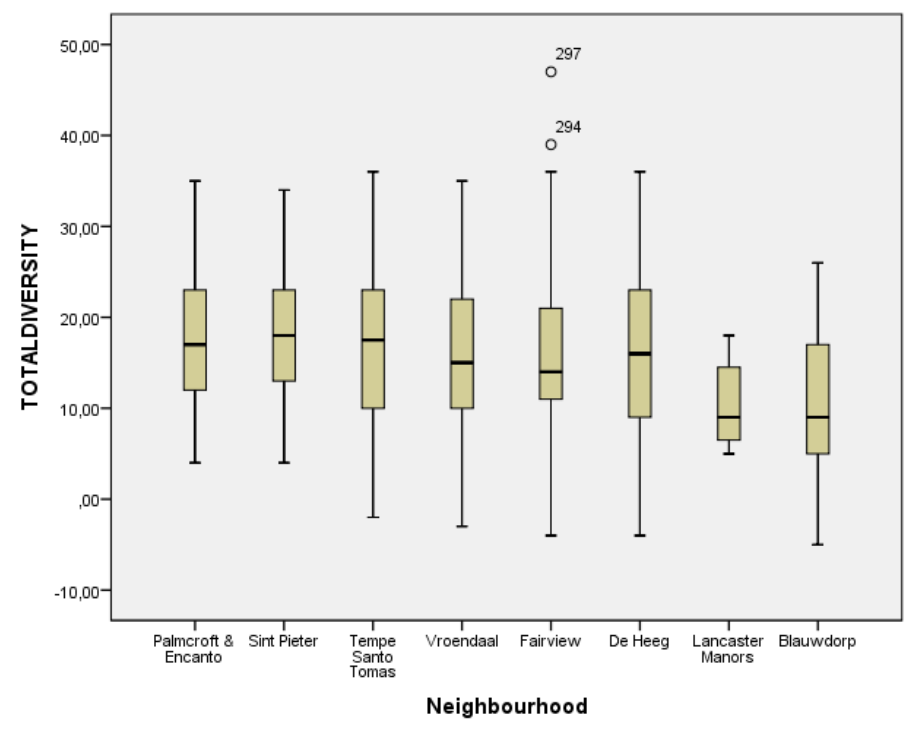

Figure 11.1 shows two outliers (yard number 294 and yard number 297). Closely assessing these outliers made us decide to keep them in the sample. Yard number 297 gives a value for a particular and highly diverse garden with a permaculture-edible design. The garden is located in the Fairview Place neighbourhood in Phoenix and has an official certification as Wildlife Habitat (NWF, 2013). These certificates are provided by the National Wildlife Federation in order to stimulate and restore habitat in residential and commercial urban areas (NWF, 2013). The quantitative value given to this garden lies in the range of possibilities, but hasn't been realised in any other assessed yard. The other 
outlier with yard number 294 is also a highly diverse yard - located close to yard 297 -which includes an edible design and many yard-factors contributing to high diversity. Statistically, on the overall sample level and on the city level the values for these yards don't influence the mean much (also see Pallant, 2005, p.62). At the neighbourhood level the two outliers explain some peculiarities in the data.

The values of TD range from a minimum contribution to diversity of -5 to a maximum contribution to diversity of 47 with a median of 15 (close to a mean of 15.6) and a standard deviation of 8.9. Based on these results we categorised the yards in the sample into various degrees of contribution to diversity on a likely scale from -20 (causing damage) to 50 (very high contribution to diversity), corresponding with the TD scores (see table 11.2). Although values in the range of 'causing damage' (-20 to -10) do not occur in our sample, it would be theoretically possible to encounter yards that would render such results.

Table 11.2. Descriptive statistics Total Diversity on total sample level $\mathrm{N}=512$

\begin{tabular}{|c|c|c|c|}
\hline & & Statistic & St.Error \\
\hline Mean & & 15,5801 & 39378 \\
\hline \multirow[t]{2}{*}{ 95\% Confidence Interval for Mean } & Lower Bound & 14,8065 & \\
\hline & Upper Bound & 16,3537 & \\
\hline $5 \%$ Trimmed Mean & & 15,6050 & \\
\hline Median & & 15,0000 & \\
\hline Variance & & 79.391 & \\
\hline Std.Deviation & & 8,91015 & \\
\hline Minimum & & $-5,00$ & \\
\hline Maximum & & 47,00 & \\
\hline Range & & 52 & \\
\hline Interquartile Range & & 12,00 & \\
\hline Skewness & & 0,69 & 108 \\
\hline Kurtosis & &,- 150 & 215 \\
\hline
\end{tabular}

The values leading to TD have been distributed based on the BIMBY indicator set. Firstly, we estimated the way the individual yards fit to the climatological zone by contextually comparing the habitat type to the regional climate (e.g. Maastricht neighbourhoods get 1 point for mesic habitat types and 0 for xeric habitat types, while Phoenix yards get 1 point for xeric habitat types and 0 points for mesic habitat types). This resulted into a number for each yard called Zone Match (1 point for match and 0 points for no-match). In the analyses, xeric can also mean that the soil is bare or the coverage is composed of pavement, so the way we use the term 'xeric' can be in contrast with the native desert landscaping style called 'xeriscaping' in the Phoenix area. Secondly, we added the value 
for the amount of green coverage, the type of soil cover other than green and the permeability. Next we added the points distributed for plant abundance, plant richness, and the points indicating the edge effect of the individual yards. Finally we added the points distributed for contributing anthropogenic factors and we deducted points for disturbance factors (see table 10.2 CHAPTER 10 for the weights given to the variables).

The combined information gives an indication of the structural composition and diversity of individual front-yards. Based on the median $(m=15)$ for TD we grouped the results into various levels of contribution to biodiversity (see figure $11.2^{*}$ ).

Figure 11.2. Levels of contribution or dis-contribution to biodiversity

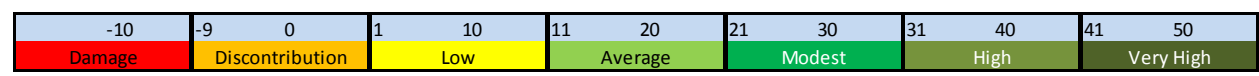

Evaluated together, in the context of the surrounding environment, and in the context of the literature we read, the assessment results deliver insight into patterns of neighbourhood contributions to the biodiversity and related ecosystem services and disservices.

\section{Limitations}

The intention of the framework is to enhance societal dialogue on biodiversity, ecosystem services and sustainability. Therefore, the framework is intended to be used by a wide range of stakeholders: citizens, scientists, governance, entrepreneurs and designers. As a form of citizen science (Silvertown, 2009), residents will be enabled to provide data about their own yards. However, in this pilot phase we did not involve the various stakeholders yet. The evaluation of the framework as a useful tool for trans-disciplinary and transformational sustainability science can be done after further research and testing on the ground. Here we focus on evaluating the analysis of the yard-pictures taken by the researchers. This will gain more insight into the value of photos for combined socio-ecological research (Ewing, 2001; White, et al., 2009; Zheng, et al., 2011).

\section{Results}

The following paragraph shows the results of the application of the BIMBY framework in the two case study areas Phoenix and Maastricht.

Table 11.3 shows that Maastricht contributes more to TD compared to Phoenix. However, also in the dis-contribution and low contribution levels, Maastricht scores higher. Comparing the medians on the neighbourhood level (see figure 11.1) reveals that there are also relevant differences in the contribution to diversity across the neighbourhoods. With a median of 18 for example, Sint Pieter in Maastricht turns out to be the most 
contributing neighbourhood of our sample, followed by Santo Tomas in Phoenix with a median of 17.5. The scores of these neighbourhoods fall within the higher side of the average contribution category. The lower income neighbourhoods Lancaster Manors in Phoenix and Blauwdorp \& Mariaberg in Maastricht score a median of 9.0 both, which can be depicted as a low contribution to diversity. Except from Lancaster Manors and Blauwdorp \& Mariaberg all the other assessed neighbourhoods can be said to contribute to diversity averagely. The median from Fairview (14.0) differs from the mean (17.1) significantly. This can be attributed to the two outliers in this neighbourhood that are of influence to the mean (see figure 11.1).

Table 11.3. Contribution levels of Phoenix and Maastricht to Total Diversity (TD)

\begin{tabular}{lllllllll}
\hline Contribution Level & discontr & low & average & modest & high & very high & Total \\
\hline Phoenix & Count & 3 & 40 & 87 & 45 & 8 & 1 & 184 \\
\multirow{2}{*}{ Maastricht } & \% of Total &, $6 \%$ & $7,8 \%$ & $17,0 \%$ & $8,8 \%$ & $1,6 \%$ &, $2 \%$ & $35,9 \%$ \\
& Count & 23 & 82 & 125 & 80 & 18 & 0 & 328 \\
\hline Total & \% of Total & $4,5 \%$ & $16,0 \%$ & $24,4 \%$ & $15,6 \%$ & $3,5 \%$ &, $0 \%$ & $64,1 \%$ \\
\hline
\end{tabular}

Regional Zone Match

One of the interesting differences we found for Maastricht and Phoenix is that of the way the front-yard soil coverage matches with the local ecological-climatological circumstances (match=1, mismatch=0). Both cities show just a slightly larger amount of matching yards than mismatching ones: Phoenix $56.5 \%$ of matching xeric yards; Maastricht $52.7 \%$ of matching mesic yards. Looking at the data on the neighbourhood level using cross-tabulation reveals that in Maastricht, Sint Pieter scores best with a mesic match score of $75 \%$. Santo Tomas in Tempe, Phoenix displays the highest match to the surrounding area with almost 93\%, which means there is a high amount of xeric yards in this neighbourhood. Especially Palmcroft \& Encanto in Phoenix and Blauwdorp \& Mariaberg in Maastricht have a large environmental mismatch. In Palmcroft and Encanto 75\% of the yards have a mesic character contradicting the surrounding desert environment. Blauwdorp \& Mariaberg shows a mismatch of $73.7 \%$, which means there is a high amount of xeric yards in this neighbourhood.

\section{Soil Cover}

Lawns: The assessed neighbourhoods in Phoenix have relatively many yards with the highest amount of lawn (37\%) compared to Maastricht (11\%). These are especially located in Palmcroft \& Encanto (65.9\%), Lancaster Manors (54.5\%) and Fairview Place (41.1\%). Santo Tomas is contrasting this trend with only $5.4 \%$ of the yards covered with 
lawn for $50 \%$ to $100 \%$ and $91.1 \%$ of yards with no lawn coverage at all. Only De Heeg and Blauwdorp \& Mariaberg in Maastricht score higher in the category 'no lawn', both with $93.4 \%$. Palmcroft \& Encanto, Sint Pieter and Fairview seem to have a substantial amount of yards combining lawn with a significant amount of other soil covering elements (table 11.4).

Gravel: The majority of the assessed yards in both cities have no gravel coverage at all (67.2\%). The Santo Tomas neighbourhood scores highest in high gravel coverage (41.1\% of the yards). This means that the low amount of lawns in Santo Tomas is compensated by the relatively high amount of gravel yards. The xeric character of the Santo Tomas neighbourhood can thus be explained by the high amount of gravel yards.

Table 11.4. Soil coverage categories in Phoenix and Maastricht

\begin{tabular}{|c|c|c|c|c|c|c|}
\hline \multicolumn{2}{|c|}{ City * Lawn Crosstabulation } & \multirow{2}{*}{$\begin{array}{l}\text { No } \\
94\end{array}$} & \multirow{2}{*}{$\begin{array}{l}<10 \% \\
1\end{array}$} & \multirow{2}{*}{$\frac{10-50 \%}{21}$} & \multirow{2}{*}{$\begin{array}{l}50-100 \% \\
68\end{array}$} & \multirow{2}{*}{$\frac{\text { Total }}{184}$} \\
\hline Phoenix & Count & & & & & \\
\hline & \% within City & $51,1 \%$ &, $5 \%$ & $11,4 \%$ & $37,0 \%$ & $100,0 \%$ \\
\hline & $\%$ within Lawn & $25,8 \%$ & $100,0 \%$ & $48,8 \%$ & $65,4 \%$ & $35,9 \%$ \\
\hline & $\%$ of Total & $18,4 \%$ &, $2 \%$ & $4,1 \%$ & $13,3 \%$ & $35,9 \%$ \\
\hline \multirow[t]{4}{*}{ Maastricht } & Count & 270 & 0 & 22 & 36 & 328 \\
\hline & $\%$ within City & $82,3 \%$ &, $0 \%$ & $6,7 \%$ & $11,0 \%$ & $100,0 \%$ \\
\hline & $\%$ within Lawn & $74,2 \%$ &, $0 \%$ & $51,2 \%$ & $34,6 \%$ & $64,1 \%$ \\
\hline & $\%$ of Total & $52,7 \%$ &, $0 \%$ & $4,3 \%$ & $7,0 \%$ & $64,1 \%$ \\
\hline \multirow[t]{4}{*}{ Total } & Count & 364 & 1 & 43 & 104 & 512 \\
\hline & $\%$ within City & $71,1 \%$ &, $2 \%$ & $8,4 \%$ & $20,3 \%$ & $100,0 \%$ \\
\hline & $\%$ within Lawn & $100,0 \%$ & $100,0 \%$ & $100,0 \%$ & $100,0 \%$ & $100,0 \%$ \\
\hline & $\%$ of Total & $71,1 \%$ &, $2 \%$ & $8,4 \%$ & $20,3 \%$ & $100,0 \%$ \\
\hline \multicolumn{2}{|c|}{ City * Gravel Crosstabulation } & No & $<10 \%$ & $10-50 \%$ & $50-100 \%$ & Total \\
\hline \multirow[t]{4}{*}{ Phoenix } & Count & 107 & 12 & 30 & 35 & 184 \\
\hline & $\%$ within City & $58,2 \%$ & $6,5 \%$ & $16,3 \%$ & $19,0 \%$ & $100,0 \%$ \\
\hline & $\%$ within Gravel & $31,1 \%$ & $44,4 \%$ & $47,6 \%$ & $44,9 \%$ & $35,9 \%$ \\
\hline & $\%$ of Total & $20,9 \%$ & $2,3 \%$ & $5,9 \%$ & $6,8 \%$ & $35,9 \%$ \\
\hline \multirow[t]{4}{*}{ Maastricht } & Count & 237 & 15 & 33 & 43 & 328 \\
\hline & \% within City & $72,3 \%$ & $4,6 \%$ & $10,1 \%$ & $13,1 \%$ & $100,0 \%$ \\
\hline & $\%$ within Gravel & $68,9 \%$ & $55,6 \%$ & $52,4 \%$ & $55,1 \%$ & $64,1 \%$ \\
\hline & $\%$ of Total & $46,3 \%$ & $2,9 \%$ & $6,4 \%$ & $8,4 \%$ & $64,1 \%$ \\
\hline \multirow[t]{4}{*}{ Total } & Count & 344 & 27 & 63 & 78 & 512 \\
\hline & \% within City & $67,2 \%$ & $5,3 \%$ & $12,3 \%$ & $15,2 \%$ & $100,0 \%$ \\
\hline & $\%$ within Gravel & $100,0 \%$ & $100,0 \%$ & $100,0 \%$ & $100,0 \%$ & $100,0 \%$ \\
\hline & $\%$ of Total & $67,2 \%$ & $5,3 \%$ & $12,3 \%$ & $15,2 \%$ & $100,0 \%$ \\
\hline
\end{tabular}




\begin{tabular}{|c|c|c|c|c|c|c|}
\hline \multicolumn{2}{|c|}{ City * Pavement Crosstabulation } & \multirow{2}{*}{$\begin{array}{l}\text { No } \\
116\end{array}$} & \multirow{2}{*}{$\begin{array}{l}<10 \% \\
41\end{array}$} & \multirow{2}{*}{$\begin{array}{l}10-50 \% \\
18\end{array}$} & \multirow{2}{*}{$\begin{array}{l}50-100 \% \\
9\end{array}$} & \multirow{2}{*}{$\begin{array}{l}\text { Total } \\
184\end{array}$} \\
\hline Phoenix & Count & & & & & \\
\hline & $\%$ within City & $63,0 \%$ & $22,3 \%$ & $9,8 \%$ & $4,9 \%$ & $100,0 \%$ \\
\hline & $\%$ within Pavement & $54,5 \%$ & $34,5 \%$ & $24,7 \%$ & $8,4 \%$ & $35,9 \%$ \\
\hline & $\%$ of Total & $22,7 \%$ & $8,0 \%$ & $3,5 \%$ & $1,8 \%$ & $35,9 \%$ \\
\hline \multirow[t]{4}{*}{ Maastricht } & Count & 97 & 78 & 55 & 98 & 328 \\
\hline & $\%$ within City & $29,6 \%$ & $23,8 \%$ & $16,8 \%$ & $29,9 \%$ & $100,0 \%$ \\
\hline & $\%$ within Pavement & $45,5 \%$ & $65,5 \%$ & $75,3 \%$ & $91,6 \%$ & $64,1 \%$ \\
\hline & $\%$ of Total & $18,9 \%$ & $15,2 \%$ & $10,7 \%$ & $19,1 \%$ & $64,1 \%$ \\
\hline \multirow[t]{4}{*}{ Total } & Count & 213 & 119 & 73 & 107 & 512 \\
\hline & \% within City & $41,6 \%$ & $23,2 \%$ & $14,3 \%$ & $20,9 \%$ & $100,0 \%$ \\
\hline & $\%$ within Pavement & $100,0 \%$ & $100,0 \%$ & $100,0 \%$ & $100,0 \%$ & $100,0 \%$ \\
\hline & $\%$ of Total & $41,6 \%$ & $23,2 \%$ & $14,3 \%$ & $20,9 \%$ & $100,0 \%$ \\
\hline \multicolumn{2}{|c|}{ City * BareSoil Crosstabulation } & No & $<10 \%$ & $10-50 \%$ & $50-100 \%$ & Total \\
\hline \multirow[t]{4}{*}{ Phoenix } & Count & 126 & 13 & 27 & 18 & 184 \\
\hline & $\%$ within City & $68,5 \%$ & $7,1 \%$ & $14,7 \%$ & $9,8 \%$ & $100,0 \%$ \\
\hline & \% within BareSoil & $30,6 \%$ & $46,4 \%$ & $55,1 \%$ & $78,3 \%$ & $35,9 \%$ \\
\hline & $\%$ of Total & $24,6 \%$ & $2,5 \%$ & $5,3 \%$ & $3,5 \%$ & $35,9 \%$ \\
\hline \multirow[t]{4}{*}{ Maastricht } & Count & 286 & 15 & 22 & 5 & 328 \\
\hline & $\%$ within City & $87,2 \%$ & $4,6 \%$ & $6,7 \%$ & $1,5 \%$ & $100,0 \%$ \\
\hline & \% within BareSoil & $69,4 \%$ & $53,6 \%$ & $44,9 \%$ & $21,7 \%$ & $64,1 \%$ \\
\hline & $\%$ of Total & $55,9 \%$ & $2,9 \%$ & $4,3 \%$ & $1,0 \%$ & $64,1 \%$ \\
\hline \multirow[t]{4}{*}{ Total } & Count & 412 & 28 & 49 & 23 & 512 \\
\hline & $\%$ within City & $80,5 \%$ & $5,5 \%$ & $9,6 \%$ & $4,5 \%$ & $100,0 \%$ \\
\hline & \% within BareSoil & $100,0 \%$ & $100,0 \%$ & $100,0 \%$ & $100,0 \%$ & $100,0 \%$ \\
\hline & $\%$ of Total & $80,5 \%$ & $5,5 \%$ & $9,6 \%$ & $4,5 \%$ & $100,0 \%$ \\
\hline \multicolumn{2}{|c|}{ City * GREENCOVERPOINTS Crosstabulation } & No & $<10 \%$ & $10-50 \%$ & $50-100 \%$ & Total \\
\hline \multirow[t]{4}{*}{ Phoenix } & Count & 23 & 78 & 62 & 21 & 184 \\
\hline & \% within City & $12,5 \%$ & $42,4 \%$ & $33,7 \%$ & $11,4 \%$ & $100,0 \%$ \\
\hline & $\%$ within GREENCOVERPOINTS & $22,3 \%$ & $46,7 \%$ & $44,3 \%$ & $20,6 \%$ & $35,9 \%$ \\
\hline & $\%$ of Total & $4,5 \%$ & $15,2 \%$ & $12,1 \%$ & $4,1 \%$ & $35,9 \%$ \\
\hline \multirow[t]{4}{*}{ Maastricht } & Count & 80 & 89 & 78 & 81 & 328 \\
\hline & $\%$ within City & $24,4 \%$ & $27,1 \%$ & $23,8 \%$ & $24,7 \%$ & $100,0 \%$ \\
\hline & $\%$ within GREENCOVERPOINTS & $77,7 \%$ & $53,3 \%$ & $55,7 \%$ & $79,4 \%$ & $64,1 \%$ \\
\hline & $\%$ of Total & $15,6 \%$ & $17,4 \%$ & $15,2 \%$ & $15,8 \%$ & $64,1 \%$ \\
\hline \multirow[t]{3}{*}{ Total } & Count & 103 & 167 & 140 & 102 & 512 \\
\hline & $\%$ within City & $20,1 \%$ & $32,6 \%$ & $27,3 \%$ & $19,9 \%$ & $100,0 \%$ \\
\hline & $\%$ within GREENCOVERPOINTS & $100,0 \%$ & $100,0 \%$ & $100,0 \%$ & $100,0 \%$ & $100,0 \%$ \\
\hline
\end{tabular}


Pavement: Comparing Maastricht to Phoenix shows there is a large difference between the amounts of paved yards in the two cities: Phoenix has a high percentage of yards with no pavement at all (63.0\%). In Maastricht this category scores much lower with 29.6\%. The highly paved yards Phoenix and Maastricht also differ significantly. Phoenix has only $4.9 \%$ of its yards paved for $50 \%$ to $100 \%$; Maastricht $29.9 \%$. Cross-tabulations for pavement on the neighbourhood levels show high percentages of half to fully paved yards in Blauwdorp \& Mariaberg (51.3\%) and in De Heeg (32.2\%), the two lower income neighbourhoods in Maastricht. Lancaster Manors has the highest amount of yards with no pavement (81.8\%). Also in Fairview Place, Santo Tomas and Palmcroft \& Encanto the majority of front-yards have no pavement at all (respectively 65.8\%, 58.9\%, 59.1\%). Santo Tomas has with $14.3 \%$ the highest amount of yards with $50 \%$ to $100 \%$ pavement in Phoenix. Front yards there are occasionally used as parking space, sometimes adorned with plantation-strips at the edges.

Bare soil: The majority of all the assessed yards in our sample have at least some soil coverage, indicated by the high scores for the 'no bare soil' category of almost all the neighbourhoods. Only Lancaster Manors has a fair amount of yards (36.4\%) with a $50 \%$ to $100 \%$ bare soil structure. In Phoenix, bare soil often indicates negligence and often leads to dusty circumstances, degrading the soil even more. Contrarily, in Maastricht bare soil often indicates the elimination of weeds by a higher care level.

Green Cover: In Phoenix many yards have less than 10\% green coverage (with plants other than lawn-species) and $10 \%$ to $50 \%$ of green coverage (respectively $42.4 \%$ and $33.7 \%$ ). Only $11.4 \%$ of the yards are highly abundant with green. In Maastricht, the green coverage abundance categories are rather evenly distributed over all the yards (around 25\% each). Especially Palmcroft \& Encanto (40.9\%) and Santo Tomas (51.8\%) in Phoenix score high in the less than $10 \%$ green coverage category. These scores can be related to the high amount of lawns in Palmcroft \& Encanto (see above) and the high level of xeric/gravelled yards in Santo Tomas (see above). Sint Pieter (30\%), Vroendaal (29.4\%) and De Heeg (27.3\%) in Maastricht score highest in the category of half to full green coverage. The highest amount of yards with no green coverage at all can be found in Blauwdorp \& Mariaberg (39.5\%), Lancaster Manors (36.4\%) and De Heeg (25.6\%). This corresponds to the high pavement levels in Blauwdorp \& Mariaberg and De Heeg and the high bare soil percentage in Lancaster Manors (see above). The values for the amounts of green coverage (with plants other than lawn-species) point towards the next paragraph where we describe the abundance and richness of plant species in the yard on the neighbourhood level. 


\section{Abundance, Richness and Edge Effect}

The plant diversity values have been composed of the combination of the points given for green coverage (see above), the abundance of perennials and annuals, on the richness of native and exotic species and on the presence of vertical diversity (edge effect). The calculation resulted into values ranging from 0 to 31 . Based on statistical assessment of normality we labelled the values as in figure 11.3 .

Figure 11.3. Scale of plant diversity

\begin{tabular}{|cc|lc|lc|lc|}
\hline 0 & $\begin{array}{c}10 \\
\text { Low }\end{array}$ & 11 & $\begin{array}{c}20 \\
\text { Average }\end{array}$ & 21 & $\begin{array}{c}30 \\
\text { High }\end{array}$ & 31 & $\begin{array}{c}40 \\
\text { Extraordinary }\end{array}$ \\
\hline
\end{tabular}

Cross-tabulations reveal that most of the assessed yards of our total sample are in the average category (61.9\%). Maastricht has with 33.5\% significantly more yards with low plant diversity than Phoenix (21.7\%). Both cities score almost equal in the high diversity category (Phoenix 8.7\% and Maastricht 8.5\%). Only Phoenix has one yard in the extraordinary category. At the neighbourhood level Lancaster Manors (54.5\%) in Phoenix and Blauwdorp \& Mariaberg (56.6\%) in Maastricht have least plant diversity. Fairview Place turns out to be the neighbourhood with the highest amount of averagely diverse yards (76.6) together with Sint Pieter (71.3\%). In the category high diversity Palmcroft \& Encanto scores best with $15.9 \%$.

\section{Perennials and annuals}

Perennials: The abundance measure for high numbers of perennials is higher in Maastricht than in Phoenix. This can logically be attributed to the different climates of the cities. Even highly diverse yards in Phoenix with a native desert landscaping style (xeriscape) (Norris-Bernzel \& Edinger, 2005) may be less abundant than yards in Maastricht because the typical desert species (cacti, aloe, etc.) require more individual space than the common wild plant species of mediate climates that can often be found in lush groups of smaller individuals. Still, the difference between the two cities here is not very high. At the neighbourhood level, De Heeg (23.6\%) and Sint Pieter (15.6\%) in Maastricht have the largest amount of high perennial numbers compared to the other neighbourhoods. The highest number of yards with only 1 to 5 perennials is located in Lancaster Manors (63.6\%) and in Blauwdorp \& Mariaberg (50\%). Compared to the other neighbourhoods, Vroendaal scores best with $17.6 \%$ in the $100>$ perennials category. De Heeg and Blauwdorp \& Mariaberg score highest compared to the other neighbourhoods in the category of no perennials at all (respectively $12.4 \%$ and $15.8 \%$ ) (table 11.5).

Annuals: The 'no annuals' category scores highest: Maastricht $80.5 \%$ and for Phoenix $71.7 \%$. Beyond this category, the 1 to 5 annuals category is the most popular in both 
cities. Starting from the 5 to 10 annuals category, the Phoenix yards present more annuals than the yards in Maastricht. Only in the 10 to 25 annuals category, the two cities equal each other. Compared to the other neighbourhoods, De Heeg has the highest percentage of annuals (23.6\%). In the category of 1 to 5 annuals Sint Pieter (16.3) and Palmcroft \& Encanto (15.9) score highest. In the category 25 to 50 annuals this only Palmcroft \& Encanto and Fairview Place score significantly.

Table 11.5. Perennials and annuals

\begin{tabular}{|c|c|c|c|c|c|c|c|c|c|}
\hline \multirow{2}{*}{\multicolumn{2}{|c|}{$\begin{array}{l}\text { City * Perennials } \\
\text { Crosstabulation }\end{array}$}} & \multicolumn{7}{|c|}{ Number of Perennials } & \multirow[t]{2}{*}{ Total } \\
\hline & & 0 & $1-5$ & $5-10$ & $10-25$ & $25-50$ & $50-100$ & $100>$ & \\
\hline \multirow[t]{4}{*}{ Phx. } & Count & 7 & 53 & 36 & 50 & 19 & 10 & 9 & 184 \\
\hline & $\%$ within City & $3,8 \%$ & $28,8 \%$ & $19,6 \%$ & $27,2 \%$ & $10,3 \%$ & $5,4 \%$ & $4,9 \%$ & $100,0 \%$ \\
\hline & $\%$ within Perennials & $20,0 \%$ & $34,2 \%$ & $43,4 \%$ & $49,0 \%$ & $27,9 \%$ & $26,3 \%$ & $29,0 \%$ & $35,9 \%$ \\
\hline & $\%$ of Total & $1,4 \%$ & $10,4 \%$ & $7,0 \%$ & $9,8 \%$ & $3,7 \%$ & $2,0 \%$ & $1,8 \%$ & $35,9 \%$ \\
\hline \multirow[t]{4}{*}{ Mstr. } & Count & 28 & 102 & 47 & 52 & 49 & 28 & 22 & 328 \\
\hline & $\%$ within City & $8,5 \%$ & $31,1 \%$ & $14,3 \%$ & $15,9 \%$ & $14,9 \%$ & $8,5 \%$ & $6,7 \%$ & $100,0 \%$ \\
\hline & $\%$ within Perennials & $80,0 \%$ & $65,8 \%$ & $56,6 \%$ & $51,0 \%$ & $72,1 \%$ & $73,7 \%$ & $71,0 \%$ & $64,1 \%$ \\
\hline & $\%$ of Total & $5,5 \%$ & $19,9 \%$ & $9,2 \%$ & $10,2 \%$ & $9,6 \%$ & $5,5 \%$ & $4,3 \%$ & $64,1 \%$ \\
\hline \multirow[t]{4}{*}{ Total } & Count & 35 & 155 & 83 & 102 & 68 & 38 & 31 & 512 \\
\hline & $\%$ within City & $6,8 \%$ & $30,3 \%$ & $16,2 \%$ & $19,9 \%$ & $13,3 \%$ & $7,4 \%$ & $6,1 \%$ & $100,0 \%$ \\
\hline & $\%$ within Perennials & $100,0 \%$ & $100,0 \%$ & $100,0 \%$ & $100,0 \%$ & $100,0 \%$ & $100,0 \%$ & $100,0 \%$ & $100,0 \%$ \\
\hline & $\%$ of Total & $6,8 \%$ & $30,3 \%$ & $16,2 \%$ & $19,9 \%$ & $13,3 \%$ & $7,4 \%$ & $6,1 \%$ & $100,0 \%$ \\
\hline \multirow{2}{*}{\multicolumn{2}{|c|}{ City * Annuals Crosstabulation }} & \multicolumn{7}{|c|}{ Number of Annuals } & Total \\
\hline & & 0 & $1-5$ & $5-10$ & $10-25$ & $25-50$ & $50-100$ & $100>$ & \\
\hline \multirow[t]{4}{*}{ Phx } & Count & 132 & 20 & 15 & 6 & 8 & 2 & 1 & 184 \\
\hline & $\%$ within City & $71,7 \%$ & $10,9 \%$ & $8,2 \%$ & $3,3 \%$ & $4,3 \%$ & $1,1 \%$ &, $5 \%$ & $100,0 \%$ \\
\hline & $\%$ within Annuals & $33,3 \%$ & $32,8 \%$ & $68,2 \%$ & $35,3 \%$ & $66,7 \%$ & $66,7 \%$ & $100,0 \%$ & $35,9 \%$ \\
\hline & $\%$ of Total & $25,8 \%$ & $3,9 \%$ & $2,9 \%$ & $1,2 \%$ & $1,6 \%$ & $4 \%$ &, $2 \%$ & $35,9 \%$ \\
\hline \multirow[t]{4}{*}{ Mstr. } & Count & 264 & 41 & 7 & 11 & 4 & 1 & 0 & 328 \\
\hline & $\%$ within City & $80,5 \%$ & $12,5 \%$ & $2,1 \%$ & $3,4 \%$ & $1,2 \%$ & ,3\% &, $0 \%$ & $100,0 \%$ \\
\hline & $\%$ within Annuals & $66,7 \%$ & $67,2 \%$ & $31,8 \%$ & $64,7 \%$ & $33,3 \%$ & $33,3 \%$ &, $0 \%$ & $64,1 \%$ \\
\hline & $\%$ of Total & $51,6 \%$ & $8,0 \%$ & $1,4 \%$ & $2,1 \%$ &, $8 \%$ &, $2 \%$ &, $0 \%$ & $64,1 \%$ \\
\hline \multirow[t]{4}{*}{ Total } & Count & 396 & 61 & 22 & 17 & 12 & 3 & 1 & 512 \\
\hline & $\%$ within City & $77,3 \%$ & $11,9 \%$ & $4,3 \%$ & $3,3 \%$ & $2,3 \%$ & ,6\% &, $2 \%$ & $100,0 \%$ \\
\hline & $\%$ within Annuals & $100,0 \%$ & $100,0 \%$ & $100,0 \%$ & $100,0 \%$ & $100,0 \%$ & $100,0 \%$ & $100,0 \%$ & $100,0 \%$ \\
\hline & $\%$ of Total & $77,3 \%$ & $11,9 \%$ & $4,3 \%$ & $3,3 \%$ & $2,3 \%$ & ,6\% &, $2 \%$ & $100,0 \%$ \\
\hline
\end{tabular}




\section{Natives and exotics}

Exotics: A majority of yards in both cities display 1 to 3 exotic species (50.5\% in Phoenix and $46 \%$ in Maastricht) (table 6). Overall, in Phoenix more yards have exotic species compared to Maastricht. Compared to Phoenix (22,8\%), more yards in Maastricht have no exotic species at all (45.1\%). At the neighbourhood level most neighbourhoods have the highest amount of yards within the 1 to 3 exotic species category $(47.7 \%$ of all the yards in all the neighbourhoods), except for Palmcroft \& Encanto. There $56.8 \%$ of the yards presents 4 to 10 exotic species. The other category that scores high is the one with no exotic species at all (37.1\%). Especially high in this category are Blauwdorp \& Mariaberg (59.2\%) and Vroendaal (51\%). Only one yard in Fairview has more than 30 exotic species. This can be related to the variety of non-desert food crops and flowers being grown in the permaculture yard. One yard in Fairview and one yard in Palmcroft \& Encanto present between 21 and 30 exotics. Three yards in Palmcroft \& Encanto have 11 to 20 exotic species. Interestingly, after Palmcroft \& Encanto Lancaster Manors scores highest in the category of 4 to 10 species. This can be attributed to the small sample of this neighbourhood.

Natives: Native species are also best represented in both cities in the 1 to 3 species category. Phoenix has a slightly higher percentage $(45.1 \%)$ compared to Maastricht (43.9\%), but the difference can almost be neglected. In the 4 to 10 native species category Maastricht scores higher with $32 \%$ over $24.5 \%$ in Phoenix. In all the other categories, Maastricht scores slightly higher on the native species level. Nevertheless, there are significantly more yards without any native species in Phoenix (20.1\%) than in Maastricht (11.9\%). Native species at the neighbourhood level are best found in De Heeg. There, $23.6 \%$ of the yards have native species. Most of the yards in De Heeg have them in the category of 1 to 3 species (40.5\%). Also 4 to 10 native species are represented fairly well in De Heeg with $28.1 \%$. This neighbourhood also has two yards with more than 30 natives and together with Sint Pieter the highest percentage of yards with 21 to 30 species compared to the other neighbourhoods. In the category of no native species at all Lancaster Manors scores highest with 54.5\%. This neighbourhood is followed by Palmcroft \& Encanto (31.8\%), which can be explained by the high amount of exotics and by the popularity of annuals and lawns in this neighbourhood (see above) (table 11.6). 
Table 11.6. Natives and exotics

\begin{tabular}{|c|c|c|c|c|c|c|c|c|}
\hline City * Exotics & Crosstabulation & $\begin{array}{l}0 \\
\text { Species }\end{array}$ & $\begin{array}{l}\text { 1-3 } \\
\text { Species }\end{array}$ & $\begin{array}{l}\text { 4-10 } \\
\text { Species }\end{array}$ & $\begin{array}{l}11-20 \\
\text { Species }\end{array}$ & $\begin{array}{l}21-30 \\
\text { Species }\end{array}$ & $\begin{array}{l}30> \\
\text { Species }\end{array}$ & Total \\
\hline \multirow[t]{4}{*}{ Phoenix } & Count & 42 & 93 & 42 & 4 & 2 & 1 & 184 \\
\hline & $\%$ within City & $22,8 \%$ & $50,5 \%$ & $22,8 \%$ & $2,2 \%$ & $1,1 \%$ &, $5 \%$ & $100,0 \%$ \\
\hline & $\%$ within Exotics & $22,1 \%$ & $38,1 \%$ & $63,6 \%$ & $44,4 \%$ & $100,0 \%$ & $100,0 \%$ & $35,9 \%$ \\
\hline & $\%$ of Total & $8,2 \%$ & $18,2 \%$ & $8,2 \%$ &, $8 \%$ &, $4 \%$ &, $2 \%$ & $35,9 \%$ \\
\hline \multirow[t]{4}{*}{ Maastricht } & Count & 148 & 151 & 24 & 5 & 0 & 0 & 328 \\
\hline & $\%$ within City & $45,1 \%$ & $46,0 \%$ & $7,3 \%$ & $1,5 \%$ &, $0 \%$ &, $0 \%$ & $100,0 \%$ \\
\hline & $\%$ within Exotics & $77,9 \%$ & $61,9 \%$ & $36,4 \%$ & $55,6 \%$ &, $0 \%$ &, $0 \%$ & $64,1 \%$ \\
\hline & $\%$ of Total & $28,9 \%$ & $29,5 \%$ & $4,7 \%$ & $1,0 \%$ &, $0 \%$ &, $0 \%$ & $64,1 \%$ \\
\hline \multirow[t]{4}{*}{ Total } & Count & 190 & 244 & 66 & 9 & 2 & 1 & 512 \\
\hline & $\%$ within City & $37,1 \%$ & $47,7 \%$ & $12,9 \%$ & $1,8 \%$ &, $4 \%$ &, $2 \%$ & $100,0 \%$ \\
\hline & $\%$ within Exotics & $100,0 \%$ & $100,0 \%$ & $100,0 \%$ & $100,0 \%$ & $100,0 \%$ & $100,0 \%$ & $100,0 \%$ \\
\hline & $\%$ of Total & $37,1 \%$ & $47,7 \%$ & $12,9 \%$ & $1,8 \%$ &, $4 \%$ &, $2 \%$ & $100,0 \%$ \\
\hline City * Natives & s Crosstabulation & $\begin{array}{l}0 \\
\text { Species }\end{array}$ & $\begin{array}{l}\text { 1-3 } \\
\text { Species }\end{array}$ & $\begin{array}{l}4-10 \\
\text { Species }\end{array}$ & $\begin{array}{l}11-20 \\
\text { Species }\end{array}$ & $\begin{array}{l}21-30 \\
\text { Species }\end{array}$ & $\begin{array}{l}30> \\
\text { Species }\end{array}$ & Total \\
\hline \multirow[t]{4}{*}{ Phoenix } & Count & 37 & 83 & 45 & 13 & 5 & 1 & 184 \\
\hline & $\%$ within City & $20,1 \%$ & $45,1 \%$ & $24,5 \%$ & $7,1 \%$ & $2,7 \%$ &, $5 \%$ & $100,0 \%$ \\
\hline & $\%$ within Natives & $48,7 \%$ & $36,6 \%$ & $30,0 \%$ & $33,3 \%$ & $29,4 \%$ & $33,3 \%$ & $35,9 \%$ \\
\hline & $\%$ of Total & $7,2 \%$ & $16,2 \%$ & $8,8 \%$ & $2,5 \%$ & $1,0 \%$ &, $2 \%$ & $35,9 \%$ \\
\hline \multirow[t]{4}{*}{ Maastricht } & Count & 39 & 144 & 105 & 26 & 12 & 2 & 328 \\
\hline & $\%$ within City & $11,9 \%$ & $43,9 \%$ & $32,0 \%$ & $7,9 \%$ & $3,7 \%$ &, $6 \%$ & $100,0 \%$ \\
\hline & $\%$ within Natives & $51,3 \%$ & $63,4 \%$ & $70,0 \%$ & $66,7 \%$ & $70,6 \%$ & $66,7 \%$ & $64,1 \%$ \\
\hline & $\%$ of Total & $7,6 \%$ & $28,1 \%$ & $20,5 \%$ & $5,1 \%$ & $2,3 \%$ & $4 \%$ & $64,1 \%$ \\
\hline \multirow[t]{4}{*}{ Total } & Count & 76 & 227 & 150 & 39 & 17 & 3 & 512 \\
\hline & $\%$ within City & $14,8 \%$ & $44,3 \%$ & $29,3 \%$ & $7,6 \%$ & $3,3 \%$ &, $6 \%$ & $100,0 \%$ \\
\hline & $\%$ within Natives & $100,0 \%$ & $100,0 \%$ & $100,0 \%$ & $100,0 \%$ & $100,0 \%$ & $100,0 \%$ & $100,0 \%$ \\
\hline & $\%$ of Total & $14,8 \%$ & $44,3 \%$ & $29,3 \%$ & $7,6 \%$ & $3,3 \%$ &, $6 \%$ & $100,0 \%$ \\
\hline
\end{tabular}

Edge effect: Another important indicator for biodiversity is the edge effect, which we measured by looking at the availability of flowers, shrubs, trees and weeds. One point was added up for the presence of each of these elements. This resulted in an overall 'edge-point' (see table 11.7). On the city level, Phoenix scores highest in the categories of a high edge effect of three $(38.6 \%)$ or four $(23.9 \%)$ points. In the case of four points it means that all the vertical features are available. Overall, most yards of our total sample score highest in the categories where two or three points are distributed (respectively 28.55 and $29.5 \%$ ). Only a small amount of yards, but still a significant $6.3 \%$ present none of the features adding to vertical diversity. 
Table 11.7. Edge effect in Phoenix and Maastricht

\begin{tabular}{|c|c|c|c|c|c|c|c|}
\hline & & \multicolumn{6}{|c|}{ EDGEPOINTS } \\
\hline & & ,00 & 1,00 & 2,00 & 3,00 & 4,00 & Total \\
\hline \multirow[t]{4}{*}{ Phoenix } & Count & 6 & 21 & 42 & 71 & 44 & 184 \\
\hline & $\%$ within City & $3,3 \%$ & $11,4 \%$ & $22,8 \%$ & $38,6 \%$ & $23,9 \%$ & $100,0 \%$ \\
\hline & $\%$ within EDGEPOINTS & $18,8 \%$ & $22,6 \%$ & $28,8 \%$ & $47,0 \%$ & $48,9 \%$ & $35,9 \%$ \\
\hline & $\%$ of Total & $1,2 \%$ & $4,1 \%$ & $8,2 \%$ & $13,9 \%$ & $8,6 \%$ & $35,9 \%$ \\
\hline \multirow[t]{4}{*}{ Maastricht } & Count & 26 & 72 & 104 & 80 & 46 & 328 \\
\hline & $\%$ within City & $7,9 \%$ & $22,0 \%$ & $31,7 \%$ & $24,4 \%$ & $14,0 \%$ & $100,0 \%$ \\
\hline & $\%$ within EDGEPOINTS & $81,3 \%$ & $77,4 \%$ & $71,2 \%$ & $53,0 \%$ & $51,1 \%$ & $64,1 \%$ \\
\hline & $\%$ of Total & $5,1 \%$ & $14,1 \%$ & $20,3 \%$ & $15,6 \%$ & $9,0 \%$ & $64,1 \%$ \\
\hline \multirow[t]{4}{*}{ Total } & Count & 32 & 93 & 146 & 151 & 90 & 512 \\
\hline & $\%$ within City & $6,3 \%$ & $18,2 \%$ & $28,5 \%$ & $29,5 \%$ & $17,6 \%$ & $100,0 \%$ \\
\hline & $\%$ within EDGEPOINTS & $100,0 \%$ & $100,0 \%$ & $100,0 \%$ & $100,0 \%$ & $100,0 \%$ & $100,0 \%$ \\
\hline & $\%$ of Total & $6,3 \%$ & $18,2 \%$ & $28,5 \%$ & $29,5 \%$ & $17,6 \%$ & $100,0 \%$ \\
\hline
\end{tabular}

Table 11.8. Edge effect on the neighbourhood level

\begin{tabular}{|c|c|c|c|c|c|c|c|c|c|c|}
\hline \multicolumn{2}{|l|}{ Neighbourhood } & \multicolumn{2}{|c|}{ Flowers } & \multicolumn{2}{|l|}{ Shrubs } & \multicolumn{2}{|l|}{ Trees } & \multicolumn{2}{|l|}{ Weeds } & \multirow{2}{*}{$\begin{array}{l}\text { Total } \\
\text { Neighbhs } \\
\text {. }\end{array}$} \\
\hline & &, 00 & 1,00 & ,00 & 1,00 & , 00 & 1,00 &, 00 & 1,00 & \\
\hline \multirow{2}{*}{$\begin{array}{l}\text { Palmcroft \& } \\
\text { Encanto }\end{array}$} & Count & 8 & 36 & 9 & 35 & 4 & 40 & 41 & 3 & 44 \\
\hline & $\%$ within Neighb & $18,2 \%$ & $81,8 \%$ & $20,5 \%$ & $79,5 \%$ & $9,1 \%$ & $90,9 \%$ & $93,2 \%$ & $6,8 \%$ & $100,0 \%$ \\
\hline \multirow{2}{*}{$\begin{array}{l}\text { Tempe Santo } \\
\text { Tomas }\end{array}$} & Count & 12 & 44 & 16 & 40 & 19 & 37 & 33 & 23 & 56 \\
\hline & $\%$ within Neighb & $21,4 \%$ & $78,6 \%$ & $28,6 \%$ & $71,4 \%$ & $33,9 \%$ & $66,1 \%$ & $58,9 \%$ & $41,1 \%$ & $100,0 \%$ \\
\hline \multirow[t]{2}{*}{ Fairview } & Count & 21 & 52 & 14 & 59 & 10 & 63 & 35 & 38 & 73 \\
\hline & $\%$ within Neighb & $28,8 \%$ & $71,2 \%$ & $19,2 \%$ & $80,8 \%$ & $13,7 \%$ & $86,3 \%$ & $47,9 \%$ & $52,1 \%$ & $100,0 \%$ \\
\hline \multirow{2}{*}{$\begin{array}{l}\text { Lancaster } \\
\text { Manors }\end{array}$} & Count & 5 & 6 & 3 & 8 & 4 & 7 & 7 & 4 & 11 \\
\hline & $\%$ within Neighb & $45,5 \%$ & $54,5 \%$ & $27,3 \%$ & $72,7 \%$ & $36,4 \%$ & $63,6 \%$ & $63,6 \%$ & $36,4 \%$ & $100,0 \%$ \\
\hline \multirow[t]{2}{*}{ Sint Pieter } & Count & 20 & 60 & 7 & 73 & 34 & 46 & 45 & 35 & 80 \\
\hline & $\%$ within Neighb & $25,0 \%$ & $75,0 \%$ & $8,8 \%$ & $91,3 \%$ & $42,5 \%$ & $57,5 \%$ & $56,3 \%$ & $43,8 \%$ & $100,0 \%$ \\
\hline \multirow[t]{2}{*}{ Vroendaal } & Count & 21 & 30 & 4 & 47 & 17 & 34 & 41 & 10 & 51 \\
\hline & $\%$ within Neighb & $41,2 \%$ & $58,8 \%$ & $7,8 \%$ & $92,2 \%$ & $33,3 \%$ & $66,7 \%$ & $80,4 \%$ & $19,6 \%$ & $100,0 \%$ \\
\hline \multirow[t]{2}{*}{ De Heeg } & Count & 45 & 76 & 28 & 93 & 81 & 40 & 84 & 37 & 121 \\
\hline & $\%$ within Neighb & $37,2 \%$ & $62,8 \%$ & $23,1 \%$ & $76,9 \%$ & $66,9 \%$ & $33,1 \%$ & $69,4 \%$ & $30,6 \%$ & $100,0 \%$ \\
\hline \multirow[t]{2}{*}{ Blauwdorp } & Count & 41 & 35 & 26 & 50 & 66 & 10 & 46 & 30 & 76 \\
\hline & $\%$ within Neighb & $53,9 \%$ & $46,1 \%$ & $34,2 \%$ & $65,8 \%$ & $86,8 \%$ & $13,2 \%$ & $60,5 \%$ & $39,5 \%$ & $100,0 \%$ \\
\hline \multirow[t]{2}{*}{ Total } & Count & 173 & 339 & 107 & 405 & 235 & 277 & 332 & 180 & 512 \\
\hline & $\%$ of Total & $33,8 \%$ & $66,2 \%$ & $20,9 \%$ & $79,1 \%$ & $45,9 \%$ & $54,1 \%$ & $64,8 \%$ & $35,2 \%$ & $100,0 \%$ \\
\hline
\end{tabular}


On the neighbourhood level Fairview (30.1\%), Santo Tomas (30.4\%) and Sint Pieter $(27.5 \%)$ score best in the category where four points are given for edge effect. Table 11.8 gives an overview on the neighbourhood level of the specific distribution of flowers, shrubs, trees and weeds that together represent the edge effect.

Trees need some special mentioning: they are best represented in Palmcroft \& Encanto where $90.9 \%$ of all the yards have one or more private trees. De Heeg (33.1) and Blauwdorp \& Mariaberg (13.2\%) score lowest in trees. However, this doesn't mean that these neighbourhoods are devoid of trees. In these neighbourhoods trees are integrated in the urban planning design, which can also be said for most of the other visited neighbourhoods, except for Lancaster Manors and Santo Tomas in Tempe. In these latter neighbourhoods low level of private trees are combined with the absence of municipal trees.

\section{Anthropogenic factors}

Using anthropogenic factors as indicators for biodiversity (as contributors or disturbers) isn't very common. Here we demonstrate that including anthropogenic variables makes sense and reveals interesting patterns. For each occurring anthropogenic feature we distributed one point. In total, not more than eight points were given to an individual neighbourhood. This point only occurred in the permaculture yard in Fairview Place.

\section{Contributors}

Although Blauwdorp \& Mariaberg score rather low in the biotic contributions to biodiversity and high in the zero-category of a-biotic contributions, it has the highest amount of bird-nesting opportunities. Coloured nest-boxes are on many of the street trees and house walls in this neighbourhood (13.2\%). A social-housing company of the neighbourhood carried out a project where these nest-boxes were made by artists together with children and patients of a psychiatric care facility (Woonpunt, 2012). A common garden that was too to take up in our sample of private front-yards would have added another large amount of nest-boxing facilities to this neighbourhood. De Heeg follows Blauwdorp \& Mariaberg in the lead on nest-boxes with 5.8\%. Nevertheless, these percentages are low. Insect-hotels weren't present in any of the visited yards. Palmcroft \& Encanto takes the lead with bird-feeders (13.6\%), closely followed by Fairview (12.3\%). Most of them are installed to feed hummingbirds. Possibly, it can be attributed to the visiting season (spring and early summer), but wild food was also low in most of the neighbourhoods. Fairview had the most wild-food (17.8\%). This can be related to the presence of the two edible yards there. Bird-bathing facilities were hardly available anywhere. Palmcroft and Encanto had the most of these facilities with only $6.8 \%$. Most of the baths we saw were not filled with water though. Palmcroft and Encanto (52.3\%) and Fairview (49.3\%) present the highest amount of plant-containers. These can be tiny 'micro-climates' with 
other soil temperatures, structures and moisture levels than surrounding yard-features. They can be favourable places for insects like carpenter bees to nest. Also, very often the containers are used to house exotic plant species that are potentially attractive to native animal species as well (Burghardt, et al., 2008; Kowarik, 2011; Heezik, et al., 2012). Compost and other organic matter can hardly be found in any of the front-yards in the visited neighbourhoods. Irrigation systems show a significantly higher abundance in Phoenix yards (28.3\%) than in Maastricht (1.2\%). Especially Fairview with $38.4 \%$ and Palmcroft and Encanto with $31.8 \%$ have many yards with visible irrigation systems. Nevertheless, based on the visual information, the use of them seems to be higher in Palmcroft and Encanto than in Fairview Place.

\section{Disturbances}

With regards to potential disturbances, artificial light scores high in the Phoenix neighbourhoods with Palmcroft \& Encanto on the lead: $52.3 \%$ of the yards have artificial light installations. Santo Tomas scores also high here with $48.2 \%$, followed by Fairview (34.2\%). The Dutch neighbourhoods have significantly less light installations, ranging from zero in Sint Pieter to 3.3\% in De Heeg. Based on the solely visual information we aren't able to say much about the dis-contributions caused by artificial fertilizers, herbicides and pesticides. Many front-yards have benches or tables installed to facilitate social time in the yards. In Lancaster Manors (45.5\%), Fairview (35.6\%) Palmcroft and Encanto (25\%) most furniture can be found. Vroendaal (5.9\%) and Santo Tomas (5.4\%) have least furniture displayed in their front-yards. The most frequently observed disturbance after the light installations and furniture is the habit of people using their yard as a place to park vehicles, like bicycles, motorbikes, baby-buggies and cars. Interestingly, the trend of parking vehicles seems to be increasing with decreasing socio-economic situations. Only De Heeg (10.7\% yards with vehicle disturbance) seems to be an exception to this 'rule'. Palmcroft \& Encanto (0\%) and Sint Pieter (6.3\%) have least vehicle disturbances whereas Lancaster Manors (18.2\%) and Blauwdorp \& Mariaberg (19.7\%) show the highest percentages. Overall, the yards in Maastricht are more often used for parking vehicles than the ones in Phoenix. This can be attributed to the many bicycles that are given a parking-spot in Dutch yards.

Another feature that we were able to include was damages in plants or garden designs, most often occurring in the Phoenix neighbourhoods because of negligence of watering exotic species like trees or grass lawns. Lancaster Manors has the highest amount of yards with damaged elements (36.4\%). Indeed, these are most often neglected lawns and trees dried out by a lack of irrigation. Also Fairview presents a percentage of $12.3 \%$ of the yards that have some damages. In Maastricht, not a lot of damages have been observed. Only Blauwdorp \& Mariaberg (3.9\%) and De Heeg (.8\%) have some occurrence of damage. 


\section{Design Style}

It may be interesting to see whether there are any relations between garden design styles and the way a garden can contribute to biodiversity and ecosystem services or disservices. Although there are globally many more styles, we only included the ones we could meaningfully identify during the field visits and photo analyses (Orians, 1980; Schulz, 1985; Lohr, 2007; Chou et al., 2011).

At the city level desert gardens (xeriscape) (Norris-Bernzel \& Edinger, 2005; Larsen \& Harlan, 2006) are most popular in Phoenix. These account for $26 \%$ of all the analysed yards in Phoenix. Second popular in Phoenix are the green English style picturesque or 'park' gardens (20.1\%) (Szilagy, 2011). Victorian gardens -- or gardenesque gardens -(Ignatieva, 2010) are third popular in Phoenix with 15.2\%. These are gardens inspired on the park type with lawns, shrubs and trees, but additionally adorned with (usually exotic) flowers in beds displaying them well.

In Maastricht 'desert-gardening' is also popular. We call these yard-types 'functional minimalist', because they combine low maintenance needs with a low occurrence of any type of green and a high occurrence of pavement or gravel, sometimes used for vehicles or with social functions equipped with furniture. The more maintenance intensive version of this type of yard often reflects elements from $18^{\text {th }}$ century Régence Gardens with fantastic and intricate forms of topiary, referred to in the literature as 'Dutch Taste' (Hopper, 1981). However, nowadays most often the topiary -- if present -- is not so intricate anymore. The functional minimalist yard occurs $35.7 \%$ of all the yards in Maastricht. Also popular in Maastricht are the picturesque gardens (12.2\%). English cottage style yards are also occurring significantly in Maastricht (8.2\%). The other design types are all less prominent in both cities (table 11.9a and b*).

Each individual neighbourhood can be said to have a general most popular design that distinguishes it from the others (see table 9). In Palmcroft \& Encanto gardenesque $(45.5 \%)$ and picturesque $(20.5 \%)$ yards prevail. Santo Tomas is characterised by native desert (xeriscape) gardens (58.9\%). Fairview Place favours park gardens most (30.1\%) and Lancaster Manors also has prevalence for the park-style design (54.5\%). In Sint Pieter in Maastricht the most occurring yard types can be described as park $(22.5 \%)$ and cottage style (20\%). Vroendaal has a high occurrence of both park (33.3\%) and functional minimalist (21.6\%) yards. De Heeg is characterized by a high level of functional minimalism (42.1\%). For Blauwdorp \& Mariaberg this is the same (56.6\%). 
Table 11.9a. Design inspiration in Maastricht

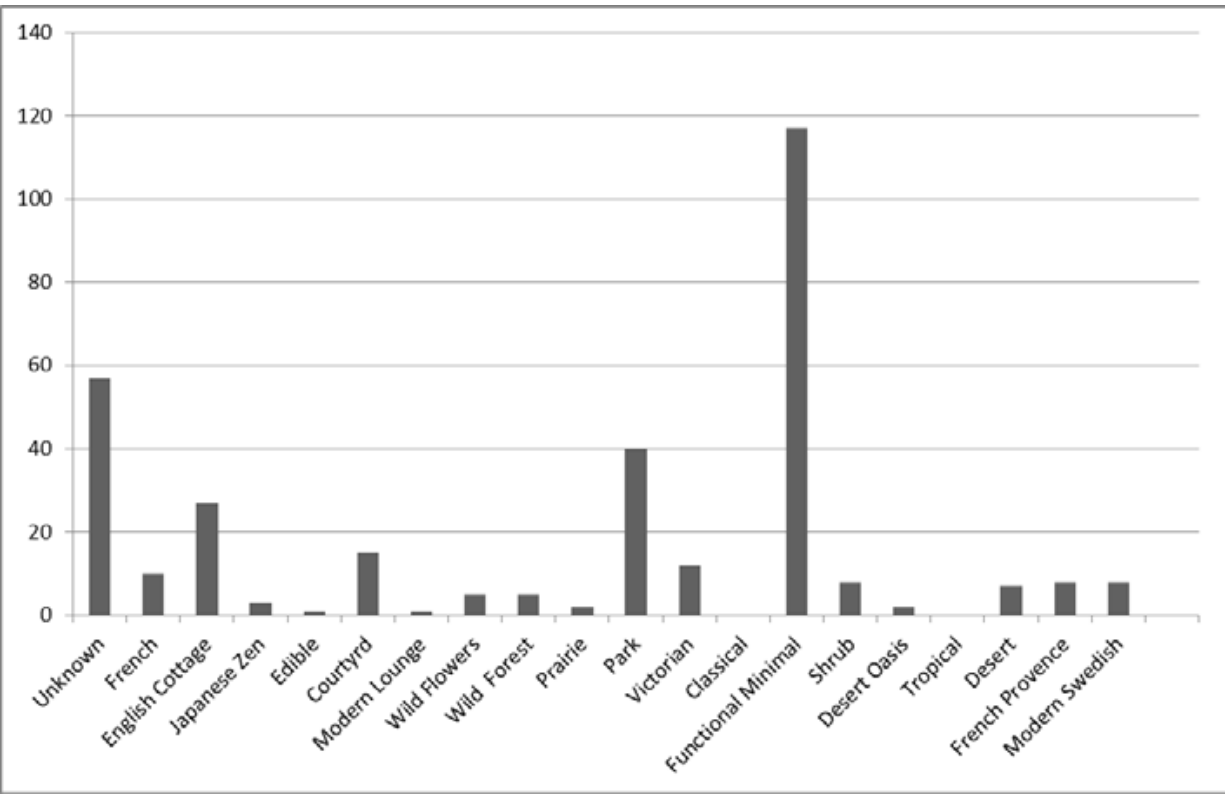

Table 11.9b. Design inspiration in Phoenix

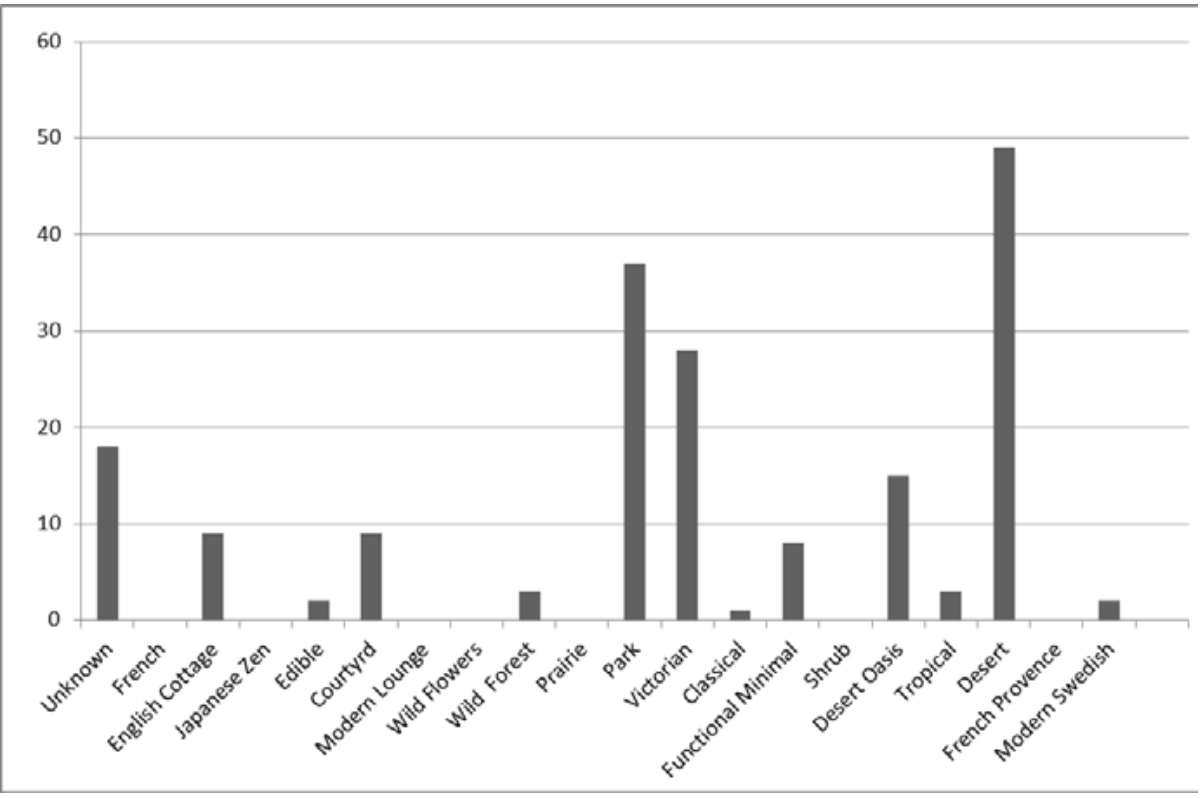




\section{Levels of intentional design}

The level of intentional design indicates how 'strictly' people apply structures and features (e.g. geometrically planted patterns, and fantastic forms of topiary, pavementdesigns, swimming pools etc.) in their yards, complementary to giving their yards space to some spontaneous 'wilder' plant growth. Overall most gardens are occurring in the category of high intentional design (45.7\% of all the yards in our sample). The highest percentage of yards with high intentional designs occurs in Vroendaal (72.5\%). This can be explained by the fact that this is a young neighbourhood (built in 2000), where design intentions are still very visible. Here the amount of design styles is highly defined by park gardens (33\% of all the yards in Vroendaal). Also a relatively high level of Versailles style gardens occurs (7.8\%), which is a style based on neatly kept geometric patterns and structures, most commonly combining (buxus) hedges with lavender, roses or hydrangea. In Phoenix, Santo Tomas displays the highest level of intentional design (50\%). This can be attributed to the many xeriscaped (Norris-Bernzel \& Edinger, 2005) yards that are - although they present the native ecological situation best -- typically 'installed' instead of emerged spontaneously. Lancaster Manors is the only neighbourhood where a low intentional design overrules medium or high intention. In Sint Pieter a medium intentional design is most common, pointing towards the high occurrence of cottage style yards $(20 \%)$ in this neighbourhood that give some space to (seemingly) spontaneous growth. Also the relatively high 'allowance' for weeds (in $43.8 \%$ of the yards) contributes to this value in Sint Pieter.

\section{Care level and care need}

Some yards are designed to have low maintenance needs and some need high maintenance to fulfil their design. The level of care that is needed for individual design styles can differ depending on climate, e.g. rainfall and temperatures. A lawn in Phoenix needs much more care (e.g. irrigation, fertilizers) (Martin, 2008) than a lawn in Maastricht. A garden full of wild flowers may seem care-intensive and time consuming to maintain, but in both regions, whilst native plants are considered in the design, this doesn't have to be the case. Comparing care levels and care needs also provides information on how engaged people are in the activity of gardening. The level of high maintenance yards in Phoenix (41.3\%) is much higher than in Maastricht (14.6\%). This can be attributed to the high occurrence of park and gardenesque styles in Phoenix that -- especially in a desert area -- need a lot of care and work. In the medium maintenance need level Maastricht scores higher, whereas the low maintenance yards are almost equally distributed across the two cities.

Interestingly, Lancaster Manors has the highest percentage of yards with a high maintenance need design. Nevertheless the actual care level in this neighbourhood is very low (45.5\%), which results into an image of negligence. Fairview (56.2\%) and Palmcroft and 
Encanto (50\%) also have high percentages of high care needs in their yard designs. The actual level of care is higher in Palmcroft (79.5\%) than in Fairview (46.6\%). In Maastricht Vroendaal has the highest need for care designs (27.5\%). Least in this category scores Blauwdorp \& Mariaberg with only 2.6\%. Vroendaal and Palmcroft and Encanto have least yards with low actual care levels (respectively $7.8 \%$ and $4.5 \%$ ).

\section{Discussion}

From a sustainability perspective, describing all the aspects we encountered in the yards in the visited neighbourhoods only makes sense if we evaluate them in the context of ecosystem services and disservices. In this section we evaluate the most important services and disservices we encountered on the level of the neighbourhoods (see figure $11.4^{*}$ ) (Beumer \& Martens, 2014).

Based on biogeography, and Species Area Relationships (SARs), more biodiversity is usually better (Rosenzweig, 2003; Whittaker \& Fernandez-Palacios, 2007). Halting the loss of biodiversity is crucial for sustaining the well-being of all inhabitants of the planet, but bringing it back to places where people once 'eliminated it' can also have adverse effects on human well-being and the environment (Lyytimäki, et al., 2008). In this discussion section we focus on the role of features that contribute to biodiversity in the context of the ideal of long-term socio-ecological well-being.

\section{Phoenix}

In Phoenix there is an overall interesting tension between neighbourhoods that contribute to biodiversity in relatively high levels, like Palmcroft and Encanto and Fairview and at the same time causes sustainability problems at the level of water usage. Much research done in the Phoenix area confirms these findings (Martin, 2008). With the ideal of maintaining a once propagated image of Phoenix as an oasis in the desert (Larsen \& Swanbrow, 2006), many species that are brought into the city are contrasting the native desert environment. This adds higher levels of diversity to the whole Phoenix region (Martin, 2008), but many of these species -- inclusive the popular lawns - need much care, water and fertiliser to survive. Pressure is on both the water resources, water quality and on people's time and money to maintain the yards in their desired states (Zube, et al., 1986). 
Figure 11.4. Potential ecosystem services and disservices in residential yards

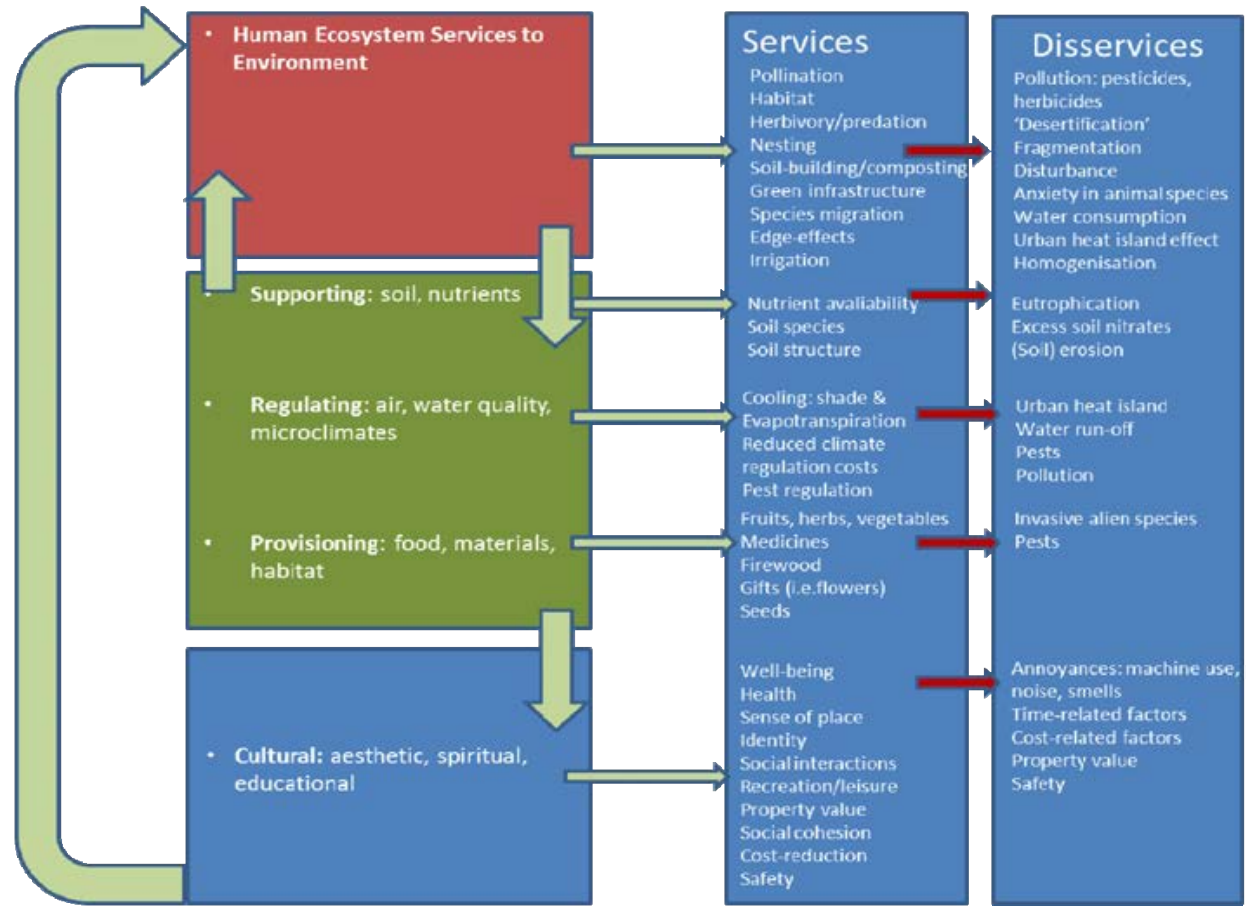

In Palmcroft \& Encanto -- two adjacent post WWII suburban neighbourhoods for the wealthier, with a variety of historic architectural styles -- this tension becomes very visible. There is some social 'pressure' of a Home Owners Association (HOA) to conform to the aesthetical standards of the historic area. The green in this neighbourhood is designed to be friendly to people: it gives people a 'break' from the harsh desert by providing a cooler, shady atmosphere through created places of high evapotranspiration (Martin, 2008); it looks like a 'patchwork' of small green oases. One can almost forget to be in a desert there. The maintenance of this atmosphere is time, fertilizer, costs- and water intensive (Nassauer, 1995b; Larsen \& Harlan, 2006).

Santo Tomas Division in Tempe is built in the 1970's and has a rather uniform character of homes with patios, small front yards and adobe-walled gardens that give the neighbourhood architecture a Mexican flavour. It contrasts the character of Palmcroft \& Encanto by having a high amount of xeriscape yards (Norris-Bernzel \& Edinger, 2005; Mee, 2011), although some green lawn yards can also be found here. With its relatively high edge effect and many native plants it potentially contributes to a functional connectivity to the desert (Rudd, et al., 2002). In Santo Tomas an ideal of contributing to the local environment through the abundant planting of native species and water saving seem to 
be reflected (Mee, 2011). Through a relatively high maintenance level of these intentionally lower maintenance yards, the neighbourhood reflects a wealthy and neat image. The downsides of Santo Tomas' front-yard designs can partly be found in the walled character. The adobe-walls may provide shade on the streets and in the backyards, but due to the plaster on most of the walls instead of providing habitat to small, insects or other animals, they mainly fragment the neighbourhood and decrease structural connectivity (Rudd, et al., 2002). Also, research pointed out that the environmental advantages of saving water in drought tolerant yards are undone by the heightened use of pesticides in such yards (Larson, et al., 2010). Other research demonstrated that the dripping-systems that are installed in xeric yards often operate at higher frequencies than is actually necessary for the survival of the desert plant species (Martin, 2008).

Fairview Place is a central Phoenix historic district, built in the 1920's with various architectural styles (Fairview, 2009). Most homes have front and backyards. The neighbourhood is flanked by a rose garden and the oasis-like Encanto Park on the East. Fairview place is characterized by a high diversity of yard design styles. The edge effect in Fairview is moderately high. A significant number of yards theoretically contribute to the functional connectivity to the native desert (Rudd, et al., 2002). Other yards contrast the desert with lush green abundance. There are two yards with edible designs based on the principles of permaculture (Mollison, 1988; Hemenway, 2009). One of these yards even contributes to biodiversity as a certified Wildlife Habitat (Rosenzweig, 2003; NWF, 2013). The yards with lawns and trees provide cooler micro-climates and higher well-being through evapotranspiration (Martin, 2008). The neighbourhood also expresses an interest in social encounter by the many seating facilities in the front-yards, by some artworks and by the educational and inspirational character of the permaculture Wildlife Habitat. Disservices are especially caused by the neglected yards where soil erosion creates dust problems and little 'deserts within a desert'. These yards can also cause a drop in property value for the surrounding homes and create potential image problems for the block.

Lancaster Manors is a deprived neighbourhood with small homes built in the 1940's and 1950's. It is located near Phoenix Sky Harbor Airport, the open air Pueblo Grande Museum and not too far away from the semi-wild urban desert Papago Park that houses the Desert Botanical Garden (DBG, 2013). All homes in the area have front and backyards. The front-yards of Lancaster Manors don't contribute much to biodiversity. However, there are some positive aspects related to sustainability: the low level of care indicates that not much water or money is spent. Signs of social encounters are present through playing equipment and furniture in some of the yards. However, the lack of care results into diminished aesthetic qualities and property values and causes a potential feeling of unsafety. The prevalent bare soil structures and the lack of trees cause a strong heat island effect and dusty air. Research points out that residents living in de- 
prived areas such as Lancaster Manors places generally have less access to green and lack the financial means to enrich their own yards with abundant life (DesJardins, 2006; Hope, et al., 2006; Martin, 2008; Mitchell \& Mueller, 2009; Pearsall \& Pierce, 2010; Beatley, 2011). A lack of experience of green can also feed back into the ongoing loss of biodiversity, considering the assumption that "people are most likely to take action for biodiversity if they have direct contact with nature (Müller, et al., 2010, p.26)."

\section{Maastricht}

Compared to Phoenix, Maastricht has a high amount of xeric yards that create a barren urban landscape. Although people may consider such yards time- and money- efficient, they have many adverse effects: they contribute to landscape fragmentation and habitat loss; to soil and water degradation (through the use of herbicides); to an increased urban heat-island effect during hot summers; to a decreased $\mathrm{CO} 2$ sequestration; and they may cause flooding-problems during strong rainfall due to the loss of soil permeability. Also functional minimalist yards lack the psychological and health benefits that are coupled to lush green environments (Kaplan, 1995; Nasar, 2011).

The wealthy Sint Pieter quarter seems most contradictive to the functional minimalist trend. Sint Pieter used to be an independent village just outside the Maastricht inner-city walls and became part of the municipality in 1920. Natural areas connected to Sint Pieter are the Pietersberg and Jekerdal with the Jeker Creek. At the East side Sint Pieter is flanked by the river Meuse. At the north side the ring road around Maastricht separates the neighbourhood from the picturesque inner-city park (Stadspark). The houses in Sint Pieter are an eclectic assemblage of architecture from the early 20th century and the late 19th century. Also more recent and even modern architectural styles can be found. In spite of its relatively high diversity of yards, this neighbourhood has a high prevalence of yards with a park design style (Szilagy, 2011). Together with a relative abundance of lush and colourful cottage style yards and a fair amount of hedges, Sint Pieter contributes comparably much to food and habitat for a diversity of animal species. The diversity and lush features of many yards make them nodes in a network of functional connectivity (Rudd, et al., 2002). Cultural services are delivered by the aesthetic quality of the neighbourhood, contributing to well-being, sports and recreation in the natural parks of Pietersberg or Jekerdal. The high quality of life contributes to high property values and the neighbourhood being a very popular area for affluent residents and visitors. Potential harm to the local environment can be caused by the spreading of invasive alien species from the yards to proximate nature. The higher maintenance levels of many yards, especially the gardenesque ones and the yards with geometric Versailles designs, can cause disturbance to nesting, feeding or sheltering animal species. Also, high maintenance levels often imply regular soil disturbance (Hemenway, 2009). 
In the newly built Vroendaal (2000) people may feel safe and sound. Vroendaal is located at the edge of the historic forest Savelsbosch. Various real estate websites promote the neighbourhood as being 'close to nature.' Close to nature in this case means 'separated' from it as well: Vroendaal is characterized by park- and monotonous functional minimalist yard-types that form a contrast to the very proximate forest Savelsbos which is a home to badgers, foxes, dear, squirrels and an abundance of many other animal species. Many of the yards have hedges that potentially provide habitat, shelter, connectivity and nesting facilities for birds, hedgehogs and other species. However, they are usually well trimmed and pruned, which can cause disturbance, anxiety and the loss of habitat functions (Martin, 2008). Soil health may be low or decreasing in this neighbourhood due to high maintenance-, lawns-, and pavement patterns. The maintenance of lawns and hedges potentially also causes nuisance for neighbours due to machine noise and fumes (Tint et al., 2012).

De Heeg is a neighbourhood with two faces: a green face and a grey face. In this district we noticed a high amount of pavement and other soil covering structures that create 'desert patches' devoid of any life. At the other side, there is tolerance for individual expression and there are quite a number of yards with highly diversely planted designs. Although there is a low amount of trees in the private yards, the municipal design of the neighbourhood is green and spacious with many trees, shrubs, grass patches and a picturesque style park meandering through the whole length of the area. Some yard-nodes contribute to functional and structural connectivity to the Savelsbos (Rudd, et al., 2002). The municipal trees and the flowered yards provide an abundance of food for pollinators and birds. Some educational services are also 'integrated' in the municipal governance of the neighbourhood green: some park-areas and road borders are grazed with sheep, which also contributes to a higher diversity of wild flowers and grasses.

Disservices of the neighbourhood can be found in the high level of 'desertification', lower levels of care, reduced feeling of safety due to abundant municipal hedges and the park that isn't illuminated during the dark hours. Because of the lack of private 'ownership' of trees, there is a higher potential for experiencing nuisance due to falling leaves of the municipal trees.

Blauwdorp \& Mariadorp seem to provide little benefits to biodiversity. The high level of pavement and gravel contribute to 'desertification' of the area with potential excessive water run-off and heat-island effects (Huynen, 2004; Huynen, 2008). The grey-ness of the district does not contribute to a colourful image and it reduces a feeling of safety. However, there is a high level of social use of the front-yards. This can be seen as a disturbance but also as a positive aspect of the way the front-yards are used, leading to higher social cohesion and neighbour encounters. Costs for people to maintain their yards are low, which is the same for the time they may spend on care and maintenance. There may be issues of environmental justice (Mitchell \& Mueller, 2009; Pearsall \& 
Pierce, 2010) due to a lack of resources and knowledge on facilitating a greener neighbourhood.

Considering the qualitative evaluation of the results we can say that more biodiversity isn't per definition ecologically sustainable: gardening styles that require irrigation may help creating lush and green micro-spaces with many plant species and attracting birds and insects. Nevertheless, the effect of irrigation on sparse water resources can be detrimental in desert areas, potentially leading to "degraded riparian ecosystems, land subsistence and inequitable access to water resources (Wiek, et al., 2012, p.16)". The same complexity accounts when looking at urban biodiversity from the perspective of socio-environmental well-being. As Lyytimäki and his colleagues state: "[t]o enable efficient biodiversity policies and management it is important to know what kind of potential harm, as well as benefit, urban ecosystems can produce to people (Lyytimäki, et al., 2008, p.169)." Nuisance, time, health issues (pollen, pests, venomous plants, allergies etc.) and safety risks (dark parks, falling tree branches, aggressive wild animals etc.) related to gardening practices and designs should not be underestimated (Lyytimäki, et al., 2008).

\section{Conclusion}

Drawing conclusions from the pilot-analyses of front-yards in Maastricht and Phoenix based on the BIMBY framework, brings us back to the initial question: how can living comfort, aesthetics and ease at the one hand and the protection of biodiversity and ecosystem services at the other hand, be reconciled in the way we design our residential areas (Rosenzweig, 2003)? In this paper, we employed a sustainability perspective and we tried to answer the question in the context of socio-ecological well-being. In Phoenix still many people grow water- and fertiliser-intensive lawns and green lush oases that resemble and reflect garden traditions and styles from the wetter climates of Europe and the East coast of the US (Larsen \& Harlan, 2006; Larsen \& Swanbrow, 2006). The question rises how long such practices can be sustained and how they affect the potential for people to live in the Sonoran desert city on the longer term. Although the Phoenix municipal governance increasingly promotes xeric yard-designs (DBG, 2013), attention should also be drawn to the research results that reveal an increased use of pesticides and herbicides in xeriscape yards (Larson, et al., 2010). In Maastricht many residents seem to be guided by the choice for ease and time-efficiency when it comes to gardening and garden designs. The installation of pavement or fully gravelled yards results in the 'desertification' of an otherwise green eco-region. Here, a discussion could be started on whether this ideal of low-maintenance has to be covered by stone-deserts. Perhaps there are other options that combine time concerns, aesthetic concerns and ecological concerns in the design. 
Evaluating the results of the analysis in the light of ecosystem services and sustainability makes it important to mention that no simple answers about 'good' or 'bad' levels of biodiversity can be gained. More biodiversity is not per definition better. Results derived through using the BIMBY indicator framework for analysis always should be considered in the socio-environmental context and evaluated with a focus on socio-ecological wellbeing and sustainability. The use of pictures as data for analysis delivered a lot of information we have been able to use for discussing the contribution of domestic gardens to biodiversity and ecosystem services. However, the use of pictures also limited the assessment in the way that we could not account for mobile elements like animal species. We also had to leave out the more subtle preference indicators and the subjective evaluation of diversity that could be given by citizens once BIMBY becomes used as a tool for citizen science. The aim of the BIMBY framework is to enhance a societal dialogue on biodiversity, ecosystem services and sustainability. The combination of elements built into the framework seems to be able to provide a wealth of material for such a dialogue. The next step to be taken is to test BIMBY in the field and involving citizens, policymakers, designers and commercial parties into the dialogue on the value of biodiversity and its conservation in and beyond urban areas. 


\section{CHAPTER 12}

\section{Urban Greening for Biodiversity}

Dutch Citizens and International

Expert Perspectives 
"If you have a garden and a library, you have everything you need."

Marcus Tullius Cicero 


\section{Introduction}

CHAPTER 12 is based on an assessment of Dutch citizens and a comparison with international expert perspectives on urban greening for biodiversity. CHAPTER 9 has been a theoretical exploration resulting into a framework for a more systematic discussion of urban greening practices and their biodiversity benefits. The biodiversity benefits framework has been tested on three case studies in the south of Limburg. Thereafter, in CHAPTER 10 and 11, the focus is placed on one particular urban greenings practice: domestic gardening12. Two pilot case studies contributed to the construction of the BIMBY indicator framework for biodiversity and ecosystem services in domestic gardens. This particular CHAPTER focuses on the human perspectives on the issue of urban greening for biodiversity. Analysis of the data discussed in this CHAPTER, reciprocally helped sharpening the frameworks and conclusions of CHAPTERS 9, 10 and 11.

I conducted two surveys: one with a representative sample of the Dutch population $(\mathrm{N}=517)$ and one with international experts on biodiversity, urban sustainability and urban ecology from around the world $(\mathrm{N}=62)$. The surveys were respectively taken in late 2012 and early 201313. The questionnaires are complementary to the theoretical explorations of CHAPTER 9 and the case studies conducted in CHAPTER 10 and 11. The aim of the surveys is threefold:

1. seeing to what extent people are aware and engaged in conservation efforts through gardening and urban greening practices;

2. seeing whether academic and professional expertise matters in relation to gardening and urban greening habits and ideas that are contributive to biodiversity on the local and the global scale; and

3. identifying the way the different cultural perspectives can be linked to gardening and urban greening practices, ideas and ideals.

In other words: I would like to get more insight into the cultural perspectives of citizens and experts on green in the city and on how these two groups contribute to and think about urban green and biodiversity conservation in their daily lives.

The main focus in this chapter will be on the Dutch survey sample. However, the results of the Dutch sample will be compared with the smaller international expert sample. The results of the two surveys show some interesting differences between international experts and citizens in the Netherlands. They demonstrate, for example, that ecological

12 We emphasise once again that our definition of gardening is broader than the American definition. With gardening we mean all activities taking place in residential outdoor spaces that contribute to the maintenance of the space (not necessarily the greening). In other words: yard work.

13 For the full questionnaires and results see Appendix A and B. 
literacy matters in the context of domestic practices with regards to urban greening and gardening for biodiversity.

\section{Methodology}

\section{Samples}

The Dutch survey covers a representative sample of the Dutch population of age 18 and older (average age 50). The Maastricht based survey agency Flycatcher14 provided the sample. The questionnaire was distributed in the Dutch language to an ISO certified panel of 850 people. The final sample contains a valid response of 517 people with a response ratio of $62 \%$. The questionnaire was filled in by 271 men and 264 women. Of the respondents $28 \%$ has completed academic education. The questionnaire was distributed and filled in according to provincial residence percentage data from the CBS (Centraal Bureau voor de Statistiek).

For the English version for international experts I have been responsible for the composition of the panel. I contacted 50 practical and/or academic experts on urban biodiversity, urban ecology, urban sustainability and sustainability science from my network and received 62 completed questionnaires. The response overshoot can be attributed to the fact that I asked the members of my network to forward the questionnaire to specified experts in their own network as well. I have been indiscriminate with regard to gender or age but aimed to diversify residence across continents. There are respondents from Asia ( $N=3)$, Australia $(N=2)$ and the Dutch Antilles, Aruba ( $N=1)$. However, the majority of respondents live in the Netherlands ( $N=29)$, in the US ( $N=14)$ or in Germany $(\mathrm{N}=6)$. Seven respondents come from a diversity of other European countries (Belgium, France, Greece, Luxembourg, Italy and England). I aimed for a majority of highly educated respondents (University Education BA/MA). Of the expert respondents 69\% has a university degree. An additional 23\% completed university degrees with postdoctoral education (PhD or Postdoc). The other respondents are professional experts.

Before sending the questionnaire to the panels, the questions were reviewed by one academic expert on the Perspectives Method (Offermans, 2012) and four other direct colleagues in the field of sustainability science. Finally a test-panel of Flycatcher additionally tested the Dutch and the English version of the survey. IBM SPSS Statistics 20 has been used for the analyses of the quantitative data of both surveys. For the qualitative open questions I used the word cloud programme Wordaizer.15

\footnotetext{
14 Flycatcher: www.flycatcher.eu

15 For Wordaizer, see: www.mosaizer.com/Wordaizer/
} 


\section{Questionnaire Design}

The questionnaires contained fifty-three content-based questions that were in many cases divided into sub-questions. The questions for the Dutch and international expert samples have been largely identical. However, the design for the experts included some additional pictures: two different desert style gardens and two dry coastal landscapes have been included to overcome a little bit of the Dutch/European bias in the questions. Also the questions on background information (gender, origin, education) have been asked slightly different (see Appendix A and B*).

The question content was largely developed on the basis of six pillars:

1. The perspectives map (see CHAPTER 5)

The perspectives map was compiled through an extensive literature review in order to explore and translate the cultural perspectives towards biodiversity and conservation. The worldview-questions have also been translated into a number of visual questions, asking people to choose one picture out of six, each representing one of the six perspectives, to which they feel most connected to. I also asked the respondents to write a brief motivation of their choice in their own words. These open comments were transformed into word clouds to give a visual representation of the overall meaning people give to the pictures. The pictures for the visual questions were selected from Google-image searches on basis of search terms that draw from the theoretical frameworks on urban greening regimes, gardening and design styles and key words from the cultural perspectives. A panel of four individual colleague researchers familiar with Cultural Theory reviewed the picture choices for each perspective and helped with adjusting the pictures for the survey.

2. An initial qualitative academic and popular literature study of urban greening projects and gardening trends and design

The questions on gardening trends were constructed through assessing academic literature about (urban) gardening and urban greening trends (Hardy, 1991; Marzluf, et al., 2008; Condon, 2010; Beatley, 2011; Certomà, 2011; Hofmann, et al., 2012; Jim, 2012; Jorgensen \& Keenan, 2012; Kurz \& Baudains, 2012); through assessing popular gardening and greening books and some Dutch gardening trend magazines (Groei \& Bloei; Home and Garden). Two annual magazines published for the Dutch gardening branch (Verdonschot, 2011, 2012) and various (non-commercial) webpages on gardening and trends also have been included in the qualitative assessment.16

16 www.tuinieren.nl; www.garden.org; 
3. A lexical assessment of two popular Dutch television programmes on gardening and design

Two Dutch television series (Eigen Huis \& Tuin and Rob's Grote Tuinverbouwing) for the years 2011 and 2012. I looked for frequencies of occurrence of words like "duurzaamheid", "biodiversiteit", "ecologisch", "biologisch", "verantwoord" and "milieuvriendelijk". Also I learned about the current gardening trends that were presented and discussed.

4. Observational visits of urban greening and gardening events

I visited the exposition La Ville Fertile: Vers Une Nature Urbaine, Paris in the spring 2011, and the World Horticulture Expo Floriade in Venlo in the summer of 2012. Also I regularly visited some commercial gardening centres (Intratuin Maastricht and Tuincentrum Gronsveld) to learn and ask about the newest trends.

5. Observational visits to various greening projects in a variety of (mainly) European cities

I learned from a variety of projects in Maastricht (Sphinxpark, Frontenpark, Avenue2); from a guided tour with an urban ecologist through Eindhoven17; from the involvement in the SUN project Vegetable Garden in Heerlen; from the design projects by Gaudí in Barcelona; from a guided tour through Paris, visiting newer and older greening projects. In Stockholm I visited Rosendal's Trädgård and the world's oldest open air museum and Skansen zoo. Another zoo that inspired learning about urban greening has been GaiaZoo in Kerkrade, the Netherlands. In Malmö I learned from the urban sustainable redevelopment project at the Bo01 Area (Västra Hamnen). Also urban greening projects in Liège, Genk, and Eupen (Belgium) were visited in the context of the SUN project. Outside of Europe I learned much from the Desert Botanical Garden, the Japanese Garden and a number of urban parks and urban national parks in Phoenix (Arizona).

The acquired knowledge and insights from these various pillars have been used to guide the questionnaire design.

\section{Visual questions}

Next to regular textual questions, a consistent part of the surveys has been based on visual material (pictures). Visual questions have been previously used in various ways, for example through visual preference surveys (Ewing, 2001), Q-Methodology (Cuppen, et

17 Robbert Snep, ecologist and consultant on urban ecology issues at Alterra, Wageningen. 
al., 2010) or Story Card-games (Smith, 2010). Recently, visual preference methodologies have been applied in in the context of urban planning and design (Ewing, 2001; Zheng, et al., 2011), perceptions on climate change (O'Neill \& Nicholson-Cole, 2009) and perspectives on water management (Offermans, 2012). Combining textual questions and visual questions provides a more inclusive 'measuring' of the worldviews of the respondents: this combination involves emotional parts of the brain: "[v]iewing the symbolic photos [...] serves to stimulate a person's subconscious and past experiences and allows those experiences to emerge as conscious expression (White, et al., 2009, p.3)." Visual preferences survey techniques also have the advantage to limit the risk of respondents of giving socially desirable answers [reference], and they are suitable in situations where respondents may lack knowledge of concepts and terminology (Smith, 2010). The questionnaire content is also very suitable for using visual questions.

\section{Operationalization}

Basically, the assessment exists of two steps: firstly, I defined perspective groups based on cultural theory typologies; secondly the groups have been used to analyse the main question. In order to do this the main question has been split up into a number of six sub-questions, which I call Core Questions (CQ) because they are again answered by another level of operationalised survey questions. In box 12.1, an overview is given of the CQs and survey- questions that contribute to the six CQs. I renumbered the survey questions for the logic of argumentation.

\section{Box 12.1. Operationalization of Survey Questions}

\section{STEP 1}

Defining cultural perspective groups

This question has been asked to get insight into the dominant cultural perspectives on nature in the Dutch group and the expert group. To operationalize the question, we developed questions based on Cultural Theory to 'measure' people's dominant perspectives, 'undercurrents' (Offermans, 2012) and attitudes. Additional questions were designed to do the same thing, but through pictures. For each question we selected six pictures. The pictures were accompanied by open questions asking to motivate the choice.

Questions: 8-13, 15-18, 20 and 22

Picture Questions: 14, 22, 38, 52, 53 and 54

\section{STEP 2}

CQ 1. How do respondents relate to global ecological issues in their daily lives? Nine questions asked respondents about their connections to the planet, planetary-scale problems, biodiversity and sustainability.

Questions: 19-21, 42, 44, 45 and 46. 
CQ 2. How do respondents relate to outside space in their (urban) living environment?

Eleven questions were formulated to ask people about their relation to gardening and being outside in their daily lives. One of the questions is a visual question.

Question: 3-7, 23, 24, 26, 36,37

Picture Question: 38

CQ 3. What are respondents' preferences with regards to yard maintenance, design and trends?

Considering this to be an important question, we operationalized it into questions on how people maintain their yard, about the design of their yard and about respondents' actual preferences.

Questions 5,7, 26-31, 33, 37 and 39

Picture Questions: 32, 34, 38 and 54

CQ 4. (How) do respondents relate and contribute to urban greening in their daily lives?

We asked four questions on how respondents participate and conceive urban greening practices. We also asked on who they think is responsible in the first place for the development and maintenance of green in the city.

Questions: 47-48 and 50

Picture Question: 49, 52 and 53

CQ 5. Do respondents connect their urban greening activities to the ideas of sustainability and biodiversity conservation?

The respondents had to answer questions about their activities for biodiversity in their yards. The questions about yard maintenance also contributed to answering this question. Furthermore we asked how respondents estimated (their) yard-work or urban greening practices as being beneficial for biodiversity.

Questions: 27-30, 35, 37, 40, 46 and 51

CQ 6. Are their significant links between respondents' perspectives and practices to where they live?

We asked for participants' living and housing situations. Are they living in urban or rural settings? Are they home-owners or renters? In which Province do they live?

Questions: 1 and 2

\section{Validation}

When validating a survey, some aspects have to be taken into account. Formally this should include face validity, content validity, construct validity (Armstrong \& Seddon, 2007).

\section{Face validity}

The questionnaires have been presented in a professionally designed electronic form that presented clusters of questions that content-wise belong together. After the design 
phase and before sending the questionnaire to the panel, the questions were reviewed by one expert of the perspectives method, four colleagues in the field of sustainability science and finally by a test-panel from Flycatcher. Through the reviews the structure of the questionnaire and the phrasing of the questions have become sharpened.

\section{Content validity}

The questions have been based on frameworks resulting from extensive multidisciplinary literature research on urban greening, gardening and landscape preferences at the one hand and the theoretical framework of Cultural Perspectives at the other hand.

\section{Construct validity}

To get the required answers and to have a relevant and legitimate insight into the perspectives of the respondents on urban greening, gardening and urban biodiversity, we chose for an extensive questionnaire design, containing relatively many questions, qualitative, quantitative and visual. Several cross checks were built in for a number of questions related to the cultural perspectives plus adding open questions to give respondents the space to illuminate their answers. These open answers were later used to qualitatively check and better interpret answers (and cross-check perspective group assignments) in some occasions. Before sending the questions to the panel, they have been reviewed by five colleagues and a test panel from Flycatcher. Through the reviews the structure of the questionnaire and the phrasing of the questions have become sharpened.

\section{Analyses}

For the quantitative part of the analysis IBM SPSS Statistics 20 has been used. For the qualitative part I used the word cloud programme Wordaizer. ${ }^{18}$ For the quantitative analysis we chose to use descriptive non-parametric statistics techniques. These are distribution-free methods which are valid under less restrictive assumptions than regular techniques. Nonparametric methods require no strong assumptions about the population distribution. Nevertheless, non-parametric statistics are based on some of the same assumptions as parametric methods: randomness and independence of the samples are still required (Gibbons, J. D., 1993). Nonparametric methods may have some disadvantages over classical techniques of statistics. They are for example less sensitive to differences between groups. In our case that could have been problematic when statistically comparing the Dutch and the expert sample groups. However, the choice was made to only compare the descriptive results of both separate samples. In our case, nonparamet- 
ric methods have added value over traditional methods, because the assess data are largely categorical (Pallant, 2005).

\section{Chi-square tests}

For a fair amount of analyses and comparisons of variables the chi-square test was used. This test is used for nominal/categorical variables and it is based on the idea of comparing observed frequencies in certain categories to the frequencies one may get in those categories by mere chance (Field, 2005). Basically, chi-square tests are categorical correlations: they check whether the frequencies of occurrences across any pair of variables (such as being an active or non-active gardener, and dominant cultural perspectives) are correlated. ${ }^{19,20}$ The chi-square test does not rely on standard statistic assumptions such as the normal distribution of data, because categorical data cannot be normally distributed: they are not continuous. There are two basic assumptions for the chi-square test.

1. A chi-square test cannot be used on a basis of repeated measures: one respondent can only contribute to one cell of the contingency table (Field, 2005).

2. Expected frequencies should be greater than 5. Many authors also allow having up to $20 \%$ of expected frequencies below 5 , whilst the contingency table is large enough. The analysis may lose some statistical power though. Expected frequencies may never be below 1. Even in the larger tables (Field, 2005; Pallant, 2005). In some cases it was helpful to recode variables into bimodal variables to do chi-square tests with $2 \times 2$ cells. In other cases we had larger contingency tables up to 5 degrees of freedom or more. We only used the chi-square cross-tabulations that did not violate the basic assumptions of the chi-square test. In some cases, when delivering enough information on their own account, we used the plain descriptive survey results or simple descriptive crosstabulations.

\section{Likert items}

Questions delivering data in the form of three-, or five point Likert items were treated as ordered categorical data (Jamieson, 2004; Field, 2005; Carifio \& Perla, 2007). In some cases we used a forced choice method for such items. In some cases an additional "neutral" or "I don't know" option has been given.

19 www.simafore.com/blog/bid/55363/3-basic-concepts-which-underpin-the-chi-square-test 20www.simafore.com/blog/bid/56480/2-key-assumptions-to-be-aware-of-before-applying-the-chi-square-test 


\section{Results}

Below the results of the surveys are described for both the Dutch sample and the international expert sample. For describing the results, I followed the logic of the two steps and the core questions (CQ). N=517 respondents filed in the complete questionnaire for the Dutch sample. The results are based on these numbers of respondents, unless indicated otherwise. This is also the case for the expert sample of $\mathrm{N}=62$ respondents.

\section{Step 1: Defining perspective groups.}

The first step in the analysis was to define perspective-stereotypes of the answers given to the questions designed to define the worldview and cultural perspective of the respondents. Once assigned perspective groups, we'd be able to use these as basic groups to work with in the analysis of the other questions.

I am interested in the way the respondents relate to nature and their environment and how their worldviews are reflected in their practices and management styles (for example, strategies of coping with local or global environmental problems). To answer this core question I aimed to define perspective groups based on the Cultural Theory Perspectives (Beumer \& Martens, 2010; Offermans, 2012; Beumer \& Martens, 2013). A number of 12 textual question and 6 visual questions have been especially designed to define these perspective groups (see Appendix*).

\section{Defining Dominant Cultural Perspectives}

The definition of the perspectives categories -- based on the results of survey-questions 8-13, 15-18, 20 and 22 and visual survey-questions 14, 22, 38, 52, 53 and 54 -- are based on the sums of the bi-modal results of each of these textual and visual question. When respondents answered 0 to 4 times to answers reflecting a specific perspective, the respondent was not attributed that perspective. When answering 5 to 18 times for similar perspective options, they were attributed the corresponding perspective. This method of defining the perspective groups proved to be useful because it finally distributes all respondents in one or two main perspective groups. $47 \%$ of the Dutch respondents can be attributed a single dominant perspective and $46 \%$ of the respondents can be attributed a clear double perspective (dominant with undercurrent). A small minority of $3 \%$ has three main perspectives. Another small minority of $5 \%$ have their view divided over more than three perspectives. Theoretically, we could have placed these minority groups into the Dynamic Integrator category. However, we first checked the qualitative answers the respondents in these groups gave in order to be able to finally give them a perspective category. Respondents with three main perspectives and scoring relatively high on the Dynamic Integrator answers have been defined Dynamic. Respondents scoring low on the Dynamic Integrator answers have been categorised based on their qualitative answers. The respondents with more than three perspectives or no clear perspec- 
tive at all have also been attributed a final category based on their qualitative answers. In some rare cases this meant that they received another perspective than their quantitative answers suggested.

The labelling of the respondents with a dominant perspective and an undercurrent resulted into 36 groups with similar combinations. Only four of these groups were large enough to evaluate them as significant (Hierarchist -Egalitarian, Egalitarian- Hierarchist, Egalitarian-Fatalist and Egalitarian-Autonomous). ${ }^{21}$ However, in our view this did not deliver any added value to our aims, and many of the other perspectives were left scattered in very small sub-groups. Therefore, finally we decided to work only with the six dominant perspectives we attributed to the respondents (Dominant). ${ }^{22}$ Chi-square based qualitative correlations for a number of questions have been used to test whether the dominant perspectives groups are worthwhile to work with. This proved to be the case.

\section{Table 12.1. Dominant Perspectives}

Dutch

\begin{tabular}{ccccc}
\hline & & Frequency & Percent & Valid Percent \\
\hline Valid & Hier & 138 & 26,7 & 26,7 \\
& Ega & 194 & 37,5 & 37,5 \\
& Ind & 44 & 8,5 & 8,5 \\
& Fat & 49 & 9,5 & 9,5 \\
& Aut & 52 & 10,1 & 10,1 \\
& Dyn & 40 & 7,7 & 7,7 \\
& Total & 517 & 100,0 & 100,0 \\
\hline
\end{tabular}

Experts

\begin{tabular}{llccc}
\hline & & Frequency & Percent & Valid Percent \\
\hline Valid & Hier & 6 & 9,7 & 9,7 \\
& Ega & 7 & 11,3 & 11,3 \\
& Ind & 4 & 6,5 & 6,5 \\
& Fat & 1 & 1,6 & 1,6 \\
& Aut & 19 & 30,6 & 30,6 \\
& Dyn & 25 & 40,3 & 40,3 \\
& Total & 62 & 100,0 & 100,0 \\
\hline
\end{tabular}

21 Based on these group-sizes we were able to conduct valid and significant chi-square tests.

22 Hereby we emphasise that in real life no person can be boxed into a perspective group. Dependent on the situation and context, people dynamically integrate each of the perspectives in their views, lives and lifestyles. However, usually some one or two perspectives appear stronger in a person compared to the others. 
The frequency analysis (see table 12.1) of the Dominant groups resulted into a highest representation of the Egalitarian perspective with $37,5 \%$, followed by the Hierarchist with $26,7 \%$ in the Dutch sample. In the International expert group the Dynamic (40,3\%) and Autonomous $(30,6 \%)$ perspectives are best represented. Interestingly, in both panels the Individualist perspective group scores relatively low. When comparing the Dominant perspectives to educational levels, the Individualist group has the most highly educated people in the Dutch sample. Also the Dynamic and Autonomous perspectives represent higher educated groups. In the expert sample - which consists of mainly highly educated people - the Dynamic and Autonomous groups are best represented. However, the Individualist is represented in this panel only to a limited extent.

\section{Discussion Step 1}

Interestingly, in both panels the Individualist perspective group scores much lower than expected. The Autonomous and Dynamic perspective groups are best represented in the expert panel. This confirms the figures for high representation of the Autonomous and Dynamic group in the higher educated group in the Dutch sample (figure 12.1a). However, although most of the international experts are highly educated, the Individualist group within the experts sample is only very small (figure 12.1.b). Obviously, the Individualists have had other education than environmental, ecological or sustainability education. This is also reflected in the further results to be discussed ahead in this CHAPTER: these show the Individualist perspective group (both in the expert and in the Dutch citizen panel) as having least affinity and engagement with environmental issues, gardening and urban greening. 
Figure 12.1.a. Educational levels Dutch sample

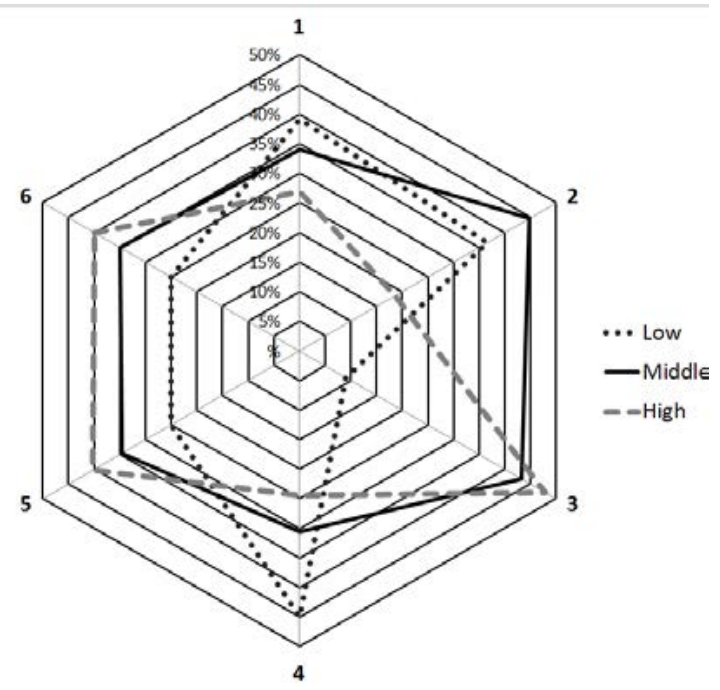

1= Hierarchist;2=Egalitarian;3=Individualist; $4=$ Fatalist; $5=$ Autonomous; $6=$ Dynamic

Figure 12.1.b. Educational levels Experts sample

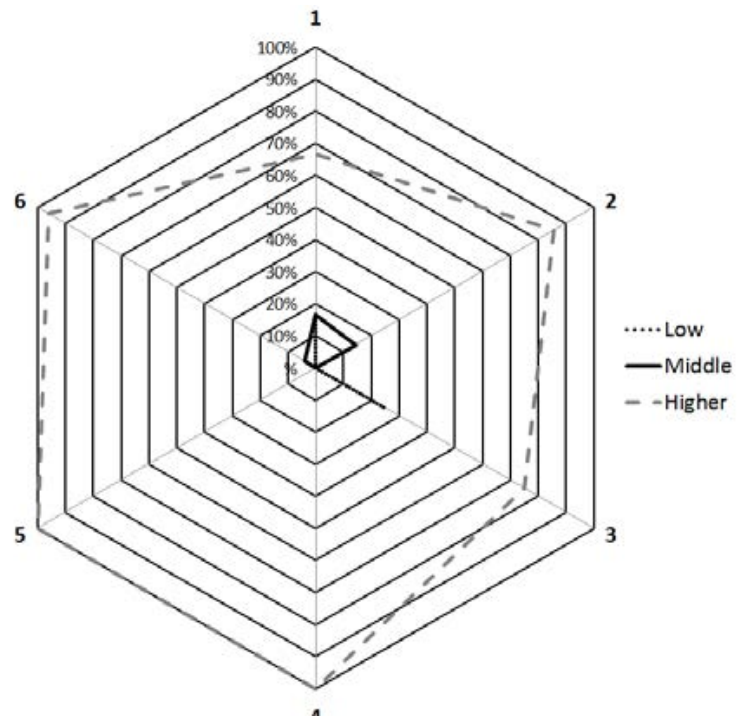

1= Hierarchist $; 2=$ Egalitarian;3=Individualist $; 4=$ Fatalist $; 5=$ Autonomous $; 6=$ Dynamic 


\section{Step 2. Answering the Core Questions}

CQ 1. How do respondents relate to global ecological issues in their daily lives?

Seven questions were asked to the respondents about their connections to the planet, planetary-scale problems, biodiversity and sustainability. This has been done in order to gain more insight into how Dutch citizens more specifically relate to these global environmental issues. Table 12.2 shows how I analysed the questions for the Dutch sample. The expert sample analyses are based on cross-tabulations and word clouds only.

Table 12.2 Analysis approach CQ1 Dutch sample

\begin{tabular}{|c|c|c|c|c|c|c|c|}
\hline Question & Survey Question* & $\mathrm{N}=$ & Minimum Expected Count** & Cells \% & Significance & Significant & Methods \\
\hline 1.1 & 19 & 517 & N.A. & N.A. & N.A. & N.A. & Crosstabulation \\
\hline 1.2 & 21 & 517 & N.A. & N.A. & N.A. & N.A. & Word Cloud \\
\hline $1.4 a$ & 43 & 517 & 10.6 & $0 \%$ & .006 & Yes & Chi-Square \\
\hline $1.4 \mathrm{~b}$ & 44.3 & 496 & N.A. & N.A. & N.A. & N.A. & Crosstabulation \\
\hline $1.4 \mathrm{c}$ & 44.2 & 494 & N.A. & N.A. & N.A. & N.A. & Crosstabulation \\
\hline $1.4 \mathrm{e}$ & 44.5 & 470 & 3.64 & $16,70 \%$ & .041 & Yes & Chi-Square \\
\hline $1.5 a$ & 45.1 & 472 & N.A. & N.A. & N.A. & N.A. & Crosstabulation \\
\hline $1.5 b$ & 45.2 & 496 & N.A. & N.A. & N.A. & N.A. & Crosstabulation \\
\hline $1.5 \mathrm{c}$ & 45.4 & 484 & N.A. & N.A. & N.A. & N.A. & Crosstabulation \\
\hline $1.5 d$ & 45.3 & 483 & 2.55 & $16,70 \%$ & .003 & Yes & Chi-Square \\
\hline
\end{tabular}

* Survey question is the number of the question in the survey

** When possible, results are based on chi-square tests.

\section{Question 1.1: Concerns about the future}

In question 1.1 it was asked how often the respondents worry about the future of the earth. Most respondents indicated to rarely worry $(54,4 \%)$. More than a quarter sais to sometimes worry $(28,6 \%)$ and only $17 \%$ mentions to worry often (between every day and once a month). Although I expected Egalitarians and Autonomous people to worry most, the results indicate that nothing can be said with statistical significance about which perspective groups worry most about the future of the earth. All I can say about these results is that the Dutch respondents don't seem to worry very often about the future of the earth. This is very different with the international experts: a majority of $56,6 \%$ indicates to worry often, whereas $17,7 \%$ worries sometimes and $25,8 \%$ rarely.

\section{Question 1.2 Participation in- and supporting charity organisations}

In question 1.2 I asked the respondents: a. whether they are in some way actively participating in causes for nature or the environment, and $b$. whether they support environmental charity organisations. The majority of $79 \%$ of the Dutch sample says not to be actively and practically involved in causes for the environment or nature. However, a small majority answered they donate money to environmental NGOs or charity organisations (51\%). Of the international experts $64 \%$ does voluntary work or is a member of an 
environmental organisation. Only $32 \%$ says not to be active. Donations are given by $50 \%$ of the experts.

Respondents could also indicate whether they do something else. This last answer category was open for a qualitative explanation. People who indicated to do something else than being practically engaged in organisations, in most of the cases relate to their personal lifestyles: being a vegetarian, buying low-energy light bulbs, ("spaarlampen") recycling of waste ("afval", "scheiden") or living environmentally friendly and aware ("milieubewust"). The qualitative results are reflected in Word Cloud 12.1.a*. People who indicated not to give money to charity or nature organisations often mentioned to participate in the national lottery (Postcodeloterij). This Lottery is financially supporting many of the large Dutch NGOs or Dutch affiliations of international NGOs and charity organisations (see Word Cloud 12.1.b*). Nothing of statistical relevance can be said about the answers in relation to the Dominant perspectives. This also accounts for the international experts. Most of their open answers point towards their jobs (teaching, research, consulting) and adapting lifestyles.

World Cloud 12.1.a. Open question on actions taken to contribute to the envi-

World Cloud 12.1.b. Open question on ronment Dutch sample
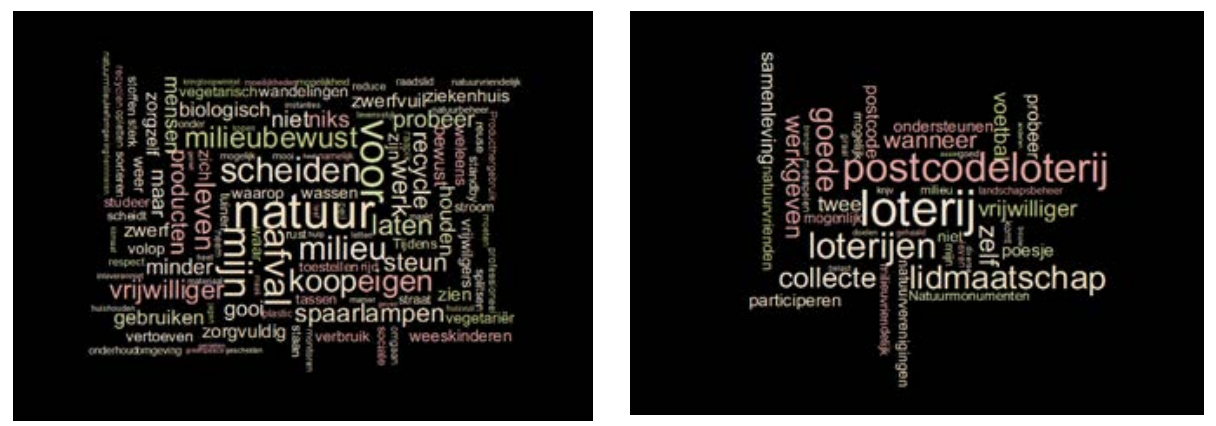

Question 1.3: Defining Sustainable Development

Question 1.3 has been an open question in which respondents could explain how they define sustainable development (see Word Cloud 12.2.a*). For processing the word cloud for this question I eliminated the words "duurzaam," "duurzaamheid" and "duurzame" just like "ontwikkeling." These words have been given in the question and have to be defined. I also eliminated the word "voor" in the cases it occurred as a preposition. Finally, I eliminated words containing only two or three letters (they were mainly prespositions). The resulting word cloud shows that most people relate sustainable development in some way to nature, the environment, the future and future generations. I expected a high occurrence of the word "energy" but it occurred only 18 times com- 
pared to "nature" (natuur), which occurred 71 times and "environment" (milieu), which occurred 54 times. This could be attributed to the content and focus of the questionnaire. However, we did not mention the idea of future generations and the "lange termijn" (long term) and people seem to be concerned with this to a high extend too. Another significantly represented combination of words related to a good use of materials and resources (goed gebruik(en) (29 times and 17 times) van materiale (29 times) en/of grondstoffen (12 times)).

Sustainability isn't an easy term to define for many people. $N=150$ of the $N=517$ respondents (29\%) said they don't know how to define sustainable development. Nobody related the definition to the Brundtland Report or the idea of 'people, planet and prosperity/profit'.

Conducting a lexical search for terms related to biodiversity delivered limited results. Only one respondent relates sustainable development to biodiversity. Two people mention animals (dier(en)), three respondents mention plants (plant(en)), trees (bomen) are mentioned three times. Flowers (bloem(en)) aren't mentioned and soil (grond or bodem) is mentioned once. Obviously, biodiversity isn't explicitly on the mind of many people when thinking about sustainability or sustainable development. However, they may think more about these biodiversity related aspects under the general umbrella of "nature."

In the Expert definition the human dimension of the future is emphasised above the natural future: 'people', 'human' and 'needs' are the terms that are mentioned most. Biodiversity is mentioned three times, conservation once and preservation four times. The Brundtland report is referred to once and the triple-p concept is mentioned three times (see Worldcloud 12.2.b*).

Word Cloud 12.2.a. Definition of Sustainable Development according to Dutch Sample

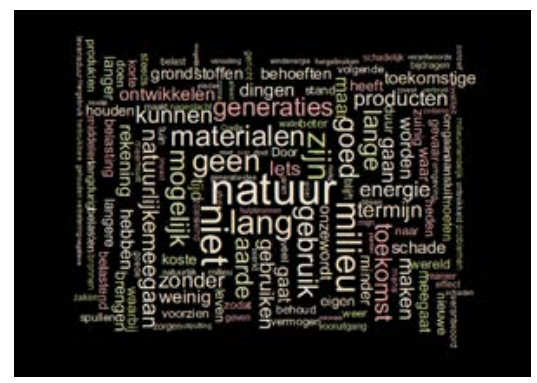

Word Cloud 12.2.b. Definition of Sustainable Development According to International Expert Sample

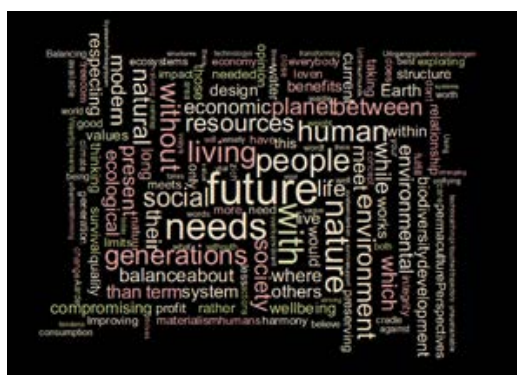




\section{Question 1.4: Thinking about sustainability}

1.4 a). In a five-point Likert item we asked how often the respondents think about sustainability (question 1.4). I compressed the results into three categories: "often" $(25,5 \%)$, "sometimes" (43,7\%), "hardly ever" $(29,8 \%)$. The "hardly ever" category numerically matches nicely with the percentage of people who answered not to know how to define sustainable development (29\%). Of the international experts $84 \%$ indicates to think often about sustainability whereas $16 \%$ says to do so sometimes. Nobody thinks about it only rarely. I tested the recoded results via a chi-square test and compared them to the dominant perspectives of the respondents (see Figure 12.3).

Figure 12.3. Thinking about sustainability in the dominant perspectives Dutch

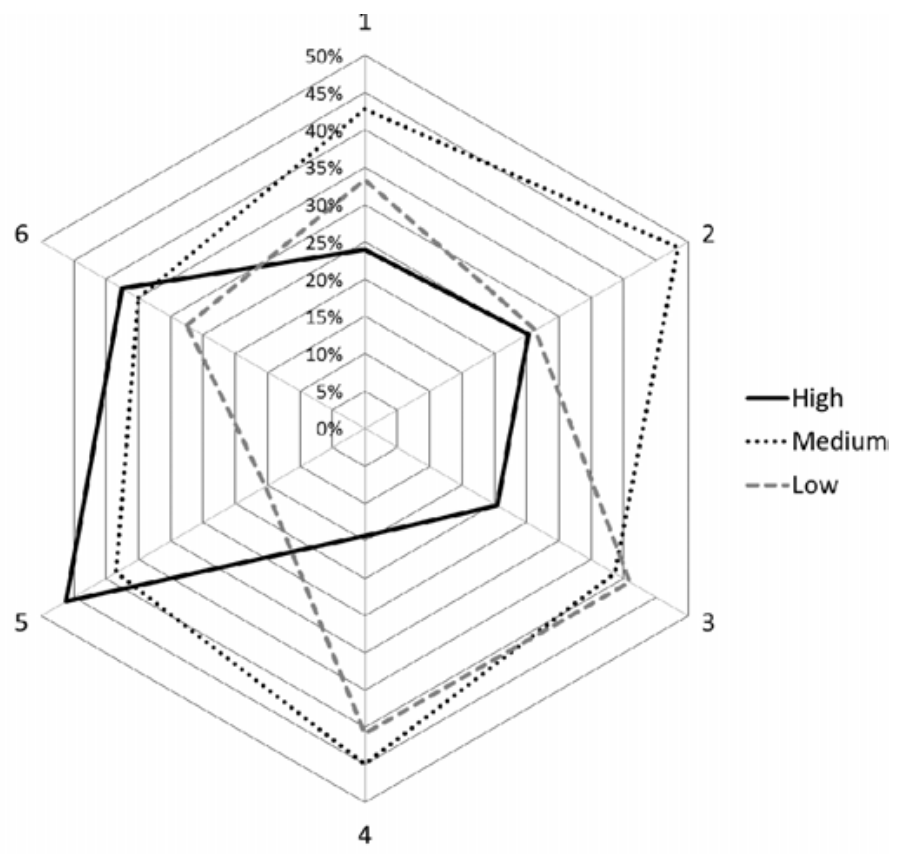

1= Hierarchist $; 2=$ Egalitarian; $3=$ =Individualist $; 4=$ Fatalist $; 5=$ Autonomous; $6=$ Dynamic

The chi-square test reveals that there are significant differences between the perspective groups. Respondents with an Autonomous perspective are the ones thinking most about sustainability $(46,2 \%)$. They are the ones also scoring lowest on thinking hardly ever about sustainability $(15,4 \%)$. They are followed by the Dynamics $(37,5 \%)$ who also appear to be thinking about sustainability often. However, a fair amount of Dynamics also hardly ever thinks about sustainability $(27,5 \%)$, or just sometimes (35\%). The Fatalists and the Individualists think least often about sustainability (respectively $14,3 \%$ and 
20,5). They also score highest when it comes to hardly ever thinking about sustainability (respectively 40,8\% and 40,9\%). Especially the Egalitarian scores high in the "sometimes" category (48,5\%). This also counts for the Hierarchist $(42,8 \%)$ and the Fatalist $(44,9 \%)$. Figure 12.3 is a spider chart representing the way the Dutch perspective groups think about sustainability. For the international experts there weren't any significant differences based on the perspectives.

1.4b). Sustainable development, is being considered important for the future of the planet and humanity by most people. Most respondents agreed with the idea that "sustainable development is important for the life on planet Earth" (34\% fully agree; 51\% agree; $14 \%$ neutral; $1 \%$ disagree; $0 \%$ fully disagree).

1.4c). Similar results were given when the same question was asked about "the importance of sustainable development on future of human life" (29\% fully agree; 52\% agree; $16 \%$ neutral; $2 \%$ disagree; $1 \%$ fully disagree. However, slightly more people consider it important for the future of the life on planet Earth than for the future of human life specifically.

1.4d). Interestingly, the respondents start to answer differently when confronted with the statement "Sustainable development will help overcome global economic problems." Although they still agree, they are more hesitant here: $36 \%$ chooses the neutral option "don't agree/don't disagree." Only 14\% fully agrees and 39\% agrees. Even 9\% of the respondents do not agree with this statement and $2 \%$ fully disagree.

1.4e). The belief in the potential of sustainable development decreases when asking whether "sustainable development will help improve global social equity." Only $9 \%$ fully agrees with this statement, whereas $28 \%$ agree; $40 \%$ are neutral; $18 \%$ disagree and $4 \%$ fully disagree.

For the statement about social equity the results can be compared to the Dominant perspectives. The Autonomous respondents clearly have the highest expectations towards the improvement of social equity by means of sustainable development. They strongly agree $(42,3 \%)$ but many are also neutral towards it $(36,5 \%)$. The highest percentage of disagreement can be found with the Individualists (36,4\%). However, also a large amount of the Individualists agrees $(31,8 \%)$. The other perspective groups are more moderate about their expectations. Again, these are interesting results that are coherent with $\mathrm{CT}$.

In the expert sample the agreements are strong for the questions $1.4 \mathrm{~b}$ to $1.4 \mathrm{e}$, with $76 \%$ of the experts fully agreeing with the statement that sustainable development is crucial for securing the future of human life. The belief that sustainable development will over- 
come global economic problems scores lowest, but is still fully agreed with by $39 \%$ of the respondents. No claims can be made on the basis of the dominant perspective groups here.

\section{Question 1.5: Thinking about sustainability issues}

Question 1.5 also consists of a series of five-point Likert items. Four questions are intended to ask how often people think about the more specific sustainable development related topics biodiversity and climate change. Two other questions relate to lifestyle habits with regards to food, which is related to both biodiversity and climate change.

\section{Impacts of biodiversity loss}

1.5a). The first question asked the respondents whether they often think about the "impact of biodiversity loss on their lives". Most of the respondents answer in the sometimes $(35,4 \%)$ or hardly category $(30,4 \%)$. Only $7,4 \%$ indicates to think about this regularly. Of the experts, $38 \%$ think about this often; $35 \%$ sometimes and $26 \%$ think about it rarely. There are big differences where the respondents think often about the issue.

1.5b). The results of the second item "Im am often thinking about the possible impacts of biodiversity loss for the planet" indicate that most respondents do not often think about the issue $(38,1 \%)$. Only $13 \%$ indicates to think about the possible impacts of biodiversity loss for the planet always or often. However, a fair amount thinks about it sometimes $(39,7 \%)$. Of the experts a majority of $57 \%$ thinks about this issue often. A big difference with the Dutch panel. Only $15 \%$ of the expert panel rarely thinks about the issue. The experts seem to be more concerned with the impact of biodiversity loss for the planet than for their own lives.

\section{Impacts of climate change}

1.5c). This item asks whether the respondents often think about the impacts of climate change for the planet. $\mathrm{N}=484$ respondents ( $94 \%$ of the total sample $\mathrm{N}=57$ ) answered this question with another option than "I don't know." Almost half of the respondents indicate to sometimes think about this (49\%) and $19 \%$ thinks about this issue often. For this group the impact of climate change on the planet seems to weigh heavier on the minds than the impact on their own lives. For the expert panel this is the same, although the experts think much more about the issue compared to the Dutch panel.

$1.5 \mathrm{~d})$. Double the amount of the Dutch sample respondents seem to be strongly concerned about the impact of climate change on the planet compared to the impact on their own lives. Only 10\% (slightly more than for biodiversity) worries often about the impacts of climate change on their own lives. However, also $49 \%$ indicate to think about this sometimes. Cross-tabulation with the dominant perspectives is statistically possible with this item. Again, the respondents with an Autonomous dominant perspective think 
most about the possible impact of climate change on the planet $(40,4 \%) ; 44,2 \%$ of them sometimes thinks about this. Only $13,5 \%$ indicate they hardly ever think about the issue. The Dynamics follow the Autonomous with $25 \%$ thinking about these impacts often and of them $40 \%$ sometimes. Of the Individualist only $22,7 \%$ of them thinks often about the issue, $31,8 \%$ sometimes and the largest portion of them hardly ever (38,6\%). The perspective thinking least often about the impacts is the Fatalist perspective: $14,3 \%$ says to think about the issue often, 38,8\% sometimes and 34,7\% rarely. More Fatalists than Individualists indicate to think sometimes about the issue.

\section{Consumption habits}

1.5e). The next item asked about the habit of buying locally produced food. $\mathrm{N}=477$ (92\% of the total sample $\mathrm{N}=517$ ) answered otherwise than "I don't know". A relatively large amount of respondents indicates to sometimes intentionally buy locally grown foods; $20,3 \%$ say to do that often and also a large amount rarely intentionally shops locally grown foods.

The chi-square test for cross-tabulation for this Likert item proves to be acceptable. The results for this test clearly match the Cultural Theory categories as expected. The Autonomous respondents again are the group that performs highest in the category of often shopping locally grown foods (32,7\%). Half of all the Autonomous respondents indicate they shop locally every now and then (50\%). The Dynamic Integrator follows (25\%), but also many of them just sometimes shop local produce (35\%) or hardly ever $(37,5 \%)$. The Individualists lead in not shopping locally produced foods very often: $50 \%$ hardly ever does it and only 15,9\% does it sometimes or often (also 15,9\%). Interesting to mention with this is that a rather high percentage of Individualist respondents answered the "I don't know" category (18,2\%). This suggests they are not much aware of what they are actually buying. Of the Hierarchists even less people go shopping for local produce often (13,8\%). Most of them never go (41,3\%), but also a fair amount of $36,2 \%$ sometimes goes. The Fatalists also don't shop local produce very often: $42,9 \%$ indicates to hardly ever do so. However, still $34,7 \%$ sometimes does it. But you won't see the Fatalist shopping local produce very often (16,3\%). The Egalitarians are basically moderate: they shop local foods mostly sometimes $(40,2 \%)$.

The experts buy locally produced for more often than the Dutch panel: $64 \%$ does so often to always; only $5 \%$ does so on a seldom basis. The results are not significant when comparing the Dominant perspectives for this sample. A similar pattern accounts for the next question on buying organically grown food.

1.5f). On the Likert item that asked a similar question about buying organically grown foods most respondents chose the options indicating hardly ever doing this $(42,4 \%)$; $35,8 \%$ sometimes intentionally buys organically grown foods and only $15,7 \%$ indicate to do this often. The chi-square test indicates that cross-tabulation with the Dominant 
perspective is possible for this item. Again we can see that of the people who indicate to often intentionally buy organically grown foods the Autonomous perspective scores highest (38,5\%). Of the Autonomous respondents 32,7\% sometimes buys organic groceries. Still a large group of them doesn't (26,9\%). Although a larger group within the Autonomous group often intentionally buys organic produce than local produce, also a significantly larger group never does this and significantly less people do this sometimes. Significantly fewer Dynamic Integrators buy organic food often compared to local food. Only $20 \%$ buys this type of food often; $35 \%$ does it sometimes and the largest percentage of this group hardly ever does it (42,5\%). However, in these two groups organically grown food seems to be more popular the in the other groups. Only 12,2\% of the Fatalists go shopping for organic food very often; 40,8\% does it sometimes and also 40,8\% rarely does. Also the Individualists are not particularly intentionally interested in organic foods: $13,6 \%$ only goes often; $34,1 \%$-- which is still fair - goes sometimes, and $43,2 \%$ hardly shops organically. Surprisingly, the Egalitarians do not score very high on intentionally buying organic foods very often as well. Only $13,4 \%$-- which is even less than the Individualist percentage - goes often. A large amount hardly ever shops organically $(37,6 \%)$. However, most of them sometimes do this (42,3\%). Respondents with a dominant Hierarchist perspective seem to be least interested in shopping organic produce: Only $10,9 \%$ goes often; $26,8 \%$ sometimes goes and a rather significant majority of $55,1 \%$ hardly ever intentionally buys organically grown foods.

\section{Question 1.6: Impact of lifestyle choices}

To conclude the series of questions asked in CQ 1, we asked the respondents whether they think that their lives and the choices they make have an influence on the future of our planet (question 1.6). This question was asked in a bi-modal manner with the additional option "I don't know." Almost half of the respondents $(48,4 \%)$ agree with the idea of having an impact on the future of the planet through their lives and choices; $24,6 \%$ don not think this is the case and $27,1 \%$ does not know.

A chi-square test indicates that cross-tabulation of this question with the Dominant perspectives is statistically valid. The respondents with an Autonomous perspective massively $(76,9 \%)$ think their lifestyles have an impact on the future of the planet. Only $9,6 \%$ of them doesn't believe this and only 13,5\% doesn't know. The Dynamic Integrator has also a majority of respondents believing to have an impact on the future of the planet $(57,5 \%)$. However, quite a percentage doesn't believe to have an impact as well (30\%). Many Fatalists hardly believe to have an impact: $42,9 \%$ do not believe their life and choices matter. Still, $30 \%$ does believe it does. Half of the Individualists (50\%) believe their life and their choices have an impact. However, still 34,1\% doesn't think so. The Egalitarians are also rather certain about their lives having an impact: $47,4 \%$ believe they have; only $20,1 \%$ think their lives don't matter so much for the future of the planet. Quite some Egalitarians are doubting though (32,5\%). The Hierarchists are also rather positive about their impact: $42 \%$ thinks their lives and choices have an impact. A quarter 
of them doesn't believe this though and 32,6\% don't know. These results confirm my assumptions regarding the cultural perspective groups.

A much larger group of the experts ( $84 \%$ compared to the $48 \%$ of the Dutch sample) believe their choices and lifestyles influence the future of the planet. Only $3 \%$ of them don't know. In the expert group there are no significant differences per Dominant perspective.

\section{Discussion CQ1}

As we have seen, the respondents of both survey groups show concern about the planet and its future. Climate change is on more people's minds than biodiversity when it comes to thinking about sustainability issues. For climate change this is almost half of the Dutch population. No significant differences could be identified between the dominant perspective groups. What is interesting to see though, is that people seem to be more concerned of the impacts of biodiversity loss and climate change on the planet than on their own lives. This may suggest that they don't experience direct impacts of these global environmental problems (yet).

When looking at life style choices people make (i.e. food consumption), we were able to distinguish clear differences between the dominant perspectives groups in the Dutch sample. Whether it relates to buying local produce, organic produce or believing lifestyle choices have an impact on the planet, the Autonomous perspective is leading in sustainable behaviour and awareness. They are often followed by the Dynamic Integrator. However, this perspective is clearly more flexible or divided about the issues as well. The Individualist perspective shows least effort and interest in sustainable lifestyle choices and awareness. This is especially interesting when considering that half of the Individualist respondents do believe in the impact their choices have on the future of the planet: it implies to confirm that people with an Individualist perspective are indeed more selfcentred than the other perspective groups when it comes to taking care of the environment. The Hierarchist and the Egalitarian are usually moderately aware and also moderately actively concerned.

In the experts sample generally higher levels of concern and lifestyle engagement can be identified compared to the Dutch sample. Dominant perspectives don't matter significantly here. In the next section we will see how the respondents relate to their direct outdoor living environments.

\section{CQ 2. How do respondents relate to outside space in their (urban) living environment?}

Eleven questions were formulated to ask people about their relation to gardening and being outside in their daily lives. These questions are relevant to the study on how peo- 
ple relate to urban green and biodiversity especially when it comes to looking at peoples' practices and actual life-styles: how do these reflect awareness about- and space for nature and biodiversity in urban areas? Table 12.3 shows the analysis approach for CQ2.

Table 12.3. Analysis approach CQ 2

\begin{tabular}{cccccccc}
\hline Question & Survey Question & $\mathrm{N}=$ & Minimum Expected Count & Cells $\%$ & Significance & Significant & Methods \\
\hline 2.1 & 23 & 517 & 3.09 & $16,70 \%$ & .051 & No & Chi-Square \\
2.2 & $3 \& 4$ & 517 & N.A. & N.A. & N.A. & N.A. \\
2.3 & 26 & 517 & N.A. & N.A. & N.A. & N.A. \\
* Survey question refers to the number of the question in the survey taken by the respondents \\
** When possible, results are based on Chi-Square tests. The minimum expected count refers to the basic assumption for a
\end{tabular}

\section{Question 2.1 Outside activities}

Most of the Dutch sample respondents go out to enjoy nature every $(41,2 \%)$ week or every month $(35,4 \%)$. Only $15,7 \%$ indicates to do this rarely (once every few months or never). It was possible to compare these results with the dominant perspectives. However, I should note the results are just on the edge of being significant (.051), which means the differences between the Dominant groups aren't strong. Nevertheless, they are interesting enough to show in a spider chart (Figure 12.4a), also when we compare them to the results of the Experts (cross-tabulation) where there are stronger differences between the dominant perspectives (Figure 12.4.b.)

The respondents of the Dutch sample with a dominant Autonomous perspective go out to enjoy nature most: $55,8 \%$-- a majority -- does so every day or several times a week; $36,5 \%$ goes regularly. Only $5,8 \%$ of them rarely go. The Egalitarians follow with frequent enjoyment of nature: $45,9 \%$ of them go every day or more times a week. Quite a lot of them $(35,1 \%)$ go between once a week and once a month; however, $14,9 \%$ indicate to go less often. That is more than double compared to the Autonomous group. The Hierarchists have the largest percentage of people who rarely go outside to enjoy nature: $21 \%$. $35,5 \%$ of the Hierarchists goes out sometimes and still $31,9 \%$ indicates to go frequently. The Egalitarian and the Autonomous groups seem to know quite well how much time they spend outside compared to the other groups. Only 4,1\% of the Egalitarians indicates not to know and $1,9 \%$ of the Autonomous isn't sure.

Of the experts the Dynamics and the Hierarchists go out to enjoy nature most often. The Fatalists go rarely and the Individualists also don't go so frequently as the other groups. 
Figure 12.4.a. Going out to enjoy nature Dutch sample

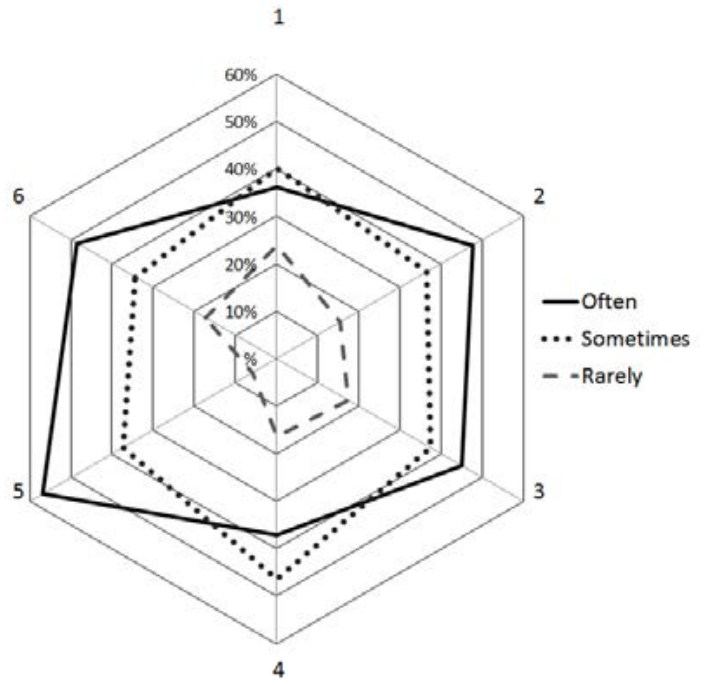

1= Hierarchist;2=Egalitarian;3=Individualist;4=Fatalist;5=Autonomous; $6=$ Dynamic

Figure 12.4.b. Going out to enjoy nature expert sample

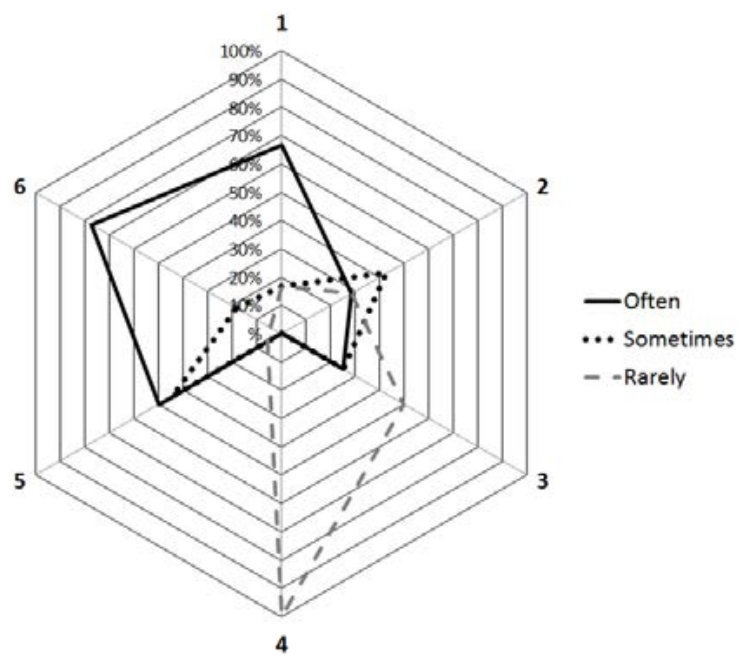

1= Hierarchist;2=Egalitarian;3=Individualist;4=Fatalist;5=Autonomous;6=Dynamic

Question 2.2 Outdoor space and its importance

In the first question I asked whether the respondents have an outdoor space, and what type of outdoor space they have. A large majority of $76 \%$ has a backyard; $65 \%$ has a front-yard; $27 \%$ has a balcony; $7 \%$ has a vegetable garden; $6 \%$ a roof terrace. Negligible percentages of respondents have a veranda (3\%), share a vegetable garden with others (3\%), or have a patio (2\%); $2 \%$ have no outdoor space. One percent of the respondents 
indicate to have another type of outdoor space. These respondents mention to have a farm with an orchard, a parking lot, or shared outdoor spaces. A large majority of $82,2 \%$ of the respondents considers the garden in the choice for their present and future home important (82\% present home; $81 \%$ future home).

In the expert panel a similar pattern is visible. The only difference is that many more people of this panel indicate to have a vegetable (34\% compared to the $7 \%$ of the Dutch panel).

\section{Question 2.3 Being and working in the garden}

I asked the respondents more specifically about their motivations of being and working in their gardens. The results suggest there are differences between what people consider important and what actually brings them into action.

For being in the garden a large majority of the Dutch panel sees it as relaxation (74\%); $30 \%$ indicate they enjoy nature and $24 \%$ goes out into the garden to do yard work. This is considerably more than what the respondents indicated about gardening as being an important activity to them (7\%). Being together with other people is considered less important (16\%), just as playing with the kids or pets (13\%). $10 \%$ of the respondents see their garden as a passageway. Only $7 \%$ indicate they grow vegetables and $6 \%$ say they don't use their garden.

Half of the respondents (50\%) indicate to work in the garden to keep it tidy. This indicates also more a feeling of necessity than one of pleasure about doing yard work. However, still $41 \%$ work in their garden in order to be outside; $26 \%$ indicates, surprisingly, to work in the yard to watch things grow and unfold and $25 \%$ indicates this provides some personal quiet time.

For the expert panel relaxing is also the most important reason for being in their garden (55\%) and $48 \%$ says to be in the garden to enjoy nature. Also $36 \%$ are in the garden to be together with friends and family - considerably more compared to the Dutch sample. Almost a quarter (24\%) is in the garden for gardening reasons and another $26 \%$ is there to grow food. This is also quite different compared to the Dutch sample. Least important to the experts is passing through (5\%).

Working in the garden is especially seen as a way to be outside by $48 \%$ of the expert panel and $36 \%$ wants to watch things grow and unfold while working in their yards. Fewer people compared to the Dutch panel (26\%) indicate to work in the garden in order to keep it tidy and another $26 \%$ works in their garden to find some peace and quiet time for themselves.

\section{Discussion CQ2}

Most of the Dutch respondents go out for the enjoyment of nature quite frequently (at least once a month). The Autonomous group goes significantly out more to enjoy nature 
than the other groups. The Autonomous group and the Egalitarian groups also know best about how often they go outside. This suggests that going outside is especially important for these groups. For the experts this is slightly different. The Dynamics and the Hierarchists are the ones going out to enjoy nature most often. The Individualists go considerably less and the Fatalists go rarely. With this in mind, the results of the expert group do not really reflect the assumptions based on the Cultural Theory archetypes. The activity of gardening itself is only important to a small group of the Dutch panel compared to the experts. A majority of the Dutch respondents go into the yards to do yard-work for maintenance and keeping their yards tidy. These results suggest a feeling of necessity over pleasure about the activity of doing yard- work. However, also many people have other reasons for doing yard work, like 'being outside', 'having some quiet time' and 'watching things grow and unfold'. These activities suggest a feeling of connectedness to nature through working in the yards, which is obviously apparent in a large part of the Dutch population. This may also suggest openness to considering sustainability and biodiversity issues in residential outside spaces.

The experts show similar motivational patterns for working in their gardens compared to the Dutch panel, except for being less steered by the motivation to keep their yards tidy. Being in the garden is motivated by being with their friends and family more than in the Dutch sample. Also more of the expert respondents can be found in their yards for gardening purposes and growing food. The latter results can be attributed to the fact that some expert respondents are professionally active in (organic) food production. It was not possible to correlate the results of both groups to the Dominant perspective groups.

One observation in the results of the surveys for the Dutch and the expert sample seems to confirm the relevance of the 'pigeon paradox' (Dunn, et al., 2006) as a motivation for urban greening for biodiversity. Comparing the results of question 2.1 to question 2.3, showed that active gardeners and urban greeners do more for biodiversity through volunteering and donating to conservation organisations compared to less active gardeners. Although the differences between active and less active gardeners for both samples are not mountain high, the more detailed questionnaire results suggested that the very active gardeners donate more to conservation organisations compared to non-active gardeners. Except for the very active gardeners (mainly within the Autonomous perspective group), who according to the survey results don't do any voluntary work for nature organisations, the active gardeners also score higher for maintaining voluntary activities for nature conservation compared to the not so active ones. Also more very active gardeners say to support environmental causes in other ways than donating or doing voluntary work, for example through lotteries or through (active) membership of conservation organisations (which of course can also be seen as donating or doing voluntary work). Similar patterns account for all the urban greening activities that were included in the survey: more people donated to or volunteered in conservation organisations who are 
also actively involved in greening their roofs, vertical gardening, urban agriculture, permaculture, guerrilla gardening, community gardening or allotment gardening.

CQ 3. What are respondents' preferences with regards to yard maintenance, design and trends?

This question was operationalized into questions on how people maintain their yard, about the design of their yard and about respondents' actual preferences reflected in their outside spaces and yard maintenance practices (table 12.4).

Table 12.4. Overview of survey questions for CQ3

\begin{tabular}{llllllll}
\hline Question & $\begin{array}{l}\text { Survey } \\
\text { Quest* }\end{array}$ & N= & $\begin{array}{l}\text { Min. Exp. } \\
\text { Count }\end{array}$ & Cells\% & Significance & Significant & Methods \\
\hline 3.1 & 5 & 517 & 3.09 & $16,70 \%$ & .002 & Yes & Chi-Square \\
3.2 & 37 & 517 & 4.11 & $11,10 \%$ & .000 & Yes & Chi-Square \\
3.3 & 27 & 517 & 4.91 & $5,60 \%$ & .000 & Yes & Chi-Square \\
3.4 & 35 & 517 & N.A. & N.A. & N.A. & N.A. & Crostabulation \\
$3.5 a$ & 28 & 517 & N.A. & N.A. & N.A. & N.A. & Crostabulation \\
$3.5 b$ & 29 & 517 & N.A. & N.A. & N.A. & N.A. & Crostabulation \\
3.6 & 31 & 517 & N.A. & N.A. & N.A. & N.A. & Crostabulation \\
3.7 & 33 & 517 & N.A. & N.A. & N.A. & N.A. & Crostabulation \\
$3.8 \mathrm{a}$ & $49 \mathrm{a}$ & 517 & N.A. & N.A. & N.A. & N.A. & Crostabulation \\
$3.8 b$ & $49 b$ & 517 & N.A. & N.A. & N.A. & N.A. & Crostabulation \\
3.9 & 39 & 517 & N.A. & N.A. & N.A. & N.A. & Word Cloud \\
$3.10 a$ & $25 a$ & 517 & 9.90 & O\% & .038 & Yes & Chi-Square \\
$3.10 b$ & $25 \mathrm{~d}$ & 517 & 5.07 & O\% & .093 & No & Chi-Square \\
\hline
\end{tabular}

* Survey question refers to the number of the question in the survey taken by the respondents

** When possible, results are based on Chi-Square tests. The minimum expected count refers to the basic assumption for a valid Chi-Square test. It has to be 5 or at least $80 \%$ of the cells need to have a minimum expected count of $5>$

The results in this section can directly be linked to the idea of biodiversity benefits (CHAPTER 9) and can be compared to the results from the empirical front-yard studies in Phoenix and Maastricht (see CHAPTER 10).

\section{Question 3.1 Preferences related to obligations}

In the first question in this set we asked "considering your current situation, your available time and other obligations, what type of garden would you choose?" Respondents were able to choose between "a green garden in need of gardening work and attention to keep it smart", "a low maintenance garden, time efficient, easy to keep smart but predominantly paved", "a wild and lush green garden that grows as it wants to," or: "I prefer to have no garden". The green garden in need of work got $22 \%$ of the votes. The 
low maintenance garden $49 \%$ and the wild garden got $21 \%$ of the votes. Only $2 \%$ prefers to have no garden. A chi-square test for the results correlated to the Dominant perspectives seems to be beneficial. The results are visually represented in Figure 12.5 and described in more detail below.

Let's start with the minority of respondents who do not wish to have a garden: Here, the Fatalist respondents score highest with $14,3 \%$. They are followed by the Individualists $(11,4 \%)$. Of the people in the Autonomous group there isn't a single person who doesn't desire for a garden. A lush, wild garden is mostly desired by the Autonomous respondents $(38,5 \%)$. They are - with a considerable gap -- followed by the Egalitarians $(22,7 \%)$ and the Dynamics (22, 5\%). The Fatalists seems to be least fond of a wild garden $(12,2 \%)$.

A neat green and intensive garden is also highly desired by the Autonomous respondents $(34,6 \%)$. This suggests that this group enjoys doing yard work. They are followed by the Egalitarians $(23,7 \%)$ and the Hierarchists $(20,3 \%)$. The Individualists and the Dynamics aren't massively fond of this yard type. Respectively $13,6 \%$ and $15 \%$ chooses this option.

A low maintenance yard is a favourite with the Dynamics. A respectable majority of $60 \%$ choose this option. They are followed by the Individualists $(56,8 \%)$ and the Hierarchist $(52,2 \%)$. Even almost half of the Egalitarians prefer to have a low maintenance yard $(47,4 \%)$. This suggests these groups prefer doing other things than doing yard work. Least interested in this type are the Autonomous respondents. However, still $26,9 \%$ of them chooses this as a favourite. Figure 12.5 shows how the preferences due to the respondents' obligations are distributed among the dominant perspectives.

The experts prefer a wild and lush garden over the other two types: $45 \%$ chooses the wild and lush type; $32 \%$ prefers a green garden in need of maintenance and only $21 \%$ would choose to have a low maintenance yard. There are no significant differences for the Dominant perspectives here. 
Figure 12.5. Garden preferences in dominant perspectives Dutch sample

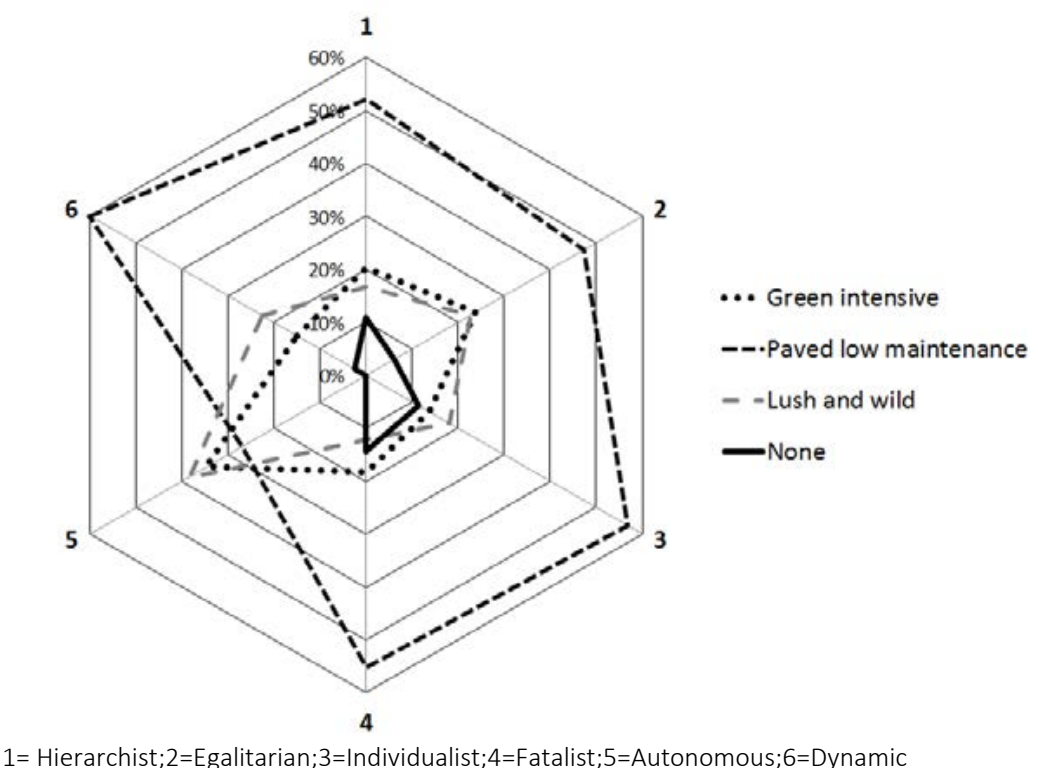

1= Hierarchist;2=Egalitarian;3=Individualist;4=Fatalist;5=Autonomous;6=Dynamic

\section{Question 3.2 Preferences related to functionality}

We asked about the quality the respondents consider most important in their gardens: the aesthetics, the practical functionality or the ecological functionality. A majority of $51,5 \%$ of the Dutch survey population considers the practical functionality of their outside spaces most important. This is in line with the high preference percentages for a low-maintenance yard in all the perspective groups. Another large group (38\%) is most concerned about the aesthetical appearance and only 10,3\% consider ecological functionality the most important quality. A chi-square test on these results reveals that the results are highly significant when cross-tabling them with the Dominant perspectives.

The results seem to reflect my expectations based on Cultural Theory very well: The Hierarchists consider practical functionality $(53,6 \%)$ and aesthetics $(40,6 \%)$ much more important over ecological functionality (5,8\%). A similar pattern accounts for the Egalitarians, although they value ecological functionality a little more than the Hierarchist $\mathrm{s}$ $(8,2 \%)$. The results for the Individualist are especially striking: this group highly values practical functionality $(59,1 \%)$. Aesthetics are also highly valued $(40,9 \%)$. However, ecological functionality isn't valued at all by the Individualists (0\%). The Autonomous results are striking as well. This group values all the elements to a large extent: aesthetics are valued by $30,8 \%$ and practical functionality by $38,5 \%$. This group values ecological functionality the most: just as important as aesthetics $(30,8 \%)$. The Dynamic group has the highest value percentage for practical functionality $(62,5 \%)$. Interestingly, this group is 
the only group who values ecological functionality (20\%) higher than aesthetics $(17,5 \%)$. The cross-tabulated results are also visually represented in Figure 12.6.

\section{Figure 12.6. Functionality preferences in dominant perspectives}

1

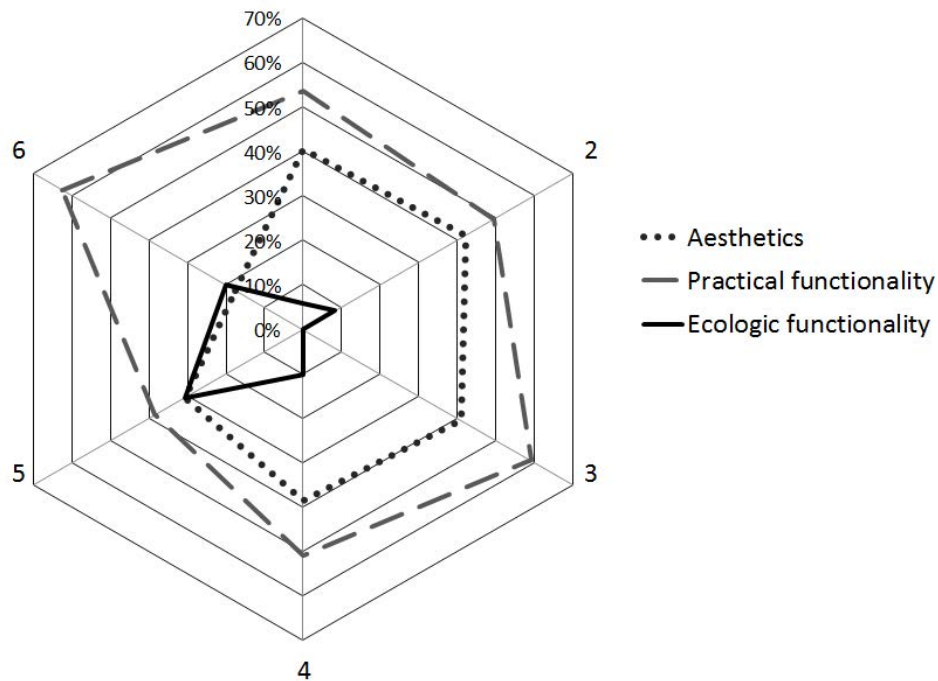

1= Hierarchist;2=Egalitarian;3=Individualist;4=Fatalist;5=Autonomous; $6=$ Dynamic

The experts choose ecological functionality over the others (52\%). Aesthetics comes second with $26 \%$ and practical functionality last with $23 \%$. No significant differences can be attributed to the Dominant perspective groups.

\section{Question 3.3 Buying plants}

A majority of the Dutch respondents (55\%) prefer to buy grown plants that give immediate results. Quite some respondents prefer to buy seeds or seedlings in order to watch them grow (33\%). Only $12 \%$ of the respondents indicate they never buy plants or seeds. A chi-square test for this question leads to highly significant results. Figure 12.7 shows how the plant purchase patterns diversify in the different dominant perspectives.

Interestingly, the Egalitarians and Hierarchists score highest when it comes to having an immediate results with fully grown plants. This may suggest they favour quick aesthetics results, which is also being confirmed by the previous results.

Seedlings and seeds are significantly preferred by the Autonomous respondents (58\%). They are followed by the Dynamics (40\%) and the Egalitarians (34,6\%). Also the Fatalist respondents seem to like watching plants grow: $31,9 \%$ of them indicates to prefer to buy seedlings or seeds. Considerably less interested in natural growth - especially 
when compared to the Autonomous and the Dynamic respondents -- are the Hierarchist $(22,2 \%)$ and the Individualist $(21,4 \%)$.

The Individualists represent the group with the most people who never buy plants or seeds $(28,6 \%)$, whereas only $7,5 \%$ of the Dynamics, $6 \%$ of the Autonomous and $3,7 \%$ of the Egalitarians mention to never buy plants or seeds.

Obviously, the best plant-shoppers are the Egalitarians. This is also represented when we recode the results into bimodal categories of "buying" and "not buying": 96\% of the Egalitarians indicates to buy plants or seedlings, $94 \%$ of the Autonomous, $92,5 \%$ of the Dynamics and $80 \%$ of the Hierarchists. The Fatalists $(76,6 \%)$ and the Individualist $(71,4 \%)$ are the perspectives buying least frequently plants and seeds. However, overall these results indicate that the Dutch people are generally spoken frequent buyers of green.

\section{Figure 12.7. Plant purchase in dominant perspectives}

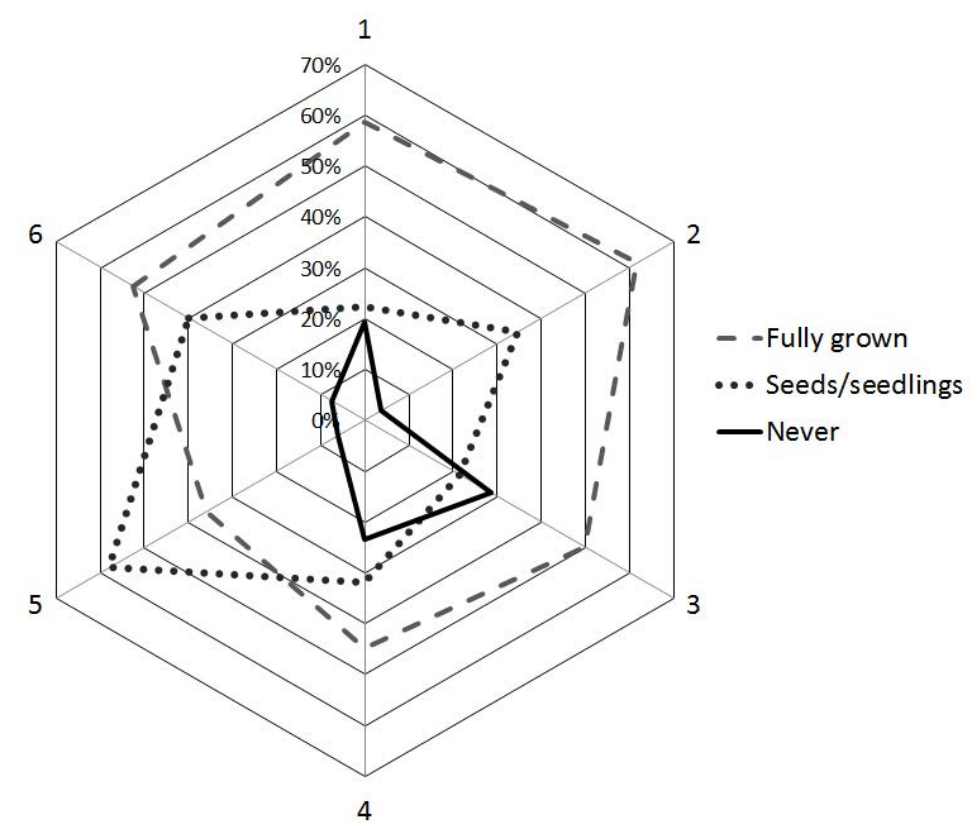

1= Hierarchist $; 2=$ Egalitarian;3=Individualist; $4=$ Fatalist; $5=$ Autonomous; $6=$ Dynamic

A majority of $53 \%$ the expert panel prefers to buy seeds or seedlings to watch them grow. Similarly to the Dutch panel, only $12 \%$ never buys plants. No significant differences can be made between the Dominant perspective groups except for the Autonomous and the Dynamic perspectives: interestingly, these groups are the only ones with respondents indicating they don't buy plants or seeds at all. We aren't able to confirm a reason for this, but it may not suggest that these people are less interested in green: they may be the ones getting access to seeds and plants "off the grid" (through 
exchange or home cultivation) or just giving nature space to take its course as it wants to.

\section{Question 3.4 Exotics and Natives}

We asked about the type of plants people have in their yards: whether they are locally/Dutch oriented or whether they are more exotic, assuming that people know more or less about which plants are occurring in the Netherlands naturally and which ones can be counted as exotics. To help the respondents a little bit, we described exotic plants as Mediterranean plants, (sub)tropical plants or cacti. A majority of $51 \%$ of the respondents indicate they have many plants that grow natively in the Netherlands; $30 \%$ answer they don't have many native plants and $18 \%$ indicates not to know. Only $3 \%$ of the respondents indicate to have many exotic plants; $19 \%$ mentions to have a few of them. The majority of $72 \%$ indicates not to have many exotics and only $6 \%$ doesn't know. A chisquare test made clear that we could not validly compare these results to the Dominant perspectives, due to not meeting the basic assumption of less than $20 \%$ of the cells having minimum expected counts less than 5 .

However, we decided to use the results for a simple cross-tabulation. For exotics there are hardly any differences between the perspective groups, so we won't go deeper into this type of plantation here. Figure 12.8 shows that there are some interesting differences between the perspective groups when it comes to native flora. The Autonomous perspective group scores highest (70\%) in confirming the availability of native plant species in their outside spaces, followed by the Egalitarian $(60,2 \%)$ and the Dynamics (55\%). Then, there is a little gap between these groups and the Hierarchist (43\%) and Fatalist (38\%) groups and a larger gap between these groups and the Individualist perspective group (19\%). In the category where the respondents were able to answer "I don't know" the Individualists score significantly higher $(35,7 \%)$ than the other groups, suggesting this group does not know so much about the origin of the plant species in their environment. The Fatalist (8,5\%), Autonomous (12\%) and Egalitarian $(13,1 \%)$ perspective groups seem to be least uncertain about this. 
1

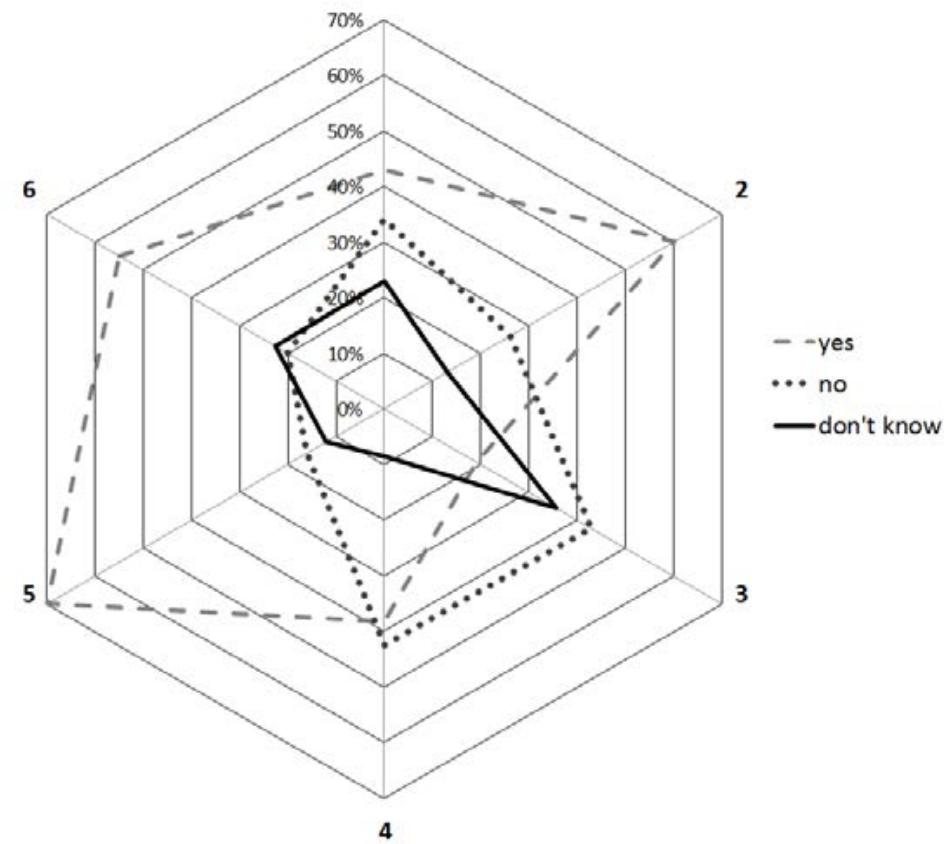

1= Hierarchist;2=Egalitarian;3=Individualist;4=Fatalist; $5=$ =Autonomous;6=Dynamic

In the expert group 57\% indicates their yards reflect the native vegetation typical for the region they live in. This is only slightly more compared to the Dutch panel; $26 \%$ of the expert respondents says their yards don't reflect the native vegetation of their area. Only $12 \%$ says they don't know. Comparing these results for the Dominant perspectives proves to be insignificant.

Relatively more respondents in the expert panel (17\%) say they have many exotics compared to the Dutch panel and 38\% indicates to have some of these plant types and another $38 \%$ says they don't and 7\% says they don't know. However, the expertAutonomous perspective group is the group with least exotic species in their yards (55\%) and the expert Individualist group has the most respondents indicating to have some (75\%).

\section{Question 3.5 Preferences chemicals}

3.5a). Another important question to ask relates to an issue having much impact on biodiversity: the use of pesticides, herbicides and fertilizers. We asked the Dutch respondents whether they use any of such materials. A majority of $52 \%$ of the respondents indicated to never use pesticides or fertilizers; $34 \%$ only use fertilizers and $2 \%$ indicate to use pesticides. $12 \%$ of the respondents mention to use both fertilizers and pesticides. Of 
the expert group $84 \%$ doesn't use pesticides or fertilizers; $5 \%$ uses both and $10 \%$ only uses fertilizers.

$3.5 b)$. The respondents who indicated to use chemicals in their yards were asked to further specify this by indicating what type of materials they use. These were $\mathrm{N}=243$ respondents ( $47 \%$ of the total sample $\mathrm{N}=517$ ). Of them, $44 \%$ indicated to use chemicals with an eco-label; $37 \%$ mentioned to buy natural organic material; $14 \%$ indicated that what they buy is as strong and effectively as possible. Because the chi-square test for this item proved not to meet the basic assumption, we made a simple cross-tabulation to see how the use of chemicals is reflected within the dominant perspective groups (see Figure 12.9).

Figure 12.9. Chemical use in dominant perspectives

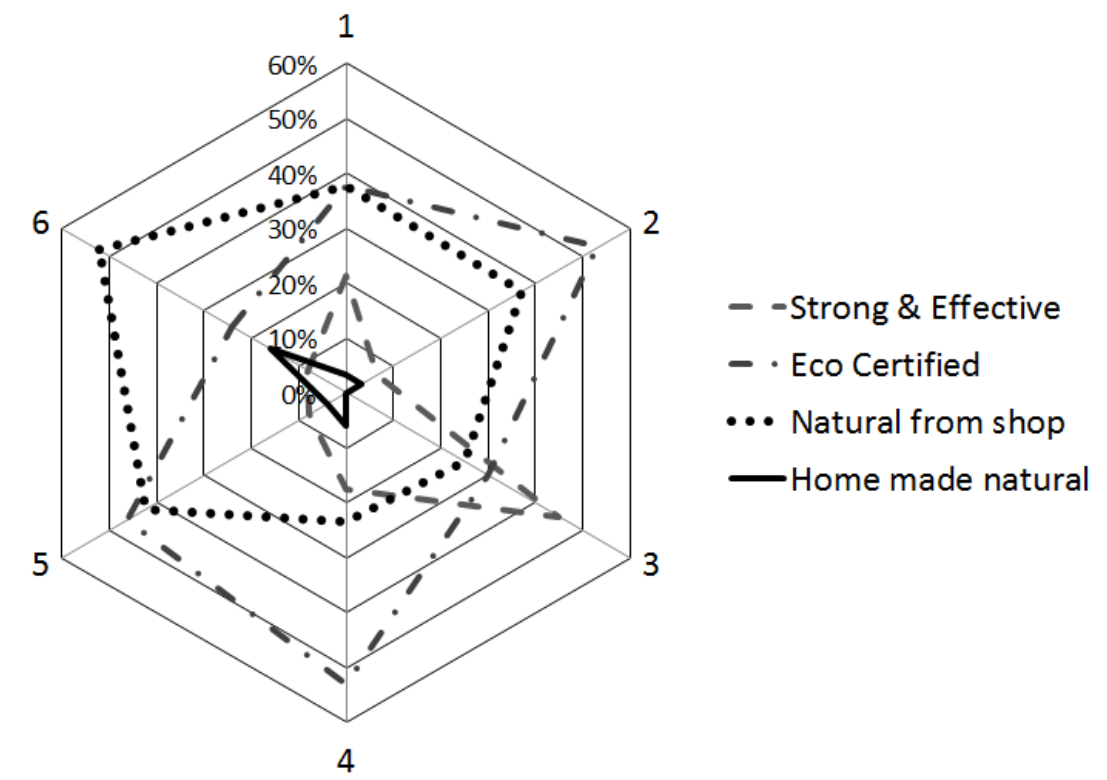

1= Hierarchist;2=Egalitarian;3=Individualist;4=Fatalist;5=Autonomous; $6=$ Dynamic

Interesting differences are visible in Figure 12.9. The Individualist perspective group prefers using strong and effective solutions (usually having environmental side effects like pollution or collateral deaths of insects or aquatic organisms). The Dynamic perspective group aims to use products that are as natural as possible and more of the Dynamics than of the other groups are being creative with making their home made solutions. The Hierarchist perspective seems to be divided between the options. Seemingly, many people try to find eco-certified products. This seems to be least relevant to the Dynamic group though. 
Of the experts using pesticides or fertilizers nobody uses strong and effective chemicals in their yards; $56 \%$ uses certified products; $22 \%$ buys organic products and another $22 \%$ makes their own traditional recipes. Nothing can be said in relation to the Dominant perspectives.

\section{Question 3.6 Present styles}

We asked the respondents about the actual looks of their outside spaces. They had to choose between one of thirteen options and pick the option that describes their outdoor space best (see Figure 12.10). Most respondents (44\%) indicated their outside space looks like a courtyard ("terras"). This corresponds with the results telling about preferences for low maintenance and practical functionality. The next highest percentage of picks went to the option "park" (12\%). This suggests a considerable gap between the amount of paved yards and greener yards. The option "wilderness" was chosen by $9 \%$ of the respondents; $8 \%$ see their yard as a refuge; $7 \%$ as a paradise; $6 \%$ indicate their yard looks like a picture from a gardening magazine (nowadays very often they show high levels of pavement or other hard surface too). Only $2 \%$ see their outside space as an ecosystem.

A cross-tabulation between the styles and the dominant perspectives shows that there are not many significant differences between the perspective groups (also see Figure 12.10). However, the Autonomous (18\%) and the Dynamic (10\%) perspective are the ones that point towards the refuge more than the others. The Autonomous group includes a higher percentage (6\%) of respondents seeing their outside space as an ecosystem compared to the other groups. More Individualist respondents than others see their yard as a picture from a gardening magazine (14,3\%). Wildernesses occurs the most in the Fatalist group (17\%). Earlier (in Question 3.1) we saw that the Fatalists are least fond of the wilder garden types. This confirms earlier findings that this group is one of the groups being least happy about their yards. 
Figure 12.10. Present styles in the dominant perspective groups

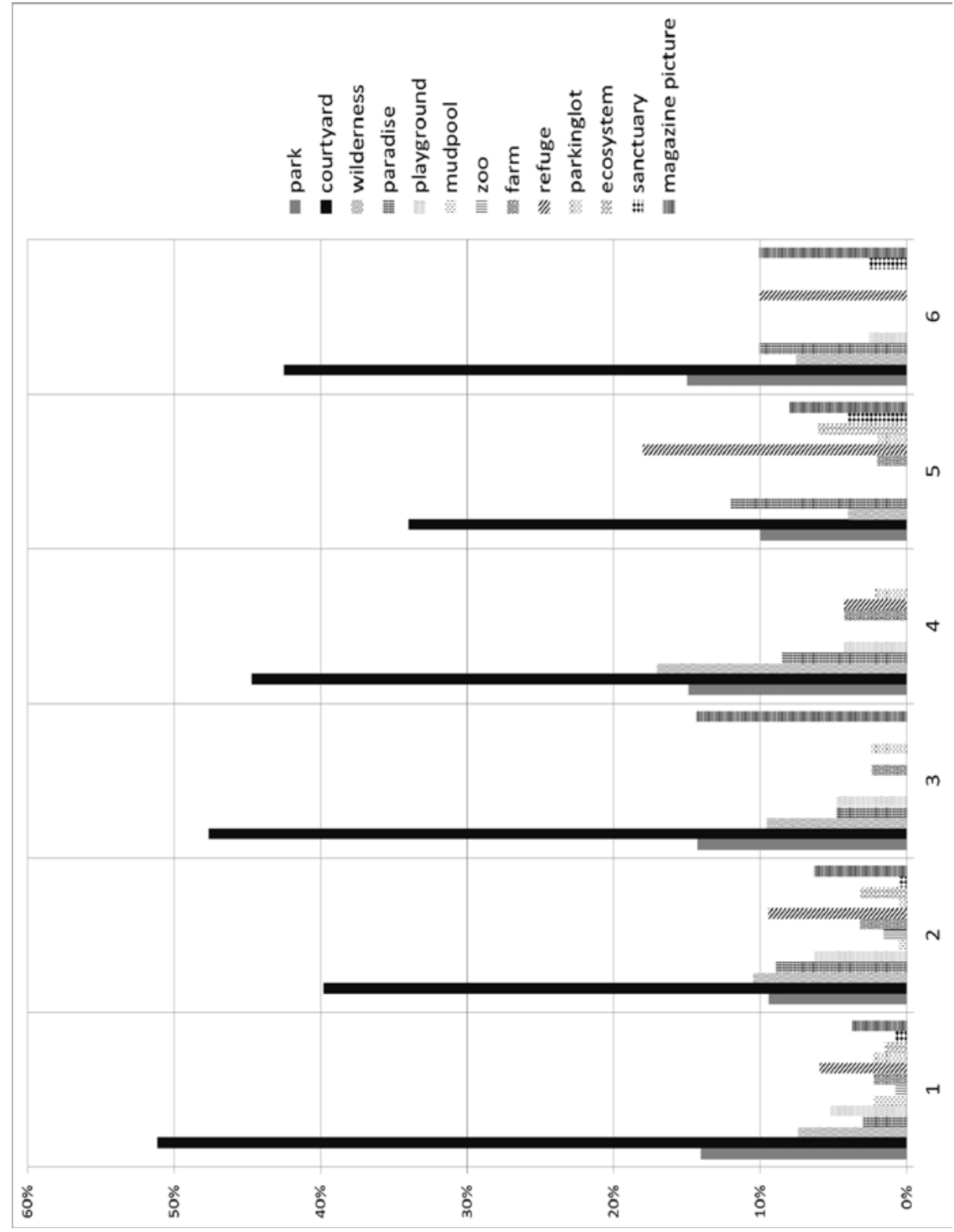

1= Hierarchist;2=Egalitarian;3=Individualist;4=Fatalist;5=Autonomous;6=Dynamic

In the expert group the results are very different: $21 \%$ of the respondents say their yard looks like a park; $19 \%$ indicates it looks like a terrace (mainly Individualists) and another $19 \%$ says it approximates a wilderness (mainly Hierarchists). Of the expert respondents $10 \%$ considers their yards to look like a farm and $7 \%$ says it resembles paradise (Auton- 
omous) or a sanctuary (Egalitarians). Yards looking like ecosystems can be found with $9 \%$ of the expert respondents.

\section{Question 3.7 Style preferences}

We asked to which gardening-concept the respondents felt most attracted. They had eleven options to choose from (see Digital Appendix*). Again and consistently, the respondents felt attracted most to the "low maintenance" concept (37\%). The other largest portion of votes (24\%) went to the option of a living garden "levende tuin." This concept was followed by the idea of the garden as an extended living room (14\%). A lounge garden is preferred by $9 \%$ and an edible garden by $7 \%$, whereas $4 \%$ of the people indicate to prefer the idea of an adventurous yard. Only one percent of the votes go to the concept of a "healing garden", a "design yard", an "exotic yard" and a "yard for the five senses".

Figure 12.11. Attractive garden design concepts in dominant perspectives

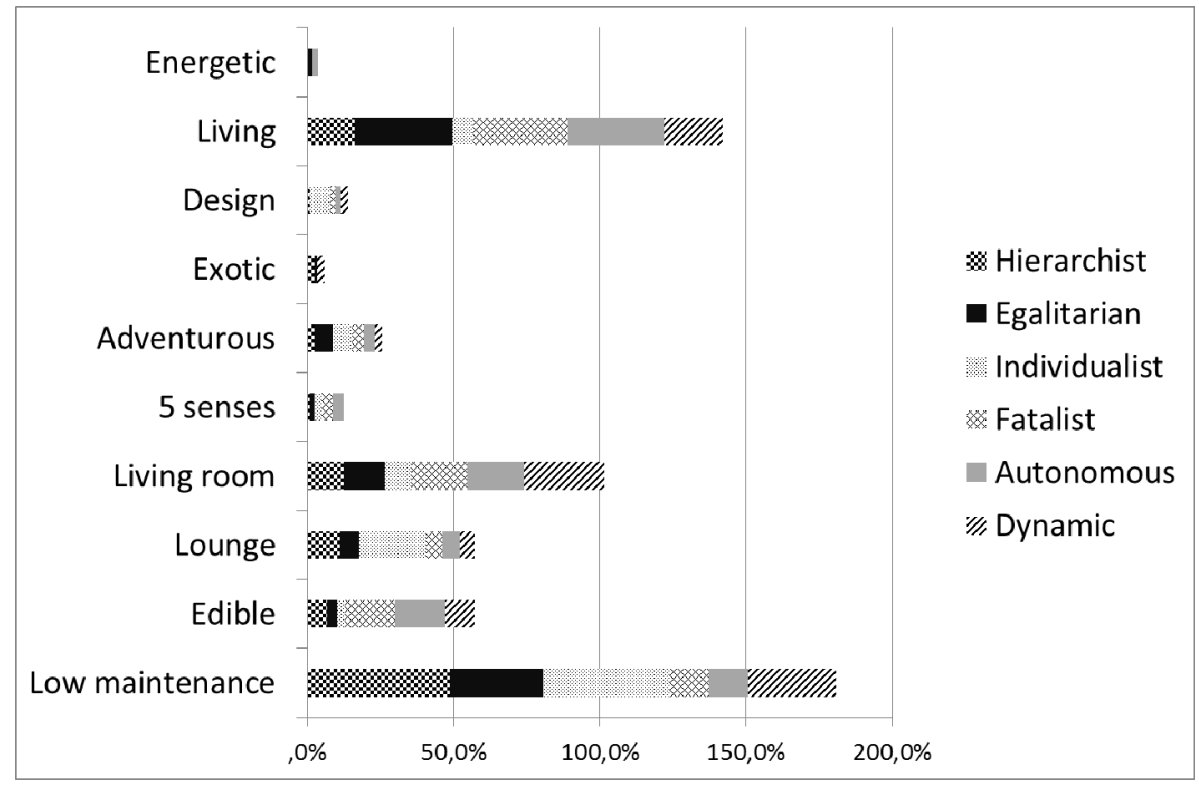

The answers were cross-tabled with the dominant perspectives. Although the chi-square test did not match its basic assumption, we found some interesting results (see Figure 12.11). Therefore these the following descriptions are based on a simple crosstabulation. The two favourite choices for each perspective group and their least preferred options are discussed.

Almost half of the Hierarchists prefer the low maintenance yard $(48,6 \%)$. Their next vote goes to the living garden. The Egalitarians choose for the living garden on the first place $(33,5 \%)$ and also like the low maintenance concept $(32,6 \%)$. The Individualists 
clearly prefer the low maintenance garden concept too. Their second choice is the Lounge garden. The Fatalists keep in line with highly preferring the low maintenance garden (46,9\%). Their second choice falls on the living garden concept. The living garden is the favourite for the Autonomous group $(32,7 \%)$. They also like to see the garden as an extension of the living room (19,2\%). 30\% of the Dynamics prefers the low maintenance concept and $27,5 \%$ likes the idea of the garden as an extension of the living room. Most respondents liked the healing garden least (0\%). The Fatalist and the Dynamic added the five senses garden concept to the least preferred ones. Exceptions were made by the Egalitarians, who least preferred the design garden concept (0\%), and the Autonomous, who did not particularly seem to like the exotic garden concept (0\%).

With the expert panel, the edible garden is most popular (34\%) as a concept especially with the Dynamics and the Autonomous, followed by a living garden (18\%), especially favoured by the Egalitarians; and a low maintenance garden (16\%), especially favoured by the Hierarchists and Individualists. Least popular are the lounge garden and the exotic garden.

\section{Question 3.8 Visual preferences}

3.8a). I compared the answers people gave to questions 3.7 to the answers they gave about their visual preferences. Eight visual options with compilations of different garden design styles were presented. In the design for this question the aim has been to make compositions of a few very attractive yard-examples for each separate style (Figure $12.12 *)$. Interestingly, most votes went to the wild garden style (29\%). The English romantic garden proved to be second most popular: $20 \%$ of the respondents chose this picture. The modern garden - that expresses functionality and low maintenance most -was chosen by only $16 \%$ of the respondents; the adventurous one by $13 \%$; the Japanese and the edible garden both by $9 \%$. Least popular are the energetic garden (3\%) and the French Versailles garden style.

The outcomes of the picture results were compared to the dominant perspectives. Although the chi-square test did not match the basic assumption we show the first two choices for each perspective in a simple cross-tabulation.

The Hierarchist chose the wild garden over the others $(25,6 \%)$ and their second choice has been the English garden (22,5\%). For the Egalitarians the wild garden has been even more popular (38,1\%). This group also chose the English garden second $(24,2 \%)$. The modern garden proved (as expected) to be the favourite with the Individualists: $45 \%$ of this group chose the modern garden. Both the English cottage garden and the edible garden scored next highest for the Individualists, with $13,6 \%$. The Fatalists liked the modern and the wild garden equally much (22,4\%). 18,4\% of the Fatalists chose the adventurous garden. The Autonomous group prefers the wild garden $(26,9 \%)$ and the edible garden $(19,2)$. In the Dynamic group most votes go to the wild garden $(30 \%)$, followed in popularity by the English garden (20\%). 
The least preferred garden for each perspective turned out to be (unexpectedly) the Versailles garden for the Hierarchist (0.7\%) and the Egalitarians (3\%); the Individualists also did not prefer the Versailles garden (2,3\%) just as the edible garden (2,3\%); the Versailles garden was also least favourite with the Fatalists (2\%), the Autonomous (0\%) and the Dynamics (2,5\%). Perhaps we did something wrong with the choices of the picture compilation for this garden style. I expected the Versailles garden to be most attractive for the Hierarchist group. Figure 12.13 shows how the garden styles are preferred in the dominant perspective groups.

Figure 12.12. Garden Styles
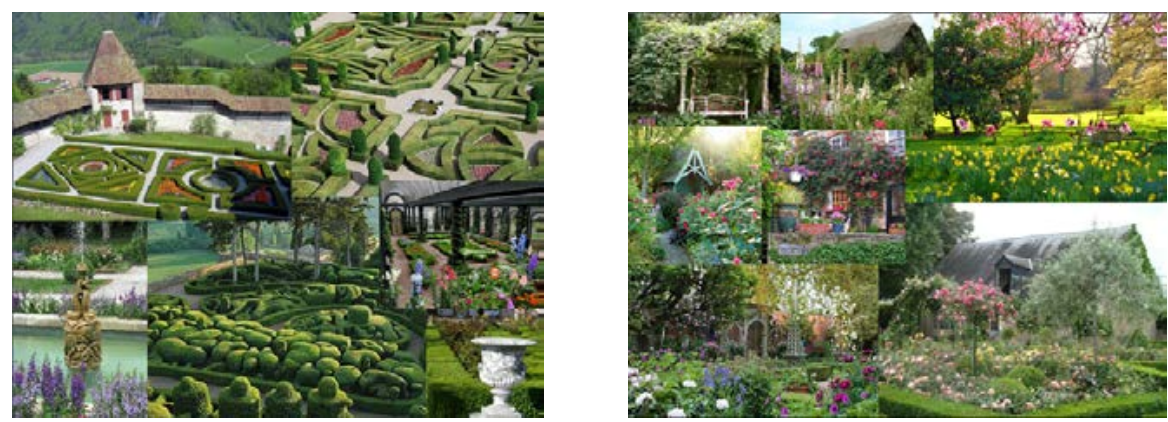

A.French Versailles Style
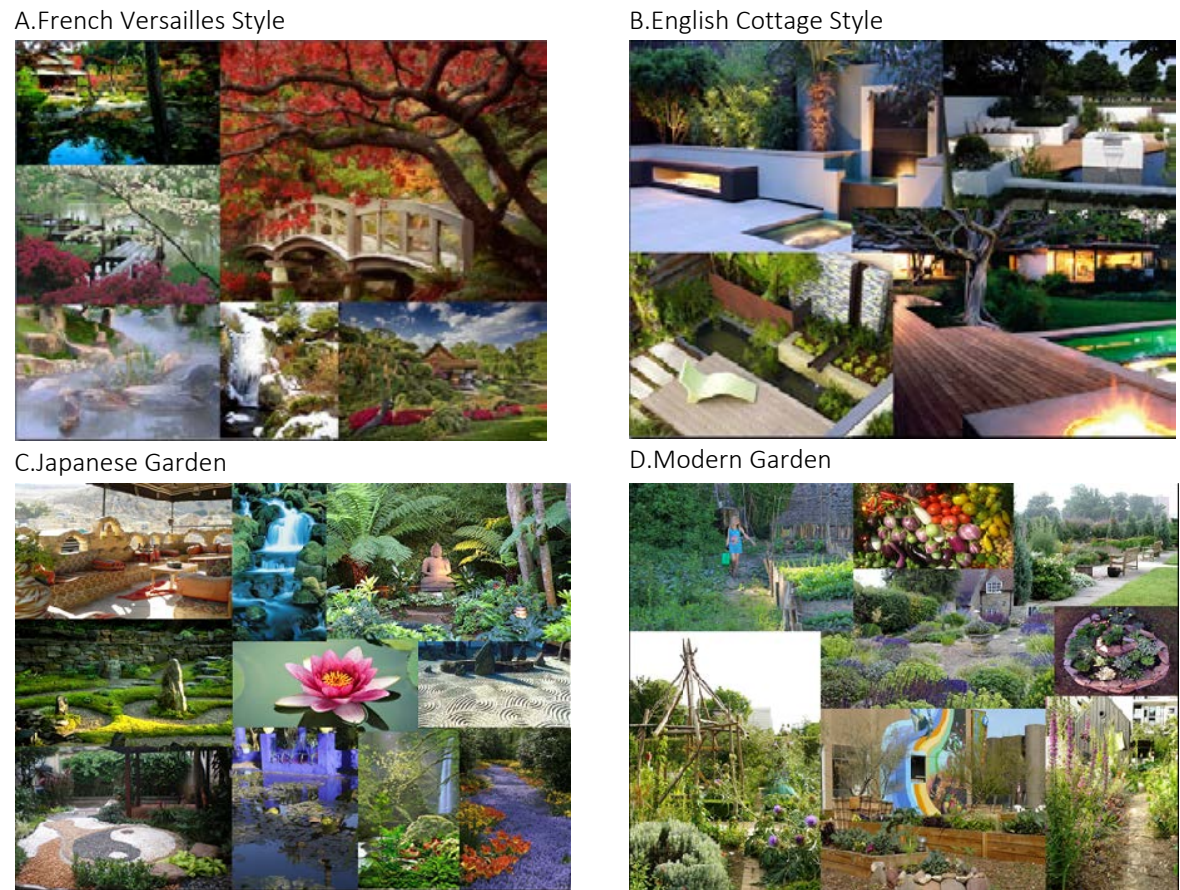

E.Energetic Healing Garden

D.Modern Garden

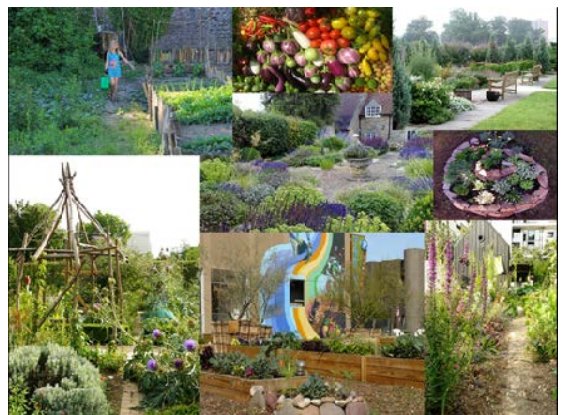

F.Edible Garden 


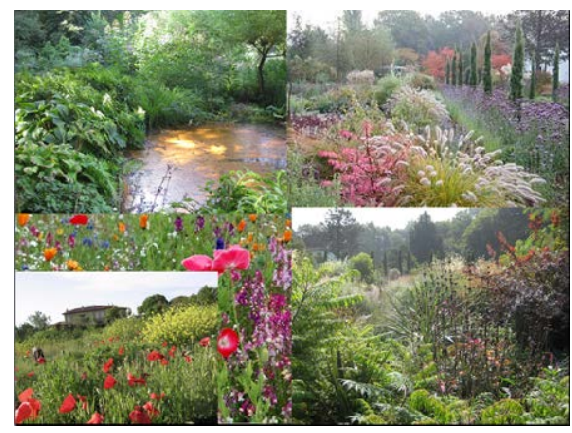

G.Wild Garden

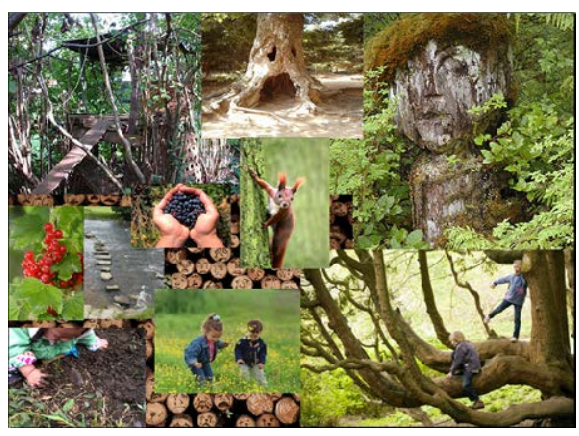

H.Adventurous Garden

Figure 12.13. Preferred garden styles in dominant perspectives

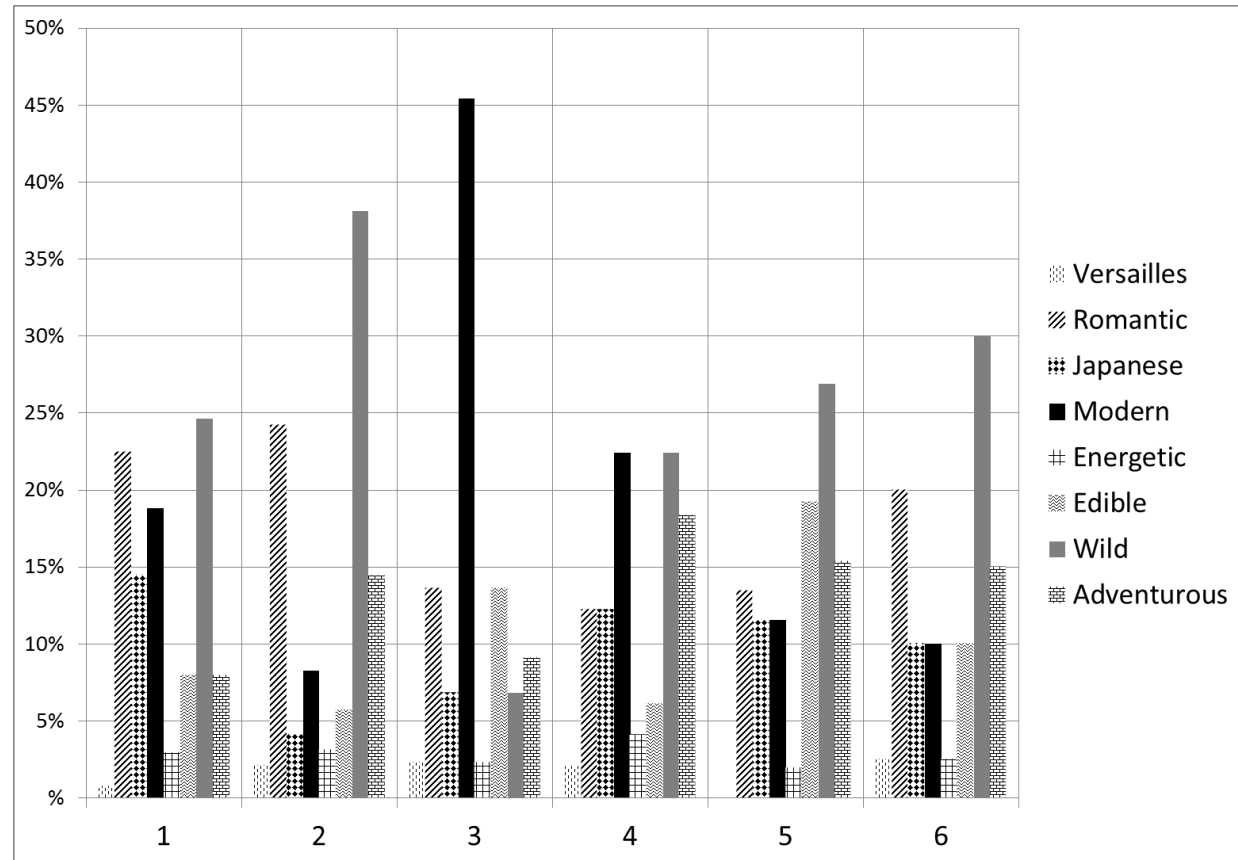

1= Hierarchist;2=Egalitarian;3=Individualist;4=Fatalist;5=Autonomous;6=Dynamic

3.8b). The respondents were asked to comment in an open question why they chose the picture they chose and what inspired them most about is. The French Versailles gardens did not get much response. One of the three respondents who filled in the open option said: "Prachtig lijnen spel maar helaas te groot voor mijn tuin en veel onderhoud." (Beautiful patterns and lines but unfortunately too large for my yard and too much work"). For the other yard-styles more explanations were given. That made it possible to summarise them in word clouds (see Word Cloud 12.4a-h*). 
Word Cloud 12.4a-h. Garden-style preferences motivated

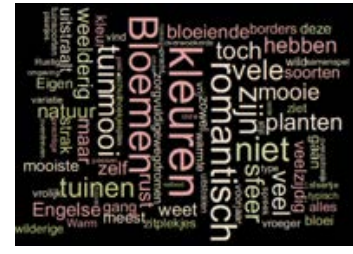

a.English romantic

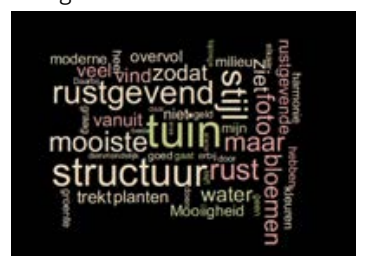

d. Energetic

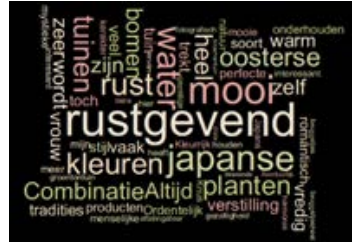

b. Japanese

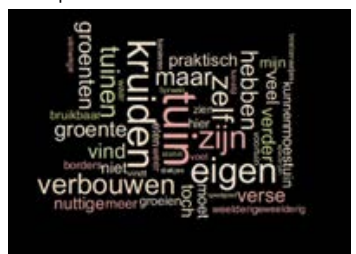

e. Edible

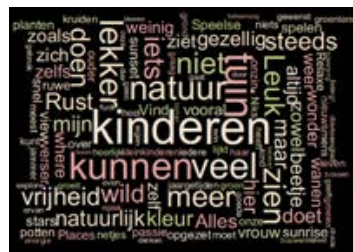

g. Adventurous

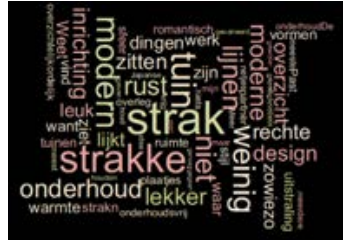

c. Modern

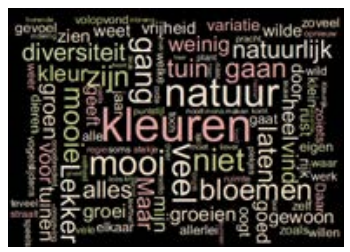

f. Wild

With the experts (Word Cloud $12.5 \mathrm{a}-\mathrm{g}^{*}$ ), herb and vegetable gardens (especially Individualists) and lush and wild gardens (especially Dynamics) are most popular (both 24\%), followed by English Romantic gardens (19\%, especially Egalitarians) and energetic or healing gardens (10\%). Least popular are the Versaille type gardens. The Fatalist seems to be the only one preferring the Versailles type garden that we' $d$ actually attributed the Hierarchist perspective group. No word clouds have been made for the Versaille garden due to lack of response. For the Versailles garden the answer given was: "The castle garden is green nature"; for the desert garden the answer was: "the desert garden it is both lush and geometric the unique plants, and growing things that occur naturally in my area."

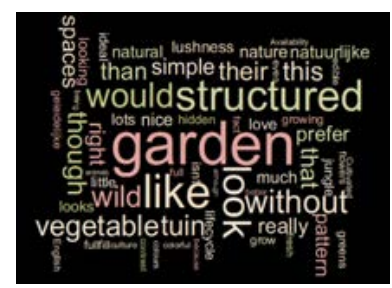

a. English romantic

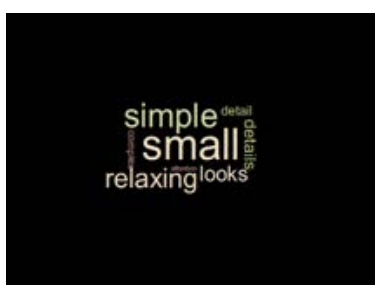

b. Japanese

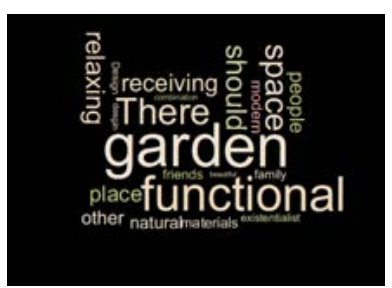

c. Modern 


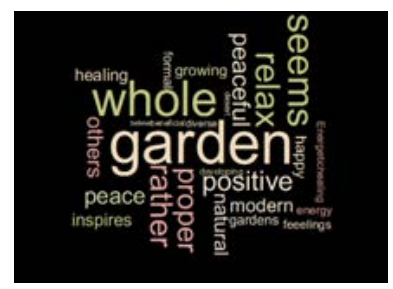

d. Energetic

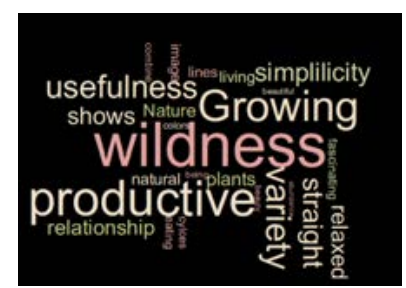

e. Edible

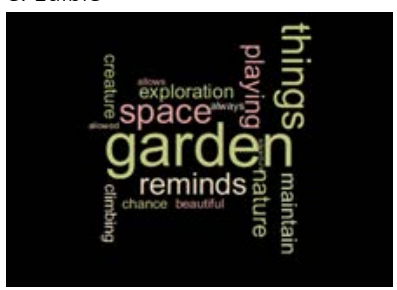

g. Adventurous

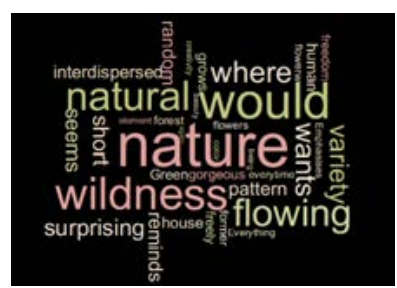

f. Wild

\section{Question 3.9 Design philosophy}

We asked the respondents whether they have any philosophy or conceptual idea about how their outside space or yard should look like. Most Dutch respondents (79\%) answered they do not have any philosophy or concept; $11 \%$ does not know. The $9 \%$ that does have a clear idea reflected on this in an open answer section.

Of the expert panel $47 \%$ indicate they have a specific philosophy. The results of their contents are summarised in a word cloud (see Word Cloud 6a and b*).

Word Cloud $12.6 \mathrm{a}$ and b. Garden Philosophy

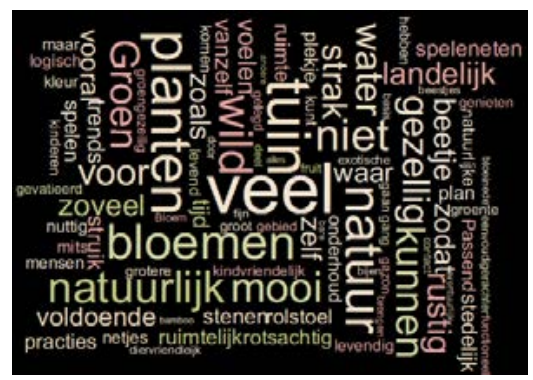

a. Garden philosophy Dutch Sample

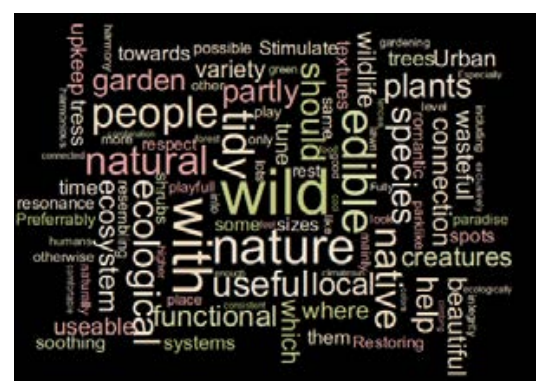

b. Garden philosophy expert sample

\section{Question 3.10 Personal relation to gardening and gardening trends}

Finally we asked people about how they personally relate to the practice of gardening (active gardeners and being influenced by neighbours). We asked this question to see whether active gardeners are active due to intrinsic motivation or by some kind of 'pres- 
sure' due to neighbourhood expectations. We used two Likert items for these questions.23

3.10a) For respondents considering themselves to be active gardeners we see that a chisquare test validates the results as useful and significant. I made the results bimodal (active-not active). In total, only a quarter of the respondents think of themselves as active gardeners (24,8\%). The other 75,2\% doesn't. The Autonomous dominant perspective group has the highest amount of active gardeners (36\%) compared to the other groups. They are followed by the Egalitarians (29,3\%). The Hierarchists have $23 \%$ of active gardeners, followed with a small gap by the Fatalists (17\%). The Dynamic group and the Individualist group represent the least active gardeners (respectively 15\% and $14,3 \%)$.

The experts are a little more active than the Dutch panel-participants: $33 \%$ of the experts consider themselves active gardeners. However $67 \%$ consider themselves not so active. The only perspective group who really considers themselves active gardeners is the Egalitarian group. The Autonomous and Dynamic groups are the only groups with very active gardeners. The Individualist and Hierarchist experts consider themselves least active.

3.10b) I asked how concerned the respondents are about the neighbours' thoughts about the looks of their yards. Neighbours' opinions about people's yards are considered moderately important (40\%) towards not so important (30\%). A cross tabulation through a chi-square test shows that the results are valid (minimum expected count $=5,07$ ), but insignificant (.093). Being pressured by neighbourhood expectations does not seem to be related to the dominant perspectives.

For $47 \%$ of the experts it is not important and not unimportant what the neighbours think of their yards. Only 19\% consider it important and 34\% consider it not so important. No interesting differences between perspective groups can be identified.

\section{Sub-Conclusion CQ3}

The results for the Dutch panel suggest that there is an interesting gap between the cognitive preferences and the visual preferences. In the verbal questions the respondents indicate to prefer paved low-maintenance gardens with practical functionality over greener, lusher gardens. However, when presenting a set of pictures with garden styles, the respondents favour the English cottage garden and the lush wild garden over the modern garden that represents low-maintenance and practical functionality the most. Contrary to these visual preferences, the respondents massively indicate their

23 Question 25 actually consists of part a,b,c, and d. We skipped discussing the results of a and b, because we think these questions are less relevant in the context of our aims than we thought beforehand. 
yards look like a courtyard. These results suggest that people actually like the looks of green, lush and wilder gardens, but don't have the time for it, or choose for practical functionality over aesthetics or ecological functionality; perhaps even though they'd actually want something looking more natural.

We saw that the Individualist perspective group (together with the Hierarchists) is the group that favours low-maintenance yards most. This group chose the modern garden as a favourite and also turned out to be the perspective group using strong pesticides and fertilizers the most. The low-maintenance preference of the Individualist group is confirmed by the result that this group represents least active gardeners (together with the Dynamics). The Individualist group also seems to be most ignorant about species and their origins, and they are least interested in watching plants grow.

The Autonomous perspective group represents the most active gardeners and the results suggest that they also enjoy yard-work highly. The Autonomous, together with the Egalitarian perspective group, prefer the concept of a "living garden". The interest in ecological dynamics (especially of the Autonomous group) is confirmed by their preference for watching plants grow and their relatively low preference for courtyards.

The Egalitarian perspective seems to be interested in quick aesthetic results. It is also the group most active in buying plants. The Dutch sample suggests that the Dutch are frequent buyers of green generally speaking. Not many exotic species are bought. This isn't very different between the perspective groups. However, the Autonomous group indicates to have native plants the most.

For the experts the cognitive and visual results seem to be more in line with each other. Less people of this group prefer low-maintenance yards (almost half the percentage compared to the Dutch respondent group) and ecological functionality is valued over practical functionality. The edible garden concept is the most popular one. This is also confirmed by the visual preferences that are given where the wild garden and the herbvegetable garden are most popular. Although still many yards of the experts also look like terraces, more respondents indicate their gardens look like parks.

With respect to the native and exotic species represented in the yards the results are remarkable and unexpected when compared to the Dutch survey results. The experts have relatively many exotic species. This corresponds with the observation that many active gardeners I spoke to in Phoenix have relatively green yards that include many species that do not naturally belong in a desert environment. I checked this by comparing the results of experts living in the Netherlands (who live in naturally green environments) and experts living in the US (mainly in Phoenix). These results seem to confirm the assumption: $33,3 \%$ of the US gardens do not reflect the native vegetation of the proximate environment, whereas in the Netherlands this is only $14,8 \%$. However, an additional visual question with 1 . a lush green highly designed garden and 2. a highly designed desert garden indicate that more American respondents favour the desert garden (64,3\%) native to the Arizona desert environment over the green garden $(35,7 \%)$. 
This is different for the Dutch experts: they clearly favour the green garden (86,2\%) over the desert garden (13,8\%). For the Arizonian gardeners there seems to be a gap in the desire for gardening conceived as - more or less literally -- greening the environment and creating a sustainable domestic outside space through desert-landscape design (xeriscaping).

Where the Dutch panel results can clearly be linked to the Cultural Theory dominant perspectives, this is much less the case for the results of the expert panel. This may suggest that a green education or occupation softens the dominant perspective lines.

CQ 4. (How) do respondents relate and contribute to urban greening in their daily lives? In this section, I look at the respondents' preferences with regards to green space on the urban scale level (Table 12.5).

Table 12.5. Analysis approach CQ 4.

\begin{tabular}{cccccccc}
\hline Question & Survey Question & $\mathrm{N}=$ & Minimum Expected Count & Cells \% & Significance & Significant & Methods \\
\hline $4.1 \mathrm{a}$ & $47 \mathrm{a}$ & 517 & N.A & N.A & N.A & N.A & Frequencies \\
$4.1 \mathrm{~b}$ & $47 \mathrm{~b}$ & 33 & N.A & N.A & N.A & N.A & Word Cloud \\
$4.2 \mathrm{a}$ & $48 \mathrm{a}$ & 54 & N.A & N.A & N.A & N.A & Crosstabulation \\
$4.2 \mathrm{~b}$ & $48 \mathrm{~b}$ & 463 & N.A & N.A & N.A & N.A & Crosstabulation \\
4.3 & 49 & 517 & N.A & N.A & N.A & N.A & Crosstabulation \\
4.4 & 50 & 517 & N.A & N.A & N.A & N.A & \\
\hline
\end{tabular}

* Survey question refers to the number of the question in the survey taken by the respondents

** When possible, results are based on Chi-Square tests. The minimum expected count refers to the basic assumption for a

valid Chi-Square test. It has to be 5 or at least $80 \%$ of the cells need to have minimum expected count of $5>$.

\section{Question 4.1 Familiarity with urban greening trends}

4.1a). I asked with which urban greening trends the participants are familiar. The large majority isn't active in the urban greening activities they are familiar with. Allotment gardening (volkstuinieren) are the best known examples of urban greening: $82 \%$ of the respondents indicates to know the concept; Green roofs are next best known (72\%). Only $2 \%$ indicate they have a green roof. Community gardens (69\%) are also a relatively well-known concept as is green infrastructure, which is known by $52 \%$ of the respondents. Least well-known are guerrilla gardening and permaculture. For each item, $87 \%$ of the respondents said not to know this. Vertical gardens follow: $57 \%$ indicates not to know this trend. Little more than half of the respondents (52\%) never heard about urban farming. Participation is largest in the allotment gardening. However, this accounts to only $4 \%$ of the respondents.

Our expert panel knows all the trends pretty well. Allotment gardening is least familiar with the experts. This may be due to the fact that it is a typically Dutch way of gardening. Participation is highest in urban farming (29\%), green infrastructure $(24 \%)$ and community gardening (23\%). Also permaculture (19\%) and guerrilla gardening (16\%) are practiced by quite some experts. It was not possible to compare the results for both groups with the Dominant perspectives in a sensible way. 
No statistical conclusions can be drawn on the basis on the dominant perspective groups compared to the diverse urban greening trends. However, cross-tabulations show that in the practice of urban greening the Egalitarian group scores highest on almost all the trends, except for permaculture (the Hierarchist (40\%) and the Autonomous (40\%) score higher here), Urban Farming (the Hierarchist scores even with the Egalitarian group (44,4\%), Vertical gardening (the Hierarchist (33,3\%) and the Autonomous (25\% Igroup score higher), and Green Rooftops (the Autonomous group scores significantly higher with 33,3\% over $22 \%$ for the Egalitarian group).

4.1b). A number of respondents ( $N=33$ for the Dutch sample and $N=13$ for the expert sample) indicated to know other trends than mentioned in the survey question. I summarised their responses in a word cloud (see Word Cloud 12.7*). Not surprisingly, parks and city-parks are mentioned most as an additional form of urban greening. Trees are mentioned and many people refer to public green space ("openbaar groen"). Foodforests ("snoepbossen) is something more in the category of novel urban greening trends. Nobody thought about mentioning gardening in their private green spaces as an additional form of urban greening, except for the "geveltuintjes" (tiny garden patches at the facades of homes). Perhaps a little less serious: the nurseries for grass (weed) (wietkwekerijen). Based on the results of this question, it can be said that there seems to be much space for improvement of knowledge on the possibilities of urban greening and of participation.

Word Cloud 12.7. Other urban greening trends

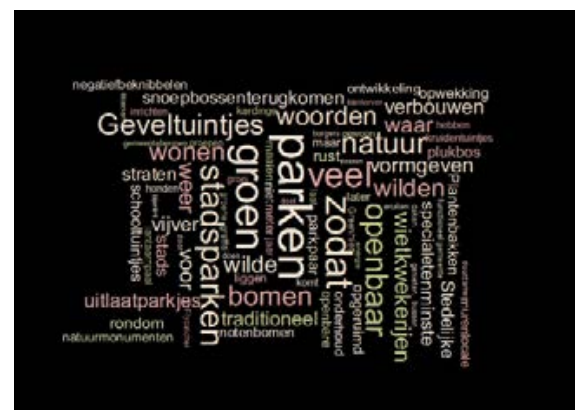

a. Dutch sample

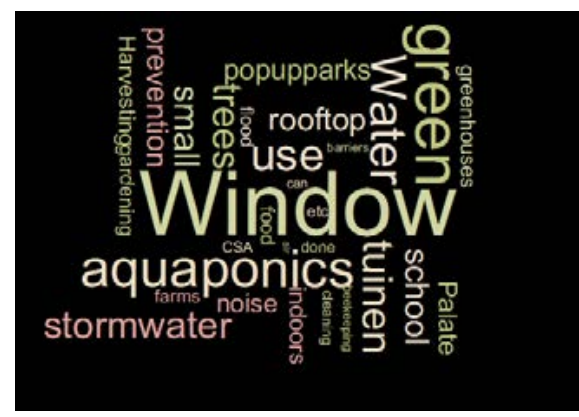

b. Expert sample

\section{Question 4.2 Motivations for urban greening activities}

4.2a) The respondents who indicated to be active in one of the urban greening trends were asked for their motivations for participation. A number of $\mathrm{N}=54$ respondents answered this question. Most of them (37\%) indicated that they love to be outside: it gives them a feeling of peace and connectedness to the planet. Within this answer, this was especially experienced so by the Autonomous group (60\%). Also the co-creation of the living environment scored high as a motivation to participate in urban greening trends 
(28\%). This answer has especially been chosen by the Hierarchists $(45,5 \%)$ and the Individualists (50\%). Meeting new people was also given by $20 \%$ of the respondents (most of them Fatalist $(42,9 \%)$ ) and $17 \%$ said they see it as their duty to do something for their direct living environment (mostly Dynamics (50\%)).

Of the expert-participants in urban greening ( $N=62)$, most people (34\%) indicate they see it as their duty to do something for the environment through urban greening. Working outside for inner peace and connectedness is mentioned by $29 \%$ of the experts and taking part in the co-creation of the living environment is a motivation for $27 \%$ of the expert participants. For $13 \%$ it is their job and $18 \%$ see it as a chance to meet other people.

4.2b). Reasons for not participating were also asked. This question has been answered by $\mathrm{N}=463$ respondents. Almost half of them in all the perspective groups said that the municipality takes care of the urban green; $32 \%$ say that their environment is already pretty green (this is especially considered by the Autonomous $(35,7 \%)$ and the Hierarchists $(34,6 \%) ; 21 \%$ of the sample for this question indicated they had never thought about participating (mostly Fatalists $(35,7 \%)$ ). Lack of time is also an issue for $17 \%$ of the respondents. This counts mostly for Individualists (35\%); almost equally rated as a lack of money (16\%) which has been referred to especially by the Autonomous $(26,2 \%) ; 11 \%$ indicate they have physical limitations. Not a lot of people primarily consider participation in urban greening not worthwhile (4\%). The ones who do are mainly Individualists $(31,1 \%)$.

Reasons for not participating for the expert panel are especially found in time limits (23\%). Only $10 \%$ says they don't participate because their local governments take care of the urban green. No clear perspective differences can be found here.

Question 4.3 Preferences for specific urban greening trends

Next, the respondents were shown seven pictures that each show collages of specific types of urban greening trends (see Figure $12.14^{*}$ ). I asked them which one of the trends they prefer. The frequencies of the choices made are given in Table 12.6. 
Figure 12.14. Urban greening trends
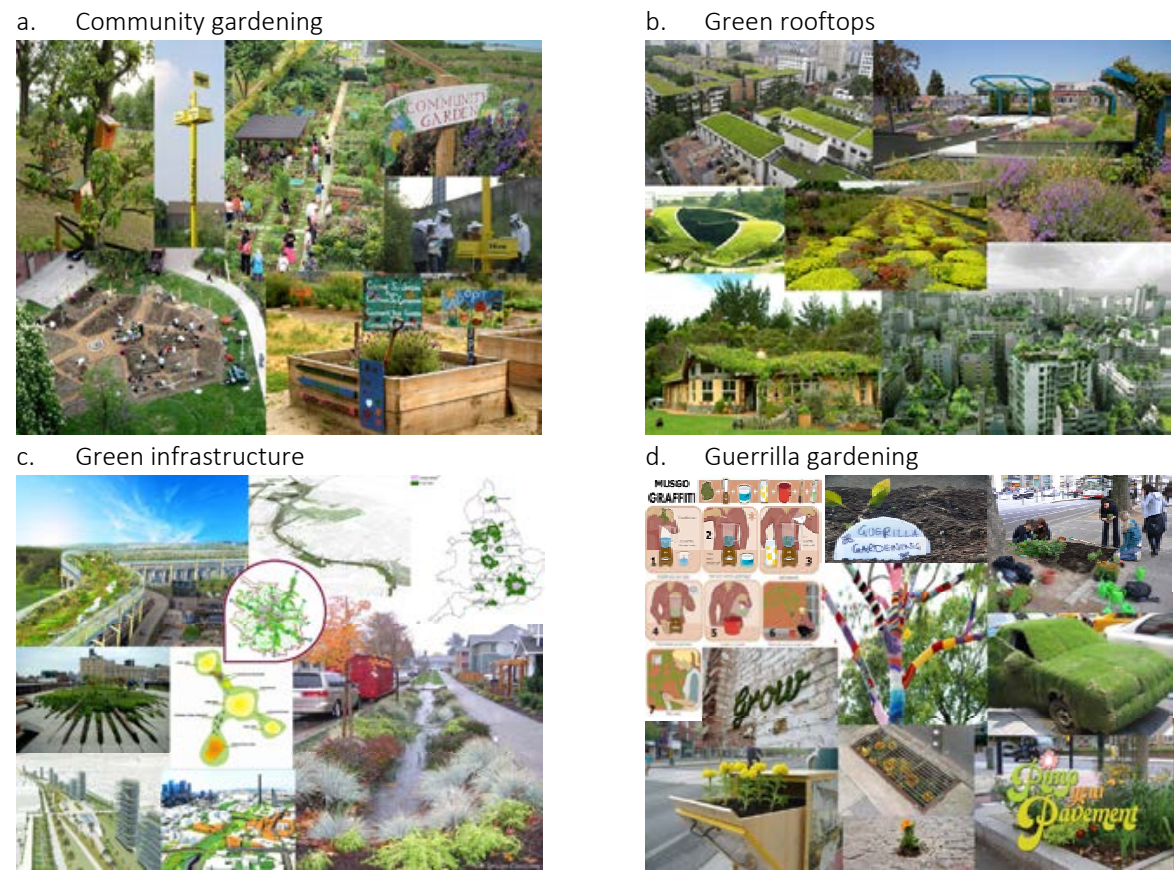

d. Guerrilla gardening

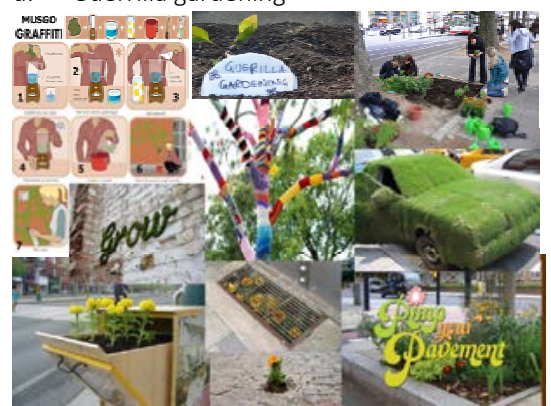

e. Permaculture
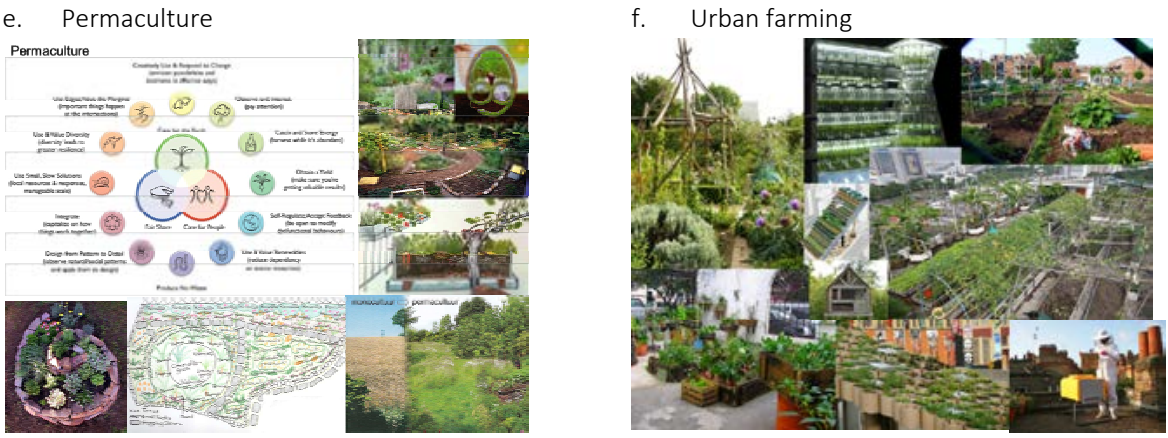

g. Vertical gardening

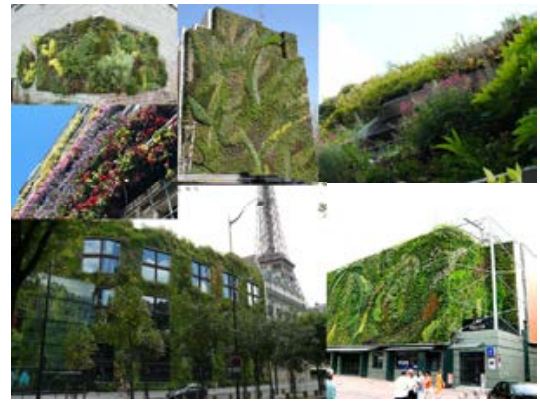


I cross tabulated these results with the Dominant perspectives. The results are visualised in a radar chart (see figure 12.15). Significant results here are that the Autonomous perspective clearly favours urban farming highly over the other perspectives $(34,6 \%)$. Green infrastructures are most popular in the Dynamic group $(32,5 \%)$ and green roofs are also attractive to this group $(27,7 \%)$. The Individualist group also feels attracted most to green infrastructure $(27,3 \%)$. The Hierarchist perspective group expresses most interest in the green roofs concept (32,6\%). Guerrilla gardening and permaculture are obviously least attractive. The Autonomous group, however, expresses most interest in both (respectively $5,8 \%$ and $13,5 \%$ ).

\section{Table 12.6. Frequencies attractivity of green trends Dutch (a.) and Experts (b.)}

a.

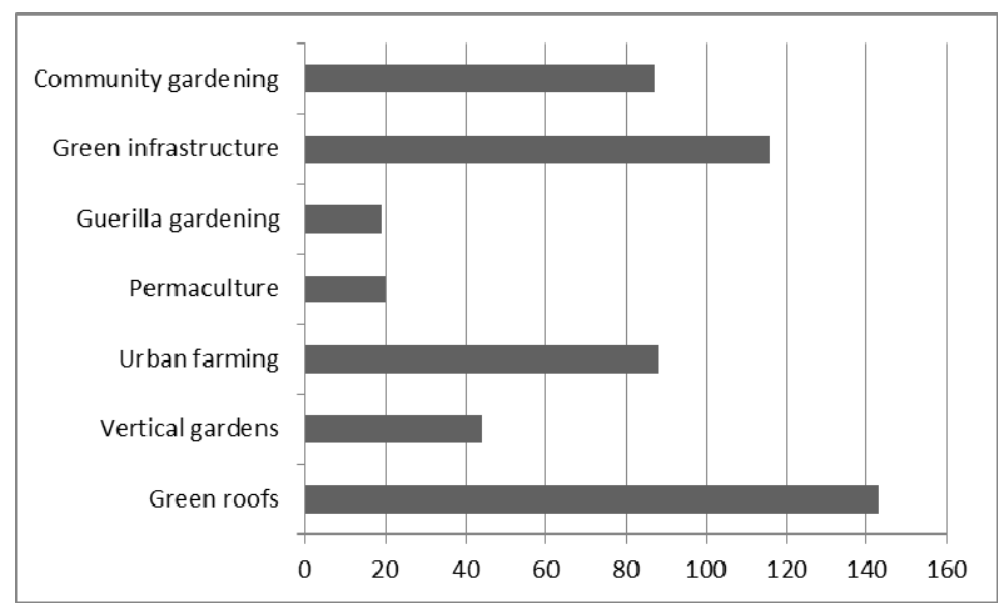

b.

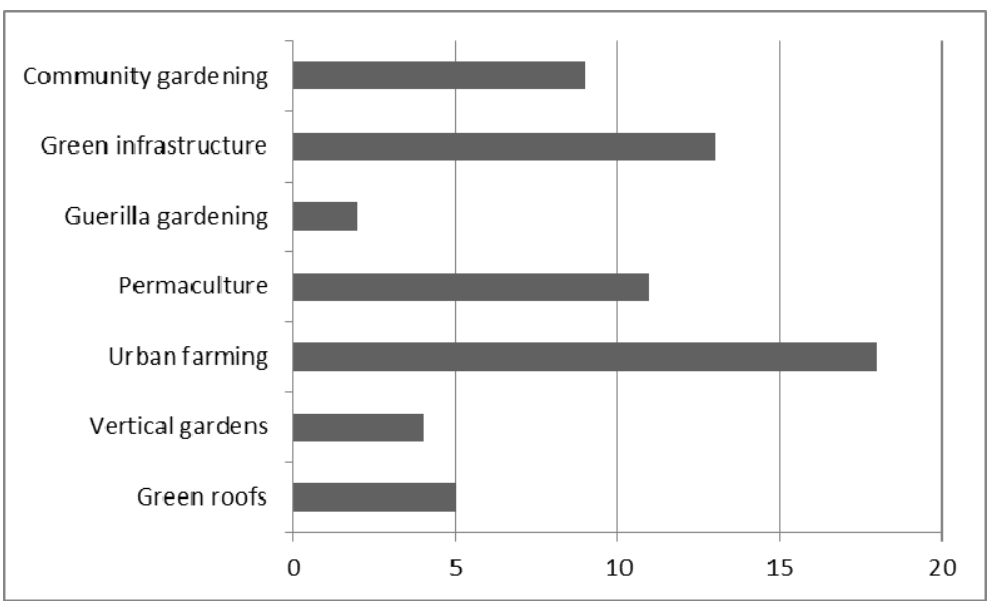




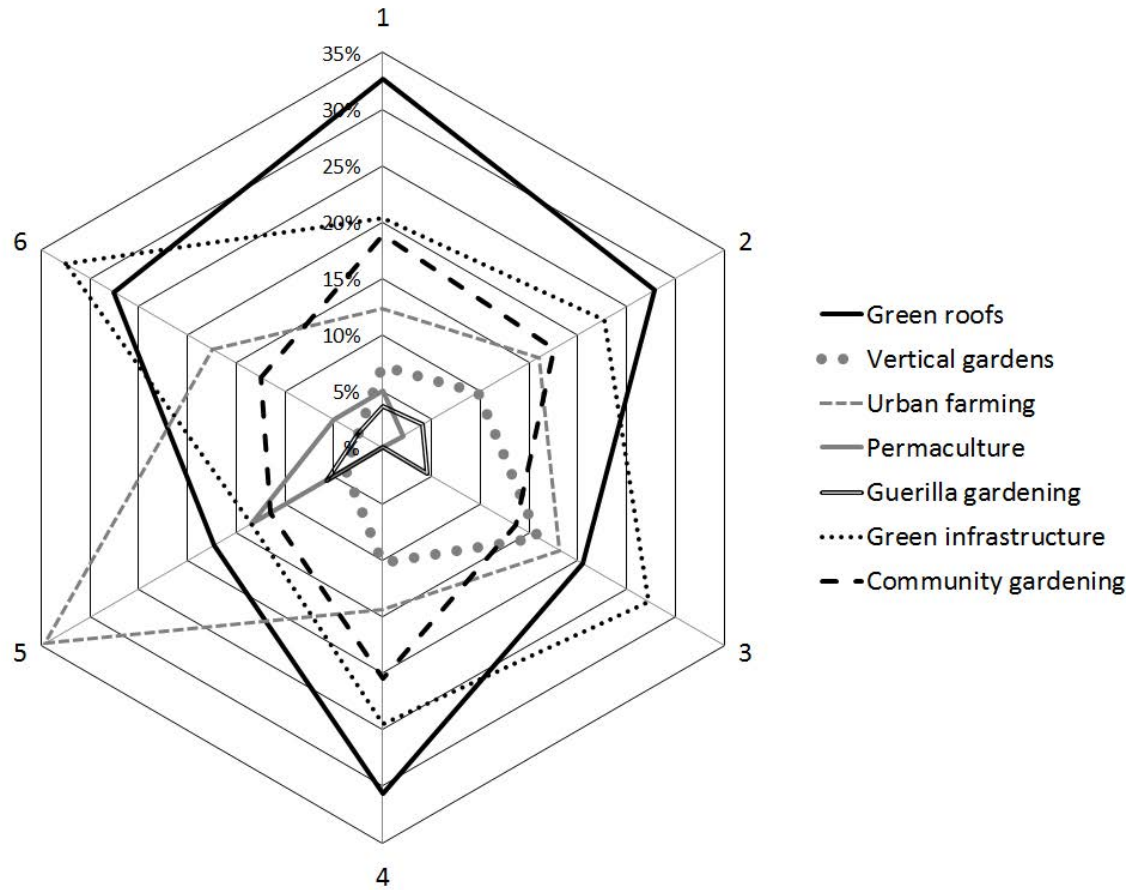

1= Hierarchist;2=Egalitarian;3=Individualist;4=Fatalist;5=Autonomous; 6 =Dynamic

For the experts, urban farming is most popular, being followed by the green infrastructure picture and permaculture. Guerrilla gardening is least popular.

\section{Question 4.4 Responsibility for urban green}

Our final question in this set asked which parties should be most responsible for the urban green in the respondents' living environments. Most respondents think that all the different actors together should be responsible (41\%). But this could also be considered as a socially desirable or an easy answer that covers all the other options. Therefore, it is more interesting to see that $37 \%$ of the respondents think that urban green is the responsibility of the local government. Only a few (3\%) see it as a responsibility of horticultural companies or as their own responsibility (4\%).

The experts see the cooperation between the different parties as being most responsible as well (55\%). A clear difference can be found with the other results compared to the Dutch panel: $21 \%$ think urban greening is the responsibility of the inhabitants of a community whereas only $18 \%$ attributes the main responsibility to the local governments. Comparing the results with the Dominant perspectives shows that there isn't much difference between the perspective groups for this question. 


\section{Sub-conclusions CQ4}

The results for CQ4 show that not many people in the Netherland participate actively in urban greening projects (only $10,44 \%$ of the total sample of $\mathrm{N}=517$ ). Allotment gardening has been chosen most frequently as an activity in which the respondents participate.

Different motivations for participation correspond with different perspective groups. The main motivation mentioned for participation in urban greening projects is for people to be outside and a feeling of connectedness to the environment it gives them. This is especially the case for the Autonomous group. The popular idea in sustainability science and sustainability project-work of the co-creation of the proxy environment is especially a motivation for Individualists and Hierarchists. These motivational differences between perspectives can be relevant when considering implementation of urban greening projects and their target groups. This is also confirmed by the different preferences for urban greening trends in the different groups. The Autonomous group for example favours urban farming, whereas the other groups express more interest in green roofs and green infrastructure.

The respondents indicate that the main reason for not participating in urban greening projects is the high contribution of local governments to the maintenance and development of urban green space. The respondents also say that the care and maintenance for urban green space should be the responsibility of local municipalities. However, not many people (and mainly Individualists) consider participation in urban greening projects as non-worthwhile, so there may be space for motivating more people to get engaged.

I hoped for respondents to mention their own yard and gardening work in the open question section for additional urban greening activities. Nobody (both in the Dutch panel and in the expert panel) seemed to make that connection.

It is obvious that in the expert group relatively more people participate in urban greening. For some it even is their job. Time restraints are the most important reasons for not participating. Interestingly, the experts tend to take more civil responsibility for urban greening compared to the Dutch panel who find it mainly a local governmental responsibility.

\section{CQ 5. Do respondents connect their urban greening activities to the ideas of} sustainability and biodiversity conservation?

In order to gain more insight for the support for the idea of helping biodiversity in urban areas I asked how respondents conceive (their) yard-work or urban greening practices as being beneficial for biodiversity. In the previous Core Questions I asked about preferences and practices that provided us mainly with indirect insights related to urban biodiversity and conservation potential. Here I directly asked the respondents what they do 
for biodiversity in their yards24 and how they think about the potential contribution of their outside space and urban environment to local nature and global biodiversity. The analysis approach is outlined in table 12.7 .

Table 12.7. Analysis approach CQ 5.

\begin{tabular}{|c|c|c|c|c|c|c|c|}
\hline Question & Survey Question* & $\mathrm{N}=$ & Minimum Expected Count* & *Cells \%** & Significance $* *$ & Significant** & Methods \\
\hline 5.1 & 35 & 517 & see table & see table & see table & see table & see table \\
\hline 5.2 & $40 a$ & 517 & 4.78 & $5,60 \%$ & .001 & Yes & Chi-Square \\
\hline 5.3 & $40 b$ & 517 & 11.14 & $0 \%$ & .000 & Yes & Chi-Square \\
\hline 5.4 & $51 a$ & 517 & N.A. & N.A. & N.A. & N.A. & Crosstabulation \\
\hline 5.5 & $51 b$ & 517 & 4.64 & $5,60 \%$ & .012 & Yes & Chi-Square \\
\hline
\end{tabular}

\section{Question 5.1 Helping native animals}

I asked the respondents what they do for the native animals visiting their outside spaces/gardens. We had a series of 16 questions about what people do in their yards or outdoor spaces. The respondents were able to choose more than one option. Most of the results were also compatible with a cross/tabulation with the Dominant perspectives. However, some of them did not meet the basic assumption of the chi/square test. Nevertheless, I decided to put all the results of question 30 in a table (table 12.8 and 12.9). The results that did meet the basic assumption of a minimum expected cell frequency of less than 5 have a grey colour in table 12.8. The ones that didn't meet the basic assumption have been left white.

As can be seen in the table, two of the valid results ("hedges \& shrubs" and "cats and dogs") are not significant, meaning that they do not say anything about whether the Dominant perspectives are relevant for these items. The other grey items are significant and thus provide information about the items related to the Dominant perspectives. I won't discuss all the items extensively here, they can be seen in the table, but a few are worth highlighting:

Half of the respondents with an Individualist perspective (50\%), for example, indicate to do nothing for native animals around their homes, compared to the Autonomous respondents of whom only $8 \%$ indicate to do nothing. The Autonomous and the Egalitarian respondents are the ones feeding the most (respectively $70 \%$ and $62,8 \%$ ). Feeding is done a lot by most of all the respondent groups (58\% of the respondents). The Individualist does it least $(40,5 \%)$. The Autonomous (56\%) and the Dynamic (32,5\%) groups try to attract pollinator insects the most. Again, the Individualist group hardly does this $(4,8 \%)$. Berry and fruit shrubs are also distributed mostly by the Autonomous and the Dynamic respondents (respectively $48 \%$ and $30 \%$ ). And, again, least by the Individualists $(7,1 \%)$.

24 For operationalization reasons we narrowed down the idea of biodiversity for this question by asking about local animal species. Earlier we had already asked about native and exotic plant species and the questions about design preferences and practice also provide information on biodiversity in people's yards. 
This trend continues for shelter and nesting facilities, organic material (although the Egalitarians contribute significantly to nesting too with $25,1 \%$, and relatively many Individualists contribute to arranging nest-boxes as well (19\%)).

The item "cats and dogs" is - intentionally -- a little bit out of range here, because these bringers of happiness to human beings often contribute significantly to the disturbance of native wildlife. Especially cats are seen as a serious threat to urban biodiversity (reference). Only Individualists and Autonomous respondents seem to have less cats and dogs playing in their yards. However, this item has been tested insignificant for providing information about the dominant perspectives.

Table 12.8. Do you do anything for the native animals in your garden (Dutch)

\begin{tabular}{|c|c|c|c|c|c|c|c|c|c|c|}
\hline \multirow{2}{*}{ Action } & \multicolumn{6}{|c|}{ Perspectives in \% } & \multirow[t]{2}{*}{ Freq. } & \multirow[t]{2}{*}{ Total } & \multirow[t]{2}{*}{ Sig. } & \multirow{2}{*}{$\begin{array}{l}\text { Min. } \\
\text { Expected } \\
\text { Count }\end{array}$} \\
\hline & Hier & Ega & Ind & Fat & Aut & Dyn & & & & \\
\hline No & 31,9 & 20,4 & 50 & 31,9 & 8 & 22,5 & 131 & $26 \%$ & .000 & 10,33 \\
\hline Feeding & 54,1 & 62,8 & 40,5 & 55,3 & 70 & 55 & 293 & $58 \%$ & .047 & 16,79 \\
\hline Nectar \& pollen & 14,1 & 26,7 & 4,8 & 14,9 & 56 & 32,5 & 120 & $24 \%$ & .000 & 9,50 \\
\hline Berries \& fruit & 18,5 & 26,7 & 7,1 & 17 & 48 & 30 & 123 & $24 \%$ & .000 & 9,70 \\
\hline Beneficial insects & 3,7 & 6,8 & 4,6 & 10,6 & 24 & 12,5 & 42 & $8 \%$ & .000 & 3,39 \\
\hline Shelter & 12,6 & 16,2 & 11,9 & 6,4 & 32 & 22,5 & 81 & $16 \%$ & .008 & 6,42 \\
\hline Nesting & 25,9 & 39,3 & 19 & 21,3 & 54 & 52,5 & 176 & $35 \%$ & .000 & 13,94 \\
\hline Insect hotel & 0 & 2,1 & 2,4 & 1,4 & 8 & 7,5 & 15 & $3 \%$ & .017 & 1,19 \\
\hline Honeybees & 0 & 1 & 0 & 2,1 & 0 & 2,5 & 4 & $1 \%$ & .977 & .32 \\
\hline Organic material & 17 & 25,1 & 7,1 & 14,9 & 44 & 25 & 113 & $22 \%$ & .000 & 8,95 \\
\hline Pond & 7,4 & 14,1 & 11,9 & 14,9 & 10 & 15 & 60 & $12 \%$ & .486 & 4,75 \\
\hline Stream/fountain & 8,9 & 9,4 & 16,7 & 6,4 & 12 & 12,5 & 51 & $10 \%$ & .627 & 4,04 \\
\hline Hedges \& shrubs & 13,3 & 14,7 & 9,5 & 12,8 & 12 & 22,5 & 71 & $14 \%$ & .634 & 5,62 \\
\hline Migration & 8,1 & 12 & 7,1 & 12,8 & 22 & 17,5 & 61 & $12 \%$ & .122 & 4,83 \\
\hline Cats \& dogs & 20 & 23,6 & 11,9 & 21,3 & 11,2 & 22,5 & 113 & $22 \%$ & .209 & 8,95 \\
\hline Other & 3 & 2,1 & 0 & 2,1 & 6 & 5 & 14 & $3 \%$ & .509 & 1,11 \\
\hline
\end{tabular}

The things experts do for native animals in their gardens are quite diverse (see table 12.9). In general, they do percentually more than the Dutch citizen panel. Where the Dutch sample is most engaged in feeding animals, the expert panel does this less and pays more attention to making sure there are flowers with nectar for pollinators. Nestboxes are also more popular in the Dutch panel compared to the expert panel. In this panel, also the Autonomous perspective group and the dynamic group are most active. The Individualist and the Fatalist groups hardly do anything. Making sure beneficial insects feel at home through increasing nectar and pollen is most popular, being followed by planting berries and fruits. Insect hotels are not really common, and also ponds or flowing water elements are not implemented frequently. No-one of the experts keeps 
honeybees. All the expert results are not compatible with a Chi-square test and only interpretable as simple cross-tabulation. The table below shows the chi-square results nonetheless to make comparison to the Dutch panel more convenient.

Table 12.9. Do you do anything for the native animals in your garden (experts)

\begin{tabular}{|c|c|c|c|c|c|c|c|c|c|c|}
\hline \multirow{2}{*}{ Action } & \multicolumn{6}{|c|}{ Perspectives in \% } & \multirow[t]{2}{*}{ Freq. } & \multirow[t]{2}{*}{ Total } & \multirow[t]{2}{*}{ Sig. } & \multirow{2}{*}{$\begin{array}{l}\text { Min. } \\
\text { Expected } \\
\text { Count }\end{array}$} \\
\hline & Hier & Ega & Ind & Fat & Aut & Dyn & & & & \\
\hline No & 100 & 28,8 & 75 & 0 & 27,8 & 22,7 & 15 & $26 \%$ & .176 & .26 \\
\hline Feeding & 16,7 & 28,6 & 25 & 0 & 33,3 & 36,4 & 18 & $31 \%$ & .918 & .31 \\
\hline Nectar \& pollen & 16,7 & 28,6 & 0 & 0 & 50 & 45,5 & 22 & $38 \%$ & .296 & .38 \\
\hline Berries \& fruit & 0 & 42,9 & 0 & 0 & 55,6 & 36,4 & 21 & $36 \%$ & .098 & .36 \\
\hline Beneficial insects & 0 & 0 & 0 & 0 & 22,2 & 40,9 & 13 & $22 \%$ & .090 & .22 \\
\hline Shelter & 16,7 & 42,9 & 0 & 0 & 27,8 & 36,4 & 17 & $29 \%$ & .593 & .29 \\
\hline Nesting & 16,7 & 28,6 & 0 & 0 & 16,7 & 22,7 & 11 & $19 \%$ & .866 & .19 \\
\hline Insect hotel & 0 & 14,3 & 0 & 0 & 11,1 & 13,6 & 6 & $10 \%$ & .895 & .10 \\
\hline Honeybees & 0 & 0 & 0 & 0 & 0 & 0 & 0 & $0 \%$ & N.A. & N.A. \\
\hline Organic material & 33,3 & 14,3 & 0 & 0 & 50 & 31,8 & 19 & $33 \%$ & .310 & .33 \\
\hline Pond & 16,7 & 14,3 & 0 & 0 & 22,2 & 18,2 & 10 & $17 \%$ & .923 & .17 \\
\hline Stream/fountain & 0 & 0 & 0 & 0 & 0 & 4,5 & 1 & $2 \%$ & .893 & .02 \\
\hline Hedges \& shrubs & 16,7 & 14,3 & 0 & 100 & 33,3 & 18,2 & 13 & $22 \%$ & .264 & .22 \\
\hline Migration & 16,7 & 0 & 0 & 0 & 27,8 & 27,3 & 12 & $21 \%$ & .504 & .21 \\
\hline Cats \& dogs & 16,7 & 42,9 & 0 & 100 & 16,7 & 27,3 & 14 & $24 \%$ & .252 & .24 \\
\hline Other & 16,7 & 0 & 0 & 0 & 0 & 9,1 & 3 & $5 \%$ & .558 & .05 \\
\hline
\end{tabular}

Question 5.2 Perceived contribution of outside spaces to local biodiversity

I asked whether the respondents believe that yards or residential outside spaces contribute to the nature in their local environment A majority of $66 \%$ of the Dutch respondents thinks this is indeed the case; $21 \%$ doesn't think so, and $12 \%$ doesn't know. A chisquare test for these results with the dominant perspective shows that there are differences between the perspective groups and how they think about this (see Figure 12.16). 
Figure 12.16. Perceived contribution of outside spaces to local nature in dominant perspectives (Dutch)

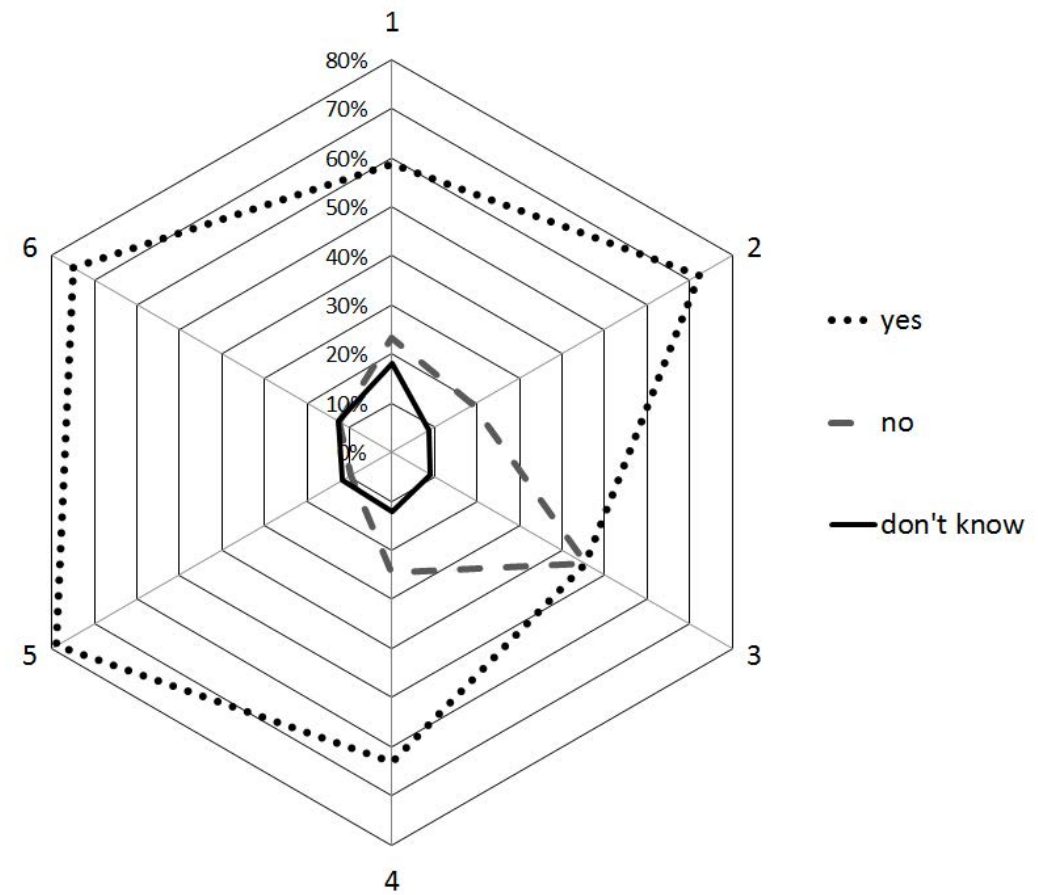

1= Hierarchist;2=Egalitarian;3=Individualist;4=Fatalist;5=Autonomous;6=Dynamic

Especially the Individualist perspective group believes significantly less in the idea that their own outside spaces contribute to their local environment (only 45,5\% believes and $45,5 \%$ doesn't believe; $9,1 \%$ of the Individualists doesn't know). This could be attributed to the fact that this group especially favours-, and has paved yards. The Autonomous group strongly believes outside spaces contribute (78,8\%). The other $25 \%$ are equally divided between not agreeing and not knowing. The Hierarchist group has the highest percentage of respondents indicating not to know $(18,1 \%)$. The other perspective groups are closer to each other in their views on this issue. However, generally the results reflect my expectations for the separate perspective groups.

An even larger majority of $73 \%$ of the expert respondents thinks contribution of domestic outside spaces to local nature is indeed the case. Only $11 \%$ doesn't think so, and $16 \%$ doesn't know. Significant claims based on the Dominant perspectives cannot be made.

Question 5.3 Perceived contribution of outside spaces to global biodiversity The same question was asked again, but then for worldwide biodiversity (see Figure 12.17). 
Figure 12.17. Perceived contribution of outside spaces to global biodiversity in Dominant perspectives (Dutch)

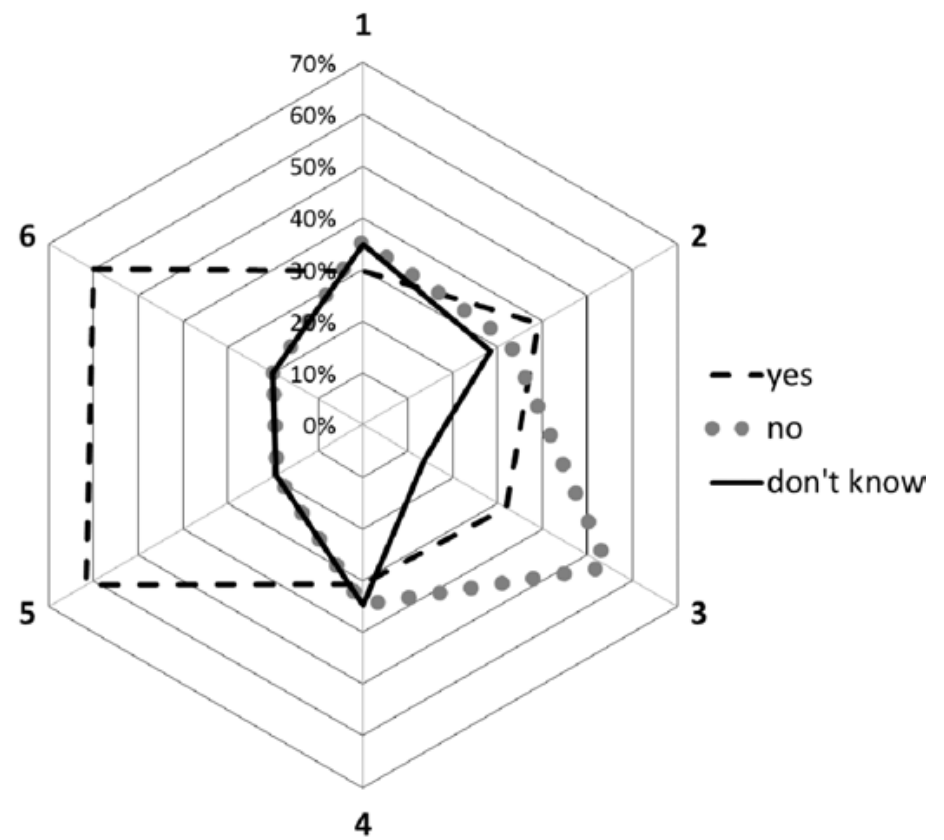

1=Hierarchist;2=Egalitarian;3=Individualist;4=Fatalist; $5=$ Autonomous; $6=$ Dynamic

Significantly less people believe that residential outside spaces contribute to global biodiversity: only 39\% believe their yards do; 33\% doesn't believe so and 28\% doesn't know. The Autonomous and the Dynamic groups show an overlap in their believes that their outside spaces contribute to global biodiversity (respectively $61,5 \%$ and $60 \%$ are positive. The Individualist group for this item is rather negative. A majority of 54,5\% doesn't think residential yards can contribute to global biodiversity. However, just like in the Hierarchist and Fatalist groups, a still considerable amount is more positive about this (31,8\% of the Individualists). Overall the belief that residential outside spaces can contribute to global biodiversity is surprisingly high (see figure 12.18). 
Figure 12.18. Perceived contribution of outside spaces to global biodiversity in Dominant perspectives (experts)

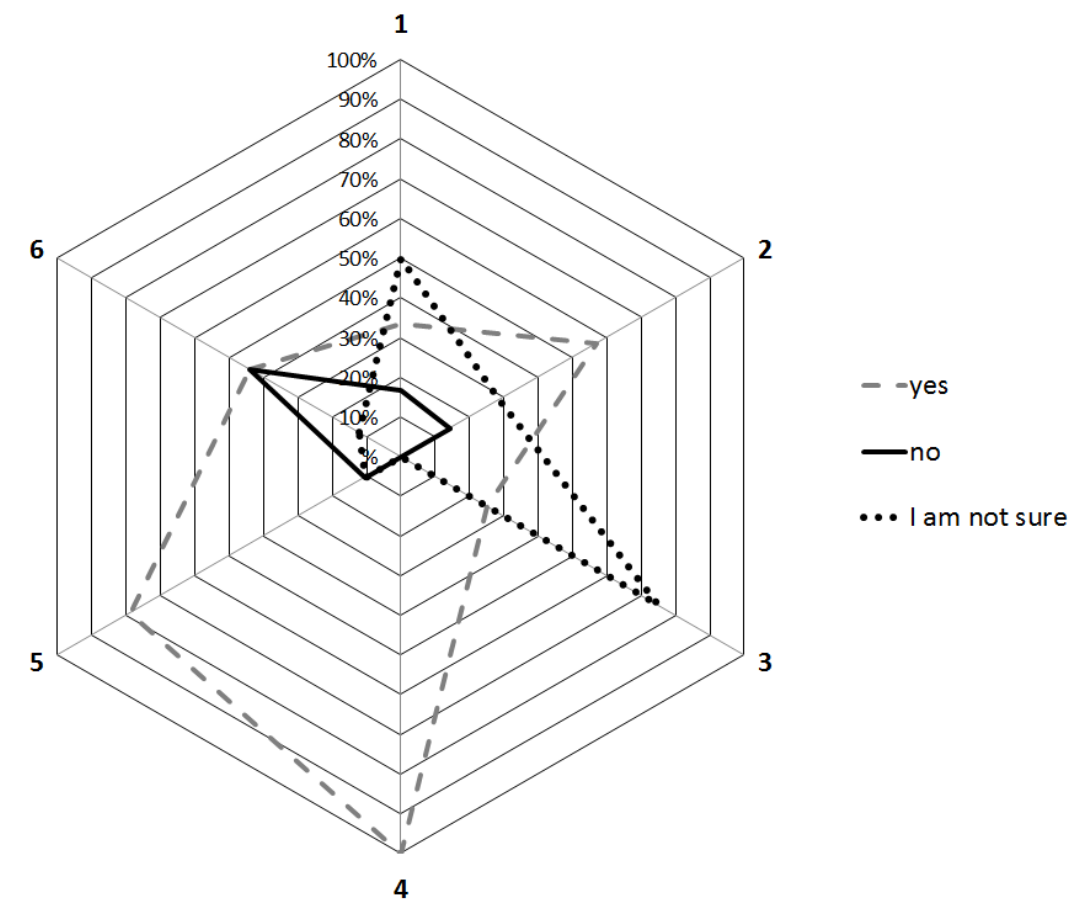

1=Hierarchist $; 2=$ Egalitarian;3=Individualist;4=Fatalist; $5=$ =Autonomous;6=Dynamic

In the expert sample, 55\% believe their yards contribute to global biodiversity; $24 \%$ don't believe and $21 \%$ do not know. A cross-tabulation shows differences between the perspective groups other than for the Dutch panel. The Egalitarians and Autonomous groups (and the single Fatalist) are most confident about the global contribution, whereas the Dynamic group doesn't really believe this and the Individualists and Hierarchists don't know.

Question 5.4 Perceived contribution of urban greening to local biodiversity I asked whether the greening of cities is seen as something that contributes to local biodiversity. A high percentage of $71 \%$ considers the greening of cities as something that can contribute to the protection of biodiversity in the local area. Only $7 \%$ are negative about it and 22\% don't know. A chi-square test for this item with the dominant perspectives isn't statistically valid, so I chose the simple cross-tabulation, because I still estimated to get some interesting insights. The patterns are rather similar and close to each other for most of the perspective groups. Only in the Individualist group more people are negative about this issue (20,5\%). Also the Fatalists scores comparably high in the negative order (14,3\%). The Dynamic perspective is most positive about the potential of 
urban greening: $85 \%$ believes this contributes to the protection of local biodiversity. None of them believes it doesn't contribute anything.

The experts are extremely positive about the contribution of urban greening to local biodiversity: $97 \%$ believe it does. Only $2 \%$ don't believe urban greening contributes to local biodiversity and 2\% don't know. Nothing of interest can be said about the Dominant perspective groups.

Question 5.5 Perceived contribution of urban greening to global biodiversity I asked the same for the scale of global biodiversity. Still a majority of $62 \%$ believes that urban greening contributes to global biodiversity. Only $12 \%$ don't think it does and $27 \%$ are not sure about it.

Again the Dynamic perspective is most confident in thinking that urban greening contributes to the protection of global biodiversity (70\%). The Individualist group, although also believing in this, clearly deviates most from the other perspectives in thinking it is not the case $(29,5 \%)$. Together with the Dynamic and the Egalitarian (64,9\%) groups the Autonomous perspective represents a high amount of respondents (a clear majority) who are positive about this contribution (61,5\%). The Fatalists and the Hierarchists score highest in the "don't know" section (respectively 32,7\% and 30,4\%) (see figure 12.19).

In the expert group (see figure 12.20) an overwhelming majority (87\%) -- consider the greening of cities as something that can contribute to the protection of global biodiversity. Only $11 \%$ think urban greening doesn't contribute and $2 \%$ indicate they don't know. 
Figure 12.19. Perceived contribution of urban greening to global biodiversity in Dominant perspectives (Dutch)

1

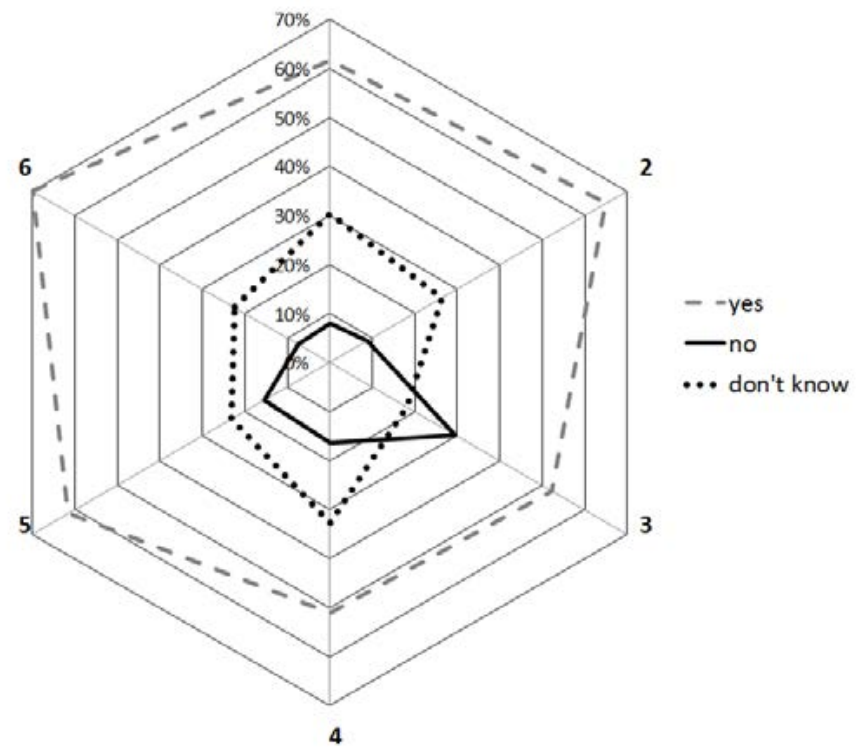

1= Hierarchist $; 2=$ Egalitarian;3=Individualist; $4=$ Fatalist; $5=$ =Autonomous $; 6=$ Dynamic

Figure 12.20. Perceived contribution of urban greening to global biodiversity in Dominant perspectives (experts)

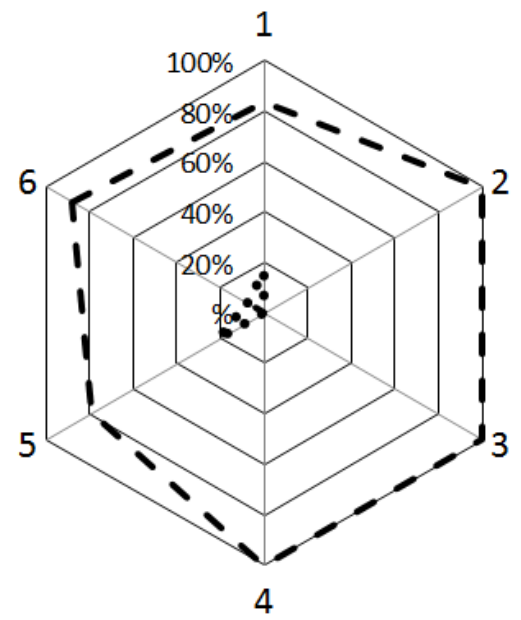

- -yes

$\bullet \cdot$ no

- I don't know

1= Hierarchist $; 2=$ Egalitarian;3=Individualist; $4=$ Fatalist; $5=$ Autonomous $; 6=$ Dynamic 


\section{Discussion CQ5}

Generally, people seem to be highly positive about the potential to contribute to local and global biodiversity through domestic gardening and urban greening activities. The experts are even more optimistic than the Dutch citizen panel. Unfortunately, I did not ask which specific greening activities people wold consider most beneficial on the local and the global scale. However, when looking at what people do for native biodiversity in their yards, the experts contribute most through planting nectar sources, whereas the Dutch panel favours feeding the animals in other ways. Feeding may be an ecologically controversial activity; however, it gives people a chance to experience the wildlife in their yards and to become connected to their proximate and distal natural environments.

There is space for improvement in both groups, especially when it comes to supporting insects: through installing insect hotels for example or through attracting beneficial insects that help keep pests and diseases away. Almost a quarter of both groups have their cats and dogs playing in their yards. Once aware of the damage that especially cats can cause, it remains a question what we'd give priority: our family pets or our wild native neighbours.

CQ 6. Are their significant links between respondents' perspectives and practices to where they live?

\section{Table 12.10. Analysis approach CQ6}

\begin{tabular}{|c|c|c|c|c|c|c|c|}
\hline Question & Survey Question* & $\mathrm{N}=$ & Minimum Expected Count* & * Cells \%** & Significance $^{* *}$ & Significant** & Methods \\
\hline 6.1 & $2 a$ & 507 & N.A. & N.A. & N.A. & N.A. & Crosstabulation \\
\hline 6.2 & Provincie & 517 & N.A. & N.A. & N.A. & N.A. & Crosstabulation \\
\hline
\end{tabular}

\section{Question 6.1 Landscape types}

Finally, the respondents were asked for their living and housing situations. Most of the respondents in the highly urbanised Dutch landscape indeed live in an area characterised by urban sprawl (47\%) or in a compact urban area (29\%). Intensive and extensive agricultural areas are accounted for by $5 \%$ each. The other $13 \%$ of the respondents is living in mixed, natural or semi-natural landscapes.25 The results were compared to the dominant perspectives. First, I recoded the nine answer-categories into six categories. However, a chi-square test for these results proves invalid due to not meeting the basic assumption. Cross tabulation doesn't reflect any significant differences. Most of the

25 (based on Dominant landscape types of Europe based on Corine land cover, 2000) http://www.eea.europa.eu/data-and-maps/figures/dominant-landscape-types-of-europe-based-on-corineland-cover-2000-1). 
respondents of any perspective live in an urban area. Of the experts, $50 \%$ lives in dense urban neighbourhoods and $40 \%$ in dispersed urban neighbourhoods. Only $8 \%$ lives in a rural pastoral landscape and $2 \%$ says to live in a composite landscape.

\section{Question 6.2 Perspectives in the Provinces}

When looking for perspective distributions across the twelve Dutch Provinces interesting differences can be found (table 12.10). Groningen and Zeeland for example, have relatively many Autonomous respondents compared to the other perspectives in the Province. And there seem to be no Dynamic respondents. Flevoland had relatively many Fatalists. The Individualist is prominently present in Utrecht, Overijssel, Drenthe and Gelderland, but less in the other Provinces. Zeeland has no Individualist respondents. The Province with the highest population density (Zuid-Holland) has relatively fewer respondents with an Egalitarian perspective. Drenthe seems to have no Fatalist respondents.

The differences across the Provinces may lead to interesting assumptions about the support for urban greening and biodiversity in the specific areas. Also, the nature of potential conflicts in the areas of urban development and conservation may be illuminated better by results like this (see table 12.10).

\section{Table 12.10. Dominant perspectives in the Dutch Provinces}

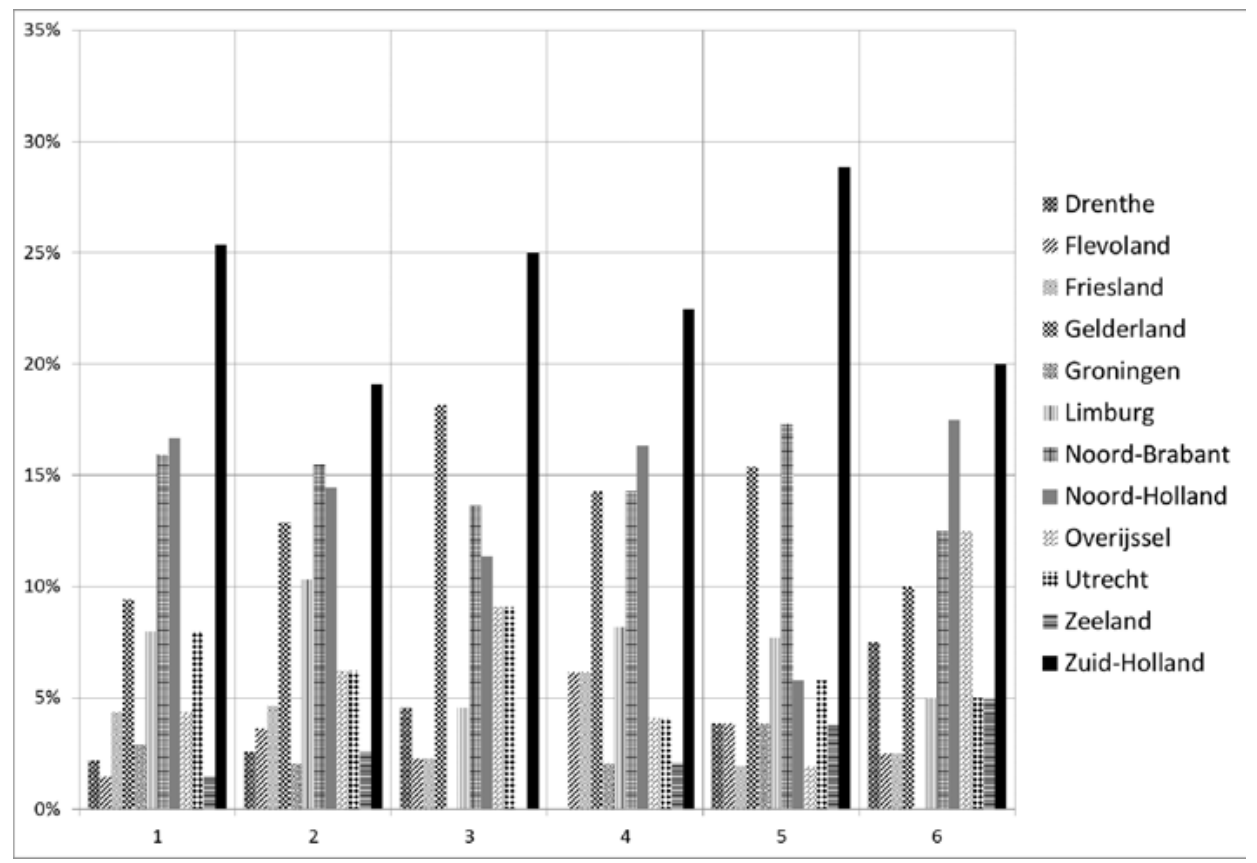

1= Hierarchist $; 2=$ Egalitarian;3=Individualist $; 4=$ Fatalist $; 5=$ Autonomous; $6=$ Dynamic 
In Groningen, the relatively large independent, freethinking Autonomous group may experience tensions with the more traditional Hierarchist and Egalitarian perspective groups. However, many perspective links exist between the Egalitarians and the Autonomous perspectives. Tensions may also exist between Hierarchically oriented people and the more activist oriented Egalitarians and Autonomous.

In the densely populated Zuid-Holland similar tensions may exist whereas Flevoland may have tensions of a different nature; between the passive Fatalists and the action oriented Egalitarians.

\section{Sub-conclusion CQ6}

In a densely populated country like the Netherlands, the majority of respondents live in urbanised areas. There are some differences between the perspectives indicating that some perspective groups live in other types of landscape areas than other perspective groups. However, these results are not statistically significant. Striking is the observation that Egalitarians say to live in forested areas more than in the other area-types. Also between the Provinces there are differences in perspective group distribution. This may indicate that different areas in the Netherlands may prefer different practices, priorities and concepts in the field of urban greening and conservation. This would be an interesting question for further research.

\section{Conclusion}

In this CHAPTER questionnaires on gardening and urban greening preferences and habits were analysed and the answers were compared to the Dominant CT perspectives. With this analysis there were three aims: 1 . seeing to what extent people are aware and engaged in conservation efforts through gardening and urban greening practices; 2 . seeing whether academic and professional expertise matters in relation to gardening and urban greening habits and ideas that are contributive to biodiversity on the local and the global scale; and 3. identifying the way the different cultural perspectives can be linked to gardening and urban greening practices, ideas and ideals.

1. The results show that both respondent groups express high confidentiality in the idea that domestic yards and urban greening practices can contribute to local and global biodiversity. Where the experts show high levels of concern for global sustainability and biodiversity issues, this is lower in the Dutch survey sample. The experts are also more active in charity, voluntary work, sustainable lifestyle habits and urban greening practices. However, being engaged in the latter activities may be the reason that they are considered an expert. The experts believe to a higher extent than the Dutch sample respondents that their choices and lifestyles have an impact on the future of the planet. 
When thinking about sustainability issues, climate change is on more peoples' minds than biodiversity is.

For both groups gardening isn't the main motivation to go outside in their yards. The yards are more visited for relaxation purposes and for simply being outside. The experts however, are more motivated by gardening reasons and more frequently growing food than the Dutch citizen panel. However, these results can also be attributed to the fact that some of the expert respondents are professionally active in (organic) food production.

When it comes to garden style preferences, visual preferences differ from conceptual preferences and actual looks of the domestic outside spaces. This is especially the case in the Dutch sample. Generally, visually green lush gardens and especially the English cottage style gardens are preferred. However, both groups favour low maintenance gardens highly as well. Especially the Dutch sample says to have low maintenance paved yards that look like terraces. Experts have these yards too to a high extent, but more of them say their yards look like parks. However, conceptually the edible garden is most popular with the experts. When the experts have to choose between practical functionality, aesthetics and ecological functionality, the latter gets most votes. The experts also do slightly more for native local animals than the Dutch citizens.

The expert panel is pretty familiar with all the urban greening trends presented to them. The Dutch sample is most familiar with the allotment garden concept. The Dutch citizens are motivated to become engaged in urban greening practices in order to be outside and getting a feeling of connectedness with their environment. Most of the experts see it as their duty to do something for their direct living environment. Not participating has also different reasons among the samples: Dutch citizens see it as a governmental responsibility to take care of the green in the urban environment whereas the experts say they themselves experience a lack of time to do it, although they feel responsible themselves. This is also reflected in the preferences for specific urban greening practices of both groups: the Dutch citizens see green roofs and green infrastructure (in the Netherlands basically subsidised or implemented by governments and construction projects) as their favourites whereas the experts have a preference for urban farming, which a lot of the expert respondents are engaged in themselves.

2. The discussion and evaluation of the results indicate that sustainability or ecological education matters indeed for increasing sustainable lifestyles and engagement in conservation through urban greening and gardening. The experts usually show higher scores on environmentally friendly values, practices and preferences compared to the Dutch panel. This can also be linked to the observation that the experts are best represented by the Autonomous and Dynamic perspective groups. Below this conclusion will be illuminated a bit closer. 
3. In the Dutch survey sample many answers can be significantly linked to the Cultural Theory perspectives. For the expert panel this is a bit less the case. This could be attributed to the fact that the expert panel was on the small side compared to the Dutch panel. Also it could suggest that a (higher) education softens the perspective differences. However, I think this is not the case because generally the expert results show some remarkable features.

Interestingly, in both panels the Individualist perspective group scores much lower than expected. The Autonomous and Dynamic perspective groups are best represented in the expert panel. This confirms the figures for high representation of the Autonomous and Dynamic perspectives in the higher educated group in the Dutch sample. However, although most of theinternational experts are highly educated, the Individualist group within the experts sample is only very small. Obviously, this suggests that the Individualists have had other education than environmental, ecological or sustainability education. This is also reflected in the further results that show the Individualist perspective group (both in the expert and in the Dutch citizen panel) as having least affinity and engagement with environmental issues, gardening and urban greening. In the Dutch citizen sample the Autonomous and the Dynamic perspective show most concern with environmental issues, gardening and urban greening. Hierarchists and especially Egalitarians are also engaged, but on a more average and conventional basis than the Autonomous and Dynamics who dare take more pronounced measures and routes to sustainability. In the spectrum from weaker to stronger sustainability, it seems we can characterise the Individualist on the weaker side (if they can be called engaged at all), the Dynamic and especially the Autonomous on the strong side, and the Hierarchists and Egalitarians in the middle. The Fatalist can be found anywhere in the spectrum. This group doesn't seem to have stable answers.

We can take these results a step further in the broader scope of this dissertation. In previous chapters we analysed the perspectives represented in the global scenario studies and by the global conservation organisation IUCN. The analysed documents suggested that a relatively important portion of the world population has an Individualist perspective and that it is important to find strategies to engage this group in conservation efforts. The results suggest that - in any case in the Netherlands - although this group may be powerful (represented by large corporations and higher educated people), it is relatively small from a democratic viewpoint. Putting so much emphasis on engaging the Individualist perspective may be a logical strategy when addressing large resource extracting and processing corporations but it neglects chances to engage greater majorities of the population onto conservation practices through lifestyles. It can also be doubted whether addressing the Individualist perspective groups in society is effective at all, because theresults show this group isn't really concerned with environmental issues at all. 
PART IV

Harvesting the Fruits 



\section{CHAPTER 13}

Synthesis

Six BiodiverCities 
"Imagination is more important than knowledge."

Albert Einstein

"After nourishment, shelter and companionship, stories are the thing we need most in the world."

Philip Pullman 


\section{Introduction}

Visions play an important role in policy and shaping (future) societies. In spring 2014, just after finishing the last revisions of my dissertation CHAPTERs, Staatsecretaris (Minister of State) Sharon Dijkma for Economic Affairs presented the new vision for nature Natuurvisie 2014 -- of the Netherlands (Dijksma, 2014). In this vision she promotes a better integration of nature in Dutch society. According to Dijksma, because of a strong protective paradigm of the last decennia, nature has become a "showcase" rather than something that is closely connected to human experience and life. In line of the new 'participation-society26' Dijksma promotes a shift in nature-policy towards less governmental 'bemoeienis' (involvement) and increased civil responsibility for nature. This includes promoting collaborations of Staatsbosbeheer (National Forestry) with the private sector to "strengthen its societal position (p.7)." The Minister of State emphasizes the idea that nature should be seen as a source for societal and economic development, and not as a hindrance of it. Furthermore, conservation effort should not concentrate on "saving the last bat, but on investing in a healthy nature for people, plants and animals (p.7)." Nature has to get a place in "the centre of society" and as such become a "nature that doesn't need protection from this society". Green entrepreneurship has to become the new device. Therefore, nature has to become "combined with agriculture, recreation, water works, cities and business sites (p.8)."

Dijksma's Rijksnatuurvisie 2014 seems to be exemplary for a shift in the Global conservation regime. In the CHAPTERs about the IUCN and the Global Scenario studies it became visible that an Individualist perspective on nature and conservation seems to become increasingly dominant. But is this embracing of the economic growth paradigm really the way forward for conservation? What other conservation futures could be optional? Throughout this dissertation Cultural Theory has been used as a heuristic tool to analyse and interpret the basic assumptions and worldviews constituting the current conservation paradigm. Once again these perspectives will be employed. This time to help structure possible urban based conservation futures: each perspective has been used to construct a desirable future vision - or storyline -- for biodiversity. The visions integrate the notion of an urbanising world. The conservation storylines are embedded in stereotypical worlds based on one of the six cultural perspectives. Six different BiodiverCities are the result.

26 A recent buzzword in Dutch media, based on the King's speech in 2013 who envisioned the Dutch state in transition from a 'welfare state' to a 'participation society'. The word has become the Dutch national word of the year 2013. 


\section{Scenarios and Future Visions of BiodiverCities}

Arnim Wiek and David Iwaniec distinguish scenarios, predictions, visions and pathways (Wiek \& Iwaniec, 2013). Visions refer to desirable states in the future; they form a subcategory of scenarios. Scenarios are defined as "possible future states" (Wiek \& Iwaniec, 2013, p.1). These should not be confused with "likely future states" (predictions). Pathways are linked to a form of backcasting, representing the steps taken to get to a desirable future state (Wiek \& Iwaniec, 2013). Scenario development and future visioning have built a strong legacy in (integrated) sustainability assessment (Gallopin, et al., 1997; Rotmans \& De Vries, 1997; Hammond, 1998; WBCSD, 1998; Swart, 2004; Notten, 2005; Van Asselt, et al., 2005; Brewer, 2007; Huynen, 2008; Wiek \& Iwaniec, 2013).

In this CHAPTER scenario construction and visioning are combined. The 'likeliness' part of scenario development is based on the aggregated research result of this dissertation: based on the outcomes of the perspective analyses in the various CHAPTERs and the results of the fieldwork and literature studies. Six perspective related narratives are put together through an accompanying process of visioning, emphasising the 'desirability' part of visioning. The visioning process has been desktop work by a single researcher (me). It may be interesting to set up a participatory visioning session in future studies to gather less person-biased visioning results.

\section{What is the Use of Future Narratives?}

If scenarios and future vision narratives are to function as a tool for policymakers and conservationists to help develop sustainable future conservation pathways, discussion could be stimulated on the question: what makes a scenario storyline useful for decision makers? What is the right balance between static simplicity and dynamic complexity of the storyline (see CHAPTER 6)? To what level can uncertainties and unforeseen events be pronounced without making the storylines unlikely? What is the right balance of explicitly presenting various basic assumptions, worldviews and ethical perspectives directing the course of events without assuming a completely "makeable" world? In other words: how can future narratives be best designed in order to be effective tools for fruitful discussion in the context of conservation policy and planning? These questions become especially relevant in the process of designing specific global biodiversity scenarios or visions. Perceptions, images of the future and cultural repertoires are no molecules in the void. While taking social, ecological and time uncertainties into account, we need to be very clear on what we want and why we want it. If we aim to envision a sustainable future, we may have to become aware of the various basic assumptions and values that underlie such visions. The Global Scenario studies evaluated in CHAPTER 6, did not explicitly show such a (self-) consciousness in the existent scenario 
studies. This may complicate the challenge to apply scenarios as a fruitful discussion-tool for concrete robust policy and conservation practice. In this CHAPTER I aim to fill this gap by providing some visions based on the cultural perspective assessments conducted throughout the dissertation study.

\section{Results 1: Perspective based conservationists}

In this paragraph a schematic overview is provided based on the categorisation of the results from the various dissertation chapters according to the six perspective groups. Six types of conservationists emerge from this exercise. These results of this paragraph fed into the visioning of six narratives of BiodiverCities.

\section{The Hierarchist}

The Hierarchist conservationist is represented by the following characteristics:

\section{Conservation approaches}

Zoos, hunting, partnerships, policy, protected areas, reintroduction, relocation

\section{Scenarios}

IPCC A2 scenario \& MA Global Orchestration

\section{Sustainability}

Medium sustainability \& climate change concern; low-medium level of local-organic consumption; medium belief in lifestyle impact on planet; low outdoor life;

\section{Gardening}

Low desire for yard maintenance; favours practical functionality\& aesthetics over ecological functionality; plantations with immediate results; moderate plant shopper; moderate native plant species; uses any available measure to deal with pests or weeds; Moderate action for biodiversity: feeding

\section{Garden style}

Having: courtyard; low maintenance; extended living room

Desiring: wild garden \& cottage garden

\section{Urban greening}

Motivation: Co-creation of living environment

Attracted to: Green roofs

Low knowledge on whether outside space contributes to local and global environment Low knowledge on role of urban greening for local and global biodiversity

\section{Represented by}

Experts: 9,7\%

Dutch population: $26,7 \%$ 


\section{The Egalitarian}

The Egalitarian conservationist is represented by the following characteristics:

\section{Conservation approaches}

NGOs, ecotourism, restoration, conservation education, reconciliation, religions, community based conservation, relocation

\section{Scenarios}

IPCC B2 \& MA Adapting Mosaic

\section{Sustainability}

Medium sustainability \& climate change concern; medium concern for local-organic consumption; high belief life-style impact; high outdoor life

\section{Gardening}

Prefering low maintenance or green intensive garden; Preferring practical functionality and aesthetics over ecological functionality; Plantations with immediate results; Very active plant shoppers; Preferring to buy native plants; Uses eco-certified and natural pest and weed remedies; Active gardeners; Moderatehigh action for biodiversity: feeding; shelter; Highest level of cats and dogs in the garden

\section{Garden style}

Having: courtyard; playground; living garden; low maintenance

Desiring: wild garden; cottage garden

\section{Urban greening}

Motivation: meeting new people

Attracted to: Green infrastructure; green roofs

Beliefs that outside space and urban greening contribute to local and global environment

\section{Represented by}

Experts: $11,5 \%$

Dutch population: $37,5 \%$

\section{The Individualist}

The Individualist conservationist is represented by the following characteristics:

\section{Conservation approaches}

Ecosystem services; ecotourism; hunting; policy (economic incentives); philanthropy; partnerships

\section{Scenarios}

IPCC A1 scenario; B1 and B2 less prominent

MA Techno Garden; Global Orchestration

\section{Sustainability}

Low sustainability and climate change concern; Low concern about local-organic consumption; Medium- 
high belief in impact of lifestyle on planet; Medium level of outdoor life; Representing higher educated but other than environmentally oriented education

\section{Gardening}

Preferring low maintenance yard; Preferring practical functionality; No ecological functionality considered; No frequent shopper for plants; no high knowledge of plan species origin; Not many native plants; Prefers strong and effective chemicals to deal with pests and weeds; No active gardeners; Hardly any action for biodiversity

\section{Garden style}

Having: courtyard; magazine picture; low maintenance; lounge

Desiring: modern yard

\section{Urban greening}

Motivation: co-creation of living environment

Attracted to: green infrastructure; vertical gardens

Low belief on whether outside space contributes to local and global environment

Low belief on role of urban greening for local and global biodiversity

\section{Represented by}

Experts: 6,5\%

Dutch population: $8,5 \%$

\section{The Fatalist}

The Fatalist conservationist is represented by the following characteristics:

\section{Conservation approaches}

None particular

\section{Scenarios}

IPCC A2 scenario

MA Order From Strength

\section{Sustainability}

Low sustainability and climate change concern; Low concern about local-organic consumption; Low belief in impact of lifestyle on planet; Low level of outdoor life

\section{Gardening}

Highest percentage of people without a garden; Preferring low maintenance garden; Preferring practical functionality and aesthetics over ecological functionality; If: any style of plant shopping; Moderate amount of native plant species; Preferring eco-certified products for dealing with pests and weeds; No active gardeners; Moderate-low action for biodiversity: feeding; hedges

\section{Garden style}

Having: courtyard; wilderness 
Desiring: modern garden; wild garden; adventurous garden

\section{Urban greening}

Motivation: meeting new people

Attracted to: green infrastructure; green roofs; community gardens

Beliefs outside space contributes to local and global biodiversity

Don't know about the role of urban greening for local and global biodiversity

\section{Represented by}

Experts: $1,6 \%$

Dutch population: $9,5 \%$

\section{The Autonomous}

The Autonomous conservationist is represented by the following characteristics:

\section{Conservation approaches}

Conservation education, reconciliation, religions, arts

\section{Scenarios}

No prominent representation in IPCC scenarios

No prominent representation in MA scenarios

\section{Sustainability}

High sustainability and climate change concern; High concern local-organic consumption; High belief lifestyle impact; High outdoor life; Higher educated Autonomous (limited group): concern biodiversity loss; High concern social equity

\section{Gardening}

Preferring: lush wild garden with wild flowers; neat garden; Preferring practical functionality, ecological functionality and aesthetics; Planting seedlings and seeds; Exchanging and gathering instead of buying; High amount of native plantation; Strong belief outside space contributes to local and global biodiversity; Natural from shop \& eco-certified treatments of pests and weeds Active gardeners; Much action for biodiversity: feeding, nectar, pollen, nesting, berries, organic matter

\section{Garden style}

Having: refuge; courtyard; ecosystem; paradise

Desiring: wild garden; edible garden

\section{Urban greening}

Motivation: peace and connectedness to planet

Attracted to: urban farming; guerrilla gardening; permaculture

\section{Represented by}

Experts: $30,6 \%$

Dutch population: $10,1 \%$ 


\section{The Dynamic Integrator}

The dynamic conservationist is represented by the following characteristics:

\section{Conservation approaches}

Genebanking, reintroduction, reconciliation

\section{Scenarios}

No prominent representation in IPCC scenarios

No prominent representation in MA scenarios

\section{Sustainability}

High sustainability and climate change concern; Medium concern about local-organic consumption; High belief in impact of lifestyle on planet; High level of outdoor life in experts group; Higher educated: high concern biodiversity loss; Education: high but limited group

\section{Gardening}

Preferring low maintenance yard; lush and wild; Preferring practical functionality, ecological functionality and aesthetics. Higher educated choose ecological functionality first; Buying \& exchanging/gathering seedlings, seeds and fully grown plantation; Many native plants; Prefers natural and home-made treatments for pests and weeds; No active gardeners; High action for biodiversity: feeding, nesting, attracting beneficial insects; High belief outside space contributes to local and global biodiversity

\section{Garden style}

Having: refuge; courtyard; living room; living garden; low maintenance

Desiring: wild garden; cottage garden

\section{Urban greening}

Motivation: duty to do something for the environment

Attracted to: green infrastructure; green roofs

High belief urban greening contributes to local and global biodiversity

Represented by

Experts: $40,3 \%$

Dutch population: $7,7 \%$

\section{Results 2: Six BiodiverCities}

\section{The Tower of Power: a Hierarchist's world}

In the Tower of Power the conservation of the human species is the prime priority. Because of the enormous population growth the pressure on resources will be considerable, even though economic growth will be only moderate because of strong protectionist trade blocks. The quantity and quality of biodiversity and ecosystems will be substantially reduced. When trade-offs have to be made, people's needs are more important 
than the ones of non-human species. Human species will live concentrated in wellorganised mega-cities. Institutions, social-, economic-, and environmental developments will largely be controlled by strong regional authorities. Although different cultures and ways of life are respected, protectionism and strong top-down governance are exercised to reduce (global) threats. The Tower of Power represents a world where people are concerned for each other, being able to live safe and cosy lives in well-protected and well-monitored urban environments.

The conservation of biodiversity is basically organised outside cities (where the wild things are) via protected areas, zoos, hunting permits, public-private partnerships, and through reintroduction and relocation measures. Citizens around the world show a medium concern for environmental sustainability. Climate change is of concern but does not really occupy the daily minds of citizens. Policy and planning are in place to deal with the impacts of climate change. People do not really belief in the impact of their own lifestyles on the planet. Consumption habits are not strongly directed towards local and organic consumption. Time and money concerns guide consumption and spending behaviour the most. Strong governance and regulation of harmful products and processes should do the trick to help people from New Jerusalem become more sustainable consumers.

Because society needs to function well, citizens are largely occupied by institutional tasks. Also the economic motor of society needs to be kept running. Therefore, people don't have much time left to spend outside. A low maintenance garden - courtyard or extended living room -- therefore is the concept most frequently applied in garden design. People like to combine practical functionality with aesthetics. Plants that give immediate aesthetic results are popular. It doesn't really matter whether they are native or not. It takes too much time to nurse seedlings at home. It is also a bit messy to grow plants from scratch. To keep the garden tidy and free from pests, any kind of treatment can be used, from organic homemade solutions to strong exterminators marketed by companies. It depends on what works best. Gardening as an activity is mainly an effort of keeping the garden neat and tidy. When people from the Tower of Power would have more time for gardening, they would prefer to have a garden with wild flowers or an English cottage garden. However, it would take a lot of time to control and trim the weeds in such gardens. The falling leaves of the municipal trees and the bird-poo on the car are already enough nuisances to deal with. When the economy would be thriving, gardening could be ideally left to professionals.

When taking part in urban greening activities - which actually should be organised by local governments - people do this in order to help co-create their direct living environment. It gives a feeling of being in control of the developments in the neighbourhood. It is also an opportunity to get to know the other neighbours. Whether urban greening or 
gardening activities contribute to the local or even global environment isn't strongly considered. The action the New Jerusalem inhabitants take for biodiversity is basically limited to feeding the birds, the hedgehogs and the squirrels. The local governments carry the main responsibility of keeping cities green and liveable. It is considered important that (urban) nature does not dominate human well-being and comfort. Nature in cities is nice when organised in a neat and tidy manner. However, nature should also best be clearly distinguished from cities. They are two different domains with a reason: nature involves risks that should be reduced for the sake of human-well-being.

\section{The Garden of Eden: an Egalitarian's world}

In the Garden of Eden social innovation and civil (inter)action has to maintain the fragile balance between people and the natural ecosystem. High value is placed on equality (social and inter-species) and globalisation processes have largely proven to hamper this. It is a world where most things are organised on a local scale level where people can know and trust each other. Education and emancipation of the masses and the marginalised is what helps the world maintain its balance. As knowledge levels in the communities are high, energy- and material efficient technology, combined with social innovative projects help reduce pressure on the ecosystems. Such projects may be organised across national boundaries. However, although people do care about global environmental problems, local and regional differences in tackling them can be large. Global biodiversity trends are therefore difficult to estimate and global environmental problems like climate change keep taking their toll. Nevertheless, citizens know how to stick together to mitigate the consequences.

In the Garden of Eden non-human species are regarded as an equal that should not be marginalised. Harmony between people and their environment is the basis for a happy and healthy community life. Taxes are paid in order to take care of common goods like nature and human health. Conservation is usually community based, taking care of both people and biodiversity at the same time. Also many people donate a portion of their income to environmental NGOs. Local scale ecotourism (wildlife friendly camping) also contributes to the respect and harmony between people and nature. Ideally, ecotourism is combined with conservation education. People love to spend their free time in the outdoors. Much empathy for nature can be fostered during outside activities of both adults and children. Religion also plays an important role for creating connections between people and their environments. Religious institutions are great awareness raisers and affect large groups of people. In urban environments reconciliation ecology is often applied as a strategy to create level playing fields. Cities should be seen as big gardens: there is a lot of potential for greening them in many ways. Especially green infrastructures, stepping stone roofs and parks have the ability to connect both people and ecosystems. Urban greening activities are a good way to connect to- and get to know your 
neighbours. Many innovative community initiatives contribute to lush green eco-cities that respect and cherish local traditions, monuments, architectural history, human wellbeing and life space for non-human urban inhabitants at the same time. Although the focus is locally oriented, positive spill-over effects emerging from urban greening practices and from knowledge sharing and raising awareness through the entire human life course contribute to a reduction in the loss of species globally.

Although there is a high belief in the impact of individual choices and lifestyles on the environment, local and organic consumption patterns are not exaggerated. When it comes to greening and gardening, practical functionality and aesthetics are considered most important. Much effort is placed in creating beautiful gardens that remind of pastoral times. Such gardens ideally combine social encounter and lush beauty. Garden centres provide a lot of inspiration and material to create beautiful little paradises. Courtyards, nicely decorated and embroidered with colourful native plant-species that do not need a lot of maintenance to keep them going are considered ideal. Space for playing children and pets should not be compromised though. Maintaining the state of Eden can best be helped with eco-certified or natural solutions for prevent or controlling pests. But taking the time to manually care for the garden is also a good and fun option.

The inhabitants of the Garden of Eden believe that the care they take for their outside spaces will reflect to local and regional biodiversity. Popular measures to help local species are the installation of feeders, nest-boxes and the construction of quiet spaces for sheltering against the disturbances of human and pet activities taking place.

\section{Biodome: an Individualist's world}

In Biodome, nature is seen as a utility treasure. Global problems can be resolved through increasing economic growth and through technological innovation. One of the greatest innovations has been the invisible nano-dome that can be programmed to create specific desired climates underneath. These domes cover the major cities and the last pieces of rainforests in the world to protect them from the effects of changed regional climates, destructive air-pollutants and nuclear radiation. The domes are also able to filter aquatic pollutants that entered the water cycle during the times the oceans turned into the plastic soup. Purified water trickles through the nano-structure of the dome after condensation at the outside in the morning, providing citizens fresh and clean rain and drinking water. Periods and strength of rain can be timed and regulated through first capturing the trickled down water in cloud-like bags. These bags can be released at beneficial moments and at desired forces. The domes are also able to capture, concentrate and/or distribute sunlight (as desired) through the nano-structure. Sunlight that would otherwise not be able to reach people anymore because of the smog filled outside atmosphere. New global environmental problems keep stalking the people of Biodome, 
but the lost ecosystem services are compensated with innovative technologies and measures. People are resilient through their creativity.

Rich philanthropists and company CEOs, in partnership with the knowledge base provided by conservation NGOs, were able to finance the development and installations of the domes. This has only been possible because of the revenues of ongoing global economic growth. Philanthropists were also able to buy the last 'unspoiled' bits of nature. Instead of letting destructive resource distracting companies in, they were now bring in revenues through ecotourism and regulated forms of trophy hunting.

The citizens of Biodome are not highly concerned about climate change or biodiversity loss. They believe their lifestyle has a relatively high impact on the environment though. However, this impact can also be seen from the side of creativity: a primary capacity of people is to actively shape and co-create their own environment. This has always been the case. The creation of technological innovation to deal with emerging problems is called progress. Educational levels therefore are high, but centred on topics as engineering, biotechnology, biomimicry and economy. Sociology, philosophy, psychology, and environmental literacy are all nice, but these soft-sciences don't really contribute to economic and technological progress.

When Biodomers go outside -- which they don't do a lot -- they do it mainly to do sports or other activities that bring either some excitement or some relaxation. Their gardens are preferably designed as luxurious lounge-spaces. The few plants in the yards are there to impress the neighbours. They are seen as objects of art or status symbols and they fit the image and lifestyle of the garden owners. The more exclusive and strange they are the better. The maintenance of green is limited to the installation of some sprinklers or automatic lawn mowers. Undesired weeds - often called native species by woolly hippies -- or pests are taken care of with strong and effective measures. The practical functionality of a garden is considered most important. There is no time to waste on soft things like gardening. However, green features in the Biodome are appreciated. They deliver cultural ecosystem services like higher estate values and the attraction of visitors and they contribute to the pleasure and leisure of people's free time. Green infrastructure and vertical gardens are especially appreciated for their contribution to these values. However, the contribution of such features to biodiversity on any scale level - if considered at all -- is considered to be limited. When attracting animal species in the garden, it is basically coincidence: they are attracted by the water-design features like ponds, pools or fountains. 


\section{Jumanji: a Fatalist's world}

Although in the world of Jumani everyone hopes for a strong authority to stand up and take control, nothing really happens. Well, nothing except for nature taking over the domains that were primarily intended for and occupied by people. Jumanji is a world that can be characterised by economic and political decentralisation and the rise of fundamental differences. It is a culturally differentiated world where people fight for their families' survival. Although economic growth is very limited due to all sorts of conflicts over trade and other social, cultural and political issues and misunderstandings, the pressure on the ecosystems will be considerable. Increasing population growth and lack of concerted conservation strategies and policies contribute to this pressure. Poaching in vulnerable areas and on lucrative species has grown beyond control and global biodiversity loss is increasing. However, on the local-scale levels greenery takes over cities and wild animals like foxes, raccoons, martens, dear, mountain lions, wild cats, birds of prey and bears are increasingly encountered in urban areas.

Due to a lack of innovative capacity, old disruptive technologies and measures in industry and daily lifestyle are still employed. Thinking about sustainability or biodiversity is considered a luxury. Survival comes first. And only the fittest will survive, regardless whether these are human or non-human species.

Gardening has lost the impact of commercial trends. They need to provide some food for the family or the community. However, inhabitants of Jumanji dream of the opportunity to have a garden for relaxing and lounging; or to go on an adventure in a wilder garden or green space. The citizens of Jumani moderately believe that their outside space potentially contributes to the wider local environment but are not sure about the role of urban greening for global biodiversity. Also their belief in the impact their lifestyle can have on the environment is low. The consumption of sustainable goods (labelled fair trade or organic) is considered a luxury. Shopping habits are opportunistic and largely depend on what is affordable.

Activities undertaken to improve the city environments are largely based on the idea to meet other people. Community gardens, where also food can be grown, are ideal for such occasions. Through a lack of municipal control, green infrastructure and green roofs are emerging in many niches and corners of the city. In some cases this occurs because of a lack of money and priority to keep it in check. In other cases people try to make their declining built environments look a bit friendlier by starting small greening projects, street art or guerrilla gardening. In most cases people start urban farming projects out of economic necessity. Permits are no longer needed. Hopes are on better times.

Although the emerging green may look a bit messy here and there, these features are appreciated for what they deliver. Citizens of Jumanji do enjoy the many birds and other 
small animals that use these emerging infrastructures. They especially make use of the many natural hedges that protectively surround the homes of the citizens of Jumanji. However, the larger animals invading the disorganised cities are evoking fear and are often considered a nuisance. Often animals are found dead, trapped, hunted or poisoned.

\section{The Shire, an Autonomous world}

In the Shire everybody grew up with Thoreau's classic book Walden; or life in the woods and with Rachel Carson's Silent Spring. Conservation-, and nature education is prominent in society. People are raised as biophilic citizens. Respect for all living entities is also strongly emphasises in the world religion and in the arts. Urban policy and planning is centred on the concept of reconciliation ecology: nature and wildlife are invited intoand protected in urban areas as they are seen as contributing to both human well-being and global biodiversity. Biodiversity is valued as the basis of life on earth. It should not be compromised and each person should have access to the high quality of life it provides.

In order to secure this access for everyone, people are taught to tread lightly and to consume within the carrying capacity of the planet. The sustainability of the planet is a high concern to be taken care of.

Individual lifestyles are considered to have a high impact on the planet. This fact is not only used to reduce consumption of natural resources, but also to improve the quality of the ecosystem. Green growth therefore equals the growth of the ecosystem; it has nothing to do with the growth of the financial system. The economy doesn't have any right of existence for its own sake. The term 'eco' - both the etymological root of economy and ecology -- comes from the Greek word Oikos, which means household. The household on all scale levels should be treated with care and love. Nature should be seen as something to be nurtured instead of used for self-interested benefit. When well nurtured and taken care of, it gives free gifts to all.

Citizens of The Shire spend half their working day on taking care of their environment: their family, friends and their gardens, green spaces, parks animals, and permaculture farms. All the basic needs and responsibilities can be taken care of during this time. The other half of the working day the inhabitants spend on working on their personal projects where they employ their individual talents for the benefit of others (like building Earthship or Cobwork homes, making clothes, doing research, teaching, nursing, settling disputes, writing poetry or making music) and to earn some extra local 'currency'. Currency is hardly ever expressed in traditional coins or virtual bits, the reminders of the disruptive capitalist economic system. It is usually based on time or on the exchange of services, skills and talents. Leisure time can be spent on individual hobbies that do not 
necessarily contribute to the well-being of all but also don't negatively affect others or other life forms or landscapes.

The Shire is a small city with a self-sufficient community. Everything is organised internally and locally, but with a global ethical outlook: natural resources such are not scare, but have to be shared equally. This can only be guaranteed when people live according to small ecological footprints. Roads can only be found surrounding the Shire. They are used to visit other cities by bike. Next to these bicycle lanes electric public transport is the way to get around. The surface of the infrastructure is permeable and the fringes are planted with wild flowers, herbs and fruit trees. The fruits can be picked for a picnic on the way. The Shire itself is small enough to go around by bicycle or by foot. No motorised traffic is allowed in.

People live in a variety of passive houses made of local and recycled materials, such as Earthships or Cobworks. The homes are small and cosy and all have individual designs but fit the landscape they are built in. Some are really merging with the scenery, by being built in hills, as ditches in the ground or within rocks or trees. The homes are not expensive to build because of the use of recycled materials and their construction is relatively easy.

Much of the design of the homes in the Shire is dedicated to local vegetation and wildlife. Homes for people are built also as shelters, nesting places and foraging places for animals. Birds live in niches in the walls and on the roofs, and wild bees, ladybugs and butterflies breed in little holes and cracks that are a part of the architectural design of the buildings. Climbing plants and rock-vegetation are similarly integrated in the design of the homes. The landscape is thriving with life because of the rich and varied planting that is carefully nurtured to be a food-forest for both people and wildlife. There is plenty of nectar, pollen, berries, fruits, organic matter and nesting and refuge opportunities for insects and wildlife. Streams and rivers are also meandering through the landscape, providing clean water, habitat and leisure space.

Although relatively many people live in The Shire, the place does not look like a city at all because of all the green vegetative design and the thriving wildlife. The only thing that reminds of urban life, are the small courtyards in the neighbourhoods intended for socializing, art exhibitions and music. Artworks can be found all over the Shire. Often they are integrated in architectural design, in natural shapes or in the way home gardens are designed. The inhabitants of the Shire enjoy being outside and nurturing the gardens. It gives them a sense of peace and connectedness to the planet. The people from The Shire like to combine practical functionality, ecological functionality and aesthetics of their gardens and wider landscape. People don't go shopping for plants in large gardening stores. Native seedlings and seeds are gathered from the wild and exchanged with 
others. All homes have small plant nurseries where the residents can watch the plants grow and enfold. Because so much space is given to non-human inhabitants of the Shire - both in physical space and in hearts and minds -- conflicts between wildlife and people rarely occur. When you ask the inhabitants of The Shire to describe their city they say it reminds them of paradise.

\section{New Atlantis, the world of the Dynamic Integrator}

New Atlantis exists of a combination of islands - left overs of terrestrial space after The Great Sea Level Rise (TGSLR). The islands are extended with agglomerations of floating neighbourhoods and sub-communities. Despite all the concern and all the knowledge about climate change, the human factors contributing to it, and the knowledge about more sustainable technologies and ways of living, it has been difficult to engage all the people with different and often competing perspectives into action that could have prevented the climatological changes of planet Earth. There was too much talking and publishing and too little real action on the ground. Politicians were hypnotised by the large industrial lobbies with stakes in fossil fuels, intensive agriculture and bio-industry.

Suddenly TGSLR happened. And it happened faster and more brutally than expected. People had to adapt to the environmental changes rapidly. In order to make psychological sense people massively started to consider the events as a part of the evolutionary processes the planet is going through since the beginnings of its existence: "We experienced a long time of global equilibrium, but finally it had to come to a stochastic shock that would change everything once again. Not a meteorite or a large volcanic eruption, but human activity has been the largest force of evolutionary change this time" is what people tell you when you ask why all this happened. The people that were best off had already moved away from coastal regions and rivers towards higher level landscapes. The ones who had acquired homes with floating capabilities or had traditionally lived in floating communities were also well off. However, much of the previous world - especially terrestrial ecosystems and species -- has been lost. And many millions of people were to be mourned. However, there was no time for pessimism. The question was how to adapt as soon and as well as possible to the marine environment, that since TGSLR has become the largest habitat for people and non-human species.

Fortunately, the anticipated changes have lead to the stocking and banking of genetic materials of all sorts of plant, crop and animal species. High efforts are now undertaken in New Atlantis to bring back to life the world and to (re)introduce all sorts of species into their (changed) habitats. Often habitats have to be artificially reconstructed on the most affected islands. Also floating devices called Ark-i-textures - which are basically artificial islands -- are used to create suitable living spaces for animal communities when their original habitats had been gone forever. Terrestrial space has become scarce. Resi- 
dential roofs have the potential to increase 'solid terrestrial' green space to the mainly floating empire of New Atlantis. Inhabitants of New Atlantis have a legal duty to convert their residential roofs into green spaces. Where possible, terrestrial green spaces are left alone in order to become as lush and as wild as possible. Where necessary, action is undertaken to restore ecosystems and to (re)introduce plant and/or animal species, populations and communities. Where there is space for some luxury, images of PreAtlantic cottage gardens are revived.

The inhabitants of New Atlantis want to avoid making the same mistakes once again. Sustainability concerns are high and nowadays projected on the newly emerged circumstances: education is environmentally centred and people apply biophilic principles on their living circumstances and lifestyles. People have a moral and legal duty to contribute something positive to their living environment. The jobs that are valued with New Atlantic currency are organic farming, teaching, nursing, caring, raising children, and any type of environmental restoration and (re)construction work. There is much work to be done for engineers and ecologists. Other jobs that were once highly valued in the old world (like bankers, speculators, lawyers, plastic surgeons and company CEOs) lost all the societal esteem they once enjoyed. Consumption levels are relatively low and mainly depending on what is locally available. However, nautical activity makes it rather easy to bring in goods from other regions of the world. Cross-Oceanic trade of goods and knowledge is also the way to keep in touch with other cultures that needed to adapt to the changed world. People from all regions highly value the need to learn from each other's experiences and different perspectives. The resilience of the human species can only be attributed to the openness to learn from other ways and habits. Many conferences workshops are set up to exchange knowledge or to co-produce new methods and technologies for living in this new world.

Sea Weed Farms are sprouting everywhere around the world, as this crop is multifunctional and can be used for human consumption, energy production (next to solar-, wind-, and tesla-power) and for the construction of all sorts of materials. Seaweed is also the main source of protein. There is no space for 'old world' animal farming. Apart from the lack of space for such practices, it is being considered as one of the biggest moral mistakes mankind has ever made. Fish and birds can't be eaten either. They are still contaminated with the effects of the plastic soup pollution and nuclear radiation leaks caused by the former 'civilization'. They are no safe source of food anymore, even though technologies have been developed to clean the oceans for a great deal. The positive side of this story is that maritime wildlife populations and communities are recovering and re-emerging with high speed. However, many mutants can be found as well. But this is also considered a part of evolution. 
Fresh water is a source of concern. All sorts of technologies are employed in order to transform the polluted salt water into clean drinking water and into clean water to farm the sea-weeds. Big storms also disrupt the newly found balance every now and then. For such occasions big floating balls have been constructed as shelters. They can be found in each community. They are tied to the ocean floor with Kevlar strings and provide a relatively stable environment when the sea becomes wild.

The qualities of the aquatic and marine environment as a human habitat are explored and combined with 'traditional knowledge' about terrestrial gardening and farming. Residents of New Atlantis have a high outdoor life as they want to learn everything possible from the newly emerging ecosystems and assemblages of plants and animals. Together, the aquatic, terrestrial and artificial island spaces create hybrid ecological infrastructures with novel dynamics and functional relations that have never been seen before. Above sea level green stepping stones are sometimes connected with floating bridges that combine wildlife corridors with recreation and human mobility. Below sea level the floating buildings are designed with structures to substitute lost coral reefs and to attract fish, sponges, sea stars and other species common to coral habitats. Through windows in the home-floors and walls the residents of New Atlantis can watch the coral sea-life increase and enfold. Slowly the corals themselves are also coming back.

"It is funny," people say, "we have always been searching for the ancient Atlantis Plato was talking about, but now it found us."

\section{Reflection}

Of course, any of these storylines on its own can be considered an unrealistic utopia. Reality is more complex and combinations and dynamic constellations of cultural perspectives will more likely colour our future world than one of the separate ones. However, unravelling and deconstructing the ongoing perspectives in society into their extremes may be considered an interesting exercise. It provides an insight in what possible extreme consequences certain modes of thought and worldviews can have. It also provides an insight into how marginalised perspectives (e.g. the Autonomous and the Dynamic Integrator at this point in time) may enrich or fundamentally transform current regimes when they would be able to gain momentum (Ray \& Anderson, 2000; Bottrell, 2009; Callo-Concha et al., 2014). At the same time they play a crucial role in societal resilience as they provide alternative ideas and solutions to the status quo (Gunderson \& Holling, 2002; Verweij, et al., 2006; Bottrell, 2009; Callo-Concha, et al., 2014).

When seeking possible pathways towards-, and narratives about sustainable futures, it makes sense to reserve a larger role for the Autonomous perspective and the perspec- 
tive of the Dynamic Integrator in the discussion. The study pointed out that they are the perspectives representing sustainability in a strong and engaged way. They are important forces in strengthening the more moderate but willing Egalitarian group in society. In the Netherlands, the Egalitarians represent a large portion of society, as the results of the questionnaires in CHAPTER 11 pointed out. The current trend of including the Individualist perspective more in the discussion - as can be seen in the partnership constructions between conservation organisations and large-environmental impact companies -- may be relevant, but could also turn out to be a futile effort when not capturing the hearts and minds of the people representing the Individualist perspective in a fundamental way (and perhaps changing their perspective). The analyses show that the Individualist perspective doesn't have a high concern for sustainability or conservation related issues. In the Netherlands, it also mainly represents a small (non-environmentally educated) section of society. Therefore, the focus for developing solutions and a future for conservation shouldn't be on this group for a too great extent.

More attention could be given by science, policy and journalism to the growing 'nongroup' of engaged Autonomous citizens that retreat in some or other way from capitalist consumption society. They are usually portrayed as a loose bunch of individuals. However, as Ray and Anderson (Ray \& Anderson, 2000) have demonstrated in their work on the Cultural Creatives, they may be representing a more homogenous group than they seem to be at a first glance. Reflecting from a complexity perspective (Chesters, 2004) and from network theory (Hassan \& Jones, 2003; Castells, 2010; Smith \& Doel, 2010), they may represent a stronger force of social innovation and global societal change than currently anticipated. However, conservative forces may experience them as a threat to the status quo and try to ridicule them or use divide and conquer strategies to weaken any possible movement-building. It takes societal courage to collectively embrace Autonomously operating 'looneys' as possible frontrunners and inspiratory forces for societal transformation towards a more sustainable humanity. 


\section{CHAPTER 14}

\section{Conclusions, Discussion and}

Future Research Questions 
"Our real discoveries come from chaos, from going to the place that looks wrong and stupid and foolish."

Chuck Palahniuk

"Chaos was the law of nature; Order was the dream of man."

Henry Adams

"True knowledge exists in knowing that you know nothing"

Socrates 


\section{Introduction}

The main question addressed in this dissertation has been whether urban greening and gardening can be a viable approach for addressing global biodiversity loss. In order to explore this complex question, a research approach has been taken where various studies and research methods complement each other. This approach resulted into enrichment of the ISA (Integrated Sustainability Assessment) toolbox with methods from the humanities and social sciences (discourse-, and content analysis and critical reflection). Given the characterisation of biodiversity conservation as a patchwork of tension ridden practices and discourses on different scale levels, and given the notion that the conservation field has to find an answer to biodiversity loss in a rapidly urbanising world, the choice has been made to divide this dissertation into two levels of assessment (global and local), four key parts and a number of sub-questions that lead to answering the central question.

In Part I key concepts and the methodological approaches are delineated.

In Part II the status of the current global conservation regime has been explored. Subquestions for this part have been:

a. What practices and discourses make up the current conservation regime (CHAPTER 4, 6 and 7)

b. What tensions and synergies can be identified in the current conservation regime (CHAPTER 5, 6 and 7)?

As an intermezzo, a critical philosophical reflection is given on the idea of the sustainable city (CHAPTER 8).

In Part III the potential role of local urban greening and gardening for biodiversity conservation is explored.

a. What urban greening and gardening practices and regimes can be identified (CHAPTER 9, 10 and 11)?

b. How ready are citizens to intentionally and practically turn home gardens into nature reserves, verges into green corridors and rooftops into stepping stones for biodiversity (CHAPTER 10, 11 and 12)? In other words: Do the greening and gardening practices and discourses reflect a societal support for urban based biodiversity conservation?

In Part IV a synthesis is made of the aggregated research results and the question has been addressed what, based on these results, future cities would look like when taking sustainability and biodiversity concerns into account. These concerns reflect six different cultural perspectives, leading to six narrative future visions of BiodiverCities (CHAPTER 13). 
Exploring the option of urban based conservation through actions of urban greening and gardening is a relevant question as by "2050, an estimated 6.3 billion people will inhabit the world's towns and cities -- an increase of 3.5 billion from 2010 (CBD, 2007a, p.2)." This has large implications for the world's landscape, ecosystems and urban environments.

After analysing discourses in the contemporary conservation regime -- the patchwork of various conservation approaches (CHAPTER 4 and 5), the Global Scenario Studies (CHAPTER 6), and IUCN (CHAPTER 7) --that has largely focused on conservation of biodiversity 'in nature' by various in situ and ex situ strategies, an intermezzo is presented. It contains a philosophical reflection on the concept of 'the sustainable city' (CHAPTER 8). Thereafter, based on literature and three case studies a framework has been developed for discussing urban greening practices and their relevance for conservation and biodiversity: the Biodiversity Benefits framework (CHAPTER 9). Fieldwork in front-yards in Maastricht and Phoenix, Arizona (CHAPTER 10 and 11) resulted into the BIMBY framework that enables an integrated cultural-ecological assessment of services to biodiversity delivered in domestic gardens and other small landscape patches. Surveys with citizens and experts in the field of urban sustainability and urban greening (CHAPTER 12) delivered more insight into current practices, discourses and preferences in relation to urban greening and gardening, and into the question whether people relate their practices and preferences to ideas of local, regional or global biodiversity conservation. Finally the findings of the individual assessments have been gathered in a synthesis chapter (CHAPTER 13) where -- based on six Cultural Perspectives - six narrative future visions for biodiversity in an urbanised world - BiodiverCities --are presented.

Considering this variety of exercises, this dissertation work reflects the patchwork character of the issue of biodiversity conservation. Different approaches and methods have been applied and, when possible, combined. This strategy resulted into this diversified book that reaches towards many horizons. Apart from reflecting the complexities and ambiguities of the phenomenon of biodiversity conservation itself, this dissertation also demonstrates the difficulties of such an exploration related to chosen methods and the human mental capacity to digest an endlessly flowing supply of interdisciplinary and trans-disciplinary knowledge. Overseeing the end of working on this dissertation I can say in a Socratic fashion: 'the more knowledge I gained, the more questions emerged.'

Now it is time to reflect on the steps taken, to formulate conclusions and to identify questions for further research. This chapter is organised in sections based on the four parts of this dissertation and the connected sub-questions. Together the sub-questions address the central research question. In each section I will formulate key findings, discuss their implications in the context of the other dissertation chapters and societal developments, and suggest questions for future research. I will start with reflecting on 
the methodological approaches that were employed for this thesis, before going deeper into the four parts.

\section{Part I.}

\section{Reflection on Used Methods and Approaches}

In order to do justice to the multifaceted issues of biodiversity conservation and urban greening, this research employed an eclectic set of methodological approaches. I am now in a position to reflect on the methodological 'patchwork approach' and the two main methodological ingredients: Integrated Assessment and the Perspectives Method based on Cultural Theory.

\section{A methodological patchwork approach for a patchwork topic}

In this dissertation I approached the topic of perspectives on biodiversity conservation in a changing world through jumping from a global level (the global scenario studies), to an organisational level (IUCN), to an urban level (urban greening and gardening; Dutch citizens and international experts). With this approach to the conservation topic I intended to contribute to the conservation debate and to conservation practice by discussing urban greening and gardening as a viable approach to address global biodiversity loss. In order to do so, I structured the dissertation study into four parts.

In part I key concepts and the methodological approach are elaborated. In Part II, through concept mapping and through conducting a DISCO analysis of a variety of conservation and urban greening related fields using the Perspectives Method, I especially aimed to address existing tensions between worldviews and management styles (Verweij, et al., 2006) in the conservation regime. Insight into the ideas and discourses behind the various conservation practices, and insight into perspective synergies, contradictions and assemblages in the conservation regime may be helpful in directing an effective and constructive dialogue about conservation in a complex, dynamic and pluralistic world. Before continuing with Part III an intermezzo is provided: an essay based on critical philosophical thinking. In Part III urban greening and gardening as approaches to conservation assessed through literature study, fieldwork and questionnaires. Two frameworks were developed through grounded theory methods to discuss the role of urban greening and gardening for biodiversity. Part IV is called harvesting the fruits. It consists of a synthesis chapter where a scenario-visioning approach was used to construct six Cultural Perspective based visions of cities (BiodiverCities) where sustainability and biodiversity concerns play an important role. Finally, conclusions reflections are given and suggestions for further research are made. 


\section{Integrated Assessment}

Based on the philosophy behind Integrated Assessment (Nowotny, et al., 2003; Rotmans, 2006; Valkering, et al., 2006; De Ridder, et al., 2007) and Sustainability Science (Funtowicz \& Ravetz, 1993; Nowotny, et al., 2003; Urry, 2005b; Brewer, 2007; Kemp \& Martens, 2007; Grosskurth, 2009; Pohl, et al., 2010; Weinstein, 2010; Spangenberg, 2011; Lang, et al., 2012; Wiek, et al., 2012; De Vries, 2013) I expected strength in the combination of a variety of methodologies. The focus of 'traditional' Integrated Assessment (IA) has been on combining modelling methods with stakeholder analyses, scenario studies and/or participatory methods. In this dissertation I included methodologies that are ongoing in the humanities, such as discourse analysis, content analysis, concept mapping, grounded theory, and critical philosophical thinking based on Critical Theory (Doorman \& Visser, 1995; Hall, 2001; Foucault, 2002; Brenner, 2009; Wodak \& Meyer, 2009; Marcuse, 2010; Mendieta, 2010). I expected the inclusion of such qualitative methods to add a deeper reflective layer to IA.

Adding grounded theory and concept mapping to the IA toolset proved valuable because it gave space to explore novel constellations of knowledge and insights, and it even resulted into new theoretical and methodological frameworks, such as the BIMBY framework (CHAPTER 10) or the framework for exploring Biodiversity Benefits of urban greening practices (CHAPTER 9). Combining literature study, fieldwork, surveys and philosophical reflection based on Critical Theory proved to be a valuable enriching approach. Empirical data become embedded in a context of intellectual legacy, which gives them extra meaning and significance. It also helps interpreting them from various disciplinary perspectives. The conducted surveys have been a valuable contribution to gaining more insight into constellations of dominant societal thought styles (Cultural Perspectives) with regards to biodiversity, sustainability, urban greening and gardening.

The combination of various sub-assessments of different qualitative and quantitative characters and methods proved valuable, but also complicated. Especially comparing and connecting results from the different studies wasn't always easy. In a next research design, it would be beneficial to put much thought into constructing strong methodological bridges between assessments of various characters in advance. The surveys for example, could have been better aligned with the front-yards assessment. It would also have been more cohesive to interview the specific garden owners in Maastricht and in Phoenix instead of conducting general surveys among Dutch citizens and international experts. Now both studies are rather independent and I wasn't able to say much of specific significance about the Cultural Perspectives that are reflected in the front yards of Maastricht and Phoenix.

With regards to the questionnaires an important thing I learned is: less is more. Splitting the questionnaire into three parts - Cultural Perspectives; conservation and sustainability; and urban greening and gardening -- would have been useful in order to 
find an easier focus and go more into depth in each of the topics. At the other side, it has been rewarding and great fun to integrate visual questions in the surveys, to include qualitative questions that can be translated into word-clouds and to compare and analyse a rich source of data with descriptive statistics. The addition of pictures and open questions in a questionnaire definitely adds to the depth and (qualitative) value of the results. And working with such diverse results definitely improved my methodologically and conceptually integrative skills.

Finally, it turned out to be possible to creatively synthesise the research findings of all the chapters into the BiodiverCity storylines of CHAPTER 13. If more time would have been available it would have been a challenge to organise this synthesis process in a participatory way through workshops involving the reflection of stakeholders in advance and after the 'construction' of the future visions. It would have given the results extra dimension and societal value. Future vision workshops on sustainable cities and biodiverse gardens based on Cultural Perspectives are attractive options to arrange in future research settings. In a series of such workshops in a longer term, also potential transitions towards sustainable gardening regimes could become identified.

\section{Cultural Theory}

As emphasised in earlier chapters, working with Cultural Theory and the Perspectives Method as a methodological framework for discourse analysis works fine, but caution has to be considered as well. Reality is complex and people or even groups and organisations cannot be realistically put into 'perspective boxes'. Nevertheless, unravelling and deconstructing the ongoing perspectives related to various levels, forms and fields of conservation has been an interesting exercise. Using the Perspectives Method to explore discourses has been especially valuable in providing novel insights into the complex and fragmented playing field of conservation. On each research level interesting information and insights emerged into how different perspective combinations are constellated around different layers of the biodiversity conservation patchwork. For conservation, biodiversity and sustainability researchers, the rising popularity of urban greening and gardening provides a rich pioneering field for assessing what thought-styles and types of urban greening practices and designs effectively benefit the conservation of biodiversity in and beyond urban areas; to what extent and under which socio-cultural circumstances citizens are willing or able to participate in daily-lifestyle-conservation efforts; and to what extent and under which socio-cultural circumstances urban based conservation adds value to the rest of the conservation patchwork. 
Part II.

\section{The Status of the Current Conservation Regime}

\section{a. What practices and discourses make up the current conservation regime?}

I started this research by exploring - through DISCO analysis -- the existing conservation regime through studying a variety of current conservation practices for their underlying discourses. Thereafter, the discourses of two major Global Scenario Studies (The Millennium Ecosystem Assessment Scenarios and the IPCC Scenarios) were analysed. Next a similar Cultural Theory based discourse analysis was conducted on the IUCN. Finally, to be able to compare the 'official' conservation regime with ongoing societal perspectives on nature, the Cultural Perspectives of Dutch citizens and international experts were assessed through surveys.

\section{Key findings}

It can be said, based on the aggregated results, that the conservation arena is characterised by a great plurality in approaches and worldviews. Some strategies may be easier linked to each other than others, and the results of the perspective analyses provide valuable directions as to where synergies and potential conflicting strategies could exist or emerge. However, along the patchwork character of the conservation practices, a deeper characterisation of the regime demonstrated a mainly Hierarchist-Egalitarian conservation regime that seems to be subject to a shift towards a dominant Individualist perspective. In the survey results with citizens and experts, this Individualist perspective reflected least incentive for conservation of all the six perspectives. Below, these conclusions are drawn and reflected in more detail.

In CHAPTER 4 different conservation approaches were mapped and in CHAPTER 5 the cultural perspectives represented in the approaches were analysed through content analysis. The results of these chapters suggested that the current regime of biodiversity conservation is dominated by an Egalitarian-Hierarchist perspective. The Autonomous perspective was identified as a leading force in classical conservation literature that inspired much of the global conservation practice. The Fatalist perspective and the Dynamic Integrator are not so profoundly represented in both conservation practices and literature.

In CHAPTERS 6 the cultural perspectives prevalent in two influential global scenario studies were thoroughly analysed using DISCO analysis: the IPCC scenarios and the Millennium Ecosystem Assessment Scenarios. In both scenario studies the conclusion was drawn that strong sustainability perspectives are weakly represented. Rather an emerging economy oriented discourse is guiding: the value of biodiversity for its deliverance of ecosystem services is emphasised in almost all the scenarios. This seems to imply that 
the Global Scenario Studies working groups foresee a change to a more Individualist approach in the future of biodiversity conservation.

A similar trend was identified in the IUCN documents analysis (CHAPTER 7). Next to a central role for promoting community engagement for conservation in non-Western (developing) countries, and mainstreaming conservation in public and private policy, much emphasis is placed on promoting a 'green economy', on engaging the private sector and on making economic sense of ecosystem services delivered by biodiversity (Beumer \& Martens, 2013) Other perspectives, like the Autonomous and the Dynamic Integrator are also weakly represented by IUCN. The results imply that IUCN largely views conservation as something that takes place 'out there' and is fundamentally carried by experts, (non-governmental) organisations and governments (increasingly funded by-, and integrated in business strategies). Main target groups for increasing conservation awareness and activity are the private sector and indigenous communities with non-western lifestyles. The impacts of lifestyles and consumption patterns of affluent citizens of Western societies are hardly addressed by IUCN. The same accounts for what individual citizens can actively do to enhance biodiversity and the quality of ecosystems in their direct living environments: not much attention is given to this option.

\section{Discussion: reflecting on the conservation regime}

Comparing the results with the results of the other chapters leads to an interesting discussion. The conclusions on the question what practices and discourses make up the current conservation regime, indicate that thinking about the future of conservation is directed by a "weaker sustainability" discourse (Robinson, 2004; Williams \& Millington, 2004; Miller, et al., 2011; Minteer \& Miller, 2011; Robinson, 2011). An often used argument is that the world we live in is currently dominated by economic, utilitarian and opportunistic thought (Pauli, 2010; UNEP, 2011b; GesNaT \& BUKO, 2012; Patel \& Crook, 2012; Spash, 2012; Martens, 2013). Involving the Individualist in conservation, for example through engaging him in public-private partnerships and through emphasizing the (economic) values of ecosystem services is therefore considered crucial (Christoffersen, 1997; IUCN, 2005a, 2007a, 2008a, 2008b, 2009e, 2010b, 2010f, 2011f, 2012b). In the opinion of stronger sustainability advocates this attitude will not lead to the desired goals of halting biodiversity loss as it represents business as usual (Miller, et al., 2011; Minteer \& Miller, 2011; Robinson, 2011). Outside the box thinking - which is deemed necessary in a world dominated by complex and wicked problems (Funtowicz \& Ravetz, 1993; Funtowicz, et al., 1998; Dresner, 2002; Nowotny, et al., 2003; Jackson, et al., 2004; Martens, 2006; Valkering, et al., 2006; Brewer, 2007; De Ridder, et al., 2007; Rees, 2010; Wiek \& Iwaniec, 2013) - doesn't seem to be leading the current conservation regime. Rather a neoliberal-conservative oriented status quo is being maintained with taking the Individualist perspective as a target group (the private sector) for promoting conservation efforts (Beumer \& Martens, 2013). 
The results of CHAPTER 12, however, demonstrated that the Dutch citizens group turned out to be dominantly representing an Egalitarian perspective. This group is open to conservation and sustainability concerns but only moderately actively involved in activities that contribute to conservation. Only a small section of the Dutch respondents and experts was characterised with a dominant Individualist perspective. This group showed least affinity with conservation or sustainability concerns. The international experts group represented mainly dynamic and Autonomous worldviews. In both survey groups, especially the Autonomous perspective demonstrated great ethical and practical concern for conservation and sustainability related issues. Comparing these results with the results of CHAPTERS 4-7 it can be suggested that there is a disconnection between the Individualist-oriented worldviews that are propagated as beneficial to biodiversity conservation on the global and the organisational level of the existing conservation regime at the one hand, and the perspectives positive towards conservation in the Dutch citizens group and the urban greening and sustainability experts group at the other hand.

Also, the question can be raised how much benefit for biodiversity can be really gained by these 'private sector engagement strategies'? Aiming for enforcing a positive impact for biodiversity by engaging powerful large resource extracting or manufacturing businesses in conservation action, awareness and behaviour is doubtfully helpful, as other publications also indicate (Turner, 2010; ETC-Group, 2011; UNEP, 2011a; GesNaT \& BUKO, 2012; Hoedeman, 2012; Patel \& Crook, 2012; Plec \& Pettenger, 2012; Spash, 2012; Martens, 2013). Considering the Egalitarian basis of Dutch society it can also be expected that when Individualist oriented arguments or strategies are employed to convince Dutch citizens to participate in conservation, it will rather be like carrying buckets of water to the ocean. Will these arguments be picked up and transformed into action at all? Psychologically speaking, the rational messages may not connect to the emotional appeals and thus will not effectively be transformed into the expected behaviour or attitudes (Smith \& Mackie, 2000).

Of course, the reflection at this point only covers significantly for the Dutch situation and a limited group of experts. Perspective studies in other countries and with more experts could help gaining insight into the question whether these perspective-mismatches can be considered a global issue. Perhaps not so much should be expected from the private sector as a positive force for conservation. Possibly, much more benefits for biodiversity can be gained by strategically addressing the dominant perspective group of any society. In the Netherlands most potential for stirring a critical mass for biodiversity can be found in the Egalitarian oriented citizens group. However, CHAPTER 12 also demonstrated that - although this group shows empathy for environmental concerns -- Egalitarian action for conservation and sustainability is limited to being moderate. It would be interesting to further assess the question why people with ethical concerns about the environment - like the Egalitarians in the Netherlands -- still refrain from taking concrete action mas- 
sively. Are any capacities for taking action -- such as (the feeling of having) knowledge and skills, time, financial resources, and political or societal support -- lacking?

Together, the analyses in CHAPTER 5, 6 and 7 of discourses in the global conservation regime demonstrate a dominant perspective combination of Egalitarian and Individualist perspectives. In CHAPTER 7, I questioned whether such a combination can be viable in real life (CHAPTER 6). These two perspectives seem to be incongruent worldviews to each other (Thompson, et al., 1990; Thompson, 1997; Mamadouh, 1999; Verweij, et al., 2006; Offermans, 2012). Can they be seen as a 'dynamic integration' and mediated compromise that is viable in the real world? Or is this combination rather a sign of cognitive dissonance and inhibitive contradiction between two opposing worldviews? I believe that the perspective combination of the Egalitarian and the Individualist could prove to be a valuable contribution to sustainable development and biodiversity conservation, whilst there is a clear balance between entrepreneurship and practical ethics. Therefore, I consider such a paradoxical perspective combination as potentially sustainable as well. However, in the real world there is the risk of becoming blindfocused on the economic benefits of biodiversity and ecosystem services at the expenses of valuing ecological integrity and the intrinsic and existence values of biodiversity and ecosystems (Opschoor, 1998; Nunes \& van den Bergh, 2001; Norton \& Noonan, 2007; Costanza, et al., 2014). Focusing on conserving biodiversity for the benefit of people and the economy might result in the decline of natural resilience. This also includes the risk of creating dependency of ecosystems on human management, as was pointed out in CHAPTERS 6 and 7 (Beumer \& Martens, 2010; Beumer \& Martens, 2013). A healthy balance between the two perspectives seems fragile at the moment.

\section{Future research questions}

1. Does the course taken by global conservation organisations fit public worldviews and perspectives across various regions and countries - developed and developing -- in the world? With this question the scope of this dissertation could be broadened towards including perspective-analysis surveys with representative citizen samples in other countries and comparing them to the perspectives represented by other global conservation organisations such as WWF, Greenpeace, Friends of the Earth etc.

2. Why do people with ethical concerns about the environment -like the Dutch Egalitarian perspective group -- often refrain from taking concrete action for the protection of the environment? Is it inherent in the worldview or can it be related to a lack of capacities for taking action -- such as for example (the feeling of having) knowledge and skills, time, financial resources, and political or societal support? More social psychological, cultural and sociological research could be done here to question this and other cognitive dissonances related to sustainable worldviews and 'inability' to act according to them. 
3. What are the real effects for biodiversity of engaging the private sector into conservation strategy?

\section{b. What tensions and synergies can be identified in the current conservation field?}

Through answering the first sub-question, some tensions and synergies have already become apparent. In this paragraph I will go a bit deeper into delineating the conclusions for this question and discussing their implications.

\section{Key findings}

In CHAPTER 5 the mapping exercise of the conservation field was continued by linked the various conservation approaches to the perspectives of Cultural Theory. This resulted into various relational patterns between the conservation approaches, such as conflicting strategies and opportunities to find some common ground based on shared worldviews.

Trophy hunting for example - a basically Individualist conservation approach --was identified as a conflicting conservation approach in its relation to several other conservation approaches, especially the ones emphasising strong ethical views on nature, such as certain religious approaches and NGOs. Controversial relations exist with ecotourism and protected areas. Strong connections were identified between the approaches of ecosystem services, partnerships, and philanthropy. Their binding factor is the Individualist perspective. Reconciliation ecology (Egalitarian-Hierarchist), relocation and NGOs largely share the same perspectives and they also may go along well with the worldviews of protected areas (Hierarchist-Egalitarian) and zoos and botanical gardens. However, although there are ideological links, direct practical links are not really established. An unexpected result has been the gap in worldviews between academia and policypractice on the conservation approach of legislation and policy. Academia represents legislation and policy as primarily Hierarchist, whereas the policy-documents themselves have a rather Individualist orientation.

The perspective mapping exercise of the conservation approaches gives more insight into the patchwork character of the conservation field. Overall, the results of the content analyses of these texts that describe or discuss the various conservation approaches indicated that the broad field of biodiversity conservation is dominated by an EgalitarianHierarchist perspective combination. The dynamic and Fatalist perspective are represented least. The Autonomous perspective seems to be a guiding force in classic conservation literature, and as such it has always been an ideological authority. However, the content analysis also demonstrated that recent popular approaches to biodiversity conservation - like the Ecosystem Services approach advocated by the Millennium Ecosystem Assessment and TEEB (2009) - reveal a more Individualist discourse that is ideologically tense with the Autonomous, Hierarchist and Egalitarian perspectives. The Fatalist 
perspective - although present for a little bit in most occasions - may not fit the proactive conservationist style. The dynamic perspective that has its fundaments in the ecological discipline and sees the wold as a complex evolutionary system also seems to be underrepresented in the contemporary conservation discourse. The results of the mapping exercise in CHAPTER 5 were confirmed by the deeper DisCo analyses of the Global Scenario Studies in CHAPTER 6 and the IUCN in CHAPTER 7.

Discussion: reflecting on tensions and synergies: perspective plurality

Reflecting on tensions and synergies leads to the question of the value of perspective plurality. The significance of Cultural Perspective-pluralism in the context of addressing biodiversity loss has been often emphasised in this dissertation. Perspective plurality is valuable in society but also it is methodologically worthwhile. Working with the Perspectives Method does not mean anything when it is only used to stratify different perspectives in society. People, groups and organisations per definition operate outside the box of a single perspective. The world is a too complex place for reductionist thinking. Societies will always consist of historically shifting combinations of more or less dominant perspective-clusters. Therefore, it is important to either avoid simplifications where possible, or to critically reflect upon them. However, in order to become aware of perspective-diversity and its potential meaning in society, unravelling practices and assumptions into separate discourses has proved to be a useful exercise.

Although I emphasise and promote a critical attitude towards using the perspectives of Cultural Theory as independent 'boxes', the framing of the different perspective groups into their extreme stereotypes is helpful: it provides an insight into what possible extreme consequences certain modes of thought and worldviews could have. It helps to question whether we want to go one or the other direction as a society or as a global community. It also provides an insight into how marginalised perspectives (e.g. the Autonomous and the Dynamic Integrator at this point in time) may enrich or fundamentally transform current regimes when they would be able to gain greater momentum (Ray \& Anderson, 2000; Bottrell, 2009; Callo-Concha, et al., 2014). Marginalised perspectives may also play a crucial role in fostering societal resilience or transitions towards new (conservation) regimes (Loorbach, 2002; Brugge, 2004; Loorbach, 2007; Rees, 2010). They provide alternative ideas and solutions when the methods and strategies of the status quo are failing (Gunderson \& Holling, 2002; Verweij, et al., 2006; Bottrell, 2009; Callo-Concha, et al., 2014).

Based on all results and reflections -- it seems to be clear that conservation is at a point where intertwined developments in the landscape level (environmental crises, economic crises, rising social inequity, world-wide (Occupy-) demonstrations) are putting pressure on the existing strategies and conservation models. This marks a somewhat chaotic time where -- at the same time -- windows of opportunity are opening for experimenting with 
visions, ideas and novel strategies (Capra, 1996; Laszlo, 1996, 2006; Wiek \& Iwaniec, 2013). A variety of smaller and larger networks and actors (niches) seem to have started to bring in novel conservation visions: integrated conservation, engaging the private sector, engaging citizens, broadening conservation to urban areas and green infrastructures, broadening conservation from professional institutions-based work towards mainstreaming conservation into national and local governance or the daily life of citizens. Winners or stable configurations based on these options are not (yet) crystallising. Perhaps they will never crystallise, as conservation is too broad a goal, too broad a concept, and too broad a praxis. Would this be a sign of lock in? Or of a backlash? Or may it after all - considering the patchwork character of the conservation field -- not be so appropriate to identify power tensions in the conservation regime from a transition theory perspective?

From another point of view the plural developments in the field of conservation together can be characterised as a movement towards a 'broad involvement for conservation'. This broad involvement already slowly starts to trickle down into the regime that starts implementing various approaches (consisting of global, national and local governance, public opinion, the economy (sustainable consumption, product labelling, sustainable banking and sustainable investments) and traditional conservation organisations). Therefore the transition of the conservation regime perhaps shouldn't be studied at the level of competing and winning niches or perspectives, but on the real effects it has on the landscape level: does it stop biodiversity loss? Does it lead to more sustainable lifestyles and eco-literate citizens? Does it transform our economy? How then, can the effects of the various conservation approaches (successes and failures) on the landscape level be measured when they are all part of a complex set of interwoven, complementary and sometimes even conflicting strategies and worldviews that are hard to untangle? Is that even possible?

\section{Future research questions}

1. What role do synergies and inherent conflicts between various worldviews and conservation strategies play in the ongoing loss of global biodiversity? A complex system analysis could provide more insight into the concrete relations between conservation approaches and the concrete impacts of these relations on achieving global biodiversity targets.

2. Can historical societal perspective changes be linked to historical changes in the conservation regime? A historical analysis of perspectives and perspective transitions in the conservation regime could provide more insight here.

3. How can perspective plurality best be employed to guide the creation of sustainable conservation patterns across the planet? Assessing theories of cultural diversity and diversity management in combination with perspective workshops amongst conservationists and other stakeholders in various constellations and settings could contribute to answering this complex question. 
4. How can the effects of the various conservation approaches (successes and failures) on the landscape level be measured? These would be interesting points for further study and theoretical discussion in the context of transformative sustainability research (Lang, et al., 2012; Wiek, et al., 2012).

\section{Intermezzo:}

\section{Critical reflection on 'The Sustainable City'}

In an intermezzo chapter, CHAPTER 8, I philosophically argued that the challenge of the coming decades is to create cities that are transcending the ancient nature-city dichotomy in an intellectual, fundamental and practical way.

\section{Key findings \& Discussion: Sustopolis or Cosmopolis?}

Transcending old images, such as the nature-city dichotomy may be a fundamental step towards creating cities that are dynamically and positively contributing to a more sustainable world. Much research and policy is directed towards making cities more sustainable or even creating sustainable cities from scratch. However, Sustopolis, the name I gave to represent the archetype of The Sustainable City, needs to be treated with caution. The blueprint for such a city can never exist as the world is a complex, dynamic place. Caution is also important, as the creation of Sustopolis also implies the creation of novel power-structures that aren't necessarily desirable. In my argumentation I also pointed towards the importance of embracing the idea of global dynamics and of the value of enhancing a multi-scale awareness: on spatial scale levels and on temporal scale levels. In order to do so, adopting the ancient image of Cosmopolis may helpful. The concept of Cosmopolis can help reflecting on the embeddedness of local actions in a regional and global context: it can help to make sense of the phrase: a better world starts in your home garden, while leaving space for individual, cultural, spatial and temporal differences.

\section{Future research questions}

1. How can the concept of Cosmopolis be operationalised towards a tool that meaningfully enables people to adopt a spatial and temporal multi-scale consciousness?

2. Which methods, strategies or events (can) contribute to increasing a multi-scale awareness and systemic thinking? This is a typical question for Integrated Sustainability Assessment, combining strategies, methods and tools from various environmental science, social science disciplines, and the humanities. 
Part III.

The Potential Role of Urban Greening and Gardening for Biodiversity Conservation

\section{a. What urban greening and gardening practices and regimes can be identified?}

This question has been addressed through literature research (CHAPTER 9), grounded theory (CHAPTER 9), fieldwork (CHAPTER 10 and 11) and questionnaires (CHAPTER 12).

\section{Key findings}

Based on different models for urban ecosystems, seven significant motivations were identified that link urban greening and gardening to global biodiversity conservation (CHAPTER 9): an economic motivation, the colonisation motivation, the global homogenisation motivation, the metabolic system motivation, the fragmentation motivation, the environmental justice motivation and Dunn's Pigeon Paradox (Dunn, et al., 2006). Urban greening practice for biodiversity can find motivational ground in all these categories. Next to these motivations for urban greening for biodiversity, seven urban greening regimes were identified: the green space planning regime, the classical conservation regime, the monument and heritage regime, the novel nature regime, the design regime, the ecosystem services regime, and the civil action regime. All these regimes express different constellations of motivational backgrounds and express preferences for specific urban greening trends. Significant contemporary urban greening trends that were identified included: urban farming, green infrastructures, vertical gardening, community gardening, civil action, Wildscapes, (landscape) architecture \& design, parks, and domestic gardening.

Based on these motivations, regimes and trends the Biodiversity Benefits framework has been developed. This framework enables a dialogue on urban greening projects and their implications for biodiversity on various scale levels. The framework can be used to create case specific configurations of building blocks that provide more insight into the relations between motivational backgrounds for urban greening projects, the greening regime they are founded in, and the benefits that can be created for biodiversity from the local to the global scale level. The framework was tested on three case studies in the South of Limburg: Avenue 2000 and Frontenpark in Maastricht, and the SUN Vegetable Garden in Heerlen. These case studies demonstrated that the framework can help identify and address potential synergies and frictions between motivations, greening regimes, between and within specific projects and practices. Next to providing insights into the discursive background of urban greening projects and practices, applying the framework to specific cases also helps identifying the gaps that can be addressed when considering the benefits for biodiversity of the urban greening practices. 
In CHAPTER 10 the BIMBY framework was developed. This indicator framework addresses contributions and dis-contributions delivered via domestic gardens to biodiversity. It combines ecological and cultural indicators that can be found in the design of home gardens. Fieldwork was done in front-yards in Maastricht and in Phoenix, Arizona (CHAPTER 10). Although many garden design style options exists, including wild flower meadows, English cottage gardens, picturesque or gardenesque gardens, Japanese gardens, adventurous forest gardens, French castle or topiary gardens, and modern lounge gardens, in Maastricht the results suggested a general preference for paved or gravelled front-yards. These results were confirmed by the questionnaire among Dutch respondents in CHAPTER 12. However, the questionnaire results also suggested that although many Dutch citizens indeed pave their yards (for ease of maintenance reasons), their visual preferences go to lush gardens with wild flowers and to colourful cottage gardens that provide space for both people and nature.

In Phoenix it became evident from the fieldwork that still many inhabitants maintain water and fertiliser intensive gardenesque designs with lawns: green lush oases that resemble and reflect garden traditions and styles from the wetter climates of Europe and the East coast of the US. This has also be confirmed by other researchers who assessed garden preferences in the Arizona region (Larsen \& Harlan, 2006; Larsen \& Swanbrow, 2006). An emerging trend advocated by scientists and increasingly by the Phoenix local government as well, is the xeric garden: a garden that reflects the desert ecosystem of the region(DBG, 2013). However, attention also needs to be drawn to research results by others that reveal an increased use of pesticides and herbicides in xeriscape yards (Larson, et al., 2010).

\section{Discussion: Sustainable urban greening and gardening}

The conclusions of CHAPTERS 9, 10, 11 and 12 lead to the following question: how can living-comfort, aesthetics and ease at the one hand and the protection of biodiversity, ecosystems and ecosystem services at the other hand be reconciled in the design of residential environments? The results in CHAPTER 12 demonstrated that Dutch citizens sympathise with sustainability and conservation goals. However, there seems to be a gap between perspective and practice as the majority of Dutch citizens paves their gardens. Main arguments used for these 'desertification' practices are based on ease and time. Obviously, a green and biodiverse garden is being linked to a lot of work.

In Phoenix other issues play a role in making choices for yard design. Earlier research done in Arizona already pointed out that drivers for implementing green yard design in the Arizonian desert environment are based on comfort (climate mitigation and reducing the urban heat island effect) and spatial-historical sentiment: a lush green garden helps compromise the harsh prickly, human hostile desert environment (Zube, et al., 1986; Hope, et al., 2006; Larsen \& Harlan, 2006; Larsen \& Swanbrow, 2006; Martin, 2008; Larson, et al., 2009; St. Hilaire, et al., 2010). The popular often irrigated lawn garden adds 
to biodiversity by attracting many native and non-native species: birds can be seen bathing in pools of water or under the irrigation system. The gardenesque lawn garden also adds to regional landscape and ecosystem diversity: it contributes green patches with cooler microclimates to a desert region. Overall, it can be said that Phoenix has been turned into an oasis by its inhabitants. However, as concluded in CHAPTER 10 more biodiversity isn't per definition a desirable goal on its own. Some species can be a menace to the well-being of people. From a sustainability perspective, the question also rises how long the water intensive gardening culture of the Sonoran desert region can be sustained and how it affects the potential for people to live in Phoenix on the longer term. Abundant eco-region specific gardening and greening examples that have the potential to increase region specific biodiversity are available. However, a shift in perspective and preferences may be necessary first in order to attract a majority of inhabitants to xeric garden designs. What factors are necessary to bring on such a transition? Besides, a large scale implementation of xeric yards may be at the cost of species that settled in the oasis-character of the city: fundamental trade-offs need to be made here.

\section{Future Research Questions}

1. How can living-comfort, aesthetics and ease at the one hand and the protection of biodiversity, ecosystems and ecosystem services at the other hand be reconciled in the design of residential environments and domestic gardens? This is a question that would involve a trans-disciplinary team of designers, sustainability scientists, ecologists and garden users to arrive at meaningful answers.

2. What types of garden/landscape design do effectively contribute to biodiversity on various scale levels and in specific contexts, and how can a biodiverse landscape design be aligned with other sustainability goals like water saving, climate change mitigation or food-production? This could be a question for a transformational sustainability research project.

3. What factors are necessary to facilitate a transition to a sustainable gardening regime in Phoenix? Are citizens ready to voluntarily adopt and develop novel garden designs, or is increased pressure from the landscape level and from governance necessary? What are the differences between cities like Phoenix and Maastricht in this respect? Interesting research can be set up that assesses transitions towards sustainable gardening.

4. Will urban greening become an anchored part of urban life or is the popularity of urban greening only a temporary fashion craze? Follow up fieldwork, policy analysis and surveys can give more insight. 


\section{b. Do the greening and gardening practices and discourses reflect a societal support for urban based biodiversity conservation?}

How ready are citizens to intentionally and practically turn home gardens into nature reserves, verges into green corridors and rooftops into stepping stones for biodiversity? This question has largely been answered by the results of the literature study in CHAPTER 9, the results of the front-yard fieldwork in CHAPTER 11 and the survey-results of CHAPTER 12.

\section{Key findings}

The survey results representative of the Dutch population (CHAPTER 12) and the fieldwork results of the front-yards (CHAPTER 11) indicated that in most cases Dutch citizens - even in cases that they are aware of the conservation potential of greening and gardening and the power of their own actions - have other priorities than integrating conservation and sustainability concerns in their private, domestic gardening practices. In Maastricht many residents - especially in the lower income neighbourhood Blauwdorp, but also in the recently built affluent Vroendaal - seem to be guided by the choice for ease and time-efficiency when it comes to gardening and garden designs. In Blauwdorp there also seems to be an element of social cohesion to the urge for paving front-yards: the often encountered furniture like tables, benches and barbeques in the front-yards seems very suited for social gatherings like barbeques and dinners with family, friends, or neighbours. However, the installation of pavement or fully gravelled yards in many front-yards of Maastricht results in the 'desertification' of an otherwise green ecoregion. In that sense, domestic gardening doesn't yet contribute much to biodiversity in practice. The low-maintenance design, however, doesn't always reflect the aesthetic preferences of the surveyed people: many people who indicated to have a paved garden said that they like the picture of a garden with semi-wild flower plantation and the English cottage garden the most (CHAPTER 12). This is an interesting paradox. Why do respondents indicate they prefer wild flower gardens over paved gardens, while at the other hand practical choices are dominated by the paved 'maintenance free', lounge' or 'living room' garden-trends?

Especially related to domestic gardening the conservation practice is limited and other values than ecological ones (practical functionality and aesthetics) dominate the garden design. Not only in relation to conservation of biodiversity, but also in the larger context of the sustainability discussion, awareness of the potential role of domestic gardens seems low. Why are inhabitants of the drought-distressed Phoenix still massively greening their gardens with lawns, trees and flowers, knowingly spilling much valuable water? Short-term well-being and heat-mitigation seem to dominate concerns for future viability of the whole desert metropolitan region. Again, the question arises whether other options that combine social concerns, comfort, time concerns, aesthetic concerns and ecological concerns in the design available? 
One observation in the results of the surveys for both the Dutch and the expert sample seems to confirm the relevance of the 'Pigeon Paradox' (Dunn, et al., 2006) as an important asset for urban greening for biodiversity and an important motivation to focus on the approach of urban based conservation. The Pigeon Paradox points to the fact that people getting in touch with home based nature are more inclined to care for regional and global conservation efforts (Dunn, et al., 2006). Active gardeners and urban greeners in the surveys do more for biodiversity on other levels. They are doing for example more voluntary work in local NGOs, more of them have memberships to nature organisations or donating money to nature organisations. Similar patterns account for all the urban greening activities that were included in the survey: more people donated to or volunteered in conservation organisations who indicated to be actively involved in greening their roofs, in vertical gardening, in urban agriculture, in permaculture, in guerrilla gardening, in community-gardening or in allotment gardening.

However, at least in the Netherlands the Pigeon Paradox is mainly 'experienced' by the limited group of the most active and environmentally aware higher educated people with an Autonomous perspective. They are the ones who spend most time outdoors and who spend most time working in their gardens. That means there is work to be done for increasing the pigeon-experience other perspective groups of Dutch society. The best group to reach for conservation purposes may be the large group of citizens representing Egalitarian worldviews. They are in a moderate sense positively open towards sustainability and conservation issues. In the Netherlands they are also the ones spending most money on plants and gardening. Reaching this Egalitarian group would therefore also influence other stakeholders (like the commercial gardening branch) who put value on economic gains.

The pigeon paradox can be mentioned by ecologists and sociologists as an important motivation for stimulating urban encounters of citizens with nature; at the other hand as a motivation in citizens to get outside the pigeon paradox effect is largely unconscious. Although gardening is believed in both surveyed groups to be influential on both local and global biodiversity, the surveyed citizens don't generally think: "let's go gardening to save the whales." A conscious correlation between outdoor activities such as greening and gardening and donating to conservation NGOs may be even more far-fetched in the cognition of the respondents. However, testing whether there is a real positive correlation between gardening and urban greening and the (unconscious or unconscious) pigeon paradox-effect has been beyond the scope of this research and could be more systematically tested in future research.

Including urban space to the spectrum of conservation approaches has already been proven relevant when considering the results of research done by other scholars for various reasons (Savard, 2000; McKinney, 2002; Rudd, et al., 2002; Zerbe, et al., 2003; Tzoulas \& James, 2004; Dearborn \& Kark, 2009; Cilliers, 2010; Goddard, et al., 2010; 
Ignatieva, 2010; Millard, 2010; Müller, et al., 2010; Kowarik, 2011; CBD, 2012). The fragmentation of landscapes by urbanisation, for example, is most often emphasised in existing academic literature as a motivation to start urban greening and gardening projects for biodiversity (CHAPTER 9). It is best reflected in practices of creating green infrastructures, consisting of corridors, patch diversity, patch connections, and stepping stones for biodiversity. Its main field of implementation has been regional, national and even international governance structures and spatial planning (e.g. the European Natura 2000 Network and the Dutch EHS). In many cases green infrastructure projects involve diversifying agricultural lands. In some cases green infrastructure projects are embedded in local 'grey' infrastructural projects (like Avenue 2000 in Maastricht) or they are implemented to compensate for ecological losses caused by such projects. However, the role citizens can play in enhancing green infrastructure networks -- especially through their home gardens -- is still getting minor attention in governance and the conservation field.

Generally, concluding on this sub-question it can be said there is still a world to win for biodiversity through involving citizens and their gardening practices. The idea of conservation in and through urban areas is already widely recognized and carried by academic researchers and it is also increasingly penetrating global and local governance institutions. Many different motivations can be given to connect urban greening with the conservation of local, regional and global biodiversity. Many different urban greening trends and practices can fill different niches for biodiversity. For many citizens with many preferences and cultural backgrounds there is a wide range of options to get active in a way that suits individual perspectives. The conservation regime itself seems to be lagging behind in capturing this rich potential: although a wide array of urban based conservation approaches exist organisations like IUCN still rather focus on engaging the private sector and addressing indigenous communities with a low global impact through lifestyles, instead of addressing lifestyle, consumption-, and gardening habits of affluent citizens. Dutch citizens themselves are open towards urban greening and the survey results suggest they see the benefits of urban greening and gardening for local and global biodiversity. However, especially the current domestic gardening practices and designs are not reflecting this awareness yet. Also many Dutch citizens see the maintenance of urban green as a responsibility of the local government (CHAPTER 12).

\section{Discussion: Shifting awareness: from surprise conservation effects to intentional urban based conservation?}

At this moment of writing (summer 2014), awareness and practices may have already profoundly changed since the time of the surveys (2012) and the fieldwork (2013). An increasing flood of public opinion and popular media is very recently paying attention to the issue of domestic gardening for biodiversity and it seems a dialogue on the role of domestic gardening for biodiversity is starting up. Some developments in the Nether- 
lands that can be mentioned in this respect are projects like Operatie Steenbreek ${ }^{27}$; De Levende Tuin28 (the living garden) of the Dutch horticulturist branche VHG; online petitions to only sell untreated pollinator plants in gardening shops ${ }^{29}$, a popular television gardener becoming an ambassador for sustainable gardening ${ }^{30}$; and the Secretary of State of Economic Affairs writing a national vision for nature (Rijksnatuurvisie 2014) (Dijksma, 2014) emphasising the need for public participation in greening the urbanised Netherlands. Related to this, it could be worthwhile to investigate the question whether the current popularity of urban greening indeed leads to two things: a substantial transition in the conservation attitudes in Dutch citizens; and to novel gardening and garden design paradigms based on concepts of ecological integrity, ecological functionality and sustainability.

Urban areas and domestic gardens are ideal places to experiment with (unconventional) species constellations and to explore ecosystems, and functional species-, and speciescontext relations that are novel and unique in specific spatial, physical and cultural settings. The BIMBY framework has the potential to be developed towards becoming a tailor-made tool to help map, assess and discuss unique urban ecosystems, species constellations and their interactions with the built, human dominated environment. BIMBY can help turn cities and their gardens into cross-cultural laboratories where much knowledge can be gained about specific urban ecosystems, novel nature, hybrid nature and the role urban ecosystems can play as stepping stones for global biodiversity. As the survey and fieldwork results suggested: there is still a world to win by involving citizens as conscious experimenters in the urban laboratories. Aligning ethical perspectives with concrete practices, actions, consumption patterns and daily lifestyles may follow from such citizen participation.

There is one important backside to the coin or urban based conservation: based on the research results of this dissertation it may be argued to emphasise that embedding conservation in urban areas can never replace traditional conservation approaches. Traditional conservation institutions (still) like IUCN, WWF etc. have a great advantage in capacities, skills and knowledge on what it takes to protect and promote biodiversity and ecosystems compared to citizens without ecological education. The importance of conservation organisations may even increase when citizens are becoming more actively involved in urban based conservation. Now the outcomes of urban greening and garden-

27 Operatie Steenbreek: http://www.rug.nl/science-and-society/science-shops/posters/postermiddag-2013/steenbreek-cirsten-zwaagstra.pdf

28 De Levende Tuin: http://www.vhg.org/vakgroepen/hoveniers/de-levende-tuin

29 Petition 'Red de Bijen': http://reddebijen.nl/

30 Popular DutchTV gardener goes 'biodiversity' and creates 'Greenlabel': http://www.nlgreenlabel.nl/homepage/nlgreenlabel/ 
ing may contribute to unintentional conservation effects, which can be called surprise conservation.

With increasing eco-literacy in society, the conservation outcomes may become more consciously reflected before and after the greening practices have taken place. Instead of surprise conservation - which may have both positive and negative effects for human well-being - conservation outcomes become more intentionally steered, reconciling (short-term) human stakes and values with the long-term sustainability of various eco-systemic levels (local, regional and global). Traditional conservation organisations have the knowledge capacity and networks that are necessary to help increase ecoliteracy in societies around the world. Still much work is to be done with regards to increasing societal eco-literacy and with regards to engaging citizens towards integrating conservation values into their daily consciousness and practices. Also considerate steps still have to be taken by the large conservation organisations themselves in redefining their role in the context of a rapidly urbanising world.

\section{Future research questions}

1. Does the current popularity of urban greening lead to a substantial shift in the conservation consciousness of citizens? This could be measured by follow up questionnaires and analysis of existing data on various forms of conservation participation amongst citizens in different contexts and cities.

2. Does the Pigeon Paradox hold in various cultural settings and urban contexts? Conducting follow up surveys within one, two, five and ten years may provide totally new insights into the question whether increasing numbers of citizens are participating in conservation, urban greening or biodiverse friendly or sustainable gardening.

3. How will the role and the future of traditional conservation organisations develop? Will their influence become smaller due to governance cuttings pairing the participation society? Or will their knowledge, skills and capacities become more broadly valued and fundamentally integrated in educational schemes where children and students are raised to become eco-literate environmentally responsible citizens? Such would be interesting questions for further scenario, envisioning and transition research.

4. What novel gardening and garden design paradigms will emerge when cities become laboratories for finding gardening concepts that integrate ecological integrity, ecological functionality and sustainability? The BIMBY indicator framework could be used in this context to help identify new gardening concepts, practices and preferences.

5. The future aim for the BIMBY framework is to use it to enhance a societal dialogue on biodiversity, ecosystem services and sustainability in and beyond urban areas. The next step for the BIMBY framework is to be developed towards becoming a tool that can be used for transformational sustainability research. 
This involves further testing BIMBY in the field, and involving citizens, policymakers, designers and commercial parties into the dialogue on the value of gardening for biodiversity and its conservation in and beyond urban areas.

6. How can mainstreaming biodiversity conservation through engaging citizens in urban greening and gardening become really effective for biodiversity? What specific capacities, knowledge and skills are necessary to anchor conservation awareness and conservation practice or eco-literacy in the daily lives of citizens and of governance institutions?

7. What are the real longer term effects of including urban based conservation in the patchwork of the conservation field? Does it help stop biodiversity loss? Does it lead to more sustainable lifestyles and eco-literate citizens? Does it transform our economy? How then, can successes and failures based on urban based conservation be measured? These can be interesting points for study and theoretical discussion in the context of transformative sustainability research.

8. How can mainstreaming biodiversity conservation through engaging citizens in urban greening and gardening become really effective for biodiversity? What specific capacities, knowledge and skills are necessary to anchor conservation awareness and conservation practice or action in the daily lives of citizens and of governance institutions?

\section{Part IV.}

\section{Urban based conservation in six BiodiverCities}

Based on scenario development using the aggregated results of the different chapters of this dissertation, combined with a visioning exercise, in CHAPTER 13 the question has been addressed what urban based conservation would look like within different cultural contexts. Below the conclusions to this question are presented followed by a brief discussion and the definition of future research questions.

\section{Key findings \& discussion}

In CHAPTER 13 the results of the different assessments were categorised on perspective outcomes. Mixed with creative visioning, this resulted into six future visions for cities embracing urban based conservation were sketched, grounded in the six different cultural perspectives: the Hierarchist city Tower of Power, the Egalitarian city Garden of Eden, the Individualist city Biodome, the Fatalist city Jumanji, the Autonomous city The Shire and the dynamic city New Atlantis.

Although all six city visions embrace sustainability and conservation values, it appears that some perspective based future visions are bleaker for conservation than others. However, these may be judgements that turn out to be different for people other than myself, having different perspectives. I therefore leave it to the individual readers 
to judge for themselves which BiodiverCity seems to be most promising for conservation. Of course, it also has to be taken into account that my personal prejudices are interwoven with the visions. Although I allowed my imagination creative freedom, I also aimed to base the narratives on the concrete research results from the empirical studies and the literature as much as possible.

The aim of the narrative visions is to stimulate discussion on the strong interconnection of (policy) decisions and cultural perspectives and that each decision taken from a certain point of view can have far reaching consequences for the way the future will emerge. In order to create more robust visions for BiodiverCities, it can be interesting to test and further develop these future world visions with stakeholders in the Netherlands and in other countries. This can enable cross-cultural comparisons of what types of urbanised future is appealing in different parts of the world.

The results in various chapters showed that the Autonomous and the dynamic perspective play an important leading role in sustainability thinking and active practices, especially in higher educated groups and experts on (urban) sustainability, greening and conservation. However, these perspective groups are only represented by an elitist minority of Dutch society. Would these perspective groups be larger if environmental education and ecological literacy would form a consistently anchored part of basic education in the Netherlands? And are the worldviews and values that are leading in conservation and sustainability thinking in the Netherlands consistent in other parts of the world? Different urban environments around the world will most likely have very different (ideal) approaches to urban based conservation and related urban design. Related to this, it can be interesting to assess the role of marginalised perspectives (and practices) for conservation in an international, intercultural context. What is the role of marginalised perspectives in different contexts and circumstances? Are they allowed freedom to behave like frontrunners, or are they oppressed by existing regimes and dominant perspectives?

\section{Questions for future research}

1. Which future urban visions are most appealing to citizens in various regions and cities around the world? It would be interesting to test and/or develop the future world visions in the Netherlands and also in other countries in a participatory way to be able to make cross-cultural comparisons (for example through surveys or in participatory workshops with role plays).

2. In which parts of the world and in which environmental, economic, sociocultural and political contextual settings is urban based conservation a relevant approach to conservation and in which parts of the world other conservation approaches may be more beneficial? This would be an interesting question for complex system analysis. 
3. In which way and to what extent is education of influence on the Cultural Perspectives and are there variations in different parts of the world? This could be assessed through linking socio-economic data with perspective analysis of representative groups of populations in various settings.

4. Are the worldviews and values that are leading in conservation and sustainability thinking consistent in different parts of the world? This could be assessed through surveys and perspective analysis of representative groups of populations in various settings.

5. What happens to conservation governance and practice in countries and cultures that have different dominant perspective constellations. A combination of policy-analysis and perspective analysis could deliver more insight here.

\section{Can urban greening and gardening be a viable approach for addressing global biodiversity loss?}

Finally, an answer to the main question of this dissertation can be given: is urban based conservation a viable approach for addressing global biodiversity loss? In other words: can cities become stepping stones for biodiversity in an urbanising world?

\section{Final Conclusions}

To answer the main question very briefly: yes, cities have the potential to become stepping stones for biodiversity in an urbanising world. Yet, it is only a potential and there are some difficulties to address. The first main difficulty can be found in the conservation regime:

In general, based on the dissertation results, it can be said that the conservation regime is aiming for an integral 31approach through a 'broad involvement for conservation'. However, as the answers to several sub-questions showed, the broad involvement for conservation as represented by the current conservation regime (constituted by the various practice fields and the discourses of IUCN and the environmental discourses of the IPCC and the Millennium Ecosystem Assessment) is largely found in mainstreaming biodiversity in governance, involving non-western communities and engaging the private sector. Although academic literature and institutions like the Convention for Biological Diversity are increasingly emphasising the importance of urban based conservation, the established conservation regime isn't focusing on involving (affluent) citizens in their

31 I distinguish between integrative (aiming for one inclusive global strategy), integrated (coordinated connection of a plurality of strategies on multiple levels) and integral conservation (raising a biophilic and eco-literate global human population that conserves biodiversity through the choices they make in their daily lives). 
home environments or changing western consumption patterns and lifestyles to a great extent yet. Therefore, it can be concluded that until now, urban based conservation which ideally needs a broad involvement of citizens to participate -- seems to be largely driven by academic and institutional elite forces. It hasn't yet trickled down to the core of the conservation regime and the public.

The second main threshold to viable urban based conservation has to be addressed in society. An increasing army of citizens around the world has been taking up urban greening projects like urban farming, guerrilla gardening or community gardening. However, the effects that these practices may have for biodiversity still remain largely unreflected in public. At this point in time, urban based conservation is still a largely unintentional process: it is unguided by critical discussions on what are sustainable and desirable outcomes for biodiversity - on different scale levels -- of certain urban greening or gardening practices and trends. As such, it can be suggested there is a knowledge gap in civil society when it comes to linking urban greening and gardening practices to biodiversity conservation concerns.

This knowledge gap could be attributed to the lack of frameworks that exist to constructively discuss the contribution of urban greening and gardening to (global) biodiversity. The BIMBY indicator framework (CHAPTER 10) and the Biodiversity Benefit framework (CHAPTER 9) can be valuable tools to start a broader societal discussion on biodiversity loss and conservation. The frameworks may bring the issue of global biodiversity loss and conservation closer to people through embedding biodiversity concerns more thoroughly and systematically into close to home practices such as urban greening and gardening.

At the same time, these frameworks provide the potential to start using urban areas, parks, gardens etc. as laboratories for transformative knowledge production about the effects of urban landscape design on biodiversity on different scale levels (local, regional, global). Much can and needs to be learned about the relation of urban based conservation, sustainability and ecosystem services in their various cultural contexts in and beyond urban settings (Bolund \& Hunhammar, 1999; Appleton, 2002; Cranz \& Boland, 2004; Lyytimäki, et al., 2008; TEEB, 2011; Jorgensen \& Keenan, 2012).

Urban based conservation may become a viable approach to address global biodiversity loss in the near future. Many motivations with a global reach can be found for fundamentally including and anchoring urban areas into the range of conservation approaches. A great variety of options for urban greening and gardening reflecting a variety of perspectives has also been identified. Experimenting with new sustainable gardening concepts and designs may also transform traditional ideas on biodiversity and ecosystems towards including novel and hybrid nature that is unique in specific spatialphysical-cultural settings. This novel nature (Kowarik, 2011) may itself be regarded as contributing to global biodiversity in a way that transcends the old city-nature dichot- 
omy. The role of marginal perspectives can be emphasised as a potential source of critical reflection, creativity, innovation and novel ideas.

Stepping Stone Cities may become important hubs in the planetary green infrastructure. Citizen creativity and engagement offers a wide range of additional strategies, tools and practices to the conservation field: urban greening and gardening practices have many forms and features and are limited only by the limits of the human creative potential.

On the other hand, caution should also be considered: urban based conservation can never replace the protection of the few wild areas still left on the Earth; the rainforests, the oceans, the rivers, the grasslands, the deserts, the mountains and the Polar Regions...

Stepping Stone Cities can only be part of a large planetary green infrastructure. They can never compensate for the loss of complex and intricate ecosystems with species and functional relations that evolved over many millions of years. But what Stepping Stone Cities can do, is become keystones of a global network - a world wild web -- of ecocultural creativity that enables a sustainable future on a green-blue-red planet that is thriving with health, wealth, and life. 
Epilogue 
"Little boxes on the hillside, Little boxes made of ticky tacky, Little boxes on the hillside, Little boxes all the same.

There's a green one and a pink one And a blue one and a yellow one, And they're all made out of ticky tacky And they all look just the same.

And the people in the houses

All went to the university, Where they were put in boxes And they came out all the same, And there's doctors and lawyers, And business executives, And they're all made out of ticky tacky And they all look just the same.

And they all play on the golf course And drink their martinis dry, And they all have pretty children And the children go to school, And the children go to summer camp And then to the university, Where they are put in boxes And they come out all the same.

And the boys go into business And marry and raise a family In boxes made of ticky tacky And they all look just the same. There's a green one and a pink one And a blue one and a yellow one, And they're all made out of ticky tacky And they all look just the same."

Malvina Reynolds 


\section{Epilogue}

Enough words have been written. The epilogue shows a text-portrait of a MAXQDA analysis of my personal perspective represented in the text of this dissertation. I sincerely hope this visual isn't taken to confuse my mind, its workings and its contents with a 'hokjesgeest'. ${ }^{32}$

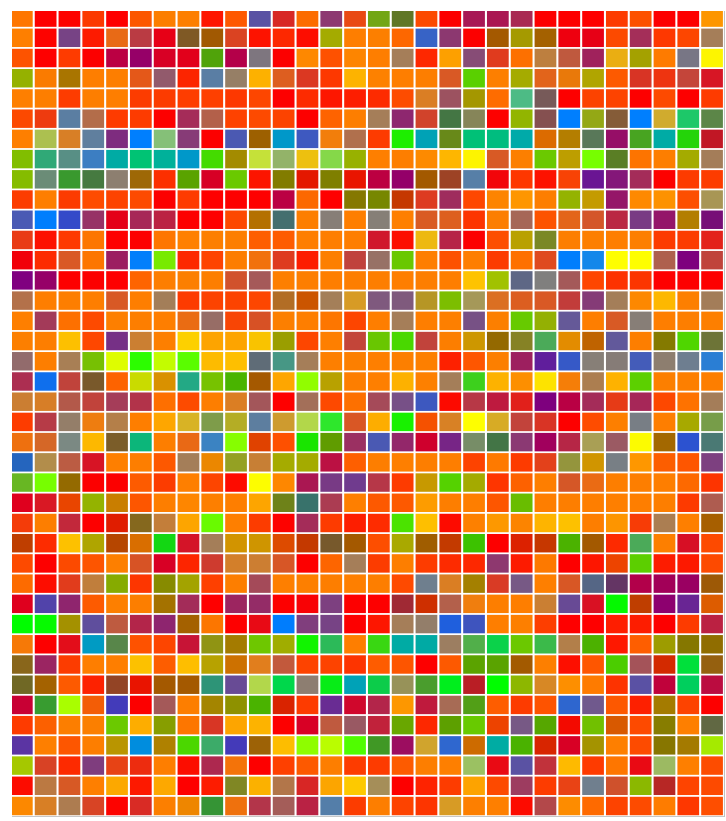

\section{Legend}

Hierarchist

Egalitarian

Individualist

Fatalist

Autonomous

Dynamic

32 'Hokjesgeest' is a Dutch word for narrow-mindedness. A 'hokje' is a little box. 'Geest' is the Dutch word for mind. A literal translation would be 'mind of little boxes'. This MAXDA picture is full of little boxes... I think a fundamental fear of a dynamic-autonomous person like me is to be narrow-minded... 
Acknowledgements 
The essence of all beautiful art, all great art, is gratitude.

Friedrich Nietzsche

Wat is het breken van het licht

Met dagenraad vervuld

Wat is het toch een mooi gezicht

Door engelen verguld.

Opa Reinier, in a dream 
Writing a dissertation is an effort you can never accomplish on your own. There are so many people and also non-human friends and life companions to thank. Where do I start? With my promotors Pim and Harro? Well, perhaps I better start with my grandparents: Oma Sietje and Opa Reinier. Although they aren't living on this planet anymore, they have helped a great deal awakening my love for literature, language, books, poetry, nature, and gardens. One of my favourite days out was going to the Hortus in Haren with Opa Reinier. His love for his garden, birds, and the way he talked and wrote about trees still inspire me today. His book about the trees on the golf club in Glimmen is on my night desk. Oma Sietje, I still miss your griesmeelpudding met vlierbessensap and our visits to the Groninger Museum.

Helmut, my Patenonkel, wherever you are now, you still guide and help me on my way through life!

Mam en pap: jullie lieten me toen ik in de kinderwagen zat gezichten zien in bomen in het bos in Bergen. Die bomen, en alle andere bomen in alle andere bossen, zijn figuren voor me geworden die me inspireren en me goede ideeën geven. Ze hebben me veel geleerd over mijzelf en zijn voor mij een 'personificatie' van de natuur waar je een diepe gevoelsrelatie mee kunt hebben. Zij representeren de onlosmakelijke samenwerking tussen de chaos en de orde van het leven waarin je als mens altijd ondergedompeld bent maar waaraan je tegelijk ook vorm kunt geven. Maar lieve pap en mam, jullie hebben me nog zo veel meer gegeven, naast het leven zelf! Dat kan allemaal niet in woorden gevat worden. Desondanks nog een paar woorden: Pap dank je wel voor je nooit aflatende steun, vertrouwen en liefde! Mam, je bent een rots in de branding en je hebt me laten zien dat het mogelijk is om altijd het goede in de mens en in mezelf te blijven zien, wat er ook gebeurt. Dat is een groot cadeau! Het maakt ook de moeilijke momenten mooi en zinvol.

Mijn liefste Rob. Dank je voor je geduld en vertrouwen dat ik dit wel een keer tot een goed einde zou brengen. De meeste mensen zeggen dat de laatste loodjes van een proefschrift het zwaarst wegen, maar met jou naast me heb ik dat niet zo ervaren. Je weet me te temperen als ik de workaholic dreig uit te hangen en je helpt me wat rust in te bouwen als dat nodig is. Helaas hebben we dit jaar niet zo veel kunnen genieten van wat we het liefste samen doen: op avontuur gaan en door de bossen struinen op zoek naar leuke beestjes en plantjes, en naar historische kuilen, greppels en roestige metalen dingetjes. Nu ik mijn boekje af heb en jij je botjes weer op de juiste volgorde hebt, kunnen we weer volop op pad. Ik verheug me op de nieuwe herinneringen die we samen gaan maken.

Caspar, met jou begon ik aan dit proefschrift-avontuur. Wat hebben we veel gepraat, gelachen, gehuild, gereisd en gesport. Dank je dat je de wereld van het hardlopen, 
fietsen en klimmen voor me geopend hebt. Noodzakelijke elementen als je voor de rest van de dag met je neus in de boeken (of achter de peecee) zit. Frankrijk, Zweden, Vietnam en China op de fiets neemt niemand ons meer af. En er zijn zo veel meer hele dierbare herinneringen dat ik er niet eens aan ga beginnen die allemaal te beschrijven. Die moeten we maar eens ophalen bij onze volgende kopjes thee. Ondanks dat onze wegen een verschillende kant op zijn gegaan voel ik me nog steeds met je verbonden: mijn tweelingvriendje zal je altijd blijven!

Pieter en Monika. Wat is het fijn om vrienden als jullie te kennen. Er zijn zoveel mooie, ontroerende, gezellige en spannende momenten die we samen hebben meegemaakt. Kamperen, fietsen, klimmen, skiën, liedjes maken, spelen, salsa dansen, koken, eten, kaas en wijn. Alles wordt een klein feestje met jullie. Zelfs voetbal kijken. Zonder vriendschap als die van jullie is het onmogelijk om een proefschrift te schrijven. De andere kant is ook waar: door de laatste loodjes van het schrijven van zo'n boek heb ik jullie de laatste tijd veel te weinig gezien. Gelukkig weten jullie zelf hoe dat allemaal werkt, met zo'n proefschrift. Laten we veel meer moois samen mee maken! Nu ook met Olga er bij!

Tanja, met jou kun je de wereld aan. Je brede horizon, eindeloze energie, liefdevolle natuur en subtiele humor zijn inspirerend. Het is fijn om samen te kletsen, te fietsen, te wandelen, concertjes te bezoeken of naar de sauna te gaan. Je weet een geluksgevoel in me los te maken. En op lastige momenten weet je precies de juiste dingen te zeggen. Dankjewel dat je mijn lieve vriendinnetje bent!

Wat ben ik toch een gelukkig persoon met zo veel lieve vrienden. Marlinda, ik mis je nog steeds in Maastricht en hoop dat ik nu eindelijk eens wat vaker naar Groningen kan komen. Als we elkaar zien is het net of er geen tijd verstreken is. Hopelijk betekent dat niet dat we niet gegroeid en veranderd zijn de afgelopen jaren! Mirthe, met jou kun je de beste intellectuele conversaties van de wereld hebben. Je bent nooit bang om moeilijke en uitdagende vragen over de betekenis van het leven te vragen. Als ik een spiegel nodig heb en een goede vriend die niet bang is om me de waarheid te zeggen, dan weet ik dat ik bij jou terecht kan. Sanne, je warme, open en lieve persoonlijkheid zijn altijd inspirerend voor me. Als ik iets verrassends tegenkom in het leven of in mijn onderzoek hoor ik altijd jouw stem in mijn geestesoor die zegt: "ja, echt?" Het herinnert mij er aan vol nieuwsgierigheid open te staan voor nieuwe inzichten. Tia, van jou is er maar één. Je tomeloze energie en optimisme zijn betoverend. Ik vind het fijn jou om me heen te hebben en we zouden meer leuke dingen samen moeten doen. Katja, dank je voor de mooie uurtjes op stal en met de paarden op de les bij Marlou en in het Kannerbos, met tapas of andere lekkere hapjes op een terras, al pratend over de betekenis van het leven, verre reizen, boeddhisme en dromen. Ook al ben ik nu niet 
meer zo vaak op een paardenrug te vinden als vroeger: de herinneringen, sommige vrolijk, sommige verdrietig, zijn me erg dierbaar. En de rest blijft gewoon.

Aukje! We groeiden samen op in de Brahmsstraat in Alkmaar. We verhuisden ook samen naar Maastricht als eerstejaars studenten. Toevallig hadden we onafhankelijk van elkaar een kamer uitgezocht in dezelfde straat. Nog geen 100 meter van elkaar. Daarna zelfs maar weer bij elkaar in het zelfde studentenhuis gaan wonen. Boven alles ben jij mijn lieve en dierbare vriendinnetje. Zoveel uurtjes samen lief en leed gedeeld. Tijdens logeerpartijtjes 's nachts stiekem advocaat-snoepjes eten en denken dat we daar dronken van zouden worden. Serieuze gesprekken over het leven en giechelend over de jongens waar we verliefd op waren. Van de sigaretten die we op het balkon probeerden kregen we hoofdpijn. De conclusie: niets voor ons. IJsjes eten in het stadspark, onze kamers verven al staande op het ooit witte krukje dat nu wel alle kleuren van de regenboog gehad moet hebben (net als onze haren). De lange wandeling van thuis naar Bergen aan Zee toen het geijzeld had en we op onze kont met een zak tijgerbrood van een duinpad af konden glijden. Onze eerste vakantie zonder ouders in Oostenrijk. Terugdenkend aan al deze 'meisjesdingen' zie ik je nu als een hele mooie vrouw en moeder van drie prachtige lieve kinderen. Ik ben trots op je en vereerd dat je mijn paranimf wilt zijn.

Mijn andere paranimf en broer: Elgar! Ik heb je zien opgroeien van een schattige baby tot een respectabele man. Toen je klein was dacht ik altijd dat je professor zou worden. Je vertelde verhalen als de beste en ik denk dat ik het vertellen van verhalen altijd aan intellect, kennis en professorschap gekoppeld heb. Je was altijd meer geïnteresseerd in politiek dan ik. En nu ik ook geïnteresseerd ben zijn we het niet altijd eens over alles, maar dat maakt onze gesprekken des te interessanter en levendiger. Voor mij zijn onze discussies een goede toetssteen voor mijn eigen aannames. Meestal blijf ik bij mijn mening, maar dan wel gefundeerder dan voorheen. Je bent nog steeds een betere verteller en debater dan ik, maar na mijn verdediging ben ik wel een stapje dichterbij professorschap dan jij. Hoewel, je weet maar nooit...

David, a whole ocean is sitting between us. I am glad we live in these times of globalisation and Skype. Thank you and Chloe -- and Pie and Elon -- for taking me into your home and life for two weeks as a true family member! Thank you Chloe for the great times going to the farmers market, to Chi Gong in the park, and to the gym together, and thank you for arranging the valuable encounters with your friends and urban gardeners of Phoenix! But thanks above all for the exquisite cooking, Chloe. I never met a better cook in my life and I am not exaggerating. It must be the love you put into the food. David, how much I enjoyed working with you on our GISER workshop, on our articles (which we still need to finish), and on the Urban Net proposal. I will never forget the fun we had baking cupcakes for Chloe's birthday; getting entangled in your palm tree and 
bougainvillea; playing music in your home and going to the jazz sessions at The Nash. I have very special memories about the night at the pond in your garden, talking until the birds started singing again. Thank you for sharing your heart with me, David. You have a special place in mine. I still can't believe how much I miss you.

Veronique and Su-Mia: we stepped into the dissertation-boat during the same time. Soon we became roommates at ICIS and we stayed roommates until recently. I guess we spent more time together than we did with our families and loved ones over the past years. I think we got to know each other very well and I am glad we had that opportunity. We shared so many of our thoughts, feelings and life events. You have been a great support on the dissertation-railway. However, we still failed to see Charlie's Angels...!

Thanks also to all my other (ex) ICIS colleagues, with special thanks to Anja and Ron. Annet, thank you for accommodating and helping wherever support is needed. Annet, you really make ICIS feel like a place called 'home'. Thank you Maud for being my first roommate, co-author and trustee! We have so much in common and it is great fun working with you and sparring and sharing thoughts about research, the academic system, education and the rest of life. Thank you Julia for your inspiring chats. I feel a strong connection with you when it comes to reflecting on science, sustainability and human nature. Ceren, thank you also for your cheerful and inspiring personality! Ex- colleagues who meant much to me: Pieter (you already got praise as my friend), you have been an astonishing ICIS colleague too. It was so much fun working with you on the SUN project and we had a fun but smelly time staying some nights in an old munition chamber in Christiania in Copenhagen. I wonder how we smelled at the conference we went to. I love the complementarity of our academic capacities. We made a perfect team. I hope we can team up somehow in the future again. Darryn, my favourite Scotsman and the only one who ever got me drunk: I was sad when you left. I am glad we kept in touch and I hope we get the chance to work on urban sustainability together in the future. Thanks for the fun times in Maastricht and Amsterdam.

Agnes, thank you for putting faith in me and reassuring me on my academic pathway. Rolf, you are an amazingly warm-hearted man. Thank you also for your support and for inviting me as your saxophonist at your song presentations. Pleun, finally I can share the results of the questionnaire with you in this book. It took a while but I did not forget you. Thanks for all the support and encouragement to get me working with SPSS. Michael, you showed me that working with SPSS and statistics is a lot of fun. It got me a bit addicted even....Let's still write that article we talked about. Christoph, although you are a hunter and I am a gardener, we share the same activist heart and the passion for a science and a university free of neo-liberal constraints. It's been inspiring working with you in the VAWO. Let's save science! 
A lot of work wouldn't have been possible without the interns who assisted me during various phases. Alex, during the SUN project: I guess I have pleased you enough with nice words after you left and I am so glad you returned to ICIS for your PhD. Floortje, we had a lot of fun at our favourite place for work-outings: GaiaZoo. Thank you Hanneke for accommodating Floortje so well! Robbert Bosscher, Marie Collard, Fatima el Handouz, Elena Hofmann, Anja Kübeneck, Iris Kühnlein, Judit Kuschnitzki, Tim Strasser and Foteini Vakitsidou: thank you for your precious hours and patience with the articles validating the work on IUCN.

The people who supported me on the BIMBY chapter: special thanks also to Elizabeth Cook, Mathieu Bruls, Jeroen Verbeek, Floortje Mennen and her father, Elke Havenstein, Pierre Buijs, Luc Habets, Tim van Wanroij, Hilde Gorissen and Torben Mulder for your pointed questions and valuable comments. Also greatest thanks to David and Chloe, Chris, Jennifer Wadsworth and Chip Satterlund for teaching me so much about Arizonian gardening. Colleagues in Operatie Steenbreek: let's break some stones and green lots of gardens with BIMBY. Mathieu and Jeroen, it is great to have met you. We make a great team of subversive people and it has been a great pleasure to start connecting our disciplines of sustainability science, architecture and landscape architecture. I am sure a fruitful future of our efforts will follow!

Very special thanks to Jan Stel, Nancy Grimm, Raf de Bont and Dolf de Groot for taking the time to review and approve my dissertation. Nancy, thank you also for your confidence in a stranger and it has been a pleasure meeting you in your house in Phoenix. I'd be happy to be taken on a long walk around the neighbourhood by of Adobe and Raleigh in the future once again. A special hug to Phil (Collins). My gratitude also goes to the corona: Jan Stel, Jose van Eijndhoven, Jens Lachmund, Raf de Bont, Robbert Snep, Arnold van Vliet, and Mark Reed. At the point of writing you make me a bit nervous but I am also looking forward to your questions with curiosity.

Without music my brains wouldn't work the way they do (it remains a question whether that is a good thing). Thanks to the many inspiring hours of making music together: all the members of Kumulus Leerorkest, Kumulus Bigband, the Tasty Town Bigband and the New Orleans Brass Connection!

Although they will never read this, I don't want to miss this opportunity to also thank my non-human friends that accompanied the pathway of writing a dissertation. I hope they can somehow feel my intention and gratitude to have them (or had them) in my life. Speedy and Mowgli who were there at the start of it all; Streepje, who is still here and all the other 'Smikkelpanters' of our street: you make life a spectacle and an enchanting pleasure that cannot be understood by people who don't know you. I hope my work here will somehow be able to benefit all your non-human wild companions. 
Last but certainly not least: my grandest thanks to Pim Martens and Harro van Lente, my promotors. Without your trust, encouragement, inspiration, and feedback I wouldn't have gotten to this point in my life and career. I am looking back at the past years with a lot of gratitude. Thanks for trusting me and my 'patchwork approach', and thank you for giving me the freedom to wander off some beaten tracks: for letting me explore what my creativity can add to science.

I hope not, but am sure I forgot some Very Important People. I want to thank you too.

Carijn Beumer

Maastricht, October 2014 
Valorisation Addendum 


\section{Introduction}

The value of an academic dissertation can be considered for its contribution to the scientific community and - if compatible with the topic of research - for its contribution to the public good or society. Considering the economic or commercial value of academic research results and methods fits the emerging climate of a neo-liberalising academia which I do not support. The economic or commercial valorisation of an academic dissertation violates the principles of fundamental research and of free academic thinking. Therefore, I will restrict this valorisation addendum to what my research could contribute to the public good defined as the Public Domain.

\section{Relevance to the public domain}

This dissertation work is motivated by a personal and by a broader societal quest for a more sustainable society that supports and nourishes a thriving biosphere. It is motivated by a search for ways to turn the tide of the exploitation of nature for private benefits and short-term human needs (or wants). In this context, the dissertation more specifically discusses the issue of biodiversity conservation in a rapidly urbanising world. Increasing human populations and land use change -- such as urbanisation -- are threatening the last pieces of wild nature. Biodiversity loss currently takes place at a level and pace that scientists started speaking of as the 'sixth great extinction wave'. This sixth wave hasn't been caused by meteorites or shifts in the axis of the planet. It is being caused by human behaviour. In this dissertation the option of Urban Based Conservation (UBC) is explored as a viable contribution for the protection of global biodiversity. It contains the assumption that urban areas are both large hubs for unsustainability, but at the same time cities hold a large potential for developing more sustainable lifestyles and human behaviour. Urban sustainable lifestyles will have an effect of the design of cities themselves, but also it may have its positive effects on the areas where cities get their resources and dispose of their wastes. UBC is a novel concept which includes the protection and enhancement of global biodiversity through enhancing green infrastructures within cities - influencing landscapes and biodiversity beyond cities -- and through engaging citizens in the greening of their direct living environments and their lifestyles, which may lead to higher levels of affection and engagement for biodiversity beyond the direct living environment. Methods and tools are developed and proposed that can contribute to a societal transformation towards integrating biodiversity conservation and sustainability considerations in the daily lives and practices of especially citizens and policymakers.

My research approach contributes something novel to the established methodologies that are ongoing in the fields of Integrated Assessment and Sustainability Science. The 
Perspectives Method has been broadened in its scope and formerly marginalised perspectives have been academically 'empowered' and legitimised as valuable addition to Cultural Theory. Also, the Perspectives Method hasn't been applied to the subjects of biodiversity conservation and urban greening and gardening before. Broadening the toolbox of Integrated Sustainability Assessment with qualitative methods from the humanities (discourse analysis, content analysis, and critical reflection) is another contribution to the Body of Knowledge of this dissertation. Also novel is the patchwork assessment approach, which makes it possible to dive into a variety of societal and landscapelevels of the subject of biodiversity conservation and bringing them together in a final synthesis. With zooming in to urban greening and gardening practices as a particular and recently emerging conservation patch, I contributed to exploring the question on how biodiversity conservation and halting global biodiversity loss can be reconciled with a rapidly changing, urbanising world. Until now, there has been a lack of integrative methodological assessments of the societal support, the awareness and the cultural perspectives on the potential of advancing cities as green 'stepping stones' for biodiversity.

\section{Target groups}

The answers that I formulated to my research questions are relevant for both the scientific community involved with conservation and sustainability questions and for the societal enhancement of a thriving planetary biosphere. The more specific role that cities and urban culture - on the level of citizen lifestyles and practices - could be playing for global biodiversity has only very recently become considered in the scientific literature, debates and in policy-making. Therefore, the results and methods used in my research can be valuable to conservation organisations and policymakers concerned with nature conservation. For these groups especially the results of the DISCO analyses of the Global Scenario Studies (CHAPTER 6) and the IUCN (CHAPTER 7) may be relevant. The provided insights into dominant and marginalised perspective groups in the conservation regime may contribute to a novel conservation debate that enables to include more societal actors and fields than is currently the case.

The chapters on urban based conservation may also be relevant to policymakers and conservationists. They provide novel tools to facilitate a more systematic societal discussion about urban greening and gardening, ecosystem services, green infrastructure and their relevance to conservation of global biodiversity. The Biodiversity Benefits framework for example, can contribute to a dialogue on urban greening projects and their implications for biodiversity on various scale levels. Structured and structural public discussions on the relation between urban greening projects and biodiversity conservation are still missing. Configurations of building blocks within the framework can provide more insight into the relations between motivational backgrounds for urban greening 
projects, the greening regimes that constitute them and the benefits that can be created for biodiversity at the local to the global scale level. In this context, the results of this dissertation may be also interesting to designers, landscape architects, urban planners, and local or regional NGOs concerned with nature development and nature education.

The BIMBY framework can be helpful with providing new ways to look at, design and maintain domestic gardens. This is relevant to citizens themselves. It can deliver ideas and guidelines to more sustainably designing, maintaining and using domestic outdoor spaces. BIMBY can also be interesting to governing parties and urban planners. They may start to include domestic gardens into their conceptualisation of green infrastructure and urban land use options that can benefit the development of sustainable cities and sustainable landscapes within and beyond urban borders. Greening domestic gardens, for example, isn't only beneficial to biodiversity; it also contributes to reducing stormwater runoff, the urban heat island effect, and it can enhance a feeling of security and well-being of urban residents. Greening urban space can help citizens to find a new connection to nature and it implicitly facilitates learning about biodiversity, ecosystem services and sustainability.

Architects and landscape architects already expressed their interest in the BIMBY framework as a way to help them design landscapes and urban spaces in more sustainable ways. The BIMBY framework is open to further development towards a publicly accessible tool that can be used in transformational citizen science projects - a concept and practice that is both interesting academically and from a governance perspective. Several Dutch cities, educational organisations, NGOs, and also the branch of commercial horticulturists expressed their interest in the BIMBY framework as a method to assess the state of gardens in the Netherlands, and as a potential tool to engage citizens in the greening of their gardens, which are currently subject to a trend of sealing and paving. Currently this conjoining interest is resulting into a new project called Operatie Steenbreek. Also the Dutch media already picked up this topic and wrote and broadcasted several items about greening domestic gardens and Operatie Steenbreek.

\section{Activities and Products}

This dissertation has resulted into two novel methodological frameworks that combine ecological, societal and cultural aspects in order to contribute to an integrative societal dialogue on the role of urban greening for biodiversity and its conservation. The Biodiversity Benefits framework and the BIMBY framework can be further developed and tested towards becoming tools that can contribute to the co-production of conceptual and actionable knowledge on the relation between urban greening, gardening and (global) biodiversity conservation. Employing these frameworks in transformational sustainability science projects or in processes of land use planning and landscape design could ideally and practically result into more sustainable landscape design and land use 
planning on smaller and larger scale levels. On all levels this could contribute to novel landscape design-concepts that combine aesthetics, practical functionality and ecological functionality. As such the frameworks can concretely contribute to better reflected and multi-functional green infrastructures. This has already started with the adoption of the BIMBY framework within Operatie Steenbreek. It's chances for ongoing development will be furthered in a VENI proposal that will be submitted to NWO in January 2015.

Furthermore, this dissertation provides insights into the cultural perspectives that are ongoing in the current conservation regime. It also provides recommendations towards which perspective groups are still largely missing from the conservation debate. This dissertation proposes ways towards how such marginalised perspectives can be included and embraced, and points towards what potential value their inclusion could have. The methods for assessment used in this dissertation can be used by other researchers as well, benefitting their assessments of sustainable landscapes and of land use while including societal and cultural perspectives and values.

Very concretely, the dissertation book includes three accepted papers in peer reviewed journals. One additional paper is under review at the time of writing and the Intermezzo chapter has been submitted as a commentary. The first paper \{Beumer, 2010 \#270\} concerns the cultural perspectives represented in two influential Global Scenario Studies (The Millennium Ecosystem assessment and the IPCC SRES Scenarios). In the second paper \{Beumer, $2013 \# 1980$ \} a discourse analysis is presented of the Cultural Perspectives represented by IUCN. The third paper \{Beumer, 2014 \#2101\} concerns the development of the BIMBY indicator framework. This paper already has a very high Altmetric score. The Altmetric score is a measure of the quality and quantity of online attention that an article has received. The paper is ranked on the first place amongst other papers of a similar age in the journal Sustainability Science and it is ranked on the second place compared to all other tracked articles in Sustainability Science. It is especially well received in the public domain. The paper under review includes pilot case studies based on the BIMBY framework.

\section{Innovation}

Novel about this dissertation is the patchwork approach that combines several scale levels of assessment, integrates critical methods from the humanities into Integrated Assessment and Sustainability Science and proposes novel methodological frameworks to enhance actionable and transformational knowledge (co-) production on the role of urban greening and gardening for biodiversity conservation. Especially the BIMBY framework can be valued in this respect, as it combines ecological principles with cultural aspects such as design style and artefacts, and citizen preferences with regards to 
functionality, maintenance and appearance. It intends to increase societal awareness and dialogue on biodiversity and its conservation, and at the same time it intends to attract citizens into action for biodiversity within in their domestic outdoor spaces. This type of engagement in the domestic area can (re)connect citizens to nature and biodiversity far beyond their own (back) yards, which is expressed in Dunn's Pigeon Paradox. The Biodiversity Benefits framework has a similar function of connecting citizens and other societal stakeholder groups to nature and biodiversity. It focuses on embedding and fostering a more structured debate about the role of urban greening and gardening and the benefits of such activities for local, regional and global biodiversity. Until now, such a dialogue is largely missing in society and in traditional conservation organisations. As such, this dissertation contributes to an integration of inter- and trans-disciplinary and critically reflected knowledge at one side, and integrated and well reflected action for biodiversity in an urbanising world at the other side.

\section{Schedule \& Implementation}

The final question that has to be answered in this valorisation addendum concerns the schedule for implementation, the risks involved, the market opportunities, and the costs involved. As I have not developed a commercial product and perhaps more importantly, as I principally object to a commercial valorisation of academic work, I consider this question unanswerable. 
Literature 

Abrams, N. E., \& Primack, J. R. (2011). The New Universe and the Human Future. London: Yale University Press. Adams, W. M. (2006). The Future of Sustainability: Re-thinking Environment and Development in the Twentyfirst Century. Cambridge, UK: University of Cambridge, Department of Geography.

Adams, W. M. (2013). Conservation in the Anthropocene: Biodiversity, Poverty and Sustainability. In D. Roe, J. Elliot, C. Sandbrook \& M. Walpole (Eds.), Biodiversity Conservation and Poverty Alleviation. Exploring the Evidence for a Link. Chichester: John Wiley and Sons.

Agger, B. (2014). Cultural studies as critical theory. New York: Routledge.

Aitken, S. (2012). The value of diversity. Biodiversity, 13(1), 1-1.

Alcamo, J., Alder, J., \& Bennet, E. M. (2005). Chapter 8: Four Scenarios. In S. Cork, G. Peterson \& G. PetschelHeld (Eds.), Millennium Ecosystem Assessment. Scenarios Assessment. New York: Island Press.

Andel, v. J., \& Aronson, J. (Eds.). (2012). Restoration Ecology. The New Frontier. Oxford: Blackwell Publishers.

Anonymous. (2013). Speech by Pope Francis 13 March 2013. Retrieved 25 July 2013, from http://www.nytimes.com/video/2013/03/13/world/europe/100000002116186/speech-by-popefrancis.html

Appleton, A. F. (2002). How New York City Used an Ecosystem Services Strategy Carried out Through an UrbanRural Partnership to Preserve the Pristine Quality of Its Drinking Water and Save Billions of Dollars and What Lessons It Teaches about Using Ecosystem Services Paper presented at the The Katoomba Conference

Armstrong, D. P., \& Seddon, P. J. (2007). Directions in reintroduction biology. Trends in Ecology \& Evolution, 23(1), 20-25.

Aronson, J., Clewell, A. F., Blignaut, J. N., \& Milton, s. J. (2006). Ecological restoration: a new fronteer for nature conservarion and economics. Journal for Nature conservation, 14(135-139).

Arthus-Bertrand, Y. (Writer). (2009). Home: http://www.youtube.com/user/homeproject.

Asselt, M. v., Rotmans, J., Elzen, M. d., \& Hilderink, H. (1995). Uncertainty in integrated assessment modeling: a cultural perspective approach (No. 461502009115 p en, 1995). Bilthoven: National Institute of Public Health and the Environment (RIVM).

AutarkHome. (2013). AutarkHome. Retrieved 16 september 2013, from http://www.autarkhome.nl/

Bacchi, C. L. (2009). Analysing policy: What's the problem represented to be? Melbourne: Pearson Education Australia.

Baker, P. J., \& Harris, S. (2007). Urban mammals: what does the future hold? An analysis of the factors affecting patterns of use in residentuial gardens in Great Britain. mammal Review, 37(297-315).

Baker, S. (2006). Sustainable Development. New York: Routledge.

Baldwin, R. f., Powell, R. B., \& Kellert, S. R. (2011). Habitat as Architecture: Integrating Conservation Planning and Human Health. AMBIO, 40, 322-327.

Bandura, A. (2004). Social and Cognitive Theory for Personal and Scoial Change by Enabling Media. In A. Singhal, M. J. Cody, E. M. Rogers \& M. Sabido (Eds.), Entertainment-Education and Social Change. History, Research, and Practice. New Yersey: Lawrence Erlbaum Associates.

Banerjee, S. B. (2003). Who sustains Whose Development? Sustainable Development and the Reinvention of Nature. Organization Studies, 24(1), 143-180.

Baratay, É., \& Hardouin-Fugier, É. (2002). Zoo: A History of Zoological Gardens in the West. London: Reaktion Books Ltd.

Barnes, J. (2003). Aristoteles. Rotterdam: Lemniscaat.

Barton, A. C., \& Tan, E. (2013). "It Changed Our Lives": Activism, Science, and Greening the Community. Canadian Journal of Science. Mathematics and Technology Education, 10(3), 207-222.

Baum, K. A., Haynes, K. J., Dillemuth, F. P., \& Cronin, J. T. (2004). The matrix enhances the effectiveness of corridors and stepping stones. Ecology, 85(10), 2671-2676.

BBC. (2013, 29 april 2013). Bee deaths: EU to ban neonicotinoid pesticides. Retrieved 15 August 2013, from http://www.bbc.co.uk/news/world-europe-22335520

Beatley, T. (2011). Biophilic Cities. Integrating Nature into Urban Design. Washington D.C.: Island Press.

Bechler, Z. (1995). Aristotle's Theory of Actuality. New York: State University Press of New York.

Bedsted, B. (2012). World Wide Views on Biodiversity. From the World's Citizens to the Biodiversity Policymakers. Copenhagen: The Danish Board of Technology Foundation.

Begon, M., Townsend, C. R., \& Harper, J. L. (2006). Ecology: From Individuals to Ecosystems (Fourth ed.). Oxford: Blackwell Publishing Ltd.

Beriatos, E., \& Gospodini, A. (2004). "Glocalising" urban landscapes: Athens and the 2004 olympics. Cities, 21(3), 187-202. 
Bernard, R. H. (2011). Research Methods in Anthropology. Qualitative and Quantitative Approaches. (5th ed.). Plymouth: AltaMira Press.

Best, S., \& Kellner, d. (1997). The Postmodern Turn. New York: The Guildford Press.

Bethge, P. (2007). Eisbaeren zum Suedpol? Der Spiegel, 47, 168-169.

Beumer, C., Huynen, M., \& Martens, P. (2008). Finding Paradise in a Complex Web: The Inter-relation of Biodiversity, Ecosystems and Human Health. In L. Westra (Ed.), Reconciling human existence with ecological integrity. London: Earthscan.

Beumer, C., \& Martens, P. (2010). Noah's Ark or World Wild Web? Cultural Perspectives in Global Scenario Studies and Their Function for Biodiversity Conservation in a Changing World. Sustainability(Special Issue Futures).

Beumer, C., \& Martens, P. (2013). IUCN and Perspectives on Biodiversity Conservation in a Changing World. Biodiversity and Conservation.

Beumer, C., \& Martens, P. (in review-a). BIMBY's first steps: a pilot case study on biodiversity and ecosystem services in domestic front-yards in Phoenix and Maastricht. Urban Ecosystems.

Beumer, C., \& Martens, P. (2014). Biodiversity in my (back) yard: a framework for assessing ecosystem services and biodiversity in residential gardens. Sustainability Science.

Beumer, C., \& Valkering, P. (2012). Een mooier MSP: daar doet u toch ook aan mee? Evaluatierapport MSP Heerlen. Maastricht: ICIS, Maastricht University.

Beumer, C., Valkering, P., \& Ruelle, C. (2010). Envisioning a Sustainable Urban Neighbourhood. Unpublished SUN Project Position Paper. ICIS Maastricht University - LEMA Ulg.

Bhagwat, S., \& Palmer, M. (2009). Conservation: the world's religions can help. Nature, 461(3 September 2009).

Bird, B., \& Pinkava, J. (2007). Ratatouille: Disney/Pixar.

Bishop, Hines, A., \& Collins, T. (2007). The current state of scenario development: an overview of techniques. Foresight, 9(1), 5-25.

Bishop, Phillips, A., \& Warren, L. (1995). Protected for ever? Factors shaping the future of protected areas policy. Land use policy, 12(4), 291-305.

Blackburn, H. (2012). Genetic Selection and Conservation of Genetic Diversity. Reproduction in Domestic Animals, Volume 47(Special Issue: Proceedings of the 17th International Congress on Animal Reproduction (ICAR)), 249-254.

Bode, M., Robert, W., Turner, W. R., Wilson, K. A., \& Venter, O. (2010). Conservation Planning with Multiple Organizations and Objectives. Conservation Biology, 25(2), 295-304.

Boeckel, J. v. (Writer). (1997). The Call of the Mountain: Arne Naess and the Deep Ecology Movement. In ReRunProducties (Producer).

Böhme, G. (1992). Natührlich Natur. Über Natur im Zeitalter ihrer technischen Reproduzierbahrkeit. Frankfurt am Main: Suhrkamp Verlag.

Bolund, P., \& Hunhammar, S. (1999). Ecosystem Services in Urban Areas. Ecological Economics, 29, $293-301$.

Boogerd, F. C. B. e. (2007). Systems Biology: Philosophical Foundations. Amsterdam: Elsevier.

Bortoft, H. (1996). The Wholeness of Nature. Goethe's Way toward a Science of Conscious Participation in Nature. New York: Lindisvarne Books.

Bottrell, D. (2009). Understanding 'Marginal' Perspectives: Towards a Social Theory of Resilience. Qualitative Social Work, 8(321), 321-339.

Boyd, J. M. (1984). The role of religion in conservation. The Environmentalist.

Braun, B. (2005). Environmental issues: writing a more-than-human urban geography. Progress in Human Geography, 29(5), 635-650.

Brenner, N. (2009). What is critical urban theory? City, 13(2-3), 198-207.

Brewer, G. D. (2007). Inventing the future: scenarios, imagination, mastery and control. Sustainability Science(2), 159-177.

Brisson, L. (1998). Plato the Myth Maker. Chicago, London: The University of Chicago Press.

Brodbeck, F., Kerschreiter, R., Mojzisch, A., Frey, D., \& Schultz-Hardt, S. (2002). Dissemination of critical, unshared information in decision-making groups: the effects of pre-discussion dissent. European Journal of Social Psychology, 32, 35-56.

Brugge, R. v. d. (2004). Transition Dynamics: the case of Dutch water management. Rotterdam: Dutch Research Institute for Transitions (DRIFT) Erasmus University Rotterdam.

Bruijn, W. d., Muur, W. v. d., Putter, J. d., Berg, J. v. d., Romeijn, D., \& Brugmans, G. (2009). Amsterdam Makeover 2040. On Tegenlicht: VPRO. 
Brundtland-Commission. (1987). Our Common Future.

Burghardt, K. T., Tallamy, D. W., \& Shriver, G. (2008). Impact of Native Plants on Bird and Butterfly Biodiversity in Suburban Landscapes. Conservation biology, 23(1), 219-224.

Burtynski, E. (Writer). (2006). Manufactured Landscapes: Zeitgeist Films.

Büscher, B. (2010). Derivative Nature: interrogating the value of conservation in 'Boundless Southern Africa'. Third World Quarterly, 31(2), 259-276.

Büscher, B., \& Whande, W. (2007). Whims of the Winds of Time? Emerging Trends in Biodiversity Conservation and Protected Area Management. Conservation and Society, Volume 5(No. 1), 22-43.

Büscher, B., \& Wolmer, W. (2007). Introduction: The Politics of Engagement between Biodiversity Conservation and the Social Sciences. Conservation and Society, Volume 5(No. 1), 1-21.

Büsscher, B. (2013). Transforming the frontier : peace parks and the politics of neoliberal conservation in southern Africa. Durham: Duke University Press.

Butler, D., \& Spencer, N. (2010). The Century of the City. Nature, 467(21 October).

Callo-Concha, D., Henning Sommer, J., Kleemann, J., Gatzweiler, F. W., \& Denich, M. (2014). Marginality from a Socio-ecological Perspective. In J. v. Braun \& F. W. Gatzweiler (Eds.), Marginality: Addressing the Nexus of Poverty, Exclusion and Ecology. Dordrecht, Heidelberg, New York, London: Springer.

Cameron, R. W. F., Blanuša, T., Taylor, J. E., Salisbury, A., Halstead, A. J., Henricot, B., \& Thompson, K. (2012). The domestic garden - Its contribution to urban green infrastructure. Urban Forestry \& Urban Greening, 11(2), 129-137.

Campbell, S. (1996). Green Cities, Growing Cities, Just Cities? Urban Plannibng and the Contradictions of Sustainable Development. Journal of the American Planning Association, 62(3), 296-312.

Capra, F. (1996). The Web of Life: A New Scientific Understanding of Living Systems. New York: Anchor Books.

Caragliu, A., Del Bo, C., \& Nijkamp, P. (2011). Smart Cities in Europe. Journal of Urban Technology, 18(2), 65-82.

Carifio, \& Perla. (2007). Ten Common Misunderstandings, Misconceptions, Persistent Myths and Urban Legends about Likert Scales and Likert Response Formats and their Antidotes. Journal of Social Sciences, $3(3), 106-116$.

Caro, T. (2010). Conservation by Proxy. Indicator, Umbrella, Keystone, Flagship, and Other Surrogate Species. London: Island Press.

Caro, T. M., \& O'Doherty, G. (2001). On the use of surrogate species in conservation biology. Conservation biology, 13(4).

Carpenter, S. (2002). Ecological futures: building an ecology of the long now. Ecology, 83, 2069-2083.

Carpenter, S., Pingali, P., Bennett, E., \& Zurek, M. (Eds.). (2005). Ecosystems and Human Well-Being: Scenarios. Findings of the Scenarios Working Group. Washington D.C. : Island Press.

Carrington, D. (2013, 29 April). Bee-harming pesticides banned in Europe. The Guardian.

Carson, R. (1962). Silent Spring. New York: Houghton Miffin Company.

Casey, E. S. (2011). The Edge(s) of Landscape: A Study in Liminology. In J. Malpas (Ed.), The Place of Landscape: Concepts, Context, Studies. Massachusetts: MIT Press.

Castells, M. (1997). The Power of Identity. Oxford: Blackwell.

Castells, M. (2010). The Rise of Network Society. The Information Age: Economy, Society and Culture. (2 ed. Vol. 1). Oxford: Blackwell.

Castro, C. J. (2004). Sustainable Development: Mainstream and Critical Perspectives. Organization \& Environment, 17(195), 195-225.

Catibog-Sinha, C. (2008). Zoo tourism: Biodiversity conservation through tourism. Journal of Ecotourism, 7(2-3), 160-178.

CBD. (2007a). Cities and Biodiversity. Paper presented at the Conference of the Parties 9, 2007, Curitiba.

CBD. (2007b). Report of the Cities and Biodiversity: Achieving the 2010 biodiversity Target. Mayors' Meeting on the Contribution of Cities to the Achievement of the 2010 Biodiversity Target. Curitiba: CBD.

CBD. (2008). Mainstreaming Biodiversity. Workshops on national biodiversity strategies and action plans. Montreal: Convention on Biological Diversity (CBD) and United Nations Environmental Programme (UNEP).

CBD. (2010). Global Biodiversity Outlook 3. Montreal: Convention on Biological Diversity.

CBD. (2011). Strategic Plan for Biodiversity 2011-2020 and the Aichi Targets: Living in Harmony with Nature. Montreal, Canada: UN-CBD-UNEP.

CBD. (2012). Cities and Biodiversity Outlook. Montreal: CBD.

Certomà, C. (2011). Critical Urban Gardening as a post-environmentalist practice. Local Environment, 16(10), 977-987. 
Chan, K. M. (2007). When Agendas Collide: Human Welfare and Biological Conservation. Journal of Conservation biology, 21(1), 59-68.

Chance, T. (2009). Towards sustainable residential communities; the Beddington Zero Energy Development (BedZED) and beyond. Environment \& Urbanization, 21(2), 527-544.

Chapin, F. S., Sala, O., \& Huber-Sannwald, E. (Eds.). (2001). Global Biodiversity in a Changing Environment: Scenarios for the 21st Century. New York: Springer-Verlag.

Charmaz, K. (2003). Grounded Theory: Objectivist and Constructivist Methods. In N. K. Denzin \& Y. S. Lincoln (Eds.), Strategies of Qualitative Inquiry (Vol. 2, pp. 249-250). Thousand Oaks, California: Sage.

Chen, X., \& Wu, J. (2009). Sustainable landscape architecture: implications of the Chinese philosophy of "unity of man with nature" and beyond. Landscape Ecology, 24, 1015-1026.

Chesters, G. (2004). Global Complexity and Global Civil Society. Voluntas: International Journey of Voluntary Nonprofit Organizations, 15(4), 323-342.

Chiesura, A. (2004). The role of urban parks for the sustainable city. Landscape and Urban Planning, 68(1), 129138.

Chivian, E. (2002). Biodiversity: It's Importance to Human Health. Harvard: Center for Health and the Global Environment \& Harvard Medical School.

Chou, W.-Y., Chang, C.-Y., \& Sullivan, W. C. (2011). Environmental qi field qualities of different landscape structures. Paper presented at the IFLA APR Congress - Hospitality: The Interaction with Land.

Chowdhury, R. R., Larson, K., Grove, M., Polsky, C., \& Cook, E. (2011). A Multi-Scalar Approach to Theorizing Socio-Ecological Dynamics of Urban Residential Landscapes. Caties and the Environment, 4(1), 1-19.

Christoffersen, L., E. (1997). IUCN: A Bridge-Builder for Nature Conservation. Green Globe Yearbook 1997, 5970.

Cilliers, S. (2010). Social Aspects of Urban Biodiversity -- An Overview. In N. Müller, P. Werner \& J. G. Kelcey (Eds.), Urban Biodiversity and Design. London: Wiley-Blackwell.

CITES. (2013). What is CITES? Retrieved 25 July 2013, from http://www.cites.org/eng/disc/what.php

Clayton, S., \& Myers, G. (2010). Conservation Psychology: Understanding and Promoting Human Care for Nature. Environmental Conservation, 37(2), 222-225.

Clement, M. T. (2010). Urbanization and the Natural Environment: An Environmental Sociological Review and Synthesis. Organization \& Environment, 23(3), 291-314.

Clemmons, J., \& Buchholz, R. (1997). Behavioural approaches to conservation in the wild. Cambridge: Cambride University Press.

Cole, D. H. (2011). From global to polycentric climate governance. Climate Law, 2, 395-413.

COMEST. (2005). The Precautionary Principle. Paris: World Commission on the Ethics of Scientific Knowledge and Technology.

Condon, P., M. (2010). Seven rules for Sustainable Communities. Design strategies for the Post-Carbon World. Washington: Island Press.

Cook, E. M., Hall, s. J., \& Larson, K. L. (2012). Residential landscapes as social-ecological systems: a synthesis of multi-scalar interactions between people and their home environment. Urban Ecosystems, 15, 19-52.

Copleston, F. (1993a). A History of Philosophy. Greeca and Rome: From the Pre-Socratics to Plotinus. (Vol. 1). New York: Image Books.

Copleston, F. (1993b). A History of Philosophy. Medieval Philosophy: From augustine to Duns Scotus (Vol. 2). New York: Image Books.

Corcoran, P. B. e. (2005). Toward a Sustainable World: The Earth Charter in Action. Amsterdam: KIT Publishers,

Coria, J., \& Calfucura, E. (2012). Ecotourism and the development of indigenous communities: The good, the bad, and the ugly. Ecological Economics, 73, 47-55.

Cornelis, J., \& Hermy, M. (2004). Biodiversity relationships in urban and suburban parks in Flanders. Landscape and Urban Planning, 69(385-401).

Costanza, R., D’Arge, R. \& De Groot, R. . (1997). The value of the world's ecosystem services and natural capital. Nature, vol 387, 253-260.

Costanza, R., De Groot, R., Sutton, P., Van der Ploeg, S., Andersond, S. J., Kubiszewski, I., Farber, S., \& Turner, R. K. (2014). Changes in the global value of ecosystem services. Global Environmental Change, 26, 152-158.

Cousteau, J.-Y., \& Dugan, J. (Writer). (1956). Le Monde du Silence. France.

Cranz, G., \& Boland, M. (2004). Defining the Sustainable Park: A Fifth Model for Urban Parks. Landscape Journal, 23(2), 102-120.

Crutzen, P., \& Stoermer, E., F. (2000). The Anthropocene. IGBP Newsletter, 41. 
Cumming, S. G., Alcamo, J., Sala, O., Swart, R., Bennet, E. M., \& Zurek, M. (2005). Are Existing Global Scenarios Consisten with Ecological Feedbacks? Ecosystems, 8, 143-152.

Cuppen, E. (2012). Diversity and constructive conflict in stakeholder dialogue: considerations for design and methods. Policy Science, 45, 23-46.

Cuppen, E., Breukers, S., Hisschemoeller, M., \& Bergsma, E. (2010). Q methodology to select participants for a stakeholder dialogue on energy options from biomass in the Netherlands. Ecological Economics, 69, 579591.

Curtis, A. (Writer). (2011). II: The Use and Abuse of Vegetational Concepts. In BBC (Producer), All Watched over by Machines of Loving Grace. England.

Dalsgaard, A. (Writer). (2013). The Human Scale. Bringing Cities to Life. In F. C. f. Real (Producer). Denmark. Dalsgaard, A. M. (Writer). (2012). The Human Scale. Bringing back cities to life. In F. C. f. Real (Producer).

Daly, H. (1987). The Economic Growth Debate: What Some Economists Have Learned But Many Have Not. Journal of environmental Economics and Management 14, 323-336.

Davies, C. E., Moss, D., \& O Hill, M. (2004). EUNIS Habitat Classification Revised: Report to the European Environment Agency and the European Topic Centre on Nature Protection and Biodiversity.

Davis, J. G., \& Whiting, D. (2013). Choosing a Soil Amendment. Retrieved 3 June 2013, from www.ext.colostate.edu/pubs/garden/07235.html

Davis, K. (1955). The origin and growth of urbanization in the world. American Journal of Sociology, 60(5), 429437.

DBG. (2013). Desert Botanical Garden. Retrieved 9 August 2013, from http://www.dbg.org/

De Jong, E. A. (2006). Natuurlijke verwantschap. Over tuin- en landschapsarchitectuur. Leiden: Universiteit Leiden.

De Ridder, W., Turnpenny, J., Nilsson, M., \& Von Raggamby, A. (2007). A Framework for Tool Selection and Use in Integrated Assessment for Sustainable Development. Joural of Environmental Assessment Policy and Management, 9(423-441).

De Vries, B. (2013). Sustainability Science. Cambridge: Cambridge University Press.

Dearborn, D. C., \& Kark, S. (2009). Motivations for Conserving Urban Biodiversity. Conservation Biology, 24(2), 432-440.

DesJardins, J. (2006). Environmental Ethics. An Introduction to Environmental Philosophy (4 ed.). Belmont: Thomson Wadsworth.

Dewaelheyns, V., Elsen, A., Vandendriessche, H., \& Gulinck, H. (2013). Garden management and soil fertility in Flemish domestic gardens. Landscape and Urban Planning, 116, 25-35.

Diamandis, P. H., \& Kotler, S. (2012). The Abundance Builders. Bethesda, US: World Future Society.

Diamond, J. (1975). The island dilemma: lessons of modern biogeographic studies for the design of natural reserves. Biological Conservation, 7, 129-146.

Diamond, J. (2005). Collapse. How Societies Choose to Survive or to Fail. London: Peguin Books.

Dijk, M. (2010). Innovation in car mobility. Co-evolution of demand and supply under sustainability pressure. Maastricht: Maastricht University Press.

Dijksma, S. (2014). Natuurlijk verder. Rijksnatuurvisie 2014. Den Haag: Ministerie van Economische Zaken.

Dohmen, J. (2005). Michel Foucault: Waarom zou niet iedereen van zijn leven een kunstwerk kunnen maken? In J. Dohmen (Ed.), Over levenskunst. De grote filosofen over het goede leven. Amsterdam: Ambo.

Doolittle, A. A. (2007). Fortress Conservation. Encyclopedia of Environment and Society, September 2005, from http://knowledge.sagepub.com/view/environment/n432.xml

Doorman, M., \& Visser, W. (1995). Denkers in de ring, filosofische polemiek uit 25 eeuwen. Amsterdam: Ooievaar.

Douglas, M. (1970). Natural Symbols: Explorations in Cosmology. London: Barry \& Rockliff.

Dresner, S. (2002). The Principles of Sustainable Development. London/Sterling, VA: Earthscan.

Dunn, R. R., Gavin, M. C., Sanchez, M. C., \& Solomon, J. N. (2006). The pigeon paradox: dependence of global conservation on urban nature. Conservation Biology, 20(6), 1814-1816.

EC. (2013). Natura 2000 Network. Retrieved 17 July 2013, from http://ec.europa.eu/environment/nature/natura2000/

Eisenstein, C. (2013). A new story of the people. On TEDxWhitechapel. Whitechapel: TED.

Elo, S., \& Kyngas, H. (2008). The Qualitative Content Analysis Process. Journal of Advanced Nursing, 62(1), 107115.

Elwell, F. (1996). Verstehen: The Sociology of Max Weber. Retrieved 6-3-2013, 2013, from http://www.faculty.rsu.edu/ felwell/Theorists/Weber/Whome.htm 
Erez, M., \& Gati, E. (2004). A dynamic, multi-level model of culture: from the micro level of the individual to the macro level of a global culture. Applied Psychology: An International Review, 53(4), 583-598.

Escobar, A. (1998). Whose knowledge, whose nature? Biodiversity, conservation and the political ecology of social movements. OJournal of Political Ecology, 5, 53-82.

Escobar, A. (1999). After Nature: Steps to an Antiessentialistr Political Ecology. Current Ecology, 40(1), 1-30.

ETC-Group. (2011). Who will Control the Green Economy? Ottawa, Canada: ETC-Group.

Evans, D. (2012). Building the European Union's Natura 2000 Network. Nature Conservation, 1, 11-26.

Ewing, R. (2001). Using a Visual Preference Survey in Transit Design. Public Works Management Policy, 5(270), 270-280.

Fairview. (2009). Retrieved 24 May 2013, from www.fairviewplace.org

Farinha-Marques, P., Lameiras, J. M., Fernandes, C., Silva, S., \& Guilherme, F. (2011). Urban biodiversity: a review of current concepts and contributions to multidisciplinary approaches. Innovation: The European Journal of Social Science Research, 24(3), 247-271.

Felson, A., \& Pickett, S. (2005). Designed experiments: new approaches to studying urban ecosystems. Frontiers in Ecology and the Environment, 3(10), 549-556.

Felson, A., \& Pickett, S. T. A. (2005). Designed experiments: new approaches to studying urban ecosystems. Frontiers in Ecology and the Environment, 3(10), 549-556.

Fenner, F. (2010). Deliberate introduction of the European rabbit, Oryctolagus cuniculus, into Australia. ev. sci. tech. Off. int. Epiz., 29(1).

Field, A. (2005). Discovering Statistics Using SPSS. London: Sage.

Fish, U. S., \& Wildlife-Service. (1973). Endangered Species Act of 1973, 108th Congress. Washington, D.C.: Department of the Interior \& U.S. Fish and Wildlife Service.

Florida, R. (2002). The Rise of the Creative Class: Revisited. New York: Basic Books.

FOEI. (2009). Letter of withdrawal from IUCN. In IUCN (Ed.) (Letter of withdrawal from IUCN ed.). Gland: Friends of The Earth.

Folke, C., Carpenter, S., Walker, B., Scheffer, M., Elmqvist, T., Gunderson, L., \& Holling, C. S. (2004). Regime Shifts, Resilience, and Biodiversity in Ecosystem Management. Annual Review of Ecology, Evolution, and Sytematics, 35, 557-581.

Folke, C., Jansson, A., Larsson, J., \& Costanza, R. (1997). Ecosystem appropriation of cities. Ambio, 26(3), 167172.

Fothergill, A. (Writer). (2006). The Future: Living together, Planet Earth. Great Britain: BBC.

Fothergill, A., Linfield, M., \& Megahey, L. (Writer). (2007). Earth. UK: Disney Nature.

Foucault, M. (2002). The Archaeology of Knowledge. Abingdon: Routledge.

Foucault, M. (2006). History of Madness. Abingdon: Routledge.

Foucault, M. ([1977] 1995). discvipline and Punish. The Birth of the Prison. Toronto: Vintage Books.

Francis, R. A., \& Lorimer, J. (2011). Urban reconciliation ecology: The potential of living roofs and walls. Journal of Environmental Management, 92, 1429-1437.

Freidberg, S. E. (2004). Gardening on the Edge: The Social Conditions of Unsustainability on an African Urban Periphery. Annals of the Association of American Geographers, 91(2), 349-369.

Friedman, J. (1986). The world city hypothesis. Development and Change, 17(1), 69-83.

Frost, W. (Ed.). (2011). Zoos and Tourism: Conservation, Education, Entertainment? Bristol: Channel View Publications.

Funtowicz, S., Ravetz, J., \& O'Connor, M. (1998). Challenges in the use of science for sustainable development. International Journal of Sustainable Development, 1(1), 99-107.

Funtowicz, S., \& Ravetz, J. R. (1993). Science for the Post-Normal Age. Futures, 739-755.

FWS. (2013). Endangered Species Act: A History of the Endangered Species Act of 1973. Retrieved 25 July 2013, from http://www.fws.gov/endangered/laws-policies/esa-history.html

Gallopin, G., Hammond, A., Raskin, P., \& Swart, R. (1997). Branch Points: Global Scenarios and Human Choice. Stockholm: Stockholm Environment Institute (SEI).

Galluzzi, G., Eyzaguirre, P., \& Negri, V. (2010). Home gardens: neglected hotspots of agro-biodiversity and cultural diversity. Biodiversit Conservation, 19, 3635-3654.

Gamborg, C., Gremmen, B., Christiansen, S. B., \& Sandoe, P. (2010). De-domestication: Ethics at the Intersection of Landscape Restoration and Animal Welfare. Environmental Values, 19(1), 57-78.

Gandy, M. (2004). Rethinking urban metabolism: Water, space and the modern city. City, 8(3), 363-379.

GAO. (1989). Content Analysis: A Methodology for Structuring and Analyzing Written Material. Washington: United States General Accounting Office. 
Gaston, K. J., Smith, R. M., Thompson, K., \& Warren, P. H. (2005a). Urban domestic gardens (II): experimental tests of methods for increasing biodiversity. Biodiversity \& Conservation, 14(2), 395-413.

Gaston, K. J., Warren, P. H., Thompson, K., \& Smith, R. R. (2005b). Urban domestic gardens (IV): the extent of the resource and its associated features. Biodiversity and Conservation, 14, 3327-3349.

Geertz, C. (1985). The uses of diversity. Paper presented at the The Tanner Lectures on Human Values.

Gehl, J. (2010). Cities for People. Washington: Island Press.

Gellert, P. K., \& Lynch, B. D. (2003). Megaprojects as displacements: UNESCO.

Genton, G. (Writer). (2006). Planet Earth. In A. Fothergill (Producer), Planet Earth. Great Britain: BBC.

Gerlitz, P. (1998). Mensch und Natur in den Weltreligionen. Darmstadt: Wissenschaftliche Buchgesellschaft.

GesNaT, \& BUKO. (2012). Ten theses of a critique of the Green Economy. Retrieved 4 March 2013, from http://rio20.net/en/documentos/ten-theses-of-a-critique-of-the-green-economy

Gibbons, J. D. (1993). Nonparametyric Statistics. an Introduction. London: Sage Publications Inc.

Gibbons, M. (2000). Mode 2 society and the emergence of context-sensitive science. Science and Public Policy, 27(3), 159-163.

Gibbons, W. (1993). Keeping all the Pieces. Perspectives on Natural History and the Environment. Washington/London: Smithsonian Institution Press.

Giddens, A. (2009). Sociology (6th ed.). Cambridge: Polity Press.

Giddings, B., Hopwood, B. \& O’Brien, G. (2002). Environment, economy, and society: fitting them together into sustainable development Sustainable Development, 10, 187-196.

Gitay, H., Suarez, A., Watson, R. T., \& Dokken, D. J. (Eds.). (2002). Climate Change and Biodiversity. IPCC Technical Paper. Geneva, Switserland: Intergovernmental Panel on Climate Change.

Gleick, J. (1998). Chaos: The Amazing Science of the Unpredictable. London: Vintage books.

Gleick, J. (1999). Faster: the Accelleration of Just About Everything. New York: Pantheon Books.

Goddard, M. A., Dougill, A. J., \& Benton, T. G. (2010). Scaling up from gardens: biodiversity conservation in urban environments. Trends in Ecology and Evolution, 25(2), 90-99.

Goklany, I. (2009). Technological Substitution and Augmentation of Ecosystem Services. In S. Levin (Ed.), The Princeton Guide to Ecology Princeton: Princeton University Press.

Grahn, P., \& Stigsdottir, U. K. (2010). The relation between perceived sensory dimensions of urban green space and stress restoration. Landscape and Urban Planning, 94(3-4), 264-275.

Grimm, N., Faeth, S., Golubiewski, N., Redman, C., Wu, J., Bai, X., \& Briggs, J. (2008). Global Change and the Ecology of Cities. Science, 319(756).

Grimm, N. B., Faeth, S., Golubiewski, N., Redman, C., Wu, J., Bai, X., \& Briggs, J. (2008). Global Change and the Ecology of Cities. Science, 319(756).

Grimm, N. B., Grove, J. M., Picket, S. T. A., \& Redman, C. L. (2000). Integrated Approaches to Long-Term Studies of Urban Ecological Systems. In J. M. Marzluf, E. Schulenberger, W. Endlicher, M. Alberti, G. Bradley, C. Ryan, U. Simon \& C. ZumBrunnen (Eds.), Urban Ecology. An International Perspective on the Interaction Between Humans and Nature. New York: Springer.

Groot, R. S. d., Wilson, M.A. \& Boumans, R.M.J. . (2002). A typology for the classification, description and valuation of ecosystem function, goods and services

Ecological Economics, 41(3), 393-408.

Grosskurth, J. (2009). Regional Sustainability. Tools for Integrated Governance., Maastricht University, Maastricht.

Gunderson, L. H., \& Holling, C. S. (Eds.). (2002). Panarchy. Understanding Transformations in Human and Natural Systems. Washington: Island Press.

Gupta, J., Asselt, H. v., Amelung, B., Bessembinder, J., Bogaardt, M.-J., Bolwidt, L., Hendrik Buiteveld, Huynen, M., Leemans, R., Martens, P., Verhagen, J., \& Wegen, M. v. d. (2006). Climate change scientific assessment and policy analysis: Assessing dangerous climate impacts for the Netherlands: Vrije Universiteit Amsterdam, ICIS, KNMI, RIZA, Wageningen UR, UNESCO-IHE.

Haase, D., \& Schetke, S. (2010). Potential of Biodiversity and Recreation in Shrinking Cities: Contextualization and Operationalization. In N. Müller, P. Werner \& J. G. Kelcey (Eds.), Urban biodiversity \& Design. Oxford: Blackwell Publishing Ltd.

Hagen, J. (1992). An Entangeld Bank. The Origins of Ecosystem Ecology. New Brunswick: Rutgers University Press.

Hagerman, S., Dowlatabadi, H., Satterfield, T., \& McDaniels, T. (2010). Expert views on biodiversity conservation in an era of climate change. Global Environmental Change, 20, 192-207.

Hall, E., \& Reed Hall, M. (1990). Understanding Cultural Differences. Yarmouth: Intercultural Press. 
Hall, S. (2001). Foucault: Power, Knowledge and Discourse. In M. Wetherell, S. Taylor \& S. J. Yates (Eds.), Discourse Theory and Practice. London: Sage.

Hamilton, M. B. (2002). Ex Situ Conservation of Wild Plant Species: Time to Reassess the Genetic Assumptions and Implications of Seed Banks. Conservation Biology, 8(1), 39-49.

Hammond, A. (1998). Which World? Scenarios for the 21st century: global destinies, regional choices. London: Earthscan.

Hampson, N. (1968). The Enlightenment. An evaluation of its assumptions, attitudes and values. London: Penguin Books.

Hancock, J. (2010). The case for an ecosystem service approach to decision-making: an overview. Bioscience Horizons, 3(2), 188-196.

Hardin, G. (1968). The Tragedy of The Commons. Science, 162, 1243-1248.

Hardy, D. (1991). From Garden Cities to New Towns. New York: Spon Press.

Harlem, G. (1987). Our Common Future. Rio de Janeiro: United Nations World Commission on Environment and Development (WCED)

Harraway, D. (1999). Modest_Witness@Second_Millennium. In D. Mackenzie \& J. Wajcman (Eds.), The Social Shaping of Technology (Vol. 2). Buckingham: Open University Press.

Harrington, L. A., Moehrenschlager, A., Gelling, M., Atkinson, R. P. D., Hughes, J., \& Macdonald, D. W., . (2013). Conflicting and Complementary Ethics of Animal Welfare Considerations in Reintroductions. Conservation Biology, 27(3), 486-500.

Harris, R., B., Cooney, R., \& Leader-Williams, N. (2013). Application of the Anthropogenic Allee Effect Model to Trophy Hunting as a Conservation Tool. Oryx, 27(5), 945-951.

Hart, J. L. (2007). Biodiversity and Edge effects: An Activity in Landscape Ecology. Journal of Natural Resources \& Life Sciences Education, 36, 103106.

Harvey, D. (2003). The Right to the City. International Journal of Urban and Regional Research, 27(4 Debates and Developments), 939-941.

Hassan, R. (2002). Time and Knowledge in the information ecology. Southern Review, 35(10).

Hassan, R., \& Jones, S. (2003). The chronoscopic society : globalization, time, and knowledge in the network economy.

Healy, S. (2010). Post-normal science in postnormal times. Futures, 43, 202-208.

Heezik, Y. v., Dickinnson, K. J. M., \& Freeman, C. (2012). Closing the Gap: Communicating to Change Gardening Practices in Support of Native Biodiversity in Urban Private Gardens. Ecology and Scoiety, 17(1)(34).

Hegger, D., De Boer, Y., Offermans, A., Merkx, F., Dieperink, C., Kemp, R., Van Lente, H., \& Cörvers, R. (2013). KennisCoCreatie. Naar productieve samenwerking tussen wetenschappers en beleidsmakers: Published by the INSPIRATOR-project, een samenwerkingsverband tussen Universiteit Maastricht, Universiteit Utrecht, YM de Boer Advies en KENNIScoCREATIE Onderzoek \& Advies.

Hekkert, M. P., Suurs, R. A. A., Negro, S. O., Kuhlmann, S., \& Smits, R. E. H. M. (2007). Functions of innovation systems: A new approach for analysing technological change. Technological Forecasting and Social Change, 74(4), 413-432.

Hemenway, T. (2009). Gaia's Garden:A Guide to Home-Scale Permaculture. White River Junction: Chelsea Green Publishing Company.

Hermy, M., \& Cornelis, J. (2000). Towards a monitoring method and a number of multifaceted and hierarchical biodiversity indicators for urban and suburban parks. Landscape and Urban Planning, 49(3-4), 149-162.

Heywood, V. H. (Ed.). (1995). Global Biodiversity Assessment. Cambridge.: Cambridge University Press.

Hills, M. D. (2002). Kluckhohn and Strodtbeck's Values Orientation Theory. Online Readings in Psychology and Culture, 4(4).

Hinchcliff, S., \& Whatmore, S. (2006). Living Cities: Towards a Politics of Conviviality. Science as Culture, 15(2), 123-128.

Hoedeman, O. (2012). RIO+20 and the greenwashing of the global economy. Retrieved from http://www.tni.org/article/rio20-and-greenwashing-global-economy

Hofmann, M., Westermann, J. R., Kowarik, I., \& Meer, v. d., Elke. (2012). Perceptions of parks and urban derelict land by landscape planners and residents. Urban Forestry \& Urban Greening, 11, 303-312.

Hofstede, G. (1991). Cultures and Organizations. Software of the Mind. New York: McGraw Hil.

Holmes, G. (2012). Biodiversity for Billionaires: Capitalism, Conservation and the Role of Philanthropy in Saving/Selling Nature. Development and Change, 43(1), 185-203.

Holmgren, D. (2011). Weeds or wild nature: a permaculture perspective. Plant Protection Quarterly, 26(3), 9297. 
Holstein, A. A., \& Gubrium, J. F. (2004). Context: working it up, down, and across. In C. Seale, G. Gobo, J. F. Gubrium \& D. Silverman (Eds.), Qualitative Research Practice. London: Sage.

Hong, S.-K., Song, I.-J., \& Wu, J. (2007). Fengshui theory in urban landscape planning. Urban Ecosystems, 10, 221-237.

Hope, D., Gries, C., Casagrande, D., Redman, C. L., Grimm, N., \& Martin, C. (2006). Drivers of Spatial Variation in Plant Diversity Across the Central Arizona -- Phoenix ecosystem. Society and Natural Resources, 19, 101116.

Hopkins, R. (2008). The Transition Handbook: from oil dependency to local resilience: Green Books.

Hoppe, R. (2010). Lost in translation? A boundary work perspective on making climate change governable. In Driessen, Peter P.J., P. Leroy \& W. v. Vierssen (Eds.), From Climate Change to Social Change. Perspectives on Science-Policy Interactions (pp. 108-130). Utrecht: International Books.

Hopper, F. (1981). The Dutch Régence Garden. Garden History, 9(2), 118-135.

Hosking, R. (Writer). (2009). A Farm for the Future: BBC.

Hospers, G.-J., \& Pen, C.-J. (2008). A View on Creative Cities Beyond the Hype. Creativity and Innovation Management, 17(4), 259-270.

Hsieh, H. F., \& Shannon, S. E. (2005). Three Approaches to Qualitative Content Analysis. Qualitative Health Research, 15(9), 1277-1288.

Huesemann, M. H. (2003). The limits of technological solutions to sustainable development. Clean Techn Environ Policy(5), 21-34.

Humboldt, F. H. A. v. (1807). Esai sur la geographie des plantes. Paris: Von Humboldt.

Huntington, S. (1992). The Clash of Civilizations? Foreing Affairs(22), 22-49.

Hutchins, M. (2003). Zoo and aquarium animal management and conservation: current trends and future challenges. International Zoo Yearbook, 38(1), 14-28.

Huynen, M. (2008). Future Health in a Globalising World. Maastricht: Maastricht University Press.

Huynen, M. M. T. E., Martens, P. \& De Groot, R.S. . (2004). Linkages between biodiversity loss and human health: a global indicator analysis. International Journal of Environmental Health Research, 14(1), 13-30.

Hyland, K. (1998). Persuasion and context: The pragmatics of academic metadiscourse. journal of Pragmatics, 30,437455 .

ICLEI. (2012). Launch of the Cities and Biodiversity Outlook. Retrieved 19 December 2012, 2012, from http://www.iclei.org/index.php?id=13001

Ifantidou, E. (2005). The semantics and pragmatics of metadiscourse. Journal of Pragmatics, 37, 1325-1353.

Ignatieva, M. (2010). Design and future of Urban Biodiversity. In N. Mueller, P. Werner \& J. G. Kelcey (Eds.), Urban Biodiversity and Design. Oxford: Blackwel Publishers Ltd.

Ignatieva, M., Stewart, G. H., \& Meurk, C. (2011). Planning and design of ecological networks in urban areas. Landscape Ecology england, 7(Biodiversity and Ecosystem Services: Importance of Cities for post 2010 perspective), 17-25.

IPCC. (2000). Special Report on Emissions Scenarios. Geneva, Switserland: Intergovernmental Panel on Climate Change.

IPCC. (2007). Climate Change 2007: The Physical Science Basis. Fourth Assessment Report. New York: Cambridge University Press.

IPCC. (2013). Climate Change 2013. The Physical Science Base. Summary for Policymakers. Switzerland: Intergovernmental Panel on Climate Change.

IUCN. (2004). Many Voices, One Earth. The IUCN Programme 2005-2008. Bankok, Thailand.

IUCN. (2005a). Our Planet Needs Solutions. Gland: IUCN.

IUCN. (2005b). People and Nature: Only One World. Ecosystemen en de Millenniumdoelstellingen : het spanningsveld tussen ecologie en economie vanuit Nederlands perspectief. Amsterdam: IUCN Netherlands Committee.

IUCN. (2007a). Transforming Business Risk into Conservation Opportunities

Gland, Switzerland: IUCN.

IUCN. (2007b). Working for Conservation. Gland, Switzerland: IUCN.

IUCN. (2008a). A 2020 Vision for IUCN. A Global Union for Sustainability. IUCN Strategy 2009-2020. Gland, Switzerland.: IUCN.

IUCN. (2008b). Building Bridges. Annual Report 2007. Gland, Switzerland: IUCN.

IUCN. (2008c). Building the Future. A Report on the IUCN Programme 2005-2008. Gland, Switzerland: IUCN.

IUCN. (2008d). Globalization: the good, the bad and the ugly. Gland, Switzerland.

IUCN. (2008e). Shaping a Sustainable Future. The IUCN programme 2009-2012. Gland: IUCN. 
IUCN. (2008f). Sixty. Is Time Running Out? World Conservation Magazine.

IUCN. (2008g). A world without biodiversity? Gland, Switzerland: IUCN.

IUCN. (2009a). Last Call. Climate and Nature. Gland, Switzerland.

IUCN. (2009b). Life Support. Human Health and the Environment. Gland, Switzwerland.

IUCN. (2009c). Operational Guidelines for Private Sector Engagement. Gland, Switzerland: IUCN.

IUCN. (2009d). Results of the IUCN Programme 2005-2008. Gland, Switzerland: IUCN.

IUCN. (2009e). Synergies. Annual Report 2008. Gland, Switzerland: IUCN.

IUCN. (2010a). Love Not Loss. Retrieved 24 August 2011, from

http://www.youtube.com/watch?v=BvldwOEzreM

IUCN. (2010b). Natural Assets: Annual Report 2009. Gland: IUCN.

IUCN. (2010c). A New Vision for Biodiversity Conservation. Nogoya, Japan: IUCN.

IUCN. (2010d). On the Move. Annual Report 2009. Gland, Switzerland: IUCN.

IUCN. (2010e). Report on the Implementation of the IUCN Programme in 2009. Gland, Switzerland: IUCN.

IUCN. (2010f). Saving biodiversity. An economic approach. Gland, Switzerland.

IUCN. (2011a). About IUCN. Retrieved 10 March 2013, from http://www.iucn.org/about/

IUCN. (2011b). The Big Plan. World Conservation Magazine. Gland, Switzerland: IUCN.

IUCN. (2011c). Communicating Biodiversity. . Gland, Switzerland: Commission on Education and Communication (CEC)

IUCN. (2011d). Investing in Nature and People. Celebrating the International Year of Biodiversity 2010. Amman Jordan: IUCN ROWA.

IUCN. (2011e). IUCN One Programme Charter. Working together to maximize Programme results. Gland, Switzerland: IUCN.

IUCN. (2011f). The Nature of Progress. Annual Report 2010. Gland, Switzerland: IUCN.

IUCN. (2012a). How to Tell a Love Story. Switzerland: IUCN.

IUCN. (2012b). IUCN Business Engagement Strategy. Gland, Switzerland.

IUCN. (2012c). THe IUCN Programme 2013-2016. Paper presented at the IUCN world Conservation Congress, 2012, Jeju, Republic of Korea.

IUCN. (2012d). IUCN Protected Areas Categories System. Retrieved 8 August 2013, from http://www.iucn.org/about/work/programmes/gpap_home/gpap_quality/gpap_pacategories/

IUCN. (2012e). Solutions, Naturally. 2011 IUCN Annual Report. Gland, Switzerland: IUCN.

IUCN. (2013a). About Biodiversity. Retrieved 8 July 2013, from www.iucn.org/what/biodiversity/about/?gclid=CP7Hr9r4n7gCFdDJtAodeEEACg

IUCN. (2013b). Blog. The inside track on global conservation. Retrieved 1 March 2013, from http://portals.iucn.org/blog/

IUCN. (2013c). CEC Annual Report. A Global Community that Loves and Values Nature. Gland, switzerland: IUCN.

IUCN. (2013d). IUCN-Shell: Sustainable development in the Arctic. Developing cross-sector industry standards. Retrieved 22 August 2013, from

http://www.iucn.org/about/work/programmes/business/bbp_work/by_engagement/bbp_shell/energy_s ector/arctic/industry_standards/

IUCN. (2013e). The IUCN Red List of Threatened Species. Retrieved 8 August 2013, from http://www.iucnredlist.org/

Ives, A. R., \& Carpenter, S. R. (2007). Stability and Diversity of Ecosystems. Science, 317(5834), 58-62

IVN. (2013). Tuinreservaten. Retrieved 6 August 2013, from http://www.ivn.nl/projecten/tuinreservaten-0

IZEA. (2005). Conservation Education - Theory and Practice. Retrieved 14 August 2013, from http://www.izea.net/education/conservationed.htm

Jackson, T. (2008). The Challenge of Sustainable Lifestyles. Washington, USA: The Worldwatch Institute.

Jackson, T., Jager, W., \& Stagl, S. (2004). Beyond Insatiability: Needs Theory, Consumption and Sustainability: Centre for Environmental Strategy University of Surrey.

Jacobson, S. K., Mcduff, M., D., \& Monroe, M. C. (2002). Promoting Conservation through the Arts: Outreach for Hearts and Minds. Conservation Biology, 21(1), 7-10.

Jagers, G. (2012). De Soortenstorm. Zeist: KNNV Uitgeverij.

Jamieson, S. (2004). Likert Scales: How to (Ab)use Them. Medical Education, 38(12), 1217-1218.

Jasanoff, S. (2004). States of Knowledge: The Co-Production of Science and the Social Order. New york: Routeledge.

Jasanoff, S. (2010). A New Climate for Society. Theory, Culture \& Society, 27(2-3), 233-253. 
Jax, K. (2011). A History of Ecology. eLS.

Jim, C. Y. (2012). Sustainable Urban Greening Strategies for Compact Cities in Developing and Developed Countries. Urban Ecosystems(October 2012).

Jones, H. R. (1965). John Muir and the Sierra Club: the Battle for Yosemite. San Francisco: Sierra Club.

Jongman, R. (1995). Nature conservation planning in europe:developing ecological networks. Landscape and Urban Planning, 32, 169-183.

Jorgensen, A., \& Keenan, R. (2012). Urban wildscapes. New York: Routledge.

Joye, Y. (2007). Architectural lessons from environmental psychology: The case of biophilic architecture. Review of General Psychology, 11(4), 305-328.

Kaplan, S. (1995). The Restorative Benefits of Nature Journal of Environmental Psychology 15, 169-182.

Karmanov, D., \& Hamel, R. (2008). Assessing the restorative potential of contemporary urban environment(s): Beyond the nature versus urban dichotomy. Landscape and Urban Planning, 86(2), 115-125.

Keesing, R. M. (1974). Theories of Culture. Annual Review of Anthropology, 3, 73-97.

Kellert, S. R., Heerwagen, J., \& Mador, M. (2008). Biophilic Design: The Theory, Science and Practice of Bringing Buildings to Life. New Jersey: John Wiley \& Sons.

Kelly, J. D. (1997). Effective conservation in the twenty-first century: the need to be more than a zoo. One organization's approach. International Zoo Yearbook, 35(1), 1-14.

Kemp, R., Loorbach, D., \& Rotmans, J. (2007). Transition Management as a model for managing processes of co-evolution towards sustainable development. International Journal of Sustainable Development \& World Ecology, 14, 78-91.

Kemp, R., \& Martens, P. (2007). Sustainable development: how to manage something that is subjective and never can be achieved? Sustainability: Science, Practice \& Policy, 3(2), 1-10.

Kendal, D., Williams, N. S. G., \& Williams, K. J. H. (2012). A Cultivated Environment: Exploring the Global Distribution of Plants in Gardens, Parks and Streetscapes. Urban Ecosystems, 15, 637-652.

Kenis, A., \& Lievens, M. (2012). De Mythe van de Groene Economie: Samenwerkende Uitgevers VOF.

Kettunen, M., Terry, A., Tucker, G., \& Jones, A. (2007). Preparatory Work for developing the guidance on the maintenance of landscape connectivity features of major importance for wild flora and fauna. Guidance on the implementation of Article 3 of the Birds Directive (79/409/EEC) and Article 10 of the Habitats Directive (92/43/EEC): IUNCN; Ecological Solutions; EC Project: 'Guidelines: Adaptation, Fragmentation'.

Keulartz, J. (1999). Struggle for Nature: A Critique of Environmental Philosophy. Florence, KY: Routledge.

Keulartz, J. (2007). Using metaphors in restoring nature. Nature and Culture, 2(1), 27-48.

Keylock, C. J. (2005). Simpson diversity and the Shannon/Wiener index as special cases of a generalized entropy. Oikos, 109(1), 203-207.

Kim, Y. (1999). A Common Framework for the Ethics of the 21st Century. Paris: UNESCO Division of Philosophy and Ethics.

Kirmer, a., \& Tischew, S. (2010). Near-Natural Restoration Strategies in Post-Mining Landscapes. In N. Müller, P. Werner \& J. G. Kelcey (Eds.), Urban Biodiveristy and Design. Oxford: Blackwell Publishing Ltd.

Kluckhohn, P. (1966). Das Ideengut der Deutschen Romantik. Tuebingen: Max Niemeyer Verlag.

Kluvánková-Oravskál, T., Chobotová, V., Banaszak, I., Slavikova, L., \& Trifunovova, S. (2009). From government to governance for biodiversity: the perspective of central and Eastern European transition countries. Environmental Policy and Governance, 19, 186-196.

Kowarik, I. (2011). Novel Urban Ecosystems, biodiversity, and conservation. Environmental Pollution, 159.

Krasny, M. E., Lundholm, C., \& Plummer, R. (2010). Environmental education, resilience, and learning: reflection and moving forward. Environmental Education Research, 16(5-6), 665-672.

Krippendorff, K. (2004). Content analysis. an Introduction to its Methodology. London: Sage Publications.

Kroll, G. (2012). Rachel Carson's Silent Spring: A brief history of ecology as a subversive subject. Encyclopedia of Earth, from http://www.eoearth.org/view/article/155637/

Krupat, E. (1998). People in Cities: The Urban Environment and its Effects. New York: Cambridge Unuversity Press.

Kuiters, L. (2012). Succesvolle herintroductie otter in Nederland. Alterra Wageningen.

Kumar, M., \& Kumar, P. (2008). Valuation of the ecosystem services: A psycho-cultural perspective. Ecological Economics, 64, 808-819.

Kurtz, T. (2002). The Psychology of Environmentally Sustainable Behavior: Fitting Together Pieces of the Puzzle. Analyses of Social Issues and Public Policy, 2(1), 257-278.

Kurz, T., \& Baudains, C. (2012). Biodiversity in the Front Yard: An Investigation of Landscape Preference in a Domestic Urban Context. Environment and Behavior, 44(166), 166-196. 
Kuyken, E. (1989). Natuurbehoud in Vlaanderen: naar Nederlands model? In W. Berends, J. Dekker, B. Hermans, T. v. Leeuwen \& R. Schröder (Eds.), Nieuwe Natuurbescherming. Utrecht: Stichting Meander.

Lachmund, J. (2013). Greening Berlin. the co-production of Science, Politics and Urban Nature. London, Cambridge: The MIT Press.

LaCroix, C. J. (2010). Urban Argiculture and Other Green Uses: Remaking the Shrinking City. The Urban Lawyer, $42(2)$.

Lakoff, G., \& Johnson, M. (1980). Metaphors we live by. Chicago: University of Chicago Press.

Lang, D. J., Wiek, A., Bergmann, M., Stauffacher, M., Martens, P., Moll, P., Swilling, M., \& Thomas, C. J. (2012). Transdiciplinary research in sustainability science: practice, principles, and challenges. Sustainability Science, 7(Supplement 1), 25-43.

Larsen, L., \& Harlan, S. L. (2006). Desert dreamscapes: Residential landscape preference and behavior. Landscape and Urban Planning, 78, 85-100.

Larsen, L., \& Swanbrow, L. (2006). Postcards of Phoenix: Images of Desert Ambivalence and Homogeneity. Landscape Journal, 25(2-6), 205-217.

Larson, E., J. (2001). De proeftuin van de Evolutie: Van Amstel/Olympus.

Larson, K. L., Casagrande, D., Harlan, S., \& Yabiku, S. T. (2009). Residents' Yard Choices and Rationales in a Desert City: Social Priorities, Ecological Impacts, and Decision Tradeoffs. Environmental Management, 44, 921-937.

Larson, K. L., Cook, E., Strawhacker, C., \& Hall, S. J. (2010). The Influence of Diverse Values, Ecological Structure, and Geographic COntext on Residents'Multifaceted Landcaping Decisions. Human Ecology, 38, 747-761.

Laszlo, E. (1996). The Systems View of the World: a Holistic Vision for Our Time. Cresskill NJ: Hampton Press Inc.

Laszlo, E. (2006). Chaos Point: the World at the Crossroads. Charlottesville: Hampton Roads Publishing Company.

Latour, B. (1988). Wetenschap in Actie. Wetenschap en technici in de maatschappij. Amsterdam: Bert Bakker.

Latour, B. (2005). Reassembling the Social. An Introduction to Actor-Network Theory. Oxford: Oxford University Press.

Lemaire, T. (2006). Filosofie van het Landschap. Baarn: Ambo.

Lemos, M. C., \& Agrawal, A. (2006). Environmental Governance. Annual Review of Environment and Resources, 31, 297-325.

Leopold, A. (1966). A Sand County Almanac: Oxford University Press.

Lewis, J. (1985). The Birth of EPA. EPA Journal, 11(6).

Lilley, K. D. (2004a). Cities of God? Medieval urban forms and their Christian symbolism. Trans Inst Br Geogr, 29, 296-313.

Lilley, K. D. (2004b). Mapping cosmopolis: moral topographies of the medieval city. Environment and Planning D: Society and Space, 22, 681-698.

Lohr, V. I. (2007). Benefits of Nature: What We Are Learning about Why People Respond to Nature. Journal of Physiological Anthropology, 26, 83-85.

Loorbach, D. (2002). Transition Management: governance for sustainability. Paper presented at the Conference for Governance and Sustainability: New Challenges for the State, Business and Society.

Loorbach, D. (2007). Transition Management. New mode of governance for sustainable development. Rotterdam: Erasmus Universiteit Rotterdam.

Loorbach, D., \& Lijnis Huffenreuter, R. (2013). Exploring the economic crisis from a transition management perspective. Environmental Innovation and Societal Transitions, 6, 35-46.

Loram, A., Warren, P. H., \& Gaston, K. J. (2008). Urban Domestic Gardens (XIV): The Characteristics of Gardens in Five Cities. Environmental Management, 42, 361-376.

Losos, J. B., \& Schluter, D. (2000). Analysis of an evolutionary species-area relationship. Nature, 408(14 December), 847-850

Lotze-Campen, H. (2008). The role of modelling tools in Integrated Sustainability Assessment (ISA). International Journal of Innovation and Sustainable Development, 3(1), 70-92.

Lovelock, J. (2000). Gaia: A New Look at Life on Earth. Oxford Oxford University Press.

Lovelock, J. (2006). The Revenge of Gaia: Why the Earth Is Fighting Back - and How We Can Still Save Humanity. Santa Barbara (California): Allen Lane.

Lowe, E., Wilder, S., \& Hochuli, D. (2014). Urbanisation at Multiple Scales Is Associated with Larger Size and Higher Fecundity of an Orb-Weaving Spider. PLOS ONE, 9(8). 
Lowry, T. S. (1981). The roots of hedonism: an ancient analysis of quantity and time. History of Political Economy, 13(4), 812-823.

Lyotard, J. F. (1979). La Condition Postmoderne. Rapport Sur le Savoir. Paris: Minuit.

Lyytimäki, J., Petersen, L. K., Normander, B., \& Bézak, P. (2008). Nature as nuisance? Ecosystem services and disservices to urban lifestyle. Environmental Sciences, 5(3), 161-172

Maathai, W. (2004). Nobel Peace Prize Acceptance Speech Oslo, Norway: Nobel Foundation.

Maathai, W. (2011). Challenge for Africa. Sustainability Science(6), 1-2.

MacDonald, K. I. (2003). IUCN: A History of Constraint. Unpublished Text of an Address given to the Permanent workshop of the Centre for Philosophy of Law Higher Institute for Philosophy of the Catholic University of Louvain (UCL), Louvain-la-Neuve. University of Toronto.

MacDonald, K. I. (2010). The Devil is in the (Bio)diversity: Private Sector "Engagement" and the Restructuring of Biodiversity Conservation. Antipode, 42(3), 513-550.

MacDougall, A. S., McCann, K. S., Gellner, G., \& Turkington, R. (2013). Diversity loss with persistent human disturbance increases vulnerability to ecosystem collapse. Nature, 494, 86-89.

Mackenzie, J. M. The Empire of Nature: Hunting, Conservation and British Imperialism. Manchester: Manchester University Press.

Mackey, T. K., \& Liang, B. A. (2012). Integrating Biodiversity Management and Indigenous Biopiracy Protection to Promote Environmental Justice and Global Health. American Journal of Public Health, 102(6), 10911095.

Mak, M. Y., \& Ng, T. S. (2005). The art and science of Feng Shui -- a study on architects' perception. Building and Environment, 40, 427-434.

Makhzoumi, J. M. (2000). Landscape Ecology as a Foundation forn Landscape Architecture: Application in Malta. Landscape and Urban Planning, 50, 167-177.

Mamadouh, V. (1999). Grid-group Cultural Theory: an Introduction. GeoJournal, 47, 395-409.

Mansfield, B., \& Mendes, W. (2013). Municipal Food Strategies and Integrated Approaches to Urban Agriculture: Exploring Three Cases from the Global North. International Planning Studies, 18(1), 37-60.

Marcotullio, P. J., Piracha, A. L., \& King, C. (2003). Urban ecosystems and the Millennium Ecosystem Assessment: Towards an Inclusive Framework: UNU/IAS.

Marcuse, P. (2010). From Critical Urban Theory to the Right to the City. City: analysis of urban trends, culture, theory, policy, action., 13(2), 185-197.

Margules, C. R., \& Pressey, R. L. (2000). Systematic conservation planning. Nature, 405, 243-253.

Martens, P. (2006). Sustainability: Science or Fiction? Sustainability: Science, Practice and Policy, 2(1), 36-41.

Martens, P. (2013, 7 March 2013). Grey, green or blue economy? It's sustainability, stupid! pimmartens.info/grey-green-or-blue-economy-it\%E2\%80\%99s-sustainability-stupid/

Martens, P., Rotmans, J., \& De Groot, R. (2003). Biodiversity: Luxury or Necessity? A Scenario Approach to Explore Future Biodiversity Patterns. Global Environmental Change, 13(2), 75-81.

Martens, P. H., M. (2003). A future without health? Health dimension in global scenario Studies. Bulletin of the World Health Organization, 81(12).

Martin, C., A. (2008). Landscape Sustainability in a Sonoran Desert City. Cities and the Environment, 1(2), 1-16.

Marton-Lefèvre, J. (2012). Putting Protected Areas to work to address global challenges. Retrieved 20 Februari 2013, from http://www.iucn.org/about/work/programmes/gpap_home/pas_gpap/gpap_perspective/?11555/Putting -Protected-Areas-to-Work-to-Address-Global-Challenges

Marton-Lefèvre, J., \& Xinsheng, Z. (2012). Nature in 2012: a look back and a look ahead.

Marzano, A. (2008). Science, Art, and Nature: Ancient Gardens in All Their Variety. American Journal of Archaeology, 111(2), 1-8.

Marzluf, J. M., Shulenberger, E., Endlicher, w., Alberti, M., Bradley, G., Ryan, C., Simon, U., \& Craig, Z. (Eds.). (2008). Urban Ecology. An International Perspective on the Interaction Between Humans and Nature. New York: Springer.

Mathey, J., \& Rink, D. (2010). Urban Wastelands -- A Chance for Biodiversity in Cities? Ecological Aspects, Social Perceptions and Acceptance of Wilderness by Residents. In N. Müller, P. Werner \& J. G. Kelcey (Eds.), Urban Biodoversity and Design. Oxford: Blackwell Publishing Ltd.

Mathieu, R., Freeman, C., \& Aryal, J. (2007). Mapping private gardens in urban areas using object-oriented techniques and very high-resolution satellite imagery. Landscape and Urban Planning, 81, 179-192.

Matteson, K. C., Ascher, J. S., \& Langellotto, G. A. (2008). Bee Richness and Abundance in New York City Urban Gardens. Annals of the Entomological Society of America, 101(1), 140-150. 
McCann, K. S. (2000). The diversity-stability debate. Nature, 405, 228-233.

McClintock, N. (2010). Why farm the city? Theorizing urban agriculture through a lens of metabolic rift. Cambridge Journal of Regions, Economy and Society, 3(2), 191-207.

Mcdonald, R. I., Kareiva, P., \& Frorman, R. T. T. (2008). The implications of current and future urbanization for global protected areas and biodiversity conservation. Biological conservation, 141, 1695-1703.

McDonough, W., \& Braungart, M. (2002). Cradle to Cradle: Remaking the Way we Make Things. New York: North Point Press.

McKinney, M., L. (2002). Urbanization, biodiversity, and Conservation. BioScience, 52(10), 883-890.

McLachlan, J. S., Hellmann, J. J., \& Schwartz, M. W. (2007). A Framework for Debate of Assisted Migration in an Era of Climate Change. Conservation biology, 21(2), 297-302.

McNeely, J. A., Faith, D. P., Albers, H. J., Dulloo, E., Goldstein, W., \& Groombridge, B. (2005). Millennium Ecosystem Assessment. Assessment of Policy Responses.

MEA. (2005). Ecosystems and Human Well-Being. Biodiversity Synthesis. Washington, DC: World Resources Institute.

Meadows, D. H., Meadows, D. L., Randers, J., \& Behrens, W. W. (1972). The Limits to Growth: The Club of Rome.

Mee, W. R. (2011). Highligts of the City of Phoenix Water Conservation Program.

Meijer, S. A., Van Timmeren, A., Crul, M. R. M., \& Brezet, H. C. (2013, 19 April 2013). From community resilience towards urban resilience: exploring the grassroot initiatives' role in cities. Paper presented at the Livinggreen Scientific Conference, Delft.

Meine, K., Soulé, M., \& Noss, R. F. (2006). "A Mission-Driven Discipline": the Growth of Conservation Biology. Conservation Biology, 20(3), 631-651.

Mendenhall, C. D., Daily, G. C., \& Ehrlich, P. R. (2012). Improving estimates of biodiversity loss. Biological Conservation, 151, 32-34.

Mendieta, E. (2010). The city to come. Critical urban theory as utopian mapping. City, 14(4), 442-447.

Mennen, F., Beumer, C., \& Martens, P. (submitted). The sustainability message: a case study on visitor and employee perspectives on education for sustainability in a 21st Century zoo. Journal of Zoo and Aquarium Research.

Mesoudi, A. (2008). Foresight in cultural evolution. Biology and Philosphy, 23, 243-255.

Mikulecky, D. C. (2007). Causality and Complexity: The Myth of Objectivity in Science. Chemistry and Biodiversity, 4(10), 2480-2491.

Millard, A. (2010). Cultural Aspects of Urban Biodiversity. In N. Müller, P. Werner \& J. G. Kelcey (Eds.), Urban Biodiversity and Design. London: Wiley-Blackwell.

Miller, J. R. (2005). Biodiversity conservation and the extinction of experience. Trends in Ecology \& Evolution, 20(8), 430-434.

Miller, J. R., \& Hobbs, R. J. (2002). Conservation Where People Live. Conservation Biology, 16(2), 330-337.

Miller, T. R., Minteer, B. A., \& Malan, L.-C. (2011). The New conservation Debate: The view from practical ethics. Biological Conservation, 144, 948-957.

Mills, L. S. (2013). Conservation of Wildlife Populations: Demography, Genetics, and Management. Oxford: John wiley \& Sons.

Minteer, B. A., \& Collins, J. P. (2012). Species Conservation, Rapid Environmental Change, and Ecological Ethics: Rethinking Conservation Values in the 21st Century. Nature Education Knowledge, 3(10).

Minteer, B. A., \& Miller, T. R. (2011). The New Conservation Debate: Ethical foundations, strategic trade-offs, and policy opportunities. Biological Conservation, 144, 945-947.

Mitchell, D. B., \& Mueller, M. P. (2009). A philosophical analysis of David Orr's theory of ecological literacy: biophilia, ecojustice and moral education in school learning communities. Cultural Studies of Science Education, 6, 193-221.

Mitchell, M. G. E., Bennett, E. M., \& Gonzalez, A. (2013). Linking Landscape Connectivity and Ecosystem Service Provision: Current Knowledge and Research Gaps. Ecosystems, 16(5), 894-908.

Mitman, G. (1996). When Nature Is the Zoo: Vision and Power in the Art and Science of Natural History. Osiris, 2(11), 117-143.

Mollison, B. (1988). Permaculture. A Designers' Manual. Tyalgum, Australia: Tagari Publications.

Moon, B. M., Hoffmann, R. R., Novak, J. D., \& Cañas, A. J. (2011). Applied Concept Mapping. Capturing, Analyzing and Organizing Knowledge. Boca Raton: CRC Press.

Moore, K. D., \& Moore, J. W. (2013). Ecological restoration and enabling behavior: a new metaphorical lens. Conservation Letters, 6, 1-5. 
Mora, C., \& Sale, P. F. (2011). Ongoing global biodiversity loss and the need to move beyond protected areas: a review of thetechnical and practical shortcomings of protected areas on land and sea. MarineEcology Progress Series, 434.

Moritz, C., \& Agudo, R. (2013). The Future of Species Under Climate Change: Resilience or Decline? Science, 341(6145), 504-508.

Morris, D. (1969). The Human Zoo. New York: Kodansha America Inc.

Morrow, K. (2012). Rio+20, the Green Economy and Re-orienting Sustainable Development. Environmental Law Review, Vol. 14(4), 279-297.

Mowat, F. (1963). Never Cry wolf. London: Back Bay Books.

Müller, N., \& Kamada, M. (2011). URBIO: an introduction to the International Network in Urban Biodiversity and Design. Landscape Ecology England, 7(1), 1-8.

Müller, N., Werner, P., \& Kelcey, J. G. (Eds.). (2010). Urban Biodiversity and Design (Vol. 7). Oxford: WileyBlackwell.

Mumford, L. (1938). The Culture of Cities. New York: Harcourt, Brace \& Co.

Mumford, L. (1961). The city in history: its origins, its transformations, its prospects. New York: Harcourt, Brace $\&$ Co.

Mumford, L. (1965). Utopia, the City and the Machine. Daedalus, 94(2), 271-292.

Musiolik, J., Markard, J., \& Hekkert, M. (2012). Networks and network resources in technological innovation systems: Towards a conceptual framework for system building. Technological Forecasting and Social Change, 79(6), 1032-1048.

Naess, A. (1995). The Shallow and the Deep, Long-Range Ecology Movement: a Summary. In A. Drenson \& Y. Inoue (Eds.), The Deep Ecology Movement: an Introductory Anthology. Berkeley, CA: North Atlantic Books.

Nagendra, H. (2002). Opposite trends in response for the Shannon and Simpson indices of landscape diversity. Applied Geography, 22(2), 175-186.

Nasar, J., L. (2011). Environmental Psychology and Urban Design. In T. Banerjee \& A. Loukaitou-Sideris (Eds.), Companion to Urban Design (pp. 162-171). New York: Routledge.

Nash, R. F. (1989). The Rights of Nature: A History of Environmental Ethics. London: University of Wisconsin Press.

Nassauer, J. I. (1995a). Culture and Changing Landscape Structure. Landscape Ecology, 10(4), 229-237.

Nassauer, J. I. (1995b). Messy ecosystems. Orderly frames. Landscape Journal, 14(2), 161-170.

Nassauer, J. I., \& Opdam, P. (2008). Design in science: extending the landscape ecology paradigm. Landscape Ecology, 23, 633-644.

Nederveen-Pieterse, J. (2004). Globalization and Culture. Lanham: Rowman and Littlefield Publishers Inc.

Negi, C. S. (2005). Religion and biodiversity conservation: not a mere analogy. International Journal of Biodiversity Science and Management 1, 85-96.

Nelleman, C. (2010). The last stand of the Gorilla. Environmental Crime and Conflict in the Congo Basin: UNEP.

Nemeth, C. J., Personnaz, B., Personnaz, M., \& Goncalo, J. A. (2004). The liberating role of conflict in group creativity: A study in two countries. European Journal of Social Psychology, 34(4), 365-374.

Newman, P. W. G. (1999). Sustainability and cities: extending the metabolism model. Landscape and Urban Planning, 44, 219-226.

Newmark, W. D., Manyanza, D. N., Gamassa, D.-G. M., \& Sariko, H. I. (1994). The Conflict between Wildlife and Local People Living Adjacent to Protected Areas in Tanzania: Human Density as a Predictor. Conservation Biology, 8(1), 249-255.

Newton, J. L., \& Freyfogle, E. T. (2005). Sustainability: a Dissent. Conservation Biology, 19(1), $23-32$.

Niemala, J. (1999). Is there a need for a theory of urban ecology? Urban Ecosystems, 3, 57-65.

Niza, S., Rosado, L., \& Ferrao, P. (2009). Urban Metabolism: Methodological Advances in Urban Material Flow Accounting Based on the Lisbon Case Study. Journal of Industrial Ecology, 13(3), 384-405.

Nooteboom, B., Van Haverbeke, W., Duysters, G., Gilsing, V., \& Van den Oord, A. (2007). Optimal cognitive distance and absorptive ca[acity. Research Policy, 36, 1016-1034.

Nordling, L. (2009). Hazy goals hold up conservation. Nature, 461(22 October), 1037.

Norris-Bernzel, K., \& Edinger, P. (2005). Gardening in the Southwest. Menlo Park, CA: Sunset Publishing Corporation.

Norton, B. (1987). Why We Preserve Natural Variety? . Princeton: Princeton University Press.

Norton, B. G., \& Noonan, D. (2007). Ecology and Valuation: Big Changes Needed. Ecological Economics, 63, 664-675.

Noske, B. (1988). Mens en Dier. Vriend of Vijand? Amsterdam: Van Gennip. 
Noss, R., F. (1990). Indicators for Monitoring Biodiversity: A Hierarchical Approach. Conservation biology, 4(4), 355-364.

Notenboom, J., Veen, v. M., \& Wesselink, L. G. (2006). Halting the loss of biodiversity in the Netherlands. Bilthoven: Netherlands Environmental Assessment Agency.

Notten, P. v. (2005). Writing on the Wall: Scenario Development in Times of Discontinuity. Boca Raton, FL, USA: Dissertation.com.

Novak, J. D., \& Cañas, A. J. (2007). The Theory Underlying Concept Maps and How to Construct Them. Thecnical Reporty IHMC Cmap Tools2006-01. Florida: Florida Institute for Human and Machine Cognition (IHMC).

Nowotny, H., Scott, P., \& Gibbons, M. (2003). 'Mode 2' Revisited: The New Production of Knowledge. Minerva, 41, 179-194.

Nunes, P., \& van den Bergh, J. (2001). Economic Valuation of Biodiversity: sense or nonsense? Ecological Economics, 39, 203-222.

NWF. (2013). Garden for Wildlife. Make Habitat at Home. Retrieved 30 July 2013, from http://www.nwf.org/How-to-Help/Garden-forWildlife.aspx?campaignid=WH10DGWP\&s_src=CWH_Wildlife_Navigation

O'Neill, S., \& Nicholson-Cole, S. (2009). Fear won't do it: Promoting Positive Engagement with Climate Change Through Visual and Iconic Representation. Science Communication, 30(355), 355-379.

Odell, R. (1980). Environmental Awakening: the New Revolution to Protect the Earth. Cambridge, Mass.: Ballinger Publishing Company.

Offermans, A. (2012). The Perspectives Method. Towards Socially Robust River Management. Maastricht: Maastricht University Press.

Offermans, A., Haasnoot, M., \& Valkering, P. (2009). A Method to Explore Social Response for Sustainable Water Management Strategies under Changing Conditions. Sustainabe Development(DOI:10.1002/sd.439).

Ohayon, J. (Writer). (2013). Crossroads: Labour Pains of a New Worldview: http://crossroadsfilm.com/.

Oldfield, E. E., Warren, R. J., Felson, A. J., Bradford, M. A., \& Bugmann, H. (2013). Challenges and future directions in urban afforestation. Journal of Applied Ecology, n/a-n/a.

Olsson, P., \& Folke, C. (2007). Adaptive Comanagement for Building Resilience in Social-Ecological Systems. Environmental Management, 34(1), 75-90.

Opschoor, J. B. (1998). The value of ecosystem services: whose values? Ecological Economics, 25, 41-43.

Orians, G. H. (1980). Habitat selection: General theory and applications to human behavior. In S. J. Lockard (Ed.), The Evolution of Human Social Behavior. New York: Elsevier.

Pallant, J. (2005). SPSS survival Manual. a step by step guide to data analysis usiong SPSS version 12 . New York: Open University Press \& McGraw-Hill.

Palmer, M. A., Menninger, H. L., \& Bernhardt, E. (2010). River Restoration, Habitat Heterogeneity and Biodiversity: a failure of theory or practice? Freshwater Biology, 55(Supplement 1), 205-222.

Palmquist, S. (2007). Emergence, Evolution, and the Geometry of Logic: Causal Leaps and the Myth of Historical Development. Foundations of Science, 12, 9-37.

Patel, R., \& Crook, M. (2012). At Rio+20, the green economy won't save the planet. But green democracy will. London: Institure of Common Wealth Studies.

Pauli, G. (2010). The Blue Economy. 10 Years, 100 Innovations, 100 Million Jobs. Report to the Club of Rome. Taos, New Mexico, USA: Paradigm Publications.

Pearsall, H., \& Pierce, J. (2010). Urban sustainability and environmental justice: evaluating the linkages in public planning/policy discourse. Local Environment: The International Journal of Justice and Sustainability, 15(6), 569- 580 .

Peterson, G., Cumming, G., \& Carpenter, S. (2003). Scenario Planning: a Tool for Conservation in an Uncertain World. Conservation Biology, 17(2), 358-366.

Pickett, S. T. A., Burch, W. R., \& Dalton, S. E. (1997). Integrated Urban Ecosystem Research. Urban Ecosystems, 1, 183-184.

Pickstock, C. (2001). Justice and Prudence: Principles of Order in the Platonic City. HeyJXLII, 269-282.

Pimm, S. L., Jenkins, C. N., Abell, R., Brooks, T. M., Gittleman, J. L., Joppa, L. N., Raven, P. H., Roberts, C. M., \& Sexton, J. O. (2014). The biodiversity of species and their rates of extinction, distribution, and protection. Science, 344(6187).

Pinch, T. J., \& Bijker, W. E. (1984). The Social Construction of Facts and Artefacts: Or How the Sociology of Science and the Sociology of Technology Might Benefit Each Other. Social studies of Science, 14(3), 399441. 
Plec, E., \& Pettenger, M. (2012). Greenwashing Consumption: The Didactic Framing of ExxonMobil's Energy Solutions. Environmental Communication: A Journal of Nature and Culture, 6(4), 459-476.

Pohl, C., Rist, S., Zimmermann, A., Fry, P., Gurung, G. S., Schneider, F., Speranza, C. I., Kiteme, B., Boillat, S., Serrano, E., Hirsch Hadorn, G., \& Wiesmann, U. (2010). Researchers' roles in knowledge co-production: experience from sustainability research in Kenya, Switzerland, Bolivia and Nepal. Science and Public Policy, 37(4), 267-281.

Posey, D. A. (1999). Cultural and Spiritual Values of Biodiversity. A Complementary Contribution to the Global Biodiversity Assessment. Nairobi, Kenya: United Nations Environment Programme.

Prigogine, I. (1980). From Being to Becoming: Time and Complexity in the Physical Sciences. San Francisco: Freeman.

Prigogine, I. (1996). The End of Certainty. Time, Chaos, and the New Laws of Nature. New York: Free Press.

Prigogine, I., \& Stengers, I. (1984). Order Out of Chaos: Man's New Dialogue with Nature. London Heinemann

Projectbureau A2 Maastricht. (2009a). De Groene Loper. Vanzelfsprekend. Integraal Plan A2 Maastricht.: Rijkswaterstaat Provincie Limburg, Gemeente Maastricht, Sfeervol Meerssen.

Projectbureau A2 Maastricht. (2009b). De Groene Loper. Vanzelfsprekend. Specialistisch Rapport Natuur. Maastricht: Rijkswaterstaat, Provincie Limburg, Gemeente Maastricht, Sfeervol Meerssen.

Puppin de Oliveira, J. A., Balaban, O., Doll, C. N. H., Moreno-Peñaranda, R., \& Gasparatos, A. (2011). Cities and biodiversity: Perspectives and governance challenges for implementing the convention on biological diversity (CBD) at the city level. Biological Conservation, 1302-1313.

Quintero, I., \& Wiens, J. J. (2013). Rates of projected climate change dramatically exceed past rates of climatic niche evolution among vertebrate species. Ecology Letters, 16(8), 1095-1103.

Qviström, M. (2013). Searching for an open future: planning historyas a means of peri-urban landscape analysis. Journal of Environmental Planning and Management.

Rand, H. (1995). Hundertwasser. Köln: Taschen-Librero.

Rands, M. R., Adams, W. M., Bennun, L., Butchart, S. H., Clements, A., Coomes, D., Entwistle, A., Hodge, I., Kapos, V., Scharlemann, J. P., Sutherland, W. J., \& Vira, B. (2010). Biodiversity conservation: challenges beyond 2010. Science, 329(5997), 1298-1303.

Ray, P. H., \& Anderson, S. R. (2000). The Cultural Creatives: How 50 Million People Change the World. New York: Harmony Books.

Redclift, M. R., \& Woodgate, G. (2010). The International Handbook of Environmental Sociology. Cheltenham: Edward Elgar Publishing Ltd.

Redford, K. H., \& Adams, W. M. (2009). Payment for Ecosystem Services and the Challenge of Saving Nature. Conservation Biology, 23(4), 785-787.

Redford, K. H., Amato, G., Baillie, J., Beldomenico, P., Bennet, E. L., Clum, N., Cook, R., Fonseca, G., Hedges, S., Launay, F., Lieberman, S., Mace, G. M., Murayama, A., Putnam, A., Robinson, J. G., Rosenbaum, H., Sanderson, E. W., Stuart, S. N., Thomas, P., \& Thorbjarnarson, J. (2006). What does it mean to succesfully conserve a (vertebrate) species? Biological Sciences, 61(1), 39-48.

Reed, B. M., Sarasan, V., Kane, M., Bunn, E., \& Pence, V. C. (2011). Biodiversity conservation and conservation biotechnology tools. In Vitro Cell.Dev.Biol. - Plant, 47(1), 1-4.

Rees, W., \& Wackernagel, M. (2008). Urban Ecological footprints: Why Cities Cannot be sustainable -- and Why They are a Key to Sustainability. In J. M. Marzluf, E. Shulenberger, W. Endlicher, M. Alberti, G. Bradley, C. Ryan, U. Simon \& C. ZumBrunnen (Eds.), Urban Ecology. New York: Springer.

Rees, w. E. (2010). Thinking 'Resilience'. In R. Heinberg \& D. Lerch (Eds.), The Post Carbon Reader: Managing the 21st Century's Sustainability Crises. Santa Rosa, California: Watershed Media, Post Carbon Institute.

Rey Benayas, J. M., Newton, A. C., Diaz, A., \& Bullock, J. M. (2009). Enhancement of biodiversity and ecosystem services by ecological restoration: a meta-analysis. Science, 325, 1121-1124.

Ricciardi, A., \& Simberloff, D. (2009). Assisted colonization is not a viable conservation strategy. Trends in Ecology \& Evolution, 24(5), 248-253.

Robinson, J. (2004). Squaring the circle? Some thoughts on the idea of sustainable development. Ecological Economics, 48(4), 369-384.

Robinson, J. G. (2011). Ethical Pluralism, pragmatism, and sustainability in conservation practice. Biological Conservation, 144, 958-965.

Rodrigues, A., Andelman, S., Bakarr, M., Biotani, L., \& Brooks, T. (2004). Effectiveness of the global protected area network in representing species diversity. Nature, 428(April), 640-643.

Rogers, P. P., Jalal, K. F., \& Boyd, J. a. (2008). An Introduction to Sustainable Development. London: Earthscan. Rolston, H. (2012). A New Environmental Ethics: The Next Millennium for Life on Earth: Routledge. 
Rosa, H. (2003). Social Acceleration: Ethical and Political Consequences of a Desynchronized High-Speeds Society. Constellations, $10(1)$.

Rosenzweig, M. L. (2003). Reconciliation Ecology and the Future of Species Diversity. Oryx, 37(2), 194-205.

Ross, P. (2014). China To Flatten Hundreds Of Mountains To Expand Cities But At Great Cost To Environment. Retrieved 5 September 2014, from http://www.ibtimes.com/china-flatten-hundreds-mountains-expandcities-great-cost-environment-1596385

Rothfels, N. (2002). Savages and Beasts: The Birth of the Modern Zoo. Baltimore: The John Hopkins University Press.

Rotmans, J. (2003). Transitiemanagement: Sleutel voor een duurzame samenleving. Assen: Van Gorcum.

Rotmans, J. (2006). Tools for Integrated Sustainability Assessment: A two-track approach. The Integrated Assessment Journal. Bridging Science and Policy., 6(4), 35-57.

Rotmans, J., Asselt, M. v., \& Vellinga, P. (2000). An integrated planning tool for sustainable cities. Environmental Impact Assessment Review, 20, 265-276.

Rotmans, J., \& De Vries, B. (Eds.). (1997). Perspectives on global change: the TARGETS approach. Cambridge: Cambridge University Press.

Rotmans, J., Kemp, R., \& Asselt, v. M. B. A. (2000). Transitions and Transition Management, the case of an emmission-free energy supply. . Maastricht: International Centre for Integrated assessment and Sustainable Develoment (ICIS).

Rudd, H., Vala, J., \& Schaefer, V. (2002). Importance of Backyard Habitat in a Comprehensive Biodiversity Conservation Strategy: A Connectivity Analysis of Urban Green Spaces. Restoration Ecology, 10(2), 368375.

Sala, O., Chapin, F. S., Armesto, J. J., Berlow, E., Bloomfield, J., \& Dirzo, R. (2000). Global Biodiversity Scenarios for the Year 2100. Science, 287(1770).

Samiei, K. (2013). Architecture and Urban Ecosystems: From Segregation to Integration. http://www.academia.edu/2604127/Vertical_Greenery_in_Iran_Attitudes_and_Prospects._Case_Study_ City_of_Tehran

Samnegård, U., Persson, A. S., \& Smith, H. G. (2011). Gardens benefit bees and enhance pollination in intensively managed farmland. Biological Conservation, 144(11), 2602-2606.

Sampford, C. (2002). Environmental Governance for Biodoversity. Environmental Science and Policy, 5, 79-90.

Sarkar, S. (1999). Wilderness preservation and biodiversity conservation -- keeping divergent goals distinct. BioScience, 49(5), 405-412.

Sassen. (1991). The Global City. New Jersey: Princeton University Press.

Sauper, H. (2004). Darwin's Nightmare. New York: International Film Circuit,.

Saura, S., Bodin, Ö., \& Fortin, M.-J. (2014). Stepping stones are crucial for species' long-distance dispersal and range expansion through habitat networks. Journal of Applied Ecology, 51(1), 171-182.

Savard, J. P. L. (2000). Biodiversity concepts and urban ecosystems. Landscape and urban planning, 48(3-4), 131-142.

Savard, M. (2011). The Lost Urban Sociology of Pierre Bourdieu. In G. Bridge \& S. Watson (Eds.), The New Blackwell Companion to the City: Blackwell Publishing Ltd.

Schäffler, A., \& Swilling, M. (2013). Valuing green infrastructure in an urban environment under pressure The Johannesburg case. Ecological Economics, 86, 246-257.

Schein, E. H. (1990). Organizational Culture. American Psychologist, 45(2), 109-119.

Schmelzkopf, K. (1995). Urban community gardens as contested space. Geographical Review, 85(3), 364-381.

Schmuck, P., \& Vlek, c. (2003). Psychologists can do much to support sustainable development. European Psychologist, 8(2).

Scholte, J. A. (2002). Globalization: a critical introduction. New York: Palgrave.

Schultz, P. W. (2002). Inclusion with nature: the psychology of human-nature relations. In P. Schmuck \& P. W. Schultz (Eds.), Psychology of Sustainable Development. Massachusetts: Kluwer Academic Publishers.

Schulz, M. (1985). Paradise Preserved: Recreations of Eden in Eighteenth and Nineteenth Century England. New York: Cambridge University Press.

Scott, G. W., Goulder, R., Wheeler, P., Scott, L. J., Tobin, M. L., \& Marsham, S. (2011). The value of fieldwork in life and environmental sciences in the context of higher education: a case study in learning about biodiversity. Journal of Science Education Technology, 21, 11-21.

Seddon, P. J. (2010). From Reintroduction to Assisted Colonization: Moving along the COnservation Translocation Spectrum. Restoration Ecology, 18(6), 796-802.

Sen, A. (1999). Development as Freedom. New York: Anchor Books. 
Shapin, S. (1996). The Scientific Revolution. London: The University of Chicago Press.

Sheldrake, P. (2007). Placing the sacred: transcendence and the city. Literature \& Theology, 21(3), $243-258$.

Shin, H. B. (2012). Looking back and ahead: Lessons from the 2008 Beijing Olympic Games.

http://eprints.Ise.ac.uk/46544/1/blogs.Ise.ac.ukLooking_back_and_ahead_Lessons_from_the_2008_Beijing_Olympic_Games.pdf

Shmelev, S. E. (2012). Sustainable Cities: Interdisciplinary Perspective. 175-193.

Silvertown, J. (2009). A new dawn for citizen science. Trends in Ecology \& Evolution, 24(9), 467-471.

Simonis, U. E. (2011). Greening urban development: on climate change and climate policy. International Journal of Social Economics, 38(11), 919-928.

Siurua, H. (2006). Nature Above People: Rolston and "Fortress" Conservation in the South. Ethics \& the Environment 11(1), 71-96.

Skibins, J. C., Powell, R. B., \& Hallo, J. C. (2013). Charisma and conservation: Charismatic megafauna's influence on safari and zoo tourists' pro-conservation behaviors. Biodiversity and Conservation, 1-24.

Slats, J. (Writer). (2013). Dierentuin Nederland: Herintroductie dieren niet volgens de regels, Zembla. The Netherlands.

Smith, E. R., \& Mackie, D. M. (2000). Social Pychology (2nd ed.). Philadelphia: Psychology Press.

Smith, L. E. D., \& Porter, K. S. (2009). Management of catchments for the protection of water resources: drawing on the New York City watershed experience. Regional Environmental Change, 10(4), 311-326.

Smith, R. G., \& Doel, M. A. (2010). Questioning the Theoretical Basis of Current Global-City Research: Structures, Networks and Actor-Network. International Journal of Urban and Regional Research, 35(1), 24-39.

Smith, R. J., Muir, R. D. J., Walpole, M. J., Balmford, A., \& Leader-Williams, N. (2003). Governance and the loss of biodiversity. Nature, 426, 67-70.

Smith, R. M., Thompson, K., Hodgson, J. G., Warren, P. H., \& Gaston, K. J. (2006). Urban domestic gardens (IX): Composition and richness of the vascular plant flora, and implications for native biodiversity. Biological Conservation, 129(3), 312-322.

Smith, S. S. (2010). Forest Story Cards, a Visual Survey Tool. Journal of Extension, 48(2), 1-5.

Snow, C. P. (2001 [1959]). The Two cultures. London: Cambridge University Press.

Soper, K. (1995). What is Nature? Oxford: Blackwell.

Spangenberg, J. H. (2006). Towards integrated long-term scenarios for assessing biodiversity risks. Revista Internacional Sostenibilidad, Tecnologia y Humanismo, 1, 91-101.

Spangenberg, J. H. (2011). Sustainability Science: a review, an analysis and some empirical lessons. Environmental Conservation, 38(3), 275-287.

Spary, E. (1999). The 'Nature' of Enlightenment. In W. Clark, J. Golinski \& S. Schaffer (Eds.), The Sciences in Enlightened Europe. Chicago: University of Chicago Press.

Spash, C., L. (2012). Green Economy, Red Herring. Environmental Values, 21(2), 95-99.

Spellerberg, I. F., \& Ferdor, P. J. (2003). A tribute to Claude Shannon (1916-2001) and a plea for more rigorous use of species richness, species diversity and the 'Shannon-Wiener' Index. Global Ecology \& Biogeography 12, 177-179.

SS2N. (2012). Stepping Stones to Nature. Annual Report Year 3. Plymouth, Wales: Plymouth City Council, Natural England, Big Lottery.

St.Hilaire, R., VanLeeuwen, D. M., \& Torres, P. (2010). Landscape preferences and Water Conservation Choices of Residents in a High Desert Environment. HortTechnology, 20(2), 308-314.

Stansfeld, S., Haines, M., \& Brown, B. (2000). Noise and Health in the Urban Environment. Reviews on Environmental Health, 15(1-2), 43-82.

Star, S. L. (2010). This is Not a Boundary Object: Reflections on the Origin of a Concept. Science, Technology, \& Human Values, 35(5), 601-617.

Star, S. L., \& Griesemer, J. R. (1989). Institutional Ecology, 'Translation' and Boundary Objects: Amateurs and Professionals in Berkeley's Museum of Vertebrate Zoology, 1907-39. Social Studies of Science, 19(3), $387-$ 420.

Steffen, W., Sanderson, A., Tyson, P. D., Jaeger, J., Matson, P. A., Moore III, B., Oldfield, F., Richardson, K., Schellnhuber, H. J., Turner II, B. L., \& Wasson, R. J. (2005). Global change and the Earth System: A Planet Under Pressure. Berlin: Springer.

Steiner, R. (1914, 20th to 23rd January 1914). Der menschliche und der kosmische Gedanke. Vier Vorträge. Paper presented at the Second General Meeting of the Anthroposophical Society, Berlin. 
Steiner, R. (1964). The Philosophy of Freedom. The Basis for a Modern World Conception. East Sussex: Rudolf Steiner Press.

Stone, R. (2010). Home, Home Outside the Range? Science, 329, 1592-1594.

Sukopp, H. (2008). On the Early History of Urban Ecology in Europe. In J. M. Marzluf, G. Bradley, E. Shulenberger, W. Endlicher, M. Alberti, C. Ryan, U. Simon \& C. ZumBrunnen (Eds.), Urban Ecology (pp. 7997). New York: Springer.

Swart, R. J., Raskin, P. \& Robinson, J. (2004). The problem of the future: sustainability science and scenario analysis. Global Environmental Change, 14, 137-146.

Swyngedouw, E. (2009). The city as a hybrid: On nature, society and cyborg urbanization. Capitalism Nature Socialism, 7(2), 65-80.

Szilagy, K. (2011). The Evolution of English Picturesque Landscape Garden to Urban Public Park. Paper presented at the First International Conference "Horticulture and Landscape Architecture in Transylvania".

Takacs, D. (1996). The Idea of Biodiversity. Philosophies of Paradise. Baltimore/London: John Hopkins University Press.

Taylor, C. (1995). Multiculturalisme. Meppel: Boom.

TEEB. (2009). The Economics of Ecosystems and Biodiversity for National and International Policy Makers: Summary: Responding to the Value of Nature. Bonn, Germany: UNEP.

TEEB. (2011). TEEB Manual for Cities: Ecosystem Services in Urban Managemen: TEEB.

Termorshuizen, J. W., \& Opdam, P. (2009). Landscape Services as a bridge between landscape ecology and sustainable development. Landscape Ecology, 24(1037-1052).

Thompson, M. (1997). Cultural Theory and Integrated Assessment. Environmental Modeling and Assessment, 2, 139-150.

Thompson, M., Ellis, R., \& Wildavsky, a. (1990). Cultural Theory. Boulder: Westview Press.

Thoreau, H. D. (1854). Walden, or: Life in the Woods. Boston: Ticknor and Fields.

Tidball, K. G. (2012). Urgent Biophilia: Human-Nature Interactions and Biological Attractions in Disaster Resilience. Ecology \& Society, 17(2)(5).

Tilman, D. (2000). Causes, consequences and ethics of biodiversity. Nature, 405, 208-211.

Tint, P., Tarmas, G., Koppel, T., Reinhold, K., \& Kalle, S. (2012). Vibration and noise caused by lawn maintenance machines in association with risk to health Aronomy Research Biosystem Engineering, Special Issue 1, 251260.

Toulmin, S. (1992). Kosmopolis. Verborgen agenda van de Moderne Tijd. Kampen: Kok Agora.

Trewhella, W. J., Rodriquez-Clark, K. M., Corp, N., Entwistle, A., Garret, S. R. T., Granek, E., Lengel, K. L., Raboude, M. J., Reason, P. F., \& Sewall, B. J. (2005). Environmental education as a component of mulsidisciplinary conservation programs: lessons from conservation initiatives for critically endangered fruit bats in the Western Indian Ocean. Conservation Biology, 19(1), 75-85.

Turner, S. D. (2010). Review of the collaborative partnership agreement between Shell International and IUCN. Alkmaar: IUCN \& SHELL.

Turner, W. R., Nakamura, T., \& Dinetti, M. (2004). Global Urbanization and the Separation of Humans from Nature. BioScience, 54(6), 585-590.

Turnpenny, J., Jones, M., \& Lorenzoni, I. (2011). Where Now for Post-Normal Science?: A Critical Review of its Development, Defintions, and Uses. Science, Technology, \& Human Values, 36(3), 287-306.

Tzoulas, K., \& James, P. (2004). Finding links between urban biodiversity and human health and well-being. Paper presented at the 4th International Postgraduate Research Conference in the Built and Human Environment, Salford, Manchester.

Tzoulas, K., \& James, P. (2010). Making Biodiversity measures accessible to non-specialists: an innovative method for rapid assessment of urban biodiversity. Urban Ecosystems, 13, 113-127.

Tzoulas, K., Korpela, K., Venn, S., Yli-Pelkonen, V., Kaźmierczak, A., Niemela, J., \& James, P. (2007). Promoting ecosystem and human health in urban areas using Green Infrastructure: A literature review. Landscape and Urban Planning, 81(3), 167-178.

UNCSD. (2012). The Future We Want: Outcome Document adopted at RIO+20. Rio de Janeiro: Brasil.

UNEP-CBD. (2011). Report of the Tenth Meeting of the Conference of the Parties to the Convention on Biological Diversity. Nagoya, Japan: UNEP.

UNEP. (1992). Convention on Biological Diversity. Rio de Janeiro: UNEP.

UNEP. (2002 ). Global Environment Outlook 3: Past Present and Future Perspectives. London: UNEP/Earthscan.

UNEP. (2007). Global Environmental Outlook 4. Environment for Development (GEO4). UNEP. 
UNEP. (2010). Busan Outcome: Third ad hoc intergovernmental and multi-stakeholder meeting on an intergovernmental science-policy platform on biodiversity and ecosystem services. Busan, Republic of Korea.

UNEP. (2011a). Environmental Assessment of Ogoniland. Nairobi, Kenya: United Nations Environment Programm.

UNEP. (2011b). Towards a Green Economy. Pathways to Sustainable Development and Poverty Eradication. Nairobi, Kenya: UNEP.

UNSCCUR. (1948). The Scientific Conference on Resource Conservation and Utilization: UNSCCUR.

Ura, D. K., \& Chophel, D. (2012, May 21-23). Buddhism Without Borders. Paper presented at the International Conference on Globalized Buddhism, Bumthang, Bhutan

Urquhart, C. (2013). Grounded Theory for Qualitative Research: A Practical Guide. London: Sage.

Urry, J. (2005a). The Complexities of the Gobal. Theory, Culture and Society, 22(235).

Urry, J. (2005b). The Complexity Turn. Theory, culture and Society, 22(5), 1-14.

Valkering. (2009). Toddling 'long the River Meuse. Integrated Assessment and Participatory Agent-Based Modelling to Support River Management. Maastricht: Universitaire Pers Maastricht.

Valkering, Offermans, A., Van Lieshout, M., Rijkens, N., Van der Brugge, R., Haasnoot, M., Hans, M., Van Deursen, W., Beersma, J., Buiteveld, H., \& Volleberg, K. (2008). Inspelen op Verandering. Naar een robuuste en flexible strategie voor waterbeheer. Eindrapportage voor de pilotstudie Perspectieven in Integraal Waterbeheer. Maastricht: ICIS; Leven Met water.

Valkering, P., Amelung, B., Van der Brugge, R., \& Rotmans, J. (2006). More Puzzle-Solving for Policy. Integrated Assessment from Theory to Practice. Maastricht: ICIS \& EFIEA.

Valkering, P., Beumer, C., Kraker, J. d., \& Ruelle, C. (2013). An analysis of learning interactions in a cross-border network for sustainable urban neighbourhood development. Journal of Cleaner Production, 49.

Valkering, P., Tabara, J. D., Wallman, P., \& Offermans, A. (2009). Modeling Cultural and Behavioural Change in Water Management: An integrated, agent based, gaming approach. . The Integrated Assessment Journal, 9(1), 1-28.

Van Asselt, M., Rotmans, J., \& Rothman, D. S. (2005). Scenario Innovation. Experiences from a European Experimental Garden. . Leiden, Netherlands: Taylor \& Francis, .

Van den Berk, J., \& Meyer Swantee, G. (Writer). (2012). Groen Goud, Tegenlicht: VPRO.

Van der Ree, P. (2000). Organische Architectuur. Mens en Natuur als Inspiratiebron voor het Bouwen. Zeist: Vrij Geestesleven.

Van Ham, C. (2013). Green architecture for more biodiversity-friendly cities. Blog. The inside track on global conservation Retrieved 16 September 2013, from https://portals.iucn.org/blog/2013/07/08/greenarchitecture-for-more-biodiversity-friendly-cities/

Van Renterghem, T., Hornikx, M., Forssen, J., \& Botteldooren, D. (2013). The potential of building envelope greening to achieve quietness. Building and Environment, 61, 34-44.

Vaughan, M. (2007). Introduction: Henry Bergson's Creative Evolution. SubStance, 36(6), 7-24.

Verdonschot, K. (Ed.). (2011). Jaarboek Tuin 2011. Sittard: T.G.M. Posthumus.

Verdonschot, K. (Ed.). (2012). Jaarboek Tuin 2012. Sittard: T.G.M. Posthumus.

Verweij, M., Douglas, M., Ellis, R., Engel, C., Hendriks, F., Lohmann, S., Ney, S., Rayner, S., \& Thompson, M. (2006). Clumsy solutions for a complex world: the case of climate change. Public Administration, 84(4), 817-843.

Visseren-Hamakers, I. J., Leroy, P., \& Glasbergen, P. (2012). Conservation Partnerships and Biodiversity Governance: Fulfilling Governance Functions through Interaction. Sustainable Development, 20, 264-275.

Visseren-Hamakers, I. J., Leroy, P., \& Glasbergen, P. (2012). Conservation partnerships and biodiversity governance: fulfilling governance functions through interaction. Sustainable Development, 20(4), 264275.

Vrščaja, B., Poggioa, L., \& Marsana, F. A. (2008). A method for soil environmental quality evaluation for management and planning in urban areas. Landscape and urban planning, 2(4), 81-94.

Wackernagel, M., \& Rees, W. (1996). Our Ecological Footprint: Reducing Human Impact on the Earth. Gabriola Island: New Society Press.

WBCSD. (1998). Exploring sustainable development: global scenarios 2000-2050. London: World Business Council for Sustainable Development.

Weaver, P., \& Rotmans, J. (2006). Integrated sustainability assessment: what is it, why do it and how? International Journal of Innovation and Sustainable Development, 1(4), 284-303. 
Weinstein, M. P. (2010). Sustainability Science: the emerging paradigm and the ecology of cities. Sustainability: Science, Practice \& Policy, 6(1), 1-5.

Westengen, O. T., Jeppson, S., \& Guarino, L. (2013). Global Ex-Situ Crop Diversity Conservation and the Svalbard Global Seed Vault: Assessing the Current Status. PLoS One, 8(5).

White, L. (1967). The Historical Roots of Our Ecologic Crisis. Science, 155, 1203-1207.

White, R., Sasser, D., Bogren, R., \& Morgan, J. (2009). Photos Can Inspire a Thousand Words: Photolanguage as a Qualitative Evaluation Method. Journal of Extension, 47(3).

Whittaker, R. J., \& Fernandez-Palacios, J. M. (2007). Island Biogeography: Ecology, Evolution, and Conservation. Oxford: Oxford University Press.

WHO. (2011). Our Planet, Our Health, Our Future. Human Health and the Rio Conventions: biological diversity, climate change and desertification. Geneva: Switzerland.

Wiek, A., \& Iwaniec, D. (2013). Quality criteria for visions and visioning in sustainability science. Sustainability Science.

Wiek, A., Ness, B., Schweizer-Ries, P., Brand, F. S., \& Farioli, F. (2012). From complex systems analysis to transformational change: a comparative appraisal of sustainability science projects. Sustainability Science, 7(Supplement 1), 5-24.

Williams, C. C., \& Millington, A. C. (2004). The diverse and contested meanings of sustainable development. The Geographical Journal, 170(2), 99-104.

Wills-Herrera, E., Islam, G., \& Hamilton, M. (2009). Subjective Well-Being in Cities: A Multidimensional Concept of Individual, Social and Cultural Variables. Applied Research Quality Life, 4, 201-2021.

Wilson, A. (1992). The culture of nature: North American landscape from Disney to the Exxon Valdez. Cambridge, MA: Blackwell.

Wilson, A. (1993). Towards an Integration of Content Analysis and Discourse Analysis: The Automatic Linkage of Key Relations in Text.

Witzenberger, K. A., \& Hochkirch, A. (2011). Ex situ conservation genetics: a review of molecular studies on the genetic consequences of captive breeding programmes for endangered animal species. Biodiversity and Conservation, 20(9), 1843-1861.

Wodak, R., \& Meyer, M. (2009). Methods of Critical Discourse Analysis. London: Sage Publications Ltd.

Wodak, R., \& Michal, K. (2008). Qualitative Discourse Analysis in the Social Sciences. New York: Palgrave Macmillan.

Woonpunt. (2012). Kunstproject met vogelhuisjes fleurt buurt op. Nieuws van Woonpunt.

WWF. (2012). Urban Solutions for a Living Planet-Learning Cases. Stockholm, Sweden: World Wildlife Fund Sweden.

York, R., Rosa, E. A., \& Dietz, T. (2003). Footprints on the earth: The environmental consequences of modernity. American Sociological Review, 68, 279-300.

Young, O. R., Berkhout, F., Gallopin, G. C., Janssen, M. A., Ostrom, E., \& Leeuw, S. v. d. (2006). The globalization of socio-ecological systems: An agenda for scientific research. Global Environmental Change, 16, 304-316.

Young, R. F. (2009). Interdisciplinary foundations of urban ecology. Urban Ecosystems, 12, 311-331.

Zerbe, S., Maurer, U., Schmitz, S., \& Sukopp, H. (2003). Biodiversity in Berlin and its potential for nature conservation. Landscape and Urban Planning, 62, 139-148.

Zheng, B., Zhang, Y., \& Chen, J. (2011). Preference to home landscape: wildness or neatness? Landscape and Urban Planning, 99, 1-8.

Zube, E. H., Simcox, D. E., \& Law, C. S. (1986). The oasis image of two desert cities. Landscape Research, 11(3), 7-11. 


\section{About the author}

Carijn Beumer was born in Alkmaar, the Netherlands on the 5th of October 1978. She graduated in the Arts and Science Studies with a specialization in Humanities and Sciences at Maastricht University in 2005. Carijn obtained certificates for the courses Introduction to Psychology and for Social Psychology at the Open University in the Netherlands. After two years with various jobs, amongst others as a research assistant, Carijn decided to stay in Academia and pursue a doctoral degree. In 2007 she started her career as a Junior Researcher and Education Coordinator at the International Centre for Integrated assessment and Sustainable development (ICIS) at Maastricht University, following a desire to work on sustainability issues. During that period, Carijn assisted in the development of the Master Programme -- Sustainability Science and Policy -- which became accredited in 2011. Carijn started as a PhD researcher in 2009. In the period 2009-2012 Carijn worked as a researcher on the Sustainable Urban Neighbourhoods project (SUN). The SUN project has been part of the Interreg IVA Euregio Meuse-Rhine programme including seven cities, three academic partners and professional partners of the Euregio Meuse-Rhine. The project aim: improving the quality of life in old industrial neighbourhoods, reinforcing community participation and increasing exchanges between the cities. In 2010 Carijn also worked on the project Sustainable Education in Limburg. In the project a quick scan was made of educational programmes on sustainable development at schools in Limburg at primary, secondary and tertiary level; to analyse the role of external providers; and to explore the role of the Province. In 2013 Carijn spent a month as a visiting researcher at the Global Institute of Sustainability (GIOS) of Arizona State University. Since 2014 Carijn is a representative of the Dutch Scientists' Union (VAWO) to the executive board of Maastricht University.

Carijn has also been involved in many educational activities: as a tutor, course coordinator, education coordinator, academic advisor, thesis supervisor, internship coordinator and -supervisor and as a lecturer. In the period 2011-2014 she has been the secretary of the board of examiners for the Master Programme Sustainability Science and Policy at Maastricht University. Carijn attained the University Teaching Qualification (Basis Kwalificatie Onderwijs).

In the future, Carijn aims to further contribute to the development of transdisciplinary and transformational sustainability science, combining actionable research activities in the field of (urban) green infrastructures and biodiversity with providing good quality academic education.

Besides work, Carijn likes reading great stories, mythology and fairy tales, outdoor sports, and she plays alto saxophone in bigbands and other jazz-oriented combinations of musicians. 


\section{Maastricht University}

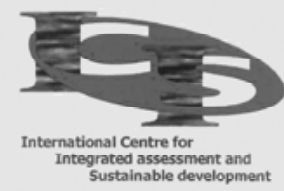

\section{Certificate}

On behalf of Maastricht University, the International Centre for

Integrated assessment and Sustainable development (ICIS) - Maastricht

University graduate school of SusTainability science (MUST) declares that

\section{Carijn Beumer}

born

5 October 1978

Alkmaar, the Netherlands

Maastricht, the Netherlands

4 December 2014
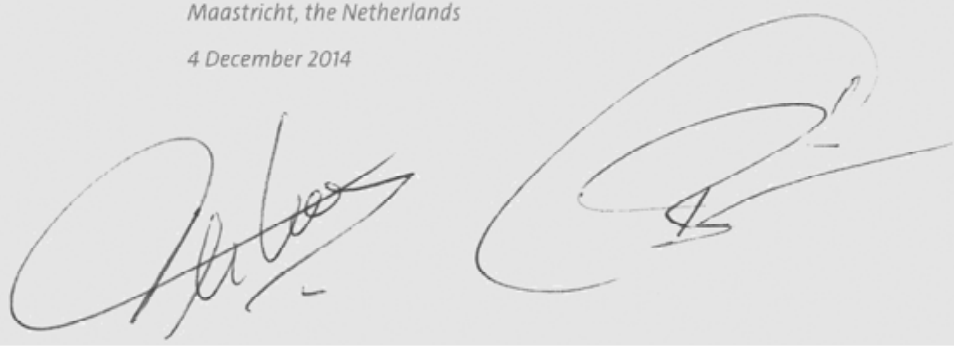

Prof. Dr. P.Martens

Dr. R.J.M. Cörvers

Chair education committee MUST

Director ICIS 


\section{Maastricht University}

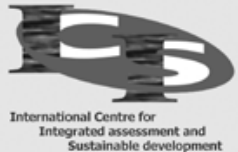

\section{PEER REVIEWED PUBLICATIONS}

- Beumer, C., Martens, P. \& Huynen, M. (2008) Finding Paradise in a Complex Web: The Inter-relation of Biodiversity, Ecosystems and Human Health. In: Westra, L. Reconciling human existence with ecological integrity. London: Earthscan.

- Beumer, C. \& Martens, P. (2010). Noah's Ark or world wild Web? Cultural Perspectives in Global Scenario Studies and Their Function for Biodiversity Conservation in a Changing World. In: Sustainability. Special Issue Futures, p. $3211-3238$

- Martens P. \& Beumer C. (2012). Biodiversiteit houdt mensen gezond. In: De Mens Centraal, Ethische dilemma's bij gezondheidsbeleid met goede zorg voor dier en natuur. Centrum voor Ethiek en Gezondheid.

- Valkering P., Beumer C., Kraker Joop de \& Ruelle C. (2012). An analysis of learning interactions in a cross-border network for sustainable urban neighbourhood development. Journal of Cleaner Production.

- Beumer, C. \& Martens, P. (2013). IUCN and perspectives on biodiversity conservation in a changing world. In: Biodiversity and Conservation. DOI 10.1007/s10531-013-0573-6

- Beumer, C. \& Martens, P. (2014). Biodiversity in my (back) yard: a framework for assessing ecosystem services and biodiversity in residential gardens. In: Sustainability Science.

\section{COURSES}

PhD courses

- Comparative Methods, MCSOG PhD programme (18-20 November 2009).

- Global Change, Complexity and Sustainability, SENSE-MUST (19-20 October 2011).

- Knowledge Production for Sustainable Development, SENSE-MUST (12-13 April 2012).

- Measuring Globalisation, MUST Workshop (22-23 November 2012).

- Integrated Sustainability Assessment: Tools and Methods, MUST Workshop (24-27 June 2013).

- Sociotechnical change: Lessons, Levels and Literature, MUST Workshop (14 \& 21 November 2013).

- Science Meets Practice, CCES Winterschool ETH Zürich (6.9 January \& 3-6 February 2014).

\section{Other courses}

- Intercultural Skills Training, Loopbaancentrum MU (2007).

- Advanced Academic Writing English, Talencentrum MU (2009). 


\section{Maastricht University}

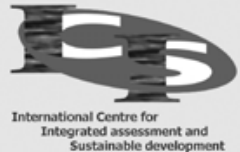

\section{SKILLS}

\section{Oral presentations at conferences}

- Poster Presentation in Copenhagen: Climate Change Global Rrisks, Challenges and Decisions (10-12 May 2009).

- Oral Presentation Resilience Conference Arizona State University: Scenario Studies and the Diversity of Conservation Perspectives (15 March 2011)

- Oral Presentation Global Ecological Integrity Group Conference (GEIG), Prague: Perspectives on Biodiversity Conservation in a Changing World (16 July 2011).

- Oral Presentation: Regional Studies Association Conference, Networked regions and cities in times of fragmentation: developing smart, sustainable and inclusive places in Delft: Sustainable Urban Neighbourhoods: Integrated Learning for Sustainable Development (15 May 2012).

\section{Management skills}

- Member of Examination Committee MSCSSP (2011-2014).

- Member of Business Advisory Board ENACTUS Maastricht (2012 - present).

- Organisation and Facilitation GISER workshop on envisioning sustainable urban futures at ASU, Phoenix, Arizona (April 2014).

- Workshop Nationale Groendag Groningen: Biodiversity in my back yard (2014).

\section{DIDACTIC SKILLS}

\section{Coordinating courses}

- Maastricht Graduate School of Governance (MCSOG): Sustainability in a Globalizing World (2007-2011).

- University College Maastricht (UCM): introduction to Sustainable Development (2008-2010).

- International Centre for Integrated assessment and Sustainable development (ICIS): MA Global Dynamics (2011-2014).

\section{Tutoring courses}

- BA course Globalization, Environmental change and Society, UCM (2007-2009)

- BA course Sustainable Development: an introduction, UCM (2008-2010)

- MA course Integrated Assessment, MCSOG (2007-2009)

- MA course Sustainability in a Globalizing World, MCSOG (2007-2011)

- MA course Clobal Dynamics, Sustainability Science and Policy, ICIS (2011-2014)

- Fundamentals of Global Health Faculty of Health Medicine and Life Sciences, FHML (2014)

- Qualitative Research Methods, FHML (2014)

\section{Other}

- Lecture Faculty of Arts and Social Science (FASOS): Biodiversity Conservation and Ecosystem Services in the Natura 2000 Network.

- Lecture Kenniscentrum Burgers en Biodiversiteit Hogeschool Van Hall Larenstein: the BIMBY method (2014).

- Thesis Supervision (22 students).

- Thesis \& Interns coordination.

- Internship supervision (12 students).

- Academic Advisor UCM. 
